\title{
Cold Climate Foundation Retrofit Experimental Hygrothermal Performance: Cloquet Residential Research Facility Laboratory Results
}

Louise F. Goldberg and Anna C. Harmon NorthernSTAR

April 2015 


\title{
NOTICE
}

This report was prepared as an account of work sponsored by an agency of the United States government. Neither the United States government nor any agency thereof, nor any of their employees, subcontractors, or affiliated partners makes any warranty, express or implied, or assumes any legal liability or responsibility for the accuracy, completeness, or usefulness of any information, apparatus, product, or process disclosed, or represents that its use would not infringe privately owned rights. Reference herein to any specific commercial product, process, or service by trade name, trademark, manufacturer, or otherwise does not necessarily constitute or imply its endorsement, recommendation, or favoring by the United States government or any agency thereof. The views and opinions of authors expressed herein do not necessarily state or reflect those of the United States government or any agency thereof.

Available electronically at http://www.osti.gov/scitech

Available for a processing fee to U.S. Department of Energy and its contractors, in paper, from:

\author{
U.S. Department of Energy \\ Office of Scientific and Technical Information \\ P.O. Box 62 \\ Oak Ridge, TN 37831-0062 \\ phone: 865.576 .8401 \\ fax: 865.576.5728 \\ email: mailto:reports@adonis.osti.gov
}

Available for sale to the public, in paper, from:

U.S. Department of Commerce

National Technical Information Service

5285 Port Royal Road

Springfield, VA 22161

phone: 800.553 .6847

fax: 703.605.6900

email: orders@ntis.fedworld.gov

online ordering: http://www.ntis.gov/ordering.htm 


\title{
Foundation Retrofit Experimental Hygrothermal Performance: Cloquet Residential Research Facility Laboratory Results
}

\author{
Prepared for: \\ The National Renewable Energy Laboratory \\ On behalf of the U.S. Department of Energy's Building America Program \\ Office of Energy Efficiency and Renewable Energy \\ 15013 Denver West Parkway \\ Golden, CO 80401 \\ NREL Contract No. DE-AC36-08GO28308 \\ Prepared by: \\ Louise F. Goldberg and Anna C. Harmon \\ NorthernSTAR \\ 322 Kaufert Laboratory, 2004 Folwell Ave, \\ St. Paul, MN 55108 \\ NREL Technical Monitor: Stacey Rothgeb \\ Prepared under Subcontract No. KNDJ-0-40338-04
}

April 2015 
The work presented in this report does not represent performance of any product relative to regulated minimum efficiency requirements.

The laboratory and/or field sites used for this work are not certified rating test facilities. The conditions and methods under which products were characterized for this work differ from standard rating conditions, as described.

Because the methods and conditions differ, the reported results are not comparable to rated product performance and should only be used to estimate performance under the measured conditions. 


\section{Contents}

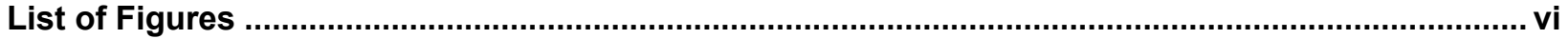

List of Tables

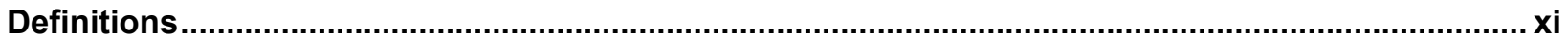

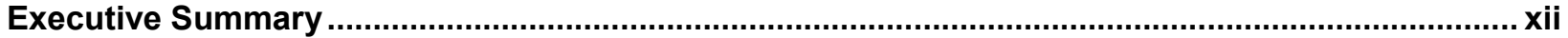

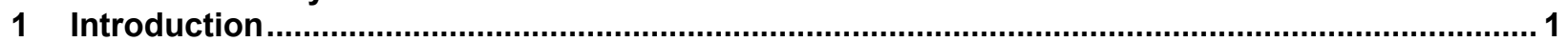

1.1 University of Minnesota Foundations Technical Background...................................................... 1

1.2 Moisture Considerations for Retrofit Foundation Insulation ................................................ 2

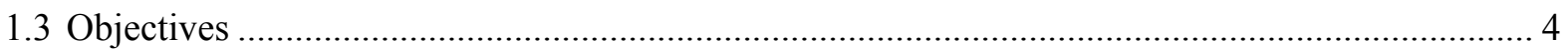

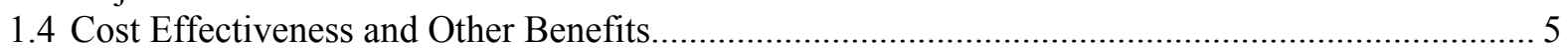

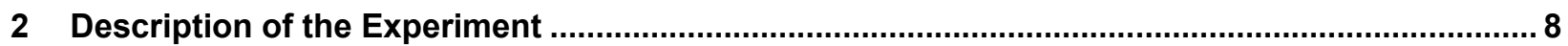

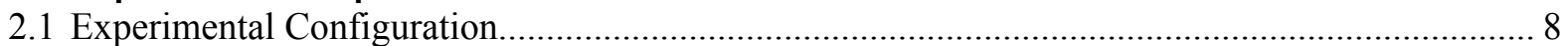

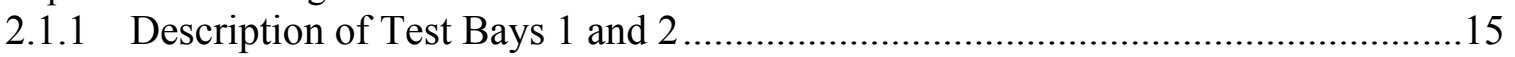

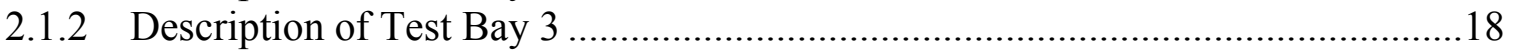

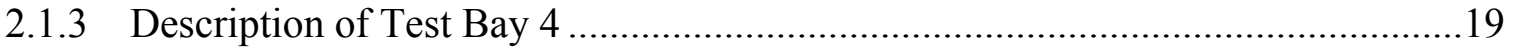

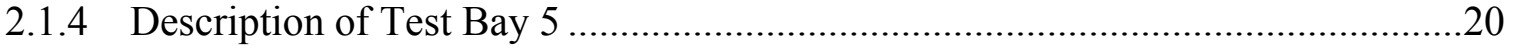

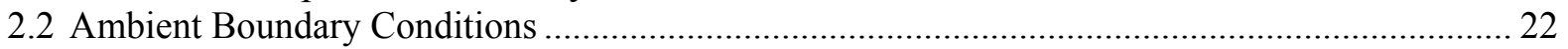

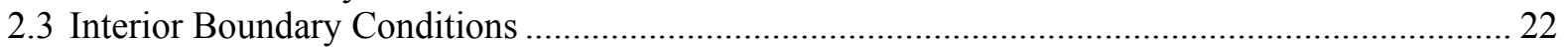

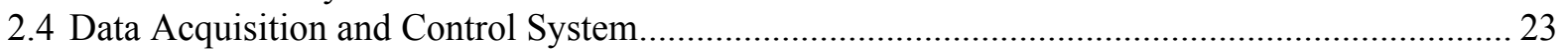

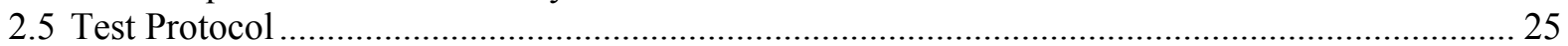

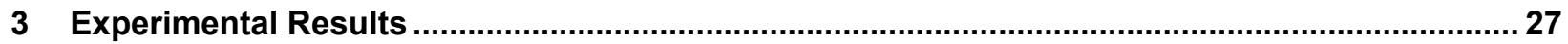

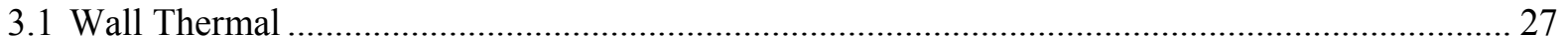

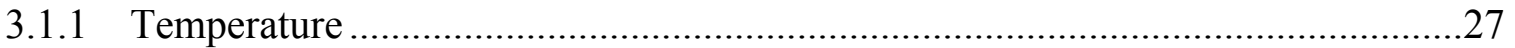

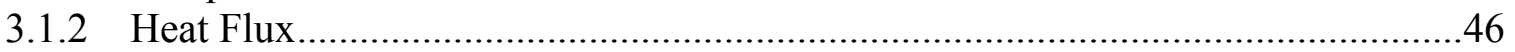

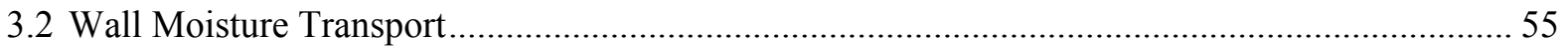

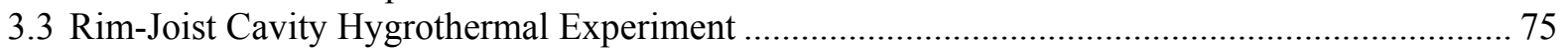

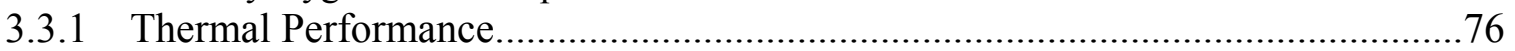

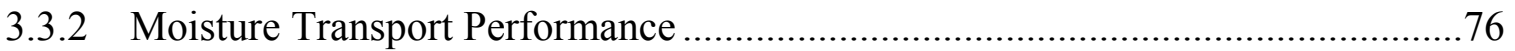

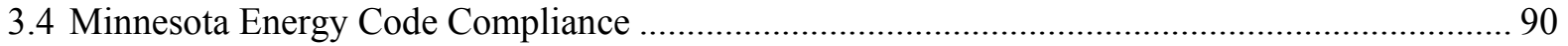

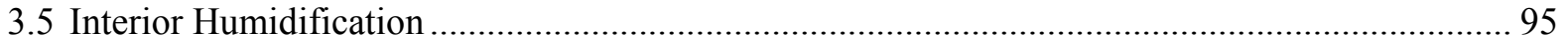

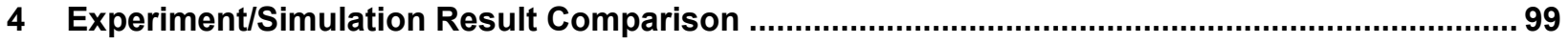

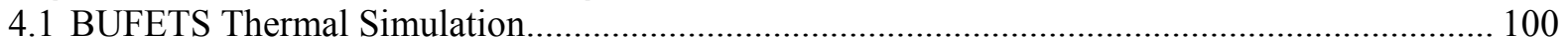

4.1.1 Test Bay 1N Experiment/Simulation Result Comparison .................................108

4.1.2 Key Factors Influencing Test Bays 2N and 3N Experiment/Simulation

Comparisons ..................................................................................... 120

4.1.3 Comparison of Bay $1 \mathrm{~N}$ and 2N Experiment/Simulation Discrepancies..............121

4.1.4 Comparison of Bay 2N and 3N Experiment/Simulation Discrepancies..............130

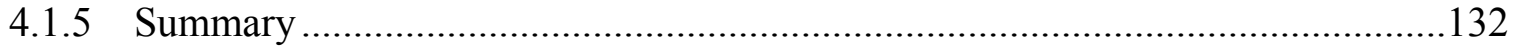

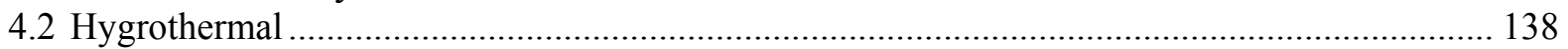

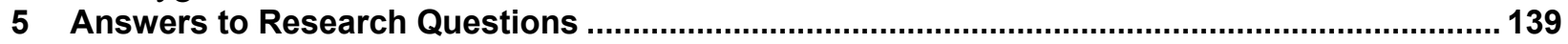

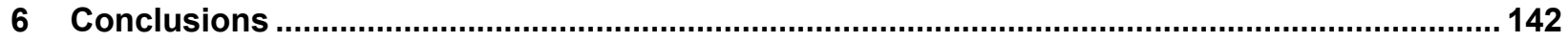

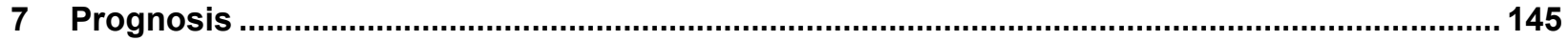

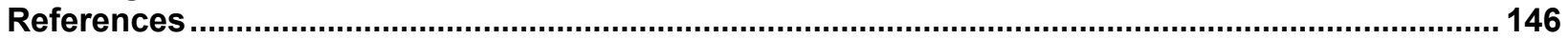

Appendix A: Instrumentation and Experimental Fabrication Record .......................................149

Appendix B: Moisture Content Sensor Development ................................................................ 162

Appendix C: Supplementary Experimental Data ..................................................................... 174

Appendix D: WUFI-2D Experiment/Simulation Result Comparison ............................................... 203

Appendix E: WUFI-2D Experiment/Simulation Comparison Data ...................................................2 216

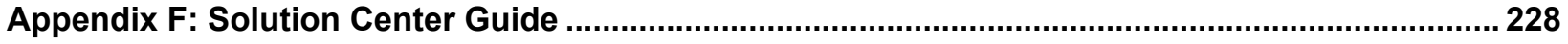




\section{List of Figures}

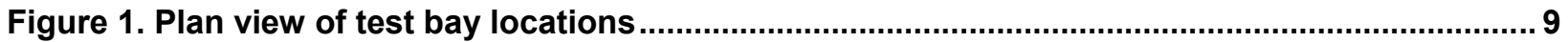

Figure 2. Bays 1 and 2 test wall system characteristics, dimensions, and instrumentation............ 10

Figure 3. Bay 3 test wall system characteristics, dimensions, and instrumentation ...................... 11

Figure 4. Bay 4 test wall system characteristics, dimensions, and instrumentation ....................... 12

Figure 5. Bay 5A insulated test rim-joist cavity system characteristics, dimensions, and

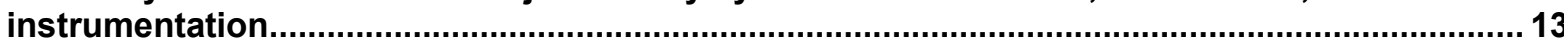

Figure 6. Bay 5B uninsulated test rim-joist cavity system characteristics, dimensions, and

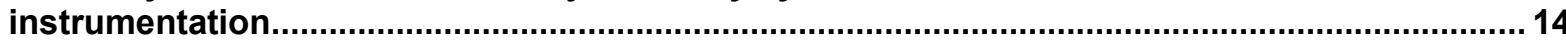

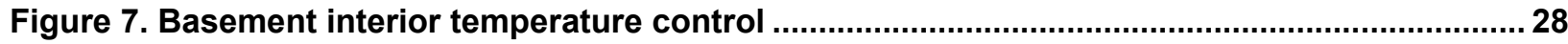

Figure 8. Exterior temperature boundary conditions ...................................................................... 29

Figure 9. Test panel interior temperature boundary conditions most remote from temperature

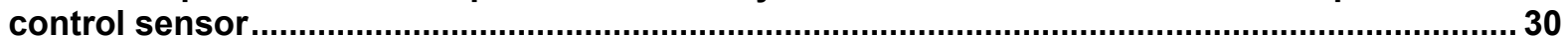

Figure 10. Terrestrial horizontal plane solar and long-wave irradiance ........................................... 31

Figure 11. Bay 2S above-grade masonry block wall temperature profiles ........................................ 33

Figure 12. Bay $2 S$ heating season masonry block wall and soil temperature profiles 40 to 79 in.

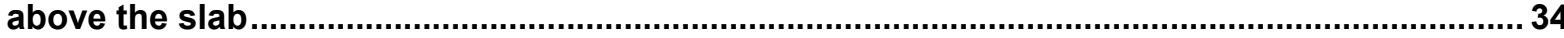

Figure 13. Bay $2 S$ cooling season masonry block wall and soil temperature profiles 40 to 79 in.

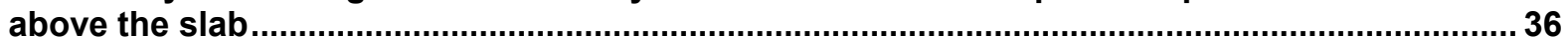

Figure 14. Bay $2 S$ heating season masonry block wall and soil temperature profiles $5-1 / 2$ to 16 in.

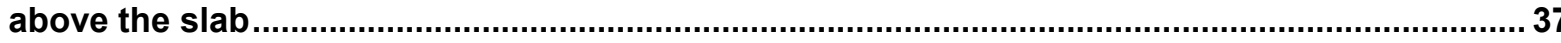

Figure 15. Bay $2 S$ cooling season masonry block wall and soil temperature profiles $5-1 / 2$ to 16 in.

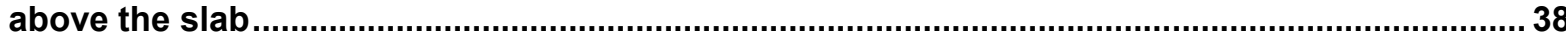

Figure 16. Bay $3 \mathrm{~N}$ heating season below-grade masonry block wall and soil temperature

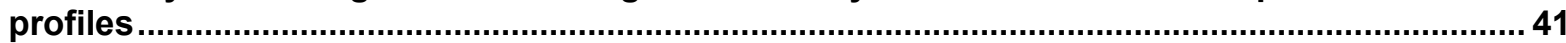

Figure 17. Bay $3 \mathrm{~N}$ cooling season below-grade masonry block wall and soil temperature profiles.

Figure 18. Bay 2S (interior insulation)/Bay 4S (exterior half-wall insulation) wall temperature comparison 40 in. above the slab.

Figure 19. Bay 2S (interior insulation)/Bay 4S (exterior half-wall insulation) wall temperature comparison 69 in. above the slab.

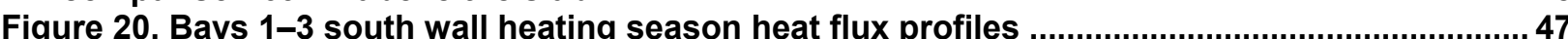

Figure 21. Bays 1-3 south wall cooling season heat flux profiles ....................................................48

Figure 22. Bays 1-3 north wall heating season heat flux profiles ..................................................... 49

Figure 23. Bays 1-3 north wall cooling season heat flux profiles .................................................. 50

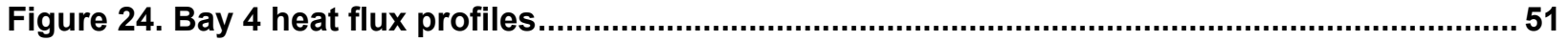

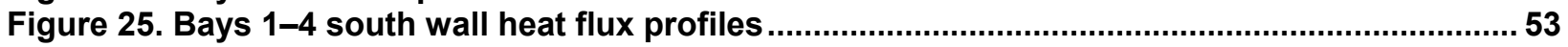

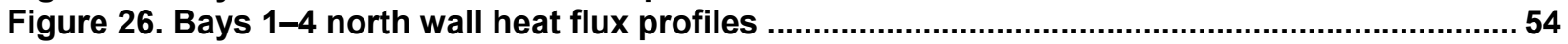

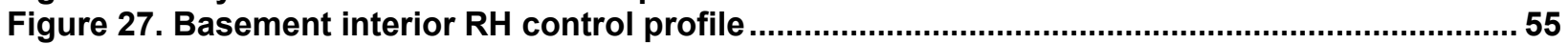

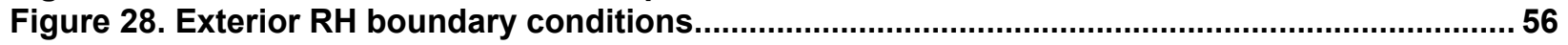

Figure 29 Terrestrial precipitation recorded by the data acquisition system................................ 57

Figure 30. Terrestrial precipitation recorded manually................................................................58

Figure 31. Snow depths on north and south sides of the CRRF..............................................59

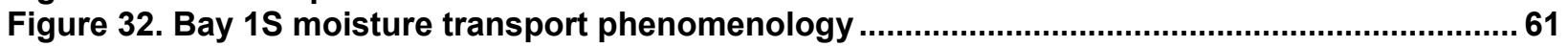

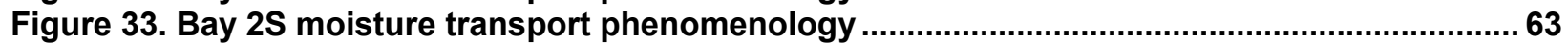

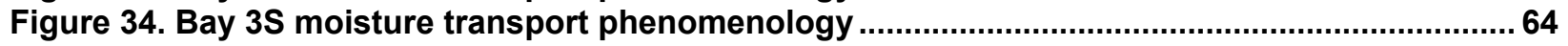

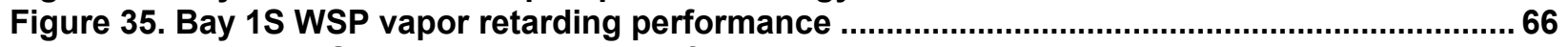

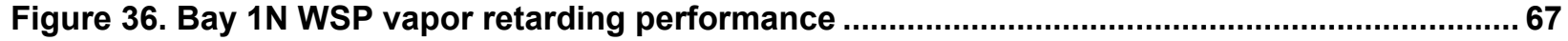

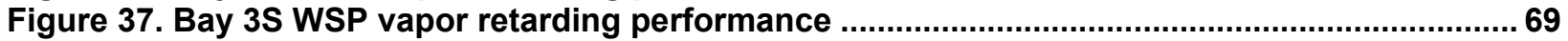

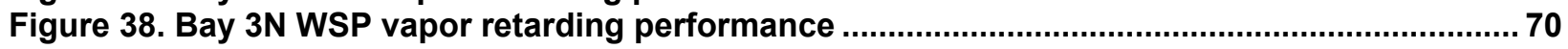

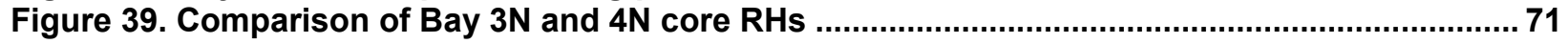

Figure 40. Bay $1 \mathrm{~S}$ and $2 \mathrm{~S}$ soil moisture contents comparison ......................................................... 73

Figure 41. Bay 1N and 2N soil moisture contents comparison.................................................... 74

Figure 42. Bay 5S rim-joist cavity rim board thermal performance .................................................... 78 
Figure 43. Bay $5 \mathrm{~N}$ rim-joist cavity rim board thermal performance ................................................79

Figure 44. Moisture performance of Bay $5 \mathrm{~N}$ rim-joist cavity with uninsulated rim board................ 80

Figure 45. Moisture performance of Bay $5 \mathrm{~N}$ rim-joist cavity with insulated rim board ..................... 81

Figure 46. Wetting/drying profiles for Bay $5 \mathrm{~N}$ rim-joist cavity with uninsulated rim board ............... 82

Figure 47. Wetting/drying profiles for Bay $5 \mathrm{~N}$ rim-joist cavity with insulated rim board ................... 83

Figure 48. Moisture performance of Bay $5 \mathrm{~N}$ bond beam block below rim-joist cavity ..................... 86

Figure 49. Water diffusion through Bay $5 \mathrm{~N}$ bond beam block below rim-joist cavity ...................... 87

Figure 50. Bay $5 \mathrm{~N}$ rim-joist cavity bounding surface vapor pressure profiles with uninsulated

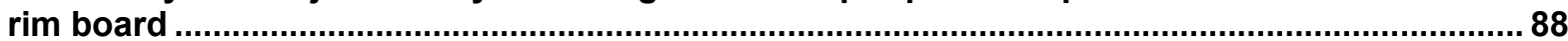

Figure 51. Bay 5N rim-joist cavity bounding surface vapor pressure profiles with insulated rim board

Figure 52. Bay 2 WSP interior condensing surface Minnesota Energy Code compliance performance ............................................................................................................................... 93

Figure 53. Bay 3 WSP interior condensing surface Minnesota Energy Code compliance

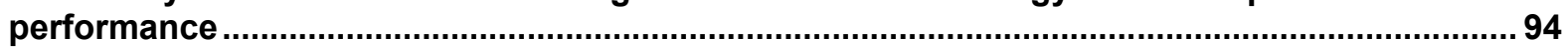

Figure 54. Bay 1 adhered WSP interior side response to basement humidification ........................96

Figure 55. Bay 2 adhered WSP interior side response to basement humidification ....................... 97

Figure 56. Bay 3 nonadhered WSP interior side response to basement humidification...................98

Figure 57. Vertical section through simulation domain ............................................................. 102

Figure 58. Horizontal section through wall ............................................................................... 103

Figure 59. Typical discretization on vertical plan perpendicular to wall......................................... 106

Figure 60. Typical discretization on vertical plane along wall ..................................................... 107

Figure 61. Bay $1 \mathrm{~N}$ wall experiment/BUFETS simulation temperature comparison $5-1 / 2 \mathrm{in}$. above the slab.

Figure 62. Bay $1 \mathrm{~N}$ wall experiment/BUFETS simulation temperature comparison $40-1 / 4 \mathrm{in}$. above

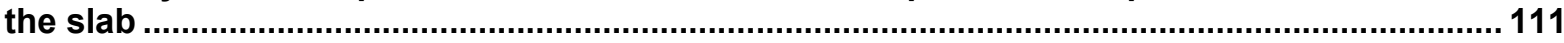

Figure 63. Bay $1 \mathrm{~N}$ wall experiment/BUFETS simulation temperature comparison $69-1 / 4 \mathrm{in}$. above the slab

Figure 64. Bay $1 \mathrm{~N}$ wall experiment/BUFETS simulation temperature comparison $79-1 / 4$ and $86-1 / 4$ in. above the slab

Figure 65. Bay $1 \mathrm{~N}$ soil vertical profile experiment/BUFETS simulation temperature comparison. 117

Figure 66. Bay $1 \mathrm{~N}$ soil horizontal profile experiment/BUFETS simulation temperature comparison

Figure 67. Bay 1N wall experiment/BUFETS simulation heat flux comparison............................119

Figure 68. Bay $2 \mathrm{~N}$ wall experiment/BUFETS simulation temperature comparison $5-1 / 2$ in. above the slab.

Figure 69. Bay $2 \mathrm{~N}$ wall experiment/BUFETS simulation temperature comparison $40-1 / 4 \mathrm{in}$. above the slab

Figure 70. Bay $2 \mathrm{~N}$ wall experiment/BUFETS simulation temperature comparison $69-1 / 4 \mathrm{in}$. above the slab.

Figure 71. Bay $2 \mathrm{~N}$ wall experiment/BUFETS simulation temperature comparison $79-1 / 4$ and $86-1 / 4$ in. above the slab

Figure 72. Bay $2 \mathrm{~N}$ soil vertical profile experiment/BUFETS simulation temperature comparison. 127

Figure 73. Bay $2 \mathrm{~N}$ soil horizontal profile experiment/BUFETS simulation temperature comparison

Figure 74. Bay $2 \mathrm{~N}$ wall experiment/BUFETS simulation heat flux comparison.

Figure 75. Bay $3 \mathrm{~N}$ wall experiment/BUFETS simulation temperature comparison $5-1 / 2$ in. above the slab....

Figure 76. Bay $3 \mathrm{~N}$ wall experiment/BUFETS simulation temperature comparison $40-1 / 4 \mathrm{in}$. above the slab

Figure 77. Bay $3 \mathrm{~N}$ wall experiment/BUFETS simulation temperature comparison $69-1 / 4 \mathrm{in}$. above the slab

Figure 78. Bay $3 \mathrm{~N}$ wall experiment/BUFETS simulation temperature comparison $86-1 / 4 \mathrm{in}$. above the slab

Figure 79. Bay $3 \mathrm{~N}$ soil vertical profile experiment/BUFETS simulation temperature comparison. 136

Figure 80. Bay $3 \mathrm{~N}$ wall experiment/BUFETS simulation heat flux comparison. 


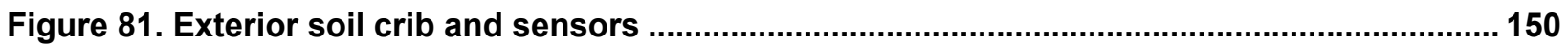

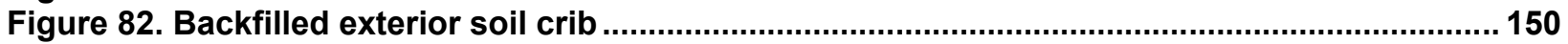

Figure 83. Interior block wall sensors (block moisture content, core humidity, and surface

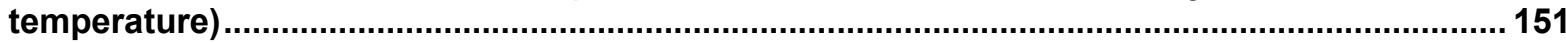

Figure 84. Exterior sensors (block moisture content and temperature) ..................................... 152

Figure 85. Sensors on the insulation interior face (humidity and temperature) ............................153

Figure 86. Humidity sensors installed in pockets on rear insulation face........................................154

Figure 87. Heat flux plates mounted on interior face of WSP ................................................. 155

Figure 88. Nonadhered WSP with attached humidity sensors (dimpled side faces the wall)......... 156

Figure 89. Nonadhered WSP drainage cavity with drainage tube at the left end ............................. 156

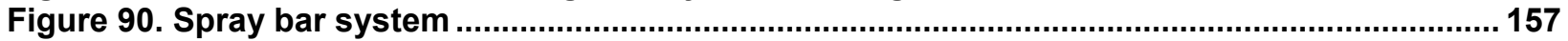

Figure 91. Insulation placement on nonadhered WSP .................................................................. 158

Figure 92. Framing and gypsum wallboard over adhered WSP ................................................ 159

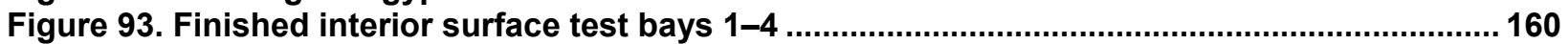

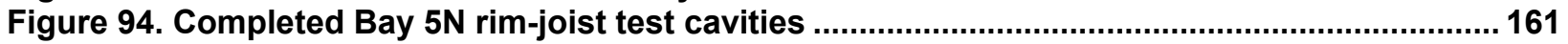

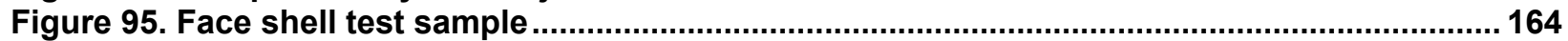

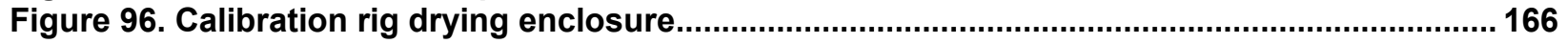

Figure 97. Raw calibration data for a masonry block face shell ................................................ 167

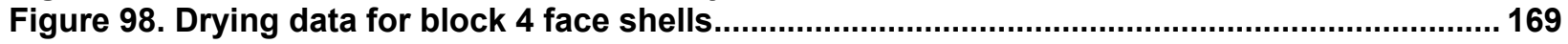

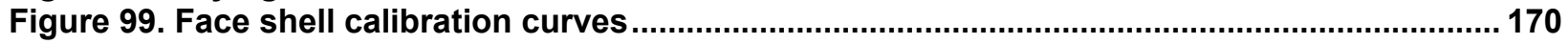

Figure 100. Wood moisture content calibration curves .................................................................... 172

Figure 101. Bay 1S above-grade masonry block wall temperature profiles ................................. 174

Figure 102. Bay 1S heating season masonry block wall and soil temperature profiles 40 to 79

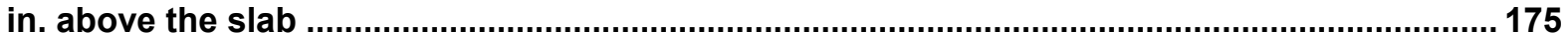

Figure 103. Bay 1S cooling season masonry block wall and soil temperature profiles 40 to 79

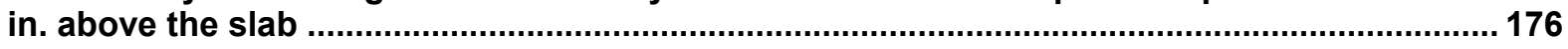

Figure 104. Bay 1S heating season masonry block wall and soil temperature profiles 5-1/2 to 16

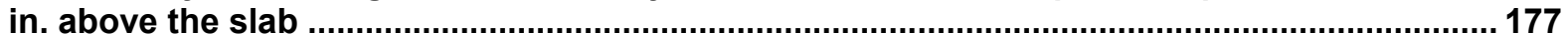

Figure 105. Bay $1 \mathrm{~S}$ cooling season masonry block wall and soil temperature profiles $5-1 / 2$ to 16

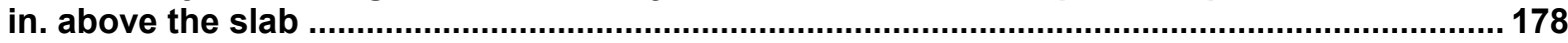

Figure 106. Bay $3 \mathrm{~N}$ above-grade masonry block wall temperature profiles .................................... 179

Figure 107. Bay 2S (interior insulation)/Bay 4S (exterior half-wall insulation) wall temperature comparison $5-1 / 2$ in. and 16 in. above the slab ................................................................. 180

Figure 108. Bay 2S (interior insulation)/Bay 4S (exterior half-wall insulation) above-grade wall

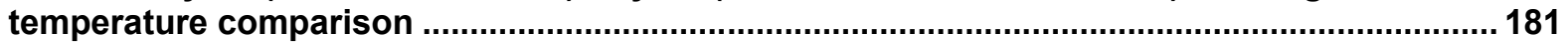

Figure 109. Bay 1N moisture transport phenomenology ...................................................... 182

Figure 110. Bay 2N heating season above-grade masonry block wall temperature profiles.......... 183

Figure 111. Bay $2 \mathrm{~N}$ heating season masonry block wall and soil temperature profiles 40 to $\mathbf{7 9}$ in. above the slab

Figure 112. Bay $2 \mathrm{~N}$ cooling season masonry block wall and soil temperature profiles 40 to 79

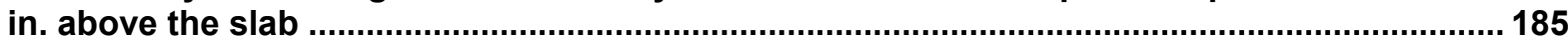

Figure 113. Bay $2 \mathrm{~N}$ heating season masonry block wall and soil temperature profiles $5-1 / 2$ to 16 in. above the slab

Figure 114. Bay $2 \mathrm{~N}$ cooling season masonry block wall and soil temperature profiles $5-1 / 2$ to 16

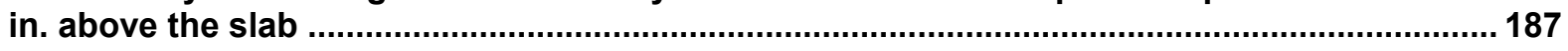

Figure 115. Bay 2N moisture transport phenomenology ........................................................... 188

Figure 116. Bay 3N moisture transport phenomenology ............................................................... 189

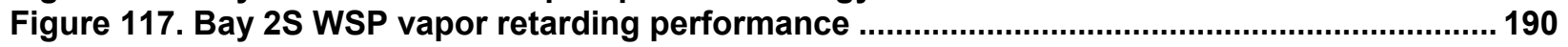

Figure 118. Bay 2N WSP vapor retarding performance ................................................................ 191

Figure 119. Moisture performance of Bay 5S rim-joist cavity with uninsulated rim board............. 192

Figure 120. Moisture performance of Bay 5S rim-joist cavity with insulated rim board ................. 193

Figure 121. Wetting/drying profiles for Bay 5S rim-joist cavity with uninsulated rim board ........... 194

Figure 122. Wetting/drying profiles for Bay 5S rim-joist cavity with insulated rim board .............. 195

Figure 123. Moisture performance of Bay $5 S$ bond beam block below rim-joist cavity .................. 196

Figure 124. Water diffusion through Bay $5 \mathrm{~S}$ bond beam block below rim-joist cavity................... 197 
Figure 125. Bay 5S rim-joist cavity bounding surface vapor pressure profiles with uninsulated rim board

Figure 126. Bay $5 \mathrm{~S}$ rim-joist cavity bounding surface vapor pressure profile with insulated rim board

Figure 127. Bay 5N rim-joist cavity interior vapor pressure gradient with uninsulated rim board 200

Figure 128. Bay $5 \mathrm{~N}$ rim-joist cavity interior vapor pressure gradient with insulated rim board..... 200

Figure 129. Bay 5S rim-joist cavity interior vapor pressure gradient with uninsulated rim board 201

Figure 130. Bay 5S rim-joist cavity interior vapor pressure gradient with insulated rim board..... 201

Figure 131. Bay 1 WSP interior condensing surface Minnesota Energy Code compliance performance

Figure 132. Two-dimensional WUFI simulation domain and boundary conditions ....................... 204

Figure 133. Two-dimensional WUFI simulation domain discretization ...........................................2 205

Figure 134. Bay 1N BUFETS/WUFI-2D wall temperature comparisons 40-1/4 in. above the slab .... 208

Figure 135. Bay 1N BUFETS/WUFI-2D wall temperature comparisons $86-1 / 4$ in. above the slab .... 210

Figure 136. Bay 1N BUFETS/WUFI-2D vertical soil temperature profile comparisons .................... 211

Figure 137. Bay 2N BUFETS/WUFI-2D wall temperature comparisons $40-1 / 4$ in. above the slab .... 213

Figure 138. Bay 2N BUFETS/WUFI-2D wall temperature comparisons $86-1 / 4$ in. above the slab .... 214

Figure 139. Bay 2N BUFETS/WUFI-2D vertical soil temperature profile comparisons .................. 215

Figure 140. Bay $1 \mathrm{~N}$ wall experiment/WUFI simulation temperature comparison $5-1 / 2$ in. above the slab

Figure 141. Bay $1 \mathrm{~N}$ wall experiment/WUFI simulation temperature comparison $40-1 / 4 \mathrm{in}$. above the slab

Figure 142. Bay $1 \mathrm{~N}$ wall experiment/WUFI simulation temperature comparison $69-1 / 4$ in. above the slab.

igure 143. Bay $1 \mathrm{~N}$ wall experiment/WUFI simulation temperature comparison $79-1 / 4 / 86-1 / 4$ in.

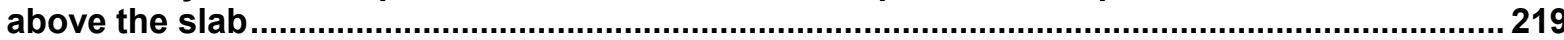

Figure 144. Bay $1 \mathrm{~N}$ soil vertical profile experiment/WUFI simulation temperature comparison.... 220

Figure 145. Bay $1 \mathrm{~N}$ soil horizontal profile experiment/WUFI simulation temperature comparison

Figure 146. Bay $2 \mathrm{~N}$ wall experiment/WUFI simulation temperature comparison $5-1 / 2$ in. above the slab

Figure 147. Bay $2 \mathrm{~N}$ wall experiment/WUFI simulation temperature comparison $40-1 / 4 \mathrm{in}$. above the slab.

Figure 148. Bay $2 \mathrm{~N}$ wall experiment/WUFI simulation temperature comparison $69-1 / 4$ in. above the slab

Figure 149. Bay $2 \mathrm{~N}$ wall experiment/WUFI simulation temperature comparison $79-1 / 4$ and $86-1 / 4$ in. above the slab.

Figure 150. Bay $2 \mathrm{~N}$ soil vertical profile experiment/WUFI simulation temperature comparison.... 226

Figure 151. Bay $2 \mathrm{~N}$ soil horizontal profile experiment/WUFI simulation temperature comparison

Unless otherwise noted, all figures were created by NorthernSTAR. 


\section{List of Tables}

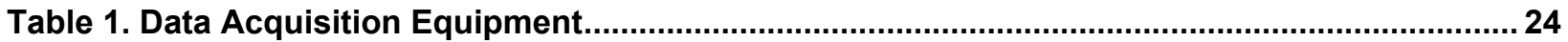

Table 2. Data Collection and Control Schedule Through March 31, 2014........................................ 26

Table 3. Annual Wetting/Drying Stability Code Compliance ...................................................... 91

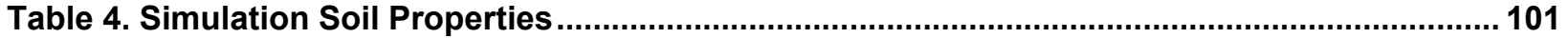

Table 5. Soil Volumetric Moisture Content 5 in. From the Wall................................................... 120

Table 6. Average Calculated Vertical Profile Soil Thermal Conductivity .......................................121

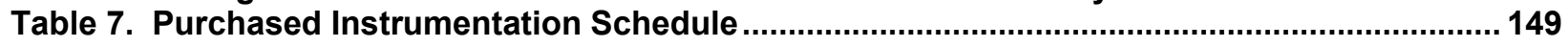

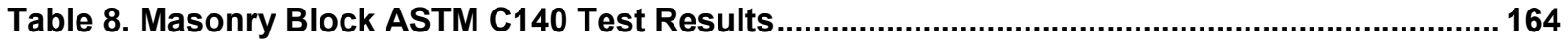

Table 9. Masonry Block Face Shell ASTM C140 Test Results ........................................................165

Table 10. Wood Sample Drying Data (per ASTM D4442).............................................................. 171

Unless otherwise noted, all tables were created by NorthernSTAR. 


\section{Definitions}

\begin{tabular}{|c|c|}
\hline $\mathrm{AH}$ & Absolute Humidity \\
\hline BEoptE+TM & Building Energy Optimization/EnergyPlus \\
\hline BUFETS & Building Foundation Energy Transport Simulation \\
\hline $\mathrm{CCW}$ & Carlisle Coatings and Waterproofing \\
\hline $\mathrm{CFC}$ & Cloquet Forestry Center \\
\hline CRRF & Cloquet Residential Research Facility \\
\hline CSV & Comma Separated Value \\
\hline ESDP & Energy Systems Design Program \\
\hline FAF & Final Archival Format \\
\hline FTF & Foundation Test Facility \\
\hline HVAC & Heating, Ventilation, and Air Conditioning \\
\hline IECC & International Energy Conservation Code \\
\hline LHS & Left-Hand Side \\
\hline M-MC & Mass Moisture Content \\
\hline NREL & National Renewable Energy Laboratory \\
\hline OSB & Oriented Strand Board \\
\hline ORNL & Oak Ridge National Laboratory \\
\hline RH & Relative Humidity \\
\hline RHS & Right-Hand Side \\
\hline V-MC & Volumetric Moisture Content \\
\hline WSP & Water Separation Plane \\
\hline WUFI & Wärme und Feuchte Instationär (Transient Heat and Moisture) \\
\hline XPS & Extruded Polystyrene \\
\hline
\end{tabular}




\section{Executive Summary}

This project was funded jointly by the National Renewable Energy Laboratory (NREL) and Oak Ridge National Laboratory (ORNL). ORNL focused on developing a full basement wall system experimental database to enable others to validate hygrothermal simulation codes. NREL focused on testing the moisture durability of practical basement wall interior insulation retrofit solutions for cold climates. The project has produced a physically credible and reliable long-term hygrothermal performance database for retrofit foundation wall insulation systems in zone 6 and 7 climates that are fully compliant with the performance criteria in the 2009 Minnesota Energy Code. These data currently span the period from November 10, 2012 through May 31, 2014 and are anticipated to be extended through November 2014. The experimental data were configured into a standard format that can be published online and that is compatible with standard commercially available spreadsheet and database software.

The main objectives of the project were to:

- Develop physically credible and reliable long-term hygrothermal performance data for retrofit foundation wall insulation systems that are fully compliant with the performance criteria in the Minnesota Energy Code.

- Generate public experimental data sets to validate and calibrate building foundation hygrothermal simulation codes that can be used to quantitatively assess compliance with the performance criteria.

- Test retrofit foundation wall systems with interior and exterior insulation placements.

- Determine experimentally whether the full basement foundation insulation retrofit systems tested are in compliance with the Minnesota Energy Code performance criteria.

- Use the heat flux, temperature, wall, and soil moisture content experimental data to investigate the validity of the Building Foundation Energy Transport Simulation (BUFETS) earth contact energy simulation program (as an example of a thermal diffusion transport-only program) when applied to the test bay wall systems under field conditions with imprecise (or fuzzy) material properties.

- Use the experimental data to ascertain whether the Wärme und Feuchte Instationär (WUFI)-2D hygrothermal simulation code can be applied to basement foundation systems.

- Ascertain whether the test wall systems meet the Minnesota Energy Code performance criteria in the presence of a severe internal humidity load during the heating season.

- Measure the vapor coupling between hollow masonry block wall cores and a sealed rimjoist cavity. Determine whether this coupling results in elevated moisture contents on the sill plate, rim board, and floor joist webs.

- Determine the impact of exterior rim board insulation with a class II permeance rating on reducing the condensation on the rim board interior surface.

- Configure the experimental data into a standard format that can be published online. 
Interior full-wall and exterior partial wall insulation retrofits were tested. No particular advantage was found for the partial wall exterior insulation system unless the insulation extends at least to the top of the rim joist, in which case the interior rim board surface relative humidity $(\mathrm{RH})$ was lowered substantially over the uninsulated case. However, the exterior insulation had no impact on the moisture contents of the sealed rim-joist cavity wood components that were the same as the uninsulated case under the experimental conditions. The heat flux performance of the partial wall exterior insulation was equivalent to that of full-wall interior insulation at the vertical center of the insulation only. It deteriorated as the top and bottom edges were approached. The experimental data showed that full-wall interior foundation insulation retrofits tested using adhered and nonadhered water separation planes (WSPs) were shown to be in compliance with the 2009 Minnesota Energy Code performance criteria.

The experimental thermal data were used to investigate the validity of the three-dimensional Building Foundation Energy Transport Simulation (BUFETS) earth contact energy simulation code when applied to the test bay walls under field conditions. The agreement between the experimental and simulation heat flux data was acceptable for calculating the seasonally integrated wall heat flows that are necessary to accurately simulate foundation envelope energy transport. Agreement between the measured and simulated wall and soil temperatures was better in the heating season and worse in the cooling season; the discrepancy in the wall temperatures decreased with height above the slab. Two omissions in the BUFETS program were recognized as being the likely causes for the discrepancies: (1) its inability to model buoyant cavity flow loops in hollow masonry block walls; and (2) its inability to model a water table with a seasonally varying height and temperature. Secondary omissions were also recognized; for example, the absence of a soil moisture transport model enabling the calculation of seasonally varying thermal conductivities as a function of soil moisture content.

The WUFI-2D hygrothermal simulation program in its current standard form was unable to model the basement foundation systems tested. The program failed to yield a solution to the moisture transport equation included in its algorithm. The team tried unsuccessfully to resolve the problems with the program developers. The thermal component of the simulation did yield results that were compared to the experimental data. In almost every comparison case, the magnitudes of the experiment/simulation temperature differences obtained with WUFI-2D were greater than those obtained with BUFETS, particularly during the heating season.

The test wall systems were exposed to conditions of high basement interior humidity $(50 \% \mathrm{RH}$ for 2 weeks) during January and February 2014. The experimental data tentatively show that the wall systems did meet the Minnesota Energy Code performance criteria for this period, but final confirmation will require dismantling of the wall system, which can be accomplished only after the part of the experiment not funded by NREL has been completed.

The data reveal that neither adhered nor nonadhered interior WSPs produced perpetually wet walls during the experiment. The data show that the $\mathrm{RH} /$ temperature/time profile in the drainage cavity between the nonadhered WSP and the wall during the experiment is sufficient to grow mold if enough nutrients are available.

The vapor coupling between hollow masonry block walls and a sealed rim-joist cavity with and without exterior rim board insulation was measured. The experimental data revealed no coupling 
between moisture-saturated $(100 \% \mathrm{RH})$ cores and the moisture content of any rim-joist cavity wooden boundary components with and without exterior insulation. No coupling was revealed between a wall top course face shell elevated moisture content and the wooden cavity boundary components. This was ascribed to the top course of the wall being a solid bond beam block that yields an adequate class II vapor retarder, which effectively isolates the rim-joist cavity from the masonry block wall cores and from elevated basement interior humidity conditions. A solid top course is adequate to isolate the rim-joist cavity from the vapor-saturated cores of a hollow masonry block wall, provided that the top course is not wetted by exterior bulk water.

Exterior rim board thermal insulation with a class II permeance rating did not reduce the condensation on the rim board interior surface under the experimental conditions. This arose because the vapor transport from all sources (including the masonry block cores and the basement interior) was so low that the potential for condensation was severely restricted. Further, even without exterior insulation, the $\mathrm{RH}$ on the rim board interior face never reached vapor saturation conditions.

Calibrated instrumentation was developed to continuously measure the exterior and interior masonry block face shell moisture contents. These data are essential for evaluating the accuracy of hygrothermal simulation programs and for determining the moisture status of basement walls before the interior insulation systems tested are installed.

The project has contributed to the understanding of long-term hygrothermal transport in foundation walls and has generated specific guidance on how to install durable basement wall insulation systems in cold climates. This contribution has been quantified in the form of a public domain experimental database that currently spans a period of about $1-1 / 2$ years. Whether this database will be made available to the public over the long term is beyond the scope of this project and will ultimately be at the discretion of the sponsors. 


\section{Introduction}

The full basement foundation insulation retrofit experimental program described in this report was funded jointly by the National Renewable Energy Laboratory (NREL) as part of the NorthernSTAR Building America program and by Oak Ridge National Laboratory (ORNL) as part of the US Climate Zone Specific Foundation Insulation Recommendations program.

The NREL and ORNL parts of the project commenced in February and July 2012, respectively. Data acquisition commenced in November 2012 and continued through March 31, 2014 for the NREL part of the project. Data will continue to be collected on the ORNL part of the project through November 2014. This report is devoted to the NREL part of the project, which focused on the experimentally measured hygrothermal phenomenology of retrofit foundation insulation systems. ORNL focused on collecting experimental data to enable others to validate and test hygrothermal simulation programs.

\subsection{University of Minnesota Foundations Technical Background}

The 2012 International Energy Conservation Code (IECC) stipulates, for climate zones 6 and 7 , foundation wall insulation resistance values of $R_{u s}-19$ for interior cavity insulation and $R_{u s}-15$ for interior, integral, or exterior continuous insulation (usually rigid or semirigid board or sprayapplied) to increase the energy conservation of residential buildings. However, the IECC provides no guidance on the hygrothermal and moisture durability requirements for the installation of this amount of insulation thermal resistance.

The state of Minnesota requires by statute (326B.115) that the commissioner "may not adopt all or part of a model energy code relating to the construction of residential buildings without research and analysis that addresses [sic], at a minimum, air quality, building durability, moisture, enforcement, enforcement cost benefit, and liability." The Energy Systems Design Program (ESDP) at the University of Minnesota was the lead in conducting the due diligence building science research for residential building foundation wall and slab insulation systems that were incorporated into the 2009 Minnesota Energy Code. This research (Goldberg and Huelman 2005) provided the physics basis for the code language in section N1 102.2.6 (Basement Walls) in chapter 1322 of the 2009 Minnesota Rules. This chapter is essentially devoted to a recitation of the requirements for installing hygrothermally durable foundation wall insulation systems in cold climates (zones 6 and 7). The chapter is further divided into two main sections: a prescriptive option and a performance option. The performance option stipulates a set of criteria necessary for all foundation systems to meet in order to achieve sustainable moisture durability and thus provides, theoretically at least, the basis for the prescriptive rules. These criteria are completely generalized. They are independent of the type, thermal resistance, placement of the foundation wall insulation, and climate. Subsequently, these criteria were generalized to the entire building envelope for all climates (Goldberg et al. 2010).

The performance criteria were based on 17 years (1988-2005) of experimental hygrothermal foundation research at the University of Minnesota's Foundation Test Facility (FTF). This facility was originally established in 1987-1988 with funding from the U.S. Department of Energy. This research was supplemented with additional experimental work conducted at the University's Cloquet Residential Research Facility (CRRF). The FTF was closed in 2009 because the lease on 
the land on which it was built could no longer be renewed. Experimental research has continued at the CRRF.

This experience of inculcating physically sound durability rules for foundations into the Minnesota Building Code has demonstrated conclusively that there is no substitute for full-scale testing of the long-term durability of foundation envelope insulation systems to prove their durability under worst-case boundary conditions. This testing is of particular value when the results are useful for validating numerical models that can be used to extend the results to other cases and boundary conditions. This is very relevant to retrofit foundation insulation systems in older residential buildings that often have foundation walls with no waterproofing, damp-proofing, or drainage systems and very high interior humidities, particularly in the cooling season. Test protocols such as the "IEA BESTEST: In-Depth Diagnostic Cases for Ground Coupled Heat Transfer Related to Slab-on-Grade Construction" (Neymark and Judkoff 2008) can be used to assess the thermal modeling accuracy of numerical models ${ }^{1}$, but these do not address hygrothermal modeling or nonlinear heat transport.

From a foundation energy modeling perspective, the cost effectiveness of installing durable retrofit foundation insulation systems is difficult to quantify because most whole-building energy simulation programs (including Building Energy Optimization E+ [BEoptE+TM]) do not adequately model latent loads. Determining such latent loads requires modeling the ground-tobasement vapor and bulk water flows so that the energy impact of reducing or eliminating these flows can be calculated.

One current key issue with the ability to design moisture durable foundation systems in general, and in meeting the performance criteria in the Minnesota Energy Code in particular, is the lack of a validated hygrothermal simulation program that can be used to quantitatively assess whether a given foundation insulation system design can meet the performance criteria. Again, the ESDP was tasked by the state of Minnesota to perform the due diligence building science durability analysis for incorporating the 2012 IECC foundation insulation thermal resistance requirements into the 2012 Minnesota Energy Code. This required that insulation systems be evaluated for which cold climate experimental hygrothermal performance data are not available. This posed a particular challenge in using a hygrothermal simulation program ${ }^{2}$ to generate adequate- even if highly approximate - supporting data (Goldberg 2012). The major issue in the lack of such simulation programs is the absence of appropriate, experimental data with which to validate the hygrothermal results. This test program seeks to remedy this problem as part of the ORNL-funded part of the project.

\subsection{Moisture Considerations for Retrofit Foundation Insulation}

The critical issue in installing retrofit foundation wall insulation is the moisture status of the wall. The status generally falls into one of three cases:

\footnotetext{
${ }^{1}$ Linear models based on Fourier's law only.

${ }^{2}$ Wärme und Feuchte Instationär (WUFI)-2D version 3.3.
} 
- The wall is dry. In this case no bulk water is leaking through the wall at the time of inspection and there is no historical record of leakage. Further, when covered with a sealed nonadhered water separation plane (WSP) on test sections around the foundation wall, no condensation appears on the exterior (or wall-side) surface of the WSP at any time during the cooling season.

- The wall is wet. There is historical or present evidence of bulk water seepage through the wall.

- The wall is intrinsically wet. In this case there is no evidence of bulk water seepage; however, vapor movement (either by diffusion or advection or both) produces condensation on the exterior surface of a test section WSP in the cooling season.

In the case of a dry wall in dry soil conditions, an interior WSP may not be necessary, even though it is required by the performance criteria in the 2009 Minnesota Energy Code. ${ }^{3}$ Nevertheless, installing an interior WSP under these conditions need not have any durability impacts (depending on the design of the interior insulation system, if any) and allows the benefits of this practice (such as a reduction in heating, ventilation, and air conditioning [HVAC] latent loads) to be realized.

With an intrinsically wet wall, an adhered WSP may be the best solution, assuming that the wall does not become wet enough for the WSP to de-adhere or for freeze/thaw cycling structural damage to occur. The chief advantage of an adhered WSP is that it eliminates the potential for a perpetually moist drainage cavity between the WSP and the wall that generally experiences temperature and relative humidity (RH) conditions favorable for mold growth (Goldberg 2012).

For a wet wall with active bulk water seepage, a nonadhered WSP may be the only practical choice. However, adhered spray-applied WSPs may be effective, assuming there is sufficient drainage within the structural wall system to effectively remove the water from the wall cores (in masonry block walls) and to keep the moisture content low enough to prevent freeze/thaw cycle structural damage. In the case of poured concrete walls, the adhered WSP would have to be robust enough to withstand hydrostatic pressure without blistering or peeling from the wall. The issue with a nonadhered WSP is the potential for a perpetually wet drainage cavity and the consequences such as possible mold growth and freeze/thaw cycle structural damage.

Usually, retrofit foundation insulation applications rely on interior insulation placement. As alluded to above, if the interior insulation system has an adequately sealed warm-side air barrier (to avoid vapor bypass through gaps in the insulation system) and the net vapor permeance of the insulation is in the class II range, ${ }^{4}$ a continuously wet interior WSP surface can be avoided (winter wetting dries out during the summer).

\footnotetext{
${ }^{3}$ The principal investigator has witnessed examples of this in a cold climate with well-drained sandy soil backfills with moderate levels of interior insulation (R-11 or lower).

${ }^{4}$ Permeance of $0.1-1$ US-perms. The recommendation proposed for spray-applied foam insulation in Goldberg (2012), for example, is "a permeance not greater than 0.8 in accordance with ASTM E96 procedure A and not less than 0.3 in accordance with ASTM E96 procedure B" (both limits in US-perms).
} 
When partial wall exterior insulation is contemplated as a retrofit solution, thermal effectiveness ${ }^{5}$ and the extent to which the exterior location improves the hygrothermal performance of an uninsulated wall need to be considered. If the effectiveness is the same as or better than full wall insulation (either exterior or interior) and the hygrothermal performance improvements are measurable, deployment of partial wall exterior insulation using hydro-vacuum excavation or other potentially less expensive techniques may be a cost-effective foundation wall insulation retrofit solution.

Installing a retrofit interior insulation system with an interior WSP can have hygrothermal impacts on the rim-joist cavity. Previous research at the CRRF (Goldberg and Huelman 2001) concluded that (1) there is vapor coupling between the cores of masonry block walls and the condensation on the interior face of the rim board; and (2) exterior rim-joist insulation does reduce the amount of condensation on the rim board interior face. However, these results were based on an experimental configuration that did not fully isolate the rim-joist cavity from the basement interior vapor source; thus, the conclusion with regard to the core/rim-joist cavity moisture coupling can only be regarded as speculative. Rim-joist treatments in foundation wall insulation retrofits are important because the rim joist is a prime target for mold and rot. The core/cavity moisture coupling phenomenology needs to be experimentally clarified and strengthened so that retrofit rim-joist cavity insulation strategies can be devised and implemented cost effectively. In particular, installing a WSP beneath the sill plate in a retrofit application can be very expensive (because the house may need to be jacked off the foundation to insert the WSP). The need for vapor isolation between the hollow core of a masonry block wall and the wood components of a rim-joist cavity (sill plate and rim board in particular) thus needs to be experimentally justified.

The experiments conducted during this project enable a comprehensive assessment of these issues.

\subsection{Objectives}

The key long-term objectives of the cold climate foundation wall insulation hygrothermal test program focused on retrofitted basement wall systems in this project are:

- Develop physically credible and reliable long-term hygrothermal performance data for retrofit foundation wall insulation systems that are fully compliant with the performance criteria in the Minnesota Energy Code.

- Generate public experimental data sets to validate and calibrate building foundation hygrothermal simulation codes that can be used to quantitatively assess compliance with the performance criteria.

- Test retrofitted foundation wall systems with interior and exterior insulation placements.

- Determine experimentally whether the full basement foundation insulation retrofitted systems tested are in compliance with the Minnesota Energy Code performance criteria.

\footnotetext{
${ }^{5}$ Thermal effectiveness is defined as the ratio: one-dimensional heat flux/three-dimensional heat flux for the same thermal resistance.
} 
- Use the heat flux, temperature, wall, and soil moisture content experimental data to investigate the validity of the BUFETS ${ }^{6}$ earth contact energy simulation program (as an example of a thermal diffusion transport-only program) when applied to the test bay wall systems under field conditions with imprecise (or fuzzy) material properties.

- Use the experimental data to ascertain whether the WUFI-2D hygrothermal simulation code can be applied to basement foundation systems.

- Ascertain whether the test wall systems meet the Minnesota Energy Code performance criteria in the presence of a severe ${ }^{7}$ internal humidity load during the heating season.

- Measure the vapor coupling between hollow masonry block wall cores and a sealed rimjoist cavity. Show whether this coupling results in elevated moisture contents on the sill plate, rim board, and floor joist webs.

- Determine the impact of exterior rim board insulation with a class II permeance rating on reducing the condensation on the rim board interior surface.

- Configure the experimental data into a standard format that can be published online.

Additional objectives include:

- Test whether an adhered WSP is susceptible to delamination.

- Investigate whether adhered or nonadhered WSPs result in perpetually wet walls. If so, determine whether the moisture content/temperature profile is sufficient to produce freeze/thaw cycle structural damage.

- Determine whether the RH/temperature/time profile within the drainage cavity between the nonadhered WSP and the wall is sufficient to grow mold and, if so, the severity of the potential.

- Measure the thermal effectiveness of exterior partial wall insulation. Compare this with that of full-wall interior insulation.

- Continuously measure the exterior and interior masonry block face shell moisture contents.

\subsection{Cost Effectiveness and Other Benefits}

Previous research has shown that the likely total site energy savings (aggregate of utility metered electricity and natural gas usage) based on sensible energy considerations only that can be expected from foundation insulation are fairly modest. For example, continuous R-15 interior insulation (compliant with 2012 IECC) installed on bare, full-basement foundation walls in a cold

\footnotetext{
${ }^{6}$ BUFETS is strictly an energy simulation code that does not include any moisture transport.

${ }^{7}$ What constitutes a "severe" heating season internal humidity load in a cold climate basement is a matter of considerable dispute. Ultimately, this reduces to an assessment of liability; that is, what is the minimum test condition necessary to ensure that the foundation wall systems will be durable in $99 \%$ of imposed field moisture conditions (for example, typical Minnesota basements operate at no higher than $40 \% \mathrm{RH}$ at $68^{\circ} \mathrm{F}$, but humidification for occupant health reasons or a failed clothes dryer vent can easily increase this beyond $50 \%$ ). In this project, the interior basement humidity was ramped up to 50\% in January 2014 and held at that level for about 2 weeks before being ramped down again.
} 
climate yielded simulated savings of $10 \%$ or $\operatorname{less}^{8}$ (Goldberg and Steigauf 2011). A well-insulated and airtight, single-story, 400- $\mathrm{ft}^{2}$ building with a monolithic, shallow, slab-on-grade foundation yielded experimental site energy savings of less than $15 \%$ with R-10 vertical and wing insulation (Goldberg 2011). The savings realized depend on a host of building parameters, such as:

- Size of the conditioned space

- Above-grade/below-grade enclosure surface area ratio

- Thermal integrity (R-value and infiltration flow rate) of the above-grade enclosure

- Whether the basement has independent temperature control

- Interior air movement, particularly buoyant, convective flows (stack effect)

- Occupant lifestyle.

The site energy savings from foundation insulation in zone 6 and 7 climates may not exceed 15\%, especially for full basement insulation when the basement is not separately zoned. Thus, achieving simple payback periods of 10 years or shorter is unlikely, making the justification of foundation insulation by this metric alone (sensible energy savings) questionable.

When considering other metrics in combination with site energy savings, foundation insulation becomes a more financially attractive proposition. Installing retrofit foundation insulation systems that are fully compliant with the Minnesota Energy Code performance criteria has several additional advantages that are more important than the energy cost savings for the homeowner. A key feature of a compliant retrofit insulation system is that it has an intact WSP that isolates the foundation interior from the surrounding soil. This adds significant value in improving occupant comfort and indoor environmental quality as follows:

- Occupant comfort improvement. Foundation wall insulation yields warmer interior wall surfaces in winter and cooler above-grade wall surfaces in summer, thus reducing the radiant heat transfer between the occupants and the walls. In basements with floating temperatures, the insulation also increases the interior stagnation temperature (accompanied by the modest energy savings noted above). Both effects promote occupant comfort.

- Reduction of water vapor and bulk water transport through the foundation walls to a negligible amount. This also promotes occupant comfort by yielding a dry and odor-free basement, particularly in the cooling season. The soil surrounding basements in cold climates typically is saturated or close to saturated throughout the year, particularly during the cooling season (99\% or greater RH, Rasmussen and Rhodes 1995). Consequently, the reduction in latent (dehumidification) load could yield a substantial reduction in cooling costs. Nevertheless, if ambient summer temperatures and humidities continue their increasing trend in zones 6 and 7, these latent load reductions, which are

\footnotetext{
${ }^{8}$ Site energy savings for a two-story home with about $4000 \mathrm{ft}^{2}$ of conditioned space meeting the 2009 IECC: Madison, Wisconsin $=6 \%$; Minneapolis, Minnesota $=8 \%$; Bemidji, Minnesota $=9 \%$.
} 
almost always met by equipment powered by increasingly expensive electricity, could become substantial.

- Enhanced efficacy of subslab depressurization radon mitigation. Radon mitigation is required in certain cold climate urban areas for existing homes on resale and is a code requirement for new construction. Having a foundation wall system with a continuous WSP that provides a full air seal between the foundation interior and the surrounding soil improves the suction pressure on the surrounding soil by substantially reducing shortcircuit leaks across the foundation envelope.

This project does not address the cost of installing foundation insulation, because the systems were built for research purposes based on quality considerations alone. No attempts were made to deploy the most cost-effective materials or minimize the installation time. Thus, the cost effectiveness of foundation insulation cannot be directly addressed. However, in demonstrating the durability of the retrofit insulation systems being tested, a consistent basis is provided upon which builders can develop installations that are compliant with the tested systems at the lowest life cycle cost. 


\section{Description of the Experiment}

Four retrofit basement foundation insulation wall systems (installed in test Bays 1-4) and two rimjoist cavity hygrothermal test systems (installed on test Bay 5) have been constructed and instrumented at the CRRF in Cloquet, Minnesota. Cloquet is approximately 22 miles southwest of Duluth, Minnesota and is in climate zone 7. Because of its proximity to Lake Superior, the CRRF experiences lake-microclimatic conditions, especially lake-effect precipitation. Two of the experimental wall systems were built in collaboration with ORNL and thus fulfill a dual purpose: to demonstrate a particular retrofit foundation insulation design and to provide archival-grade experimental data for hygrothermal simulation code purposes.

The set of data collected as discussed below for Bays 1 and 2 was designed specifically to meet ORNL's requirements for validating the WUFI-2D hygrothermal simulation program. ${ }^{9}$ A key issue is the number of soil temperature and moisture content measurements and the locations of the ambient boundary condition measurements. Fewer than the ideal number of soil sensors may have been deployed in this experiment because of constraints imposed by ORNL.

The instrumentation for Bays 3-5 was designed to capture the key experimental metrics of foundation hygrothermal performance. The selection of this instrumentation was based on more than a decade of experimental experience at the University of Minnesota's FTF (Goldberg 2011).

\subsection{Experimental Configuration}

The experiment was built in five 10 -ft wide bays, each with a north and south wall of identical construction. Figure 1 shows a plan of the layout of the test bays in the west basement of the CRRF. The design and instrumentation for each unique test bay configuration are discussed separately. The specification and manufacturer's listed performance specifications of all the instrumentation purchased for use in the project at the CRRF are listed in Table 7 in Appendix A. Where provided (soil temperature and moisture content, RH and heat flux), the manufacturer's calibrations for the individual sensors were used. The thermocouple temperatures were calibrated via the National Institute of Standards and Technology monograph 125 tabulations. Masonry block and wood moisture contents were measured with electrical conductance-based instrumentation developed and calibrated during the project as described in Appendix B.

Figure 2 through Figure 6 show schematic drawings of the four wall and two rim-joist cavity systems. Appendix A provides a photographic record of the experiment's construction. Each schematic shows the physical and instrumentation designs. The designs of the wall systems suitable for a retrofit application experiment were determined by the requirements discussed by Goldberg and Steigauf (2011). In summary, these requirements reduce to the need for the retrofit foundation wall systems to be in compliance with the performance requirements of the 2009 Minnesota Energy Code. ${ }^{10}$

\footnotetext{
${ }^{9}$ Bays 1 and 2 are the "validation" test bays; ORNL provided most of the funding for these bays and approved all the specific sensors and quantity of the instrumentation installed.

${ }^{10}$ Minnesota Statutes, Chapter 1322, Section N1102.2.6.12.1.
} 


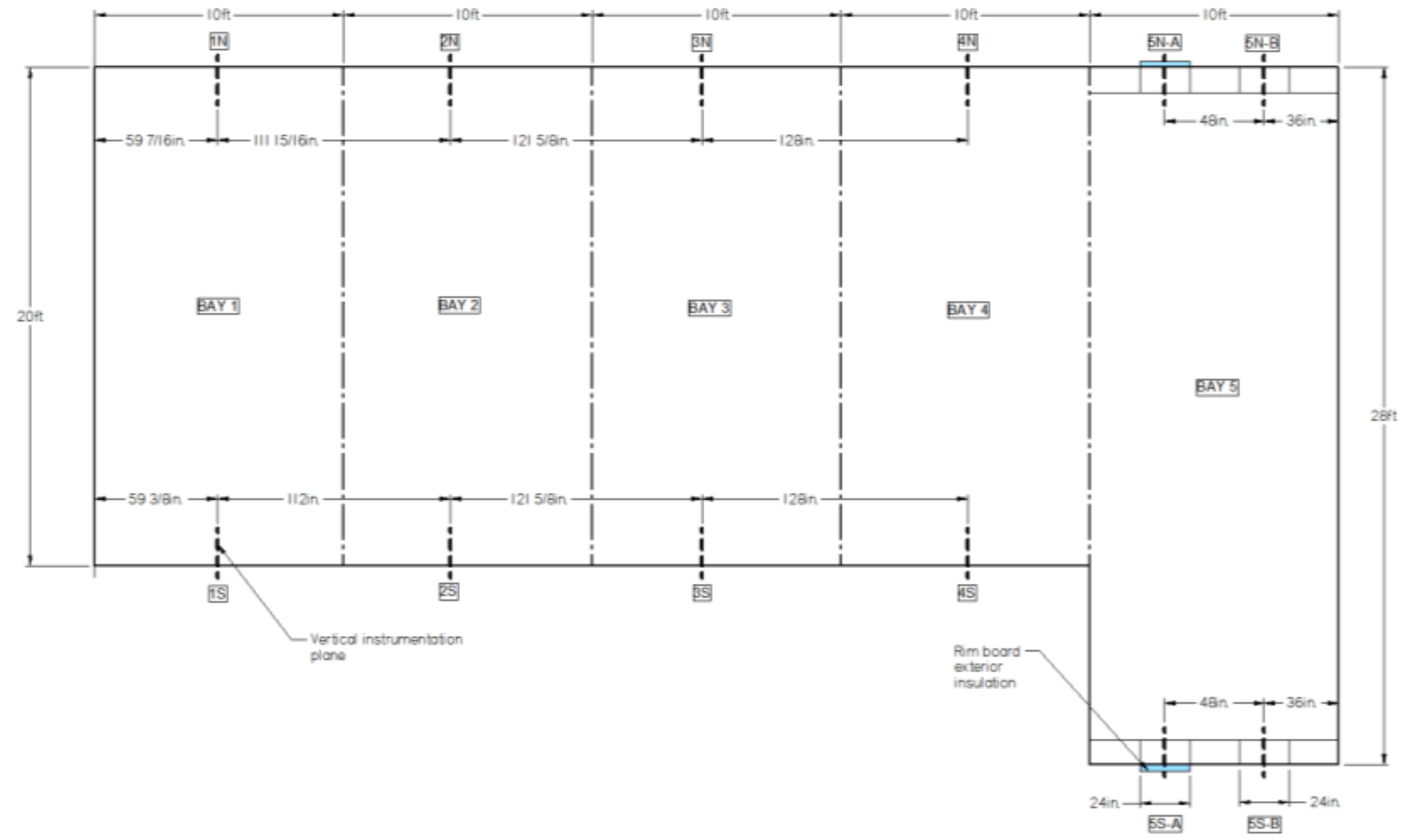

Figure 1. Plan view of test bay locations 

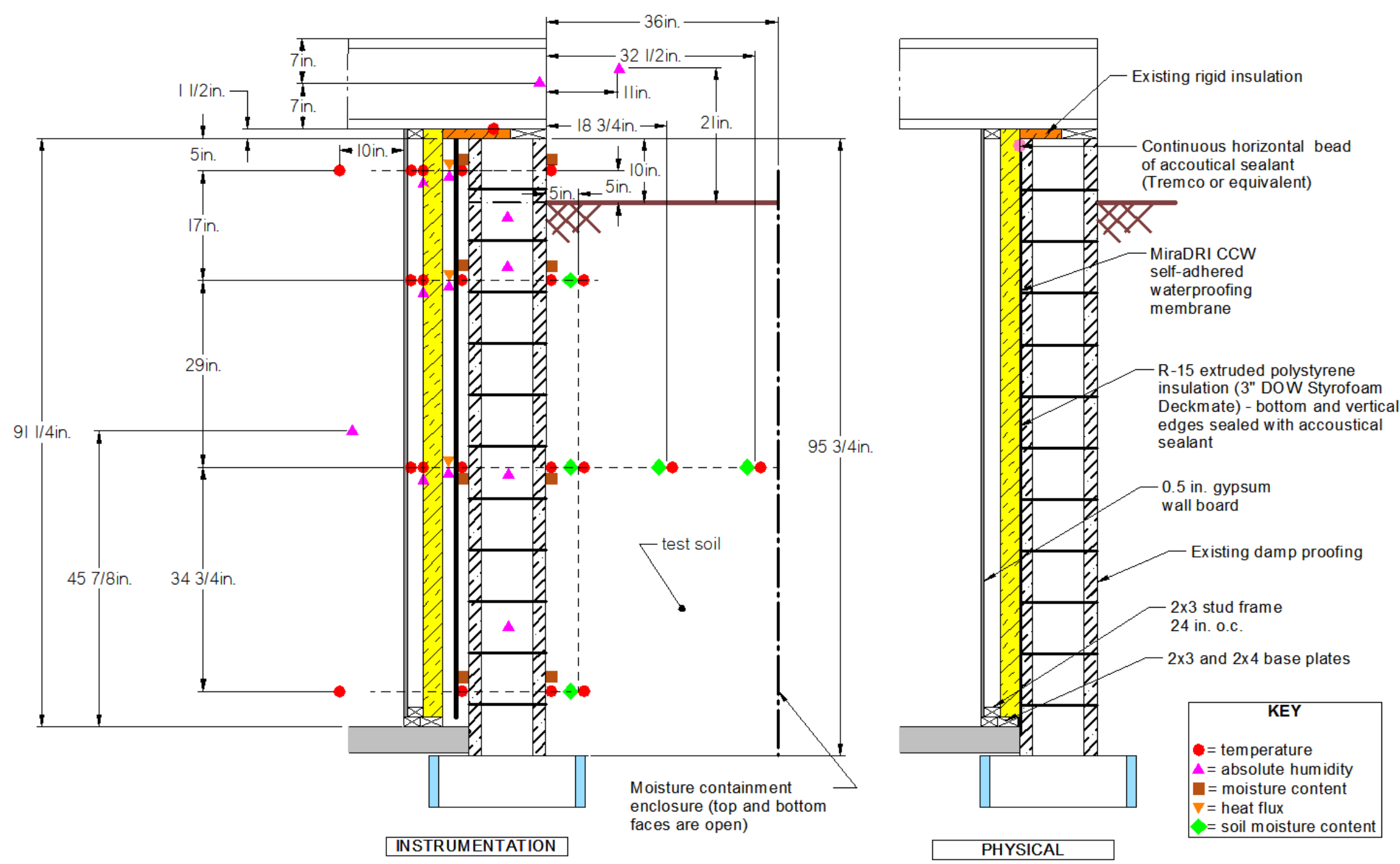

Figure 2. Bays 1 and 2 test wall system characteristics, dimensions, and instrumentation 


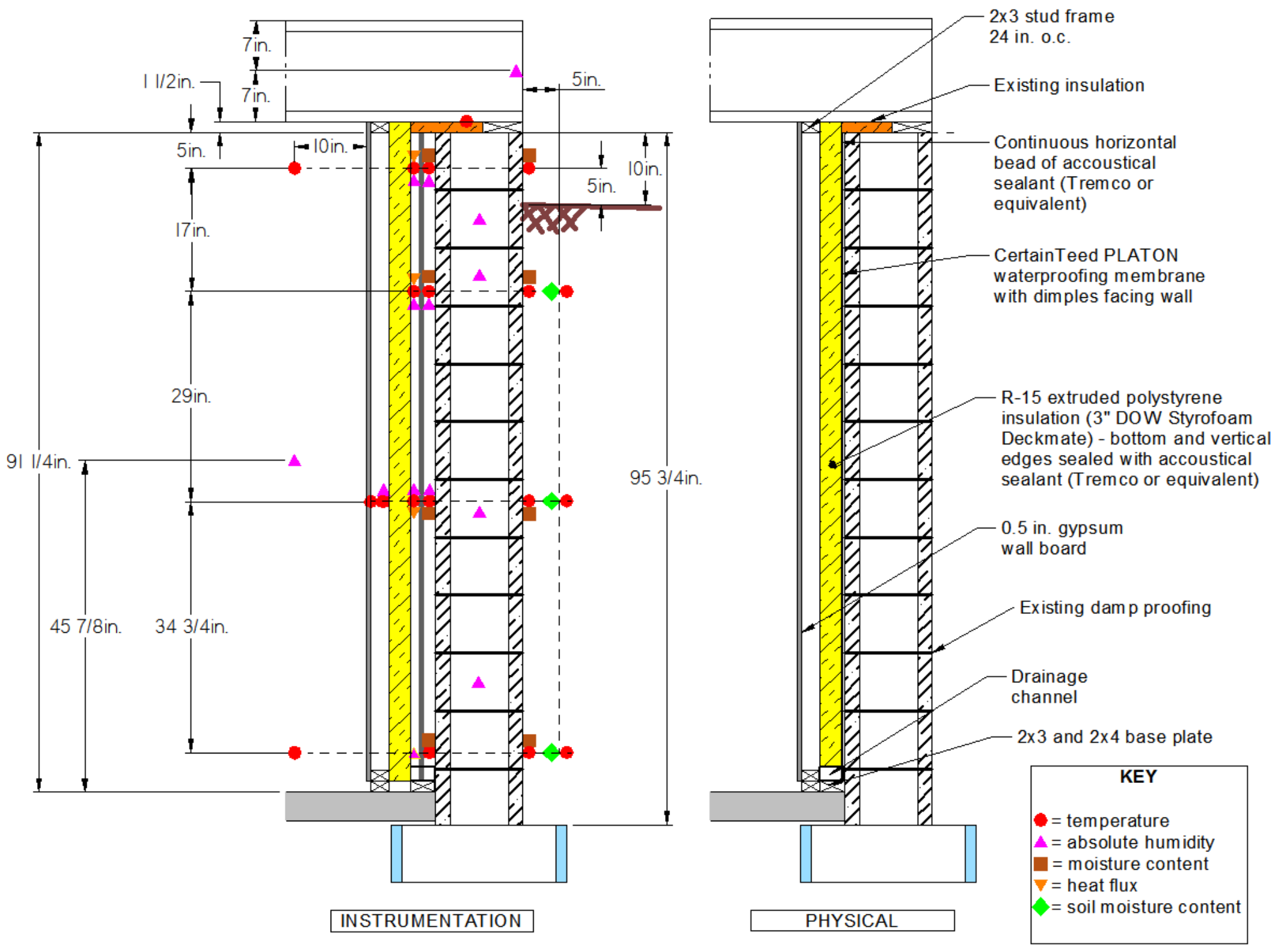

Figure 3. Bay 3 test wall system characteristics, dimensions, and instrumentation 


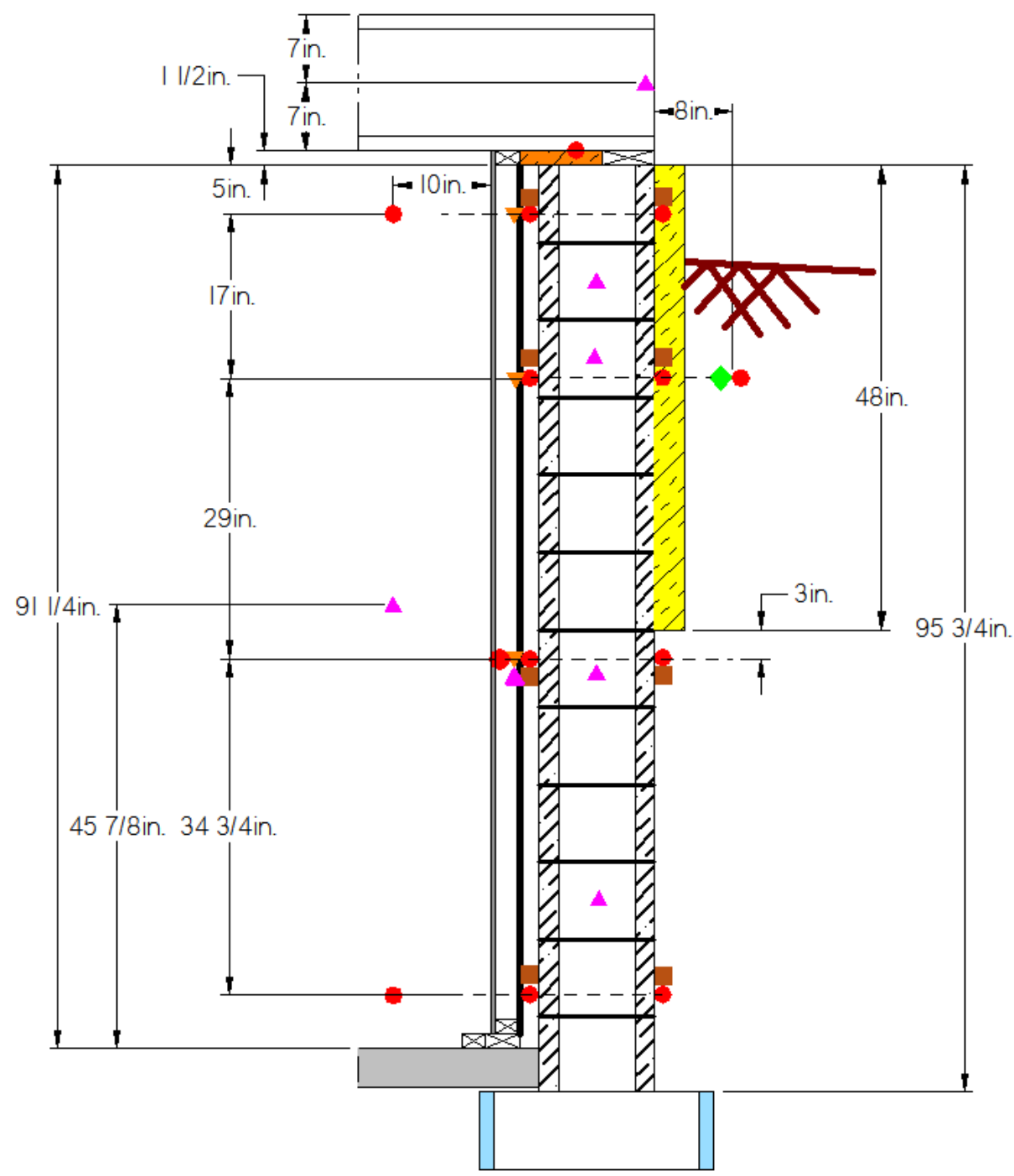

INSTRUMENTATION

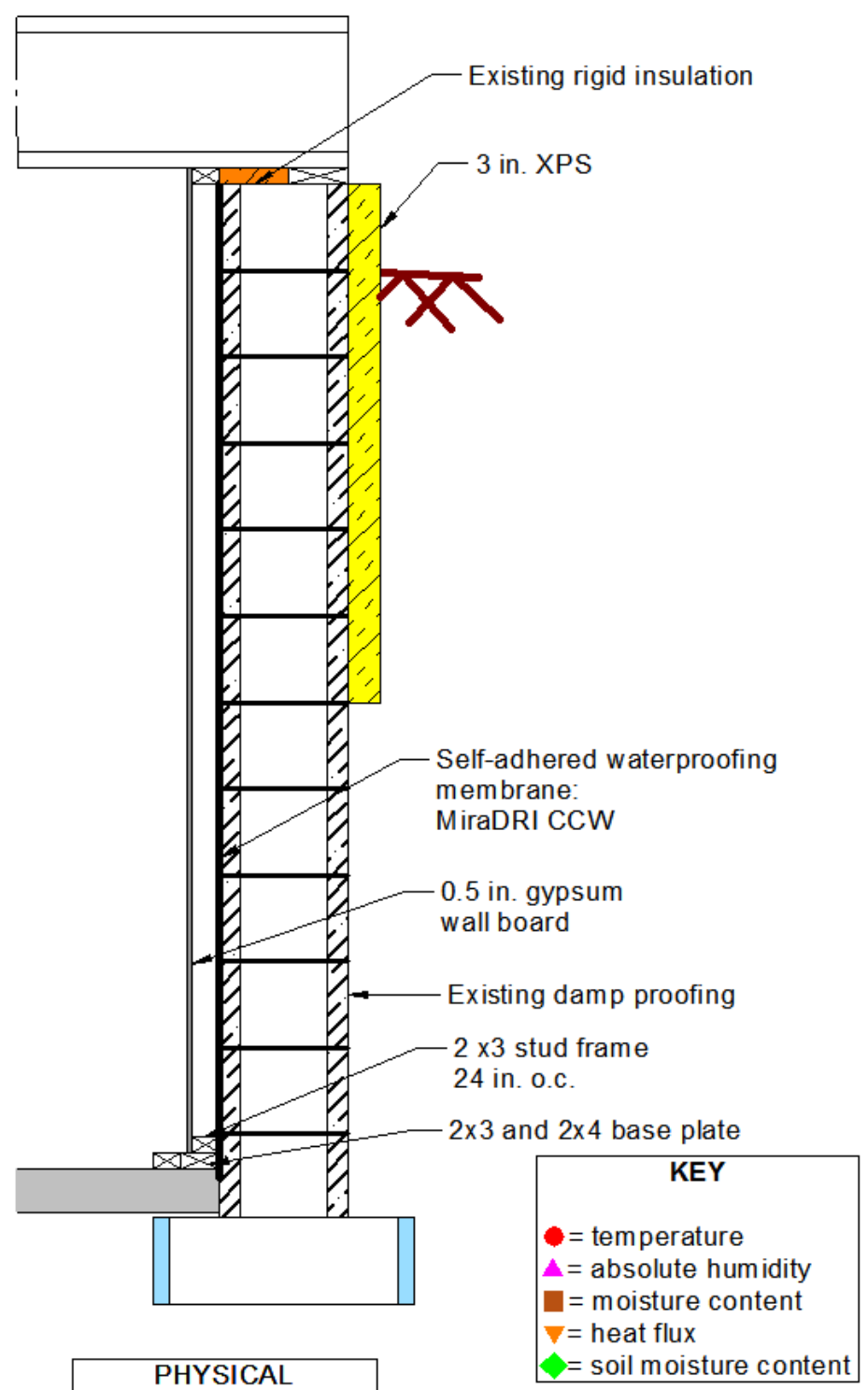

Figure 4. Bay 4 test wall system characteristics, dimensions, and instrumentation 

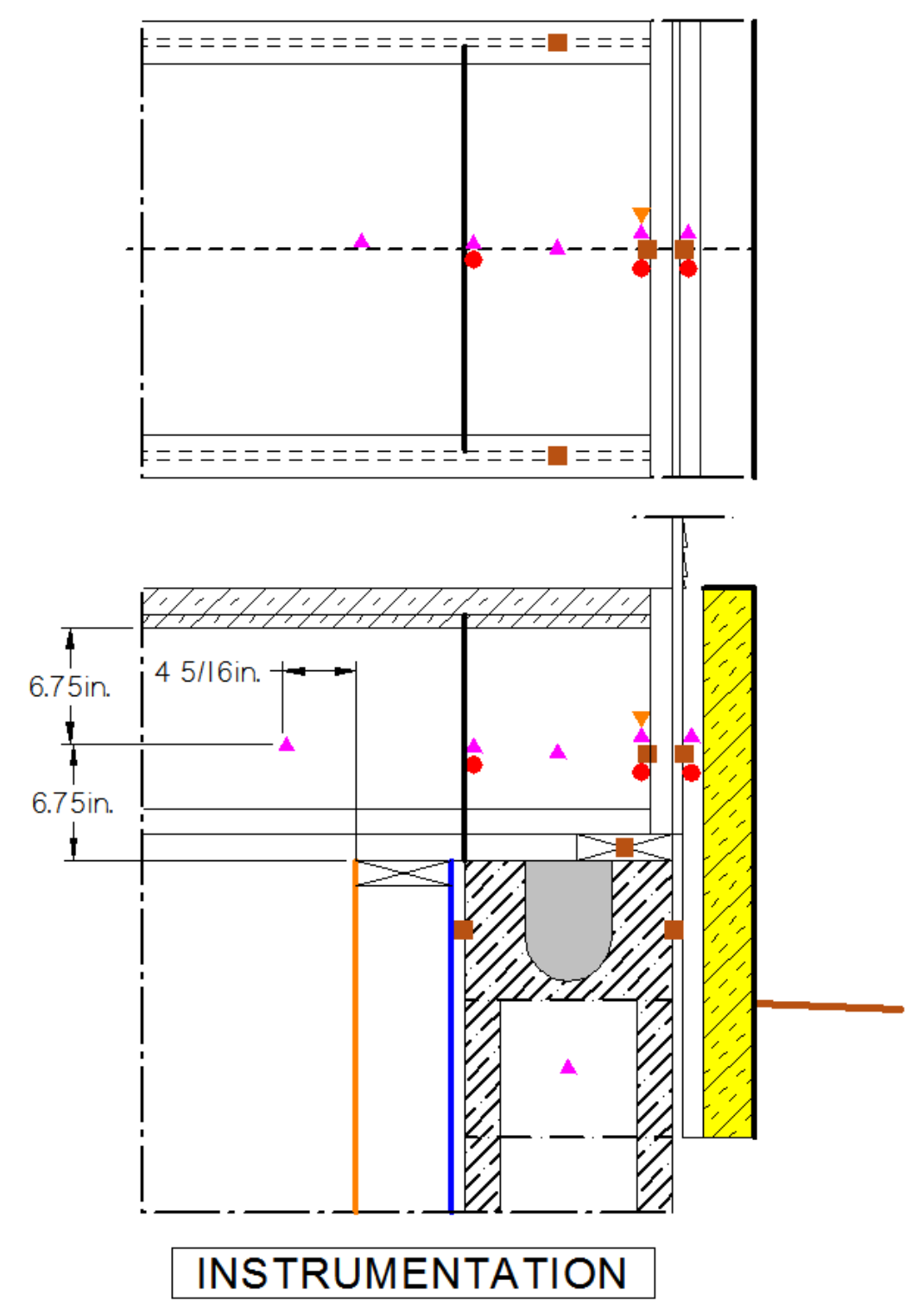
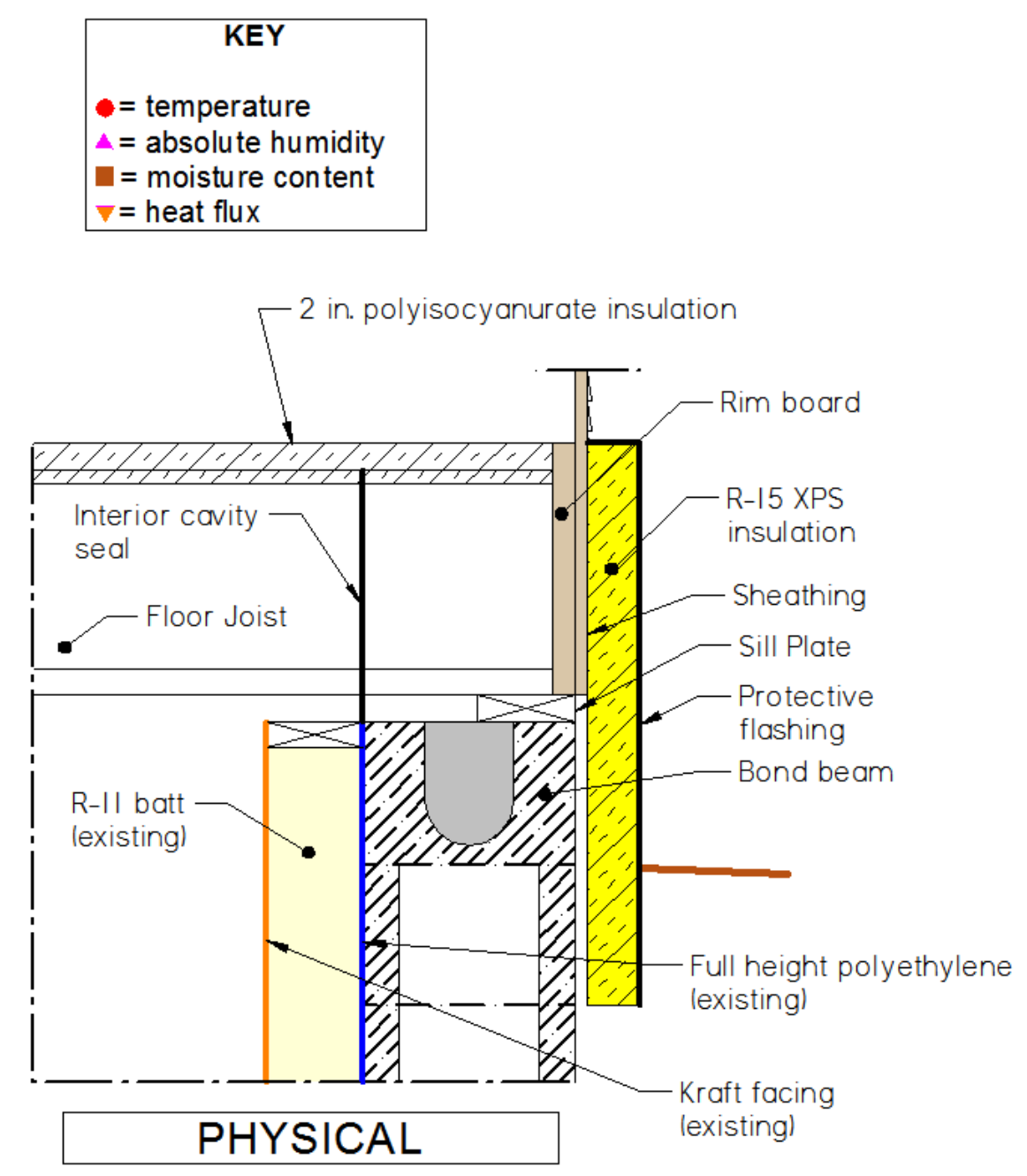

Figure 5. Bay 5A insulated test rim-joist cavity system characteristics, dimensions, and instrumentation 

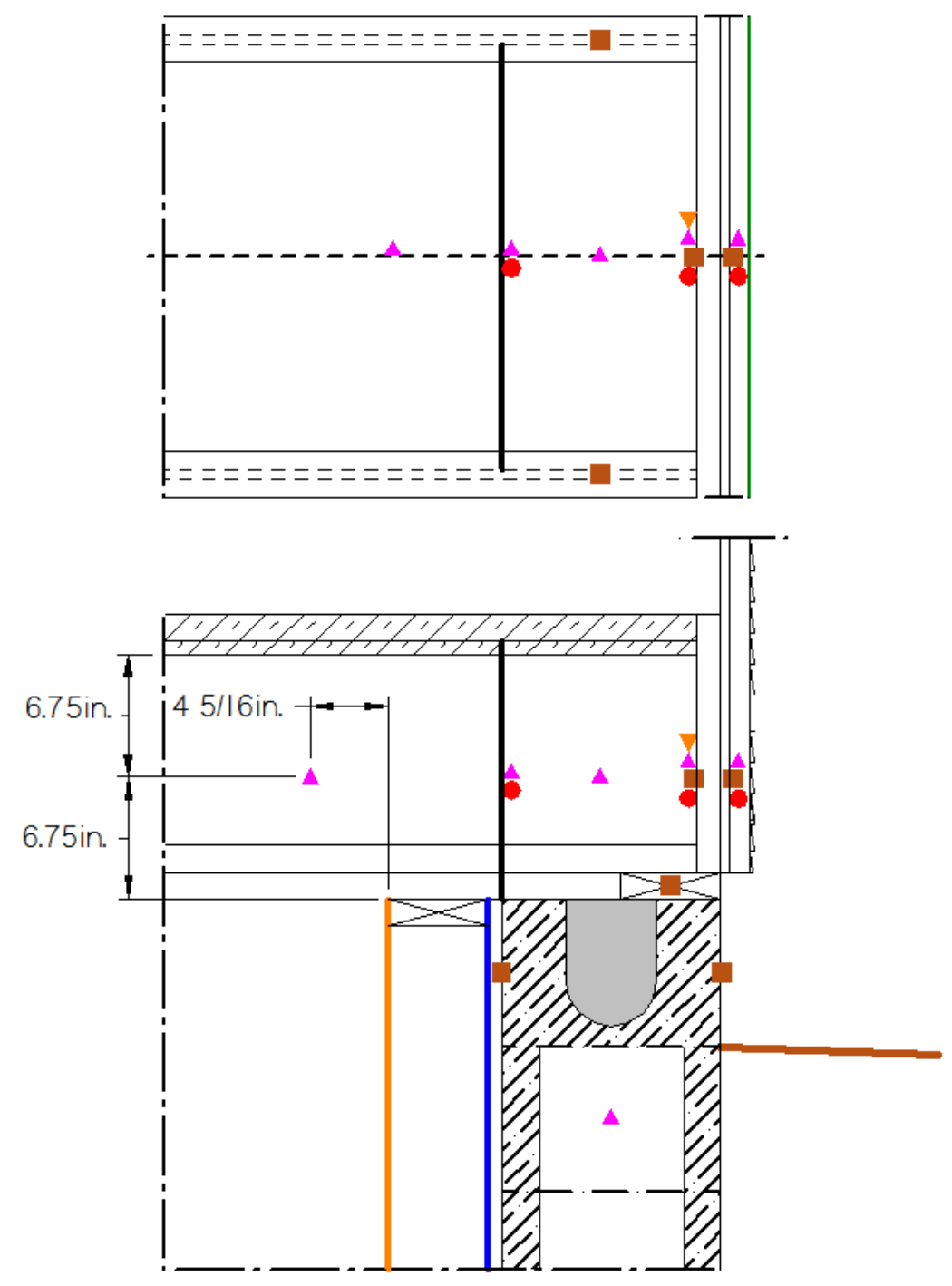

\section{INSTRUMENTATION}
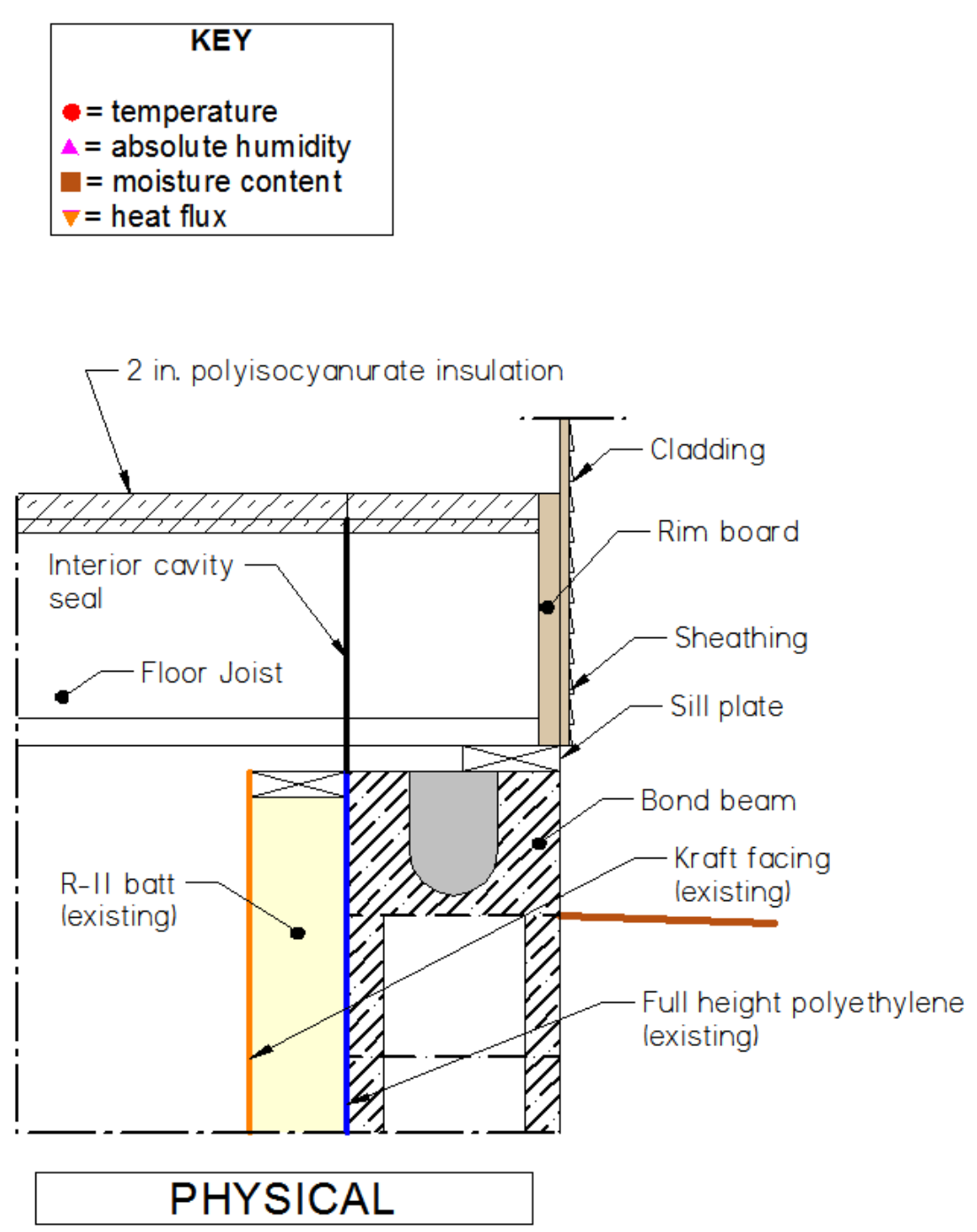

Figure 6. Bay 5B uninsulated test rim-joist cavity system characteristics, dimensions, and instrumentation 
The basement walls are constructed of 12 -in. wide masonry blocks that have a verified "stretcher" configuration. The blocks have reinforcing rod in filled cores nominally $4 \mathrm{ft}$ on center. The top course consists of a solid bond beam block; the cores of the bottom course are mostly filled with excess grout. The blocks are covered on their exterior surfaces with a masonry parging and painted with a bituminous damp-proofing. A drain tile is located on the interior and exterior faces of the footing ${ }^{11}$ and connected to interior sumps at the east and west ends of the building. The drain tile is embedded in gravel and covered with a filter fabric.

In general, with reference to Figure 2 through Figure 4, the following measurements were made on each test bay wall (the instrumentation for the rim-joist test cavities in Bay 5 is discussed in Section 2.1.4):

- Soil moisture content and temperature principally on a vertical profile 5 in. from the foundation wall at 5-1/4, 40-1/4, 69-1/4, and 86-1/4 in. above the slab in Bays $1-3$ and at $69-1 / 4$ in. only above the slab in Bay 4 . Bays 1 and 2 also have a horizontal profile at $40-1 / 4 \mathrm{in}$. above the floor slab with additional sensors $18-3 / 4$ and 36 in. from the wall.

- Moisture content of the interior and exterior masonry block face shells at the four levels noted above

- Surface and cavity temperatures

- Absolute humidity (AH) (a combination of RH and temperature measured in very close proximity to each other in the same sensor body)

- Heat flux.

Appendix A provides the specifications of all the instrumentation used in the five test bays.

\subsubsection{Description of Test Bays 1 and 2}

Bays 1 and 2 (Figure 2) had the same configuration except that the Bay 1 wall exterior surface was in contact with a loam backfill and Bay 2 had a sand backfill. ${ }^{12}$ The backfilled soils were contained within 3-ft $\times 9$-ft $\times 7$-ft, 7-in. deep enclosures (termed soil "cribs") that fit tight to the exterior of the basement wall and extend down to the top of the building footing. Each enclosure consisted of a polyvinyl chloride frame wrapped with Platon ${ }^{13}$ waterproofing membrane on three sides (the top and bottom were open) to separate the imported soil from the adjacent native soils and create a watertight perimeter (see Figure 82 and Figure 83 in Appendix A).

Per the requirements of the ORNL research plan, the soils in Bays 1 and 2 were evaluated using ASTM test procedures C136 and D422 to ascertain their classification. This classification enabled the correct soil type to be selected for use with the manufacturer's soil sensor calibrations and to provide ORNL with the necessary input data for its theoretical soil property determinations (Kehrer et al. 2012).

\footnotetext{
11 "Form-A-Drain" manufactured by the CertainTeed Corporation that creates the form into which the concrete for the footing is poured.

${ }^{12}$ In terms of the U.S. Department of Agriculture soil triangle classification.

${ }^{13}$ A dimpled foundation waterproofing membrane was provided by the CertainTeed Corporation.
} 
Given that the soil material properties are a function of the soil density, soil compaction is a critical issue. In this project the approach adopted was to manipulate the soil backfilling process to arrive at a natural field compaction state in which the soil density profile can be determined by scaling models relating soil density to moisture content (for example, Bird and Perrier 2003). Thus, the Bay 1 and 2 experiments are being conducted for a period of 2 years. The soil was initially backfilled to achieve an uncompacted condition. During the first year, soil was added to the tops of the cribs to maintain a constant soil height as settlement occurred. Bay 2 (sand) and Bays 3 and 4 (backfilled with the native silty sand) showed little settlement. Bay 1 (loam) showed significant settlement as expected, but a steady-state fully naturally compacted state was achieved after about 10 months. It would be highly desirable to collect core samples at the end of the experiment to measure the final compacted vertical density profiles. However, whether these tests will be performed is at ORNL's budgetary discretion.

On the inside face of the basement wall, Carlisle Coatings and Waterproofing (CCW) Miradri 860/861 waterproofing membrane (forming the 2009 Minnesota Energy Code performance option required WSP) was adhered to the concrete block wall with CCW 702 quick-dry sheet membrane adhesive. Three inches of Styrofoam extruded polystyrene (XPS) insulation ${ }^{14}$ (per 2012 IECC) was fitted tight to the waterproofing membrane and the top, bottom, and vertical joints were sealed with PL 300 foam board construction adhesive. A $2 \times 3$ stud frame with studs at $24 \mathrm{in}$. on center was constructed against the insulation and 1/2-in. gypsum board was attached to the stud frame.

Figure 2 also describes the instrumentation layout for Bays 1 and 2. All the instruments were placed using the top of the wall as a reference.

On the interior face of the block wall, the temperature sensors were placed at the horizontal midpoint of the concrete block core nearest the centerline of the 10-ft bay (see Figure 83 in Appendix A). The concrete blocks that comprise the wall are not perfectly aligned; therefore, the temperature sensors are not perfectly aligned vertically. On the exterior face of the wall, the existing damp-proofing covered the concrete block from the top of the footing to $8 \mathrm{in}$. below the top of the wall. The top exterior block wall temperature sensor was placed via the same method used on the interior. The remaining exterior block wall temperature sensors were aligned with the top exterior block wall temperature sensor; therefore, they were not precisely aligned with the midpoint of the concrete block core because the parging/damp-proofing rendered the exterior surfaces of the masonry blocks invisible (see Figure 81 and Figure 84 in Appendix A). On the interior of the wall system, the horizontal difference between the locations of the temperature sensors on the interior face of the block wall was averaged and the temperature sensors on the face of the insulation, on the back of the gypsum board, and in the room were placed along this line (see Figure 81 and Figure 82 in Appendix A).

The combined soil moisture content and temperature sensor has four prongs (each $2-1 / 4 \mathrm{in}$. long) that were positioned vertically in the soil. The midpoint of the prongs was aligned with the elevation of the exterior concrete block wall temperature sensors. This provides for at least 1 in. of settlement before the sensor becomes vertically misaligned.

\footnotetext{
${ }^{14}$ Provided by the Dow Chemical Company.
} 
The concrete block moisture sensors were placed in the same concrete block as the temperature sensor at the corresponding elevation. A concrete block moisture sensor consists of two probes spaced horizontally approximately $10-1 / 16 \mathrm{in}$. apart. The midpoint between the probes corresponds with the midpoint of the concrete block and the probes were placed at the block midheight. Because the concrete block moisture sensors were always placed at midheight of the concrete block, there is an offset between the block moisture sensor and the corresponding temperature sensor (see Figure 83 in Appendix A). On the exterior face, the moisture sensors were placed the same distance from the top of wall as they were on the interior; again, this was done because the damp-proofing system prevented visual confirmation that the sensors were at the midheight of the block (see Figure 84 in Appendix A).

The AH sensors in the block wall cores were usually placed in the same concrete block as the temperature sensor, but in the adjacent core. A hole was drilled at a 15-degree downward angle from the horizontal in the interior face of the concrete block wall $1-\frac{1}{2}$ in. above the midpoint of the block where the humidity sensor was installed so that the sensor port was at the concrete block midheight (see Figure 83 in Appendix A). The sensors were installed at an angle to prevent condensate accumulation within the sensor, centered horizontally in the core of the concrete block. The top humidity sensor was moved down one course and the bottom humidity sensor was moved up one course from the locations of the corresponding temperature sensors, because the top course is a bond beam and the second masonry block course (from the bottom) (Figure 2) was filled with grout in at least one location. For consistency, the bottom AH sensor was placed in the third course above the footing in all the test bays.

The AH sensors on the interior face of the WSP were installed by cutting a pocket into the back of the insulation and fitting the sensor into it (see Figure 86 in Appendix A). The edge of the sensor was flush with the back face of the insulation with an open port facing the WSP. This allowed the insulation to fit tight to the wall; otherwise, air gaps would form around the humidity sensors. The sensors were offset $1 \mathrm{in}$. horizontally from the centerline of the temperature sensors on the face of the insulation. This was done so the temperature sensors and heat flux plates would be under a full 3 in. of insulation, not beneath a humidity sensor pocket. The humidity sensors on the interior face of the insulation were aligned with those on the face of the WSP and mounted on the surface of the insulation.

The heat flux plates were placed on the interior face of the WSP (see Figure 87 in Appendix A). The plates were not embedded in the insulation, which produces a small air gap (approximately $1 / 8$ in.) around the plate because the insulation is not flush with the WSP at the heat flux plate location. ${ }^{15}$ The plates are 2 in. $^{2} \times 2$ in. ${ }^{2}$ and were offset $1-1 / 2 \mathrm{in}$. horizontally from the centerline of the temperature sensors on the face of the masonry block on the side opposite the humidity sensors. This was done because the temperature sensor behind the waterproofing membrane created a small bump that would have prevented the plate from fitting tight to the membrane, and as noted above, it permits the heat flux plates to be covered by a full 3 in. of insulation. However, at one location in Bay 1-south at approximately 40 in. above the floor, the bump in the WSP produced by the

\footnotetext{
${ }^{15}$ Because the thermal conductivity of the sensor is much greater than that of the insulation, embedding the sensor in the insulation produces an insulation-WSP interface heat flux error that is larger than the error resulting from a $1 / 8$-in. air gap around the sensor.
} 
temperature sensor behind the waterproofing material was small enough to permit the heat flux plate to be mounted flush against the WSP. Thus, at this location, the heat flux plate was not offset from the centerline of the temperature sensor and the humidity sensor was still only offset 1 in. as noted above. This means that at this location, the humidity sensor was placed on top of the heat flux plate and the insulation thickness was reduced (to approximately $2-1 / 2 \mathrm{in}$.).

A temperature sensor was installed on the upper surface of the insulation adjacent to the wall sill plate to provide a boundary condition at that surface to validate simulation programs. Similarly, a humidity sensor was placed on the interior face of the rim board to provide a wall-top $\mathrm{RH}$ boundary condition. The rim-joist cavities above the instrumented wall test sections were uninsulated and without an interior vapor retarder or air barrier allowing them to be essentially in equilibrium with the interior conditions. This condition is the same for all the instrumented test sections, allowing all the test walls to experience substantially the same rim-joist boundary conditions.

The interior air temperature and humidity boundary conditions were measured approximately 12 in. from the gypsum wallboard interior surface. These measurements consisted of humidity and temperature at the midwall position with additional air temperatures above the slab and below the floor joists. In this configuration, the air temperature sensors were partially shielded from infrared radiation. This arrangement allowed the interior vertical temperature stratification to be measured.

\subsubsection{Description of Test Bay 3}

Figure 3 shows the design of the Bay 3 insulation system. For the initial heating season (20122013) the ground was left undisturbed to provide an uninsulated thermal reference for Bays 1 and 2. The soil was the native sandy silt with properties fairly close to those of the sand adjacent to Bay 2.

The principal difference in comparison with the design of Bays 1 and 2 (Figure 2) was that an adhered WSP was replaced with a nonadhered WSP on the interior face of the foundation wall. The nonadhered WSP was formed from a Platon dimpled waterproofing membrane with the dimples facing the masonry block wall (Figure 88 in Appendix A), creating a drainage cavity between the wall and the WSP. The WSP was fitted into a drainage trough at the base of the wall, allowing any bulk water in the drainage cavity to be removed from the system via a drainage tube (Figure 89 in Appendix A). A spray bar was mounted onto the wall surface just below grade height that allowed bulk water to be introduced into the drainage cavity during the cooling season (Figure 90 in Appendix A). This enabled the effect of a bulk water leak in an actual wall system to be simulated during the cooling season (because the CRRF foundation walls do not have any bulk water leaks). The 3-in. interior XPS was fitted flush to the plain side of the WSP and its interior seam on the top of the collection trough air and water sealed as shown in Figure 91 (Appendix A). The wall was completed with a $2 \times 324$ in. on center stud frame and $1 / 2$-in. gypsum wallboard in the same manner as for Bays 1 and 2.

The instrumentation installed on Bay 3 (Figure 2) was the same as that installed on Bays 1 and 2 (Figure 1), with the following exceptions: 
- The heat flux plates were moved from the surface of the wall to the plain (interior) surface of the WSP (Figure 91) at the same vertical levels so that heat fluxes were measured consistently on the exterior surface of the insulation.

- Additional temperature sensors were mounted on the plain (interior) surface of the WSP adjacent to the heat flux plates (Figure 91) at the three upper horizontal sensor levels to measure the temperature difference across the WSP drainage cavity.

- Humidity sensors were installed on the dimpled side of the WSP at the upper three horizontal sensor levels to measure the RH and vapor pressure within the WSP drainage cavity.

- An additional humidity sensor was installed on the exterior side of the insulation at the bottom sensor level for a total of four humidity sensors on this plane to quantify the humidity gradient across the full height of the drainage gap.

- Only three soil moisture content sensors were placed (at the end of May 2013) about 5 in. from the wall in comparison with the five sensors deployed in Bays 1 and 2 because the horizontal sensor arrays deployed in these bays were not necessary for measuring the moisture transport phenomenology across the wall system.

Because the ground was undisturbed during the 2012-2013 heating season, none of the external wall sensors (masonry block shell moisture content and external temperature) or soil moisture content sensors were installed on Bay 3. They were all installed toward the end of May 2013.

\subsubsection{Description of Test Bay 4}

The Bay 4 wall design is shown in Figure 4. This wall had the least complex design and consisted simply of an adhered interior WSP (as in Bays 1 and 2) with 3-in. exterior XPS insulation. The exterior insulation extends nominally from the top of the wall (in reality, from the underside of the above-grade vinyl siding "J"-channel) to about 38 in. below grade. During the initial 2012-2013 heating season, the soil was not excavated but was left in its natural state. Thus, no exterior insulation was present, allowing Bay 4 to serve as an uninsulated control for Bays 1-3. This permitted a direct measurement of the major effect of interior insulation on wall heat flux for Bays 1-3. A 2-ft $\times 3$-ft, 24-in. on center stud wall was fitted flush against the adhered WSP and covered with $1 / 2$-in. gypsum wallboard on its interior face (Figure 92 in Appendix A) in compliance with the other test walls. The resulting finished interior wall surface for all the test walls in Bays 1-4 is shown in Figure 93 (Appendix A). All the vertical seams between the gypsum wallboards were sealed with caulk.

Figure 4 also shows the instrumentation for the Bay 4 walls. In this case, the instrumentation on the masonry block walls (interior and exterior shell moisture content and surface temperatures and core humidities) was the same as in Bays 1-3. However, the instrumentation on the interior side of the adhered WSP was considerably simplified compared to Bays 1 and 2 because it has no interior condensing surfaces (because of the exterior insulation placement). The interior instrumentation was thus limited to heat flux plates on the interior surface of the WSP at the upper three instrumentation levels (Figure 92), a humidity sensor at the midwall below-grade height, and a temperature sensor at the corresponding height on the cavity side of the gypsum wallboard. 
Because the ground was undisturbed during the 2012-2013 heating season, none of the exterior wall sensors were deployed in Bay 4. As with Bay 3, these sensors were installed toward the end of May 2013. In this case, however, only a single soil moisture sensor was placed about 5 in. from the exterior surface of the insulation.

\subsubsection{Description of Test Bay 5}

Bay 5 focused on the performance of the rim-joist cavity with and without exterior insulation. Because the bay was $10 \mathrm{ft}$ wide with floor joists at $24 \mathrm{in}$. on center, the two systems were placed in the rim-joist cavity at the one-third points on the wall that allowed an open rim-joist cavity between the test cavities to act as a buffer. The existing basement wall system was left in place and only the rim-joist cavities were altered. This masonry block wall was covered on the interior with a 6-mil polyethylene vapor barrier. A $2 \times 4$ stud wall filled with kraft-faced fiberglass insulation that extended to the top of the block wall was placed flush against the vapor retarder. There was no interior gypsum.

Figure 5 shows the insulated rim-joist cavity (Bay 5A) configuration. Figure 6 shows the configuration of the uninsulated rim-joist cavity (Bay 5B). The insulated system left the existing oriented strand board (OSB) rim board, OSB exterior sheathing, and building paper weather barrier in place and added a layer of 3-in. XPS insulation between the building paper and the vinyl siding. The vinyl siding was reinstalled over the insulation. The 3 -in. insulation was $4 \mathrm{ft}$. wide, centered on the rim-joist cavity, and extended from the bottom of the floor deck (top of the rim-joist cavity) to the bottom of the exterior sheathing (approximately 15-1/2 in.). A $1-1 / 2-$ in. thick XPS insulation board was installed at the base of the 3-in. insulation, tight to the exterior face of the concrete block wall.

The 1-1/2-in. insulation was $4 \mathrm{ft}$ wide, centered on the rim-joist cavity, and extended to just below the top of the grade (10-1/2 and 7-1/4 in. high on the south and north walls, respectively). The insulation was installed using screws and washers to prevent the screws from penetrating the insulation face and the insulation pulling out. Metal flashing was installed over the face of the $1-1 / 2-$ in. insulation and across the top edge of the 3-in. insulation to protect it from ultraviolet damage (the rest of the insulation was covered with vinyl siding).

The construction on the interior of the Bay 5A and 5B cavities was the same. An existing 2-in. thick foil-faced polyisocyanurate board was left in place on the top of the cavity (attached to the bottom of the floor deck). A $1-1 / 2$-in. XPS insulation board that extended from the face of the wall to the face of the sill plate over the entire length of the bay was placed on the top of the concrete block wall. In the test cavities, the 1-1/2-in. insulation board was removed between the floor I-joist flanges. The insulation was left in place under the I-joist flanges and in the adjacent rim-joist cavity. This acted as a thermal barrier between the rim-joist cavity and the surrounding environment.

Flush with the interior face of the concrete block wall, a separation plane was constructed to isolate the rim-joist cavity from the surrounding environment. A wood frame was constructed around the perimeter of the cavity and the top plate of the frame was set into the floor insulation board. The joints between the frame and block wall, I-joists, and floor sheathing were caulked with polyurethane sealant to eliminate air leakage. A layer of 6-mil polyethylene was attached to the framing using construction adhesive and then a second layer of 6-mil polyethylene was attached to 
the first layer using a bead of caulk around the perimeter of the first layer. The joint between the polyethylene layers and the frame was further sealed with a waterproof, foil-faced, butyl rubber tape.

The instrumentation on Bays 5A and 5B was identical. On the interior and exterior of the concrete block wall, a moisture content sensor was installed in the top course. The sensor was placed in the concrete block nearest the centerline of the rim-joist cavity. The centerline of the concrete block was offset from the centerline of the cavity by $1 / 2$ in. on Bay $5 \mathrm{~S}-\mathrm{A}, 7 / 8$ in. on Bay $5 \mathrm{~S}-\mathrm{B}, 3-1 / 2$ in. on $5 \mathrm{~N}-\mathrm{A}$, and $3-5 / 8$ in. on $5 \mathrm{~N}-\mathrm{B}$. A core humidity sensor was in the second course from the top of the wall because the top course masonry block was a solid bond beam block. The humidity sensor was placed in the core nearest the centerline of the cavity. The block moisture content and core humidity sensors were installed using the same method used for Bays 1 and 2 (see Section 2.1.1 above).

The wood moisture content sensors consisted of two epoxy-coated stainless steel probes spaced 1 in. apart and nailed into the wood. The probes in the sill plate and rim board were inset $3 / 4$ in. into the wood. The moisture content probes in the OSB webs of the floor I-joists were inset $1 / 4$ in. The part of the probe protruding out of the wood was then coated with marine epoxy to protect it from moisture (see Section B.2 in Appendix B for details about the wood moisture sensors).

Figure 5 shows the sensor layouts on the interior of the rim joist and on the exterior sheathing for Bay 5A. Beginning with the sensors on the interior face of the rim joist, the temperature sensor was placed on the horizontal centerline of the rim-joist cavity and at approximately midheight of the cavity (between the top of the concrete block wall and the bottom of the polyisocyanurate board). The 2 in. $\times 2$ in. heat flux plate was placed at midheight of the cavity and offset horizontally from the temperature sensor by $1-3 / 4$ in. The humidity sensor was placed at midheight and offset $3 / 4$ in. from the temperature sensor to the opposite side of the heat flux plate. The moisture content probes were placed at the horizontal midpoint of the cavity and the centerline of the probes was offset 1 in. down from the centerline of the temperature sensor.

On the exterior face of the wall, the sensors were installed on the face of the OSB sheathing and the building paper was reinstalled over the top of the sensors. The exterior temperature sensor and humidity sensor were aligned with the temperature and humidity sensor on the interior face of the rim board. The probes of the moisture content sensor were placed $1 / 2 \mathrm{in}$. below the centerline of the temperature sensor and the centerline of the probes was aligned with the horizontal centerline of the cavity (and temperature sensor).

A moisture content sensor was placed in the web of each joist enclosing the cavity. The probes of the sensors were placed at approximately midheight of the cavity (same height as the temperature sensors on the rim joist). The centerline of the probes was at approximately middepth of the cavity (between the face of the interior polyethylene membranes and the face of the OSB rim board). The moisture sensor in the sill plate was placed at the horizontal midpoint of the cavity.

The humidity sensor at midheight and middepth of the cavity was fastened to two spring-loaded horizontal strings that attached to the joists. The temperature and humidity sensors at the cavityside face of the polyethylene barrier were installed using the same method as the humidity sensor in the middle of the cavity and aligned with this sensor. The interior boundary condition humidity 
sensor was aligned with the humidity sensor in the middle of the cavity and approximately 4-5/16 in. from the face of the wood stud wall frame. This humidity sensor was installed on a vertical string that extended from the floor deck to a horizontal cross-member between the bottom flanges of the joists.

All the cables from the exterior instrumentation for each test cavity were routed to the interior through a hole in the rim board in the buffer cavity between the test cavities. The hole was then caulked and the building paper was reinstalled over the wires. On the interior, the wires for the sensors within the rim-joist cavities were routed through close-fitting holes in the bottom member of the sealing frames and the holes were then filled with caulk. An interior view of the completed rim-joist test cavities is given in Figure 94 (Appendix A).

\subsection{Ambient Boundary Conditions}

The following ambient condition/weather data were collected continuously at the CRRF weather station:

- $\mathrm{RH}$

- Temperature

- Barometric pressure

- Wind direction

- Wind speed

- Horizontal solar radiation flux (pyranometer)

- Horizontal long-wave radiation flux in the far infrared range (pyrgeometer)

- Precipitation (unheated tipping-bucket gauge).

The following additional ambient data were collected at the CRRF building:

- Snow depth adjacent to the north and south faces (ultrasonic snow depth gauge)

- Temperature and RH above the soil cribs in Bays 1 and 2 (added prior to the second heating season in mid-October 2014)

- Precipitation (heated tipping bucket precipitation gauge)

- Horizontal solar radiation flux (pyranometer). ${ }^{16}$

\subsection{Interior Boundary Conditions}

The basement interior temperature and humidity were controlled during the heating season by an electric furnace and a steam humidifier respectively. During the first heating season (2012-2013) only the interior temperature was controlled digitally from the beginning of February 2013 to a

\footnotetext{
${ }^{16}$ A second pyranometer was added at the end of July 2013 after it was discovered that the calibration of the pyranometer at the weather station was inaccurate (it had been deployed atop a $65-\mathrm{ft}$ mast for at least 20 years without inspection). The second pyranometer was used to develop a new calibration for the old pyranometer, allowing the weather station solar radiation data to be recalibrated to yield accurate data.
} 
nominal set point temperature of $20^{\circ} \mathrm{C}$ with a nominal variability of $\pm 1^{\circ} \mathrm{C}$ at the process temperature measurement location (an average of the north and south wall interior temperature measured at 46 in. above the slab in the center of Bay 3; see Figure 3). The interior boundary temperature conditions were measured at three locations on the interior side of the wall test bays (see Figure 2 through Figure 4) and at one location on the interior side of the rim-joist test cavities (Figure 5 and Figure 6).

The RH was measured at a single midwall location in front of each wall test bay (Figure 2 through Figure 4) and in front of the rim-joist test cavities (Figure 5 and Figure 6). The interior barometric pressure was measured in the center of the basement space containing all the test bays.

During the 2013-2014 heating season, the humidity was controlled as well to reach a maximum value of $50 \%$ to stress the insulation systems to determine their response to high levels of interior humidity. During the 2013 cooling season, the humidity did not need to be controlled via a standalone dehumidifier. Because no air conditioning was installed in the CRRF during the experiment, the temperatures during the cooling season were not controlled.

\subsection{Data Acquisition and Control System}

The details of the data acquisition and control system hardware are listed in Table 1. A PCI-MIO16XE50 16-bit A/D converter was used to digitize the voltage signals from all the sensors except the masonry block moisture content transducers. These were digitized by the NI 9219 24-bit A/D converter to obtain adequate resolution for the very small voltages generated in the conductance sensor half-bridges of order nano-Volts. The PCI-6220 16-bit A/D converter was used exclusively to capture the temperature and voltage signal used in the HVAC plant control system.

Uncalibrated raw data were captured at no more than 12-minute intervals (5-minute intervals were used initially for approximately the first week of data capture for diagnostic purposes). These data were stored in duplicate on the CRRF data acquisition and control server and on a secure cloud server managed by the University of Minnesota's Office of Information Technology. The cloud server is backed up frequently. The raw data were converted into calibrated engineering units and stored in a set of flat-form ASCII databases (termed the Intermediate Archival Format) by postprocessing secondary software with one database per instrumentation controller (four instrumentation controllers were used in the experiment at the CRRF). The Intermediate Archival Format databases also are stored on the secure Office of Information Technology cloud server. This arrangement allows the calibrations to be updated and modified as necessary and provides a record of exactly how the raw data have been manipulated. A second processing step integrates the separate controller databases into a single database with a unified time stamp (termed the Final Archival Format, FAF), which is also stored on the secure Office of Information Technology cloud server. Finally, tertiary software recovers the data from the FAF for analysis, graphing, and custom data channel extraction. This three-step data management process establishes the necessary provenance for the FAF database that allows it to be designated as archival. 
Table 1. Data Acquisition Equipment

\begin{tabular}{|c|c|c|c|c|}
\hline Component & Manufacturer & Qty. & Model No. & Listed Performance \\
\hline $\begin{array}{l}\text { A/D Converter } \\
\text { (16 Bit) }\end{array}$ & $\begin{array}{l}\text { National } \\
\text { Instruments }\end{array}$ & 1 & $\begin{array}{l}\text { PCI-MIO- } \\
16 \text { XE50 }\end{array}$ & $\begin{array}{c}\text { Accuracy: } \pm 54 \mu \mathrm{V} \text { at } \\
0 \text { to } \pm 100 \mathrm{mV} \text { range; } \\
\pm 1.443 \mathrm{mV} \text { at } 0 \text { to } \pm 10 \mathrm{~V} \text { range }\end{array}$ \\
\hline $\begin{array}{l}\text { A/D Converter } \\
\text { (16 Bit) }\end{array}$ & $\begin{array}{l}\text { National } \\
\text { Instruments }\end{array}$ & 1 & PCI-6220 & $\begin{array}{c}\text { Accuracy: } \pm 112 \mu \mathrm{V} \text { at } \\
0 \text { to } \pm 200 \mathrm{mV} \text { range; } \\
\pm 3.1 \mathrm{mV} \text { at } 0 \text { to } \pm 10 \mathrm{~V} \text { range }\end{array}$ \\
\hline $\begin{array}{l}\text { A/D Converter } \\
\text { (24 Bit) }\end{array}$ & $\begin{array}{l}\text { National } \\
\text { Instruments }\end{array}$ & 1 & NI 9219 & $\begin{array}{c}\text { Accuracy: } \pm 0.3 \% \text { at } \\
0 \text { to } \pm 60 \mathrm{~V} \text { range; } \\
\pm 0.1 \% \text { at } 0 \text { to } \pm 1 \mathrm{~V} \text { range }\end{array}$ \\
\hline $\begin{array}{l}\text { RS485 Serial } \\
\text { Interface }\end{array}$ & $\begin{array}{l}\text { National } \\
\text { Instruments }\end{array}$ & 1 & PCI-485/2 & Max baud: 115.2 kbits/s \\
\hline Digital Signal Input & $\begin{array}{l}\text { National } \\
\text { Instruments }\end{array}$ & 1 & NI 9421 & $\begin{array}{c}\text { Channels: } 8 \\
\text { Mode: } 5 \text { V sinking }\end{array}$ \\
\hline Digital Signal Output & $\begin{array}{l}\text { National } \\
\text { Instruments }\end{array}$ & 1 & NI 9475 & $\begin{array}{c}\text { Channels: } 8 \\
\text { Mode: } 60 \mathrm{~V} \text { maximum } \\
\text { sourcing }\end{array}$ \\
\hline Digital Signal Output & $\begin{array}{c}\text { National } \\
\text { Instruments }\end{array}$ & 2 & $\begin{array}{c}\text { SCXI- } \\
1163 \mathrm{R} / \\
\text { SCXI-1326 }\end{array}$ & $\begin{array}{c}\text { Channels: } 8 \\
\text { Mode: optically isolated } \\
\text { solid-state relay }\end{array}$ \\
\hline $\begin{array}{l}\text { Thermocouple/ } \\
\text { Voltage Signal } \\
\text { Conditioning: }\end{array}$ & $\begin{array}{l}\text { National } \\
\text { Instruments }\end{array}$ & 11 & $\begin{array}{l}\text { SCXI-1100/ } \\
\text { SCXI-1303 }\end{array}$ & $\begin{array}{c}\text { Channels: } 32 \\
\text { Maximum gain: } 2000 \\
\text { Accuracy: } 0.006 \% \text { at } \\
30 \mu \text { s settling time }\end{array}$ \\
\hline $\begin{array}{l}\text { Thermocouple/ } \\
\text { Voltage Signal } \\
\text { Conditioning }\end{array}$ & $\begin{array}{c}\text { National } \\
\text { Instruments }\end{array}$ & 2 & $\begin{array}{l}\text { SCXI-1102/ } \\
\text { SCXI-1303 }\end{array}$ & $\begin{array}{c}\text { Channels: } 32 \\
\text { Accuracy: } 0.0061 \% \text { at } \\
10 \mu \text { settling time }\end{array}$ \\
\hline $\begin{array}{l}\text { Voltage Signal } \\
\text { Conditioning }\end{array}$ & $\begin{array}{c}\text { National } \\
\text { Instruments }\end{array}$ & 4 & $\begin{array}{l}\text { SCXI-1100/ } \\
\text { SCXI-1300 }\end{array}$ & $\begin{array}{c}\text { Channels: } 32 \\
\text { Maximum gain: } 2000 \\
\text { Accuracy: } 0.006 \% \text { at } \\
30 \mu \text { s settling time }\end{array}$ \\
\hline Relay Multiplexer & $\begin{array}{l}\text { Campbell } \\
\text { Scientific }\end{array}$ & 6 & AM16/32B & Channels: 32 differential \\
\hline $\begin{array}{c}\text { Signal Conditioning } \\
\text { Chassis }\end{array}$ & $\begin{array}{c}\text { National } \\
\text { Instruments }\end{array}$ & 2 & SCXI-1001 & No. of slots: 12 \\
\hline $\begin{array}{c}\text { Signal Conditioning } \\
\text { Chassis }\end{array}$ & $\begin{array}{c}\text { National } \\
\text { Instruments }\end{array}$ & 1 & SCXI-1000 & No. of slots: 4 \\
\hline $\begin{array}{c}\text { Signal Conditioning } \\
\text { Chassis }\end{array}$ & $\begin{array}{c}\text { National } \\
\text { Instruments }\end{array}$ & 1 & cDAQ-9188 & No. of slots: 8 \\
\hline $\begin{array}{c}\text { Weather Station } \\
\text { Controller }\end{array}$ & $\begin{array}{l}\text { Campbell } \\
\text { Scientific }\end{array}$ & 1 & CR10X & $\begin{array}{l}\text { Analog channels: } 12 \text { single- } \\
\text { ended or } 6 \text { differential }\end{array}$ \\
\hline
\end{tabular}




\subsection{Test Protocol}

Data collection commenced on November 2, 2012. The period from November 2, 2012 through November 9, 2012 was used for debugging the system so that even though data were collected, the FAF archival data commenced on November 10, 2012, after the weather station came online. The data collection and control schedule through March 31, 2014 (data freeze date for this report) proceeded according to the schedule in Table 2. As shown, the number of data points archived increased from 246 on November 10, 2012 to 607 on March 31, 2014 (the end of the reporting period).

Initially, the furnace was controlled by the backup mechanical thermostat in the HVAC control circuit. The resulting interior boundary temperature condition on Bay $1 \mathrm{~S}$ (most remote from the thermostat) was a rather poor $21.1+3.0 /-1.6^{\circ} \mathrm{C}$ for a typical day. The digital HVAC control was activated on January 28, 2013 using an average of the Bay 3S and 3N interior air temperature sensors $46 \mathrm{in}$. above the floor height as the process control temperature. Under these conditions, the daily interior temperatures at the Bay 3 midwall locations were $19.7 \pm 0.5$ and $20.3+0.4 /-0.3^{\circ} \mathrm{C}$ for the north and south walls, respectively, with the nominal control set point at $20^{\circ} \mathrm{C}$. Interior heating was terminated for the 2012-2013 heating season on May 1, 2013.

The soil adjacent to Bays 3 and 4 was excavated in late May 2013 and all the exterior sensors for these bays began generating data on June 6, 2013. Construction of the Bay 5 rim-joist cavity experiments was completed by mid-July 2013 and the complete data set from these experiments was collected from July 19, 2013 onward.

Bulk water injection between the wall and the WSP in Bay 3 commenced on September 4, 2013 and terminated on October 11,2013, yielding a full month of wetted conditions. Heating for the 2013-2014 heating season commenced on November 5, 2013 and continued through March 31, 2014, when the data were frozen for this report. To understand the temperature results of the simulations and to glean additional insight to the mechanics of the heat transfer around the base of the walls, the investigators placed $4-\mathrm{ft} \times 8$ - $\mathrm{ft}$ sheets of $\mathrm{R}-15$ rigid XPS insulation on the slab adjacent to Bays 3S and 3N on December 13, 2013 and removed them on January 22, 2014. Interior humidification began on January 10, 2014. The humidity was ramped up at the rate of 5\% per week until it reached a maximum of $50 \%$ that was held for 2 weeks. The RH set point was then ramped down in 5\% steps in response to the interior RH decrease; the set point reached $35 \%$ by March 31, 2014. 
Table 2. Data Collection and Control Schedule Through March 31, 2014

\begin{tabular}{|c|c|c|c|}
\hline $\begin{array}{l}\text { Data } \\
\text { Status }\end{array}$ & Activity & $\begin{array}{l}\text { Total No. of } \\
\text { FAF Data } \\
\text { Channels }\end{array}$ & Date \\
\hline Debug & $\begin{array}{l}\text { Commence data collection for Bays } 1 \text { and } 2 \text { (excluding } \\
\text { masonry block moisture content sensors) }\end{array}$ & 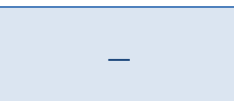 & $11 / 2 / 2012$ \\
\hline Debug & $\begin{array}{l}\text { Heating only with furnace controlled by backup } \\
\text { mechanical thermostat. Bay } 1 \mathrm{~S} \text { midheight daily interior } \\
\text { temperature range }=21.1+3.0 /-1.6^{\circ} \mathrm{C}\end{array}$ & - & $11 / 2 / 2012$ \\
\hline Debug & $\begin{array}{l}\text { Add remaining channels to Bays } 1 \text { and } 2 \text { data collection } \\
\text { (excluding masonry block moisture content sensors) }\end{array}$ & - & $11 / 8 / 2012$ \\
\hline Debug & Commence data collection from CRRF weather station & - & $11 / 9 / 2012$ \\
\hline Archive & Commence data archival & 246 & $11 / 10 / 2012$ \\
\hline Archive & Add pyrgeometer to CRRF weather station & 250 & $11 / 29 / 2012$ \\
\hline Archive & Add snow depth gauges & 252 & $11 / 30 / 2012$ \\
\hline Archive & Add heated precipitation gauge adjacent to CRRF & 253 & $12 / 8 / 2012$ \\
\hline Archive & $\begin{array}{l}\text { Commence data collection from Bays } 3 \text { and } 4 \\
\text { (excluding wall exterior and soil sensors) }\end{array}$ & 368 & $1 / 18 / 2013$ \\
\hline Archive & $\begin{array}{l}\text { Add masonry block moisture content } \\
\text { sensors to Bays } 1 \text { and } 2\end{array}$ & 436 & $1 / 18 / 2013$ \\
\hline Archive & Change to digital furnace control & 436 & $1 / 28 / 2013$ \\
\hline Archive & $\begin{array}{l}\text { Terminate interior heating for 2012-2013 heating } \\
\text { season }\end{array}$ & 436 & $5 / 1 / 2013$ \\
\hline Archive & Add exterior wall sensors on Bays 3 and 4 & 452 & $5 / 31 / 2013$ \\
\hline Archive & Add exterior soil sensors on Bays 3 and 4 & 469 & $6 / 6 / 2013$ \\
\hline Archive & Add Bay 5 rim-joist cavity experiment sensors & 573 & $7 / 19 / 2013$ \\
\hline Archive & Add pyranometer to CRRF roof peak & 574 & $7 / 31 / 2013$ \\
\hline Archive & Add bulk water injection system behind WSP on Bay 3 & 574 & $8 / 28 / 2013$ \\
\hline Archive & Commence wetting Bay 3 interior drainage cavities & 577 & $9 / 4 / 2013$ \\
\hline Archive & $\begin{array}{l}\text { Add ambient temperature and RH sensors above } \\
\text { Bay } 1 \text { and } 2 \text { soil cribs }\end{array}$ & 586 & $10 / 11 / 2013$ \\
\hline Archive & Terminate wetting Bay 3 interior drainage cavities & 586 & $10 / 11 / 2013$ \\
\hline Archive & Begin interior heating for 2013-2014 season & 586 & $11 / 5 / 2013$ \\
\hline Archive & Add temporary floor insulation to Bay 3S and 3N & & $12 / 13 / 2013$ \\
\hline Archive & Remove temporary floor insulation from Bay $3 \mathrm{~S}$ and $3 \mathrm{~N}$ & 587 & $1 / 22 / 2014$ \\
\hline Archive & $\begin{array}{l}\text { Begin interior humidification for } \\
2013-2014 \text { heating season }\end{array}$ & 587 & $1 / 10 / 2014$ \\
\hline Archive & Freeze data set for this report & 607 & $3 / 31 / 2014$ \\
\hline
\end{tabular}




\section{Experimental Results}

At the time of writing this report, the archived experimental database covered the period from November 10, 2012 through May 3, 2014 when more than 600 calibrated data points were generated every 12 minutes. This constitutes a vast trove of information that will take a significant amount of time and effort to mine. The project scope/plan therefore only allowed for the preparation of a summary overview of the main findings gleaned at the time of writing. All the results discussed below were extracted from Harmon (2014).

The results are presented in five main sections as follows:

- Thermal results (temperature and heat flux) from Bays 1-4 (Sections 3.1.1 and 3.1.2)

- Moisture transport through the walls on the exterior of the WSP for Bays 1-4 (Section 3.2)

- Results from the rim-joist cavity hygrothermal experiments (Section 3.3).

- Assessment of the thermal compliance of the retrofitted insulation systems with the performance requirements of the 2009 Minnesota Energy Code currently in force (Section 3.4)

- Results of the basement humidification experiment in which the interior RH was ramped up to and down from 50\% (Section 3.5).

Processing the raw experimental data to extract the graphical results discussed below was a complex task and required substantial software development, as described by Harmon (2014) as part of the ORNL part of the project. In most cases, the results are presented with the time increment of the data collected by the governing instrumentation host computer; that is, at a nominal 12-minute time increment. On occasions (such as a host computer failure), the time increment was longer or shorter, depending on the established hierarchy of host computers.

\subsection{Wall Thermal}

The wall and immediately adjacent soil temperatures and the wall heat fluxes are discussed for the full monitoring period through May 3, 2014. A more detailed discussion of the soil temperatures for the 2013 calendar year is presented in Section 4.1 as part of the experiment/ simulation comparison where the simulation results provide a contextual reference for understanding the measured soil temperatures.

\subsubsection{Temperature}

Figure 7 through Figure 10 depict the boundary conditions. Figure 7 shows the furnace temperature set point and process control values for the duration of the experiment (see Table 2). The set point was maintained at $20^{\circ} \mathrm{C}$ during the heating seasons and at $15.6^{\circ} \mathrm{C}$ during the cooling season. The temperature was controlled by a backup mechanical thermostat through January 28, 2013, which yielded the very wide temperature band shown. Thereafter, the realtime digital control system assumed control, but the system did not store the process temperatures until October. Hence, the process temperatures reported from January 28, 2013 through October 1, 2013 are the average of the temperature sensors nearest to the process sensors. 


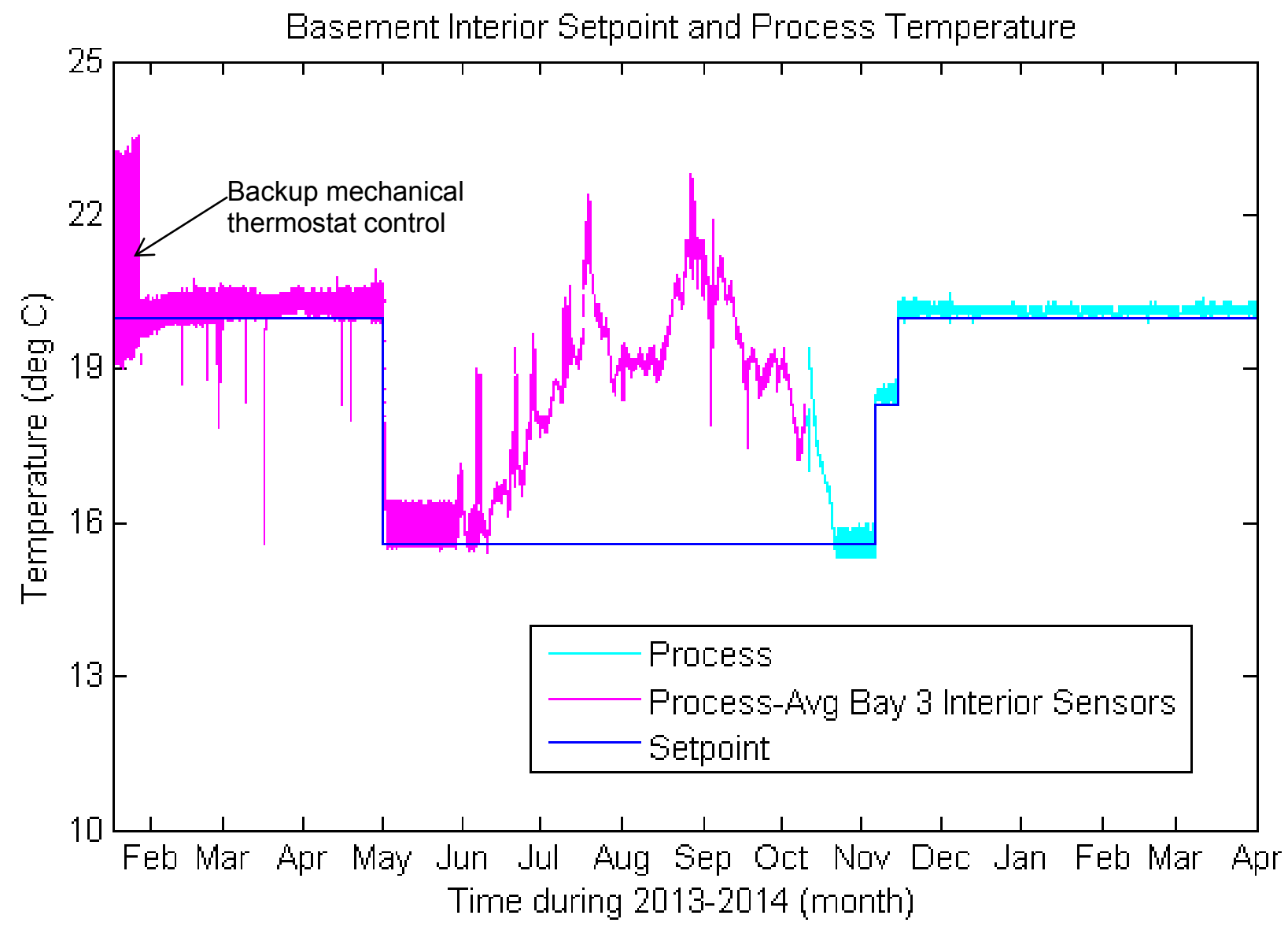

Figure 7. Basement interior temperature control 


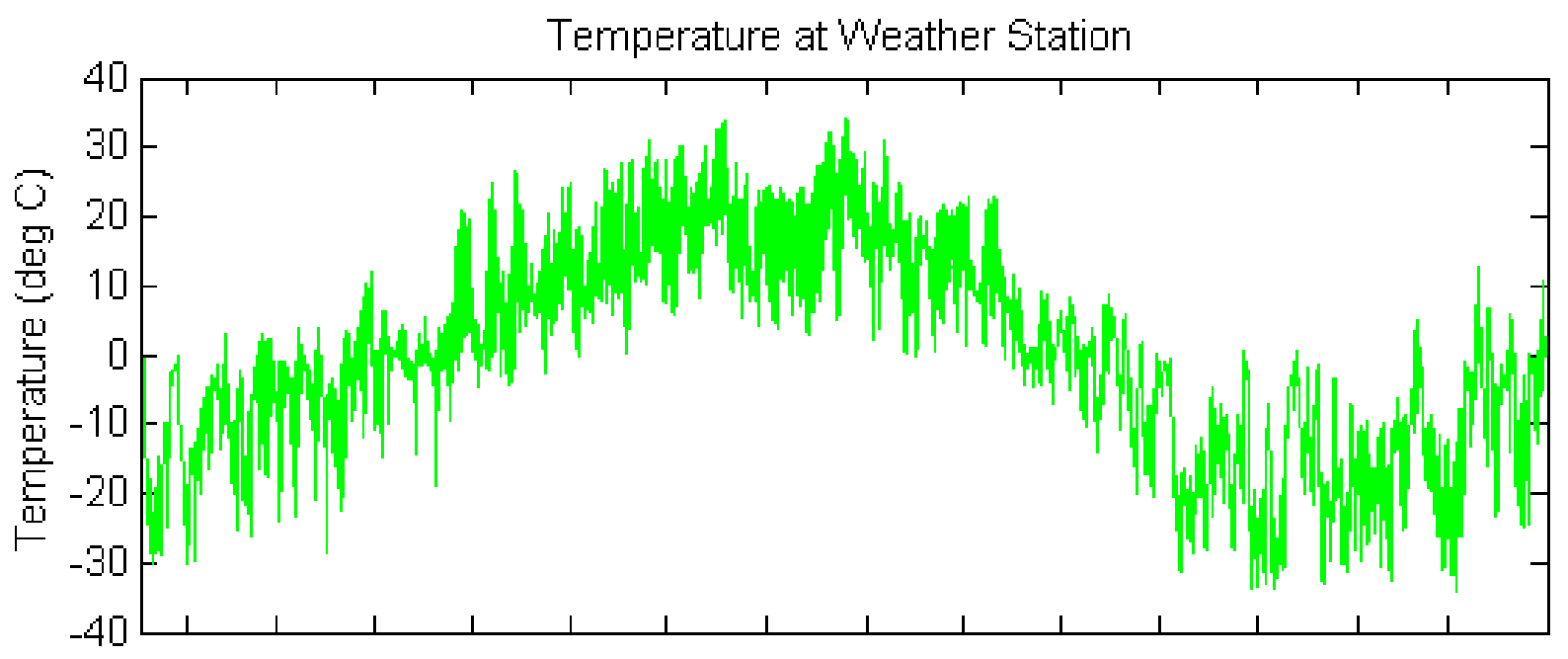

Temperature Above Bay 1 Soil Cribs

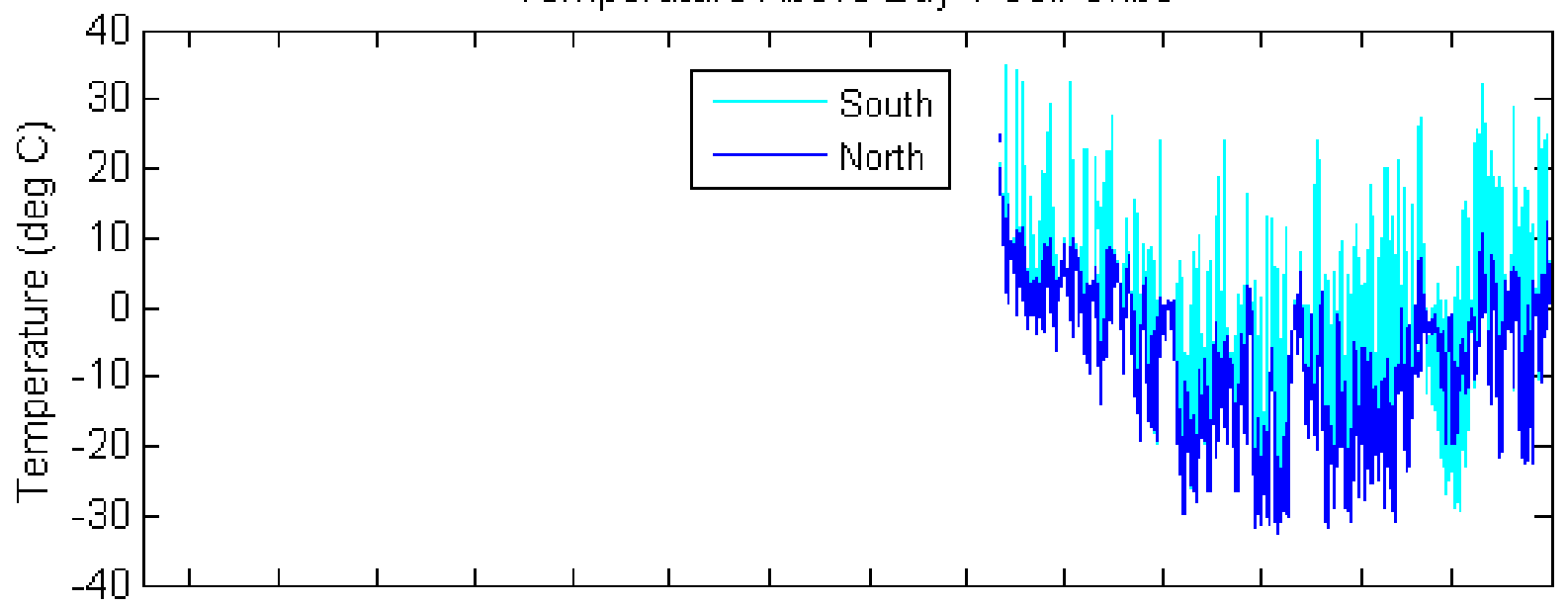

Temperature Above Bay 2 Soil Cribs

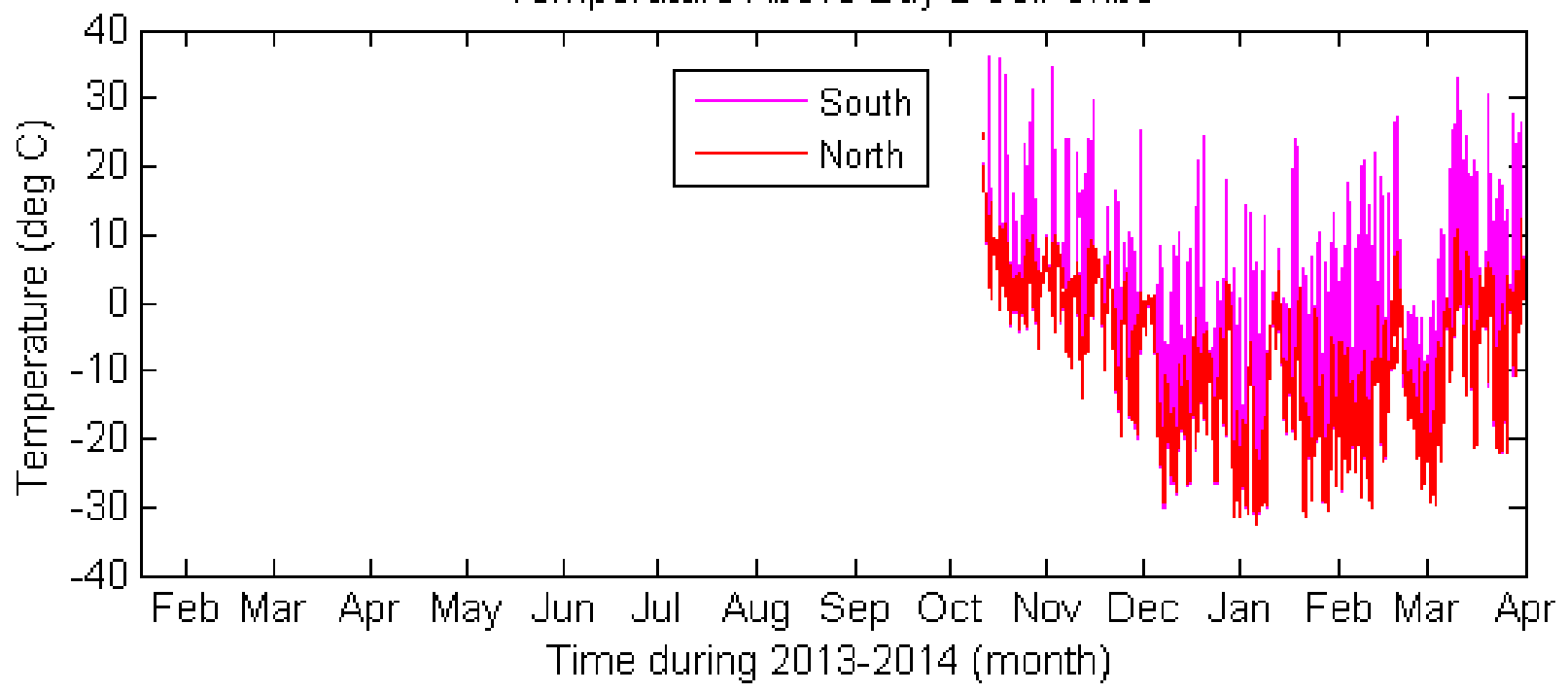

Figure 8. Exterior temperature boundary conditions 


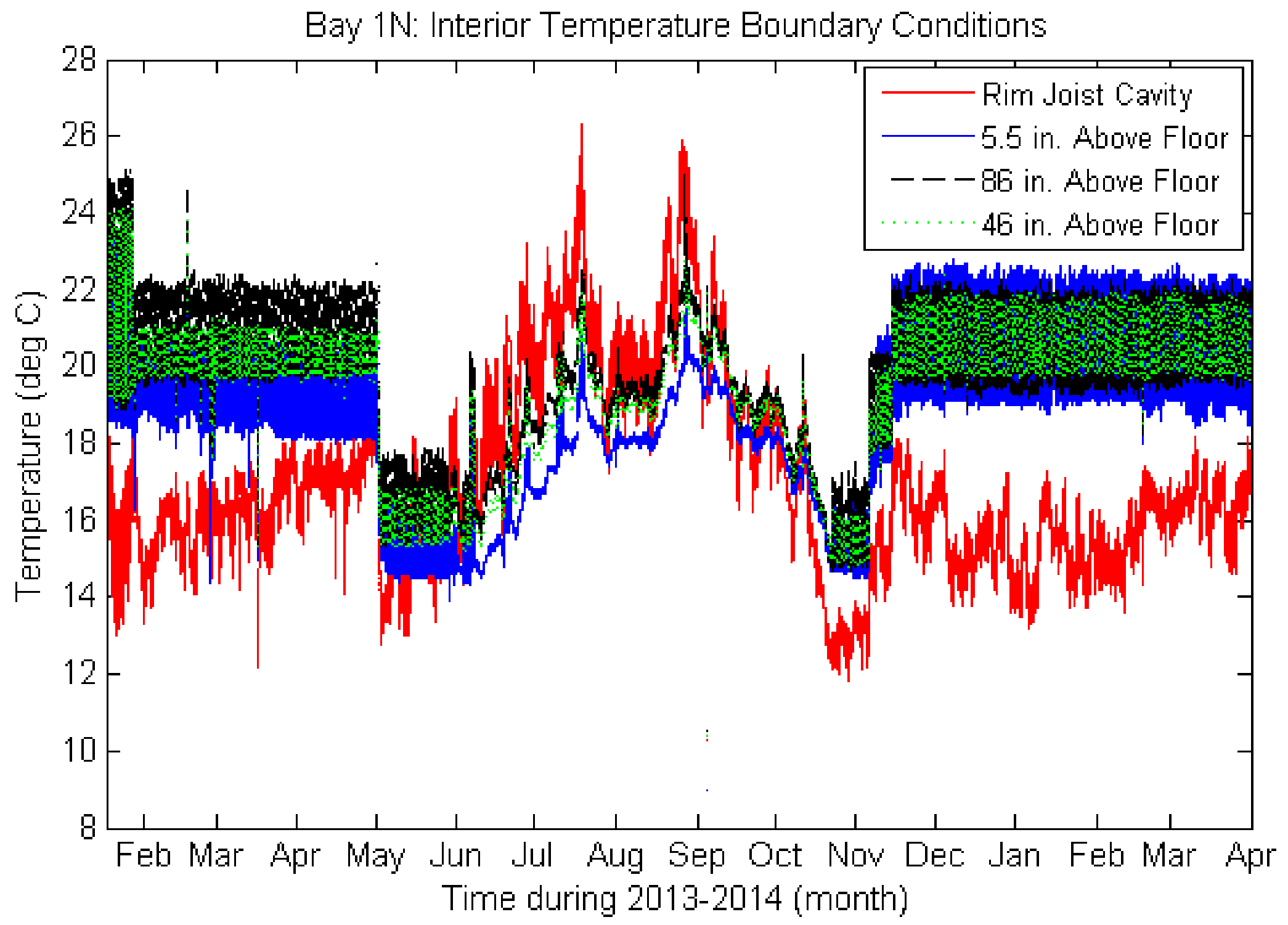

Figure 9. Test panel interior temperature boundary conditions most remote from temperature control sensor 
Horizontal Plane Solar Irradiance

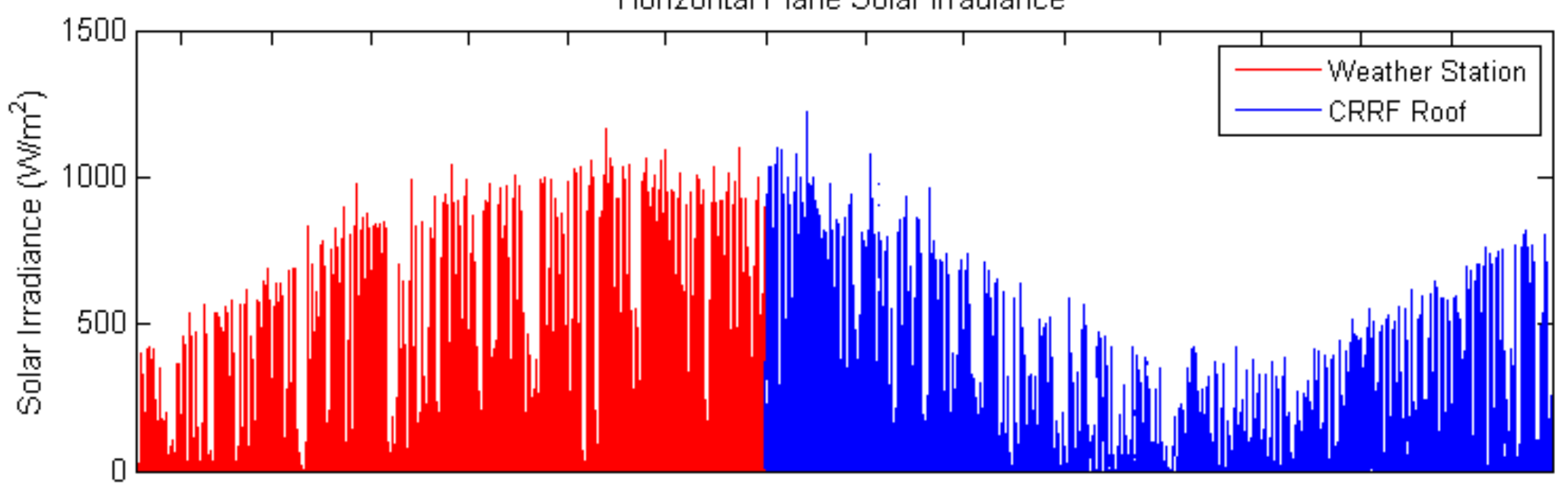

Horizontal Plane Net Long-wave Irradiance

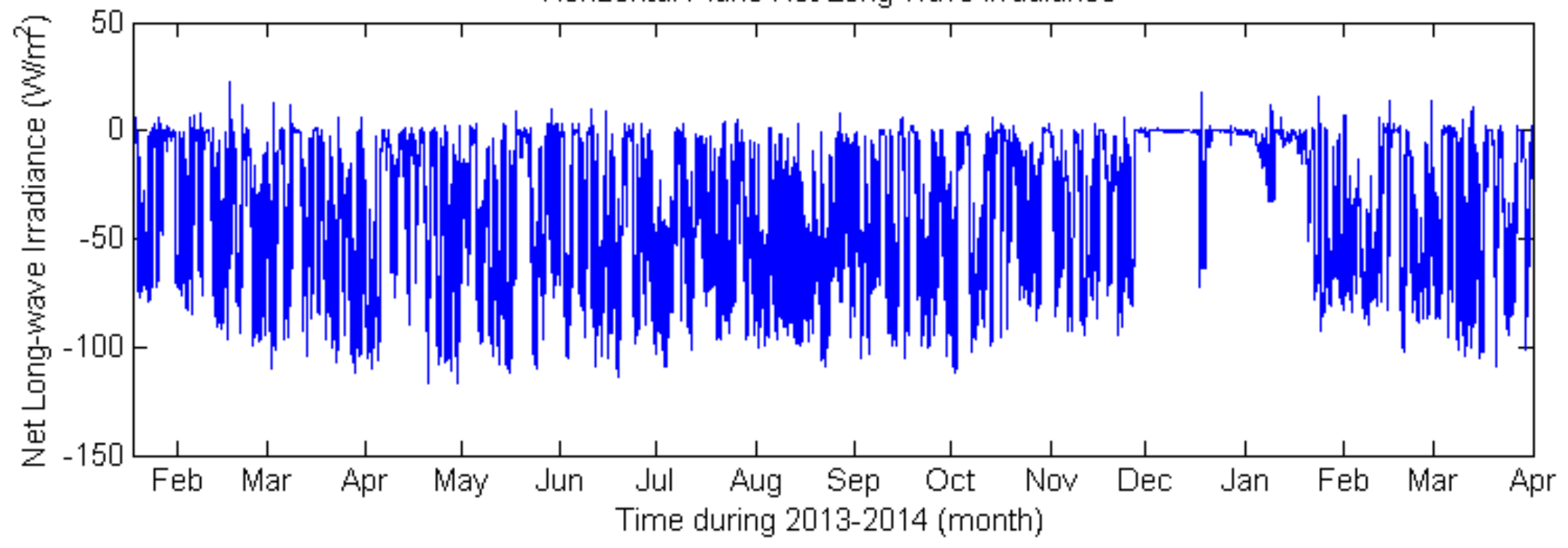

Figure 10. Terrestrial horizontal plane solar and long-wave irradiance 
Figure 8 shows the exterior ambient temperatures. It also shows the temperature profile recorded at the CRRF weather station, located about 1000 yards from the building, together with the profiles recorded above the soil cribs in Bays 1 and 2 from mid-October onward. As expected, the ambient temperatures on the south side of the building were warmer than those on the north side, with a greater diurnal variation. The north side temperatures adjacent to the building were also slightly warmer than those recorded at the weather station by, on average, $1^{\circ}-2^{\circ} \mathrm{C}$ because of the building's sheltering effect. The weather station temperature was measured in an exposed, unsheltered, and windswept location with higher convective heat transfer (all these sensors were equipped with radiation shields).

Figure 9 depicts the interior temperatures adjacent to the gypsum wallboard and in the rim joist at a location most remote from the heating process temperature locations.

The temperature amplitudes on the interior of Bay $1 \mathrm{~N}$ were much larger than the process temperature amplitudes because of internal air movement within the basement. Rather than attempt to equalize the interior temperature distribution, it was determined at the outset of operations at the CRRF that it was preferable to measure the interior temperature vertical profile for each test bay panel separately. These profiles can then be used to normalize the results where appropriate; they are also suitable for establishing computer simulation boundary conditions.

Figure 10 shows the horizontal plane terrestrial solar irradiance and net long-wave radiation exchange with the sky. At the end of July, a new pyranometer was installed at the roof peak on the CRRF, because the calibration of the pyranometer on the weather station mast had lost validity after more than 17 years of service. The new pyranometer was used to recalibrate the weather station pyranometer. The resulting accurately calibrated composite solar irradiance from both pyranometers is shown. The net long-wave irradiance collected from a pyrgeometer at the weather station shows zero readings during December 2013 and January 2014. This was a result of the failure of the Cloquet Forestry Center (CFC) maintenance staff to keep the pyrgeometer clear of snow during the holiday season.

Figure 11 through Figure 15 show the above- and below-grade masonry block wall temperatures for Bay 2S. At the top of the wall (Figure 11), the interior and exterior face shell temperatures were measured on the above-grade bond beam block. However, the core temperature was measured in the hollow core of the block immediately below the bond beam block, right at grade level. The core temperatures are plotted separately in Figure 12 and Figure 13. In this context, ignoring the elevated exterior face shell temperatures produced by the solar gain on the above-grade part of the south-facing wall, during the heating seasons, the interior face shell temperature was on average higher than the exterior face shell temperature. This is consistent with diffusion heat transport through the bond beam block. However, the core temperature one block below was roughly equal to the interior face shell during the first heating season and higher than the interior face shell temperature during the second heating season (mid-November to about mid-April; see Figure 12). 
Bay 2S: Masonry Block Wall Temperatures 86 in. Above the Slab During Non-Heating Season
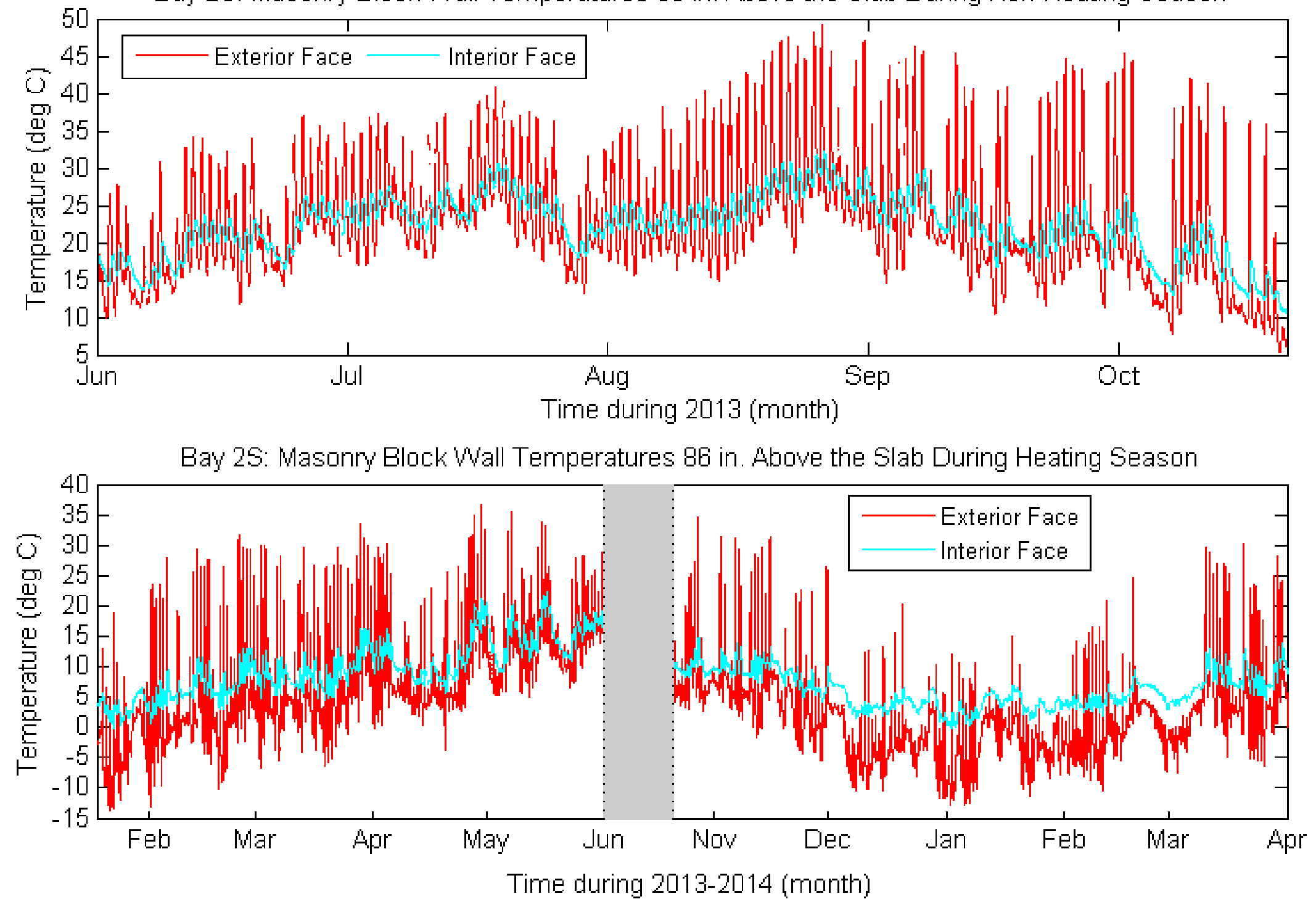

Figure 11. Bay 2S above-grade masonry block wall temperature profiles 

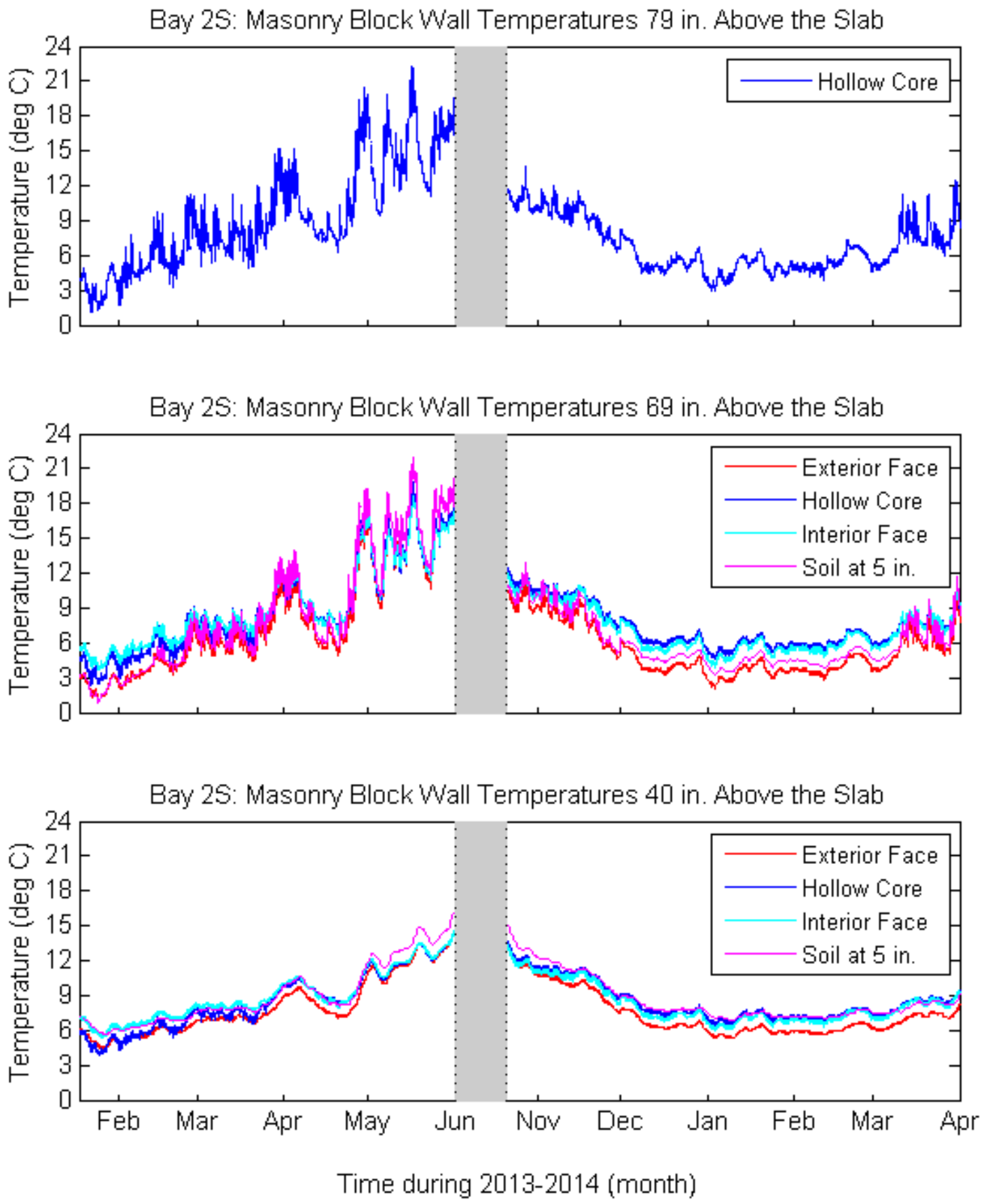

Figure 12. Bay $2 S$ heating season masonry block wall and soil temperature profiles 40 to 79 in. above the slab

With reference to Figure 12, at 40 and 69 in. above the slab (wall vertical center section) the heating season below-grade temperature profiles reveal phenomenology consistent with buoyant cavity flows in the hollow cores of the masonry block cores. This is particularly noticeable in the second heating season after mid-November, but was present during the first heating season as well, from the end of February to the end of April. In particular: 
- The exterior face shell temperature was colder than the soil temperature that, in turn, was comparable to the interior face shell and core temperatures. This is not possible with diffusive thermal transport and indicates a buoyant cavity flow loop transporting cold air from the above-grade part of the wall downward along the exterior face shell.

- During the second heating season, the core temperature was marginally warmer than the interior face shell temperature, indicating a warmed air plume that increased in width from the base of the wall upward. Hence, at the center of the block, the measured air temperature reflected the warmer interior face shell temperatures from below. This also is a feature of buoyant cavity flow loops.

- The impact of the flow loop decreased with depth (downward flow was warmed by the soil). This also is shown in the data, because at 69 in. above the slab, the soil temperature was cooler than the interior face shell temperature, whereas at $40 \mathrm{in}$. above the slab it was warmer or equal to the face shell temperature.

- At the top of the core cavity in the center of the wall at approximately grade level, the core temperature had the same magnitude as the core and face shell temperatures below grade. Again, this would not be possible with diffusion-only heat transport. This yields colder core air at the top of the wall relative to the below-grade core air temperatures because of diffusion heat transfer from the cold exterior face shell in contact with the ambient air.

Figure 13 does not reveal any cavity flow loops during the cooling season (Harmon 2014), so at the resolution of the graph, the temperatures across the wall were very similar at 40 and 69 in. above the slab. Further, the core air temperature at $79 \mathrm{in}$. above the slab was warmer than that below grade. For example, at the peak temperatures recorded toward the end of August, the core air temperature was about $4^{\circ}$ and $9^{\circ} \mathrm{C}$ warmer than the temperatures 69 and $40 \mathrm{in}$. above the slab, respectively. Of interest is that the soil temperatures were consistently warmer than the wall temperatures during the cooling season, an effect that indicates the wall was being cooled by greater diffusion heat transport in the wall downward to the cool footing relative to the soil (wall thermal conductivity greater than soil conductivity).

At $5-1 / 2$ in. above the slab during the heating season (Figure 14), again the soil temperature was warmer than the exterior face shell temperature through the end of March during the first heating season, as well as during the second heating season from mid-November through about midMarch. However, the soil temperature was within $1^{\circ} \mathrm{C}$ of the interior face shell temperature during the first heating season but much warmer during the second heating season. This increase provides significant evidence of a heat source beneath the footing during the cooling season.

Figure 15 shows soil temperatures that were consistently warmer than the face shell temperatures (by about $2^{\circ} \mathrm{C}$ at $5-1 / 2$ in. above the slab) during the cooling season. This will be addressed below in the context of a comparison between Bays $2 \mathrm{~N}$ and $3 \mathrm{~N}$. 


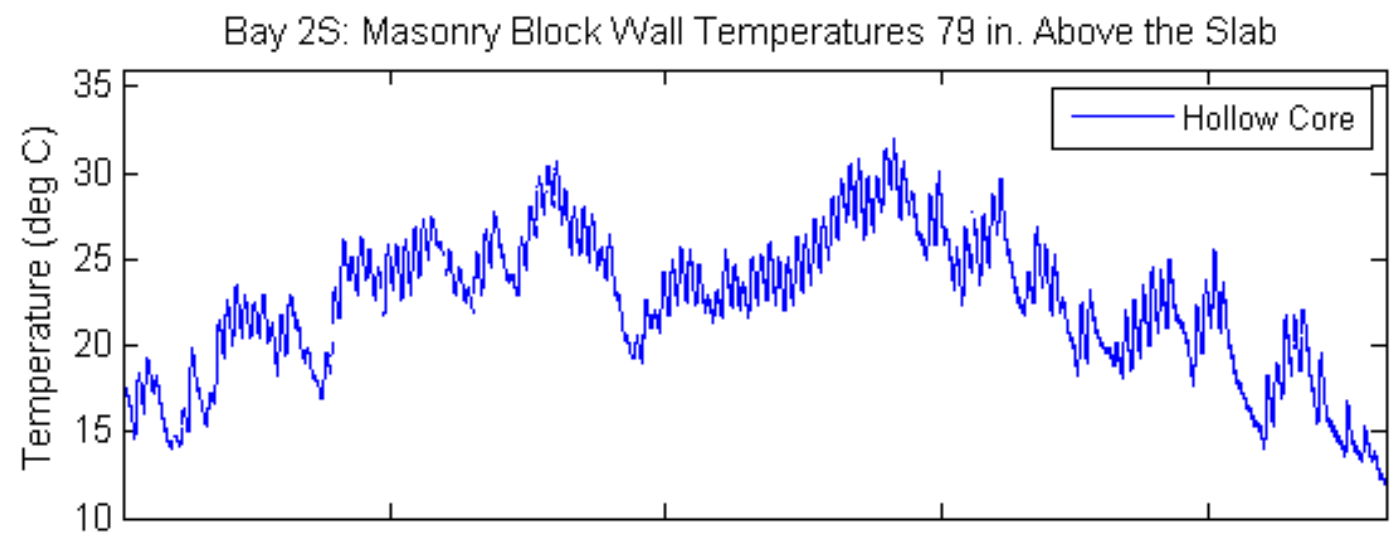

Bay 2S: Masonry Block Wall Temperatures 69 in. Above the Slab

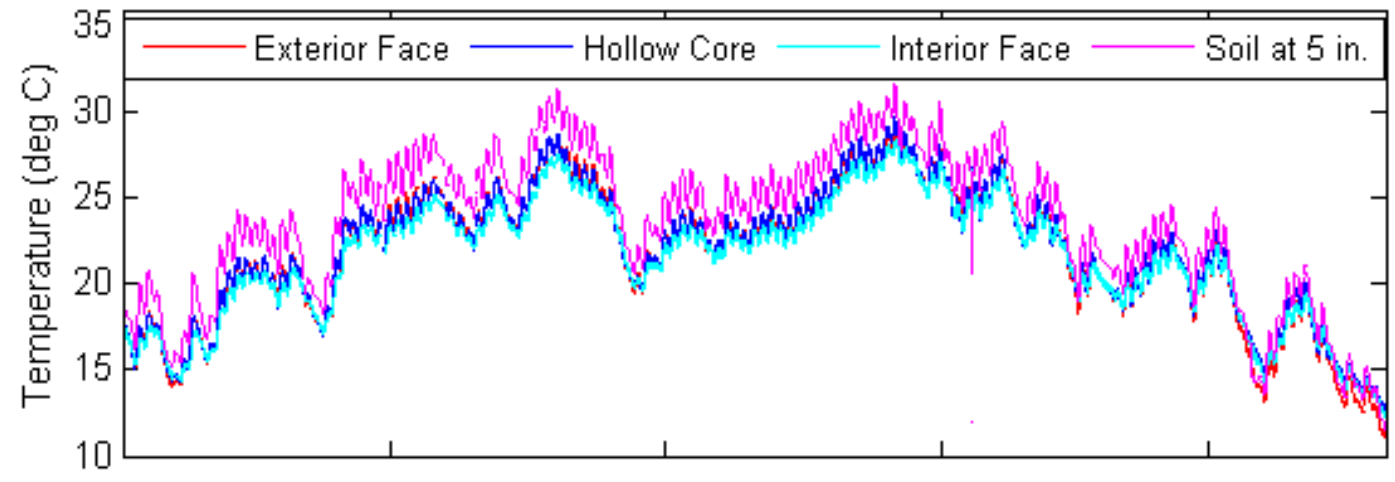

Bay 2S: Masonry Block Wall Temperatures 40 in. Above the Slab

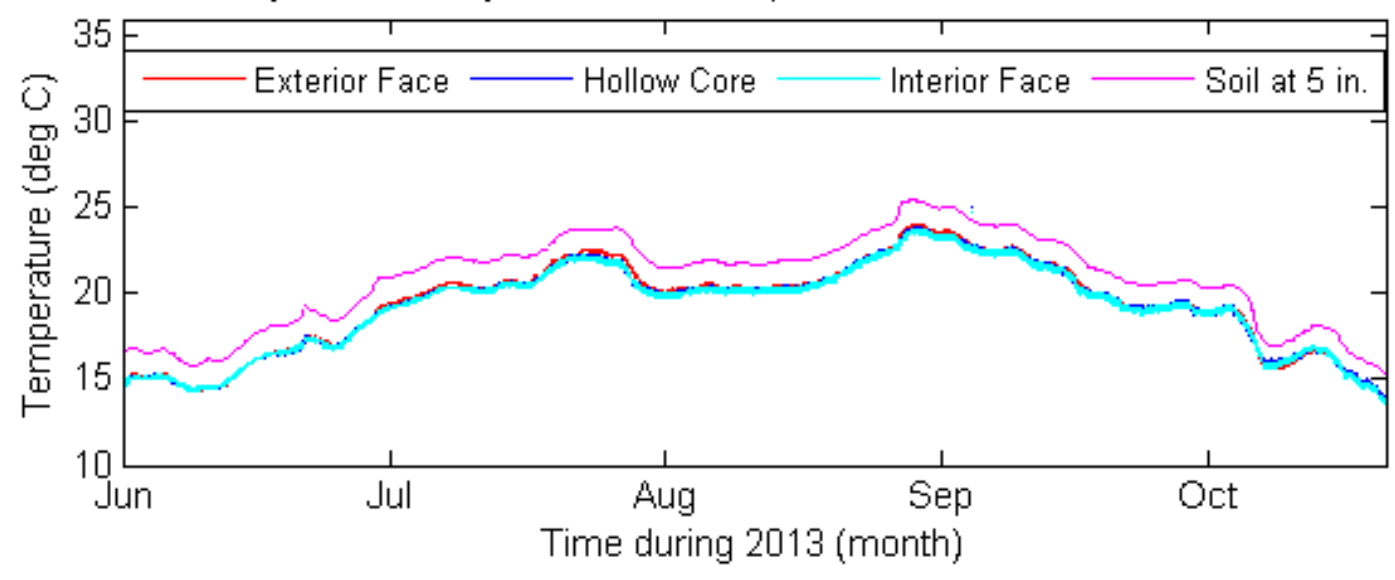

Figure 13. Bay $2 S$ cooling season masonry block wall and soil temperature profiles 40 to $79 \mathrm{in}$. above the slab 

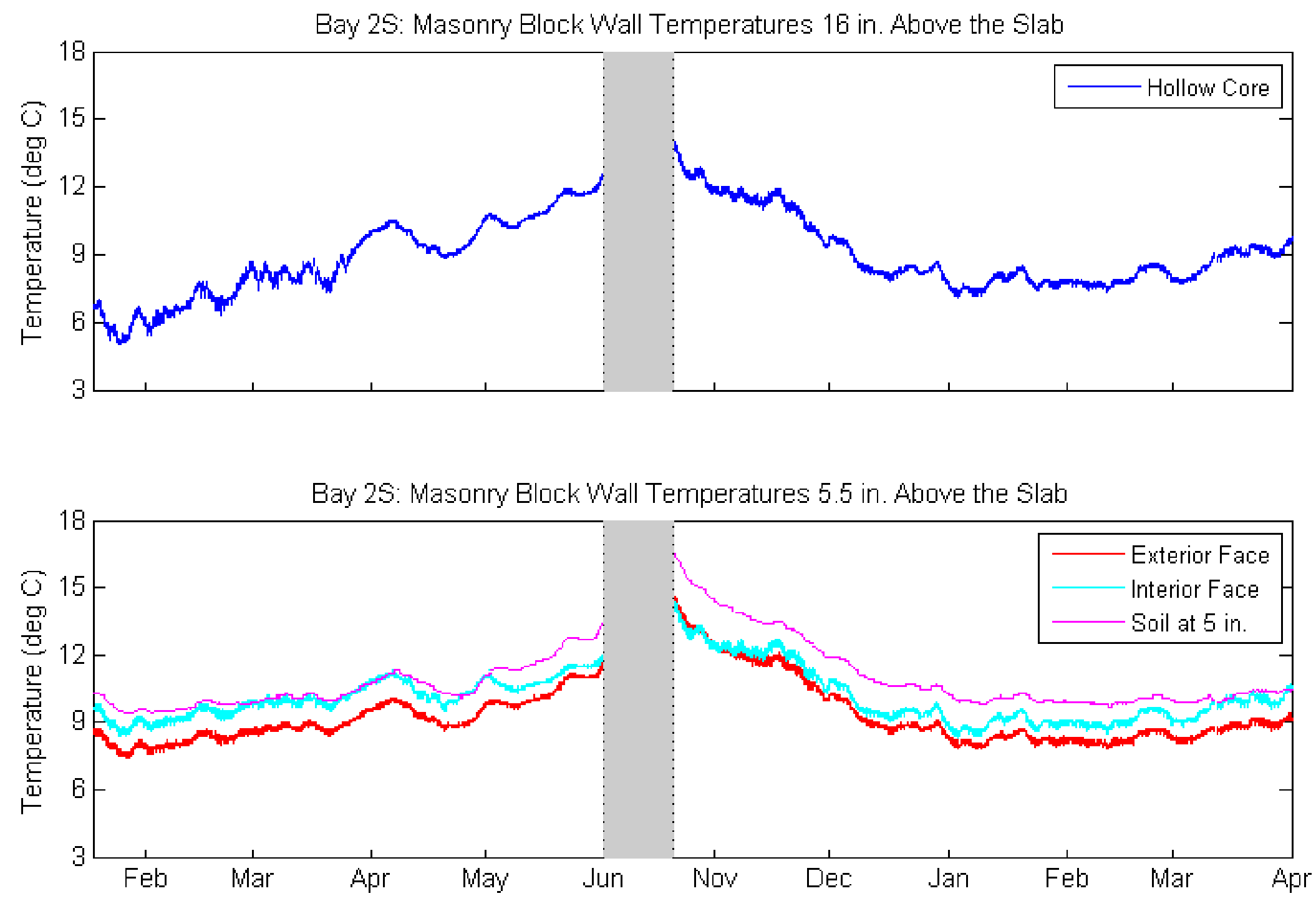

Figure 14. Bay $2 S$ heating season masonry block wall and soil temperature profiles $5-1 / 2$ to 16 in. above the slab 

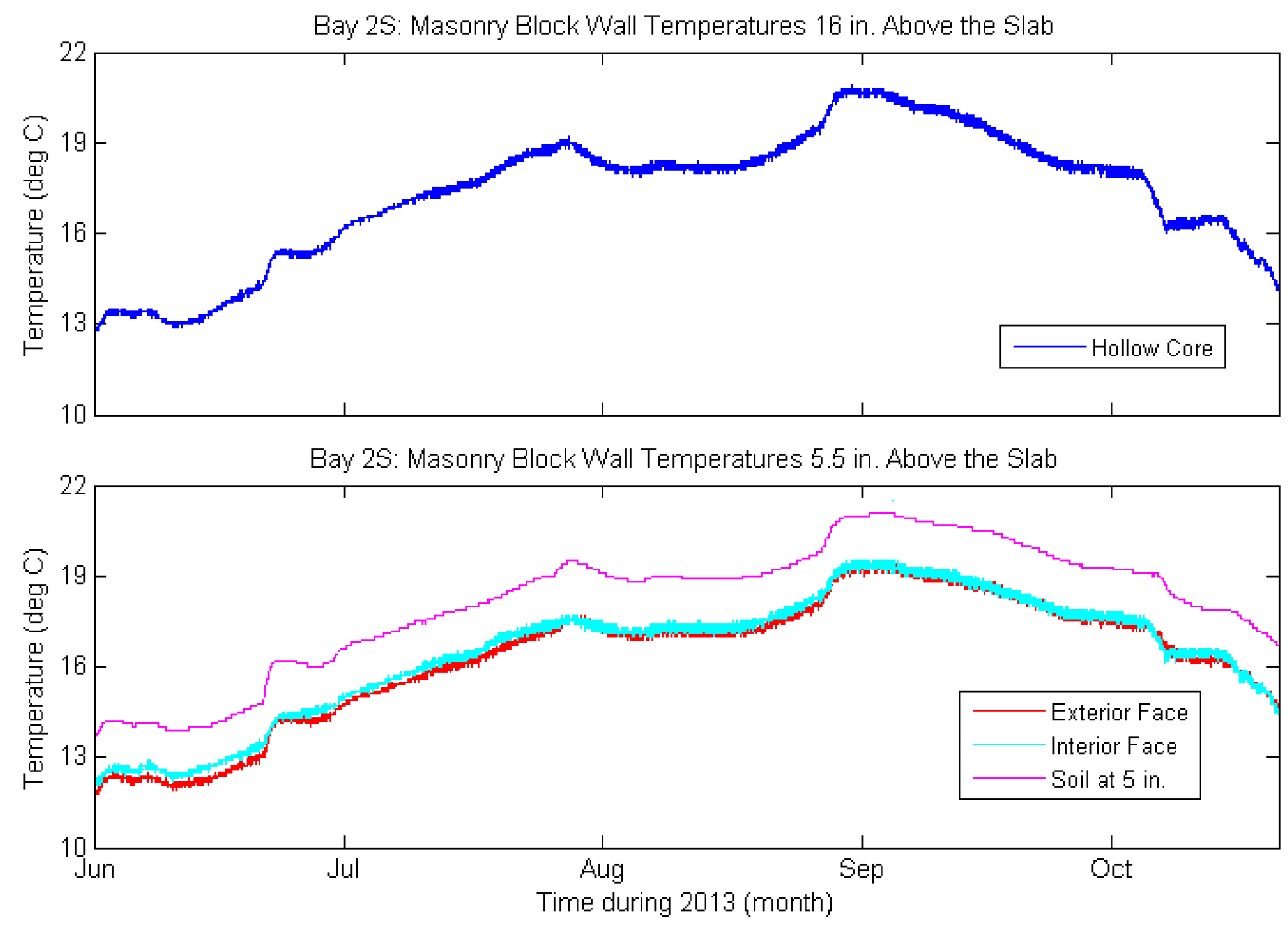

Figure 15. Bay $2 S$ cooling season masonry block wall and soil temperature profiles $5-1 / 2$ to 16 in. above the slab 
These Bay 2S data suggest that during the heating season, the cores of the masonry block wall had a buoyant cavity flow loop, but did not have the loop during the cooling season as expected (Harmon 2014) when the top of the wall is warmer than its base owing to heat gain from the ambient environment (the insulation shields the wall from increased interior cooling season temperatures). The data also suggest a heat source beneath the foundation during the cooling season. This is consistent with a higher and warmer water table during the cooling season, which is possible with the ground hydrology and topography around the CRRF (Harmon 2014).

The same patterns prevail on the north side for Bay 2N (Figure 110 through Figure 114 in Appendix C). The only appreciable difference is in Figure 110 at the top of the wall where the asymmetric diurnal variations of the external face shell temperature shown in Figure 11 were absent because the north side above-grade walls were always shaded (except during the early mornings in June and July around the summer solstice - the walls are shaded by the surrounding forest in the late afternoon). Of note, though, is a comparison of the heating season temperatures 40 and 69 in. above the slab in Figure 111 (Bay 2N) and Figure 12 (Bay 2S). These figures show that the exterior face shell temperatures at these locations were clearly colder than the core, interior face shell and soil temperatures during the first heating season in Bay $2 \mathrm{~N}$, unlike the corresponding case in Bay 2S. This is because colder above-grade wall temperatures on the north side were advected to the below-grade exterior face shell by the cavity flow loop.

Appendix C provides the wall temperature data for Bay 1S (Figure 101 through Figure 105). The Bay $1 \mathrm{~S}$ data show very similar phenomenology to Bay $2 \mathrm{~S}$ discussed above and no further comment is warranted. However, a comparison of the Bay $3 \mathrm{~N}$ and $2 \mathrm{~N}$ below-grade wall and soil temperature data is very instructive (the Bay $2 \mathrm{~N}$ and $3 \mathrm{~N}$ above-grade wall temperatures again are very similar - the above-grade Bay 3N data are reported in Figure 106 in Appendix C). This arises because the masonry block wall core at the Bay $3 \mathrm{~N}$ instrumentation plane is grouted solid (Figure 58 ), so the instrumentation plane in Bay $3 \mathrm{~N}$ has no buoyant cavity flow loop. In other words, the heat flow in the Bay $3 \mathrm{~N}$ core is by diffusion only, while that in Bay $2 \mathrm{~N}$ is by advection and longwave radiation. Thus, a comparison of the Bay $2 \mathrm{~N}$ and $3 \mathrm{~N}$ below-grade horizontal temperature profiles should demonstrate the presence of a convective loop in Bay $2 \mathrm{~N}$ and its absence (that is, diffusive heat flow only) in Bay $3 \mathrm{~N}$.

A comparison of the temperature profiles in Figure 111 (Appendix C; Bay 2N) and Figure 16 (Bay $3 \mathrm{~N}$ ) during the heating season confirm that this is the case. At 69 in. above the slab during the second heating season, ${ }^{17}$ in Bay $3 \mathrm{~N}$ the soil was colder than the exterior face shell temperature, while as noted above, it was warmer than the exterior face shell in Bay $2 \mathrm{~N} 40$ in. above the slab. In Bay $3 \mathrm{~N}$, the soil and exterior face shell temperatures were essentially the same (at the scale of Figure 16) while the interior face shell temperature was warmer than the exterior face shell temperature. In contrast, the Bay $2 \mathrm{~N}$ exterior face shell temperature was clearly colder than the soil temperature that, in turn, was slightly warmer than the interior face shell temperature. A similar pattern holds at $5-1 / 2$ in. above the slab during the heating season. In Bay 2N (Figure 113) during the second heating season, the soil temperature is warmer than the interior face shell temperature, while in Bay $3 \mathrm{~N}$ (Figure 16), the interior face shell temperature is warmer than the soil temperature that, in turn, is approximately equal to the exterior face shell temperature.

\footnotetext{
${ }^{17}$ Exterior face shell and soil sensors were installed in Bay $3 \mathrm{~N}$ after the first heating season ended.
} 
A comparison of Figure 112 (Bay 2N) with Figure 17 (Bay 3N) shows that while the soil temperature was higher than the exterior face shell temperature at both 69 and $40 \mathrm{in}$. above grade during the cooling season, the difference was significantly smaller in Bay $3 \mathrm{~N}$. The same applies 5$1 / 2$ in. above grade, as shown in Figure 114 and Figure 17 for Bays $2 \mathrm{~N}$ and $3 \mathrm{~N}$, respectively. The fact that the solid block core significantly reduced the difference between the soil and exterior face shell temperatures compared with the hollow core suggests that the solid wall acts as a far better conductor of heat from the warm above-grade wall, thus increasing the wall temperature relative to the soil temperature. In turn, the hollow core in Bay $2 \mathrm{~N}$ is a better insulator that inhibits the wall from warming up as quickly or as much from its cooler heating season temperatures that were chilled below those of Bay $3 \mathrm{~N}$ by the cavity flow loop. Further, the insulating effect of the air core demonstrates the absence of a flow loop in the cooling season, because any such loop would largely negate the insulating impact of still core air. The heat flux profiles reported in Figure 22 do not show this effect because, generally, the Bay $2 \mathrm{~N}$ heat fluxes were larger in magnitude than those of Bay $3 \mathrm{~N}$. This was caused by the air gap created by the nonadhered WSP on the interior face of the Bay $3 \mathrm{~N}$ wall, which added sufficient insulation to cancel out the effect of the higher diffusive heat transport through the solid core. 
Bay 3N: Masonry Block Wall Temperatures 69 in. Above the Slab

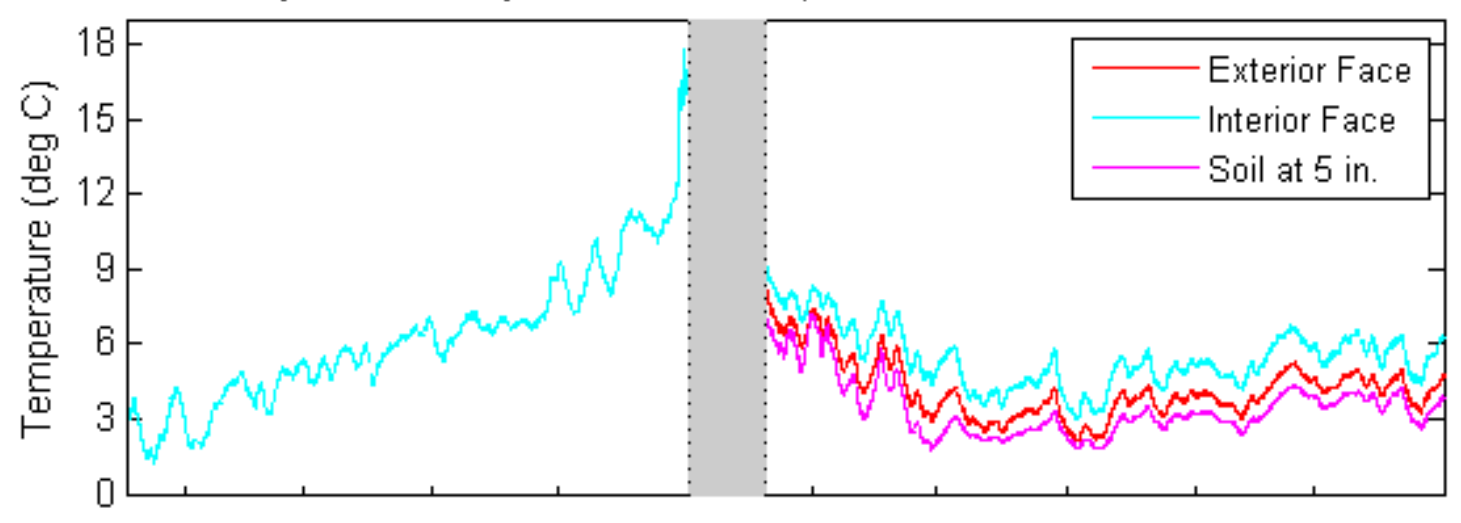

Bay 3N: Masonry Block Wall Temperatures 40 in. Above the Slab

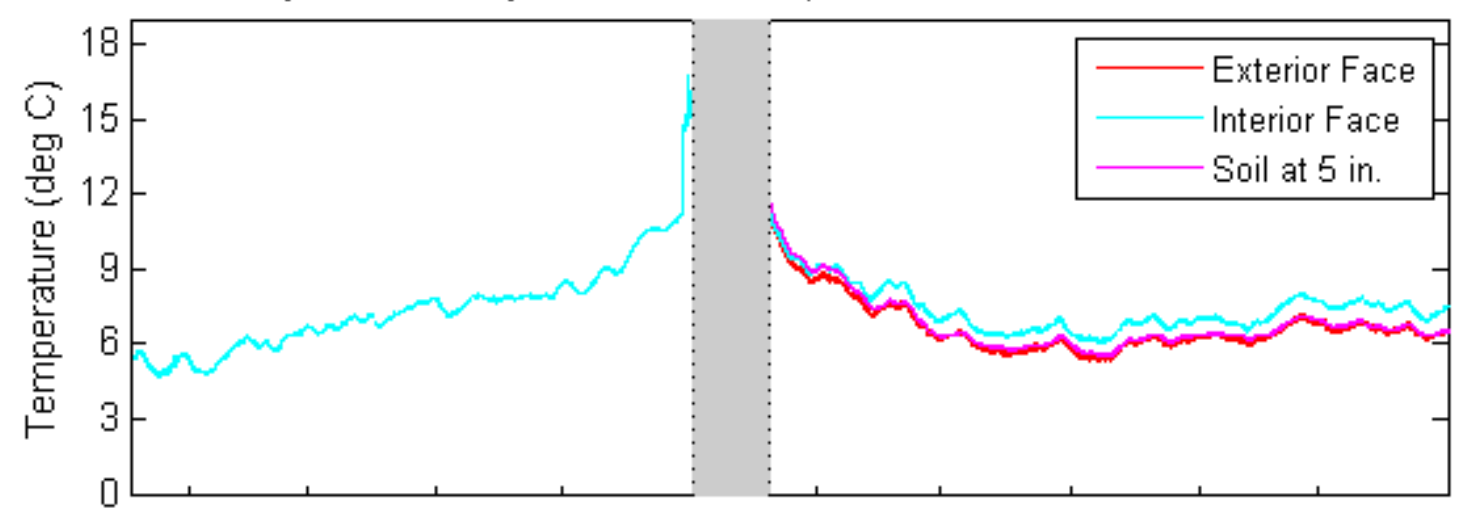

Bay 3N: Masonry Block Wall Temperatures 5.5 in. Above the Slab

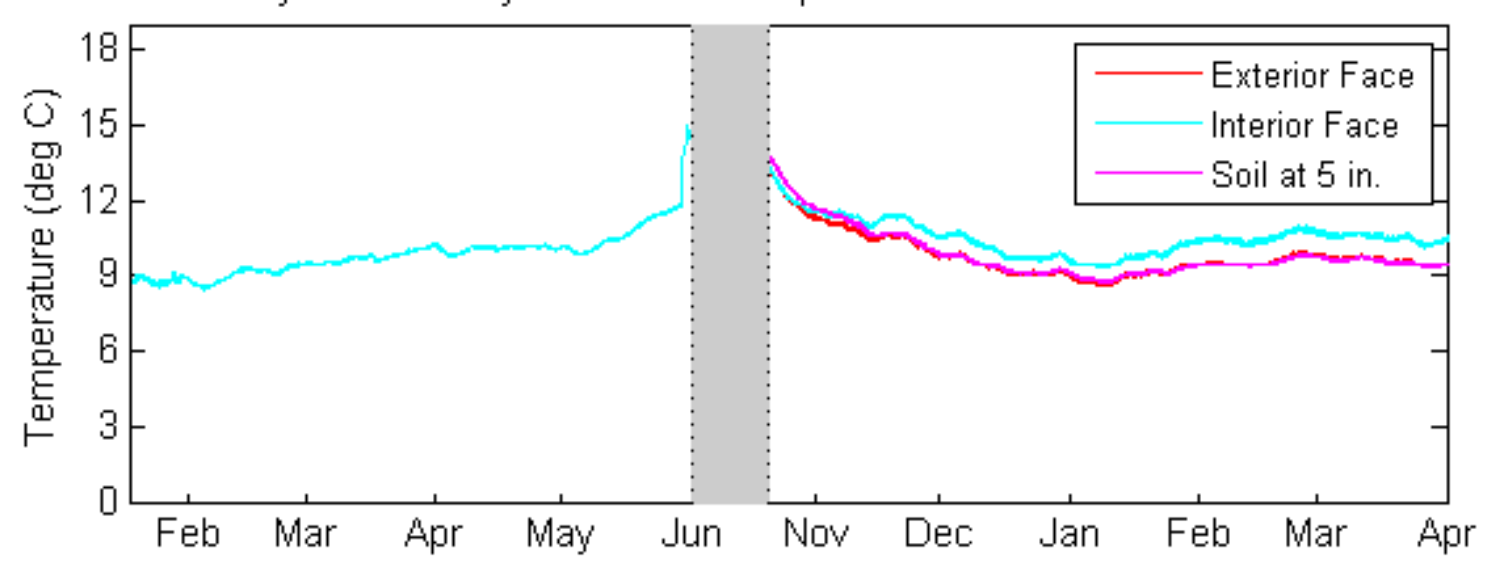

Time during 2013-2014 (month)

Figure 16. Bay $3 \mathrm{~N}$ heating season below-grade masonry block wall and soil temperature profiles 


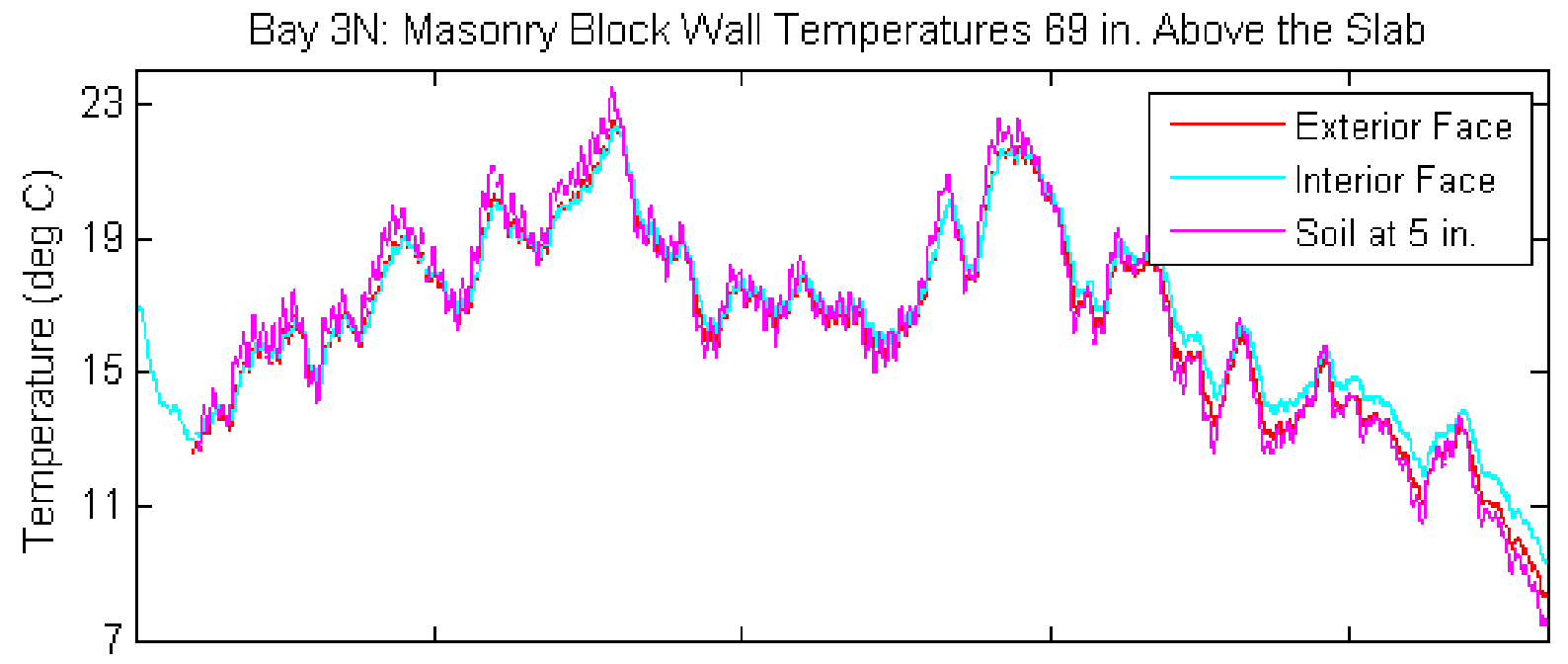

Bay 3N: Masonry Block Wall Temperatures 40 in. Above the Slab

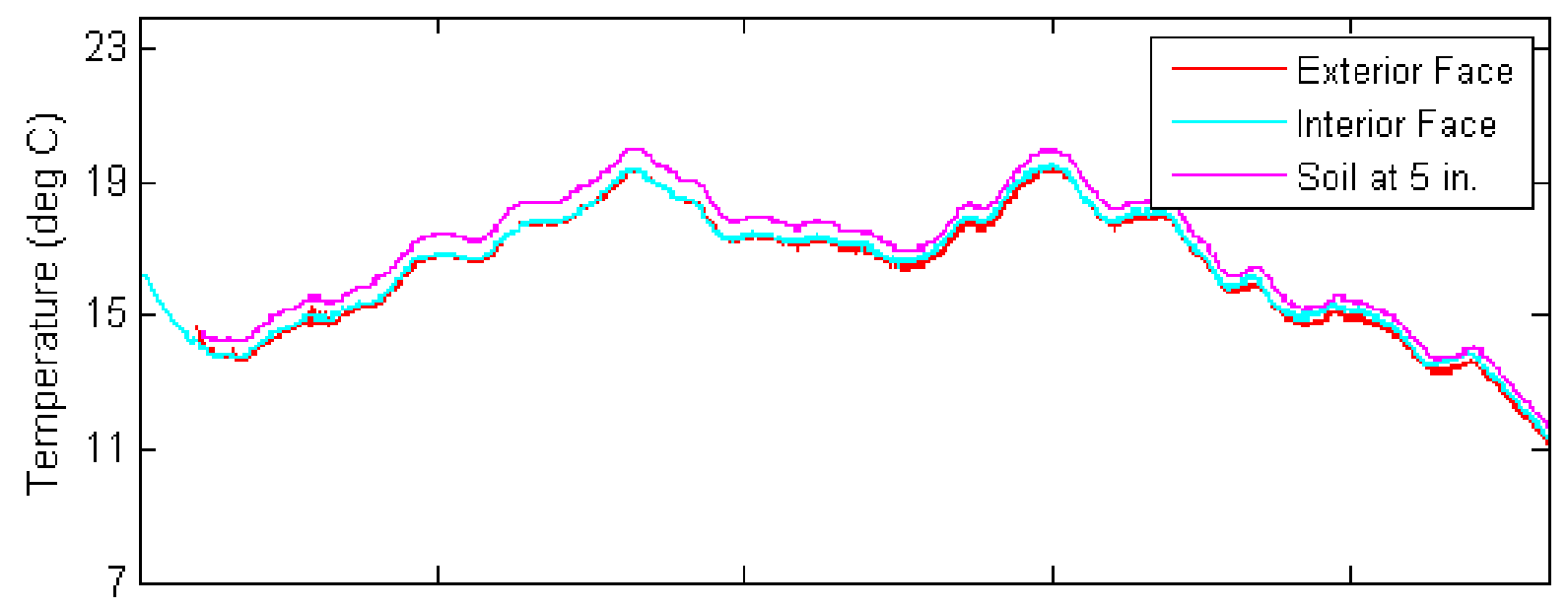

Bay 3N: Masonry Block Wall Temperatures 5.5 in. Above the Slab

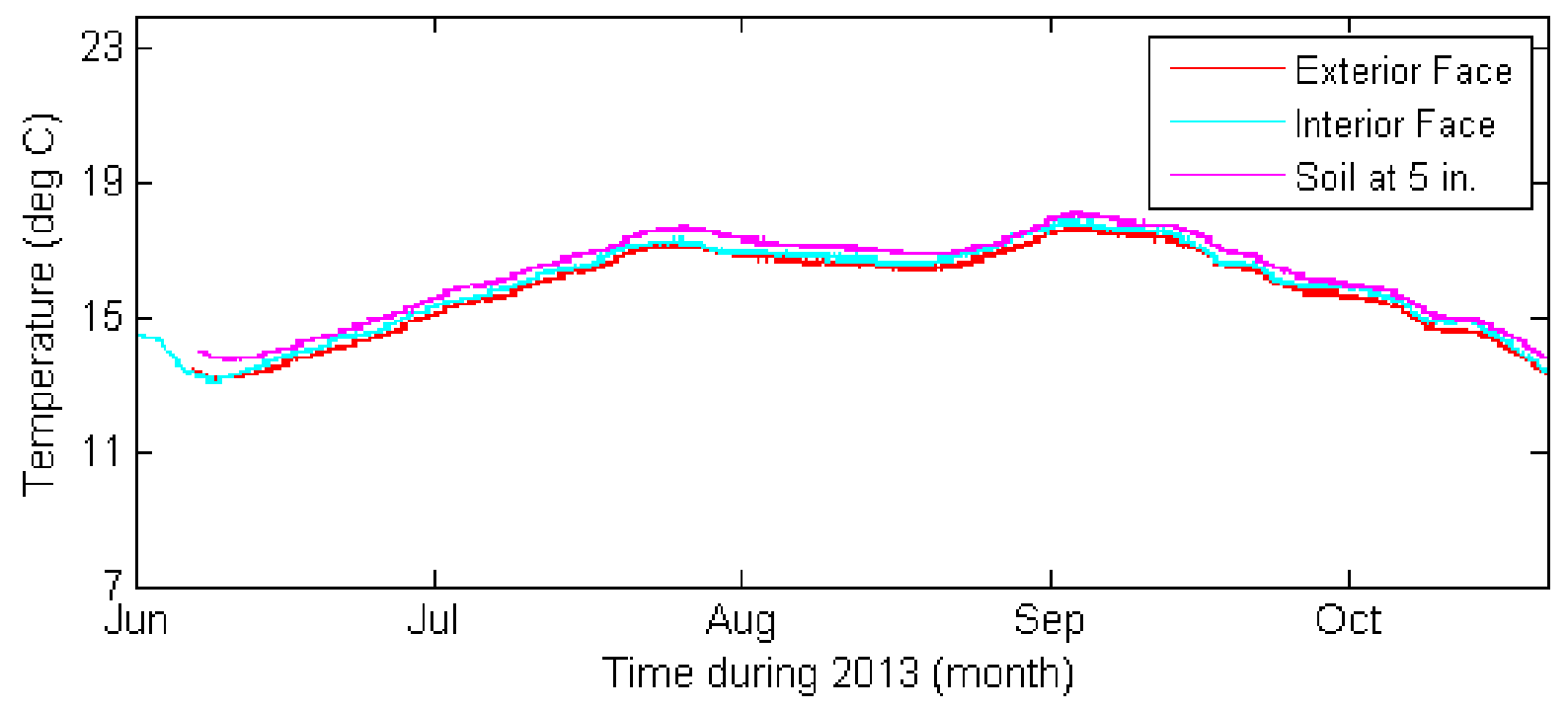

Figure 17. Bay $3 \mathrm{~N}$ cooling season below-grade masonry block wall and soil temperature profiles 
Additional insight to the buoyant cavity flow phenomenology may be gleaned from a comparison of the wall temperature profiles between Bays 2S and 4S shown in Figure 18 and Figure 19, respectively. The upper half-wall exterior insulation was installed on Bay $4 \mathrm{~S}$ at the end of May 2013; Bay 2S had interior insulation for the duration of the experiment. Therefore, there were different upper half wall exterior boundary conditions on Bay 4S during the first and second heating seasons that would affect the buoyant cavity flows in this wall.

Generally, full wall exterior insulation suppresses buoyant cavity flows in hollow masonry block walls because the face shell temperature difference is too small (Grashof number too low), but the extent to which this suppression occurs in partially insulated walls has not been reported in the literature (see Huelman et al. 2013 for a discussion). The upper panel of Figure 18 shows that before the exterior insulation was installed on Bay $4 \mathrm{~S}$, the temperatures at 40 in. above the slab (3 in. below the insulation; see Figure 4) were significantly warmer than those in Bay $2 \mathrm{~S}$ and that the interior/exterior face shell temperature difference was greater in Bay $4 \mathrm{~S}$ because of the absence of insulation. After the insulation was installed, through the beginning of November, both bays showed the same phenomenology of the exterior face shell temperature being sometimes just slightly warmer than the interior face shell temperature until the beginning of October. The maximum exterior face shell temperatures in Bays $2 \mathrm{~S}$ and $4 \mathrm{~S}$ of about $24^{\circ}$ and $20^{\circ} \mathrm{C}$, respectively, occurred at the end of August, indicating that the diurnal average temperature reduction caused by the top of the wall being insulated in Bay $4 \mathrm{~S}$ was about $4{ }^{\circ} \mathrm{C}$ just below the insulation. This is also reflected in the upper wall Bay $4 \mathrm{~S}$ heat flux profiles given in Figure 24. The upper half-wall heat fluxes were smaller in magnitude during the second heating season compared with the first after the exterior insulation was added.

After mid-October, the temperature profile just below the insulation in Bay $4 \mathrm{~S}$ was strictly monotonic on the horizontal plane, decreasing from the interior to the exterior consistent with diffusion-only heat flow; that is, a complete absence of any buoyant cavity flow loop as expected. In contrast, with reference to Figure 12, Bay $2 \mathrm{~S}$ shows a temperature inversion (core temperature warmer than face shell temperatures) that is consistent with a flow loop.

Figure 19 shows that 12 in. below grade, after mid-November during the second heating season, the temperatures were again consistent with diffusion-only heat flow in Bay 4S as expected, while in Bay $2 \mathrm{~S}$ the core temperature was warmer than the interior face shell temperature and the soil temperature was warmer than the exterior face shell temperature (with reference to Figure 12) through mid-March. Further, the insulation in Bay 4S yielded a minimum soil temperature below zero in mid-February compared with $4^{\circ} \mathrm{C}$ in Bay $2 \mathrm{~S}$. During the cooling season, toward the end of August, the soil temperatures 12 in. below grade were about the same, again expected because the wall heat transfer phenomenology is purely diffusive during the cooling season and the soil temperatures are primarily influenced by ambient conditions. The insulation in Bay 4S yielded cooler face shell temperatures than measured on Bay $2 \mathrm{~S}$ by about $8^{\circ} \mathrm{C}$ at the end of August.

The Bay 4S and 2S wall temperature profile comparisons at the bottom and top of the wall are given in Appendix C (Figure 107 and Figure 108). These figures show thermal behavior consistent with the insulation placement; namely, warmer temperatures at the bottom of the wall in Bay $4 \mathrm{~S}$ during the heating season (because of the absence of interior insulation) and cooler wall temperatures with less diurnal variation (because of exterior insulation in Bay 4S). 
Bay 4S: Masonry Block Wall Temperatures 40 in. Above the Slab

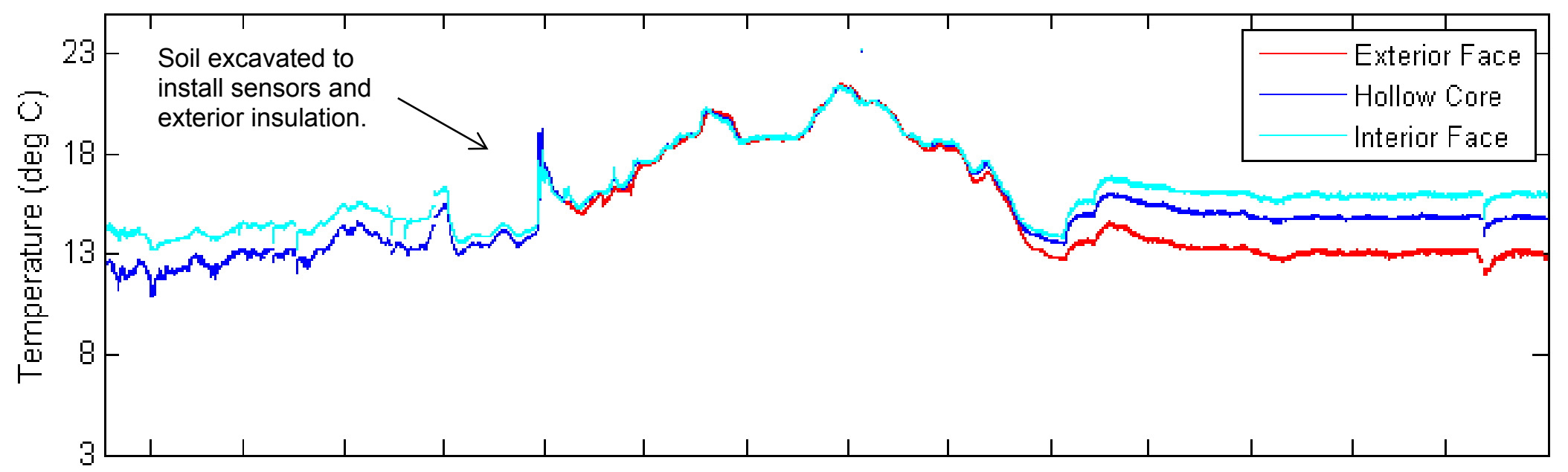

Bay 2S: Masonry Block Wall Temperatures 40 in. Above the Slab

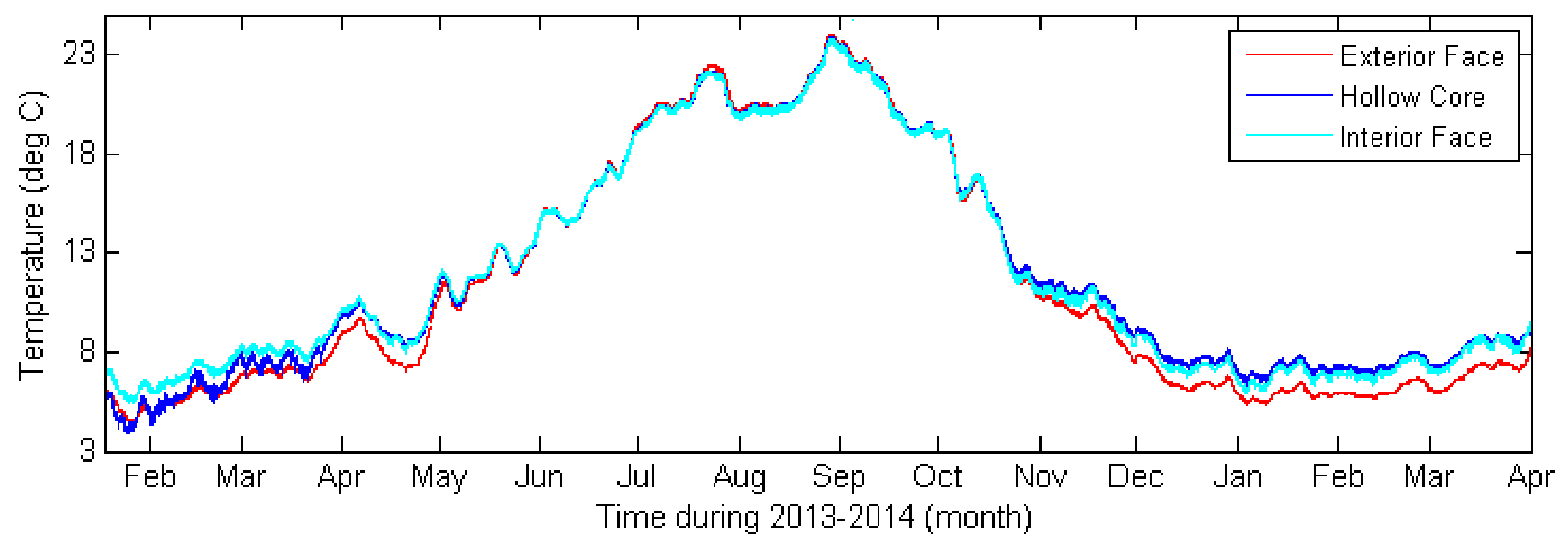

Figure 18. Bay $2 S$ (interior insulation)/Bay $4 S$ (exterior half-wall insulation) wall temperature comparison $40 \mathrm{in.}$ above the slab 
Bay 4S: Masonry Block Wall Temperatures 69 in. Above the Slab

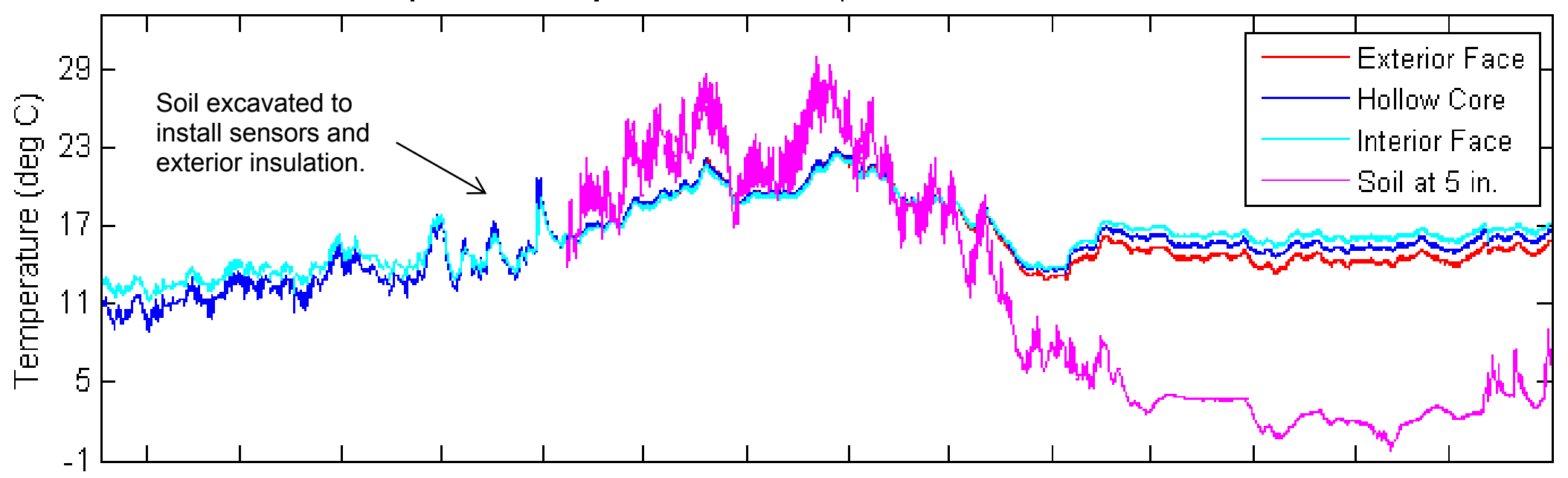

Bay 2S: Masonry Block Wall Temperatures 69 in. Above the Slab

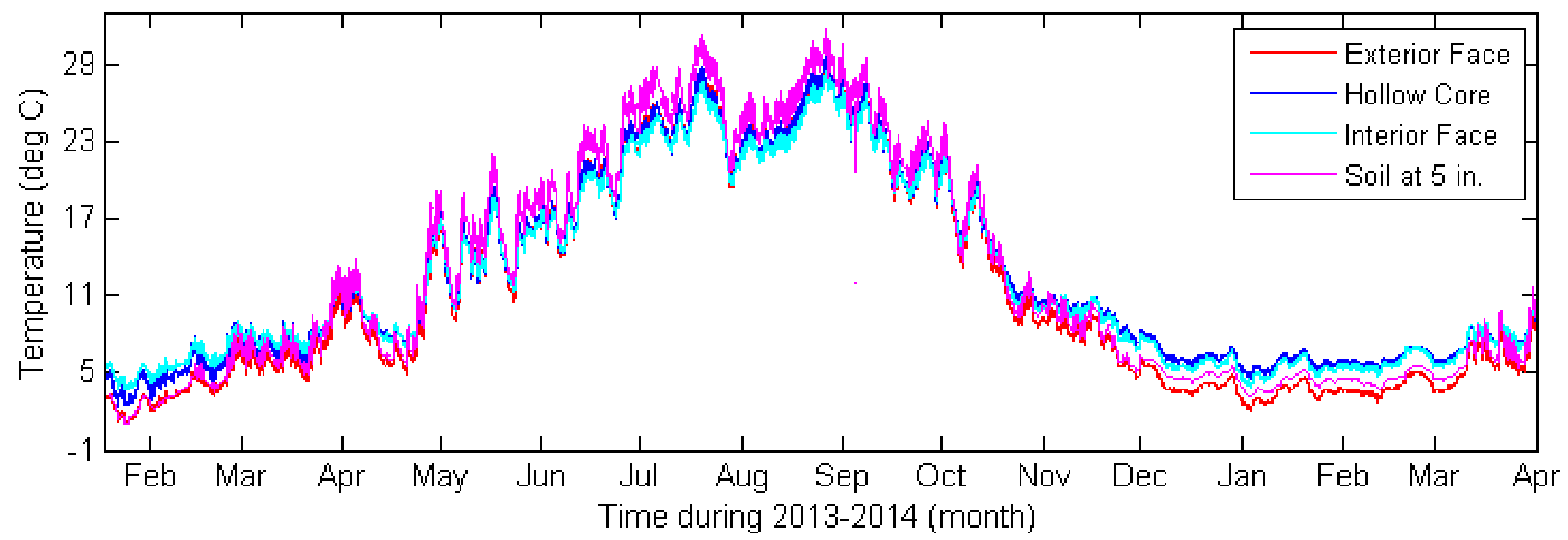

Figure 19. Bay $2 S$ (interior insulation)/Bay $4 S$ (exterior half-wall insulation) wall temperature comparison 69 in. above the slab 
The difference in temperature profiles between Bays $4 \mathrm{~S}$ and $2 \mathrm{~S}$ demonstrates a buoyant cavity flow loop in Bay $2 \mathrm{~S}$ during the heating season that Bay $4 \mathrm{~S}$ does not have. During the cooling season (June through October), the temperature profiles show no cavity flow loops in both bays.

\subsubsection{Heat Flux}

The heat fluxes measured on the interior face of the WSP at 40, 69, and $86 \mathrm{in}$. above the slab are shown in Figure 20 through Figure 26. In all the figures, positive values of heat flux indicate heat flow into the basement and negative values indicate heat flow out of the basement.

Figure 20 shows very comparable heat fluxes on the Bay 1-3 south walls over the heating season. In general, Bay 1 shows the highest negative heat flux magnitude (highest heat flow out of the basement), while Bay 3 shows the lowest negative heat flux magnitude (lowest heat flow out of the basement) at the top of the wall (Bays 2 and 3 have almost identical heat fluxes $40 \mathrm{in}$. above the slab). This arises because of the air gap between the WSP and the wall in Bay 3 (to the exterior of the heat flux plate). The air gap provided some additional thermal insulation while the actual soil thermal conductivity (higher moisture content in a different soil) in Bay 1 evidently was greater than that in Bay 2 during the heating season (see Table 5). This yielded greater heat losses in Bay 1 (contrary to the calculated thermal conductivities in Table 6 for the north side).

Figure 21 fairly consistently shows the largest positive heat flux magnitudes during the cooling season (largest heat flow into the basement) for Bay $2 \mathrm{~S}$ and the smallest for Bay $1 \mathrm{~S}$ at all levels. This is somewhat consistent with the calculated soil thermal conductivities in Table 6, which reports Bay 1 as having the lowest thermal conductivity. Further, the heat flux decreases with height as the influence of the surface solar irradiance diminishes.

Figure 22 reveals very similar patterns for Bays $1-3$ on the north side during the heating season, absent the diurnal variations at the top of the wall caused by the solar irradiance. The heat transfer phenomenology essentially was congruent on the north and south walls, while the congruency supports the consistency of the heat flux measurements. In absolute terms, the heat flow negative magnitudes were slightly larger on the north elevation, with the largest difference measured at the top of the wall because the north side has no solar irradiance. The same observations apply to the cooling season heat fluxes shown in Figure 23.

The key observations for Bays 4S and 4N shown in Figure 24 relate to the installation of the exterior wall half-height insulation at the beginning of June. During the first heating season until the end of May, the measured heat fluxes were $20-25 \mathrm{~W} / \mathrm{m}^{2}$ larger in negative magnitude (greater heat flow out of the basement) above grade ( $86 \mathrm{in}$. above the slab) without exterior insulation compared to the heat fluxes with exterior insulation from the beginning of November onward. Of more interest, perhaps, is that during the first heating season, the negative heat flux magnitudes increased with height above the slab as expected, with the largest negative heat flux recorded at the top of the wall. However, during the second heating season, while the top of the wall heat flux still had the highest negative magnitude, the heat loss 69 in. above the slab was lower than that at 40 in. above the slab because the insulation terminated at 43 in. above the slab. 
Heat Flux at 86 in. Above the Slab on South Walls

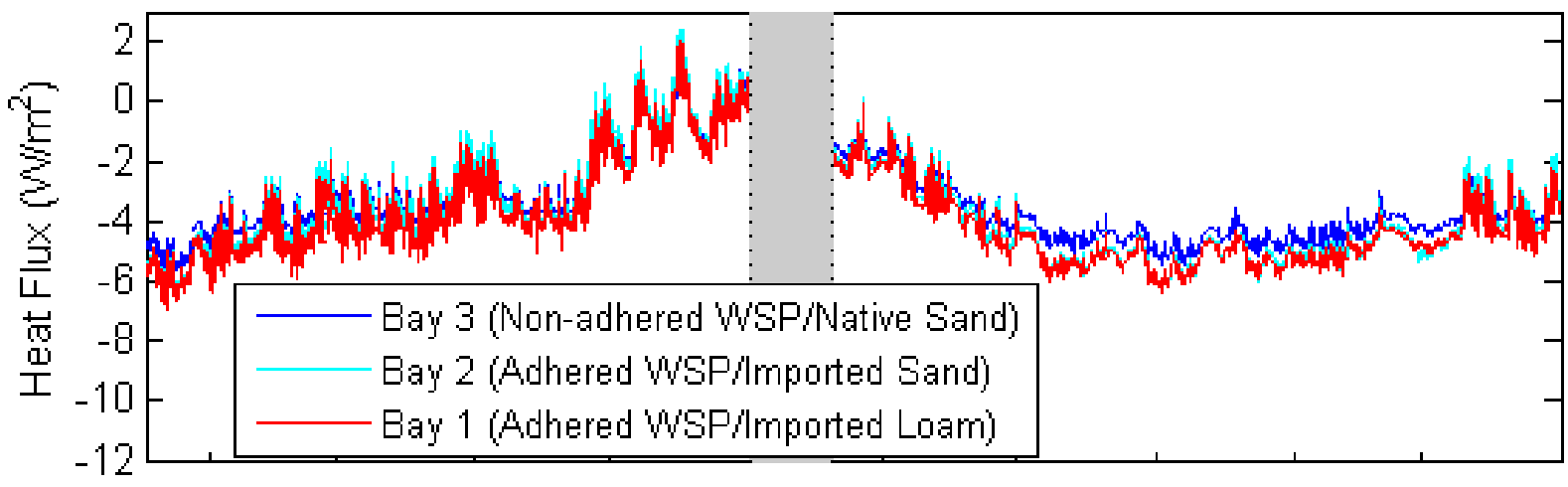

Heat Flux at 69 in. Above the Slab on South Walls

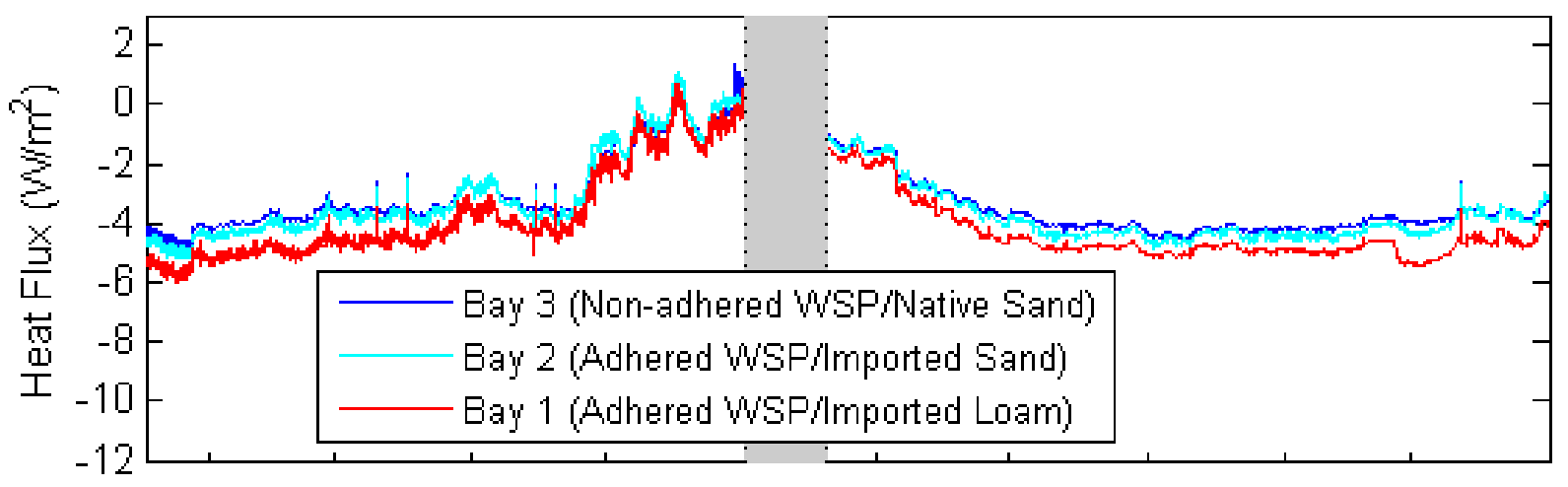

Heat Flux at 40 in. Above the Slab on South Walls

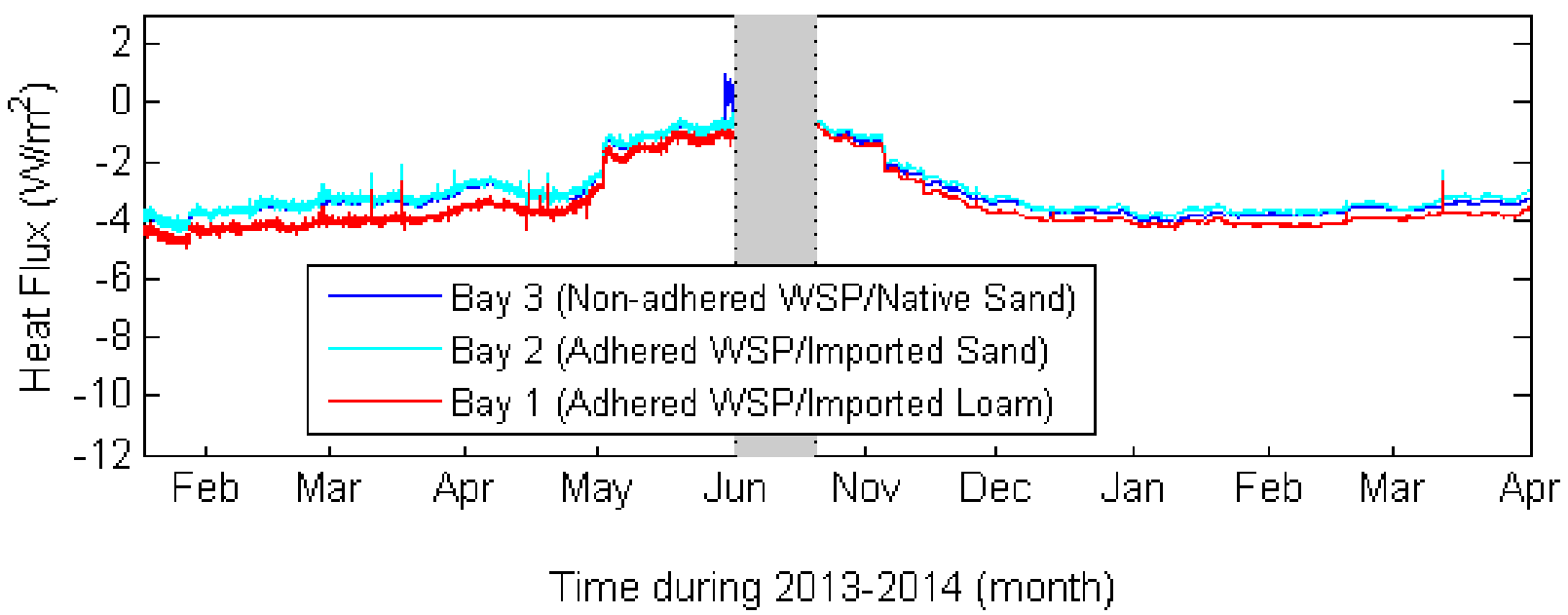

Figure 20. Bays 1-3 south wall heating season heat flux profiles 
Heat Flux at 86 in. Above the Slab on South Walls
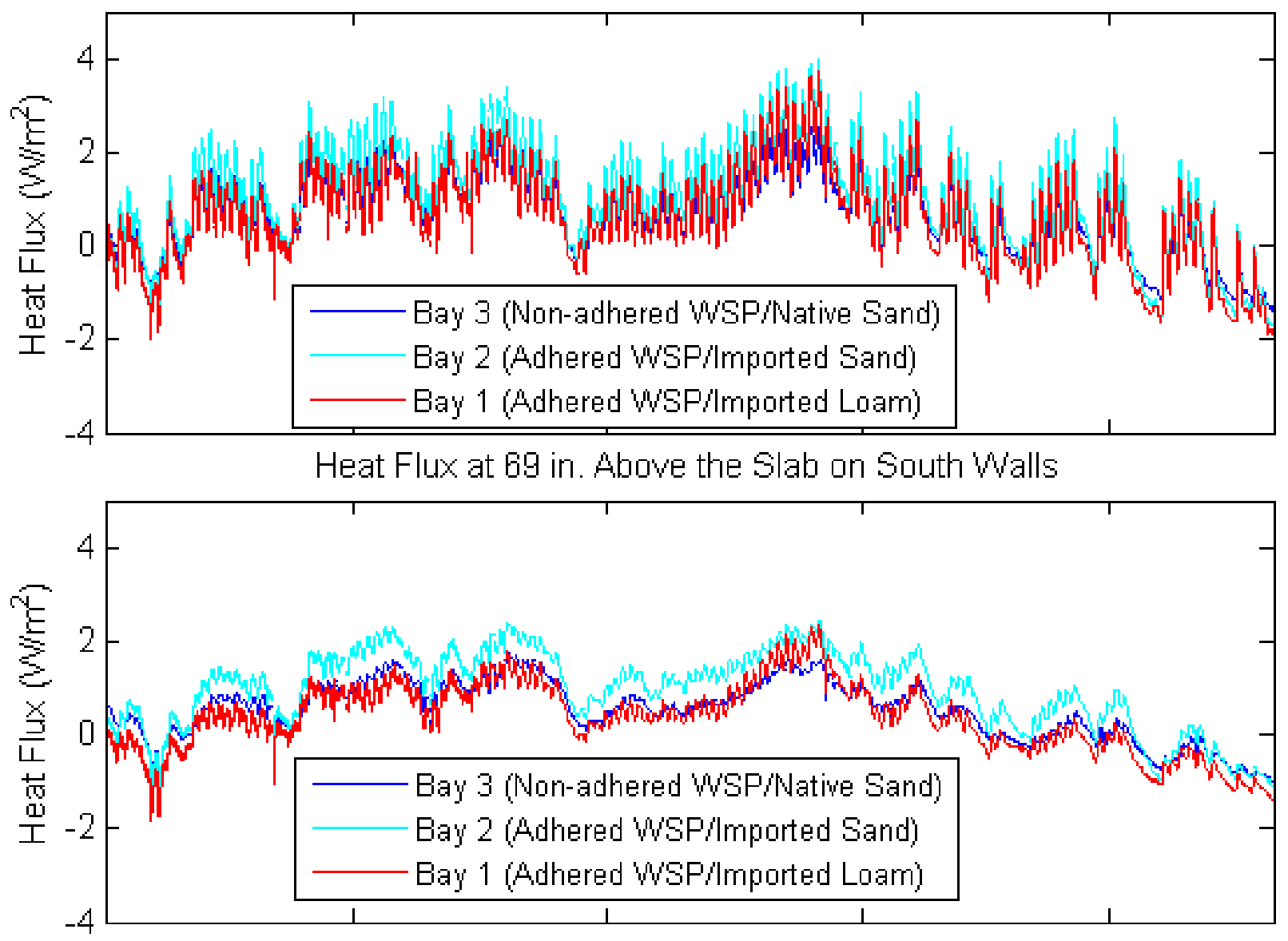

Heat Flux at 40 in. Above the Slab on South Walls

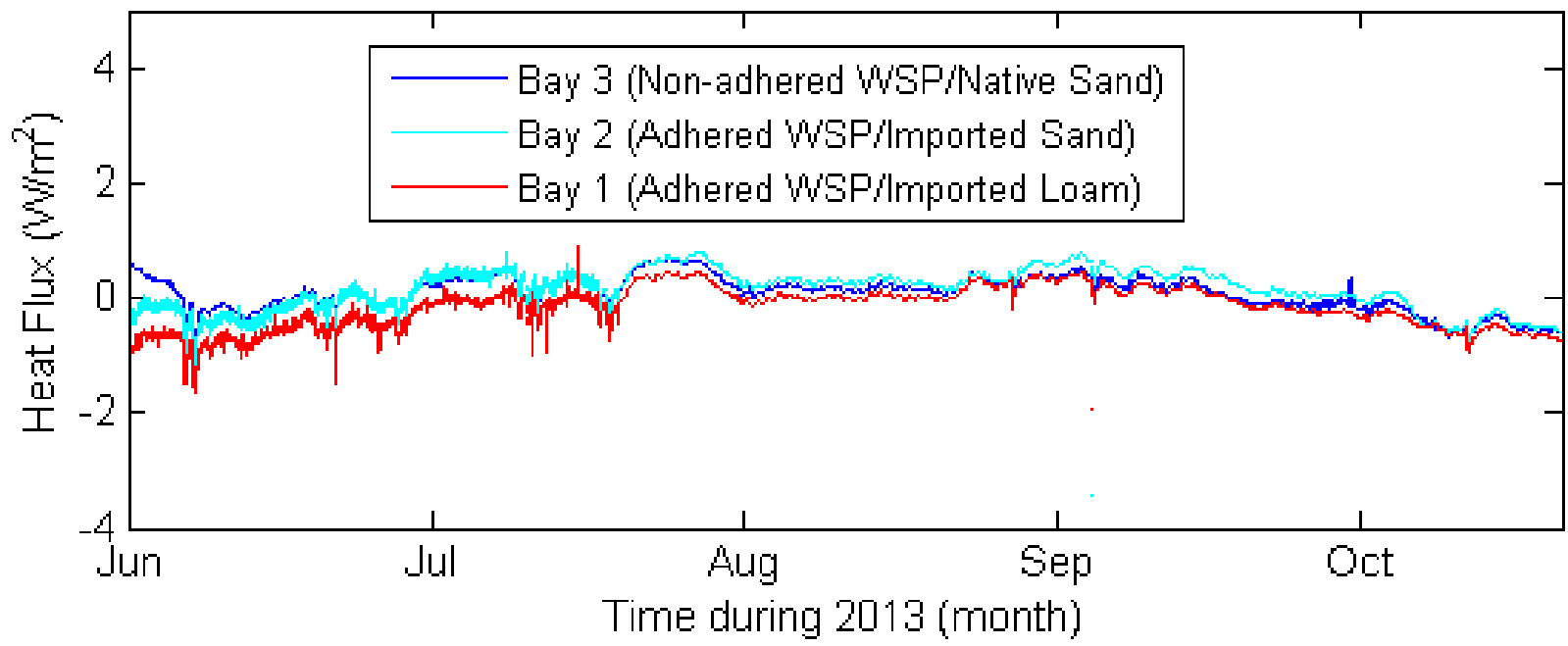

Figure 21. Bays 1-3 south wall cooling season heat flux profiles 
Heat Flux at 86 in. Above the Slab on North Walls

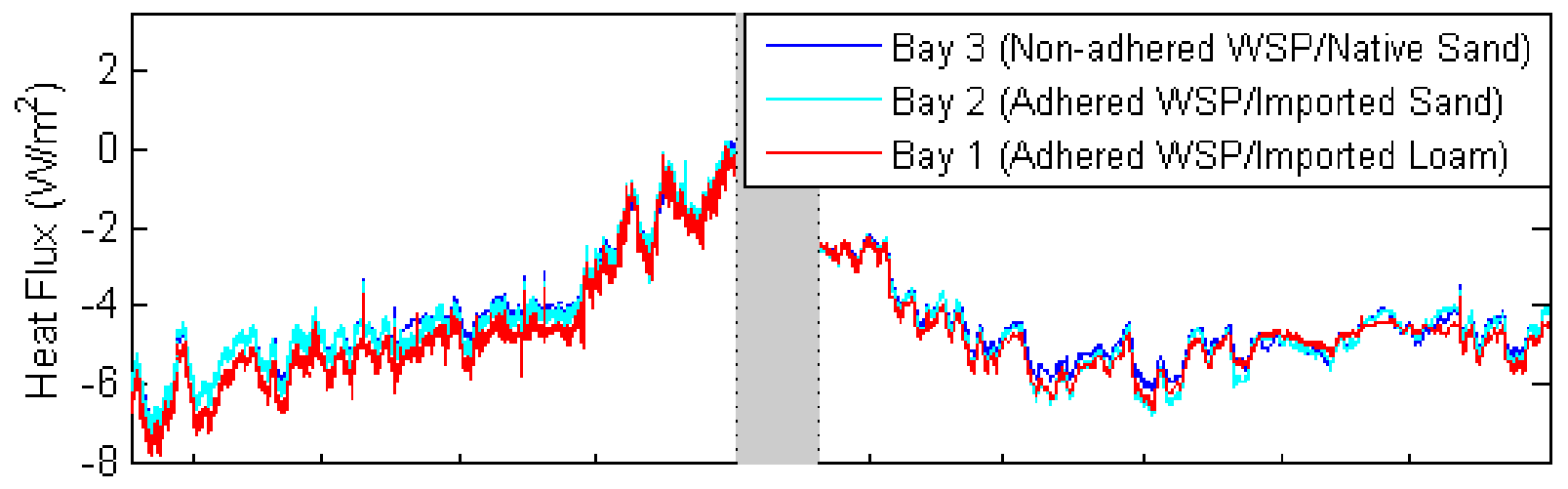

Heat Flux at 69 in. Above the Slab on North Walls

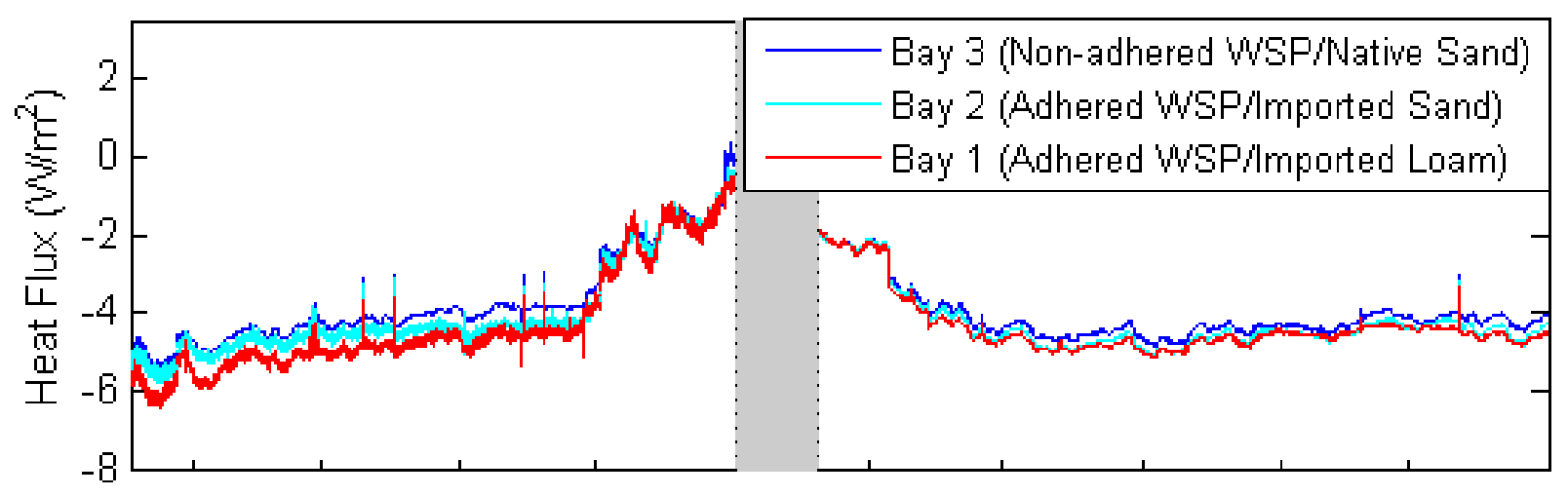

Heat Flux at 40 in. Above the Slab on North Walls

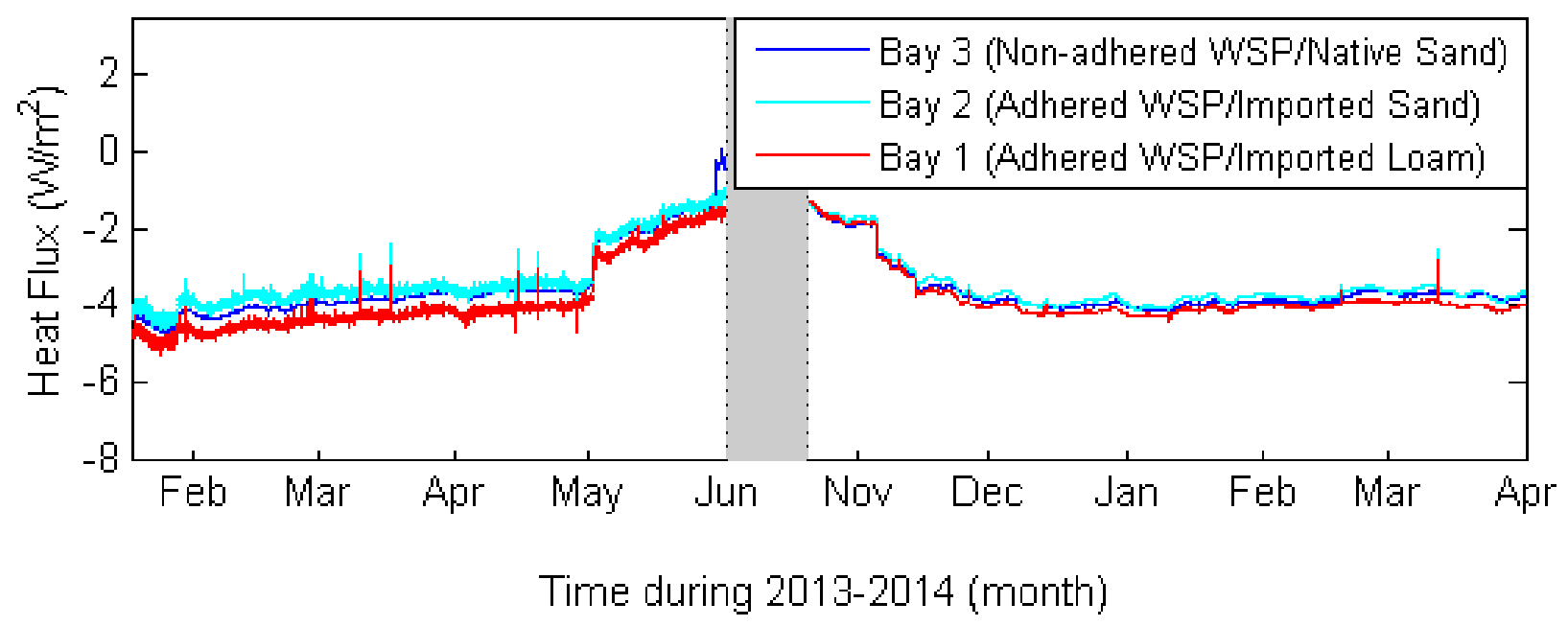

Figure 22. Bays 1-3 north wall heating season heat flux profiles 
Heat Flux at 86 in. Above the Slab on North Walls

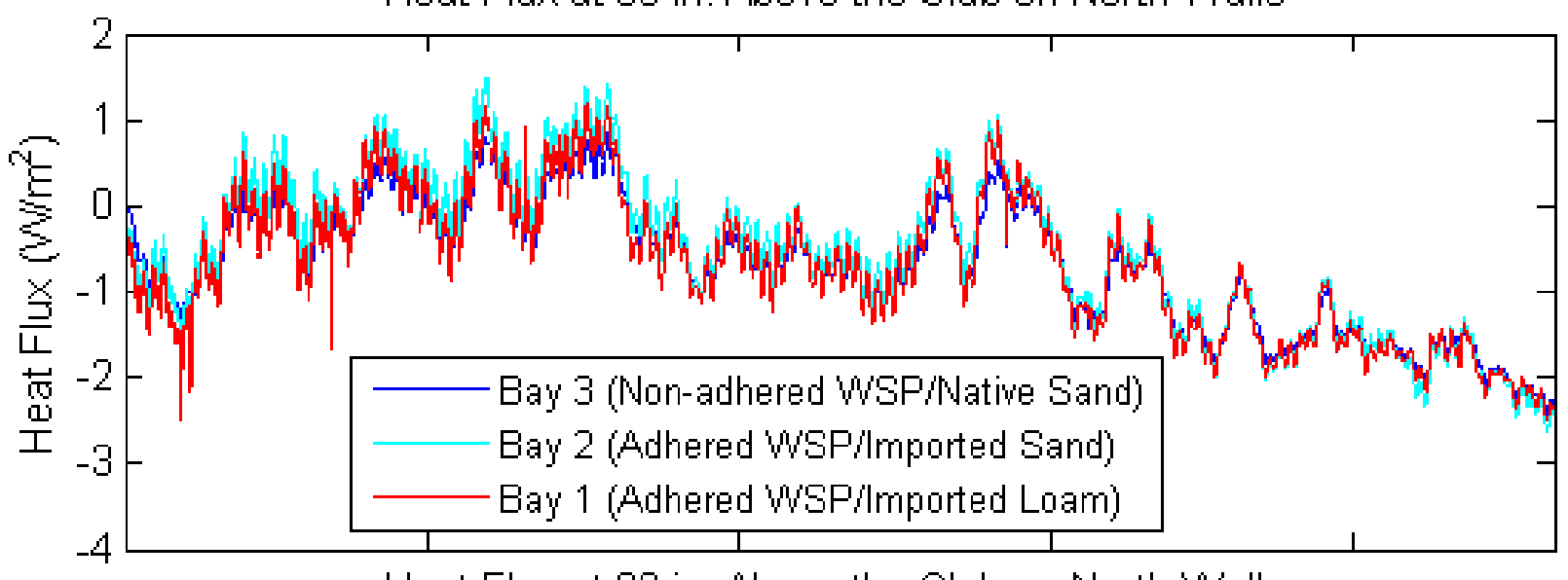

Heat Flux at 69 in. Above the Slab on North Walls
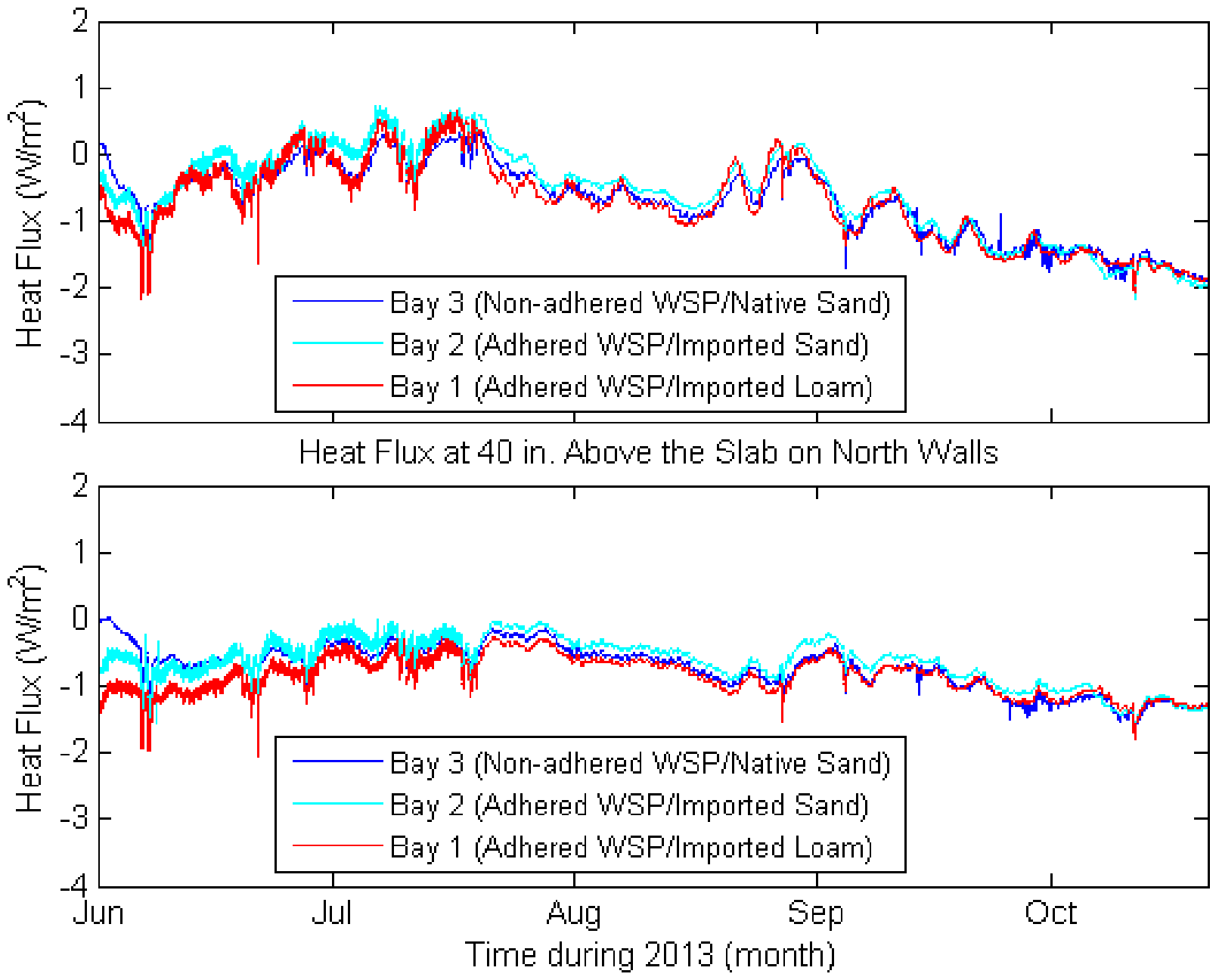

Figure 23. Bays 1-3 north wall cooling season heat flux profiles 

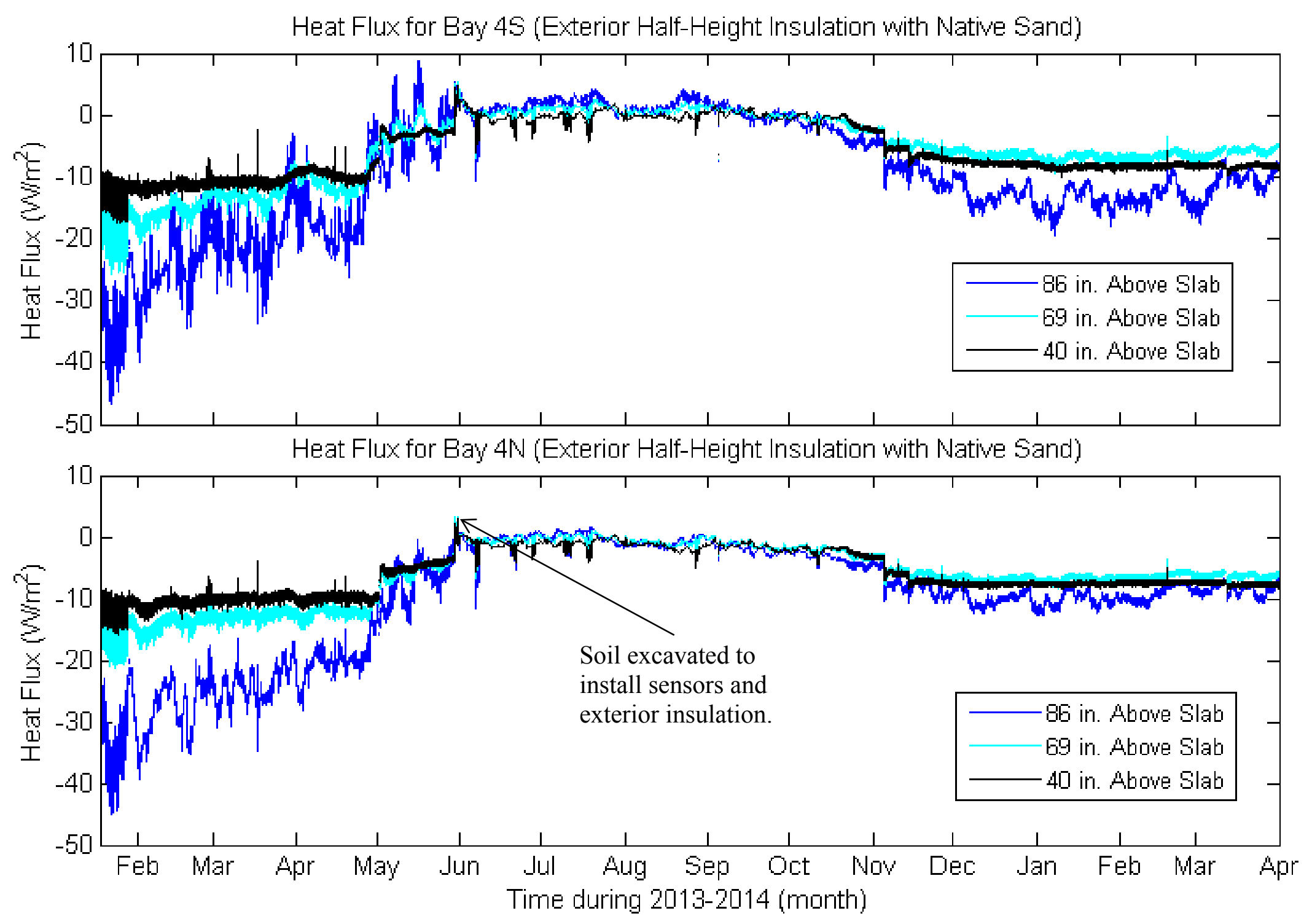

Figure 24. Bay 4 heat flux profiles 
A comparison of the heat flux profiles between Bay 4 (with no and half-wall height exterior insulation during the first and second heating seasons, respectively) and Bays 1-3 are shown for the south and north exposures in Figure 25 and Figure 26, respectively. Figure 25 shows very similar heat fluxes for Bays 1-3 during the first and second heating seasons on the south side, which always had a smaller negative magnitude than those for Bay 4 (smaller basement heat losses). During the cooling season, roughly from the beginning of May through the beginning of November) the heat fluxes for all the bays were very similar. Without any insulation during the first heating season, the Bay 4 fluxes had larger negative magnitudes than those of Bays 1-3 (greater heat flow out of the basement) and the difference decreased with height above the slab as anticipated.

During the second heating season, in the presence of half-wall height exterior insulation, the heat flux difference between Bay 4 and Bays 1-3 at the top of the wall ( 86 in. above the slab) is quite interesting. Because the same amount of insulation (R-15) was installed on both the interior and exterior, the heat flux difference might be expected to be smaller (about $10 \mathrm{~W} / \mathrm{m}^{2}$ from midDecember to mid-January). This is particularly noteworthy compared with the much smaller difference at $69 \mathrm{in}$. above the slab $\left(1-2 \mathrm{~W} / \mathrm{m}^{2}\right), 26 \mathrm{in}$. above the below-grade insulation edge (approximately at the vertical center of the insulation). This was undoubtedly a result of a thermal bridge at the top of the wall in Bay 4, where the above-grade heat flux was measured just 4 in. below the top of the insulation. These data show that exterior wall insulation needs to extend as far above the top of the wall as possible and at least to the top of the rim-joist cavity.

The heat flux measured 40 in. above the slab ( 3 in. below the edge of the insulation) in Figure 25 was about double that measured in the middle of the insulation $69 \mathrm{in}$. above the slab. This illustrates the rapid increase in heat loss from the basement below the edge of the insulation and suggests that extending exterior below-grade insulation as close to the footing as possible is always a best practice.

The results on the north side in Figure 26 mirror those discussed above for the south side. The only notable observation is a smaller difference between the Bays 1-3 and Bay 4 heat fluxes during the second heating season at the top of the wall ( 86 in. above the slab). This was a result of deeper above-grade snow on the north side reducing the impact of the thermal bridge at the top of the wall.

Generally, the heat flux results confirm the results from previous research (Goldberg 2011). Halfwall exterior retrofit insulation does reduce heat losses from the basement at the top of the wall but it is less effective than full-wall interior insulation, particularly if the exterior insulation does not extend above the top of the wall. Below the exterior insulation, the heat losses increase rapidly, so installing exterior insulation to the greatest depth possible is always preferable. 


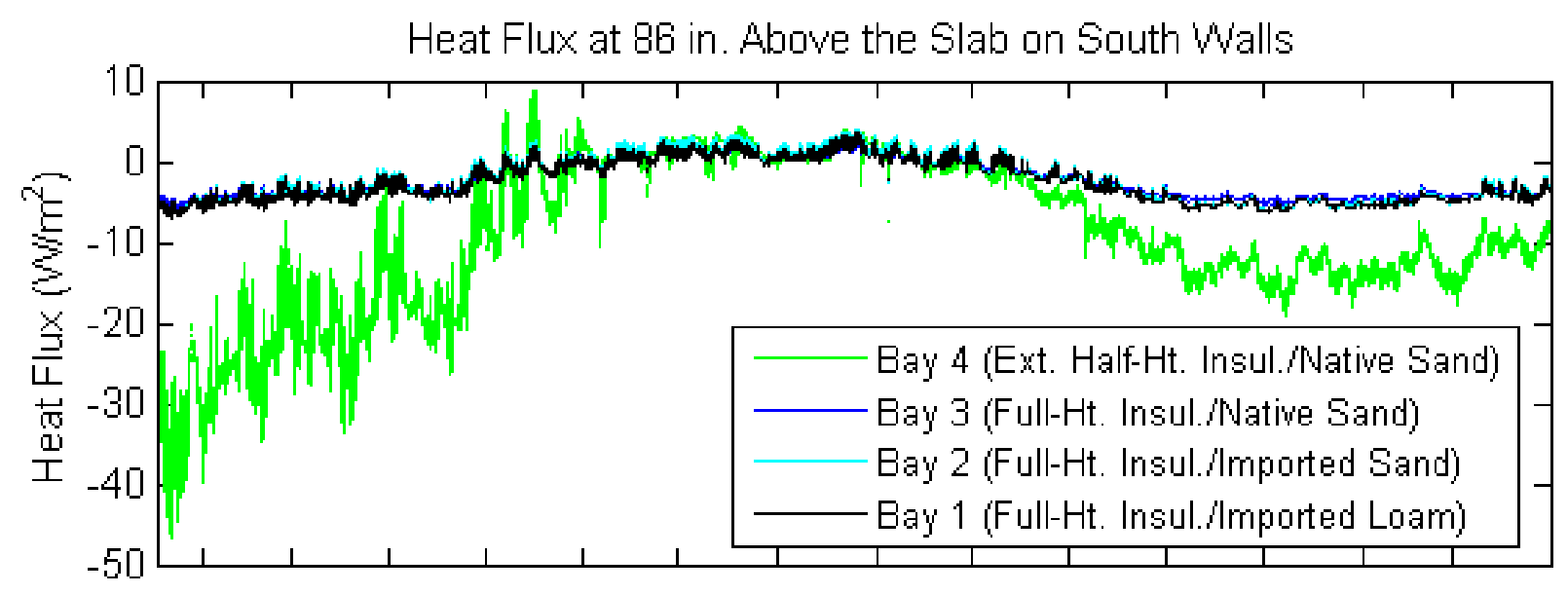

Heat Flux at 69 in. Above the Slab on South Walls

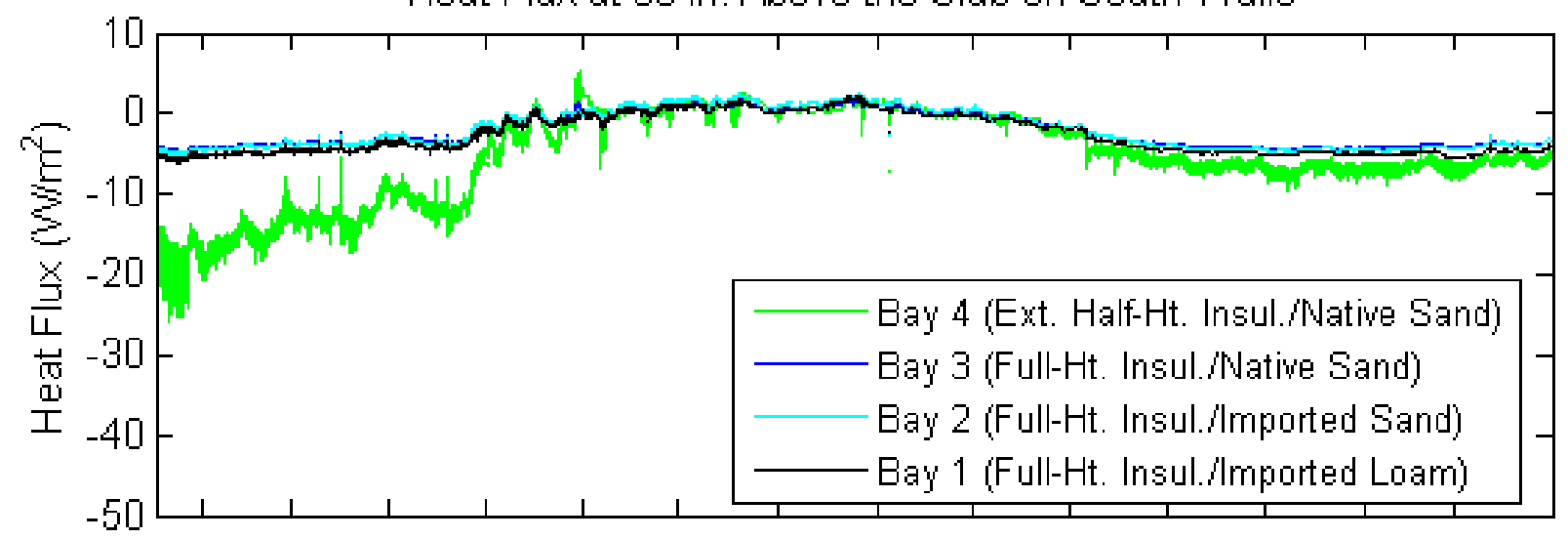

Heat Flux at 40 in. Above the Slab on South Walls

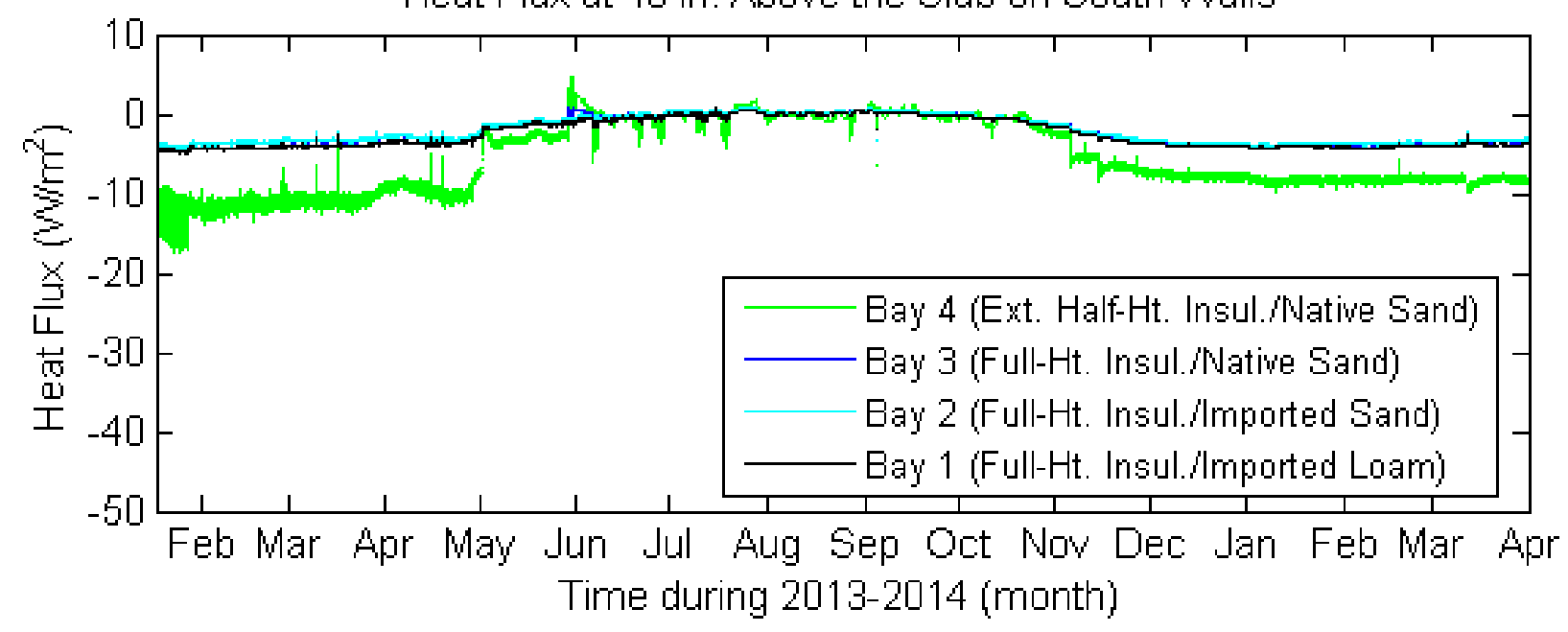

Figure 25. Bays 1-4 south wall heat flux profiles 
Heat Flux at 86 in. Above the Slab on North Walls

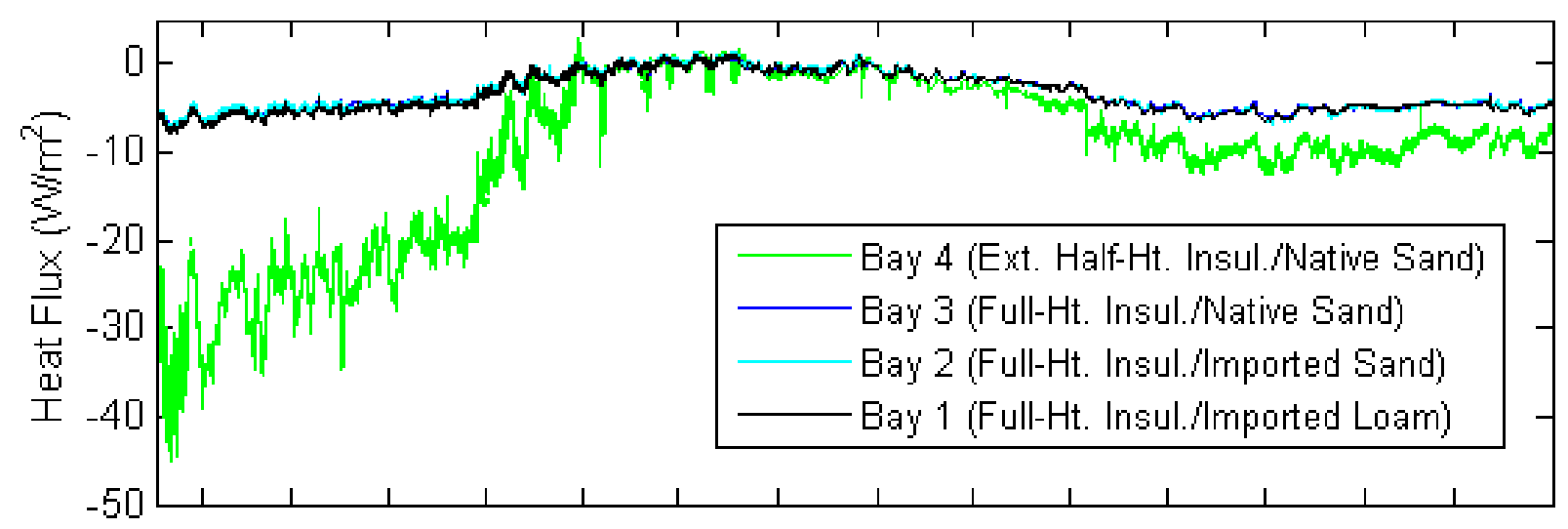

Heat Flux at 69 in. Above the Slab on North Walls

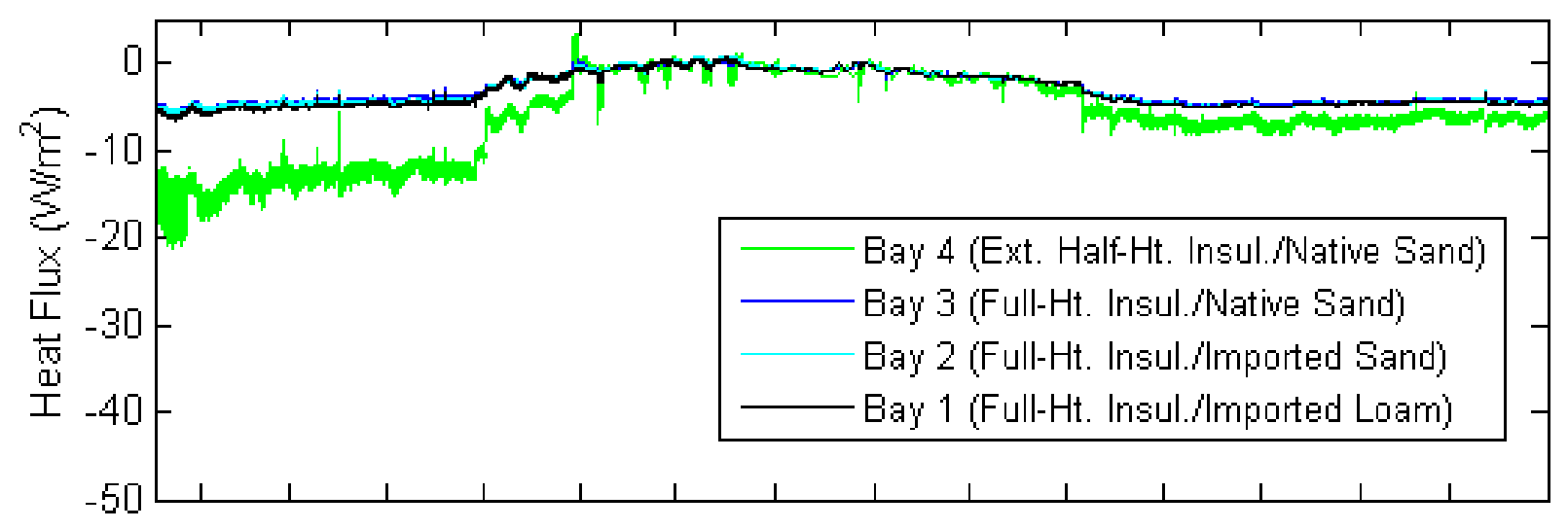

Heat Flux at 40 in. Above the Slab on North Walls

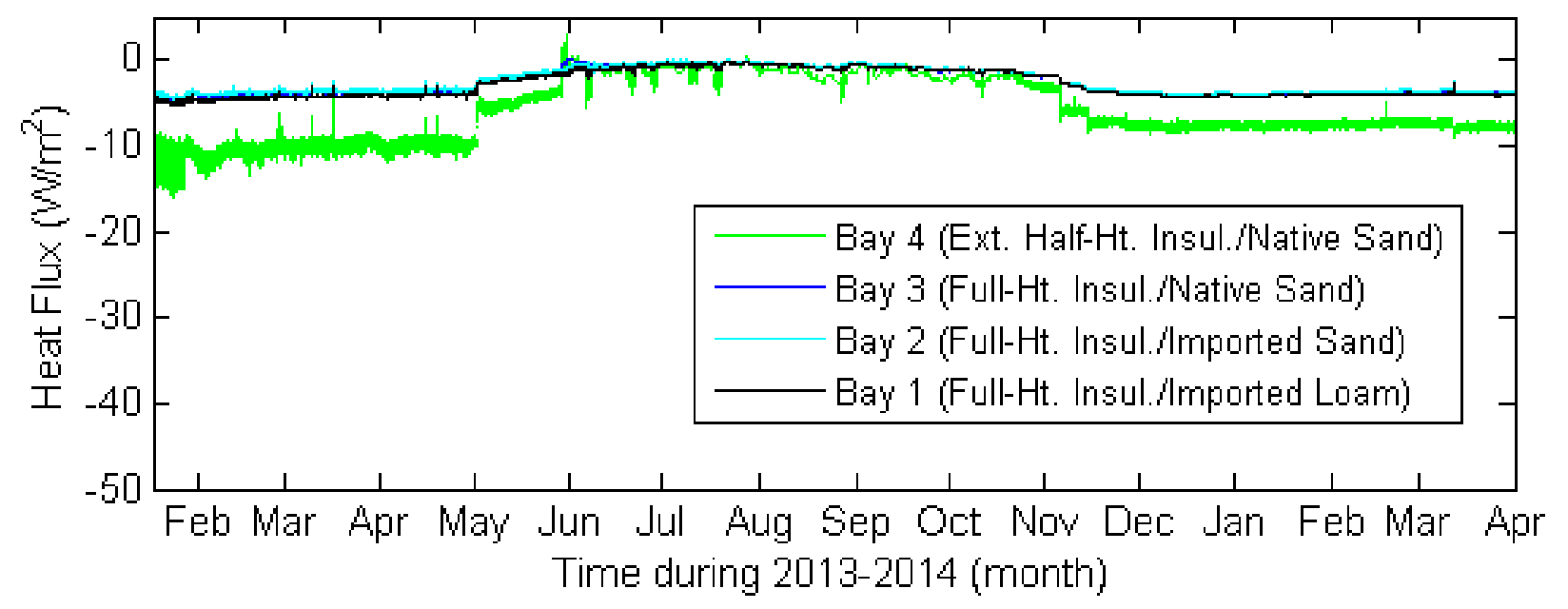

Figure 26. Bays 1-4 north wall heat flux profiles 


\subsection{Wall Moisture Transport}

In addition to the thermal boundary conditions discussed in Section 3.1.1, RH and moisture source boundary conditions are depicted in Figure 27 through Figure 31. Figure 27 shows the interior humidification schedule. No interior humidification was applied from the beginning of the experiment in November 2012 until mid-January 2013 during the second heating season in order to assess the quantitative compliance of the interior insulation retrofit systems with the Minnesota Energy Code. Beginning in mid-January, the interior RH was increased to $50 \%$; at the beginning of February it was ramped down again. After about the first week of March, no interior humidity was added mechanically and the basement interior RH started to increase in response to the walls drying to the interior (as a result of warmer above-grade temperatures). Although not shown, this drying trend continued through May yielding an $\mathrm{RH}$ of about $70 \%$ at an interior temperature of about $63^{\circ} \mathrm{F}$ at the end of May 2014.

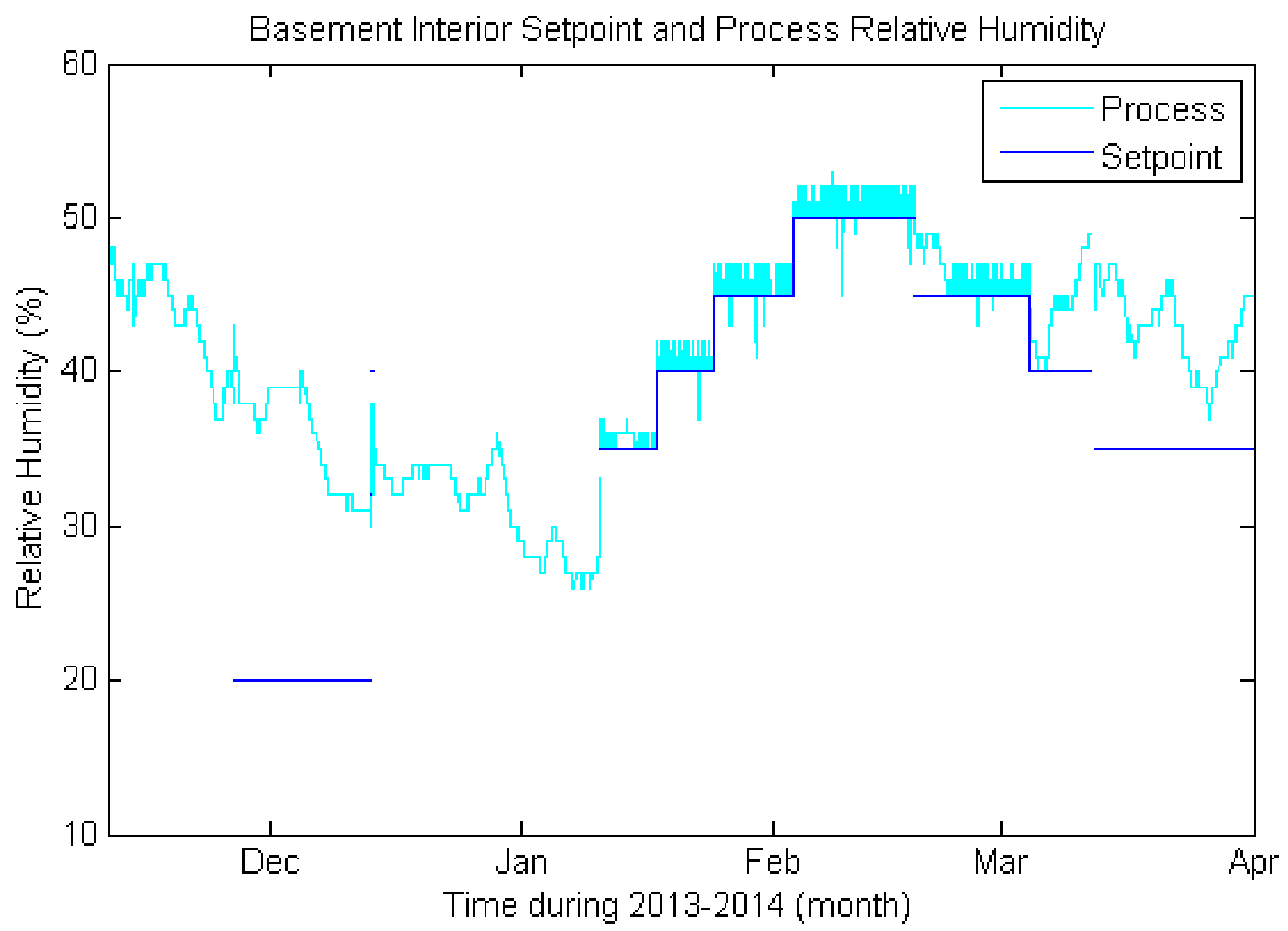

Figure 27. Basement interior RH control profile

The ambient exterior RH profiles are depicted in Figure 28, both at the CRRF weather station and, after mid-October, above the soil cribs in Bays 1 and 2. The correspondence in the measured RH at the weather station and at the building is fairly consistent with the north side showing a higher RH as a result of the lower ambient temperature during the second heating season. 


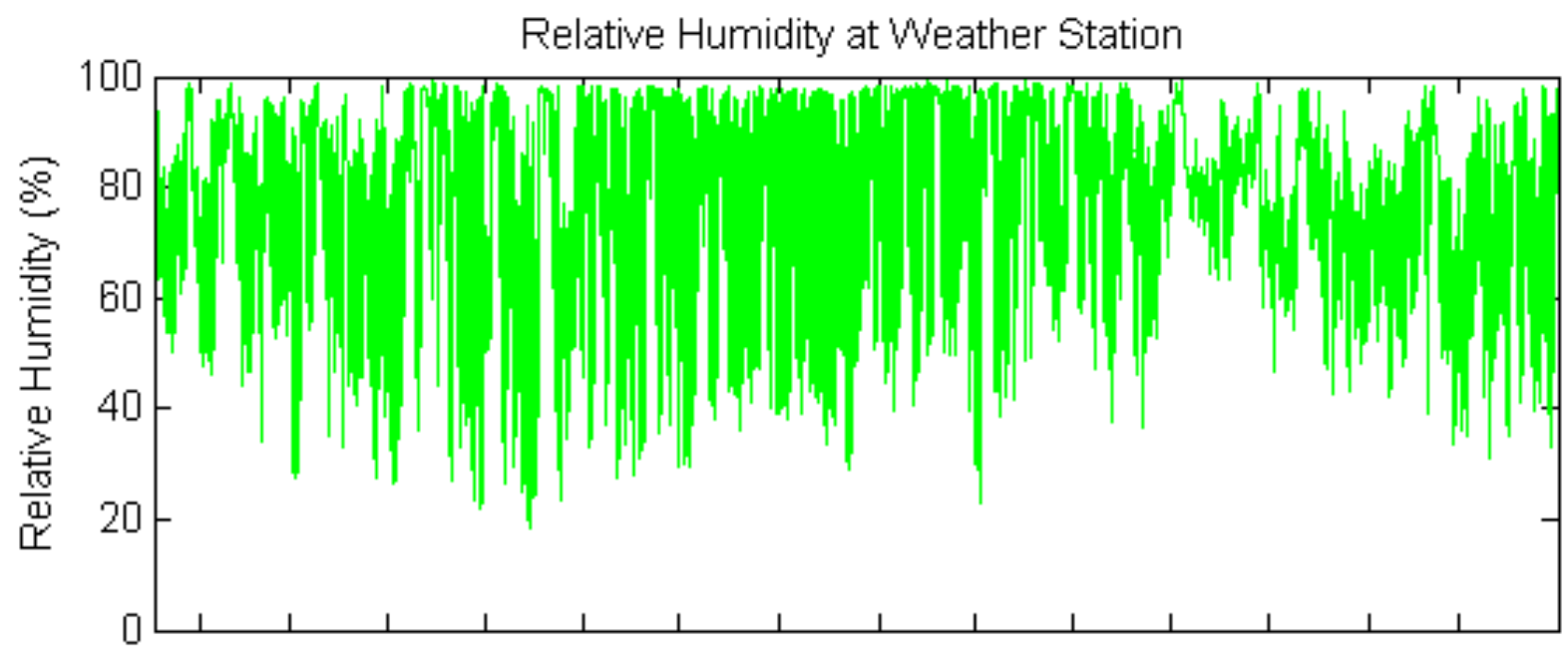

Relative Humidity Above Bay 1 Soil Cribs

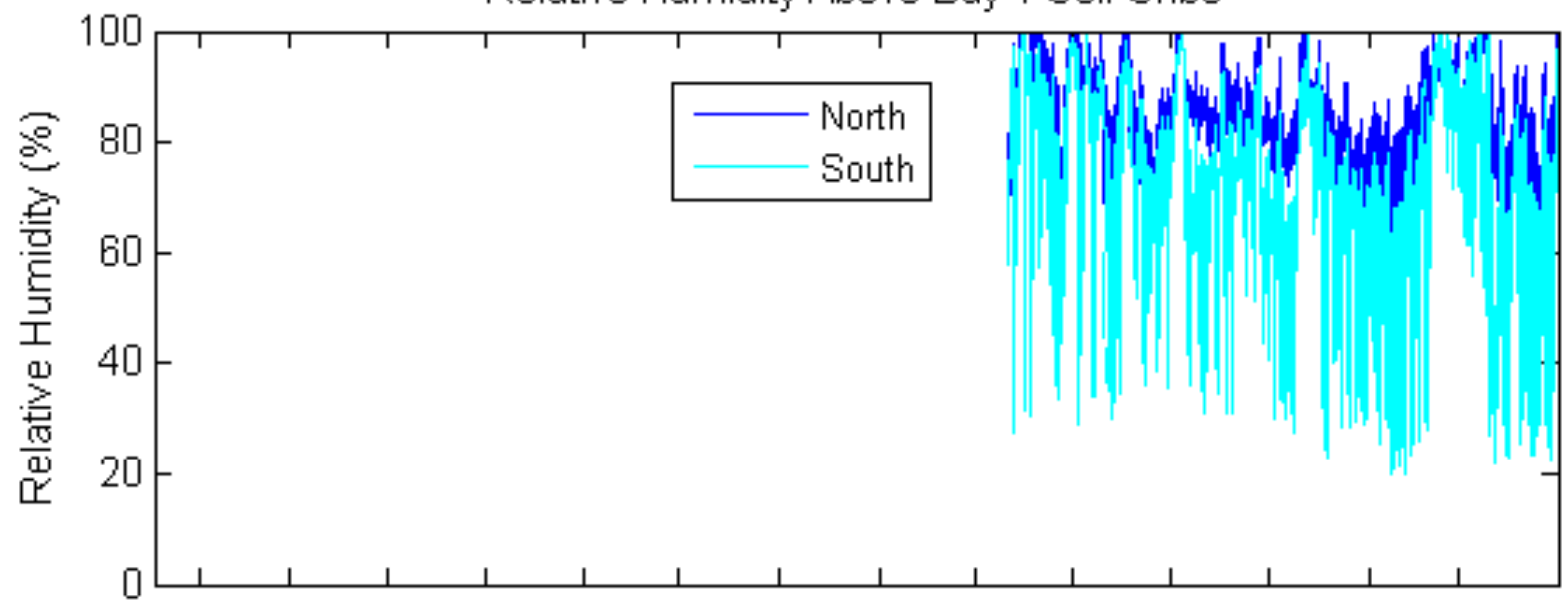

Relative Humidity Above Bay 2 Soil Cribs

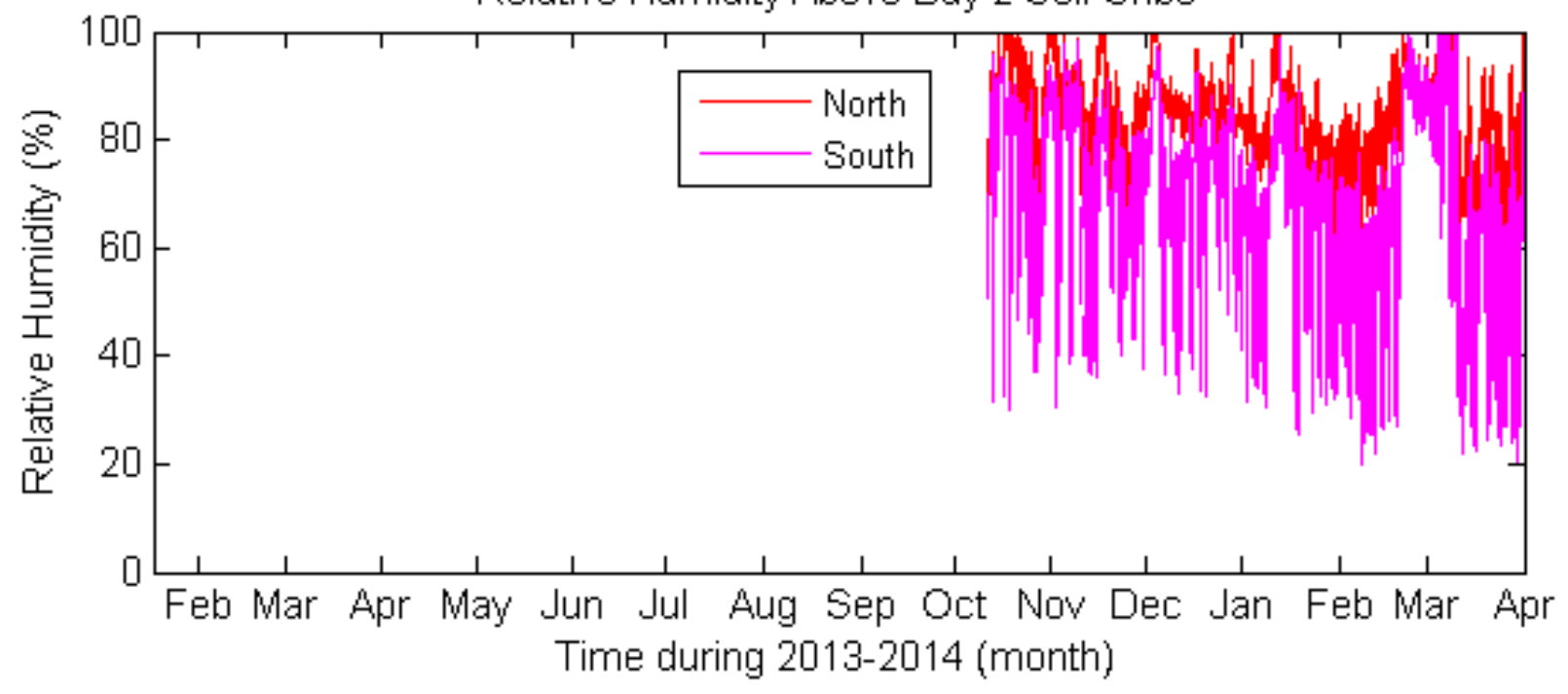

Figure 28. Exterior RH boundary conditions 
The terrestrial precipitation measured automatically via the data acquisition system is shown in Figure 29. Two precipitation data series are plotted, the first at the CFC weather station using an unheated tipping bucket precipitation gauge and a second series measured next to the CRRF using a heated tipping bucket precipitation gauge. The daily precipitation measured manually at the $\mathrm{CFC}^{18}$ weather station is shown for comparison in Figure 30. The CFC staff collects these data once a day by at approximately the same time. During the heating season, the precipitation is measured by melting the collected snow column. The automatically and manually recorded data are in qualitative agreement, but the individual manual readings are higher than the automatic readings because one manual reading corresponds to the summation of about 24 hours of automatic readings.

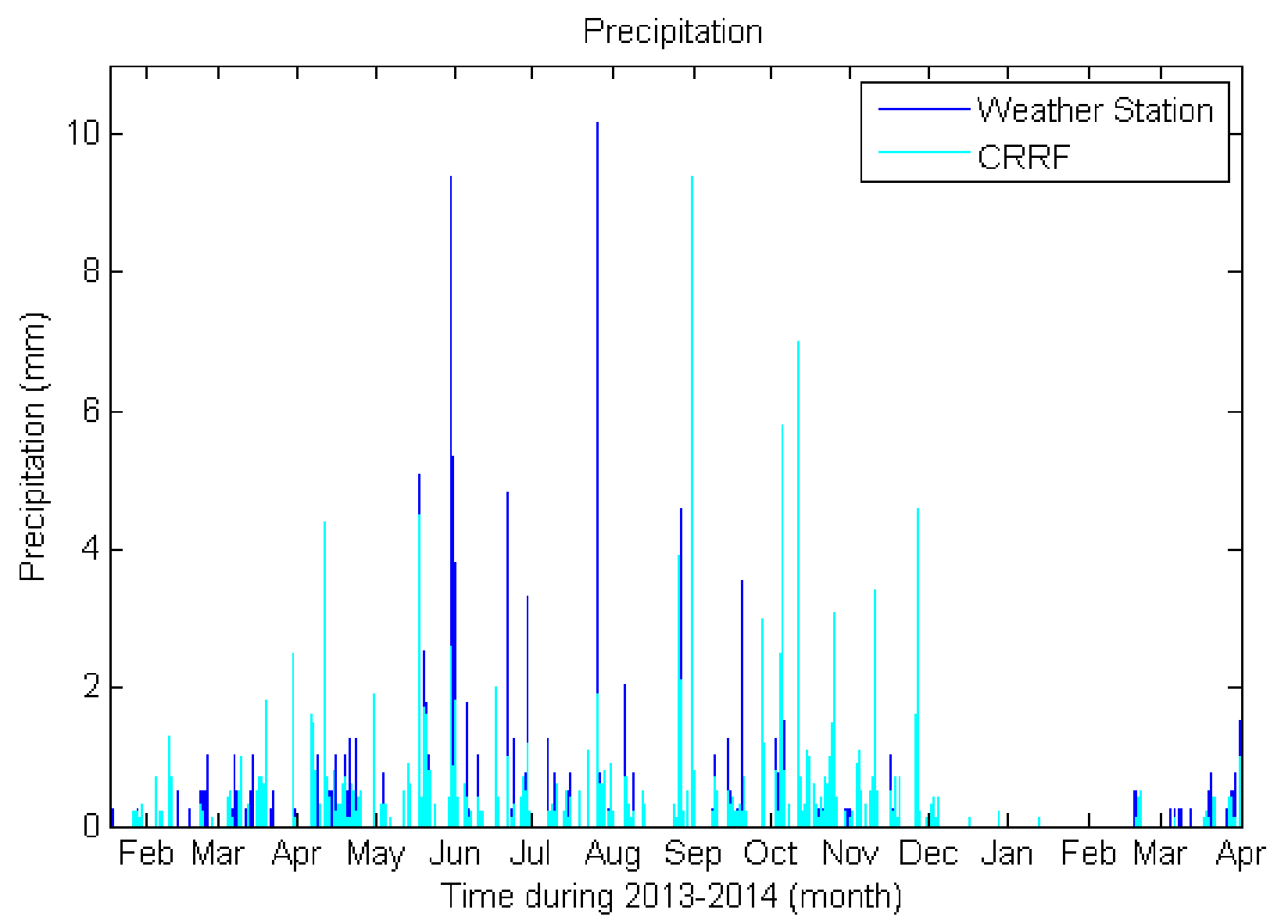

Figure 29 Terrestrial precipitation recorded by the data acquisition system

Generally, more precipitation was recorded automatically adjacent to the CRRF than at the weather station during the heating season as expected, because the gauge is unheated. During the cooling season, more precipitation was recorded at the weather station on average than next to the CRRF.

\footnotetext{
${ }^{18}$ These data are reported to the National Climatic Data Center and designated as a GHCN (Global Historical Climatology Network) data set for weather station GHCND:USC00211630. (http://www.ncdc.noaa.gov/cdoweb/datasets/GHCND/stations/GHCND:USC00211630/detail).
} 
Comparing these data to the manual data in Figure 30 recorded at the $\mathrm{CFC}$ weather station shows that data are missing from December 2013 through mid-February 2014. This occurred when the heated precipitation gauge adjacent to the CRRF froze solid because the ambient temperatures were consistently lower than the manufacturer's specified minimum temperature of $-20^{\circ} \mathrm{C}$. The gauge adjacent to the CRRF also had the orifice at the base of the collection cone plugged with dirt on a couple of occasions. A composite precipitation profile will need to be built from all three data sets in future research. ${ }^{19}$

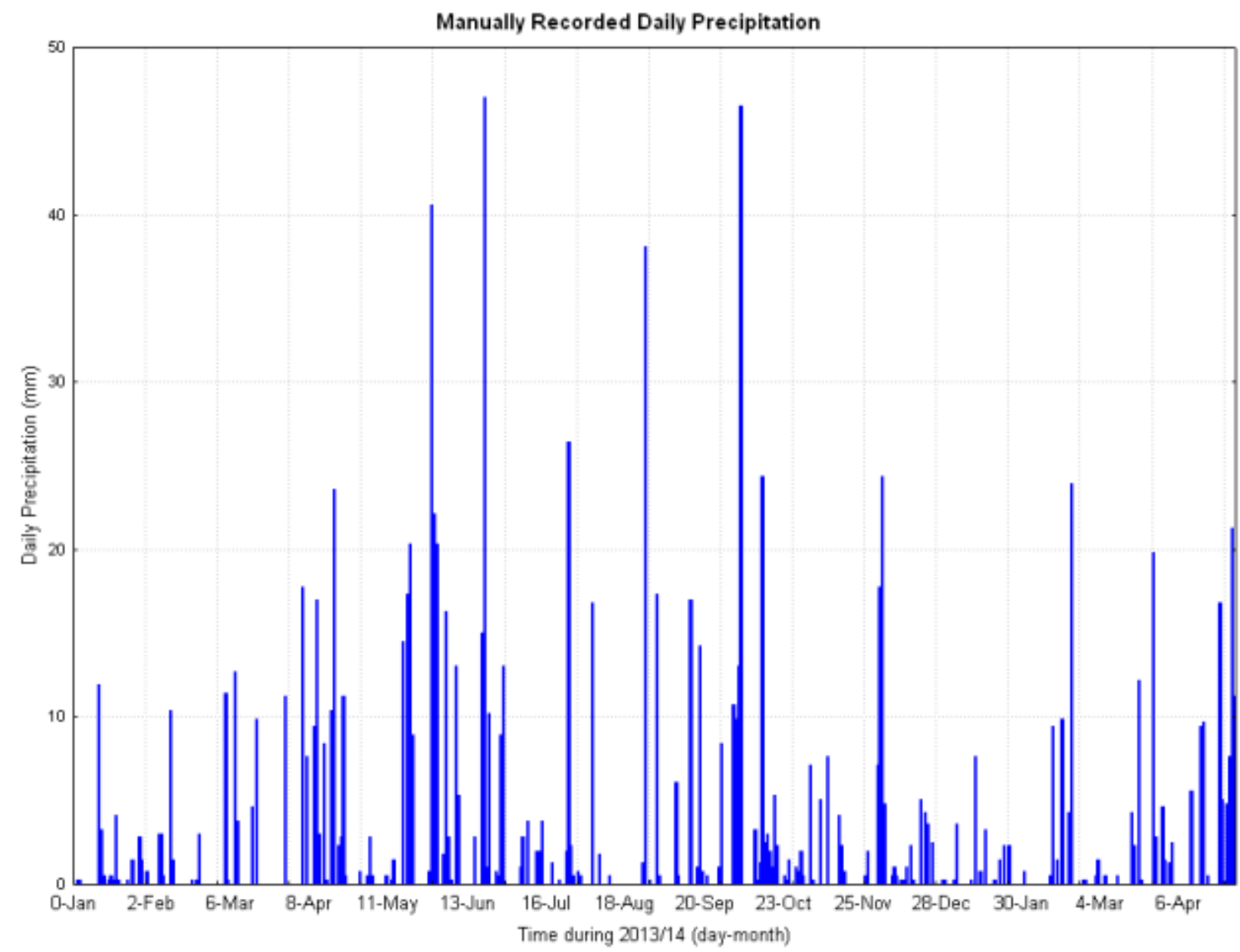

Figure 30. Terrestrial precipitation recorded manually

Figure 31 shows the snow depths measured on the north and south sides of the CRRF within $2-1 / 2 \mathrm{ft}$ of the building. The recorded snow was consistently deeper on the north side because the building provides shading that significantly reduced the sublimation (decrease in south side snow depth relative to the north side) after mid-February in both heating seasons. The increase in snow depth during the heating season is correlated with the recorded precipitation (in Figure 29).

\footnotetext{
${ }^{19}$ Automatic precipitation measurement is not trivial in a zone 7 climate. The complete methodology developed and the resulting composite precipitation graph are reported by Harmon (2014).
} 
The fundamental moisture transport performance of the south walls for Bays 1-3 is reported in Figure 32 through Figure 34. The corresponding performance for the north side is reported in Appendix C (Figure 109 through Figure 116). For the below-grade parts of the wall, these figures report the volumetric moisture content (V-MC) in the soil adjacent to the wall as well as in the interior and exterior face shells on the left-hand side (LHS) ordinate access with the hollow core vapor pressure on the right-hand side (RHS) ordinate axis. Note that at $5-1 / 2$ in. above the slab, the core vapor pressure was measured one course above this level, 16 in. above the slab (discussed in Section 4.1).

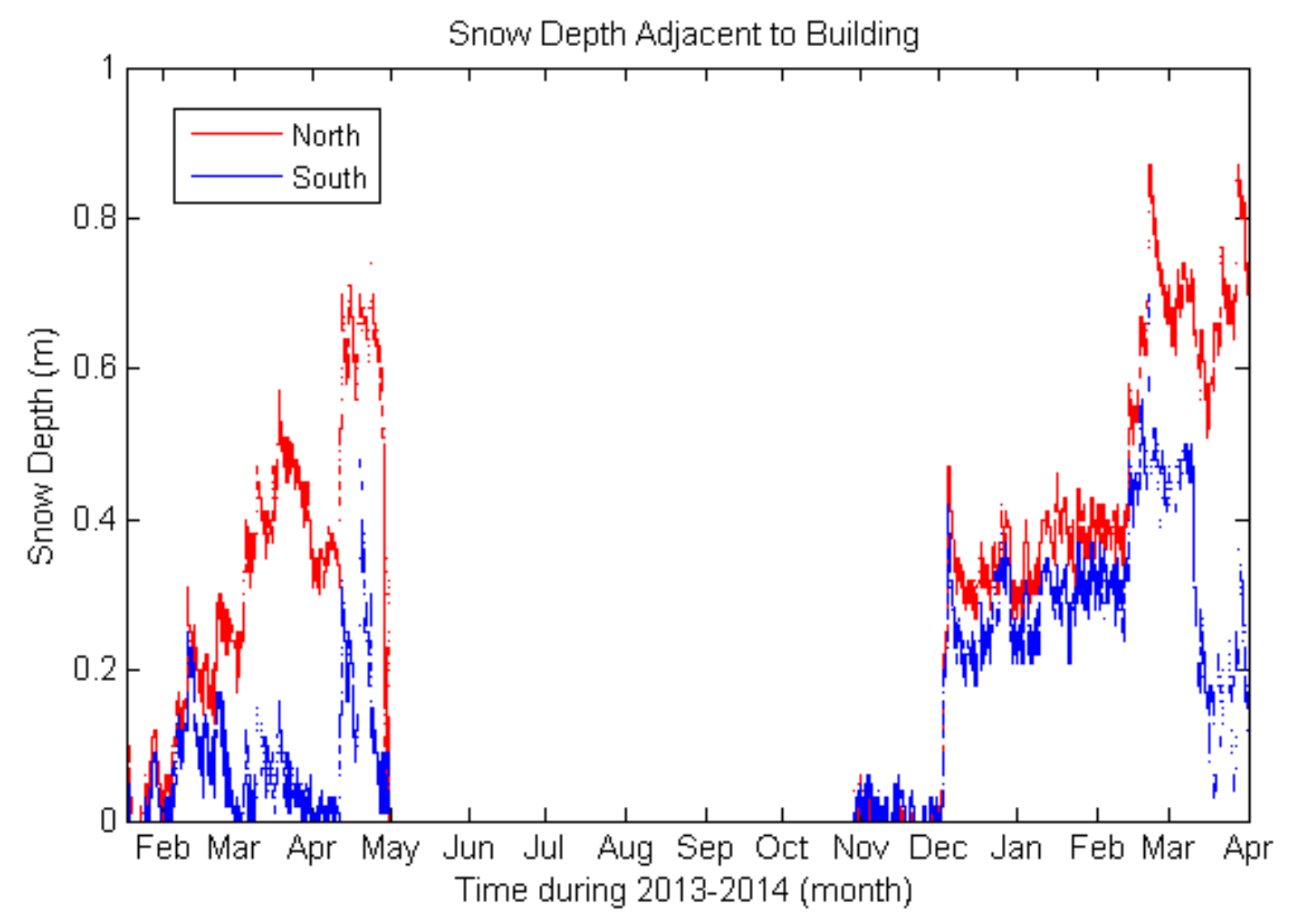

Figure 31. Snow depths on north and south sides of the CRRF

Figure 32 reports the moisture transport phenomenology for Bay 1S. The soil and face shell VMCs are plotted on the LHS ordinate axis and the resulting masonry block core vapor pressure is plotted on the RHS axis. Figure 32 shows that, for Bay 1S, the soil moisture content increased with depth below grade over the entire test period with increases at the upper two levels (69 and 40 in. above the slab), particularly after the snow melted around the beginning of March in both heating seasons. The melted snow percolated down to the bottom of the wall through April and May of the first heating season, but did not drain from the bottom of the wall as might be expected, yielding an elevated V-MC 5-1/2 in. above the slab throughout the cooling season. In contrast, the soil V-MC at 40 and $69 \mathrm{in}$. above the slab did decrease during the cooling season after the snow melting period, indicating drainage of the melted snow. The higher soil V-MC at the base of the wall provides evidence of a high water table during the cooling season, throughout which the CRRF sump pumps 
operated intermittently. This supports the argument of a water table heat source during the cooling season (see Section 3.1.1).

The exterior wall V-MC sensors failed toward the end of March 2013 at 69 in. above the slab; in mid-April 2013, at $40 \mathrm{in}$. above the slab; and in mid-February at 5-1/2 in. above the slab (indicated by the initial sharp drop in the readings). These failures are speculated to be a result of the electrode conductive epoxy sealant failing under prolonged wetting. Prior to the failures, the exterior V-MC readings decreased with wall height in congruence with the soil V-MCs as expected. 
Bay 1S: Moisture Profile at 69 in. Above the Slab

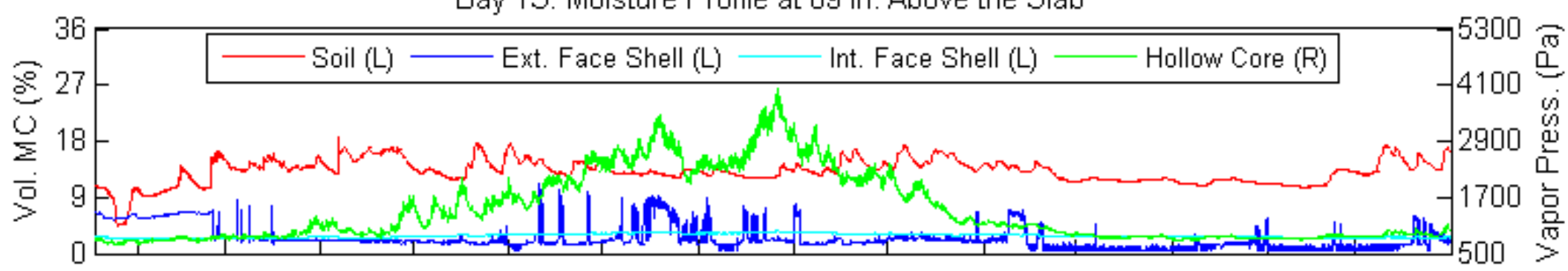

Bay 1S: Moisture Profile at 40 in. Above the Slab

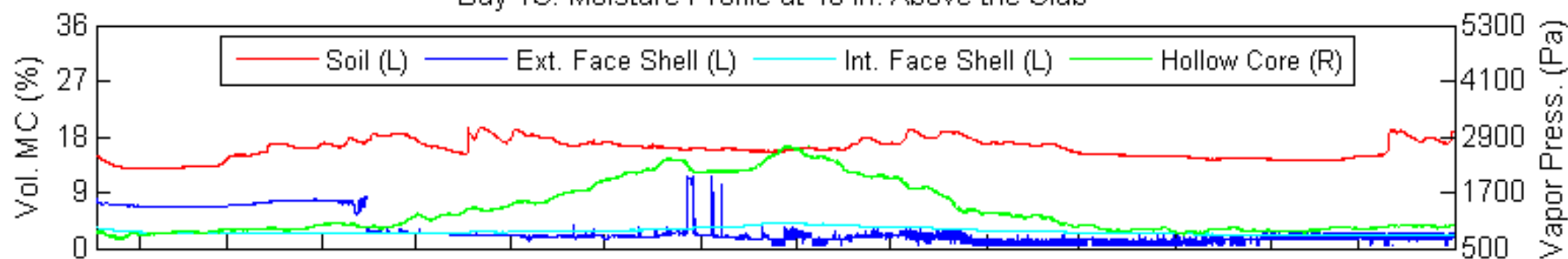

Bay 1S: Moisture Profile at 5.5 in. Above the $S$ lab

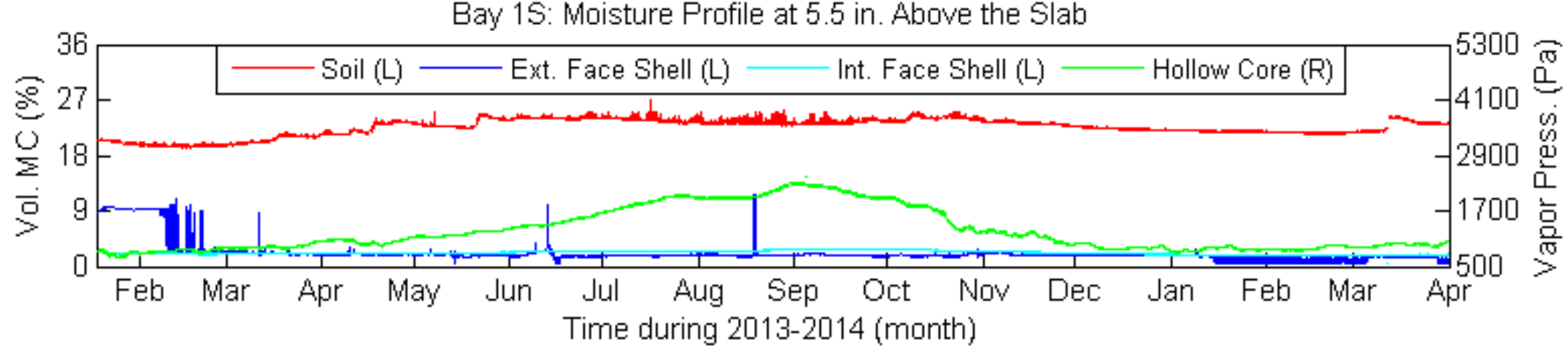

Figure 32. Bay 1S moisture transport phenomenology 
Figure 32 provides evidence of moisture migration from the exterior to the interior face shells, as shown by the higher interior face shell V-MCs during the cooling season (the interior wall V-MC sensors did not fail). This is most noticeable 69 in. above the slab starting in mid-June at 69 in., in mid-July at $40 \mathrm{in}$. and in mid-August at $5-1 / 2$ in. above the slab. This was in response to the elevated vapor pressures produced by evaporation of the liquid from the wetter exterior face shell that reached a consistent staggered set of peaks (mid-August at 69 in., end of August at 40 in., and beginning of September at $5-1 / 2$ in. above the slab). The vapor pressures also showed a fairly strong vertical gradient, from a maximum of $4100 \mathrm{~Pa}$ at $69 \mathrm{in}$. to $2800 \mathrm{~Pa}$ at $40 \mathrm{in}$. to $2300 \mathrm{~Pa}$ at $5-1 / 2$ in. above the slab. This is strong evidence for the absence of any buoyant cavity flow loop during the cooling season that, if present, would have not produced the vapor pressure gradient.

Other than the slightly increased cooling season interior face shell V-MC (about 1\% higher than that in the heating season), the interior face shell $\mathrm{V}-\mathrm{MC}$ remained at a low $3 \%$, corresponding to a saturation ratio of about 0.26 . Over the whole measurement period, the maximum saturation ratio did not exceed about 0.34 , indicating that the interior wall surface remained dry to the touch; thus, the chance of the interior adhered WSP delaminating from the wall surface was slight. ${ }^{20}$

The basic moisture transport phenomenology discussed for Bay 1S applies to Bay 2S, as depicted in Figure 33. Note that the V-MC scale on the LHS ordinate axis is three times lower than that in Figure 32, reflecting much lower levels of soil moisture in the well-draining sand adjacent to Bay 2. In Bay 2S, the V-MC sensor 69 in. above the slab functioned until the end of September 2013 before failing because of the fairly dry wall conditions near the grade in sand. Below grade, where the walls were much wetter, the sensor at 40 in. above the slab failed in early February 2013 and at $5-1 / 2$ in. above the slab, the failure occurred in the beginning of April 2013. Prior to the sensor failures, the exterior wall V-MCs at 5-1/2 and $40 \mathrm{in}$. above the slab were similar, unlike the case for Bay $1 \mathrm{~S}(5-1 / 2$ in. at V-MC greater than that at 40 in.). The exterior wall V-MC at 69 in. was lower than both. The magnitude and vertical gradient of the core vapor pressure profiles in Bays $1 \mathrm{~S}$ and $2 \mathrm{~S}$ were essentially the same. The interior face shell volumetric moisture contents did not exceed $3 \%$ anywhere, so de-adherence of the WSP was unlikely in Bay $2 \mathrm{~S}$ as well.

Figure 34 shows the moisture transport performance of Bay $3 \mathrm{~S}$ and includes one additional data series; namely, the vapor pressure measured in the drainage gap between the WSP and the interior face shell. In this bay, the soil moisture content measurement commenced at the beginning of June. Again, the reported phenomenology is similar to that reported for Bays $2 \mathrm{~S}$ and $3 \mathrm{~S}$ in Figure 32 and Figure 33, respectively. The exterior wall V-MC sensors failed toward the end of July, at the end of June, and in early June 2013 at 69, 40, and 5-1/2 in. above the slab, respectively. The WSP drainage gap and masonry block core vapor pressures at 69 and 40 in. above the slab were essentially equal. Marginally lower pressures were recorded in the drainage gap during the first heating season with evidence of slightly greater vapor pressures at 40 in. above the slab during the second heating season. Water was sprayed into the drainage cavity from mid-September until mid-November from a spray bar located one half block course above the moisture content sensors 69 in. above the slab.

\footnotetext{
${ }^{20}$ This will be determined only when the wall assemblies are disassembled.
} 

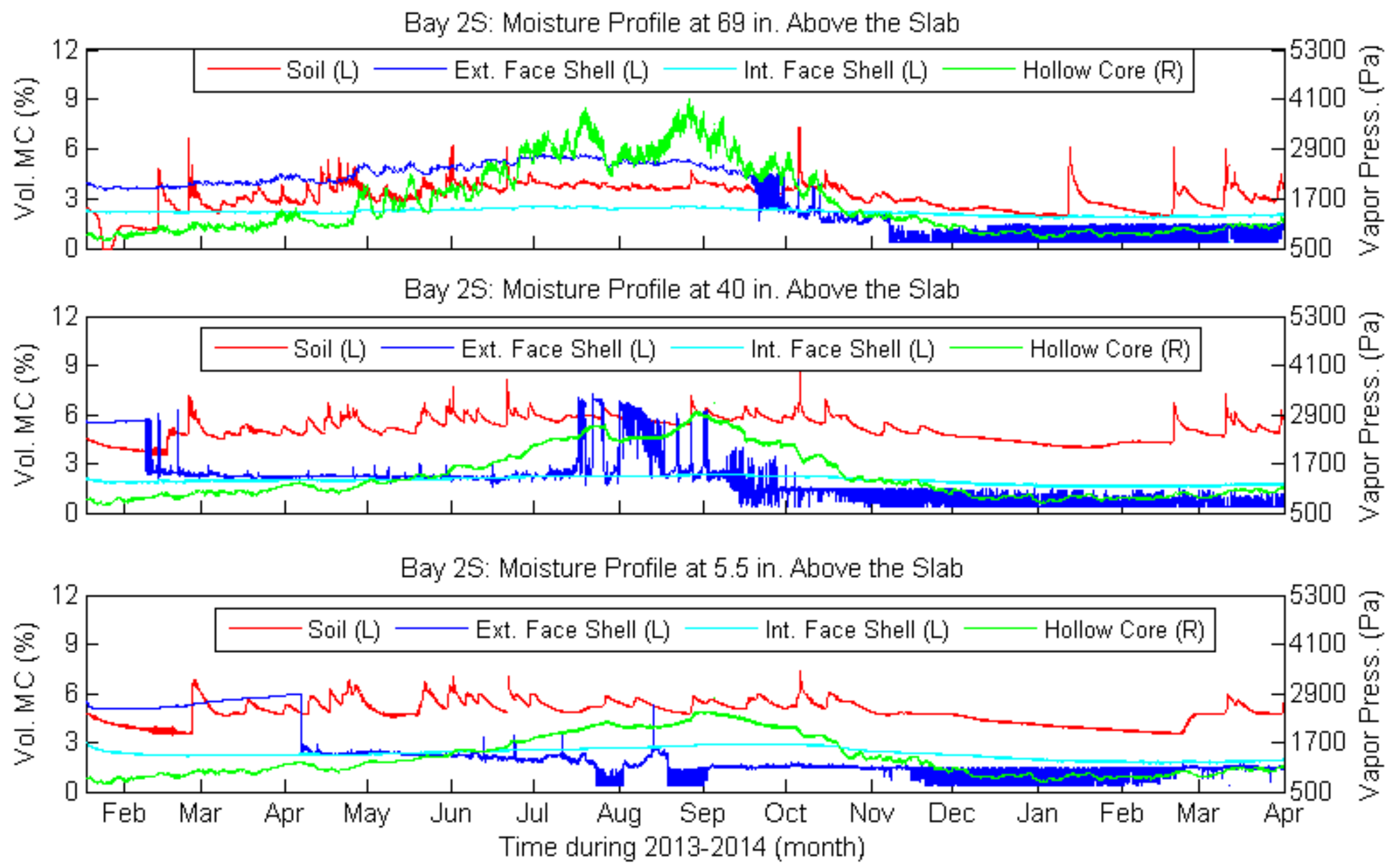

Figure 33. Bay $2 \mathrm{~S}$ moisture transport phenomenology 
Bay 3S: Moisture Profile at 69 in. Above the Slab

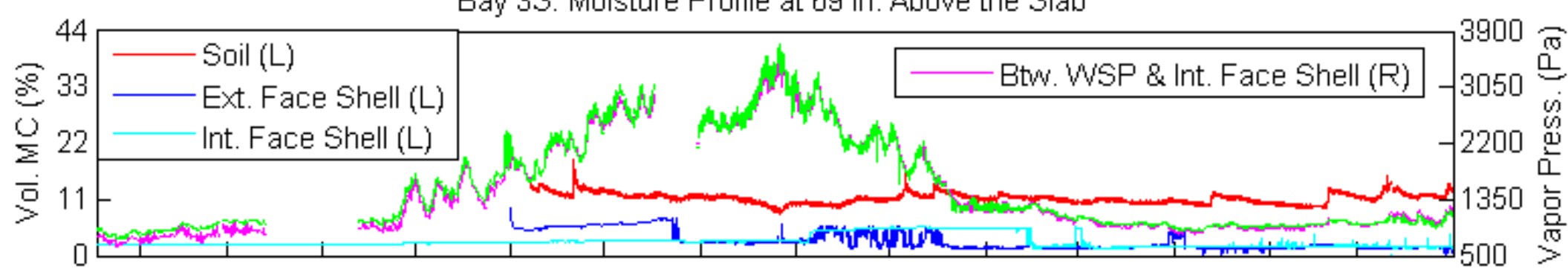

Bay 35: Moisture Profile at 40 in. Above the Slab

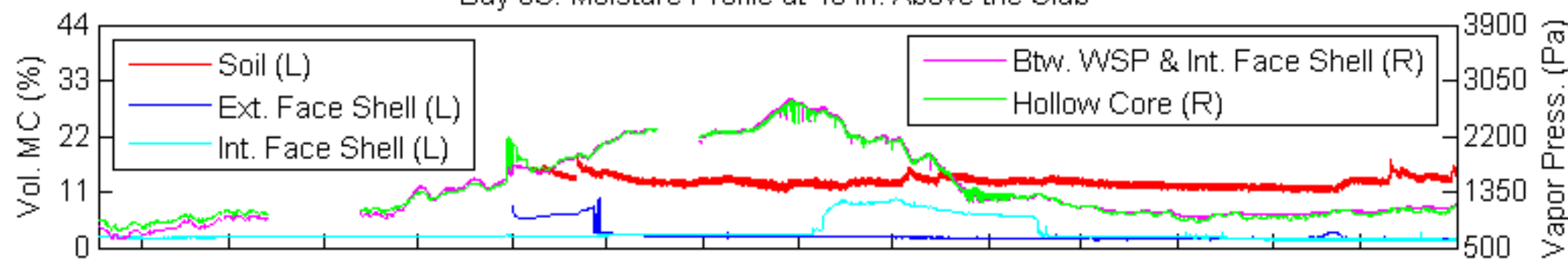

Bay 3S: Moisture Profile at 5.5 in. Above the Slab

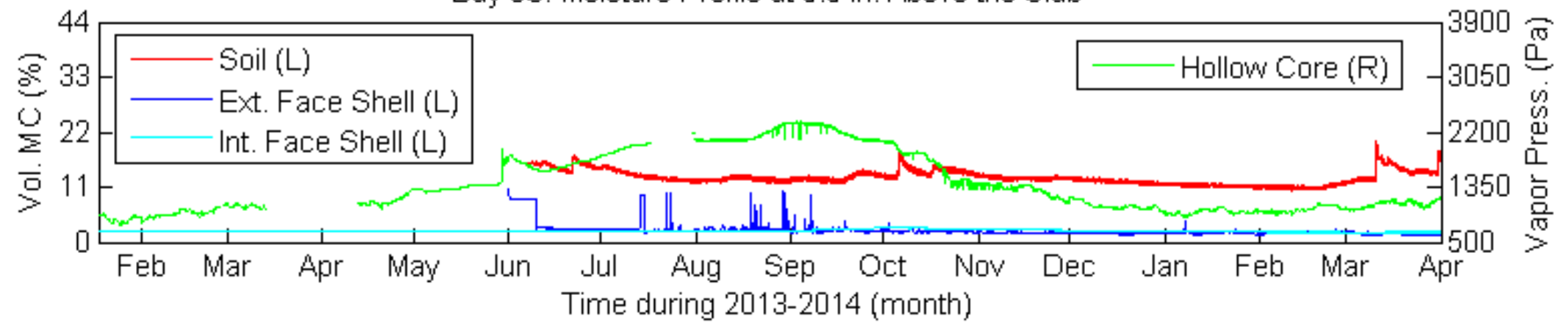

Figure 34. Bay 35 moisture transport phenomenology 
This increased the interior face shell V-MC to a maximum of about $6 \%$ and $10 \%$ (saturation ratios of 0.5 and 0.9 ) at 69 and $40 \mathrm{in}$. above grade, respectively (top and middle panels of Figure 34). The injected water had a negligible impact on the interior face shell V-MC at 5-1/2 in. above the slab during the first half of October only. After the water injection terminated, the interior face shells dried rapidly, all reverting to their prewetting moisture contents by the end of the first week of December.

Figure 34 shows that the nonadhered WSP effectively contained and drained the injected water and allowed the interior face shell to dry out before the onset of severe cold temperatures toward midDecember. The drainage gap and block core vapor pressures revealed no major pressure differences, indicating a vapor pressure equilibrium between the core and the drainage gap. Based on these data, the effectiveness of an interior nonadhered WSP for containing bulk water leakage through the wall was demonstrated.

The same phenomenology discussed above for the south side was replicated on the north side (see Figure 109 through Figure 116 in Appendix C). The only major difference was higher soil moisture contents on the north side, particularly in Bay $1 \mathrm{~N}$ with the loam soil, because of the larger volume of surface snow melt on the north side. With regard to Bay 3, the north interior face shell V-MCs were lower than those measured on the south side (no doubt a result of the spray bar jets directing water at a higher upward angle in Bay $3 \mathrm{~N}$ than in Bay $3 \mathrm{~S}$ ), so the latter provided a more strenuous test of the drying and draining performance of the adhered WSP.

The effectiveness of the WSP is addressed in Figure 35 through Figure 38 for Bays 1 and 3 for the adhered and nonadhered WSPs; WSP effectiveness for Bay 2 (also an adhered WSP so essentially the same as Bay 1) is reported in Figure 117 and Figure 118 in Appendix C.

For Bay 1 on both the south and north sides (Figure 37 and Figure 38, respectively), the block core RH at 86 and $69 \mathrm{in}$. above grade was uniformly saturated throughout the measurement period as expected (which motivates the use of vapor pressure for discussing moisture transport phenomenology in Figure 32 through Figure 34). At 40 in. above the slab, the RH was also mostly saturated with reductions to a minimum of $80 \%$ in the heating seasons (beginning of November through the end of March). Prior to the onset of interior humidification in mid-January of the second heating season, the RH on the WSP interior surface was below saturation everywhere on the south side (Figure 35) and reached 100\% on the north side in November at the 86 and 69 in. above the slab locations. The RHs were higher on the north side because of the colder average wall temperatures in the absence of solar irradiation. Thus the data demonstrate that, prior to the onset of interior humidification, the WSP effectively isolated the interior from the exterior moisture environment in compliance with the foundation hygrothermal performance requirements of the Minnesota Energy Code.

After humidification commenced in mid-January of the second heating season, the RH on the interior surface of the WSP rose until it reached saturation in mid-February on the south side and slightly earlier on the north side at 69 and $40 \mathrm{in}$. above the slab. Saturation was reached eventually $40 \mathrm{in}$. above the slab on the south side in mid-March but never on the north side. The $\mathrm{RH}$ on the warm surface of the insulation was measured at $40 \mathrm{in}$. above the slab only and the increase of this RH to $50 \%$ in mid-February is evident compared to the $30 \% \mathrm{RH}$ prevalent during the first heating season without interior humidification. 
Relative Humidity Across Water Separation Plane at 86 in. Above the Slab

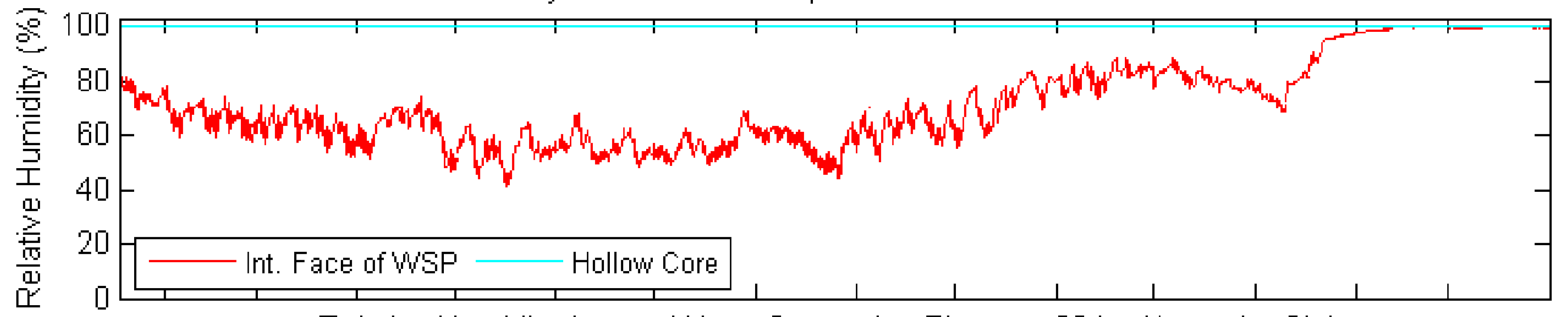

Relative Humidity Across Water Separation Plane at 69 in. Above the Slab
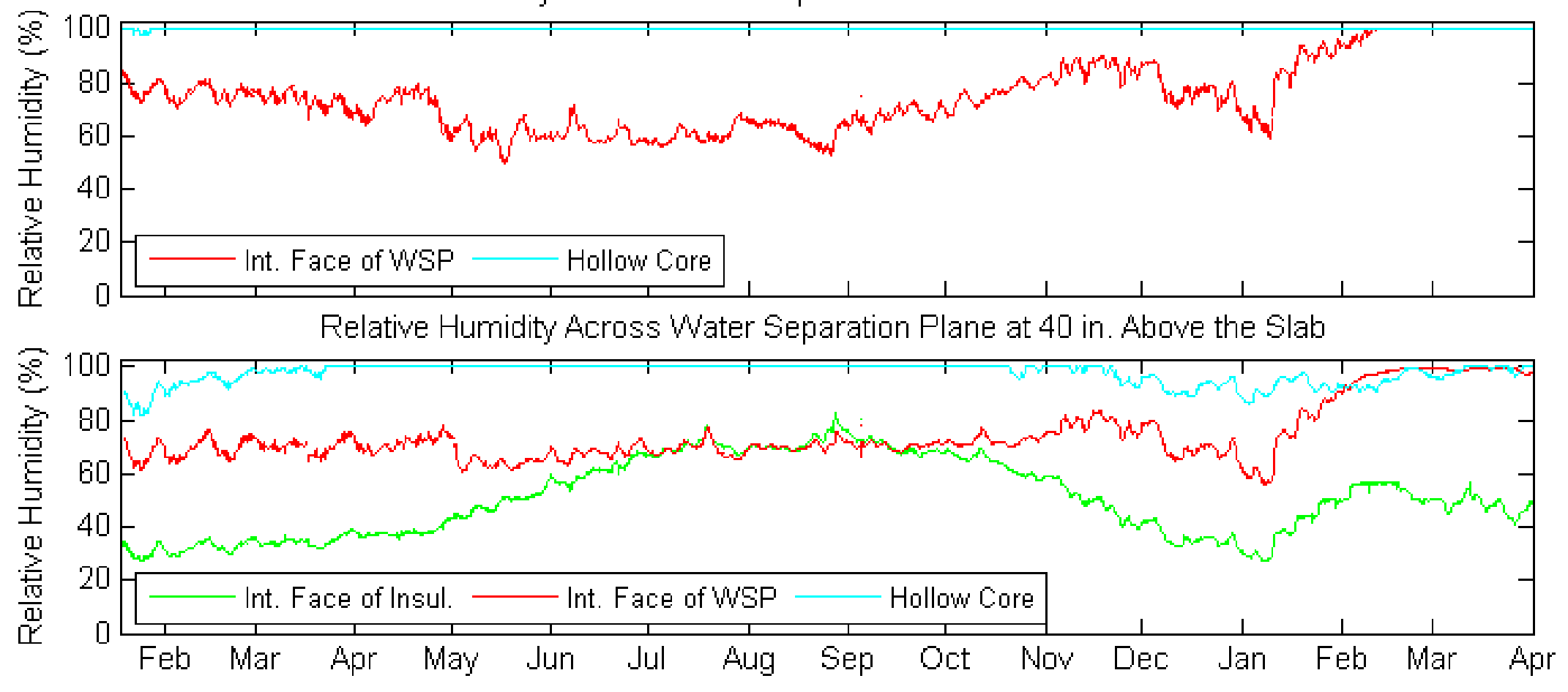

Figure 35. Bay 1S WSP vapor retarding performance 
Relative Humidity Across Water Separation Plane at 86 in. Above the Slab
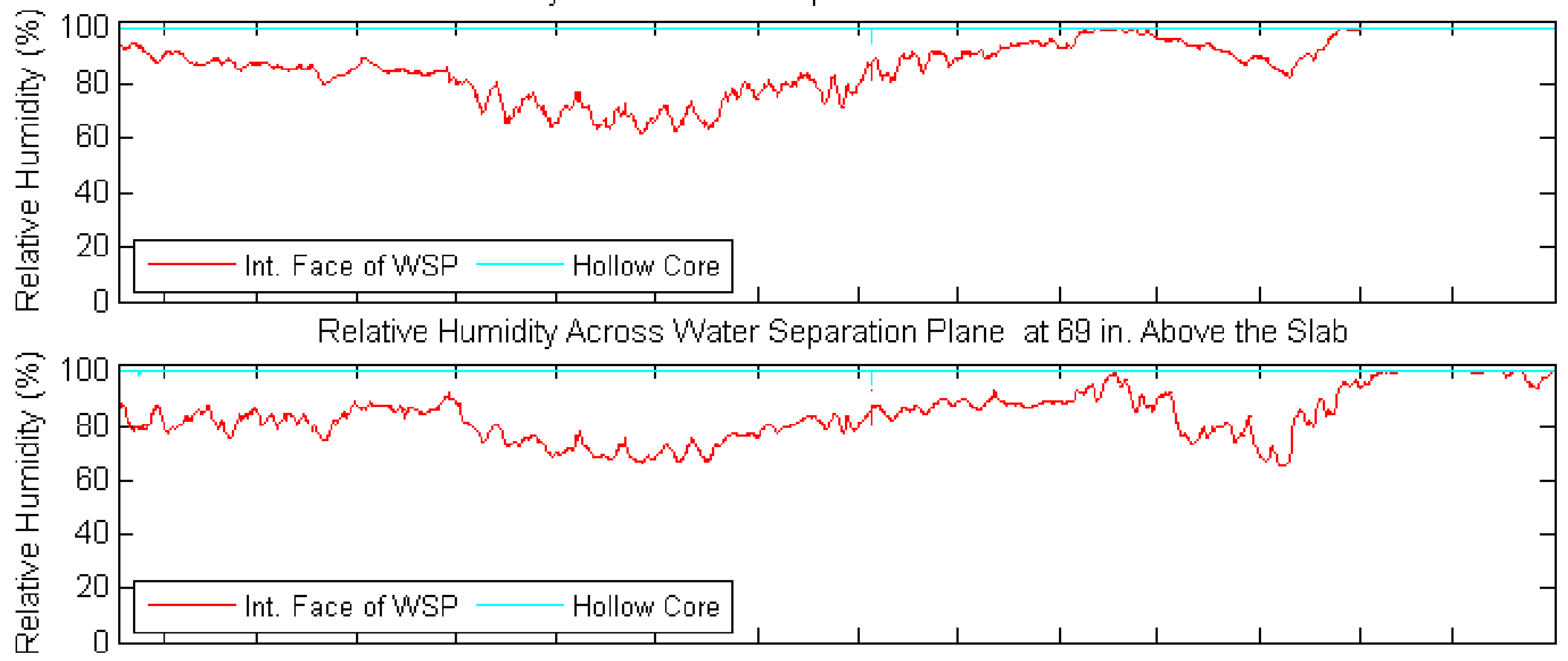

Relative Humidity Across Water Separation Plane at 40 in. Above the Slab

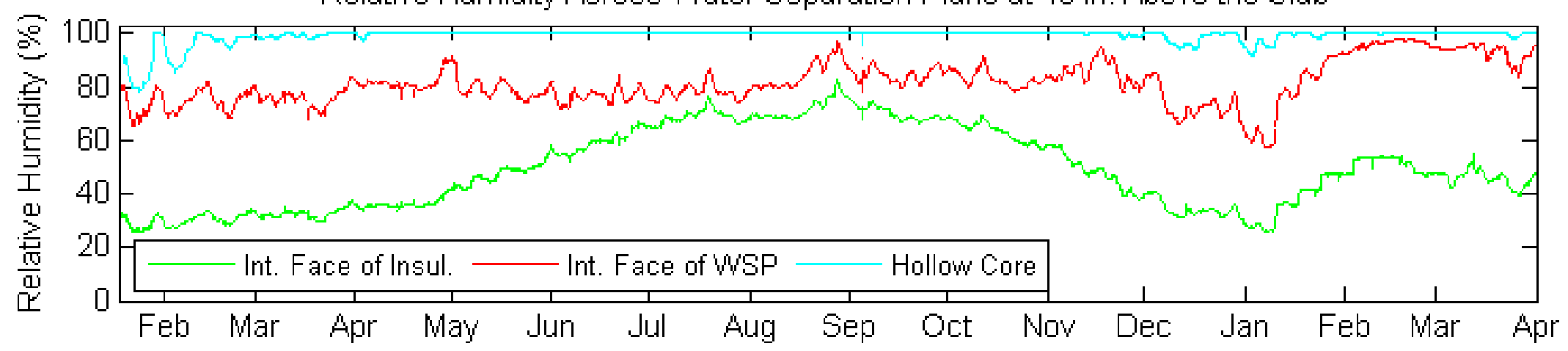

Figure 36. Bay 1N WSP vapor retarding performance 
Figure 37 and Figure 38 show the performance of the nonadhered WSP for Bay 3. These figures also record the RH in the drainage gap on the WSP exterior for completeness. The RH phenomenology across the WSP is very similar to that described above for Bay 1S, so from the perspective of WSP moisture separation performance, the adhered and nonadhered WSPs are equivalent. $^{21}$ The RH profiles shown in the drainage gaps on the north and the south sides all reached saturation by September, except for the north side 86 in. above the slab, which never quite reached a steady $100 \% \mathrm{RH}$ through the end of the measurement period. Intermittent freezing interior face shell temperatures above grade on the north side (see Figure 106 in Appendix C) may well have condensed and frozen the vapor on the wall surface in the drainage gap, reducing the $\mathrm{AH}$ at the top of the wall and yielding the lower measured RH there. On the south side above grade during the heating season, intermittent reductions of the drainage gap RH from saturation (Figure 37) were a result of increased temperatures produced by solar irradiance on the exterior wall surface. Generally though, it must be concluded that drainage gaps between the wall and an interior WSP remain perpetually saturated and thus are susceptible to mold growth at some time during a year given the availability of nutrients. This is another reason for thoroughly air sealing the edges of nonadhered WSPs to prevent the transfer of mold spores from the drainage gap to the basement interior and the reverse movement of nutrients from the basement interior to the drainage gap.

Figure 39 shows a comparison of the masonry block core RHs for Bays $4 \mathrm{~N}$ and $3 \mathrm{~N}$ to demonstrate the impact of exterior insulation on core humidity. During the first heating season, the Bay $4 \mathrm{~N}$ core RHs were lower than those of Bay $3 \mathrm{~N}$ because of the warmer prevailing core temperatures in the absence of interior insulation. During the second heating season, this was also the case for all levels except 16 in. above the slab. In other words, over the wall height covered or nearly covered (in the case of the $40 \mathrm{in}$. level, which was $3 \mathrm{in}$. below the edge of the insulation) by the exterior insulation, the core temperature was warm enough to keep the Bay $4 \mathrm{~N}$ core temperatures warmer than those of Bay $3 \mathrm{~N}$, permitting lower RHs.

However, at 16 in. above the slab, the absence of exterior insulation in Bay $4 \mathrm{~N}$ yielded core temperatures too cold to reduce the RHs there below those of Bay $3 \mathrm{~N}$. To the contrary, the RH profiles were reversed-Bay $3 \mathrm{~N}$ showed lower RHs than Bay $4 \mathrm{~N}$ despite the colder core temperatures in Bay $3 \mathrm{~N}$ caused by the interior insulation. In the absence of warmer temperatures to reduce Bay $4 \mathrm{~N} \mathrm{RH}$ at the base of the wall, the higher RH in Bay $4 \mathrm{~N}$ indicates that the $\mathrm{AH}$ was greater in the cores of Bay $4 \mathrm{~N}$ than in the cores of Bay $3 \mathrm{~N}$. This arises because, as explained by Harmon (2014), the exterior insulation acted as a vapor retarder in Bay 4N, preventing the core from drying to the exterior and resulting in higher core AHs in Bay 4N. The vapor-retarding action of the exterior insulation over the upper half of Bay $4 \mathrm{~N}$ also prevented vapor transport into the cores from the soil and ambient air, but this was not significant because the vapor drive into the wall cavity occurred mainly below grade during the heating season. The ambient AH at the CRRF was close to zero and the ground was cold or frozen in the near surface region, so there was a small vapor source at the top of the wall. Hence during the heating season, the vapor drive was from the core to the exterior at the top of the wall in Bay $3 \mathrm{~N}$ where the cores were continuously saturated and the ambient diurnal average RH was about $80 \%$ (see Figure 28 ) with very low AH.

\footnotetext{
${ }^{21}$ Only true because the edges of the nonadhered WSPs in Bay 3 were very well vapor sealed. Inadequate nonadhered WSP edge seals rapidly degrade the moisture isolation performance of nonadhered WSPs.
} 
Relative Humidity Across Water Separation Plane at 86 in. Above the Slab

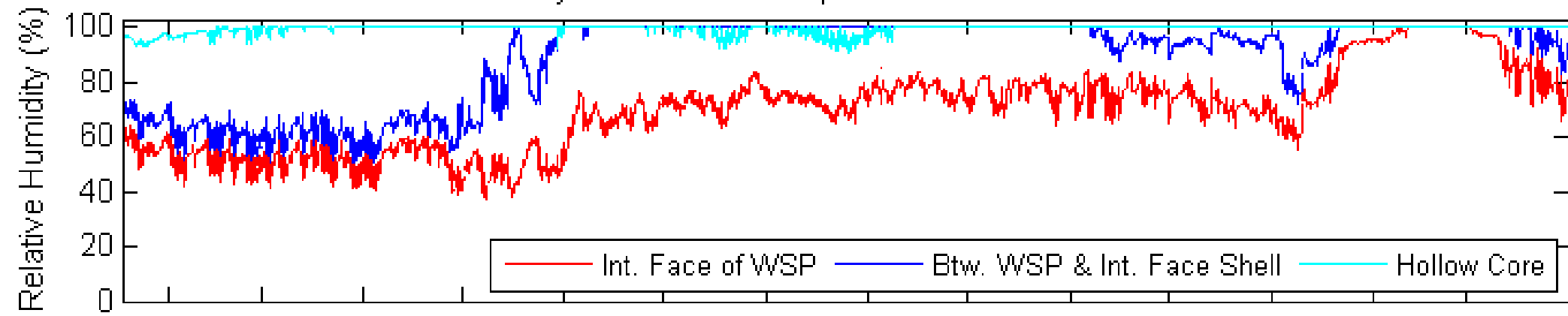

Relative Humidity Across Water Separation Plane at 69 in. Above the Slab

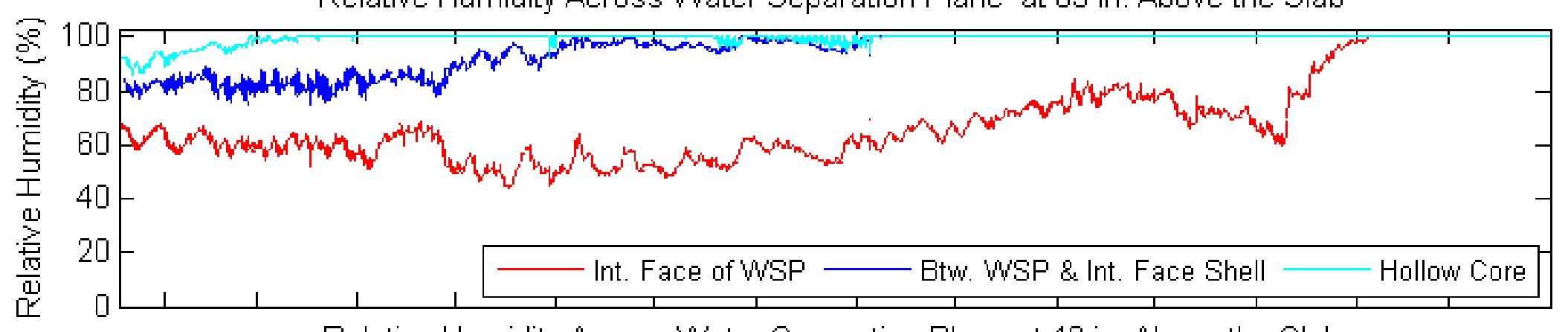

Relative Humidity Across Water Separation Plane at 40 in. Above the Slab

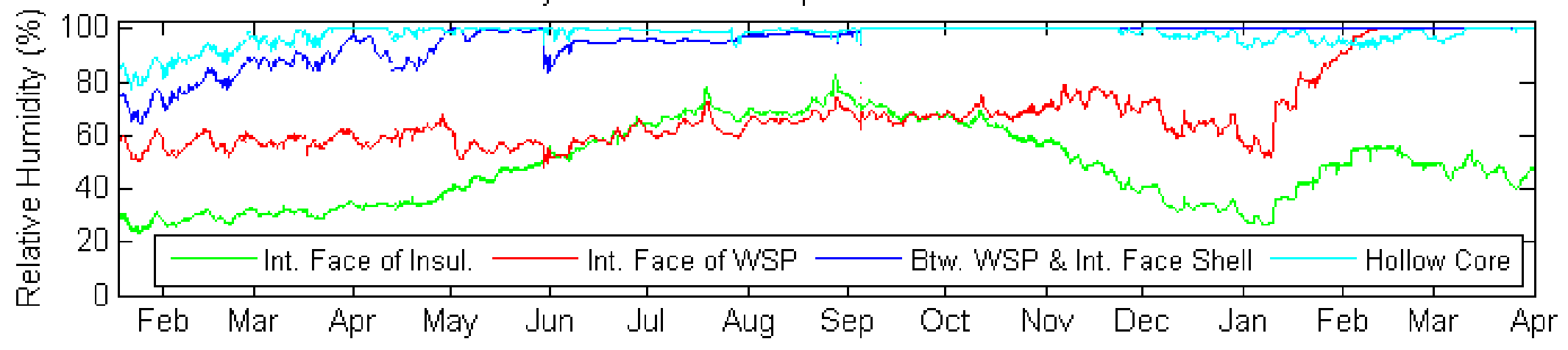

Figure 37. Bay 3S WSP vapor retarding performance 
Relative Humidity Across Water Separation Plane at 86 in. Above the Slab

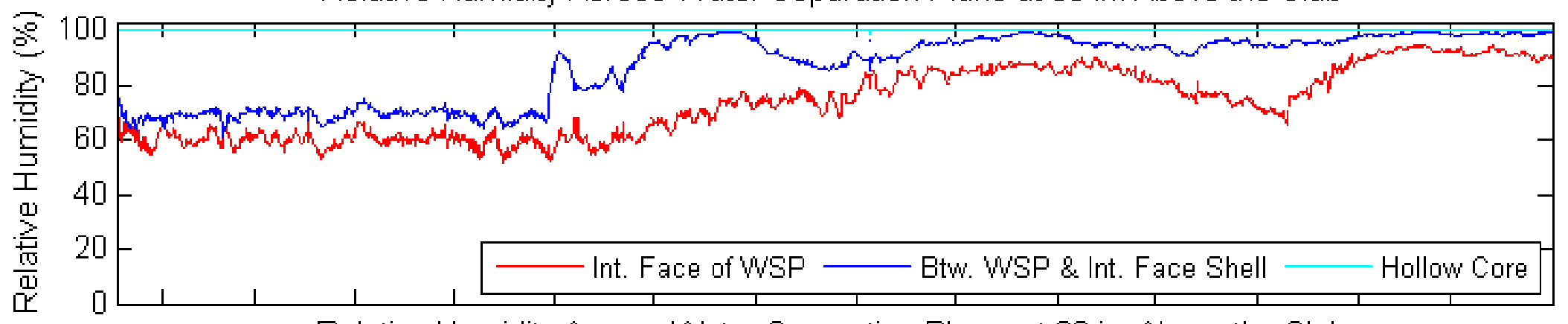

Relative Humidity Across Water Separation Plane at 69 in. Above the Slab

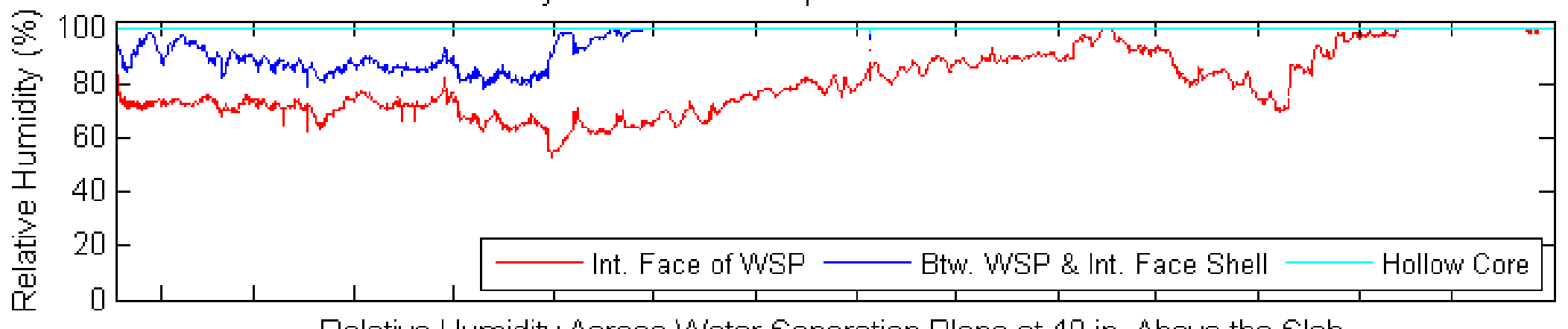

Relative Humidity Across Water Separation Plane at 40 in. Above the Slab

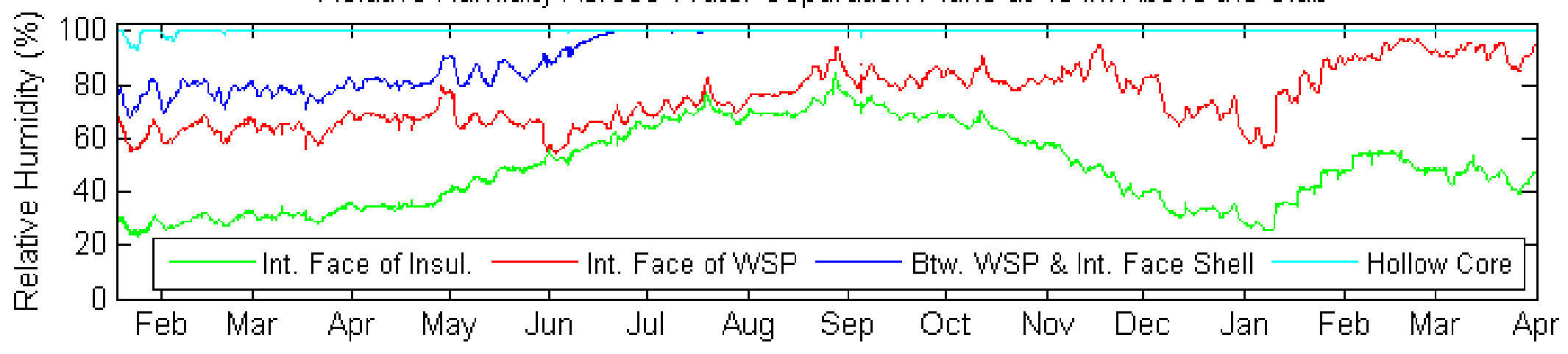

Figure 38. Bay $3 \mathrm{~N}$ WSP vapor retarding performance 
Relative Humidity in Hollow Core Masonry Block at 79 in. Above the Slab

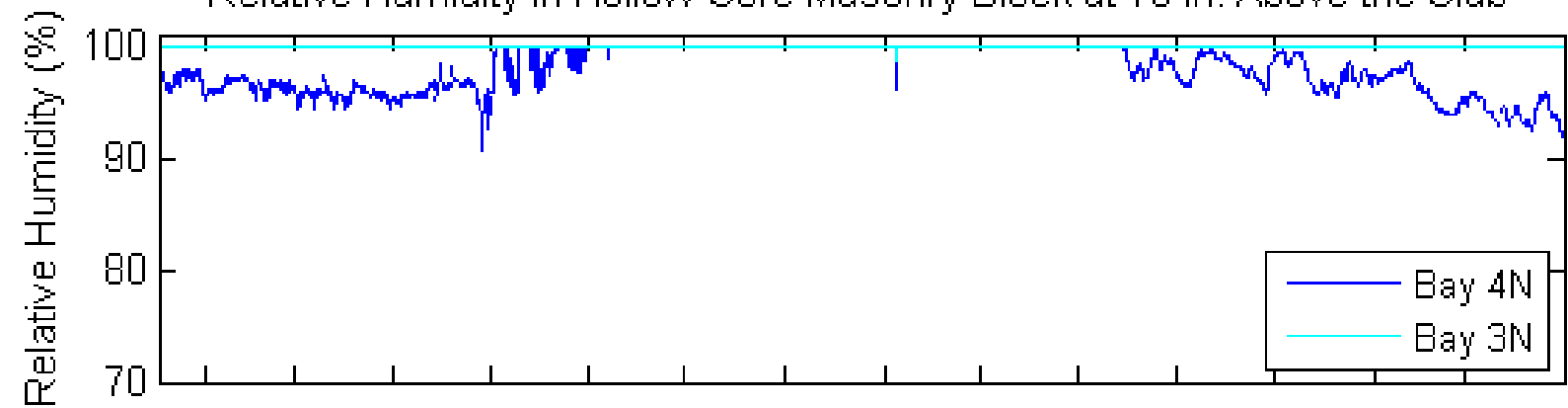

Relative Humidity in Hollow Core Masonry Block at 69 in. Above the Slab

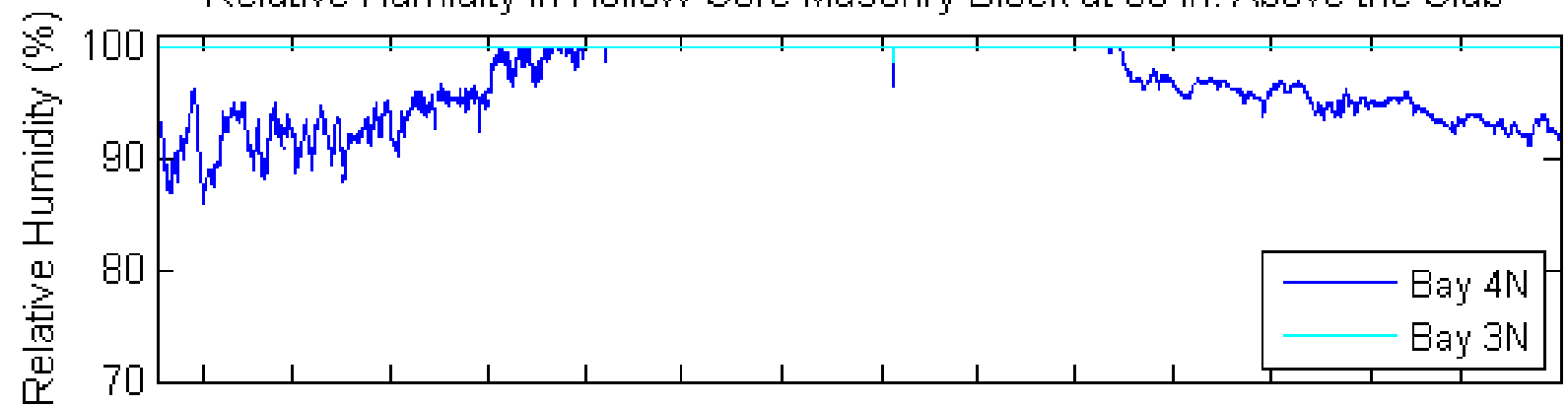

Relative Humidity in Hollow Core Masonry Block at 40 in. Above the Slab

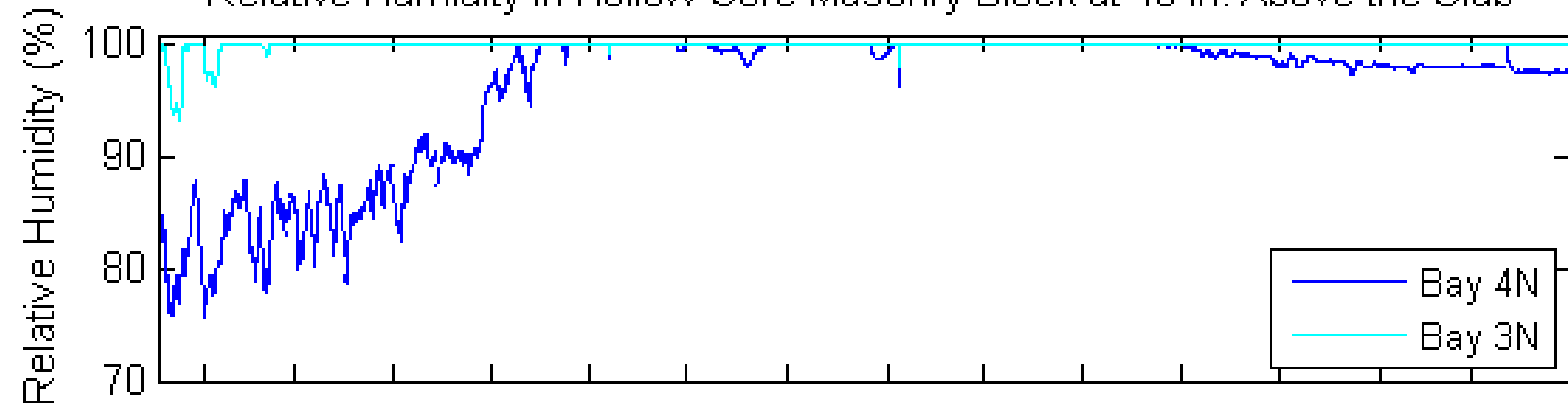

Relative Humidity in Hollow Core Masonry Block at 16 in. Above the Slab

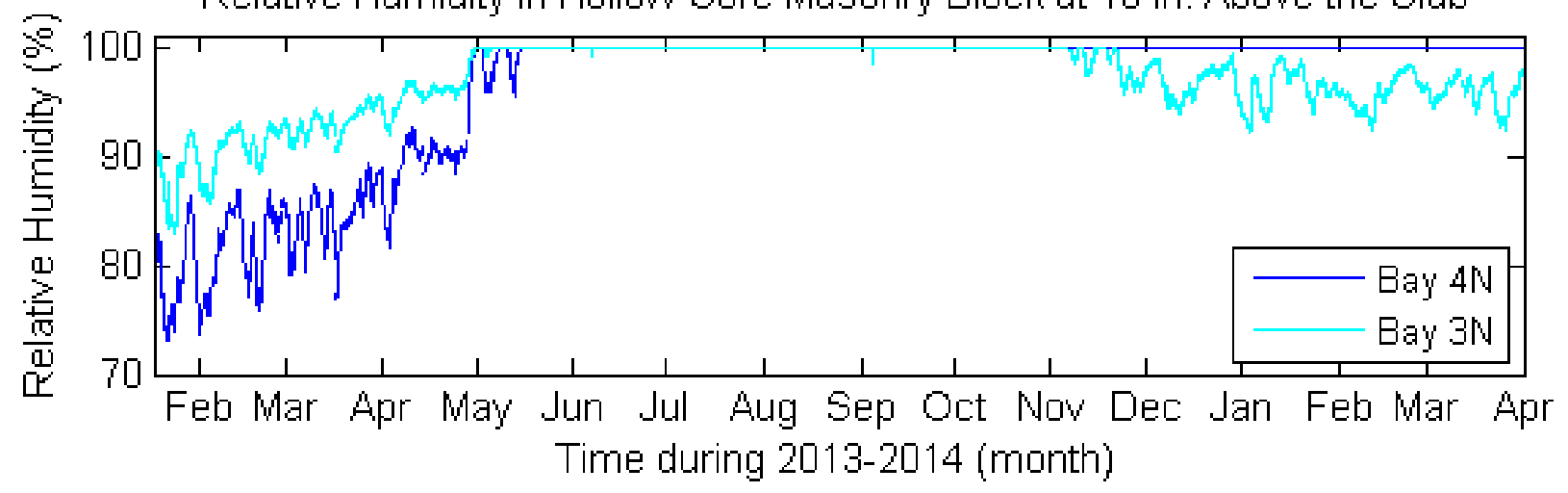

Figure 39. Comparison of Bay $3 \mathrm{~N}$ and $4 \mathrm{~N}$ core $\mathrm{RHs}$

This effect can be reduced by extending the exterior insulation as deeply as possible below grade to provide a vapor retarder over as much of the exterior wall surface as possible in the absence of an exterior WSP. Nevertheless, the data reveal that partial exterior retrofit insulation can have deleterious impacts on the wall moisture performance. 
Finally, the horizontal soil V-MC profiles are reported for Bays 1 and 2 in Figure 40 and Figure 41, respectively (they were not measured for the other bays). There is no consistent pattern to these $\mathrm{V}$ MC profiles, except that those in Bay 1 show higher moisture contents than those in Bay 2 because the sand adjacent to Bay 2 - relative to the loam adjacent to Bay 1 -affords good drainage. For example, in Figure 40, on the south side, the highest V-MC was measured 32 in. from the wall in Bay $1 \mathrm{~S}$ and 5 in. from the wall in Bay 2S. On the north side, the highest soil moisture content was measured 18 in. from the wall in both Bays $1 \mathrm{~N}$ and $2 \mathrm{~N}$, but the lowest soil moisture content occurred 5 in. from the wall in Bay $1 \mathrm{~N}$ and 32 in. from the wall in Bay $2 \mathrm{~N}$, exactly the reverse. The data spikes during the cooling season (May through October) were a consequence of liquid precipitation (see Figure 29 and Figure 30). The spikes in March and April were produced by melted snow percolating into the soil. During the heating season, the soil surface crust was frozen, inhibiting the percolation of water into the soil. These data reveal the highly random and pathcontingent nature of water transport in soils under the influence of gravity, which is extremely difficult to model for any particular case. Generally, only average flows can be computed over an ensemble of cases, so attempting to validate simulated moisture transport in soils in the Vadose zone $^{22}$ for any specific case (such as the four experimental cases discussed) is essentially hopeless in practice.

Taken as a whole, the experimental moisture transport phenomenology discussed for Bays 1-4 reveals that adhered and nonadhered interior WSPs are adequate to meet the foundation hygrothermal performance criteria of the Minnesota Energy Code. Nonadhered WSPs are satisfactory in cases where the wall interior face shell is quantitatively dry with a saturation ratio of $25 \%$ or lower, based on a conservative interpretation of the experimental results. For all other cases, a nonadhered WSP is recommended at this stage. If all the adhered WSPs have not separated from the interior wall surface when the test bays eventually are dismantled, it may be possible to increase the saturation ratio threshold for adhered WSPs above $25 \%$ with confidence.

\footnotetext{
${ }^{22}$ The region of the Earth's crust between the surface and the position at which the water pressure in the soil pores is equal to atmospheric pressure (nominally the top of the water table).
} 
Bay 1S: Soil Volumetric Moisture Content Profiles at 40 in. Above the Slab

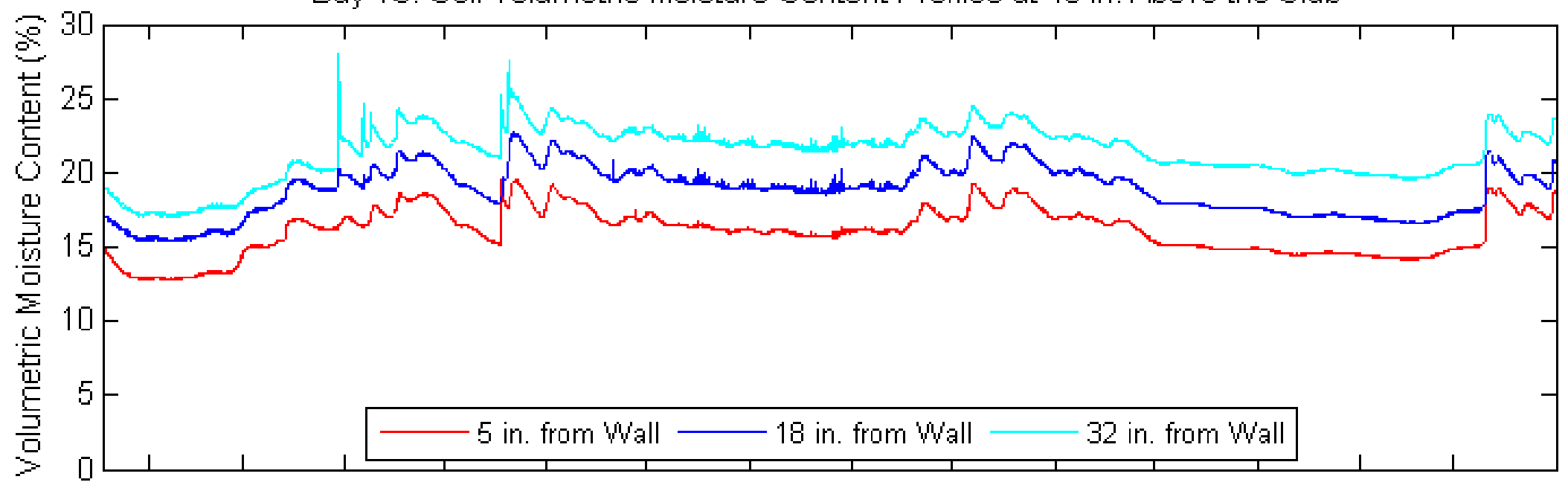

Bay 2S: Soil Volumetric Moisture Content Profiles at 40 in. Above the Slab

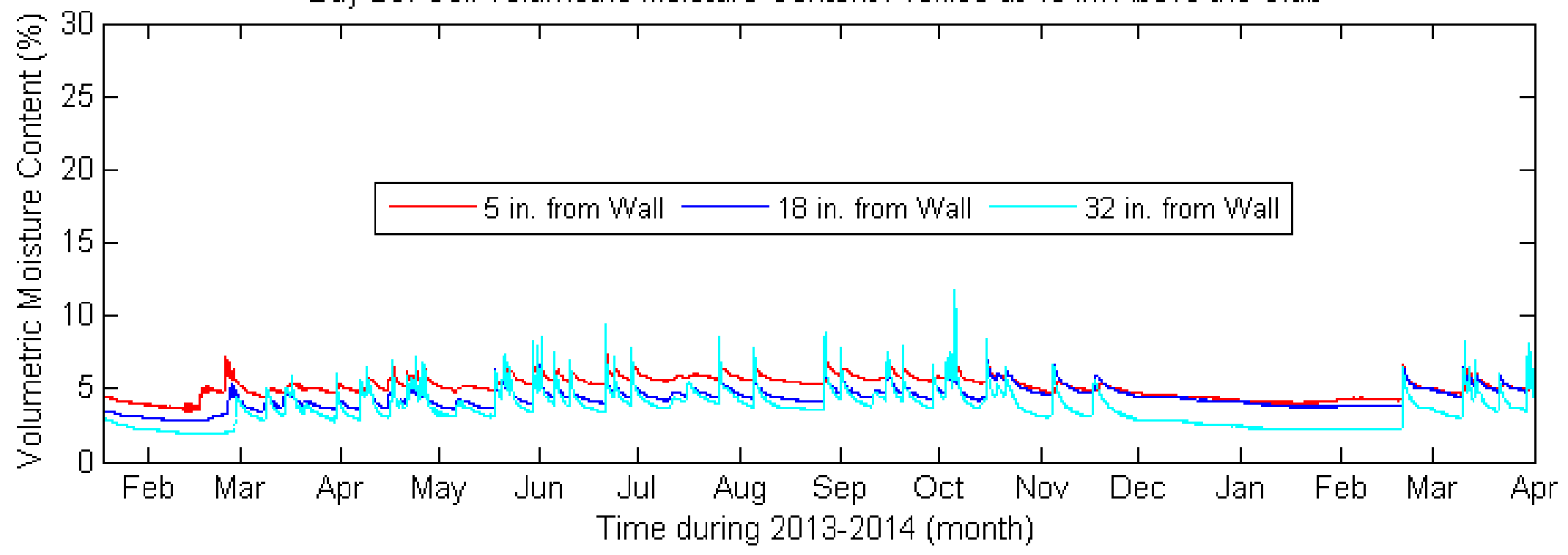

Figure 40. Bay $1 \mathrm{~S}$ and $2 \mathrm{~S}$ soil moisture contents comparison 
Bay 1N: Soil Volumetric Moisture Content Profiles at 40 in. Above the Slab

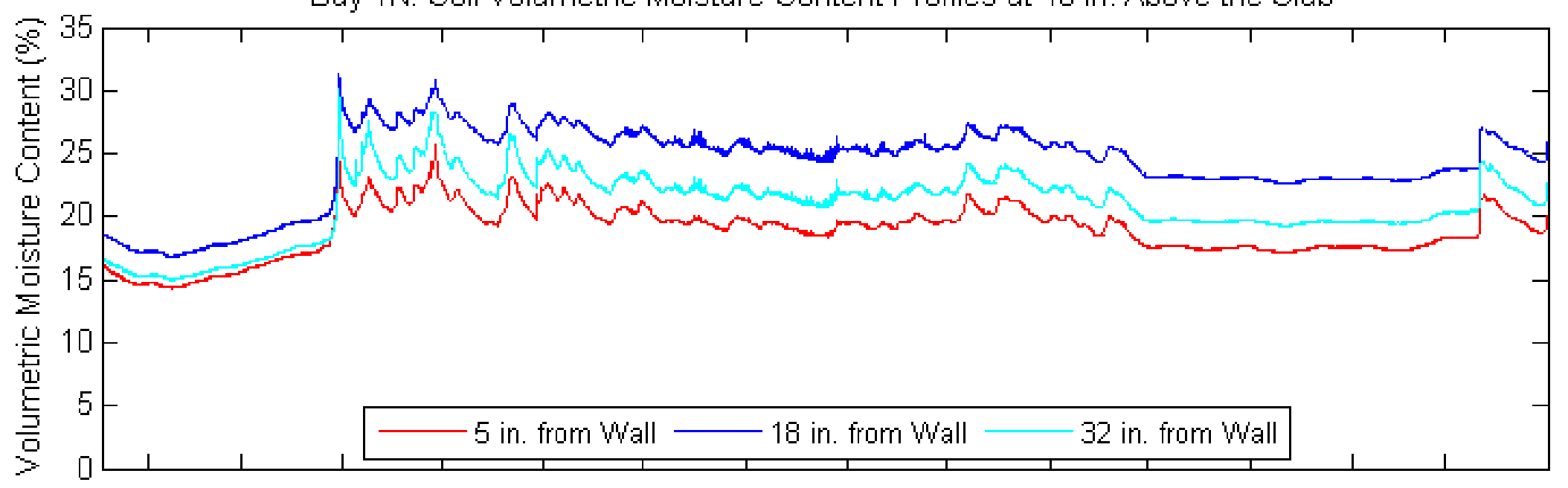

Bay 2N: Soil Volumetric Moisture Content Profiles at 40 in. Above the Slab

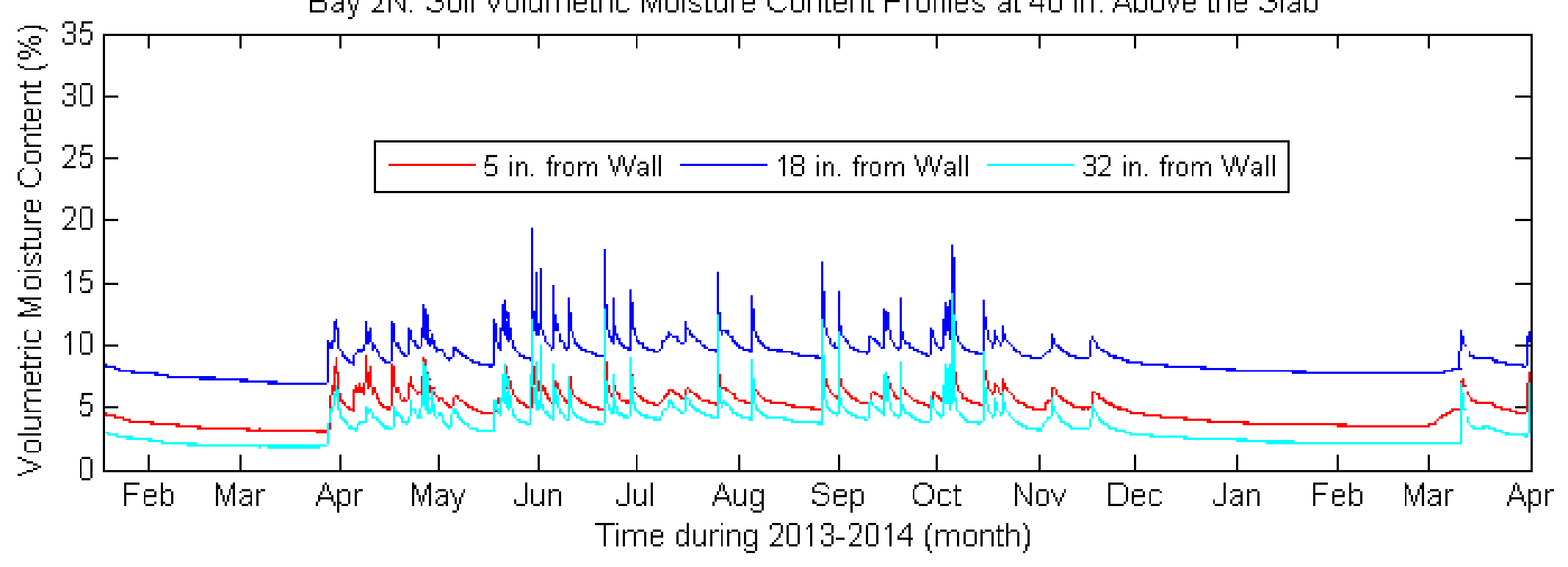

Figure 41. Bay $1 \mathrm{~N}$ and $2 \mathrm{~N}$ soil moisture contents comparison 


\subsection{Rim-Joist Cavity Hygrothermal Experiment}

As discussed in Section 1.2, the purpose of the rim-joist cavity hygrothermal experiment was to experimentally resolve the issue of whether water vapor in the hollow cores of masonry block walls produces high humidity in sealed rim-joist cavities. This humidity manifests as condensation on the rim board and wall sill plate surfaces in particular. This is of particular importance in interior foundation insulation retrofits where sealing the interior wall face, either with insulation only (if an exterior WSP is present) or with an interior WSP that inhibits or prevents drying of the wall to the interior, potentially increases the vapor drive to the rim-joist cavity.

With reference to Figure 5 and Figure 6 (showing the experimental configuration and instrumentation), the experiment built in test Bays $5 \mathrm{~S}$ and $5 \mathrm{~N}$ was designed to enable the three primary vapor fluxes crossing the boundaries of a tightly air sealed rim-joist cavity to be measured, namely:

- Across the rim board

- Across the interior vapor retarder (consisting of a double layer of 6-mil polyethylene membrane with each layer separately air sealed)

- Across the solid wall bond beam block between the hollow masonry block cores and the rim cavity.

The top of the cavity was sealed with polyisocyanurate insulation board with foil-facing on both sides. The first floor space was unconditioned during the experiment, yielding close to ambient boundary conditions. The sides of the rim-joist cavity comprised the $1 / 2$-in. thick OSB webs of engineered I-joist trusses exposed to basement interior conditions on their outer faces. The vapor pressures were measured on five sides of the rim-joist cavity (the vapor pressure above the floor was assumed to be the same as the ambient vapor pressure) and within the cavity at three locations (on the rim board face, on the vapor retarder face, and at the cavity center). Combining these vapor pressures with measurements of the moisture contents of the sill plate, rim board, and I-joist webs allowed empirical relationships to be developed between the boundary vapor fluxes and the moisture contents. This enabled the relative contribution of the masonry block wall core humidity to the rim-joist cavity bounding surface moisture contents to be measured. The potential for this contribution was maximized because the wall was covered with an interior 6-mil polyethylene membrane WSP.

Two experiments were built on both the north and south walls. One had no exterior insulation; the other had exterior R-15 rigid insulation extending from the top of the rim-joist cavity to about 6 in. below grade. The intent was to determine whether a warmer rim board would reduce the amount of interior surface condensation.

The experiment commenced in mid-July and data collection for this report was frozen at the end of April. The data span almost the entire 2013-2014 heating season and the latter half of the 2013 
cooling season, giving adequate coverage of the seasonal impacts. ${ }^{23}$ The results are discussed in Sections 3.3.1 and 3.3.2.

\subsubsection{Thermal Performance}

The thermal performance of the rim board bounding surface is shown in Figure 42 and Figure 43 for the south and north exposures, respectively. On the south side, Figure 42 shows that the rim board insulation reduced the peak heating season heat loss by about $20 \mathrm{~W} / \mathrm{m}^{2}$ on average while substantially reducing the diurnal swing produced by the solar irradiation. The effect on the temperature was less significant; the insulation increased the rim board surface temperature by about $6^{\circ} \mathrm{C}$ at the time of peak heat loss (early January). ${ }^{24}$

On the north side, the results were similar (see Figure 43), except that the diurnal variations of heat flux and temperature were reduced because of the absence of solar gain. In this case, the rim board insulation reduced the maximum heat flux loss by about $25 \mathrm{~W} / \mathrm{m}^{2}$ on average and increased the corresponding rim board interior surface temperature by about $9^{\circ} \mathrm{C}$. The greater impacts on the north side were a result of the colder prevailing ambient temperatures. The rim board insulation effectively reduced both the heat loss through and the potential for condensation on the interior surface of the rim board as expected.

\subsubsection{Moisture Transport Performance}

The highest levels of surface moisture with the highest interior surface RHs were recorded for the north wall rim-joist cavities (Bay $5 \mathrm{~N}$ ). The results for the north wall are given in Figure 44 and Figure 45 for the uninsulated and insulated cases, respectively (the data for the south side are recorded in Figure 119 and Figure 120 in Appendix C). These figures show the following:

- Top panel: Mass moisture content (M-MC) of the interior rim board face and the M-MC difference between the interior and exterior faces on the LHS ordinate axis and the rim board interior surface RH on the RHS ordinate axis

- Center panel: East floor joist M-MC and the M-MC difference between the east and west joists on the LHS ordinate axis and the rim-joist cavity center RH on the RHS ordinate axis

- Bottom panel: Sill plate M-MC on the LHS ordinate axis and the cavity center and rim board interior RHs on the RHS ordinate axis.

These data reveal that, with or without insulation, no condensation occurred on any wood bounding components over the reported duration of the experiment. The measured moisture content of the sill plates did not exceed $8 \%$, while that of the OSB components (rim board and joist webs) did not exceed $6 \%$ in the uninsulated cavity and $5 \%$ in the insulated cavity. The maximum RH of $91 \%$ was recorded on the interior face of the uninsulated rim board during midFebruary and had no impact on the M-MC on either side of the rim board. The measured interior

\footnotetext{
${ }^{23}$ Data are scheduled to be collected through the end of November 2014 , so more than an entire year of data will be available for analysis at a later date.

${ }^{24}$ A partial instrumentation failure occurred from mid-August through mid-November when a defective thermocouple multiplexer was replaced. During that period, the diurnal variation data were lost, but the mean diurnal temperature data were recovered.
} 
surface RHs on the wood components in the insulated cavity was significantly lower than those in the uninsulated cavity (for example, a difference between maxima of $22 \%$ for the rim board). Rim board insulation does provide an increased margin of safety against condensation, but in this experiment provided no condensation reduction (because none was measured in the uninsulated cavity).

The wetting/drying profiles for the worst-case north side cavity wood bounding components are shown in Figure 46 and Figure 47 for the uninsulated and insulated cases, respectively; the south side data are correspondingly reported in Figure 121 and Figure 122 in Appendix C. In all cases over the data reporting period, the dry bulb temperature (referred to as the sensible temperature in the figures) exceeds the dew point temperature; the difference is larger in the cavity with rim board insulation. These data perhaps give a better perspective on the margin of safety provided by exterior rim board insulation, particularly on the interior face of the rim board. 
Heat Flux on South Interior Rim Board Surface

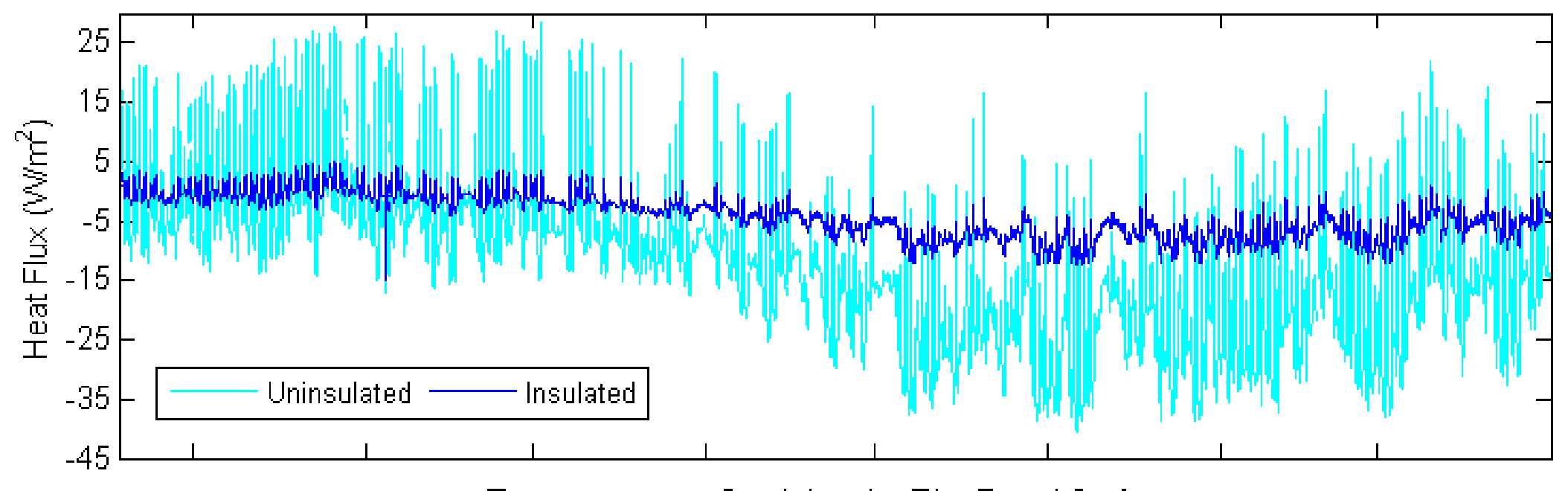

Temperature on South Interior Rim Board Surface

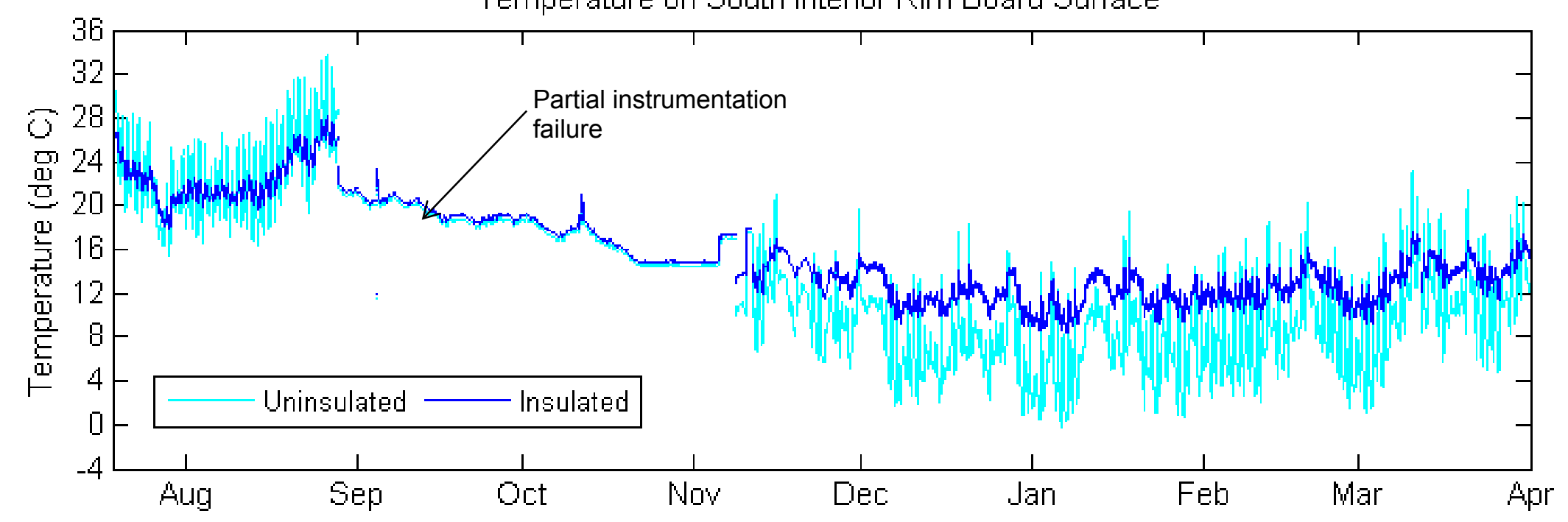

Figure 42. Bay $5 \mathrm{~S}$ rim-joist cavity rim board thermal performance 
Heat Flux on North Interior Rim Board Surface

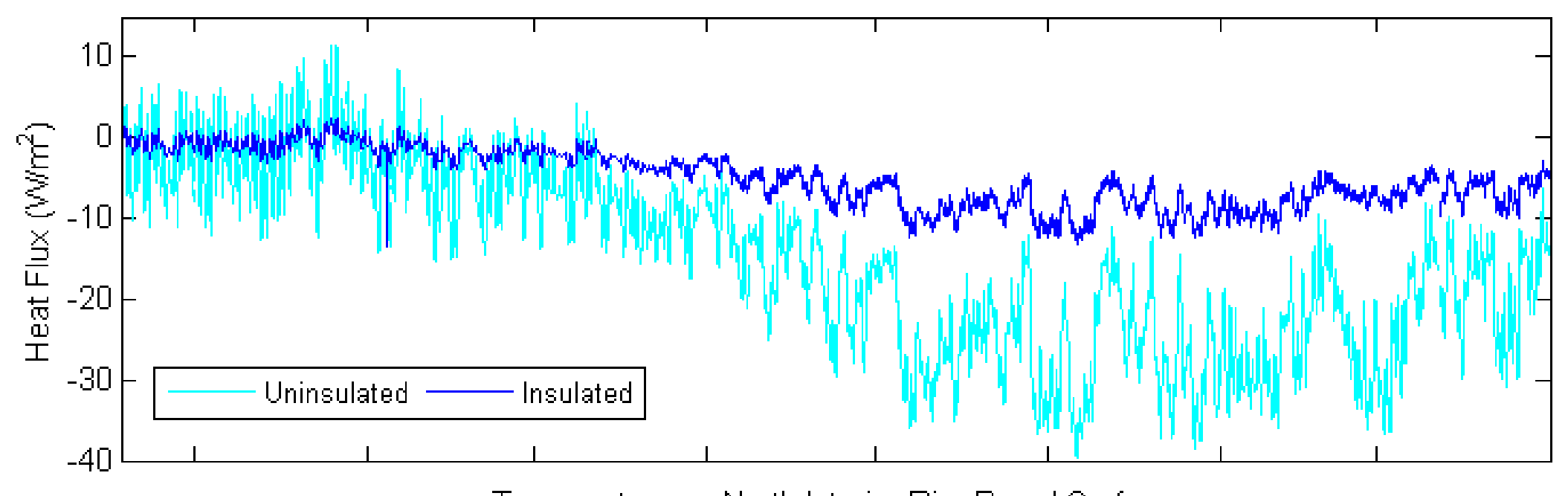

Temperature on North Interior Rim Board Surface

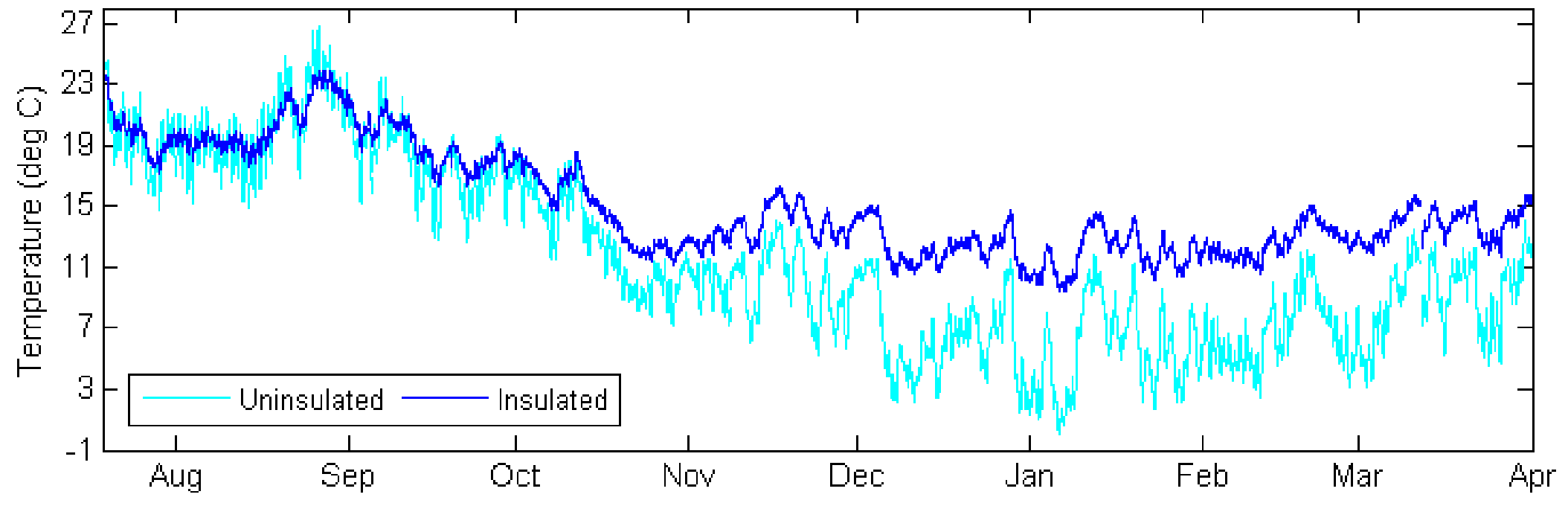

Figure 43. Bay $5 \mathrm{~N}$ rim-joist cavity rim board thermal performance 


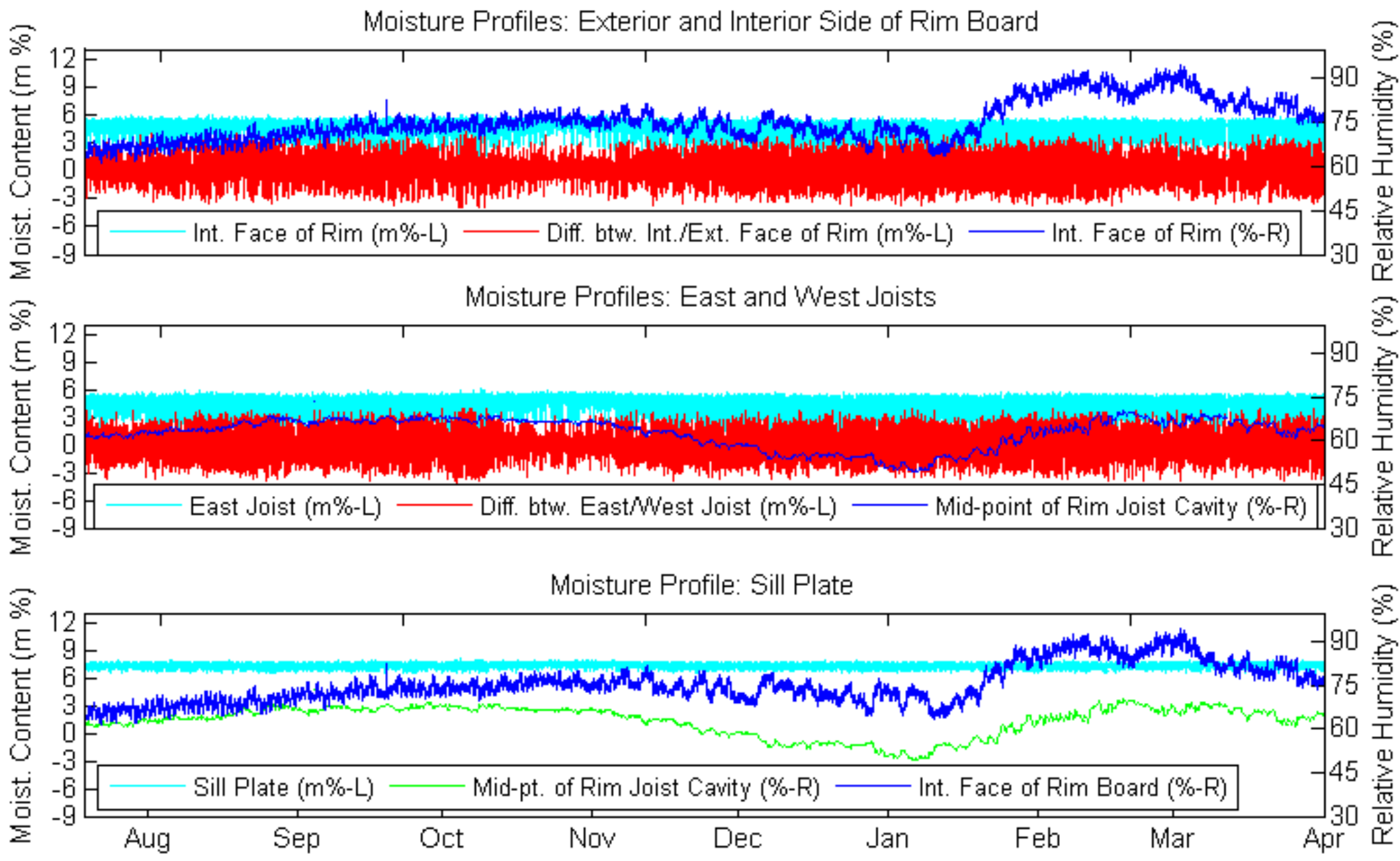

Figure 44. Moisture performance of Bay $5 \mathrm{~N}$ rim-joist cavity with uninsulated rim board 


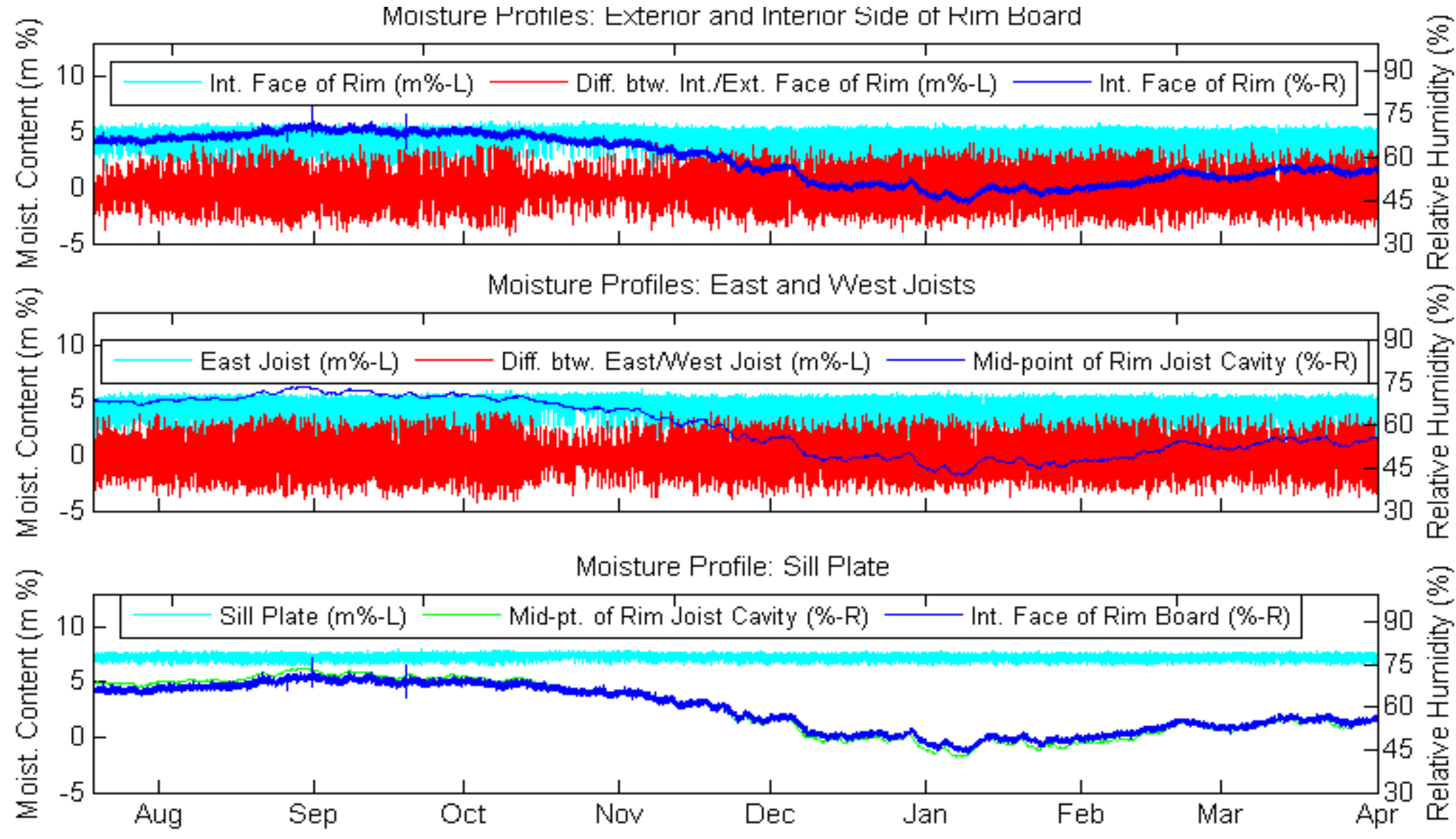

Figure 45. Moisture performance of Bay $5 \mathrm{~N}$ rim-joist cavity with insulated rim board 
North Uninsulated Rim Joist Cavity: Rim Board Interior Face Wetting and Drying Profile
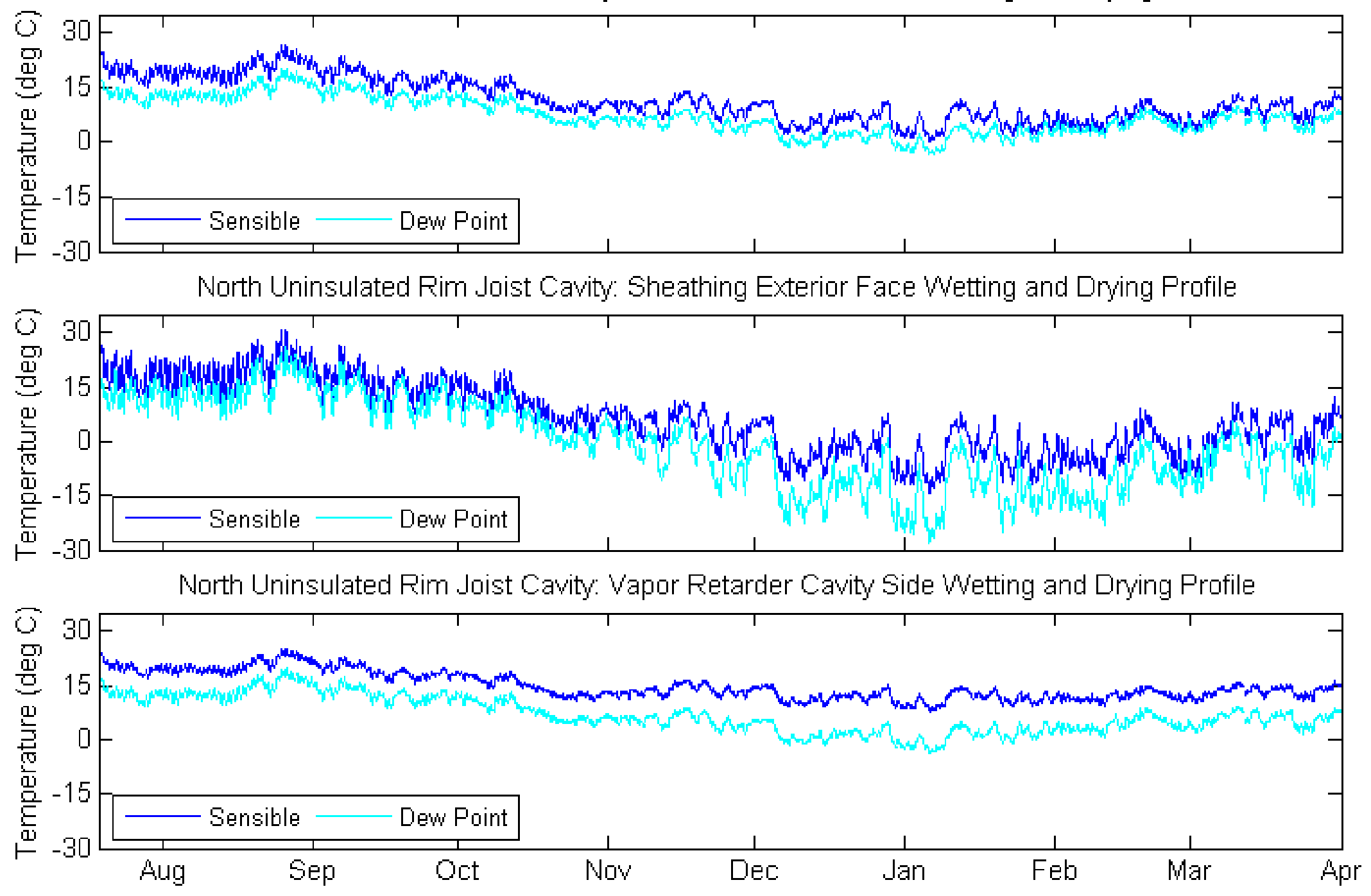

Figure 46. Wetting/drying profiles for Bay $5 \mathrm{~N}$ rim-joist cavity with uninsulated rim board 
North Insulated Rim Joist Cavity. Rim Board Interior Face Wetting and Drying Profile

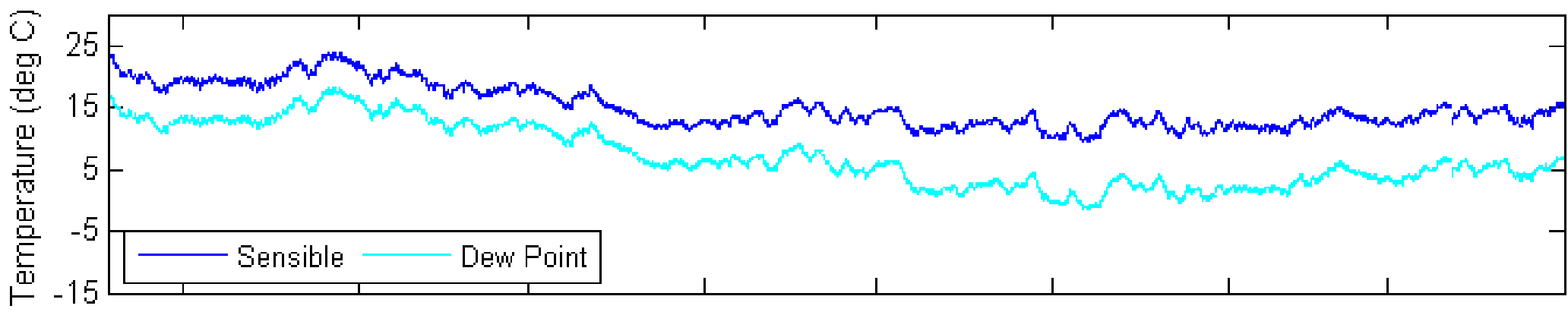

North Insulated Rim Joist Cavity. Sheathing Exterior Face Wetting and Drying Profile
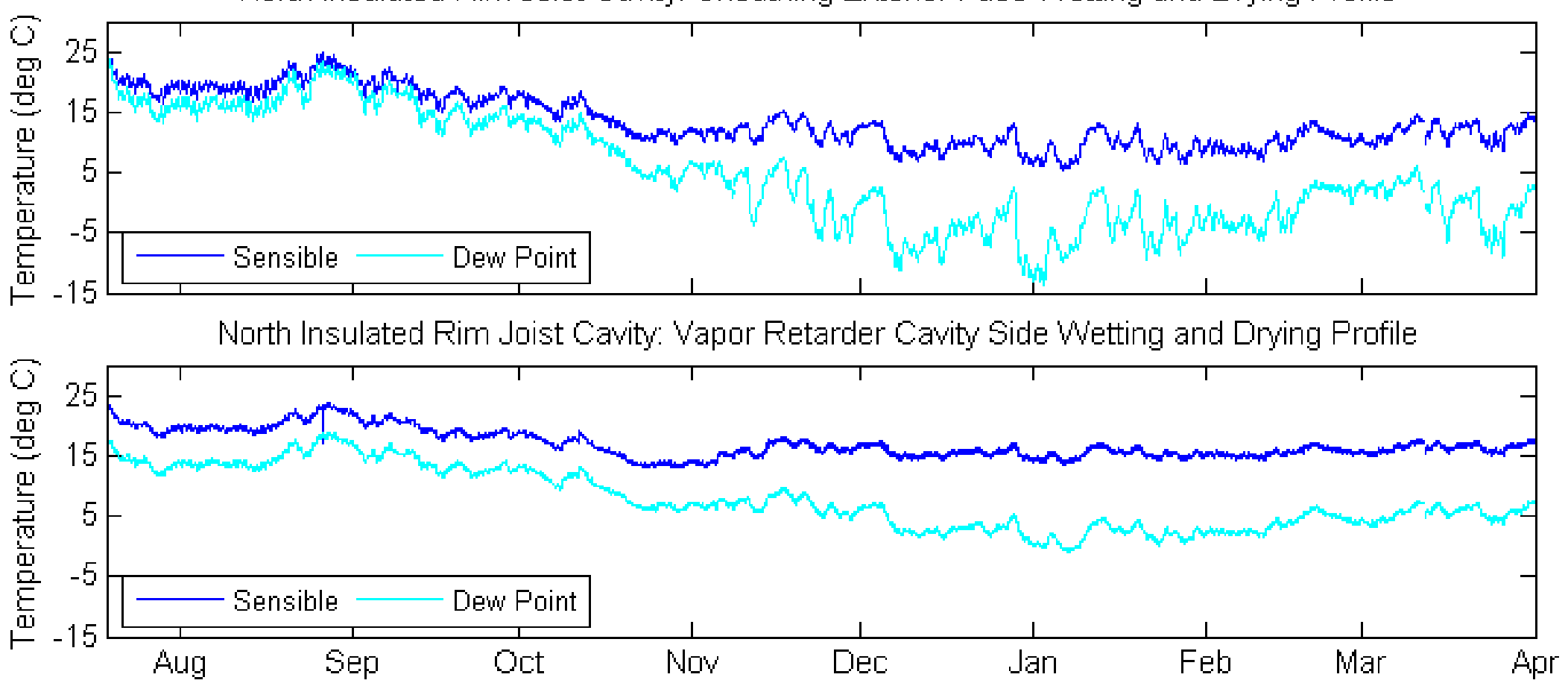

Figure 47. Wetting/drying profiles for Bay $5 \mathrm{~N}$ rim-joist cavity with insulated rim board 
Figure 48 and Figure 49 show the worst-case moisture phenomenology recorded for the north side bond beam block (above the masonry block core RH measurement location at the top of the wall); the south side data are shown in Appendix C (Figure 123 and Figure 124). For the insulated and uninsulated cavities in Figure 48, the core humidity remained at $100 \%$ over the measurement period while rim-joist cavity center $\mathrm{RH}$ was significantly lower by at least $33 \%$ (worst case in the insulated cavity at the end of August). The vapor drive was nominally ${ }^{25}$ from the block cores to the rim-joist cavity over most of the measurement duration (substantiated in Figure 50 and Figure 51). The interior and exterior bond beam block face shell V-MCs did not exceed 4\% (0.34 saturation ratio) at any point; the readings were mostly $3 \%$ or lower. The increase in interior face shell V-MC on the cavity bond beam blocks from mid-January onward corresponded to the onset of basement interior humidification and demonstrates that there were vapor bypasses across the interior WSP at the top of the wall adjacent to both the insulated and uninsulated cavities.

No moisture condensing on the hollow core surface of the bond beam block diffused to either the interior or exterior face shell surfaces or to the rim-joist cavity surface. This latter diffusion would have manifested as either an increase in the sill plate moisture content or a saturated cavity RH or both, neither of which was measured. This is reinforced in Figure 49, which shows the sill plate M$\mathrm{MC}$ along with the bond beam face shell V-MCs. The data reveal that neither the insulated nor the uninsulated case showed a change in the sill plate $\mathrm{M}-\mathrm{MC}$ (which remained below $8 \%$ ) in response to the increased $\mathrm{V}$-MC measured on the interior face shell during basement humidification after mid-January. Taken together, the data in Figure 48, Figure 49, Figure 123, and Figure 124 show that the permeance of the solid bond beam block was adequate to sufficiently retard vapor transport from both the hollow core and the interior face shell to the rim-joist cavity. This permeance is estimated to be approximately 0.4 US-perm at most between the hollow core and the rim-joist cavity interior based on a typical ASHRAE permeability value for concrete (ASHRAE 2001). The solid bond beam block functioned as an adequate class II vapor retarder (0.1 to 1.0 US-perm).

The vapor pressure gradients across the bounding surfaces of the rim-joist cavity are shown for the north side cavities in Figure 50 and Figure 51 for the uninsulated and insulated cavities, respectively; the corresponding data for the south side are given in Appendix C (Figure 125 and Figure 126). For the insulated and uninsulated cavities, the following observations may be made:

- The block core vapor pressure was stronger than the cavity pressure over the data reporting period with a greater difference in the insulated cavity. The vapor drive was predominantly from the core into the cavity.

- Across the rim board, the vapor drive was from the exterior to the cavity through the first week of October, when it reversed for the duration of the measurements as the ambient AH declined.

- The vapor pressure difference across the vapor retarder separating the cavity from the basement oscillated around zero through mid-January upon commencement of basement humidification. Thereafter, the pressure on the basement side was larger until the pressures equilibrated again after the beginning of March. The slow rate of equilibration

\footnotetext{
${ }^{25}$ Using RH data to establish the vapor flux direction is not correct because of the different temperatures in the rim joist and block cores.
} 
points to diffusive water vapor flow through the I-Joist OSB webs (permeance at 50\% $\mathrm{RH}$ of about 2.2 US-perm) from the basement interior.

- The vapor transport was from the hollow masonry block cores to the basement interior through the beginning of February, when the flow reversed for about a couple of weeks during the period of basement humidification (as a result of the vapor bypasses in the wall WSP discussed previously).

In terms of the relevant magnitudes of the vapor pressure differences on the cavity boundaries, the largest persistent positive drive (vapor diffusion into the cavity) is from the block core and the most negative (although nonpersistent) drive (vapor diffusion out of the cavity) is through the rim board with the uninsulated rim board having a more negative drive. The same phenomena were present on the south side; vapor pressures were higher in the hollow block core because of solar irradiation on the exterior surface. The vapor pressure gradients across the rim-joist cavity from the vapor retarder interior face to the surface of the rim board oscillated around zero for all the cavities, showing that the vapor pressures in the cavities were uniform over the data reporting period (Figure 127 through Figure 130 in Appendix C).

The overall conclusion from the rim-joist cavity experiments is unambiguous. A solid masonry block wall top course provides an adequate vapor retarder for preventing moisture in the hollow cores under saturated conditions from diffusing into the rim-joist cavity in great enough quantities to produce condensation on any of the wood boundary components. 

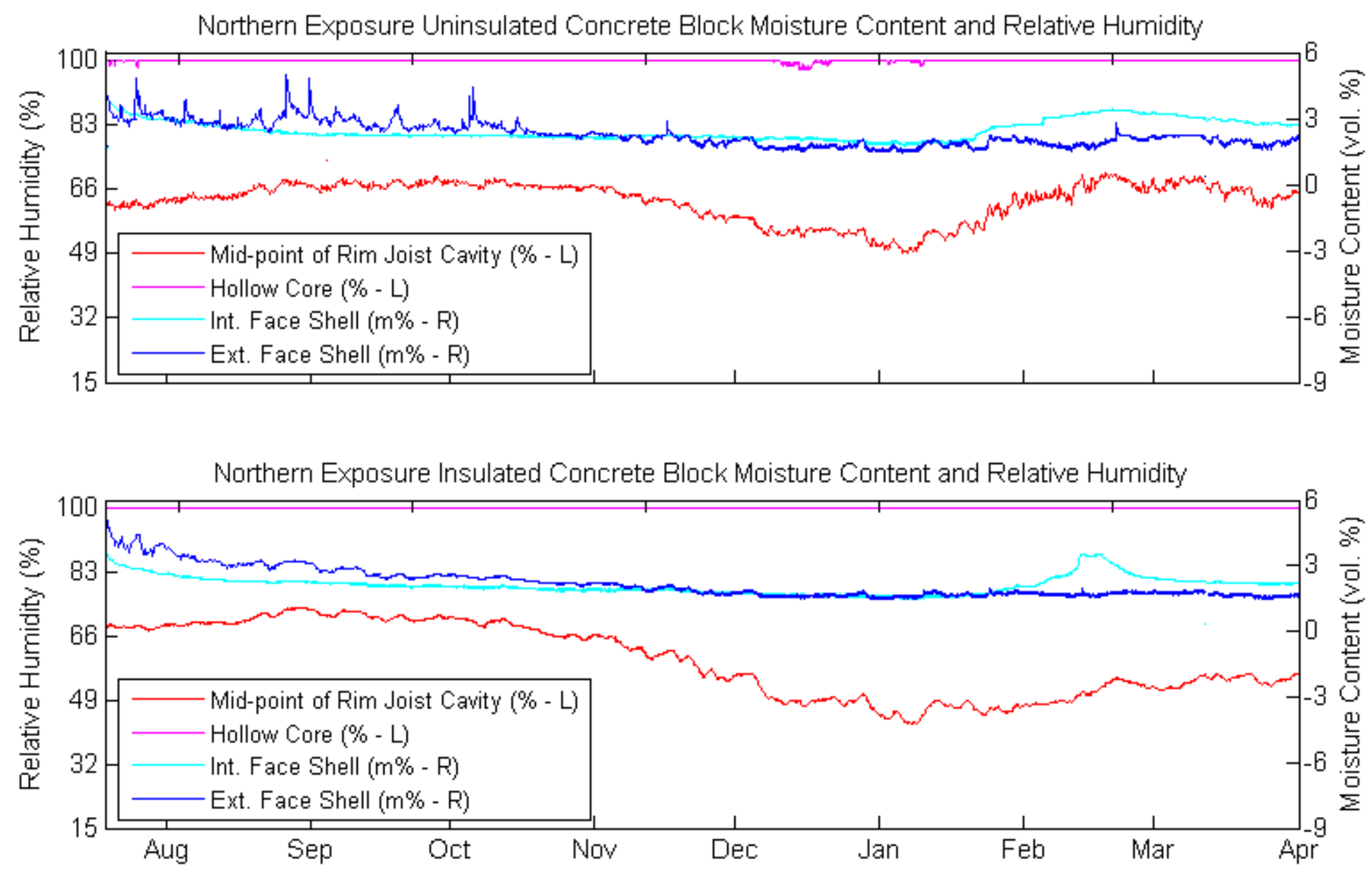

Figure 48. Moisture performance of Bay $5 \mathrm{~N}$ bond beam block below rim-joist cavity 

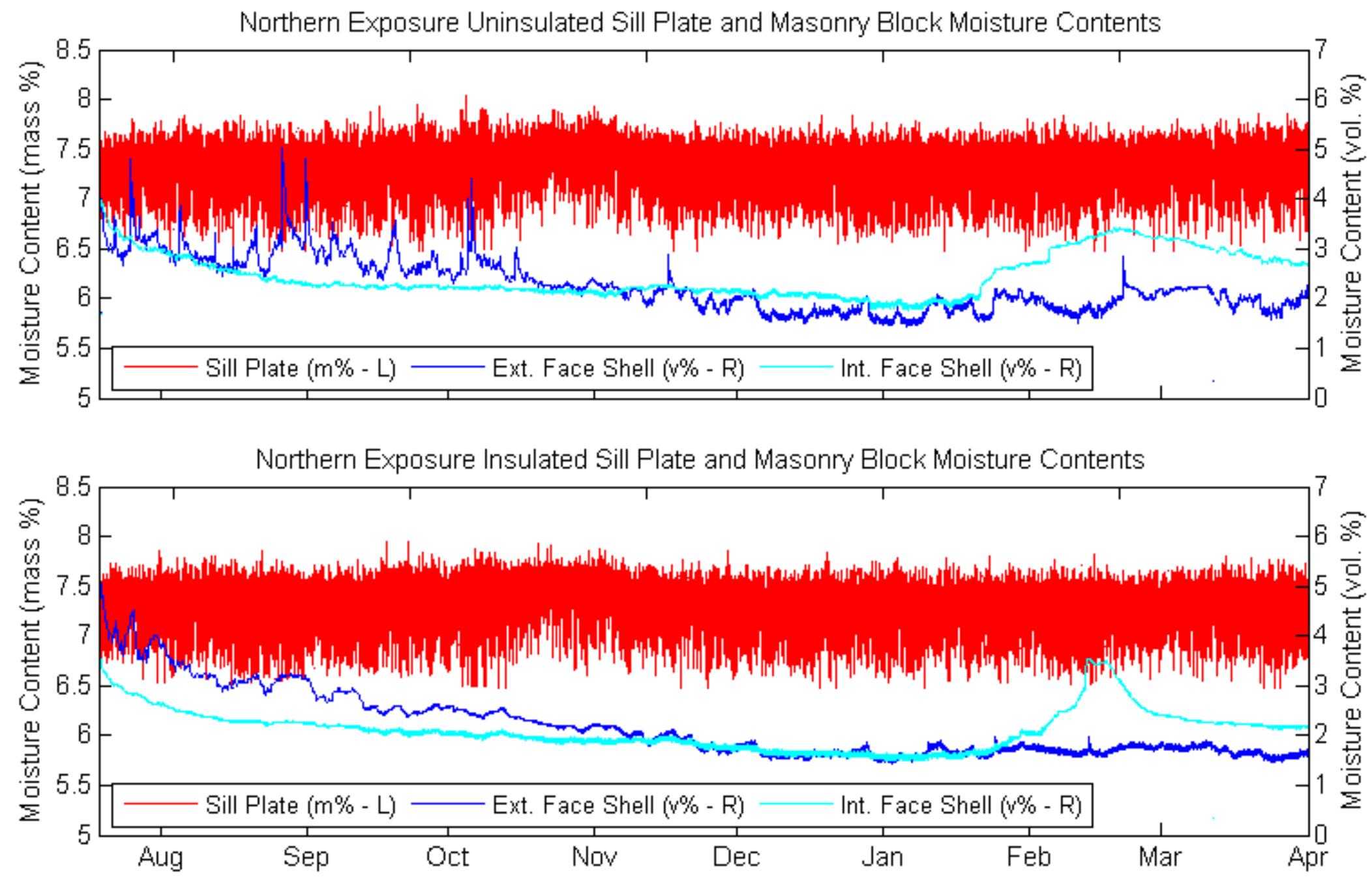

Figure 49. Water diffusion through Bay $5 \mathrm{~N}$ bond beam block below rim-joist cavity 


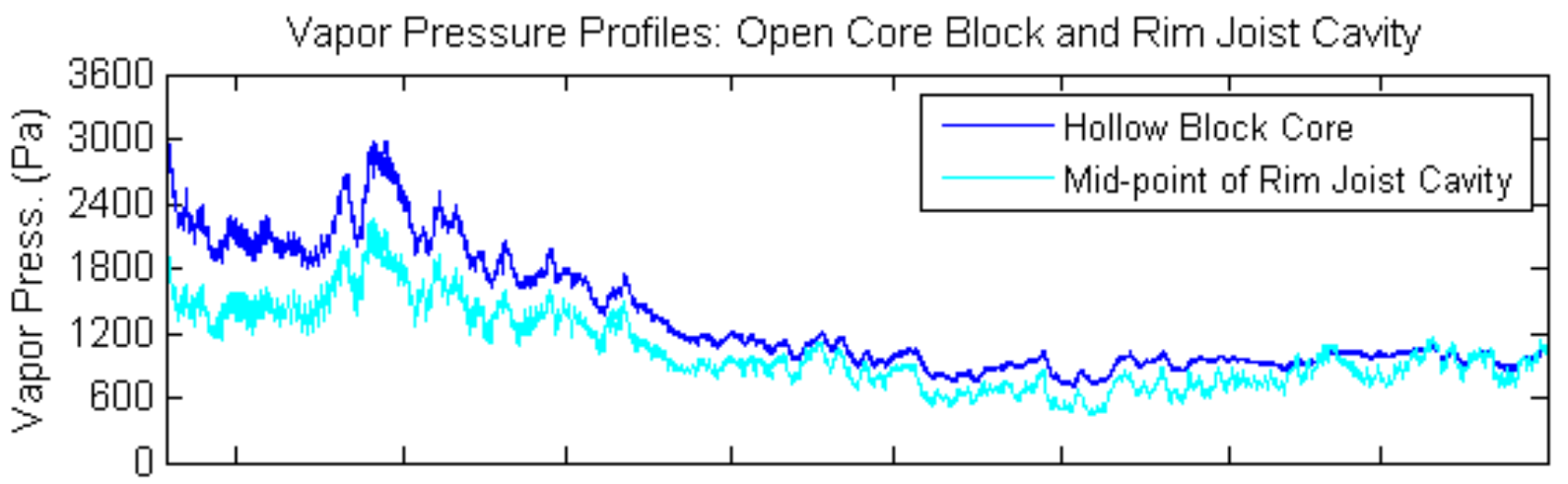

Vapor Pressure Profiles: Exterior and Interior Side of Rim Board
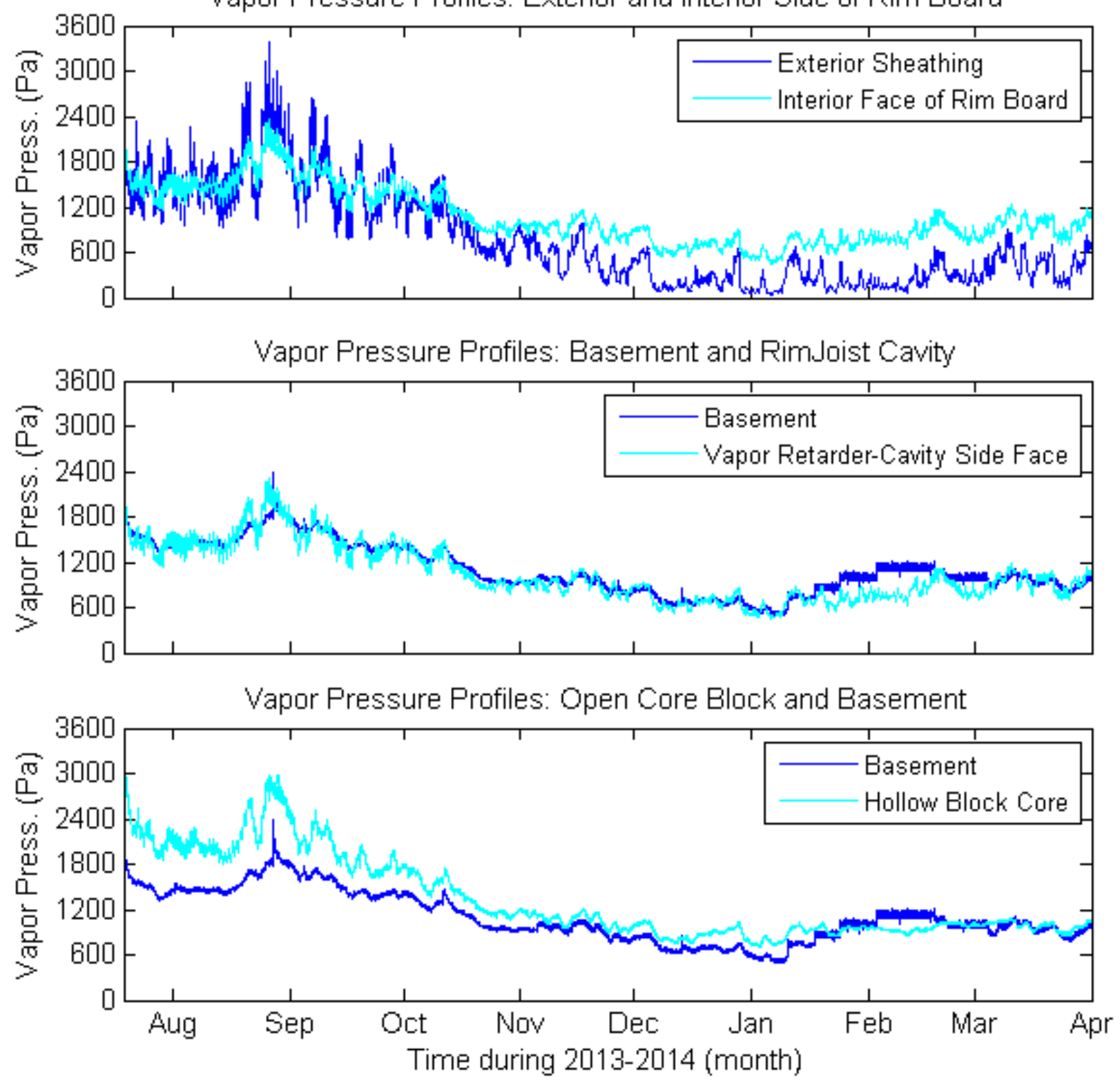

Figure 50. Bay $5 \mathrm{~N}$ rim-joist cavity bounding surface vapor pressure profiles with uninsulated rim board 


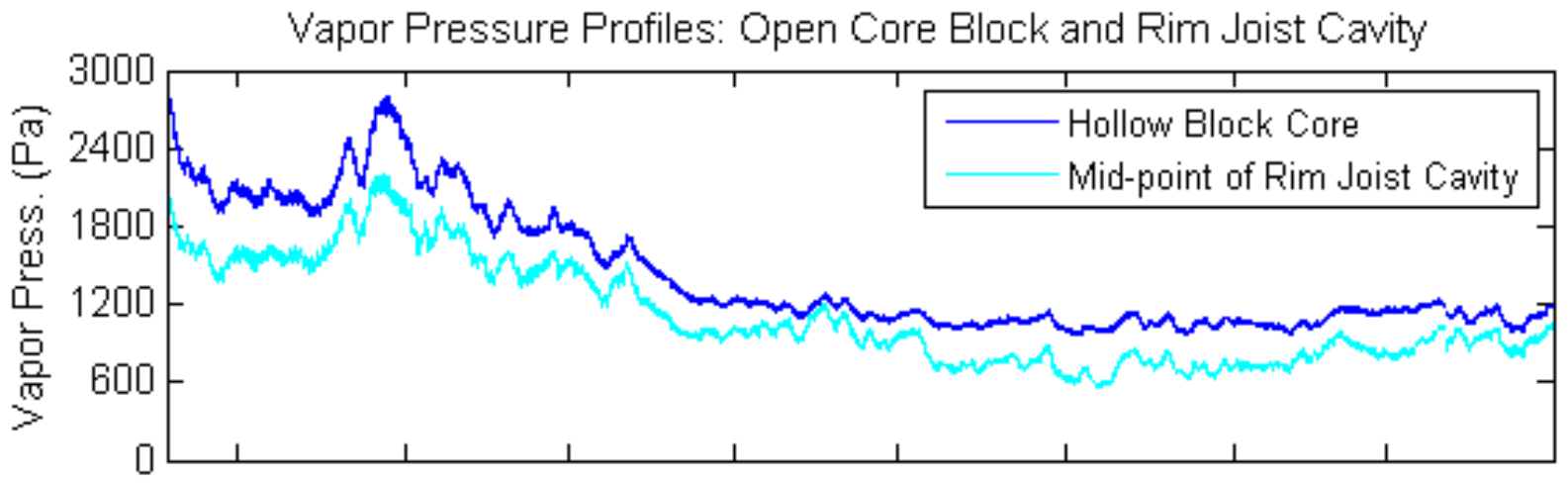

Vapor Pressure Profiles: Exterior and Interior Side of Rim Board

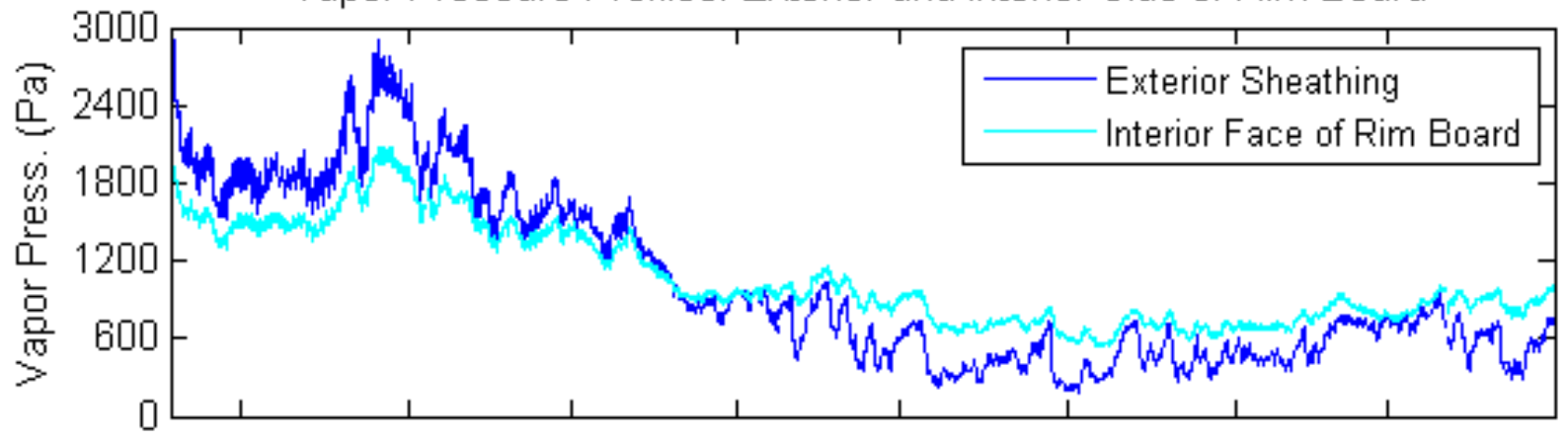

Vapor Pressure Profiles: Basement and Rim.Joist Cavity

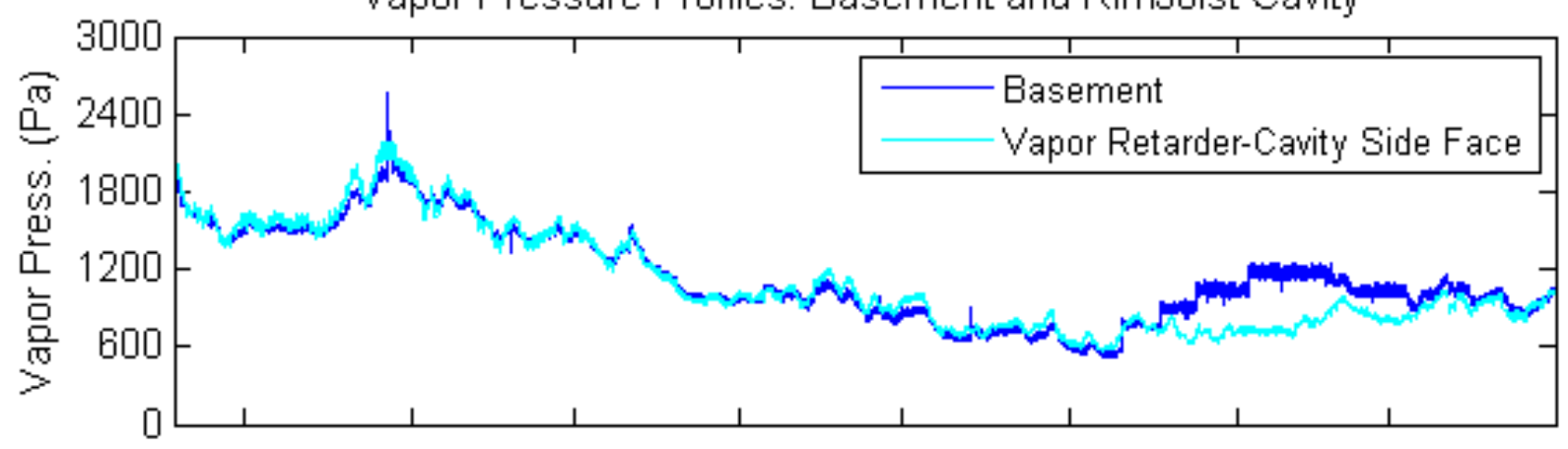

Vapor Pressure Profiles: Open Core Block and Basement

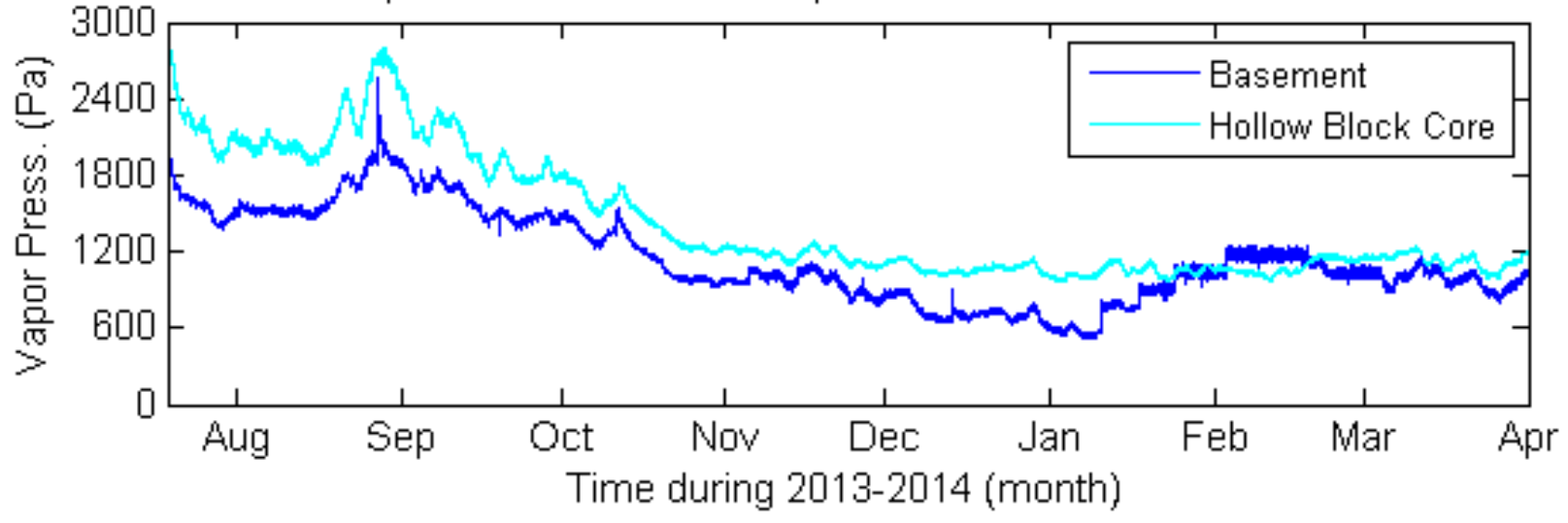

Figure 51. Bay $5 \mathrm{~N}$ rim-joist cavity bounding surface vapor pressure profiles with insulated rim board 


\subsection{Minnesota Energy Code Compliance}

The purpose of this section is to meet the following project objective (see Section 1.3):

Determine experimentally whether the full basement foundation insulation retrofit systems tested are in compliance with the Minnesota Energy Code performance criteria.

The experimental results are used to ascertain compliance with the Minnesota Energy Code requirements. The primary code requirements are underlined and the requirement subsections are listed in normal text. The compliance discussion is italicized.

The performance option for foundation insulation systems in the Minnesota Energy Code currently in force (Minnesota Statutes Chapter 1322, 2009) is defined in section N1102.2.6.12. Each requirement will be addressed with reference to the data presented above and in this section.

N1 102.2.6.12.1 Water Separation Plane The foundation shell be designed and built to have a continuous water separation plane between the interior and the exterior.

IN COMPLIANCE: Figure 2 for an adhered WSP, Figure 3 for a nonadhered WSP.

The interior side of the WSP must:

1. Have a stable annual wetting/drying cycle whereby foundation wall system water (solid, liquid, and vapor) transport processes produce no net accumulation of ice or water over a full calendar year.

IN COMPLIANCE: Wetting/drying cycle stability is determined by comparing the moisture contents of condensing plane materials on the interior of the WSP at the beginning and end of the test year. Generally a tolerance of $+5 \%$ of the beginning moisture content is allowed at the end of the year in practice (Goldberg et al. 2010). In this case, as the adhered and nonadhered WSPs are nonsorptive (that is, they always have a zero installed moisture content), the wetting/drying stability moisture content is assessed on the wall-side surface of the XPS. This is calculated by relating the measured $R H$ at the WSP/insulation interface to the insulation surface moisture content via a sorption isotherm.

As shown in Figure 52 and Figure 131 for the adhered WSP in Bays 1 and 2 and as summarized in Table 3, the RH in the drainage gap at the end of the test calendar year was lower than that at the beginning of the calendar year, showing strict wetting/drying stability because a lower RH yields a lower moisture content on the insulation surface. 
Table 3. Annual Wetting/Drying Stability Code Compliance

\begin{tabular}{|c|c|c|c|c|c|}
\hline $\begin{array}{l}\text { Test } \\
\text { Bay }\end{array}$ & $\begin{array}{l}\text { Location } \\
\text { Above Slab } \\
\text { (in.) }\end{array}$ & $\begin{array}{c}\text { 12-Hour } \\
\text { Average Start } \\
\text { RH on } 1 / 10 / 2013 \\
(\%) \\
\end{array}$ & $\begin{array}{c}\text { 12-Hour } \\
\text { Average Start } \\
\text { RH on } 1 / 18 / 2013 \\
(\%) \\
\end{array}$ & $\begin{array}{c}\text { 12-Hour } \\
\text { Average End } \\
\text { RH on } 1 / 9 / 2014 \\
(\%) \\
\end{array}$ & $\begin{array}{c}\text { RH } \\
\text { Change } \\
(\%)\end{array}$ \\
\hline \multirow{3}{*}{$1 \mathrm{~N}$} & 40 & 81.6 & & 58.5 & -23.1 \\
\hline & 69 & 88.2 & & 66.0 & -22.2 \\
\hline & 86 & 89.7 & & 82.9 & -6.8 \\
\hline \multirow{3}{*}{$\mathbf{1 S}$} & 40 & 73.7 & & 56.7 & -17.0 \\
\hline & 69 & 80.5 & & 60.6 & -19.9 \\
\hline & 86 & 70.8 & & 69.1 & -1.7 \\
\hline \multirow{3}{*}{$2 \mathrm{~N}$} & 40 & 72.4 & & 56.6 & -15.8 \\
\hline & 69 & 82.8 & & 68.8 & -14.0 \\
\hline & 86 & 80.2 & & 79.7 & -0.5 \\
\hline \multirow{3}{*}{$2 S$} & 40 & 66.0 & & 52.1 & -13.9 \\
\hline & 69 & 66.2 & & 55.2 & -11.0 \\
\hline & 86 & 62.6 & & 62.3 & -0.3 \\
\hline \multirow{3}{*}{$3 \mathbf{N}$} & 40 & & 66.8 & 57.5 & -9.3 \\
\hline & 69 & & 78.8 & 70.6 & -8.2 \\
\hline & 86 & & 64.4 & 66.5 & 2.1 \\
\hline \multirow{3}{*}{$3 S$} & 40 & & 58.5 & 52.9 & -5.6 \\
\hline & 69 & & 66.7 & 61.3 & -5.4 \\
\hline & 86 & & 60.7 & 60.7 & 0.0 \\
\hline
\end{tabular}

For the nonadhered WSP in Bay 3, the test period was strictly 51 weeks because measurements commenced on January 18, 2013, even though Bay 3 fabrication was completed a week previously. However, there was no significant change in interior or exterior boundary conditions (Figure 8, Figure 9, Figure 28, and Figure 53) over the week of January 10 to January 18, 2013, yielding essentially the same WSP interior surface RH over that week as that recorded on January 18, 2013. For practical purposes, a 1-year test period was achieved. The largest $R H$ difference measured for the nonadhered WSP was in Bay 3N, 86 in. above the slab with a value of $2.1 \%$. The beginning $R H$ of $64.4 \%$ corresponds to a moisture content of $0.1816 \mathrm{~kg} / \mathrm{m}^{3}$ and the ending RH of $66.5 \%$ yields a moisture content of $0.18475 \mathrm{~kg} / \mathrm{m}^{3}$, so the increase in moisture content over the year was $1.7 \%$, well within the 5\% tolerance. All the other Bay 3 RH differences were negative or zero and thus met the strict wetting/drying cycle stability requirement.

and the foundation wall system is free of absorbed water for at least four months over a calendar year;

IN COMPLIANCE: On the interior side of the WSP there was no condensation and no absorbed water during the test year that prevailed for more than 2 weeks cumulatively (in Bay 3N, 69 in. above the slab in Figure 53 and in Bay 1N, 86 in. above the slab in Figure 131, both events occurring in November 2013). 
2. Prevent conditions of moisture and temperature to prevail for a time period favorable to mold growth for the materials used.

IN COMPLIANCE: The materials bounding the condensation plane on the interior WSP (high density polyethylene and XPS) do not provide nutrients for mold growth and the minimal gap between them was air sealed from the basement interior. The moisture conditions on the condensation plane were too dry to support mold growth for the required period of time (Sedlbauer et al. 2003).

3. Prevent liquid water from the foundation wall system from reaching the foundation floor system at any time during a full calendar year.

IN COMPLIANCE: On the interior of the WSP, insufficient condensate was produced on the WSP interior surface drainage plane (Figure 52, Figure 53, and Figure 131) for Bays 1-3 to trickle down to the experimental frame base plate. No such leakage was observed over the test year.

N1 102.2.6.12.3 Installation. The water separation plane shall be designed and installed to prevent external liquid or capillary water flow across it after the foundation is backfilled.

IN COMPLIANCE: All the WSPs were installed on the interior of the foundation wall and thus were isolated from backfilling against the exterior wall surface.

N1 102.2.6.12.4 Foundation air barrier. The foundation insulation system shall be designed and installed to have a foundation air barrier system between the interior and the exterior. The foundation air barrier system must be a material or combination of materials that is continuous with all joints sealed and is durable for the intended application. Material used for the foundation air barrier system must have an air permeability not to exceed $0.004 \mathrm{ft}^{3} / \mathrm{min} . \mathrm{ft}^{2}$ under a pressure differential of $0.3 \mathrm{in}$. water $(1.57 \mathrm{psf})\left(0.02 \mathrm{~L} / \mathrm{s}^{2} \mathrm{~m}^{2}\right.$ at $\left.75 \mathrm{~Pa}\right)$ as determined by either commonly accepted engineering tables or by being labeled by the manufacturer as having these values when tested in accordance with ASTM E2178.

IN COMPLIANCE: The high density polyethylene dimple sheet used for the nonadhered WSP and the rubberized asphalt laminated to 4-mil polyethylene used for the adhered WSP have lower air permeability than $3 / 8$-in. thick plywood that is in compliance with the cited ASTM E2178 test limits (Washington State Statutes Title 51, Chapter 51-11C, section C402.4.1 [Air Barriers] subsection C402.4.1.2.1 [Materials]).

The adhered and nonadhered WSPs tested in the experiment are in compliance with the performance criteria for foundation insulation systems listed in the applicable 2009 Minnesota Statute. 

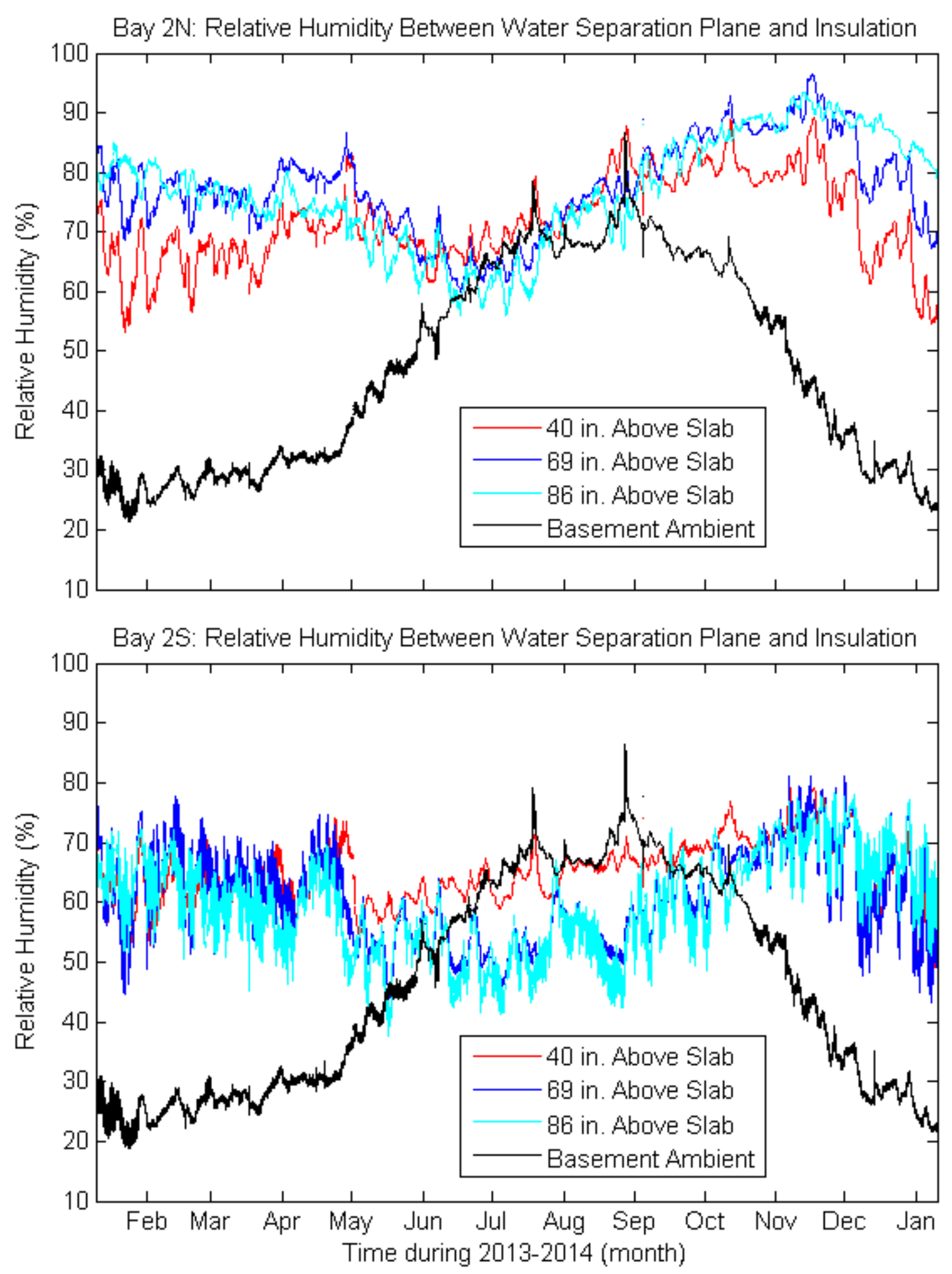

Figure 52. Bay 2 WSP interior condensing surface Minnesota Energy Code compliance performance 
Bay 3N: Relative Humidity Between Water Separation Plane and Insulation

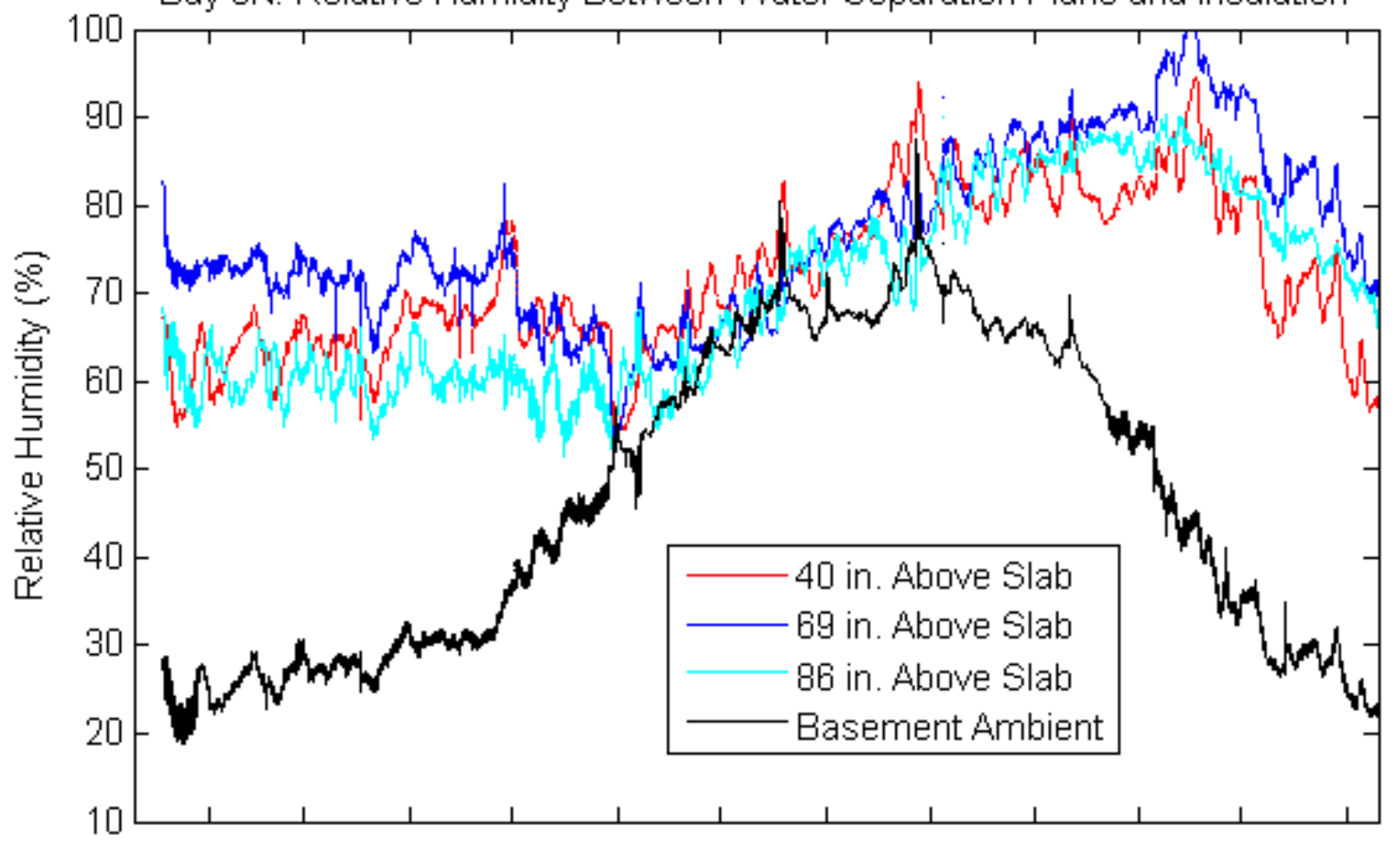

Bay 35: Relative Humidity Between Water Separation Plane and Insulation

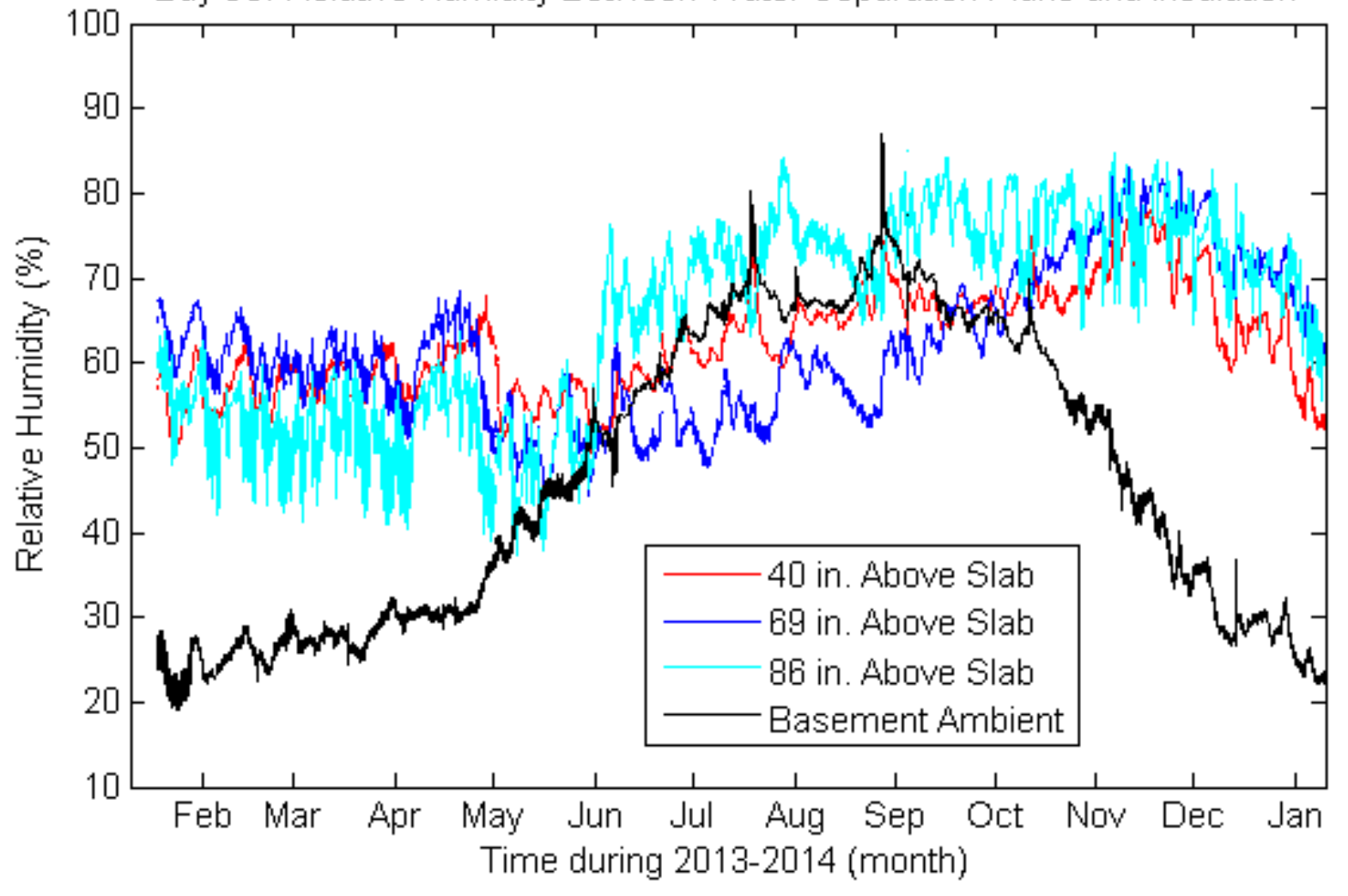

Figure 53. Bay 3 WSP interior condensing surface Minnesota Energy Code compliance performance 


\subsection{Interior Humidification}

The impact of the basement interior humidification that commenced on January 10, 2014 on the WSP interior surface RH is shown in Figure 54 through Figure 56 for Bays 1-3, respectively. Comparing the bottom panels of Figure 54 and Figure 55 for Bays $1 \mathrm{~S}$ and 2S, the RH levels measured in Bay 2S were lower than those recorded in Bay 1S because the Bay 2S wall temperatures were higher (Figure 12) than those of Bay 1S (Figure 102 in Appendix C). However, a comparison of the top panels of Figure 55 and Figure 56 for Bays $2 \mathrm{~N}$ and 3N, respectively, shows that the RH profiles at 69 and 86 in. above the slab in Bay 3N were lower than those in Bay $2 \mathrm{~N}$. This arose because the interior WSP surface in Bay $3 \mathrm{~N}$ was warmer because of the additional insulation provided by the drainage cavity air gap. But this was not the case at $40 \mathrm{in}$. above the slab where the Bay $3 \mathrm{~N}$ RHs were higher than those of Bay $2 \mathrm{~N}$, especially toward the end of March. The inconsistency is even more apparent in the lower panels of Figure 55 and Figure 56 where at all levels, the Bay $3 \mathrm{~N}$ measured RHs were significantly higher than those in Bay $2 \mathrm{~N}$ from midFebruary to the beginning of March. In fact, Bay 2S experienced a relatively short cumulative period of vapor saturation on the WSP interior surface (mid-February and March) compared with Bay 3S. WSP surface temperatures were not the only factor in play in this case, and the warmer surface temperatures were likely overwhelmed by a locally higher effective insulation permeance in Bay 3S. This could have been caused by imperfect air sealing around the perimeter of a rigid insulation board leading to a local vapor bypass (more likely) or, perhaps, differences in the thickness or material density of the insulation in Bays 2S and 3S (less likely).

All the bays except $2 \mathrm{~S}$ showed vapor saturation at least at one level for a prolonged period in response to the basement interior RH reaching 50\%. The question is whether the resulting vapor flux was sufficient to yield measurable condensation on the interior surface of the vapor retarder. Previous test data collected at the University of Minnesota's FTF provided photographic evidence (Goldberg 2004) that addresses this question. This evidence shows that 5- $1 / 2$ in. of open-cell spray polyurethane foam insulation without any warm-side vapor retarder and covered with gypsum wallboard only, yielded significant amounts of condensation on the surface of a masonry block wall interior WSP in response to basement elevated interior RH conditions of $50 \%$. Based on manufacturers' specifications, 5-1/2 in. of open-cell spray foam has a permeance of $9.1 \mathrm{US}$-perms in comparison with 0.5 US-perms for 3-in. thick XPS yielding a nominal vapor flux 18.2 times lower for the XPS under similar conditions. An 18-fold reduction of the volume of condensate observed with open-cell spray polyurethane foam would at most yield a thin film of condensate on the surface of the WSP that likely would not have sufficient mass to run down.

No condensate rundown was observed at the CRRF after January 10, 2014 on Bays 1-3. However, the final determination whether any condensation occurred will be made when the test bays are dismantled at some future date and evidence of rundown is found or not. 
Bay 1N: Relative Humidity Between Water Separation Plane and Insulation during Basement Humidification

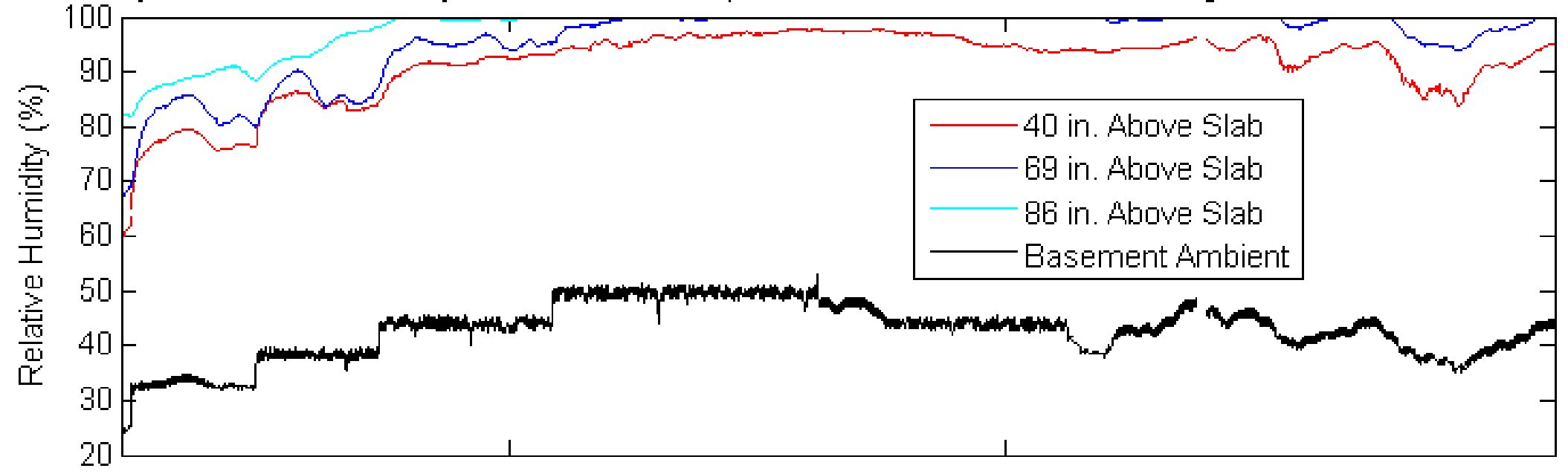

Bay 1S: Relative Humidity Between Water Separation Plane and Insulation during Basement Humidification

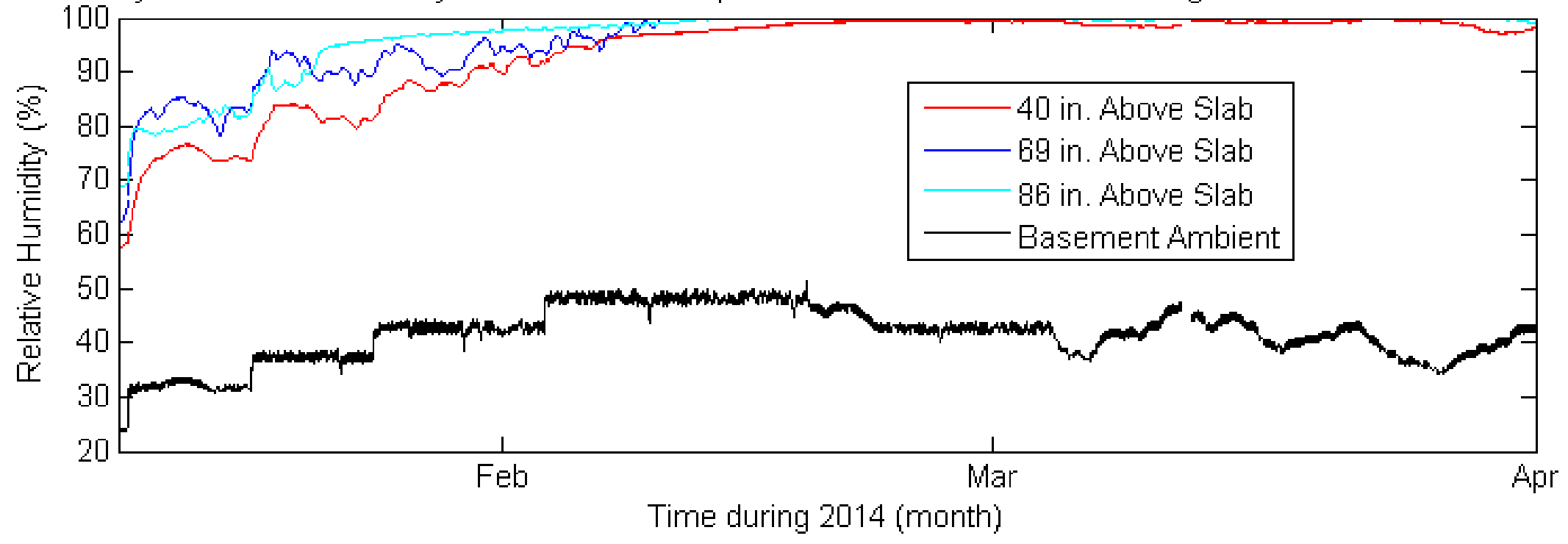

Figure 54. Bay 1 adhered WSP interior side response to basement humidification 
Bay 2N: Relative Humidity Between Water Separation Plane and Insulation during Basement Humidification

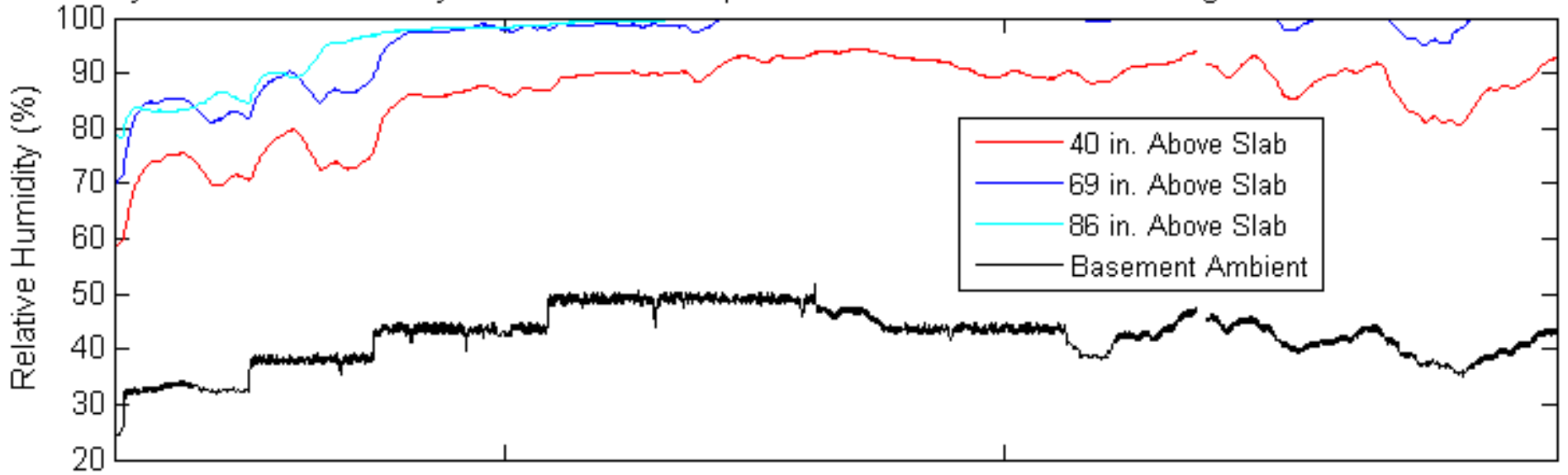

Bay 2S: Relative Humidity Between Water Separation Plane and Insulation during Basement Humidification

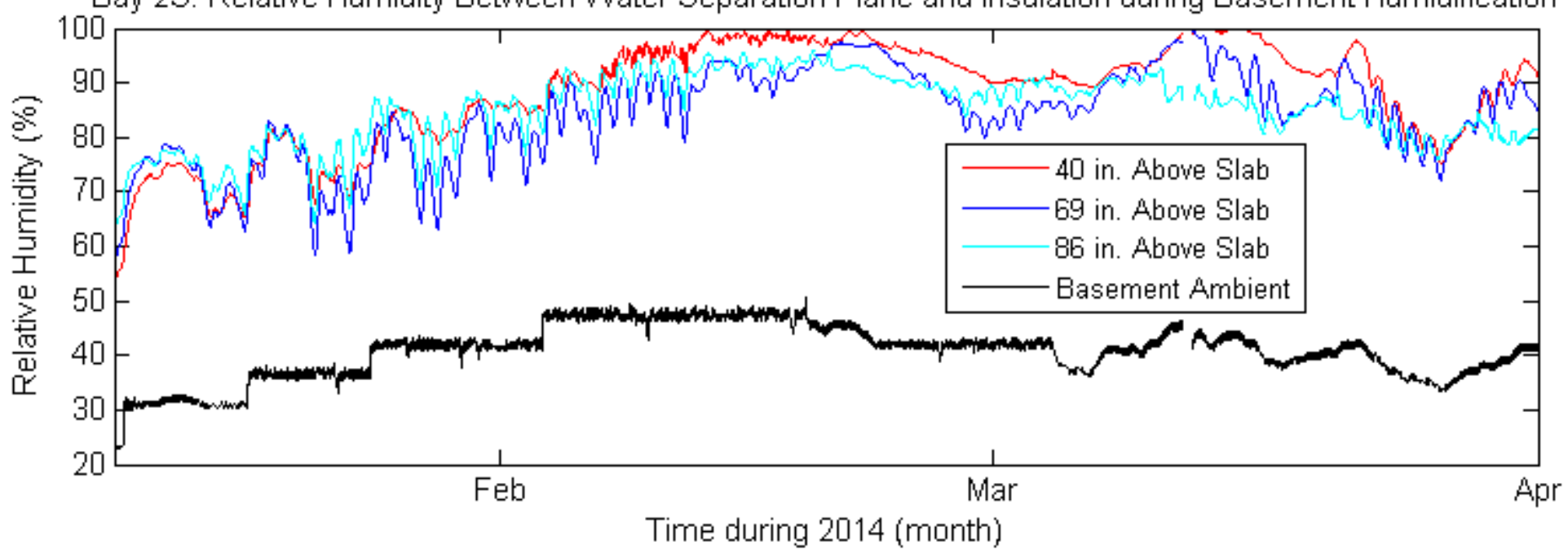

Figure 55. Bay 2 adhered WSP interior side response to basement humidification 
Bay 3N: Relative Humidity Between Water Separation Plane and Insulation during Basement Humidification

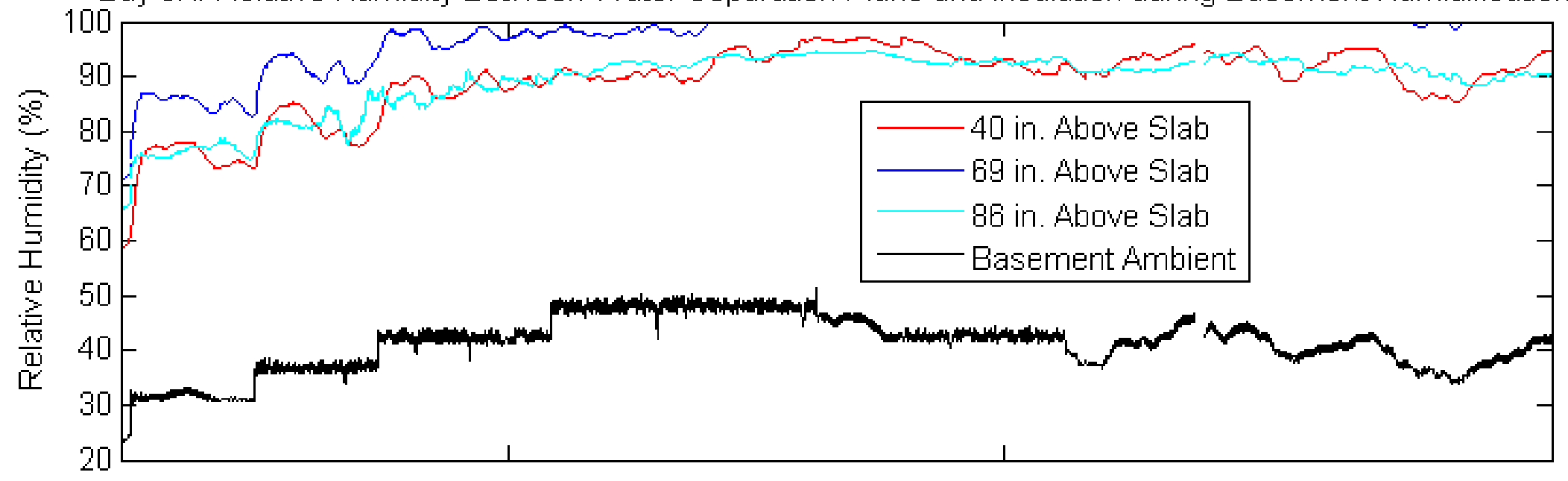

Bay 3S: Relative Humidity Between Water Separation Plane and Insulation during Basement Humidification

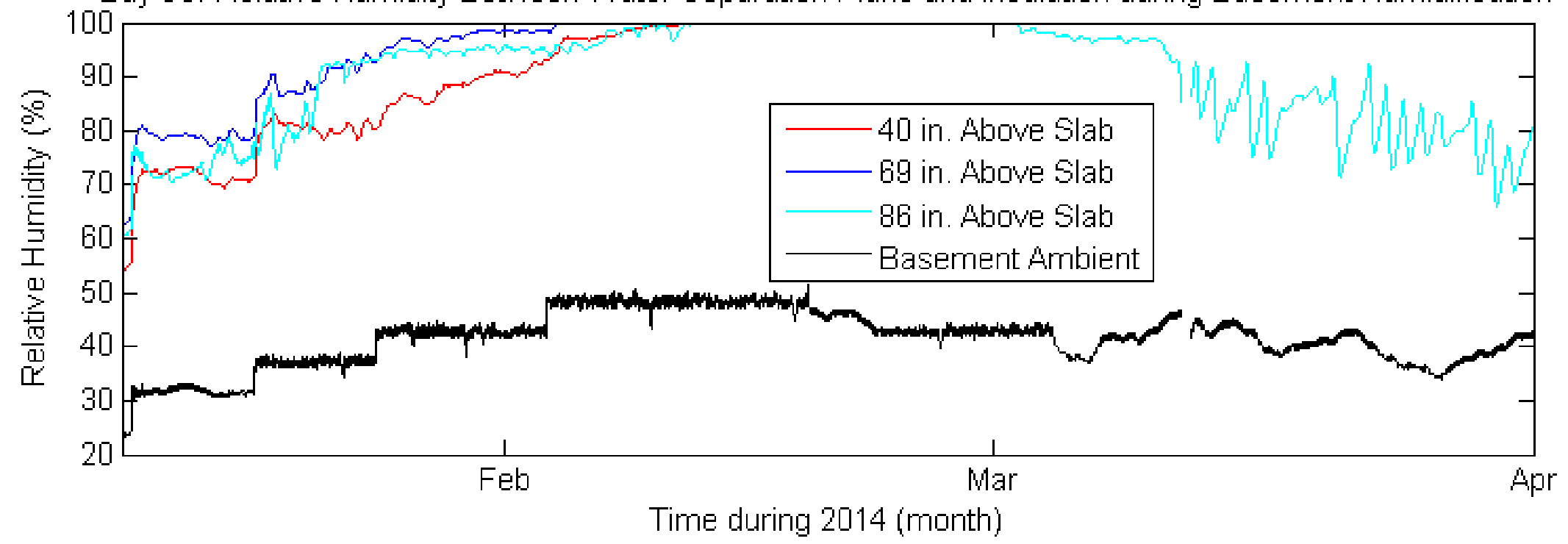

Figure 56. Bay 3 nonadhered WSP interior side response to basement humidification 


\section{Experiment/Simulation Result Comparison}

The purpose of the experiment/simulation comparison was to evaluate the effectiveness of the experimental database as a tool for assessing the accuracy of earth contact simulation codes. In this context, the emphasis was on determining whether the experimental data gathered are adequate to determine whether the predictions of the simulation codes are physically reasonable and to ascertain whether any discrepancies can be explained in terms of the heat and mass transport physics revealed by the experimental data. The purpose was not to calibrate the simulation codes by manipulating their input parameters or to modify their algorithms to achieve agreement; in other words, not to determine how to improve the validity of the codes. The codes were applied in their standard configuration using standard methods of preparing the input data set (geometry, boundary conditions, and material properties) from the available experimental data.

Further, the codes were applied in a "real-world" context in which building energy simulation codes are used to predict the performance of actual buildings. In this context, soil material properties and boundary conditions are not known with any accuracy and often such important boundary conditions (such as snow depth) are ignored because they are not recorded in standard boundary condition data (such as the Typical Meteorological Year, series 3 weather files). In this context, one objective was to see how close the codes chosen could come to the measured data when used with a fuzzy input material properties data set that is typical in actual practice. However, in this case, experimentally measured boundary conditions were used that reduced the uncertainties in the boundary conditions to very small levels.

Two codes were chosen for this purpose. The BUFETS earth contact heat transfer simulation was selected for the thermal comparison in the project test plan because this simulation has been used in Minnesota since 2005 to develop the technical basis (Goldberg and Huelman 2005) for the foundation rules in the Minnesota Energy Code (Minnesota Statutes 2009). It has also been used in conjunction with BEoptE + to assess the whole-house energy savings of foundation retrofits in cold climates (Goldberg and Steigauf 2011; Huelman et al. 2013) for the NREL Building America program. ${ }^{26}$ A particular goal of the thermal comparison was to examine the correlation between the measured and simulated heat flux data and to ascertain how the correlation was affected by soil type and moisture content. One research question in the Test Plan was "Are existing hygrothermal simulation codes (such as WUFI-2D) useful in any way for retrofit foundation insulation designs? Are their predictions qualitatively or quantitatively valid?" To answer this question, the WUFI-2D program was selected as the hygrothermal code because it is the only such code currently available commercially that has been applied to hollow masonry block walls that were tested in this project (Goldberg 2012; Huelman et al. 2013). Further, this code was the hygrothermal validation target for the ORNL part of this project and the assessment of WUFI-2D was carried out in collaboration with ORNL.

\footnotetext{
${ }^{26}$ BUFETS has not been specifically tested using the IEA BESTEST Slab-on-Grade In-Depth Diagnostic Cases (Neymark and Judkoff 2008).
} 


\subsection{BUFETS Thermal Simulation}

The BUFETS code has been described in detail elsewhere (Goldberg and Steigauf 2011). In summary, BUFETS is a three-dimensional transient energy simulation code capable of representing complex foundation system geometries with arbitrary interior and exterior boundary conditions. It includes diffusion energy transport only and a rigorous phase change model based on actual quantized phase change physics (that is, the change between liquid and solid states is not continuous at any point). The soil is described using a constant soil moisture content field imposed as an initial condition; that is, moisture transport is not explicitly modeled. BUFETS also incorporates a snow depth model that includes the effect of snow compaction in calculating the effective thermal resistance of the snow cover (Sturm et al. 1995; Sturm et al. 2010; Calonne et al. 2011). ${ }^{27}$ The specific salient features of BUFETS are:

- Nonlinear material properties as arbitrary functions of temperature and moisture content

- Three-dimensional geometry

- Arbitrary, time-dependent boundary conditions

- Boolean geometry specification and mesh generator

- Inclusion of fully discontinuous phase change physics with frost-front tracking

- High-speed stable solver (enables multiyear real time simulation of large discrete volume meshes $(>100,000$ volumes)

- Graphical animation outputs

- Arbitrary coupling of data outputs (fluxes, temperatures, U-values)

- 8760 hours simulated per year with an arbitrary time step size (typically 1 hour to comply with standard Typical Meteorological Year weather data).

BUFETS also has the following limitations:

- No inclusion of any gaseous (air, water vapor) transport. Thus, hollow masonry block walls cannot be accurately modeled, especially when there is a buoyant cavity flow in the cores. This also applies to porous interior insulation such as fiberglass batts.

- No inclusion of any bulk water transport. The soil moisture content field is entered as a simulation parameter and held constant.

The simulation input parameters were prepared using standard protocols. The soil material properties are described in Table 4. In the standard protocol, ASTM C136 and D422 tests (where available) are used to determine the soil textural class in terms of the gravel, sand, silt, and clay fractions. If not available, the Unified Soil Classification System classification of the soil is generally known (true in this case for the CRRF subslab sand) and is used instead.

\footnotetext{
${ }^{27}$ Data to determine the snow classification at the CRRF were provided by the National Center for Atmospheric Research/Earth Observing Laboratory under sponsorship of the National Science Foundation, http://data.eol.ucar.edu/codiac/dss/id=106.ARCSS045 (Global Seasonal Snow Classification System).
} 
Table 4. Simulation Soil Properties

\begin{tabular}{|c|c|c|c|c|}
\hline & Native Soil & Subslab Sand & Bay 1 Crib Soil & Bay 2 Crib Soil \\
\hline $\begin{array}{c}\text { Unified Soil } \\
\text { Classification } \\
\text { System } \\
\text { Classification }\end{array}$ & SP-SM & Not tested & $\mathrm{ML}$ & $\mathrm{SP}$ \\
\hline $\begin{array}{c}\text { Soil Textural } \\
\text { Triangle } \\
\text { Classification }\end{array}$ & Sand & Not tested & Loam & Sand \\
\hline \% Gravel & 5.9 & Not tested & 4.6 & 0.2 \\
\hline \% Sand & 85.8 & Not tested & 37.8 & 97.6 \\
\hline$\%$ Silt & 4.8 & Not tested & 46.7 & 1.5 \\
\hline \% Clay & 3.5 & Not tested & 10.8 & 0.6 \\
\hline $\begin{array}{l}\text { Kersten Soil } \\
\text { Model }\end{array}$ & $\begin{array}{l}\text { Northway } \\
\text { fine sand }\end{array}$ & Fairbanks sand & $\begin{array}{l}\text { Northway silt } \\
\text { loam/Ramsey } \\
\text { sandy loam }\end{array}$ & Fairbanks sand \\
\hline $\begin{array}{c}\text { Skeleton Density } \\
\text { (kg/M3) }\end{array}$ & 2760 & 2720 & 2690 & 2720 \\
\hline $\begin{array}{c}\text { Dry Heat } \\
\text { Capacity }(J / k g . K)\end{array}$ & 837 & 837 & 837 & 837 \\
\hline $\begin{array}{c}\text { Thermal } \\
\text { Conductivity }\end{array}$ & $\begin{array}{c}\text { Johansen's } \\
\text { method }\end{array}$ & $\begin{array}{l}\text { Johansen's } \\
\text { method }\end{array}$ & $\begin{array}{l}\text { Johansen's } \\
\text { method }\end{array}$ & $\begin{array}{c}\text { Johansen's } \\
\text { method }\end{array}$ \\
\hline Porosity & 0.428 & 0.42 & 0.522 & 0.371 \\
\hline Isotropy & Anisotropic & Anisotropic & Anisotropic & Anisotropic \\
\hline
\end{tabular}

The textural or Unified Soil Classification System classification is matched to a soil reported in Kersten (1948) that is selected as the model soil. The model soil is used to generate the skeleton density (or specific gravity) and porosity. The dry heat capacity is taken from the literature (Bowers and Hanks 1962, for example) and has a value that is fairly constant over all textural classifications because of the basic relatively invariant mineral content of soils (expressed as the Dulong-Petit law, Petit and Dulong 1819). The skeleton density, porosity, transient temperature and soil saturation ratio are used in an algorithm incorporating Johansen's method (Johansen 1975) for calculating the transient frozen and unfrozen soil thermal conductivities.

The above-grade boundary conditions required for BUFETS (ambient air temperature, wind speed, snow depth, and solar radiation and interior temperatures) were extracted from the experimental database and time averaged over the 1-hour time increment used in the simulations. As shown in Figure 57, for interior boundary condition purposes, the wall was divided into four zones, three on the interior vertical surface (with the low zone temperature also used for the slab) and one in the rim-joist cavity. 


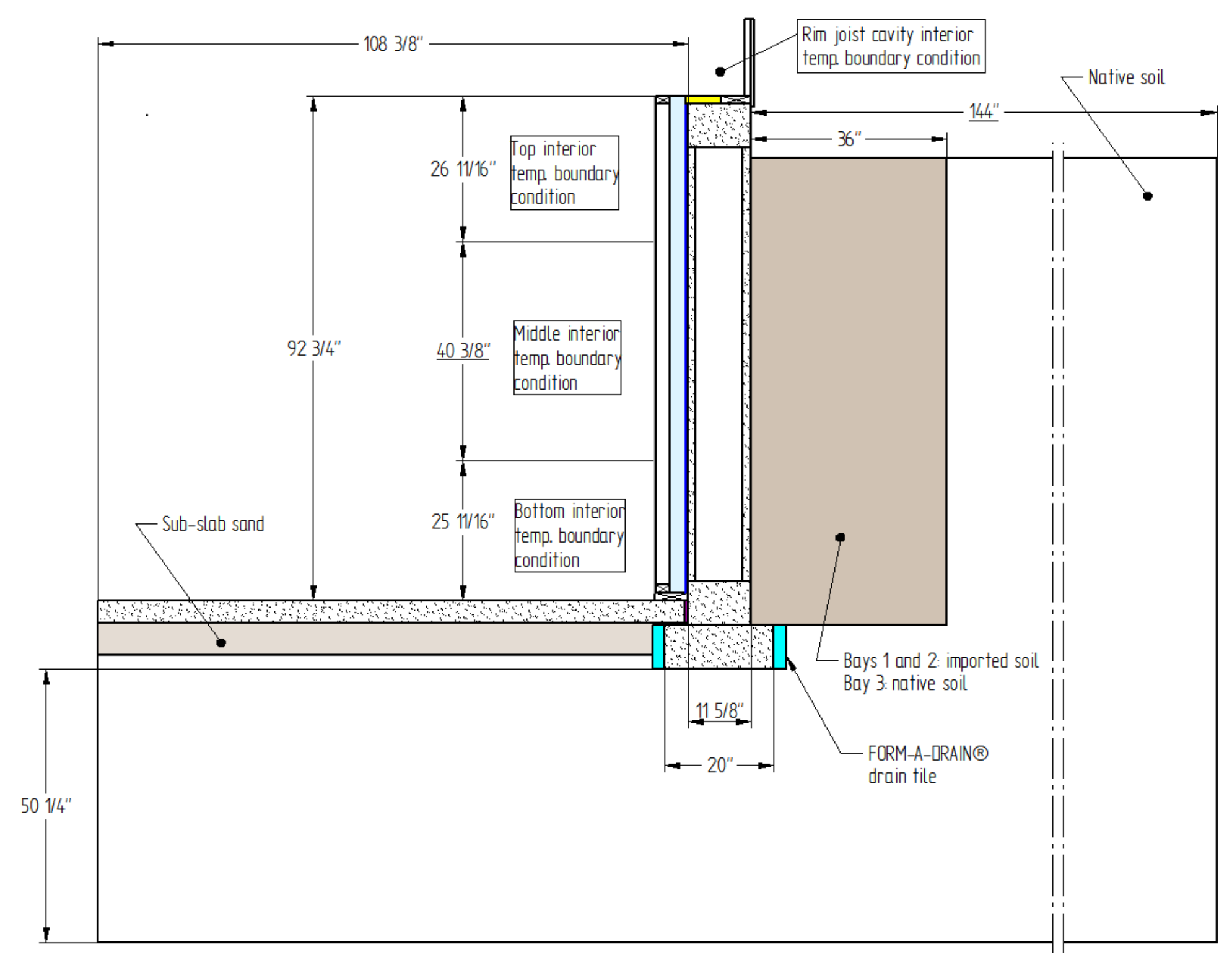

Figure 57. Vertical section through simulation domain 

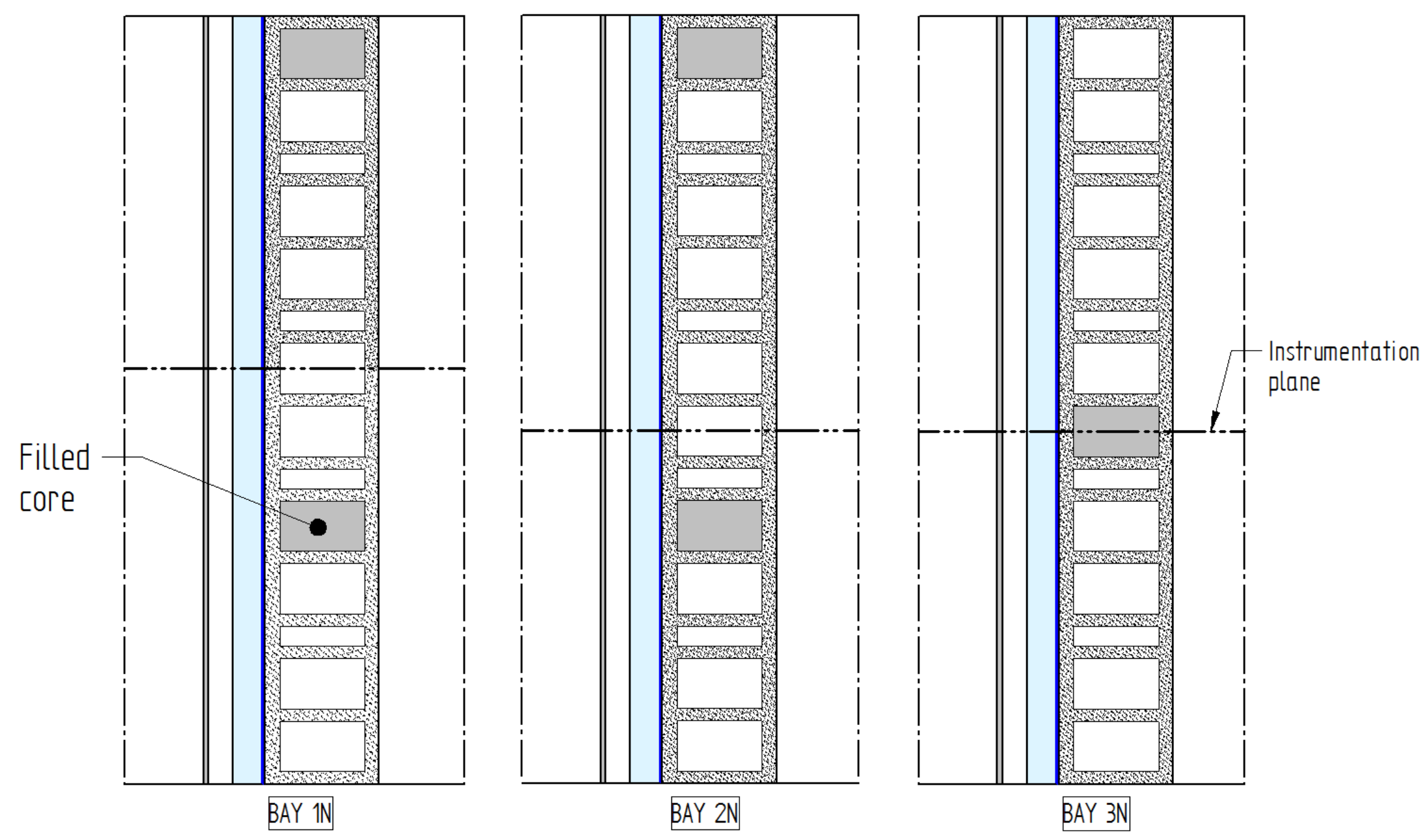

Figure 58. Horizontal section through wall 
The simulation domain bottom boundary condition at the CRRF is problematic because experience has shown (from the operation of the sump pumps) that the heating season water table is lower than the cooling season height (the basement was flooded in June 2012 after a period of heavy rains) and moreover, the summer water table height has increased over the years the CRRF has operated. Well measurements in the vicinity show a near surface water table with cooler average annual temperatures than the traditional deep well temperatures. Thus the 50-1/4 in. sub-slab depth of the water table shown in Figure 57 locates the water table roughly at the height of a marsh about $100 \mathrm{ft}$ from the building. The water table height is assumed to be constant (BUFETS has no capacity to model variable water table heights) and the temperature was assumed to remain constant at $39.5^{\circ} \mathrm{F}$ (EPA 2013), although an annual temperature variation is more than likely (Harmon 2014).

The overall three-dimensional simulation domain is shown in Figure 57 and Figure 58. Bays 1N, $2 \mathrm{~N}$ and $3 \mathrm{~N}$ were modeled separately with the soils appropriate to the specific bay. Each simulation domain was represented by one of the horizontal cross-sections in Figure 58 combined with the vertical cross-section of Figure 57. The BUFETS simulation domain reproduced Figure 57 and Figure 58 exactly, including:

- All the hollow cores

- The relative positions of the hollow and filled cores and the instrumentation plane

- Drain tile air spaces

- Air spaces in the insulation system

- Expansion joints and other small details.

Only the north side bays were modeled, because these were shaded by the building and surrounding trees. BUFETS does not include a soil shading model, so restricting the simulation to the north side of the building where insolation is largely absent (except for an hour or two at sunrise at the height of summer), avoids errors arising from the absence of a shading model.

The cross-sectional view of Figure 57 depicts every element of the construction geometry simulated, including the "Form-A-Drain" drain tile, the thickness of the adhered or nonadhered WSP, air gaps wherever they occur, and the vertical and horizontal expansion joints at the edge of the footing. Particular attention needs to be paid to the bottom of the wall where, for consistency, the second block course above the footing was modeled arbitrarily as being hollow in all the bays. In the experiment, the exact status of this core was indeterminate. In the first sensor installation, the core in the second course above the slab was sufficiently obstructed with grout that an AH sensor could not be inserted into it. The AH sensor was installed into the core of the third course above the footing because its primary function was to measure the core air RH and vapor pressure. For consistency, the bottom core AH sensor was placed in the third course above the slab in all the test bays and the third course proved to be open in all cases. The face shell temperatures were measured one block below the core temperature. In the simulations, the colinear face shell and core temperatures are reported, but only the measured face shell temperatures are shown on that plane, because their non-congruent locations cause the simulated and experimental core temperatures at the base of the wall to be not comparable. 
The horizontal cross-section of Figure 58 shows all the cores in each cross-section and which ones were filled. The locations of the instrumentation planes for each of the three walls modeled, and for which the experiment/simulation comparisons were made, are also depicted. Note that the core fill pattern was based on structural considerations and was not designed specifically to accommodate foundation wall thermal experimentation. The walls were used for foundation experimental work after the fact; the experiments were designed to fit the existing core fill pattern. In this experiment, the Bay $3 \mathrm{~N}$ centerline corresponded to a filled core that was used as comparative control for the other bays in which all the vertical experimental planes were through hollow cores. In this context, the intent was to examine the real case of an isolated filled core adjacent to hollow cores on both sides, not the performance of a masonry block wall with filled cores. The latter case is analogous to a poured concrete wall that has been simulated often before (for example, Shen 1986). Examples of typical mesh discretizations for the simulation domain are given in Figure 59 (corresponding to the plane of Figure 57) and Figure 60 (perpendicular to the horizontal plan of Figure 58).

The experiment/simulation comparison was performed for each of the three north test bays $(1 \mathrm{~N}$, $2 \mathrm{~N}$, and $3 \mathrm{~N}$ ) separately. The comparison for Bays $1 \mathrm{~N}$ and $2 \mathrm{~N}$ with loam and sand crib soils, respectively, and hollow core masonry blocks target the accuracy with respect to soil thermal modeling, because this was the only difference between the bays. The instrumentation plane on Bay $3 \mathrm{~N}$ was placed through a solid core, so it provided a control to evaluate the impact of using a diffusion-only thermal transport representation of a masonry block hollow core in Bays $1 \mathrm{~N}$ and $2 \mathrm{~N}$ that is physically invalid. ${ }^{28}$

High Rayleigh number, high aspect ratio, and transient buoyant cavity flows with nonlinear boundary conditions have a profound impact on the thermal energy transfer through a hollow masonry block wall (Huelman et al. 2013; McBride 2013). Further, the only solution for threedimensional buoyant cavity flow in a high-aspect ratio cavity that could be found in the literature is for steady-state, laminar flow with constant temperature boundary conditions (Gossard et al. 2011). Published solutions for the transient buoyant cavity flows in the masonry block cores tested at the CRRF that are subjected to nonlinear, transient boundary conditions could not be found.

Huelman et al. (2013) investigated the use of experimental data to develop artificial still air equivalent thermal conductivities that yield simulated integrated heating season wall heat transfers that match the experimentally measured values for full basements with hollow masonry block walls. These values of still air conductivity in the masonry block walls were used in the BUFETS simulations here as the best available alternative to a standard temperature-dependent still air thermal conductivity that was determined to be invalid.

In the case of Bays $1 \mathrm{~N}$ and $2 \mathrm{~N}$ for which archival data were gathered from November 10, 2012 onward, the period from November 10 through December 31 was used for soil conditioning, followed by 12 months of comparison data generation. For Bay $3 \mathrm{~N}$, for which archival data commence on January 18, 2013, the period from December 8, 2012 through January 20, 2013 was used for soil conditioning, followed by 12 months of comparison data generation.

\footnotetext{
${ }^{28}$ The instrumentation planes on the south wall test bays all passed through hollow core blocks, so a filled-core control is not possible for the south walls.
} 
Because interior boundary condition data were not available for Bay 3N from December 8, 2012 through January 18, 2013, Bay $2 \mathrm{~N}$ interior data were used for this period that were adequate for soil conditioning purposes.

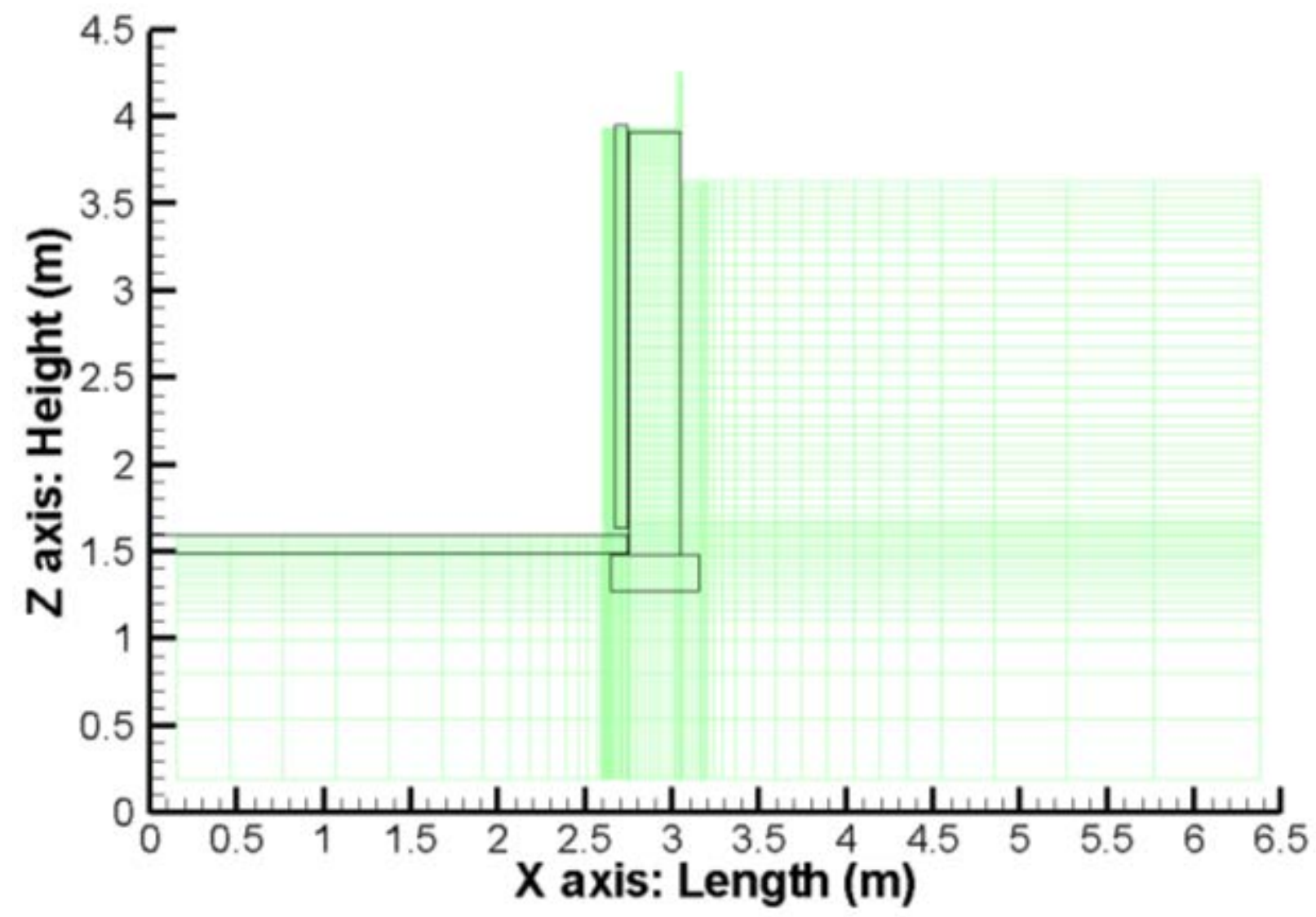

Figure 59. Typical discretization on vertical plan perpendicular to wall

Only the 12 months of comparison data are reported below. In all cases, the soil saturation ratios for the whole domain were established using the experimentally measured volumetric moisture contents prevailing at the commencement of the comparison period. ${ }^{29}$

The experiment/simulation data comparison is expressed in terms of measured temperatures on the outside of the WSP and in terms of the heat fluxes measured on the interior surface of the WSP. The heat flux measurement captures the impact of the diffusion-only heat transfer through the insulation on the interior of the WSP that is not problematic, but is subject to inaccuracy because of incorrectly simulated interior masonry block face shell temperatures. The major problems and inaccuracies with the simulation results were expected on the exterior side of the WSP, so all the following measured temperatures are included in the temperature comparison (with the single exception, as explained above, of the masonry block core temperature at the base of the wall):

\footnotetext{
${ }^{29}$ It would be preferable to use the measured soil moisture contents in the simulation on a transient basis. However, as currently implemented, BUFETS does not have this capability.
} 
- Interior and exterior masonry block face shell

- Masonry block core

- Soil.

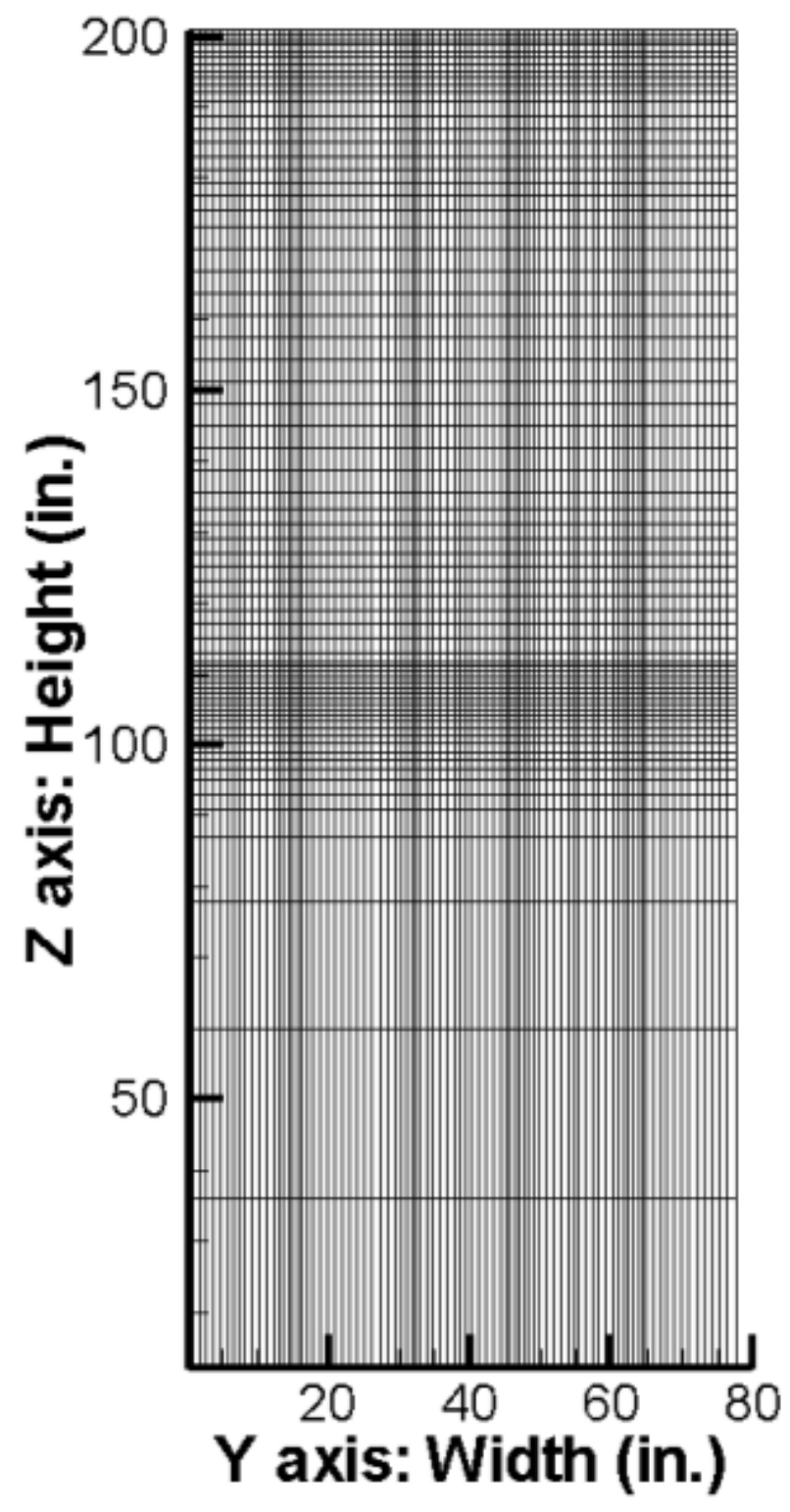

Figure 60. Typical discretization on vertical plane along wall 


\subsubsection{Test Bay 1N Experiment/Simulation Result Comparison}

The baseline comparison was performed for Bay $1 \mathrm{~N}$ because it had a loam soil with higher measured moisture contents compared with those of Bays 2 and 3 with similar sandy soils. The temperature comparison results for Bay 1N are shown in Figure 61 through Figure 66. In Figure 61 through Figure 63, the simulated and experimental wall temperatures for the lower three vertical measurement locations $(5-1 / 2,40-1 / 4$, and $69-1 / 4$ in. above the slab) are shown on the same plot for the interior and exterior face shells and the core together. At $86-1 / 4$ in. above the slab, the interior and exterior face shell and core temperatures are shown in different plots for enhanced legibility.

Beginning with Figure 61, 5-1/2 in. above the slab, a significant mismatch between the measured and simulated temperatures is evident. The essential features of the mismatch are:

- Throughout the year the simulated wall temperatures decreased monotonically across the wall as expected for diffusion-only transport. The experimental interior face shell temperature was always warmer than its exterior counterpart.

- The simulated face shell temperatures were lower than those measured throughout the year. The discrepancy in the magnitudes of the simulated wall temperatures was significantly larger during the cooling season $\left(6^{\circ}-7^{\circ} \mathrm{C}\right)$ than during the heating season (within $2^{\circ} \mathrm{C}$ ). This might arise because during the cooling season, as noted above, the groundwater table beneath the CRRF was higher and warmer than in the heating season; in the simulation, the groundwater table was assumed to be at a constant height and temperature throughout the year.

- At all locations, the measured temperatures were warmer at the end of the comparison period than they were at the beginning, whereas the simulated temperatures were about $1{ }^{\circ} \mathrm{C}$ colder at the end than at the beginning. This also can be attributed to a groundwater table temperature increase during the cooling season that functioned as a heat source. At 40-1/4 in. above the slab in Figure 62, the same effects noted in Figure 61 are present but to a lesser degree. The following observations may be made:

- In both the experiment and the simulation, throughout the year, the temperature profile across the core was mostly monotonic with the core temperature bounded by the face shell temperatures.

- The simulated temperatures were still lower than those measured throughout the year, but the differences were smaller (within $1.5^{\circ} \mathrm{C}$ during the heating season, and within $4^{\circ} \mathrm{C}$ during the cooling season) than at the bottom of the wall (Figure 61). Diffusion-only thermal transport yields a fairly sharp increase in temperature with height above the slab during the cooling season, so the decrease in discrepancy is expected. Further, the impact of a cooling season water table heat source diminishes with height above the footing.

- The experimental temperatures were still higher at the end of the comparison period compared with the beginning and the simulation temperatures still lower, but the difference in both cases was smaller than at the bottom of the wall. 
BAY 1N WALL EXPERIMENTISIMULATION TEMPERATURE COMPARISON BOTTOM: 5.5 in. ABOVE SLAB (HOLLOW MASONRY BLOCK CORE)

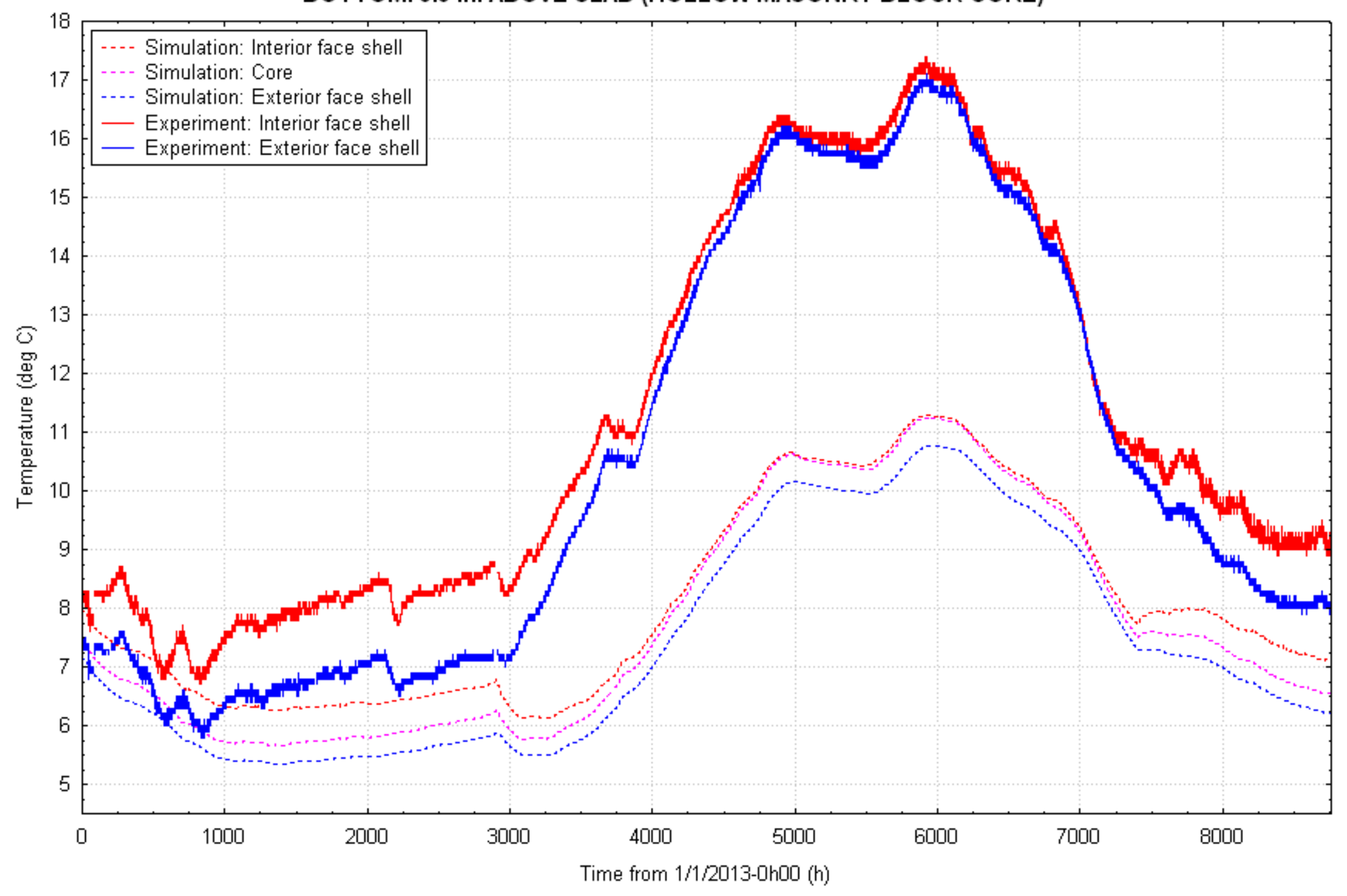

Figure 61. Bay $1 \mathrm{~N}$ wall experiment/BUFETS simulation temperature comparison $5-1 / 2$ in. above the slab 
Compared with the $5-1 / 2$ and $40-1 / 4$ in. levels, at $69-1 / 4$ in. above the slab, Figure 63 shows an even greater degree of convergence between the simulated and experimental data during the cooling season (within $2^{\circ} \mathrm{C}$ ), but a slightly worse convergence during the heating season (as much as $8^{\circ} \mathrm{C}$ ).

- Interestingly, at this level, the experimental wall temperatures were clearly monotonic during the heating season, but the simulated temperature profiles show that the core temperature was occasionally colder than the exterior face shell temperature. During the cooling season, the experimental core temperatures appeared to be marginally higher than the face shell temperatures.

- The magnitudes of the simulated and experimental temperatures still show a notable discrepancy during the heating season (within $8^{\circ} \mathrm{C}$ ), but the discrepancy is much smaller during the cooling season (mostly within $2.5^{\circ} \mathrm{C}$ ). This again is consistent with the increase in wall temperatures with height for diffusion-only thermal transport during the cooling season and an even lower impact of the groundwater table heat source.

- The increase in experimental temperature over the comparison year is still evident, but the difference in the simulated temperatures largely disappeared, which is expected for diffusive thermal flow as grade level is approached (bulk soil thermal heat capacity effects are reduced).

- It may be speculated that, taken together, the coplanar temperature profile experiment/simulation comparisons at $40-1 / 4$ and $69-1 / 4$ in. above the slab offer some evidence of a buoyant cavity flow loop in the hollow masonry block walls during the heating season only (the experimental evidence is discussed in Section 3.1.1). This arises because the measured temperatures are consistently higher than the simulated temperatures, an effect that could be produced by a buoyant cavity flow loop. Harmon (2014) showed that the major cause of the discrepancy between the simulated and experimental wall temperatures in particular (as well as the soil temperatures discussed below) was that the simulated water table height was too low and the depth beneath the footing too great. She also showed that correcting these errors reduced the experiment/simulation wall temperature discrepancy to $3{ }^{\circ} \mathrm{C}$ or less during the heating season. 
BAY 1N WALL EXPERIMENTISIMULATION TEMPERATURE COMPARISON

MID-HEIGHT: 40.25 in. ABOVE SLAB (HOLLOW MASONRY BLOCK CORE)

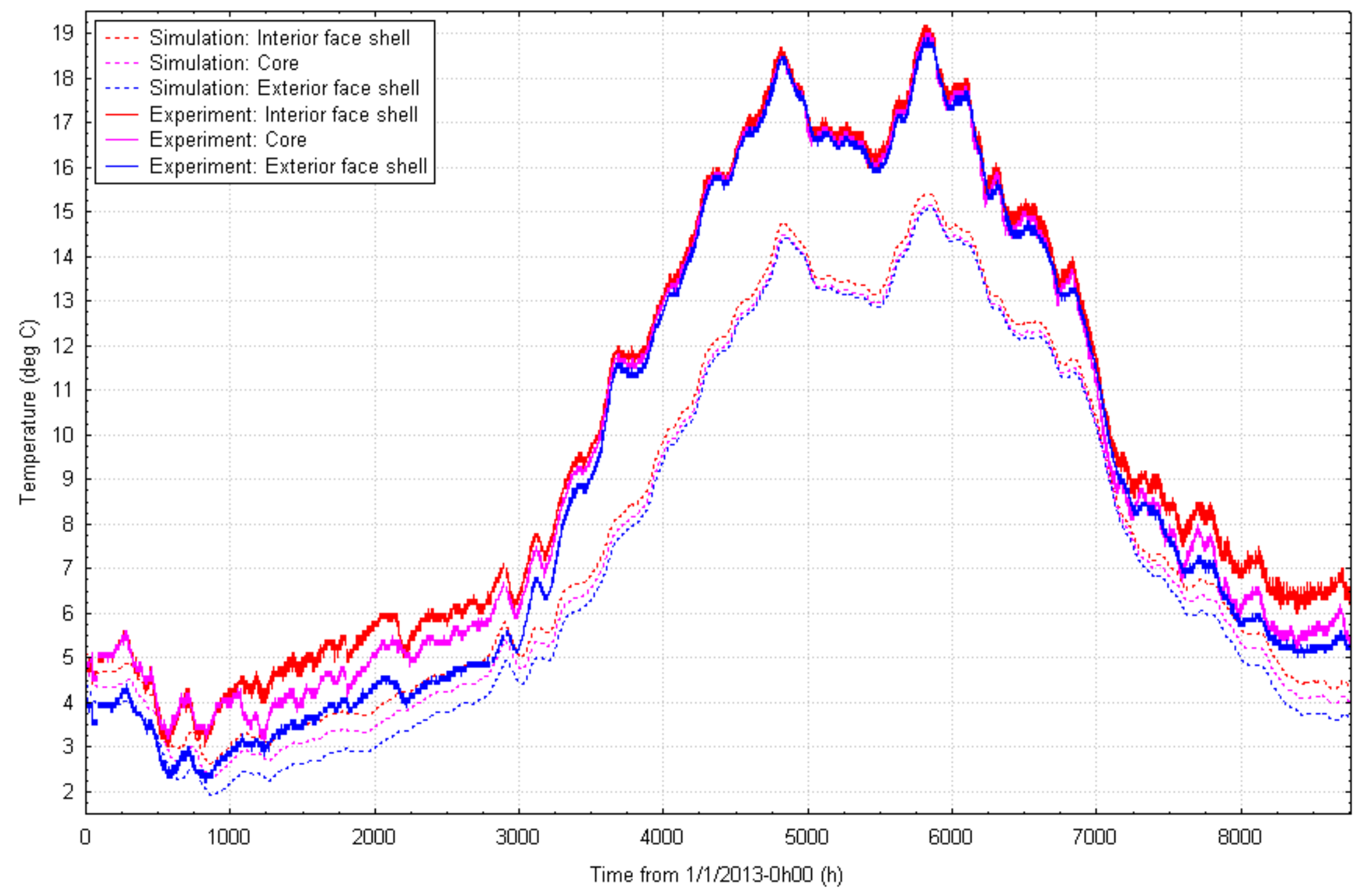

Figure 62. Bay $1 \mathrm{~N}$ wall experiment/BUFETS simulation temperature comparison $40-1 / 4$ in. above the slab 


\section{BAY 1N WALL EXPERIMENTISIMULATION TEMPERATURE COMPARISON}

GRADE-HEIGHT: 69.25 in. ABOVE SLAB (HOLLOW MASONRY BLOCK CORE)

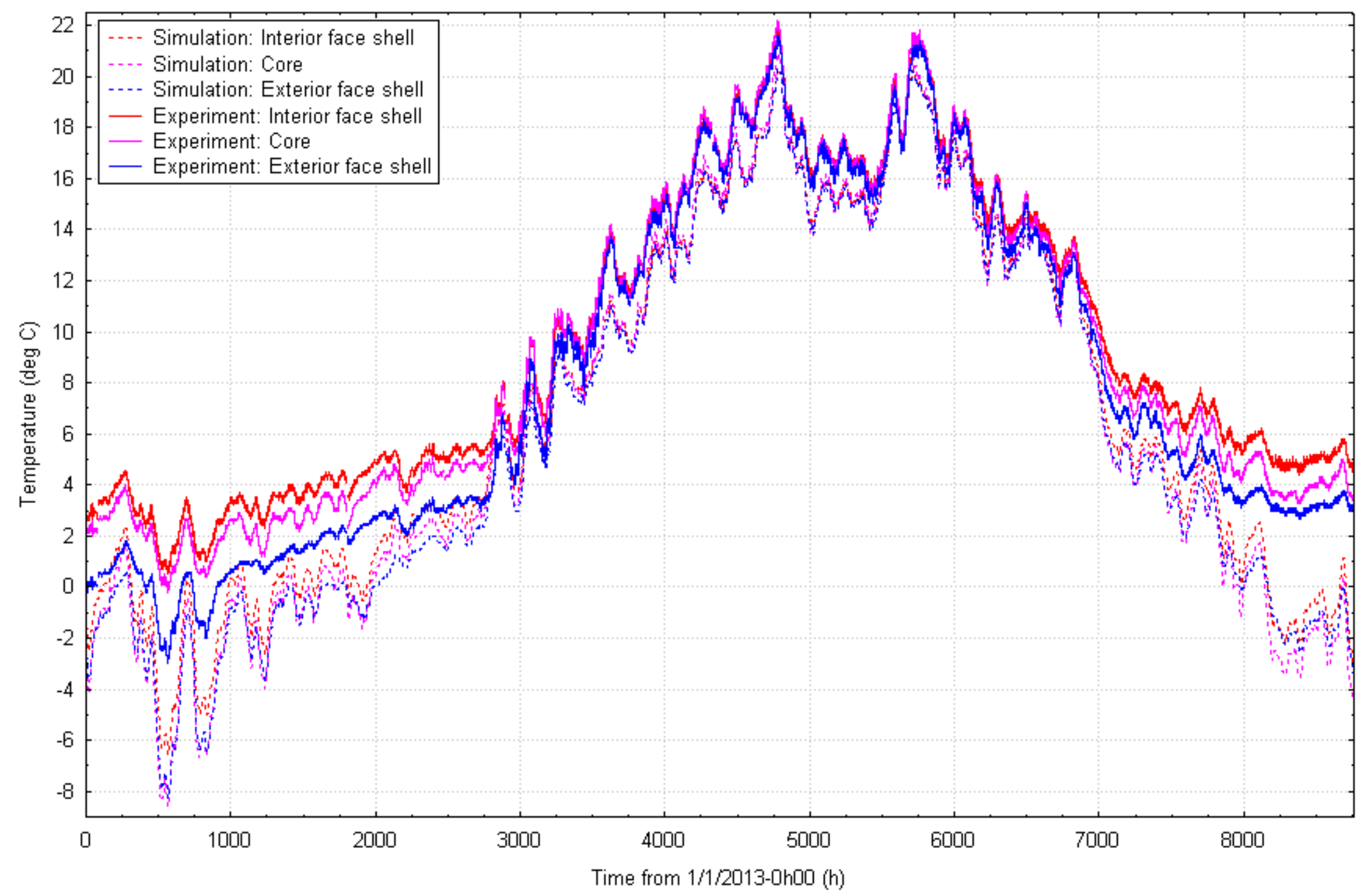

Figure 63. Bay $1 \mathrm{~N}$ wall experiment/BUFETS simulation temperature comparison $69-1 / 4 \mathrm{in}$. above the slab 
At the top of the wall 86- $1 / 4$ in. above the slab in Figure 64, different conditions existed because at this location the wall was solid (a bond beam block). The core temperature was measured in the hollow core block immediately below the bond beam block, so in this case also the face shell and core temperatures were not horizontally colinear. The following observations are pertinent:

- On the interior face shell, the experimental temperatures were still $5^{\circ} \mathrm{C}$ higher than those simulated during the heating season, doubtless because of the vertical conduction up the interior face shell from the consistently warmer face shell over the below-grade height of the wall. During the cooling season, without a cavity flow loop, the simulated and experimental temperatures were within $3^{\circ} \mathrm{C}$ of each other because of the purely diffusive heat flow at the top of the wall.

- Almost the same pattern appeared in the core one block below the bond beam, although the difference between the simulated and experimental temperatures was larger (within $5^{\circ} \mathrm{C}$ ) during the heating season, again demonstrating a cavity flow loop during this period.

- On the above-grade exterior face shell, the simulated and experimental temperatures were within $4^{\circ} \mathrm{C}$ through 8000 hours. The difference after 8000 hours during the 2013-2014 heating season (experimental temperatures were up to $8^{\circ} \mathrm{C}$ higher) is a consequence of the very deep snow that insulated the above-grade foundation wall from the ambient environment. This effect is not modeled in BUFETS, which assumes that the above-grade wall is always exposed to the ambient air temperature.

Taken together, the wall temperature comparison results indicate major discrepancies between the simulated and experimental wall temperatures. The data suggest that this can be attributed to an absence in the simulation of buoyant cavity flow loop modeling in the heating season and an incorrectly modeled water table (Harmon 2014). 


\section{BAY IN WALL EXPERIMENTISIMULATION TEMPERATURE COMPARISON}
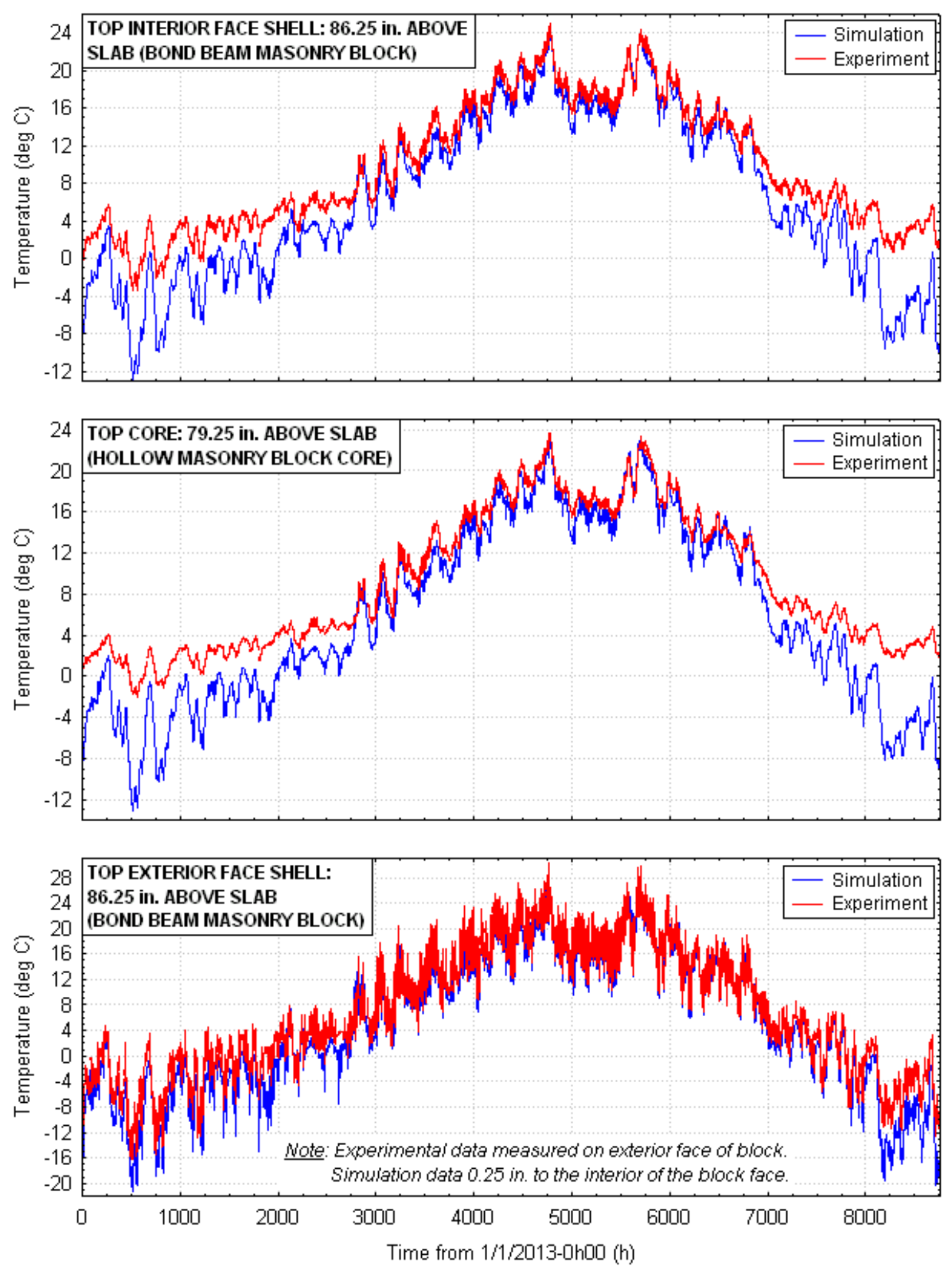

Figure 64. Bay 1N wall experiment/BUFETS simulation temperature comparison $79-1 / 4$ and $86-1 / 4$ in. above the slab 
The discrepancy is inversely proportional to the height above the slab during the cooling season as the thermal impact of a water table heat source diminishes. The discrepancy is much smaller in the heating season, but the discrepancies are largest in the middle of the wall where the impact of a buoyant cavity flow loop would be greatest. Clearly at the midwall locations, the use of an equivalent thermal conductivity for the air cores in the simulation did not effectively reduce the experiment/simulation temperature discrepancies.

The effects of the experiment/simulation discrepancy in the wall temperatures were carried through to the soil, as shown in the vertical soil temperature profiles in Figure 65. At 69-1/4 in. above the slab, the measured temperatures exceeded those simulated by about $3^{\circ} \mathrm{C}$ during the heating season and diminished to about $2^{\circ} \mathrm{C}$ during the cooling season. Progressing down the wall, the heating season discrepancy diminished $\left(3^{\circ} \mathrm{C}\right.$ and $2^{\circ} \mathrm{C}$ at $40-1 / 4$ and $5-1 / 2$ in. above the slab, respectively) and the cooling season discrepancy increased $\left(6^{\circ} \mathrm{C}\right.$ and $9^{\circ} \mathrm{C}$ at $40-1 / 4$ and $5-1 / 2$ in. above the slab, respectively). Comparing Figure 65 to Figure 61 at $5-1 / 2$ in. above the slab demonstrates how the effect of the postulated summer water table heat source (confirmed by Harmon [2014]) diffused through the soil with the peak summer experiment/simulation discrepancy increasing from $6^{\circ} \mathrm{C}$ in the wall to $9^{\circ} \mathrm{C}$ in the soil at 5000 hours. This also points to the simulation possibly

underpredicting the soil thermal conductivity because the assumed fixed soil moisture content was higher during the cooling season (at $5-1 / 2$ in. above the slab the moisture content was measured at $0.20 \mathrm{~V} \%$ on January 15,2013 and at $0.24 \mathrm{~V} \%$ on July 15,2013$)$. The absence of moisture transport modeling in the simulation clearly had measurable impacts on the predicted soil temperature field.

The horizontal soil temperature comparison is shown in Figure 66 at $40-1 / 4$ in. above the slab. The temperature discrepancy $5 \mathrm{in}$. from the wall increases with distance from the wall as expected from diffusion-only transport. The differences between the profiles $18-3 / 4$ and $32-1 / 2$ in. from the wall were very small, indicating that the 36 -in. width of the soil crib was sufficient to encapsulate most of the wall heat transfer effects in the experiment. ${ }^{30}$

This observation provides additional evidence for heat transfer phenomenology other than buoyant cavity flows in the wall cores being active. This phenomeology is not being captured by the simulation because, if this is the only mechanism missing in the simulation, the experiment/simulation discrepancy would be expected to decrease with distance from a wall with R-15 insulation. The following additional mechanism has been proposed:

As discussed above, because of the high water table (as noted, the CRRF basement flooded during the summer of 2012) and higher average ambient temperatures in recent years, it is entirely feasible that the bottom Dirichlet boundary condition used for the simulation (a constant $39^{\circ} \mathrm{F}$ at $50-1 / 4$ in. beneath the footing, see Figure 57) was too deep and too cold and did not include the effect of varying water table depth and temperature. The impact of water table height and temperature can be investigated parametrically using computer simulation in future research. As noted above, Harmon (2014) demonstrated that a major cause of the experiment/simulation temperature discrepancies can be attributed to an incorrectly modeled water table.

\footnotetext{
${ }^{30}$ This is true only for insulated foundation walls where the heat isoflux lines are distorted to be essentially vertical adjacent to the wall. It is not true for uninsulated walls where the isoflux lines are more radial so that the wall heat transfer zone has a width approximately equal to the below-grade depth of the wall.
} 
Finally, the experiment/simulation heat flux comparison on the interior face of the WSP is shown in Figure 67. At the top of the wall where the heat flow is entirely diffusive, there is a fairly small discrepancy $\left(0.5 \mathrm{~W} / \mathrm{m}^{2}\right.$ at most) between the measured and experimental heat fluxes. The simulated heat fluxes were slightly larger after 8000 hours because colder wall temperatures were produced by ignoring the insulating effect of the snow on the wall, as discussed with reference to Figure 64.

Progressing down the wall, at $69-1 / 4$ in. above the slab, the experiment/simulation discrepancy is within $0.8 \mathrm{~W} / \mathrm{m}^{2}$; the biggest effect is observable in the cooling season when the simulated interior face shell temperature is slightly lower than that measured (Figure 63).

At 40 in. above the slab, the discrepancies increase to $1 \mathrm{~W} / \mathrm{m}^{2}$ or more in both the heating and cooling seasons because of the larger differences between the experimental and measured interior face shell temperatures (Figure 62). The experiment/simulation heat flux discrepancies are consistent with the wall temperature discrepancies. 
BAY 1N VERT. SOIL TEMP. PROFILE EXPERIMENT/SIMULATION COMPARISON
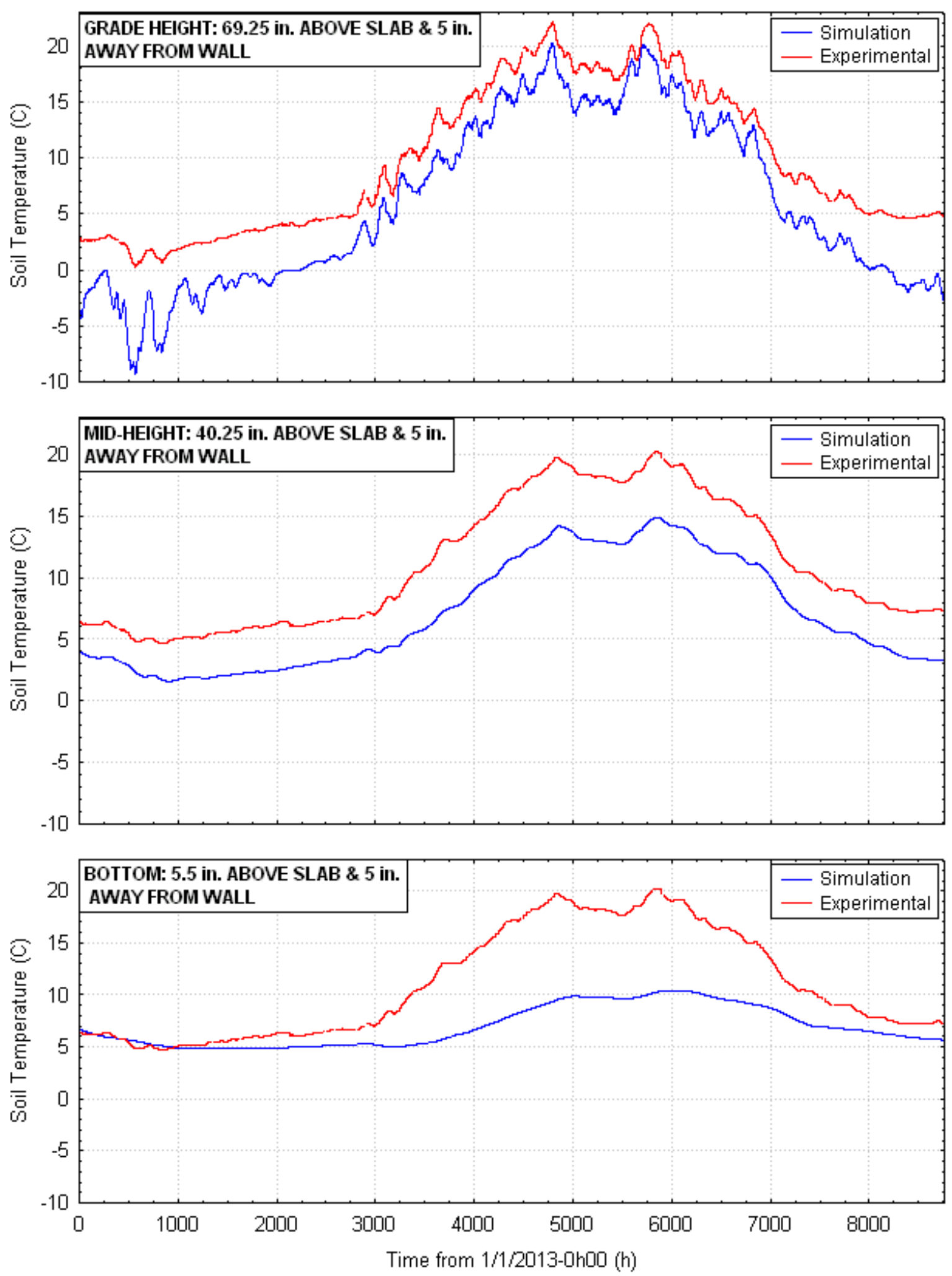

Figure 65. Bay $1 \mathrm{~N}$ soil vertical profile experiment/BUFETS simulation temperature comparison 
BAY 1N HORIZ. SOIL TEMP. PROFILE EXPERIMENTISIMULATION COMPARISON
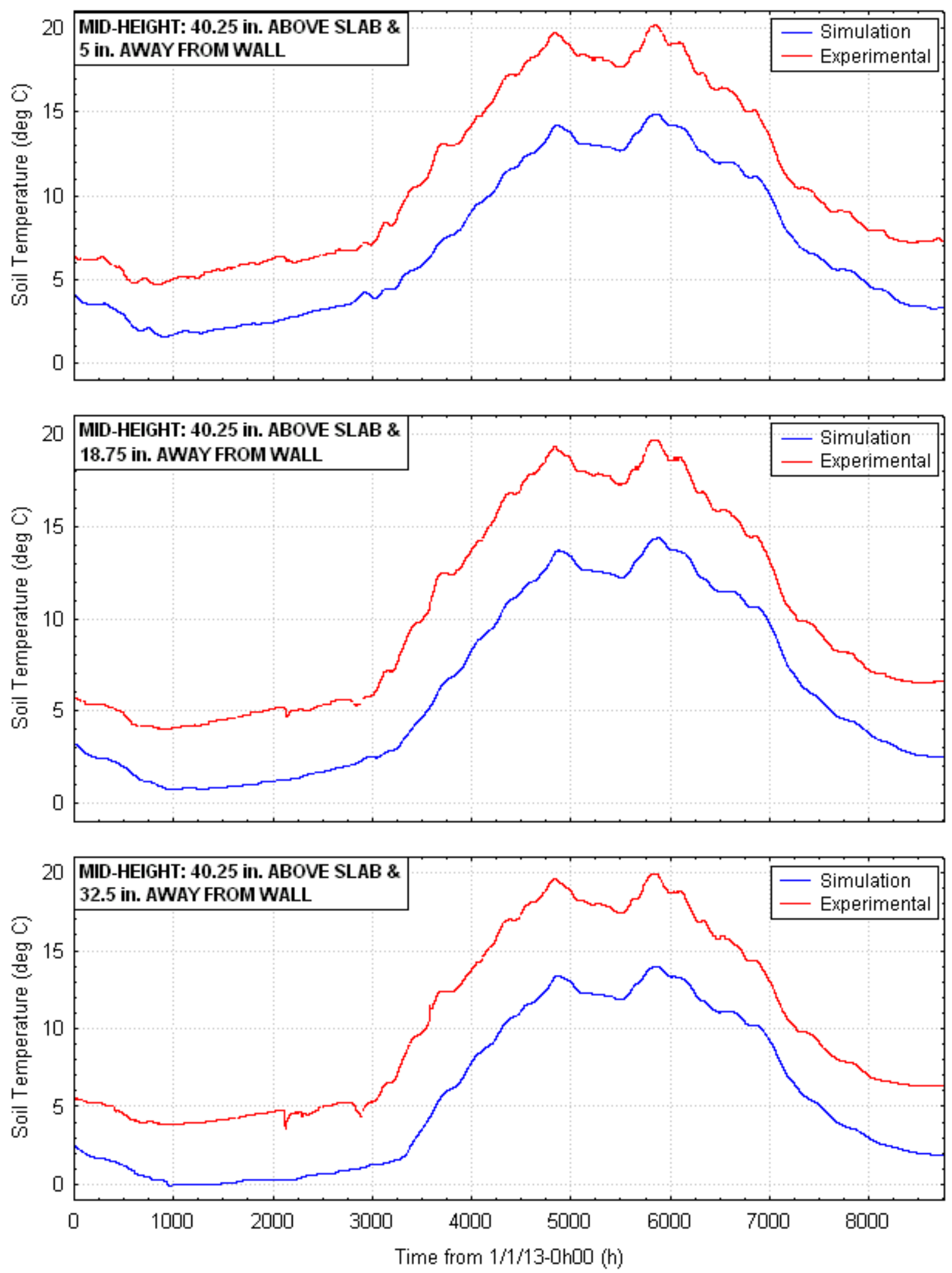

Figure 66. Bay $1 \mathrm{~N}$ soil horizontal profile experiment/BUFETS simulation temperature comparison 


\section{BAY 1N HEAT FLUX EXPERIMENTISIMULATION COMPARISON}
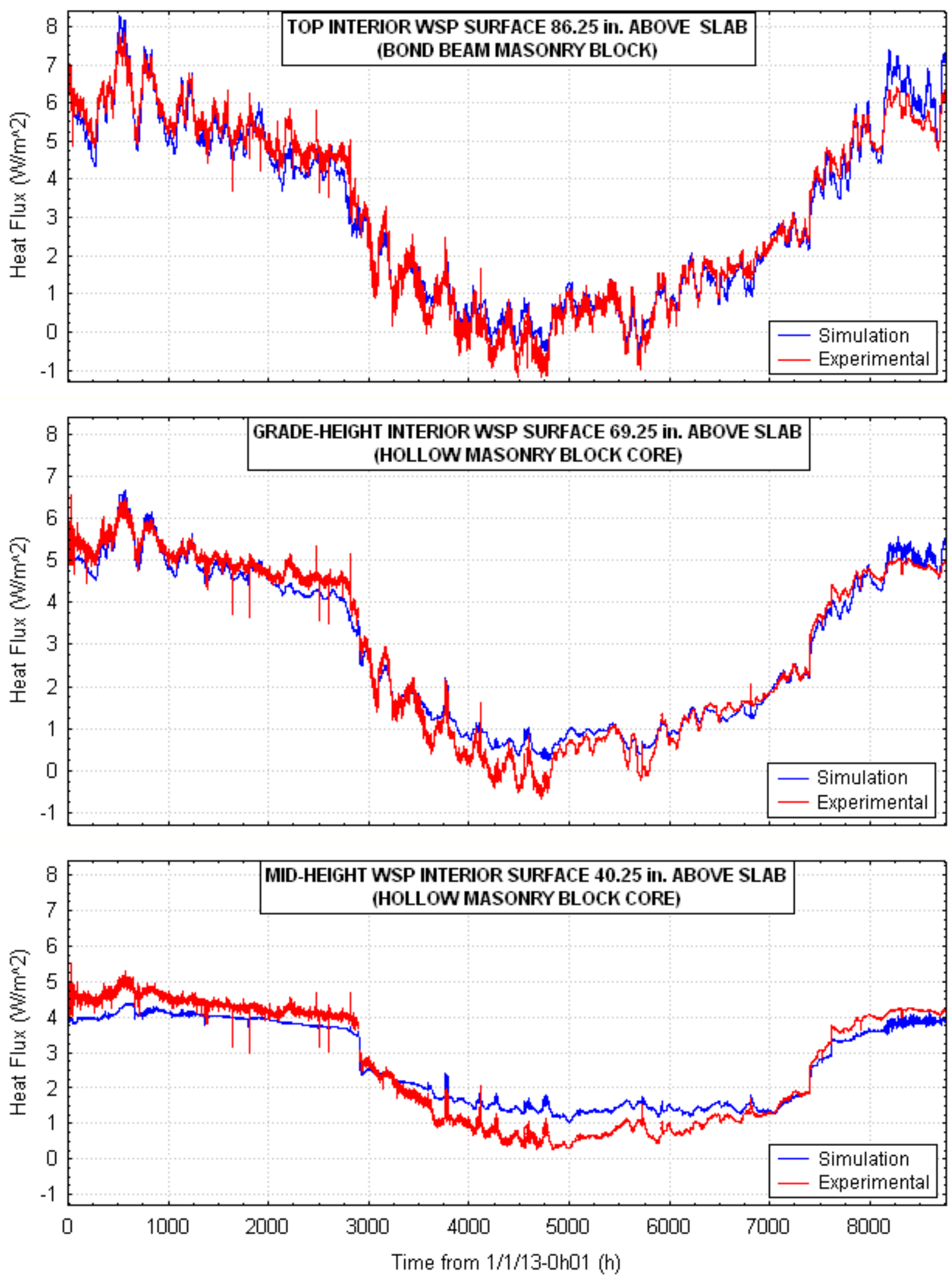

Figure 67. Bay 1N wall experiment/BUFETS simulation heat flux comparison 


\subsubsection{Key Factors Influencing Test Bays $2 \mathrm{~N}$ and $3 \mathrm{~N}$ Experiment/Simulation Comparisons}

The essential phenomenology discussed in some depth for Bay $1 \mathrm{~N}$ also applies to Bays $2 \mathrm{~N}$ and $3 \mathrm{~N}$. So instead of repeating the previous discussion, this section focuses on the impacts of the differences between Bays $1 \mathrm{~N}$ and $2 \mathrm{~N}$ and between Bays $2 \mathrm{~N}$ and $3 \mathrm{~N}$. There were two fundamental differences:

- The loam soil in Bay 1 yielded a much higher soil moisture content profile than in either Bay 2 or Bay 3. Although the soils in Bays 2 and 3 were both classified as sand, the higher silt and clay content of the Bay 3 soil yielded a moisture content higher than Bay 2 but lower than Bay 1 (the native soil was used as the Bay 3 fill; Table 4). The resulting average soil moisture content differences of $17 \%$ for Bays $1 \mathrm{~N}$ and $2 \mathrm{~N}$ and $7 \%$ for Bays $1 \mathrm{~N}$ and $3 \mathrm{~N}$ translate into soil conductivities that increase with moisture content. These thermal conductivities in turn influence the experiment/simulation temperature and heat flux comparisons. Table 5 shows a comparison of the daily average volumetric soil moisture contents in the three north exposure bays simulated in the middle of summer and winter.

Table 5. Soil Volumetric Moisture Content 5 in. From the Wall

\begin{tabular}{|c|c|c|c|c|}
\hline Date & $\begin{array}{l}\text { Test } \\
\text { Bay }\end{array}$ & $\begin{array}{c}5-1 / 2 \text { in. Above } \\
\text { the Slab } \\
(V \%)\end{array}$ & $\begin{array}{c}40-1 / 4 \text { in. Above } \\
\text { the Slab } \\
(\mathrm{V} \%)\end{array}$ & $\begin{array}{c}69-1 / 4 \text { in. Above } \\
\text { the Slab } \\
(V \%)\end{array}$ \\
\hline \multirow{3}{*}{$7 / 15 / 13$} & $1 \mathrm{~N}$ & 28 & 20 & 20 \\
\hline & $2 \mathrm{~N}$ & 6 & 6 & 5 \\
\hline & $3 \mathrm{~N}$ & 19 & 15 & 13 \\
\hline \multirow{3}{*}{$1 / 15 / 14$} & $1 \mathrm{~N}$ & 26 & 17 & 18 \\
\hline & $2 \mathrm{~N}$ & 4 & 4 & 4 \\
\hline & $3 \mathrm{~N}$ & 16 & 13 & 11 \\
\hline
\end{tabular}

The moisture content data confirm that the almost pure sand adjacent to Bay $2 \mathrm{~N}$ yielded significantly lower soil moisture contents than either Bay $1 \mathrm{~N}$ or $3 \mathrm{~N}$. However, notably, the relatively small aggregate silt and clay content excess of the native (Bay 3) soil compared with the Bay 2 sand of $6.2 \%$ yielded a substantial increase in soil moisture content (at least a factor of 2). Table 6 shows a comparison of the calculated unfrozen soil conductivities on July 15, 2013 and January 15, 2014 using Johansen's method (Table 4, Johansen 1975).

The skeleton thermal conductivity of the sand in Bay 2 of $7.44 \mathrm{~W} / \mathrm{m} . \mathrm{K}$ was much higher than that of the loam in Bay 1 of $2.58 \mathrm{~W} / \mathrm{m} . \mathrm{K}$ (a factor of 2.9). The higher skeleton volumetric ratio of 0.629 in Bay 2 also was higher than that for Bay 1 with a value of 0.478 (a factor of 1.3). For Bay 1, these two factors combined to offset the much higher moisture content of Bay $1 \mathrm{~N}$ relative to Bay $2 \mathrm{~N}$ (a factor of 4) yielding a lower soil thermal conductivity in Bay1N compared with Bay $2 \mathrm{~N}$. Comparing Bays $2 \mathrm{~N}$ and $3 \mathrm{~N}$ with similar soils, the higher moisture content of Bay $3 \mathrm{~N}$ relative to Bay $2 \mathrm{~N}$ (a factor of 2.8 ) yielded a higher thermal conductivity in Bay $3 \mathrm{~N}$. This is contrary to the experimental evidence (see Section 3.1.2, which suggests Bay 1 had the highest thermal conductivity as might be expected from the largest soil moisture contents being measured there). 
Table 6. Average Calculated Vertical Profile Soil Thermal Conductivity

\begin{tabular}{c|c|c|c|c}
\hline \multirow{2}{*}{ Date } & $\begin{array}{c}\text { Test } \\
\text { Bay }\end{array}$ & $\begin{array}{c}\text { Wet Thermal } \\
\text { Conductivity } \\
\text { (W/m.K) }\end{array}$ & $\begin{array}{c}\text { Dry Thermal } \\
\text { Conductivity } \\
(\mathbf{W} / \mathbf{m} . \mathbf{K})\end{array}$ & $\begin{array}{c}\text { Moist/Dry Soil } \\
\text { Thermal } \\
\text { Conductivity Ratio }\end{array}$ \\
\hline \multirow{3}{*}{$\mathbf{7 1 5 / 1 3}$} & 1N & 0.786 & 0.119 & 6.6 \\
& 2N & 1.365 & 0.279 & 4.9 \\
\hline \multirow{2}{*}{$\mathbf{1 5 / 1 4}$} & 3N & 1.446 & 0.233 & 6.2 \\
& 1N & 0.741 & 0.120 & 6.2 \\
& 2N & 1.132 & 0.276 & 4.1 \\
\hline
\end{tabular}

- The instrumentation plane in Bay $3 \mathrm{~N}$ passed through a filled core while that in Bays $1 \mathrm{~N}$ and $2 \mathrm{~N}$ passed through a hollow core.

These differences are relevant to understanding the differences in the experiment/simulation discrepancies between Bays $1 \mathrm{~N}$ and $2 \mathrm{~N}$ and Bays $2 \mathrm{~N}$ and $3 \mathrm{~N}$.

\subsubsection{Comparison of Bay $1 \mathrm{~N}$ and $2 \mathrm{~N}$ Experiment/Simulation Discrepancies}

At the base of the wall 5-1/2 in. above the slab, the temperatures are reported in Figure 61 and Figure 68 for Bays $1 \mathrm{~N}$ and 2N, respectively. The results are similar in both cases. The difference between the face shell temperatures was smaller in Bay $2 \mathrm{~N}$ before 3000 and after 7000 hours. The difference between the simulation and experimental temperatures was greater in Bay $2 \mathrm{~N}$ than in Bay $1 \mathrm{~N}$ because the erroneous simulated higher soil conductivity in Bay $2 \mathrm{~N}$ better transported heat away from the footing in the heating season and down from the grade surface during the cooling season.

The same trends are evident in a comparison of Figure 62 and Figure 69, 40-1/4 in. above the slab. Generally the magnitude of the simulated temperatures was the same while the measured experimental temperatures were higher in Bay $2 \mathrm{~N}$.

Figure 69 shows that the measured wall temperatures were essentially uniform across the wall during the cooling season; Figure 62 reveals an interior to exterior gradient. This again may be ascribed to a warmer exterior face shell in Bay $2 \mathrm{~N}$ (by about $1^{\circ} \mathrm{C}$ ) as a result of greater conduction from the warm grade surface (evidence in this case for the accuracy of the calculated thermal conductivity). Alternatively, the difference may be ascribed to a systematic effect whereby the experimental data are measured at single points and the simulated data are strictly spatial averages over discrete volumes.

The trend continues in Figure 63 and Figure 70, 69-1/4 in. above the slab. The simulated temperatures were very similar for Bays $1 \mathrm{~N}$ and $2 \mathrm{~N}$, while the measured temperatures were about $2^{\circ} \mathrm{C}$ warmer in Bay $2 \mathrm{~N}$. The experiment/simulation discrepancy is roughly larger by the same amount in Bay $2 \mathrm{~N}$.

The top of the wall $86-1 / 4$ in. above the slab shows little difference between the experiment/simulation discrepancies in Figure 64 and Figure 71 for Bays 1N and 2N, respectively. In this case, the magnitude of the temperature profiles is similar as expected, because the face shell temperatures were measured above grade and thus the soil thermal conductivity difference had a lesser impact. 


\section{BAY 2N WALL EXPERIMENTISIMULATION TEMPERATURE COMPARISON}

BOTTOM: 5.5 in. ABOVE SLAB (HOLLOW MASONRY BLOCK CORE)

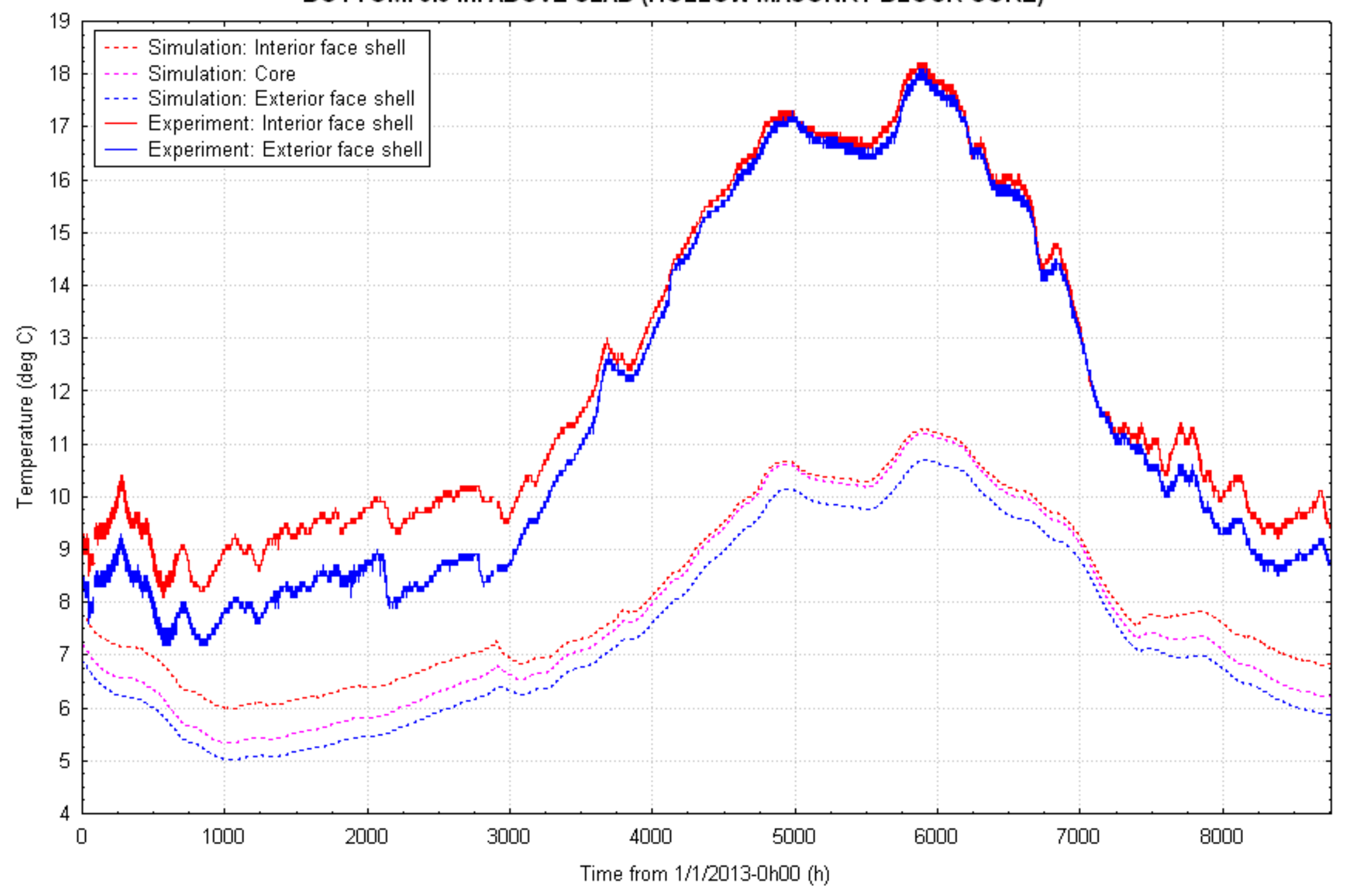

Figure 68. Bay $2 \mathrm{~N}$ wall experiment/BUFETS simulation temperature comparison $5-1 / 2$ in. above the slab 
BAY 2N WALL EXPERIMENTISIMULATION TEMPERATURE COMPARISON

MID-HEIGHT: 40.25 in. ABOVE SLAB (HOLLOW MASONRY BLOCK CORE)

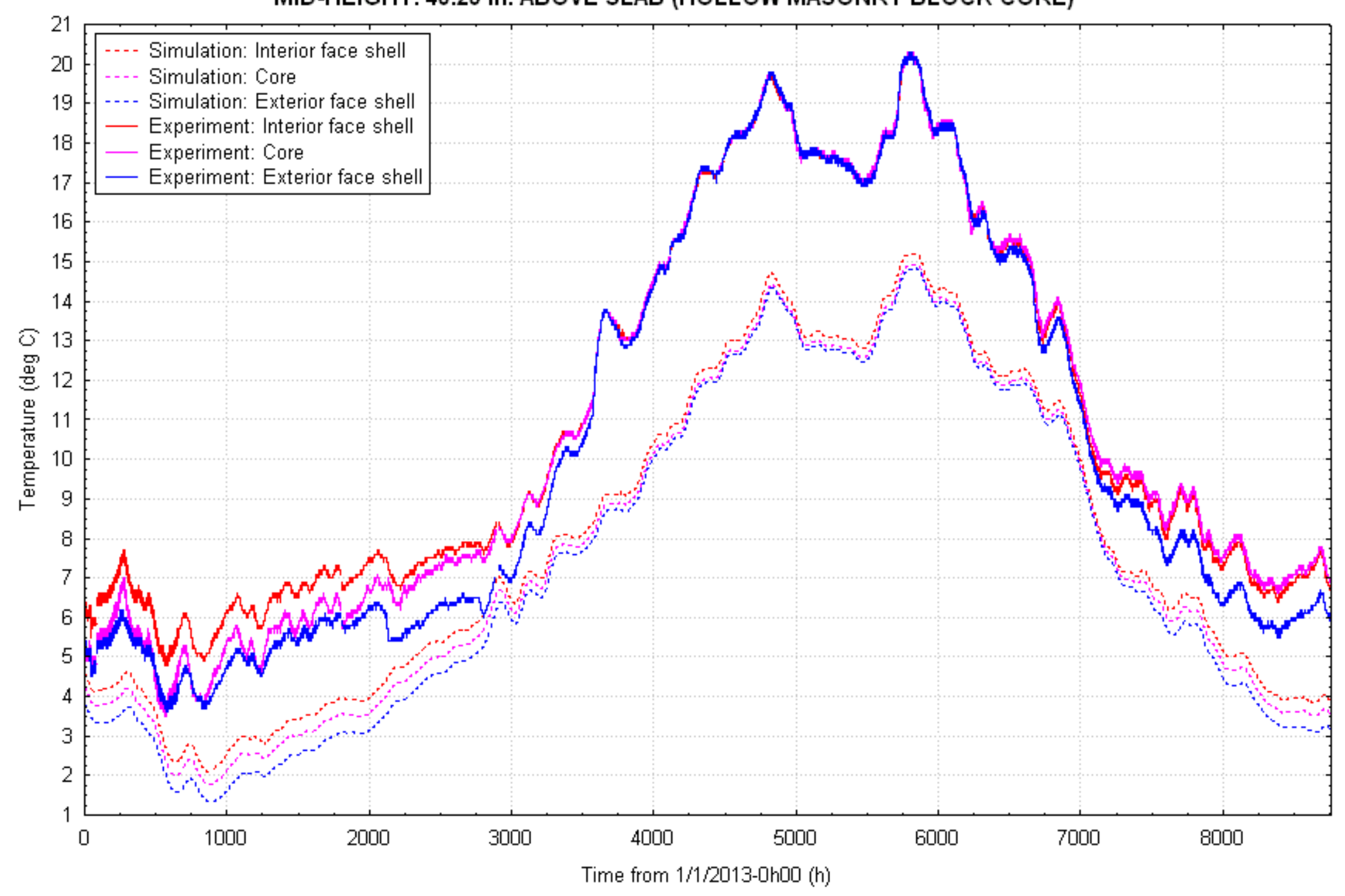

Figure 69. Bay $2 \mathrm{~N}$ wall experiment/BUFETS simulation temperature comparison $40-1 / 4 \mathrm{in}$. above the slab 
BAY 2N WALL EXPERIMENTISIMULATION TEMPERATURE COMPARISON GRADE-HEIGHT: 69.25 in. ABOVE SLAB (HOLLOW MASONRY BLOCK CORE)

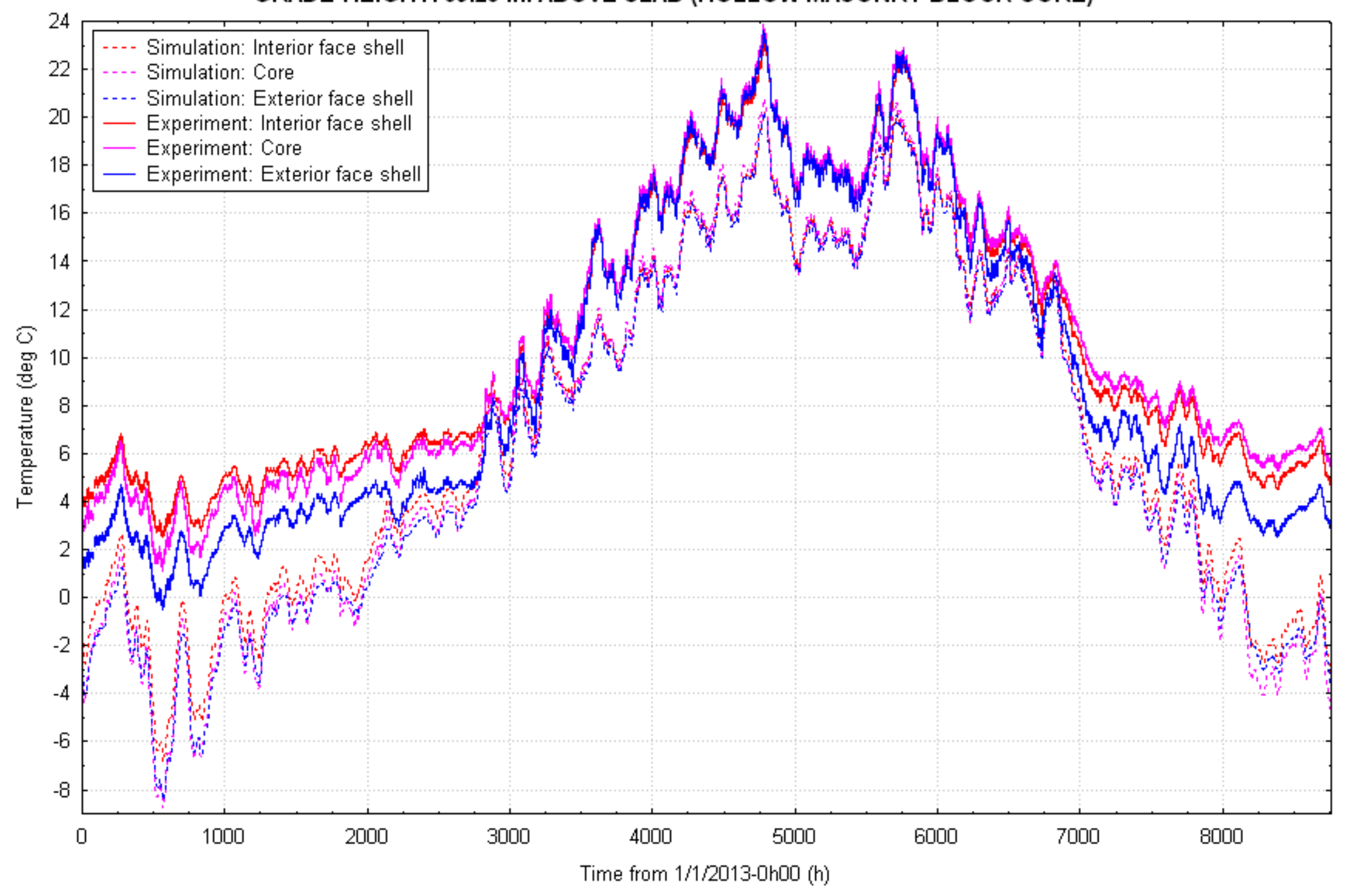

Figure 70. Bay $2 \mathrm{~N}$ wall experiment/BUFETS simulation temperature comparison $69-1 / 4 \mathrm{in}$. above the slab 
BAY 2N WALL EXPERIMENTISIMULATION TEMPERATURE COMPARISON
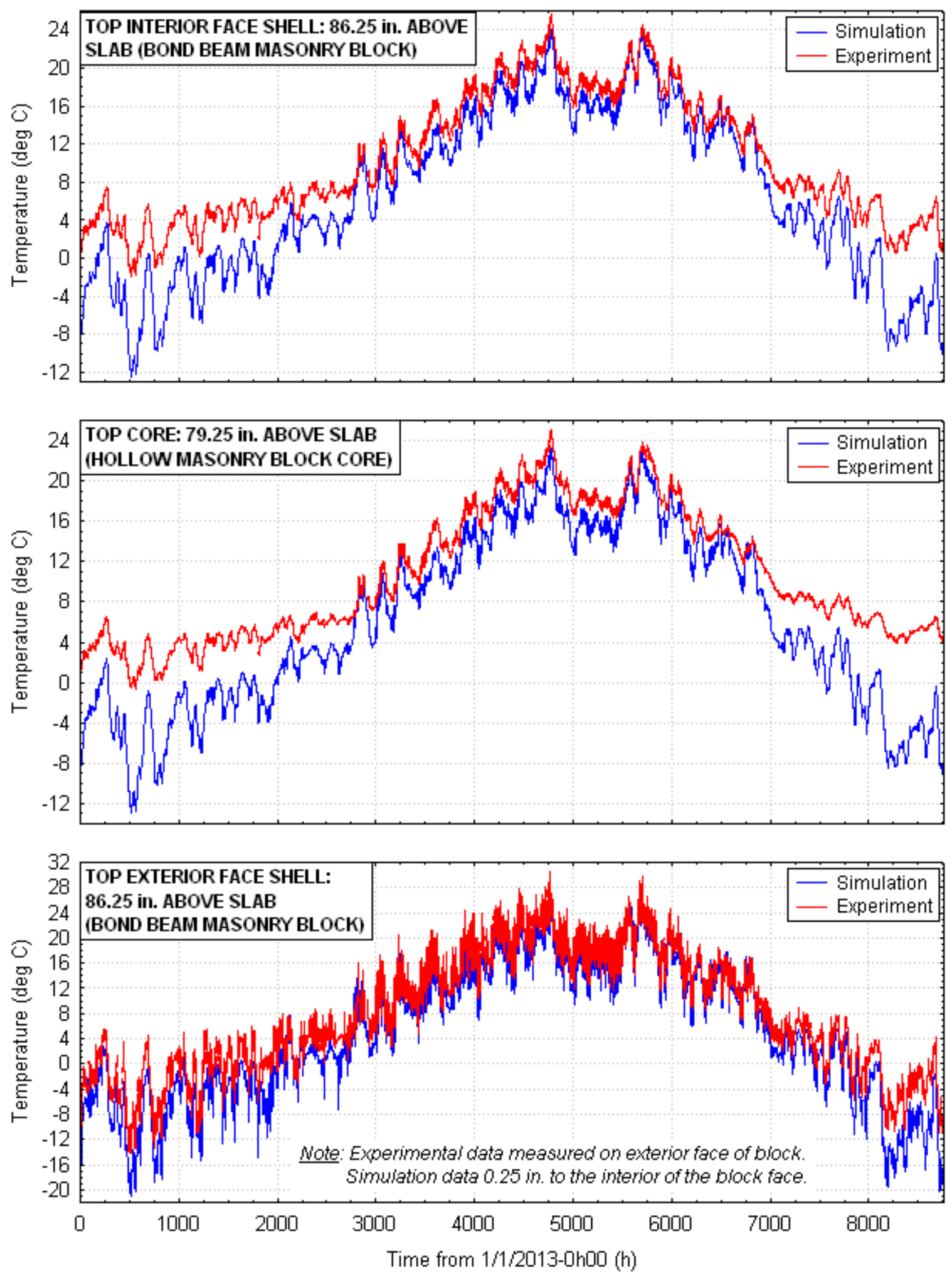

Figure 71. Bay 2N wall experiment/BUFETS simulation temperature comparison $79-1 / 4$ and $86-1 / 4$ in. above the slab 
The effect of the thermal conductivity can still be seen for the core temperature comparisons $79-1 / 4$ in. above grade that were measured just below the grade line, in that the measured Bay $2 \mathrm{~N}$ core temperature (Figure 71) was slightly higher than that of Bay 1N (Figure 64).

There is very little difference between the Bay $1 \mathrm{~N}$ and $2 \mathrm{~N}$ soil vertical temperature profile discrepancies in Figure 65 and Figure 72, respectively. The figures show some differences; for example, a slightly smaller temperature discrepancy at $5-1 / 2$ in. above the slab for Bay $1 \mathrm{~N}$ prior to 1000 hours. In this case, the soil conductivity difference appears to have had almost no influence on the measured and simulated temperatures.

A difference is visible in the horizontal soil temperature profiles in Figure 66 and Figure 73 for Bays $1 \mathrm{~N}$ and $2 \mathrm{~N}$, respectively. In particular, the discrepancies at 2800 and 7000 hours (during the swing seasons) are smaller for Bay $2 \mathrm{~N}$. The magnitudes of the peak measured temperatures during the cooling season were larger for Bay $2 \mathrm{~N}$ by about $2^{\circ}-3^{\circ} \mathrm{C}$, showing the effect of the increased calculated soil thermal conductivity. No increase is shown in the corresponding simulated temperatures. However, the effect may be attributable to different simulation and experimental surface heat transfer coefficients, a possibility that also can be examined parametrically using simulation in future research.

The heat flux profiles for Bays 1N and 2N shown in Figure 67 and Figure 74 show the same pattern of experiment/simulation discrepancy with increased discrepancy magnitudes in Bay $2 \mathrm{~N}$. At the top of the wall $(86-1 / 4$ in. above the slab) the discrepancies between Bays $1 \mathrm{~N}$ and $2 \mathrm{~N}$ are comparable, perhaps with a slightly larger simulated heat flux during the cooling season caused by a slightly colder simulated interior face shell temperature for Bay $2 \mathrm{~N}$ (Figure 71). At grade height (69-1/4 in. above the slab), again the shapes of the heat flux profiles for Bays $1 \mathrm{~N}$ and $2 \mathrm{~N}$ are similar and the experiment/simulation discrepancy is larger for Bay $2 \mathrm{~N}$ because of a larger difference between the measured and simulated interior face shell temperatures for Bay $2 \mathrm{~N}$ than for Bay $1 \mathrm{~N}$ (Figure 70 and Figure 63, respectively). At the midwall location (40-1/4 in. above the slab), Figure 67 and Figure 74 again show congruent profile shapes, but the magnitude of the experiment/simulation discrepancy is somewhat different. From Figure 62 and Figure 69 the experiment/simulation interior face shell temperature difference is larger for Bay $2 \mathrm{~N}$ than for Bay $1 \mathrm{~N}$ so that the simulated heat flux in Figure 74 is greater relative to the measured heat flux in Bay $2 \mathrm{~N}$ than in Bay $1 \mathrm{~N}$. This yields better agreement between the experimental and measured heat flux profiles during the heating seasons ( $\sim$ before 3000 and after $\sim 7300$ hours) and a bigger discrepancy during the cooling season. 
BAY 2N VERT. SOIL TEMP. PROFILE EXPERIMENTISIMULATION COMPARISON
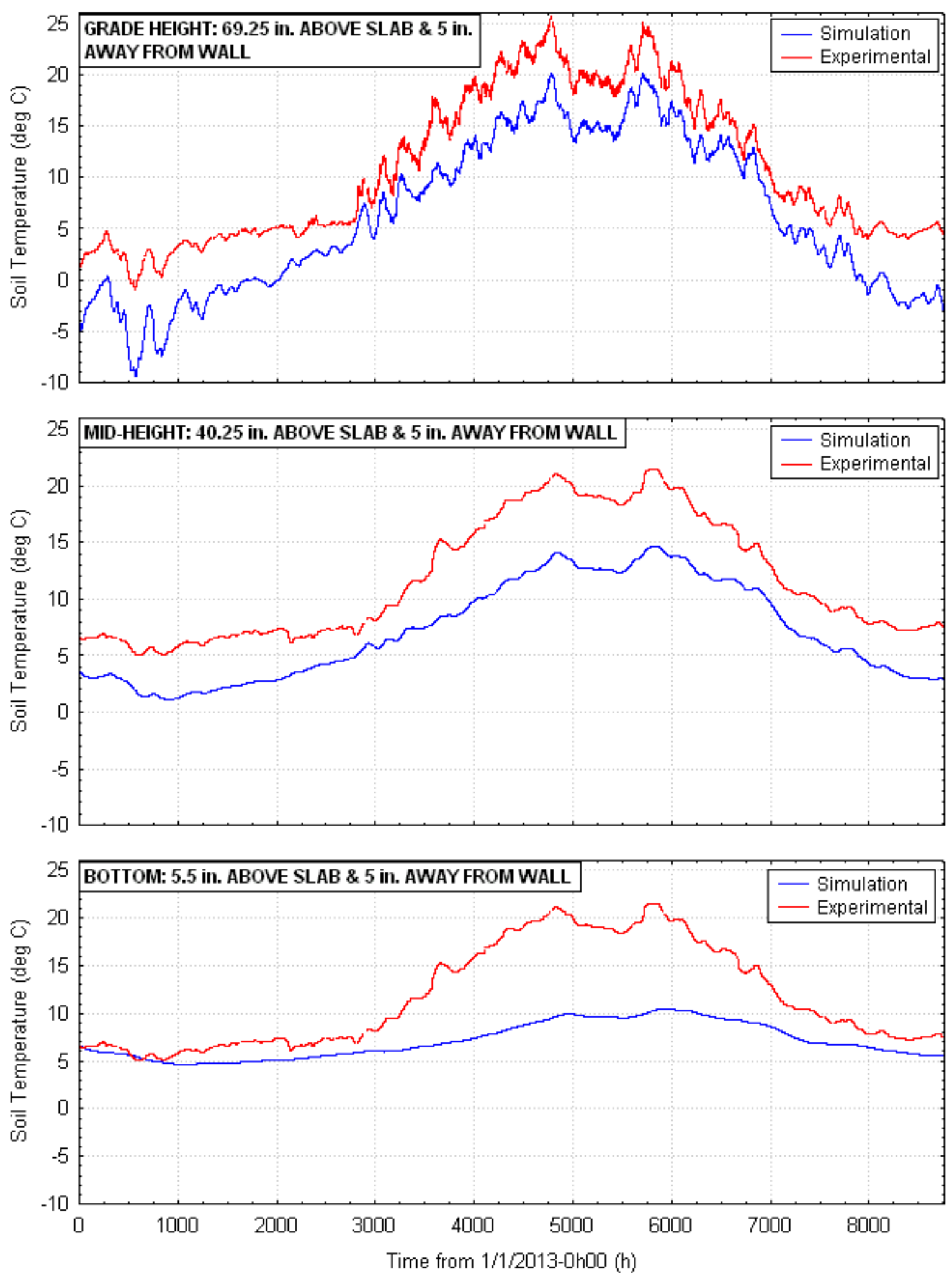

Figure 72. Bay $2 \mathrm{~N}$ soil vertical profile experiment/BUFETS simulation temperature comparison 
BAY 2N HORIZ. SOIL TEMP. PROFILE EXPERIMENTISIMULATION COMPARISON
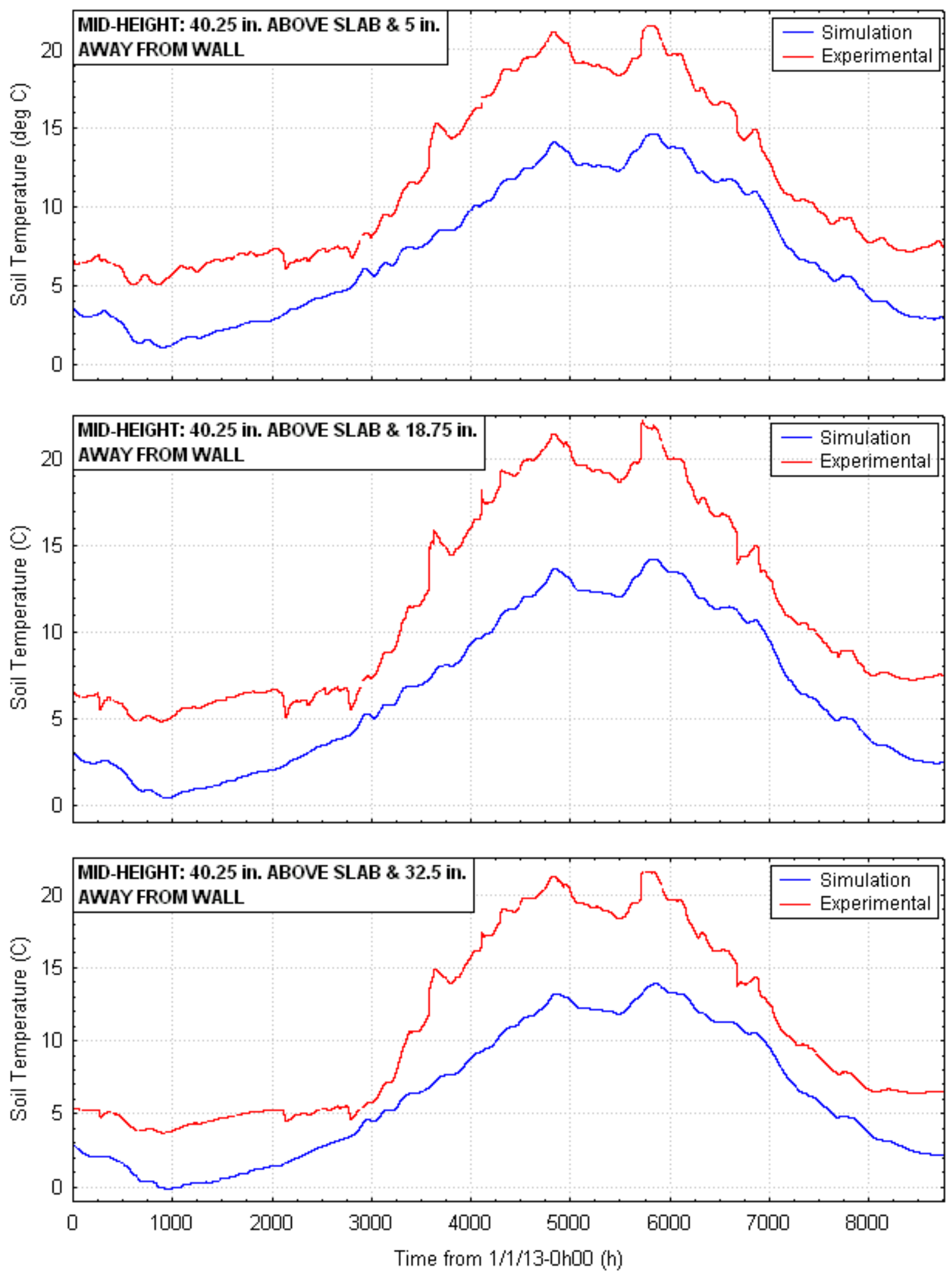

Figure 73. Bay $2 \mathrm{~N}$ soil horizontal profile experiment/BUFETS simulation temperature comparison 


\section{BAY 2N HEAT FLUX EXPERIMENT/SIMULATION COMPARISON}
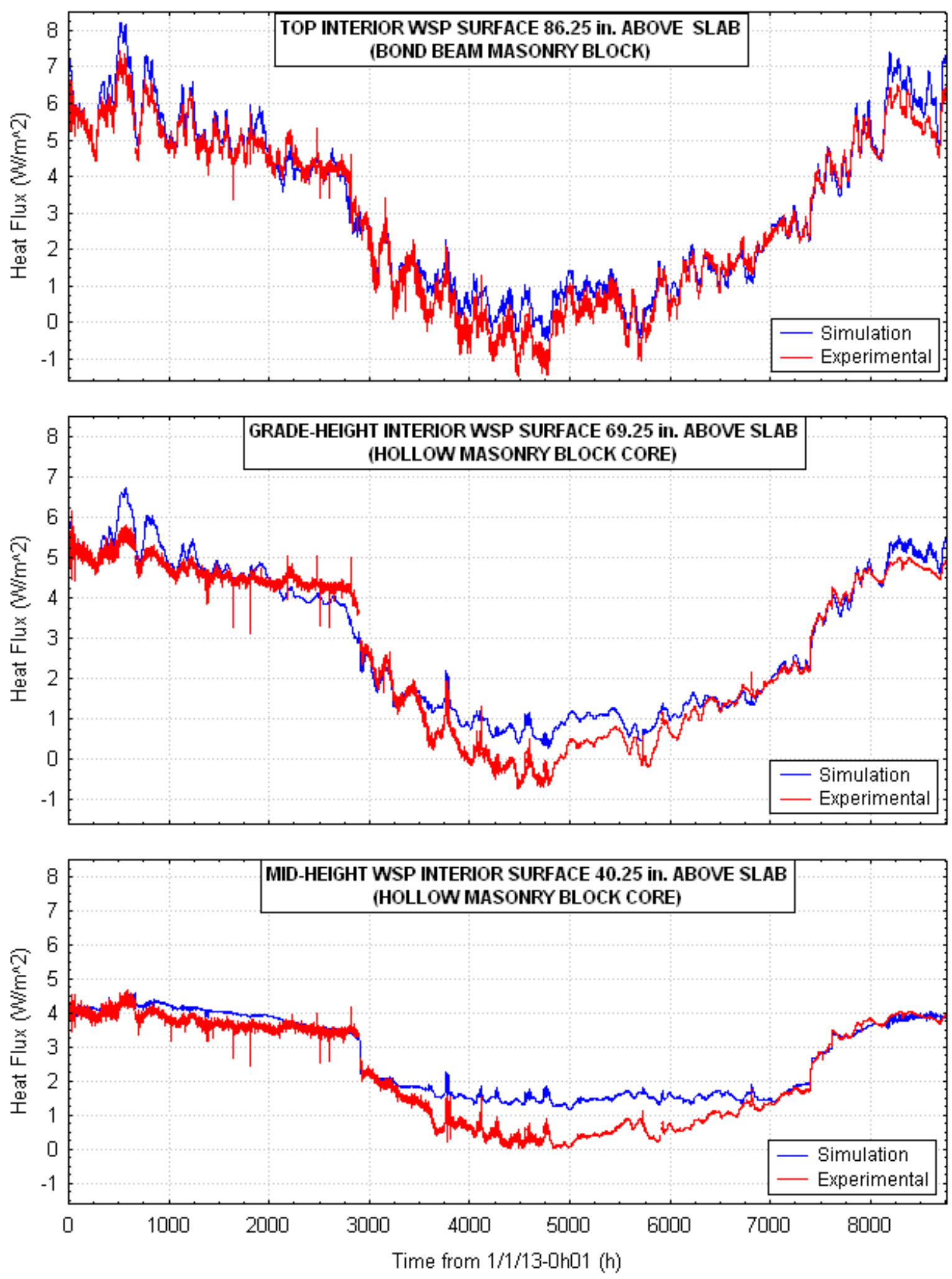

Figure 74. Bay $2 \mathrm{~N}$ wall experiment/BUFETS simulation heat flux comparison 


\subsubsection{Comparison of Bay $2 \mathrm{~N}$ and $3 \mathrm{~N}$ Experiment/Simulation Discrepancies}

The key difference between Bay $2 \mathrm{~N}$ and Bay $3 \mathrm{~N}$ was that the instrumentation plane in Bay $2 \mathrm{~N}$ passed through a hollow masonry block core while the Bay $3 \mathrm{~N}$ instrumentation plane passed through a solid core (Figure 58). The calculated soil thermal conductivity difference of $6 \%$ on July 15,2013 and $13 \%$ on January 15, 2014 were significantly smaller between Bay $2 \mathrm{~N}$ and $3 \mathrm{~N}$ than the $42 \%$ and 35\% differences on July 15, 2013 and January 15, 2014, respectively, between Bay $2 \mathrm{~N}$ and Bay $1 \mathrm{~N}$.

The experiment/simulation temperature comparison at 5-1/2 in. above the slab is shown in Figure 68 and Figure 75 for Bays $2 \mathrm{~N}$ and $3 \mathrm{~N}$, respectively. The core temperature was not measured directly between the face shell temperatures in Bay $3 \mathrm{~N}$ (it was measured in a hollow core adjacent to the solid core, see Figure 58), so the core temperature profiles are omitted from the Bay $3 \mathrm{~N}$ temperature graphs. In Figure 75, the exterior masonry block face shell temperature sensor was installed at the end of May 2013, so the recorded temperatures are available only from that date onward. The temperature spike in the interior face shell profile in Figure 75 that resulted from the exterior soil being excavated to install the soil and wall exterior sensors is apparent. After the soil was backfilled, the continuity of the interior face shell temperature was maintained even after the excavated soil pile was mixed and exposed to ambient temperature conditions for at least 24 hours. This effect is observable in all the Bay $3 \mathrm{~N}$ temperature plots and so will not be noted again. Further, the Bay 2N plots begin on January 1, 2013 and the Bay $3 \mathrm{~N}$ plots begin on January 21, 2013.

After about 6600 hours, Figure 68 reveals a smaller temperature difference across the hollow core than is evident for the temperature difference across the solid core in Figure 75, which is another indicator of a convective flow loop in the Bay $2 \mathrm{~N}$ wall during the heating season. During the cooling season, the peak measured face shell temperature magnitudes were larger by $1^{\circ}-1.5^{\circ} \mathrm{C}$ in Bay $2 \mathrm{~N}$ than in Bay $3 \mathrm{~N}$. Otherwise the measured face shell temperature profiles were similar between the two bays. The simulated temperature profiles reflect the higher thermal conductivity for solid concrete core in Bay $3 \mathrm{~N}$ compared with the effective air conductivity used for the air core in Bay $2 \mathrm{~N}$. 


\section{BAY 3N WALL EXPERIMENTISIMULATION TEMPERATURE COMPARISON}

BOTTOM: 5.5 in. ABOVE SLAB (FILLED MASONRY BLOCK CORE)

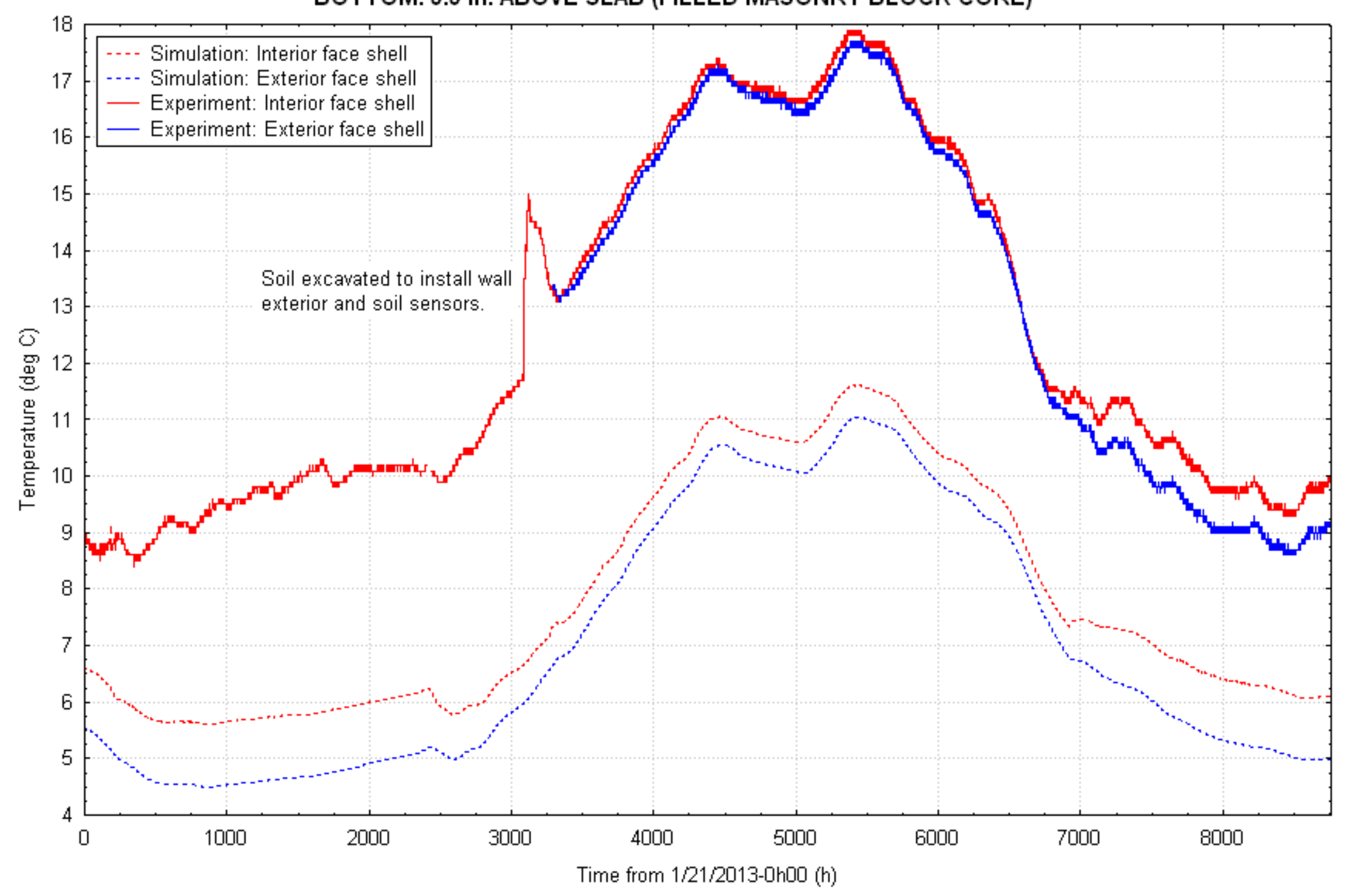

Figure 75. Bay $3 \mathrm{~N}$ wall experiment/BUFETS simulation temperature comparison $5-1 / 2$ in. above the slab 
This yielded higher Bay $2 \mathrm{~N}$ simulated temperatures in the heating seasons and lower simulated temperatures during the cooling seasons. However, the experiment/simulation discrepancies are not significantly reduced in Figure 75, as might be expected if the temperature field were twodimensional and the convective loop were eliminated. The three-dimensional nature of the heat flow in the wall with relatively high masonry thermal conductivity $(\sim 1.4 \mathrm{~W} / \mathrm{m} . \mathrm{K})$ has significant consequences. It ensures that the higher temperatures in the hollow cores adjacent to the solid core in Bay $3 \mathrm{~N}$ putatively produced by the convective loops have a noticeable impact on the solid core temperature profiles.

At $40-1 / 4$ in. above the slab, Figure 69 and Figure 76 for Bays $2 \mathrm{~N}$ and $3 \mathrm{~N}$, respectively, both show reduced experiment/simulation temperature profile discrepancies during the cooling season and increased discrepancies during the heating seasons. So again, elimination of the core convective loops in Bay $3 \mathrm{~N}$ does not reduce the discrepancy overall because of three-dimensional diffusion effects through the solid parts of the masonry blocks.

At grade level (69-1/4 in. above the slab), Figure 70 and Figure 77 show the same discrepancy trends observed before with a lower difference between the simulated and experimental temperatures during the cooling season. The temperatures overall are about $2^{\circ} \mathrm{C}$ warmer in Bay $2 \mathrm{~N}$ compared with Bay $3 \mathrm{~N}$ for the simulated and measured temperatures. These may be ascribed to the additional thermal resistance provided by the gap between the nonadhered WSP and the wall. This is mostly a diffusion thermal transport phenomenon, so the simulation replicated the measured impact of the WSP air gap fairly well.

At the top of the wall at the bond beam block, Figure 71 and Figure 78 for Bays $2 \mathrm{~N}$ and $3 \mathrm{~N}$, respectively (the core temperature plot is omitted in Figure 78), show no appreciable differences between the bays because the wall configuration was the same. The experiment/simulation discrepancies also are visually similar; for example, a maximum experiment/simulation discrepancy of $10^{\circ} \mathrm{C}$ at 500 hours for Bays $2 \mathrm{~N}$ and $3 \mathrm{~N}$.

In terms of the soil vertical temperature profile comparison ${ }^{31}$ for Bays $2 \mathrm{~N}$ and $3 \mathrm{~N}$ shown in Figure 72 and Figure 79, respectively, the experiment/simulation temperature discrepancy generally is reduced in Bay $3 \mathrm{~N}$ at all vertical heights. This is doubtless a result of the simulation more accurately modeling the solid core in Bay $3 \mathrm{~N}$ than the hollow core in Bay $2 \mathrm{~N}$. However, the discrepancies still are not eliminated because of three-dimensional effects from the surrounding hollow cores in Bay $3 \mathrm{~N}$.

The heat flux comparisons shown in Figure 74 and Figure 80 for Bay $2 \mathrm{~N}$ and 3N, respectively, reveal lower experiment/simulation discrepancies in general in Bay $3 \mathrm{~N}$, again as expected with diffusive thermal transport in the instrumentation plane masonry block cores in both the simulation and the experiment.

\subsubsection{Summary}

The experiment/simulation comparison demonstrates that the experimental data are effective for evaluating the accuracy of thermal transport foundation simulation programs. The experimental data also provide insight into the possible physical mechanisms underlying discrepancies between the simulation and experimental results.

\footnotetext{
${ }^{31}$ Note there was no horizontal soil temperature plane measurement in Bay $3 \mathrm{~N}$, so the horizontal soil temperature comparison is omitted.
} 
BAY 3N WALL EXPERIMENTISIMULATION TEMPERATURE COMPARISON

MID-HEIGHT: 40.25 in. ABOVE SLAB (FILLED MASONRY BLOCK CORE)

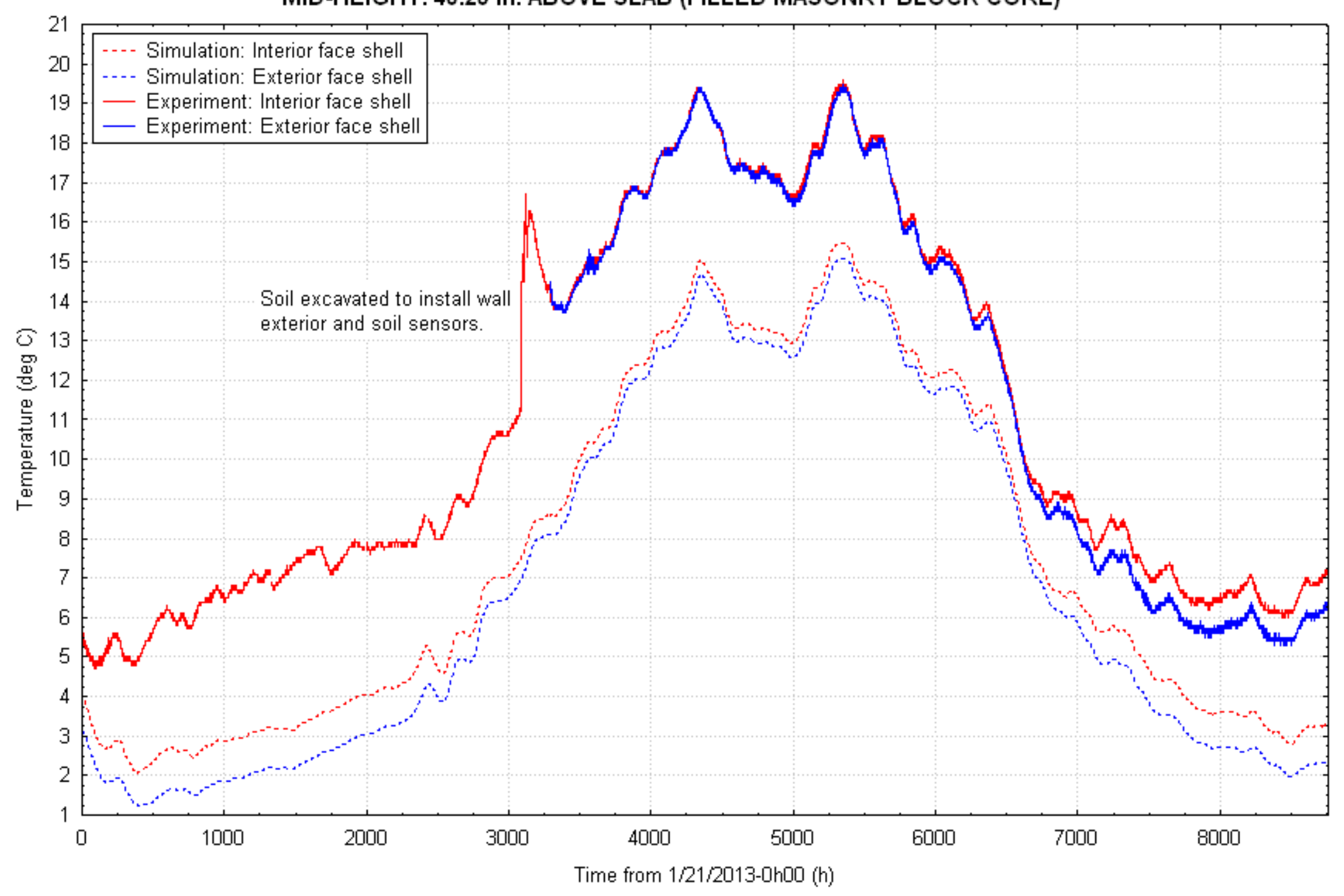

Figure 76. Bay $3 \mathrm{~N}$ wall experiment/BUFETS simulation temperature comparison $40-1 / 4 \mathrm{in}$. above the slab 


\section{BAY 3N WALL EXPERIMENTISIMULATION TEMPERATURE COMPARISON}

GRADE-HEIGHT: 69.25 in. ABOVE SLAB (FILLED MASONRY BLOCK CORE)

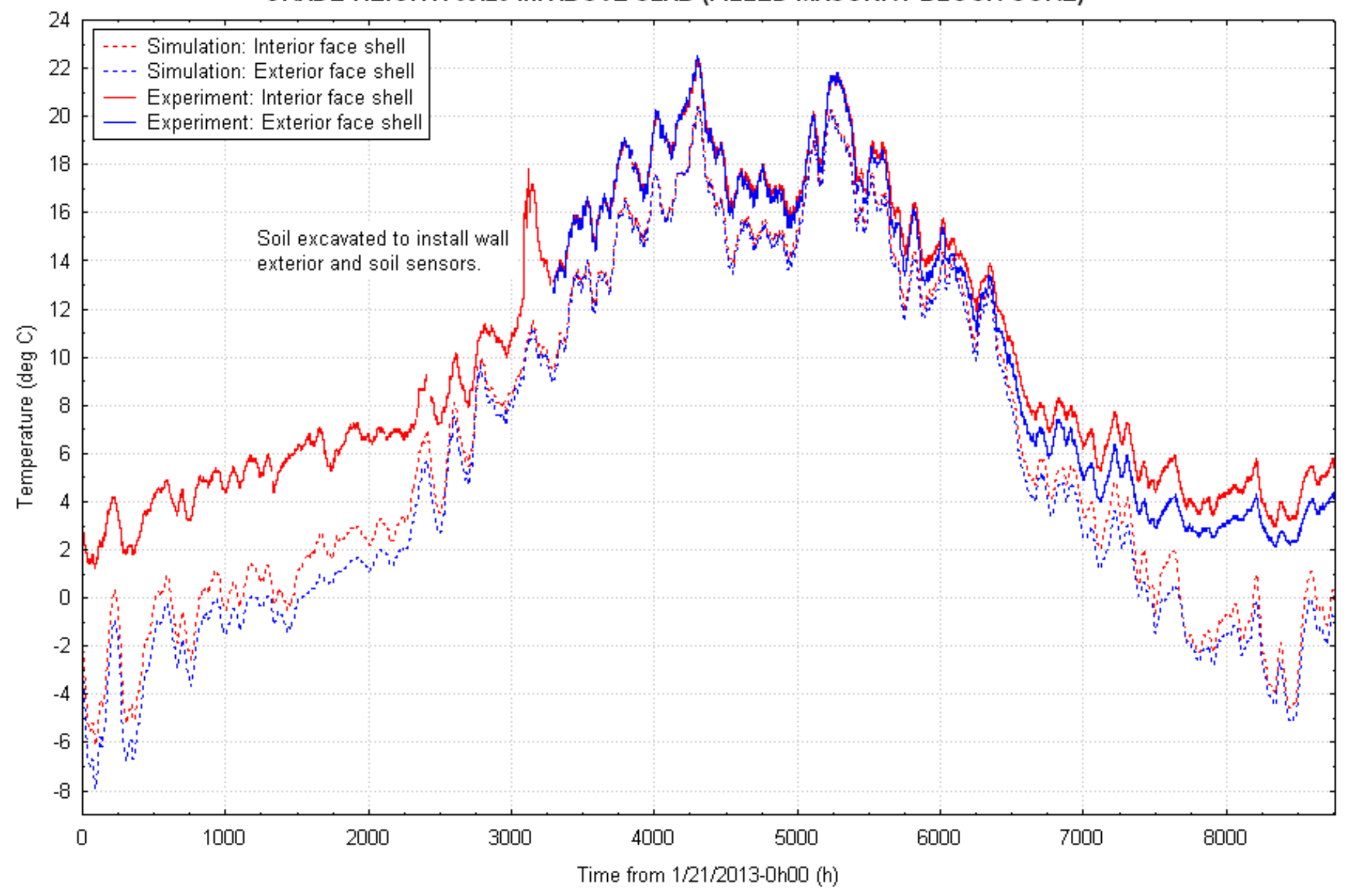

Figure 77. Bay $3 \mathrm{~N}$ wall experiment/BUFETS simulation temperature comparison $69-1 / 4 \mathrm{in}$. above the slab 
BAY 3N WALL EXPERIMENTISIMULATION TEMPERATURE COMPARISON
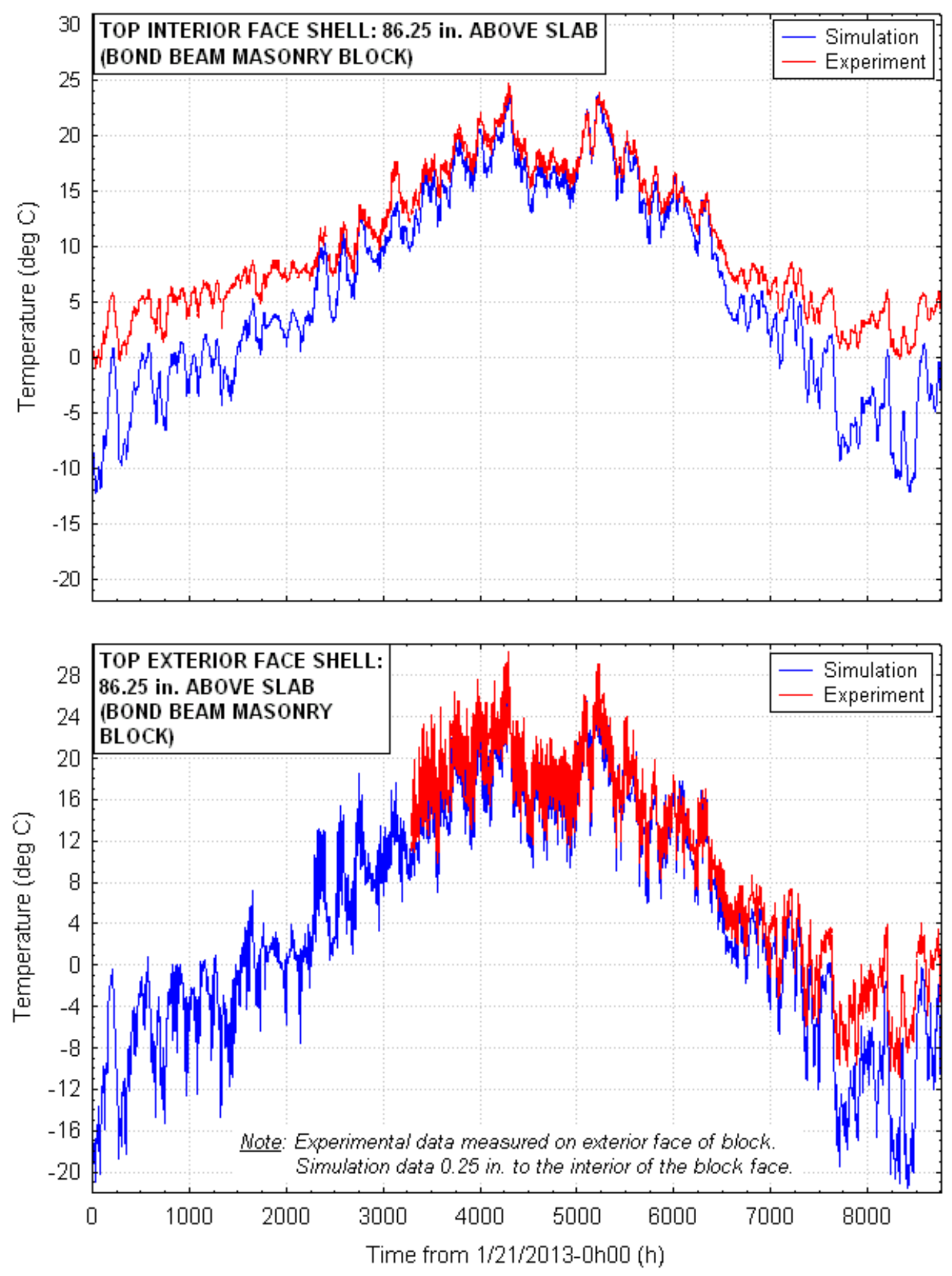

Figure 78. Bay $3 \mathrm{~N}$ wall experiment/BUFETS simulation temperature comparison $86-1 / 4$ in. above the slab 
BAY 3N VERT. SOIL TEMP. PROFILE EXPERIMENTISIMULATION COMPARISON
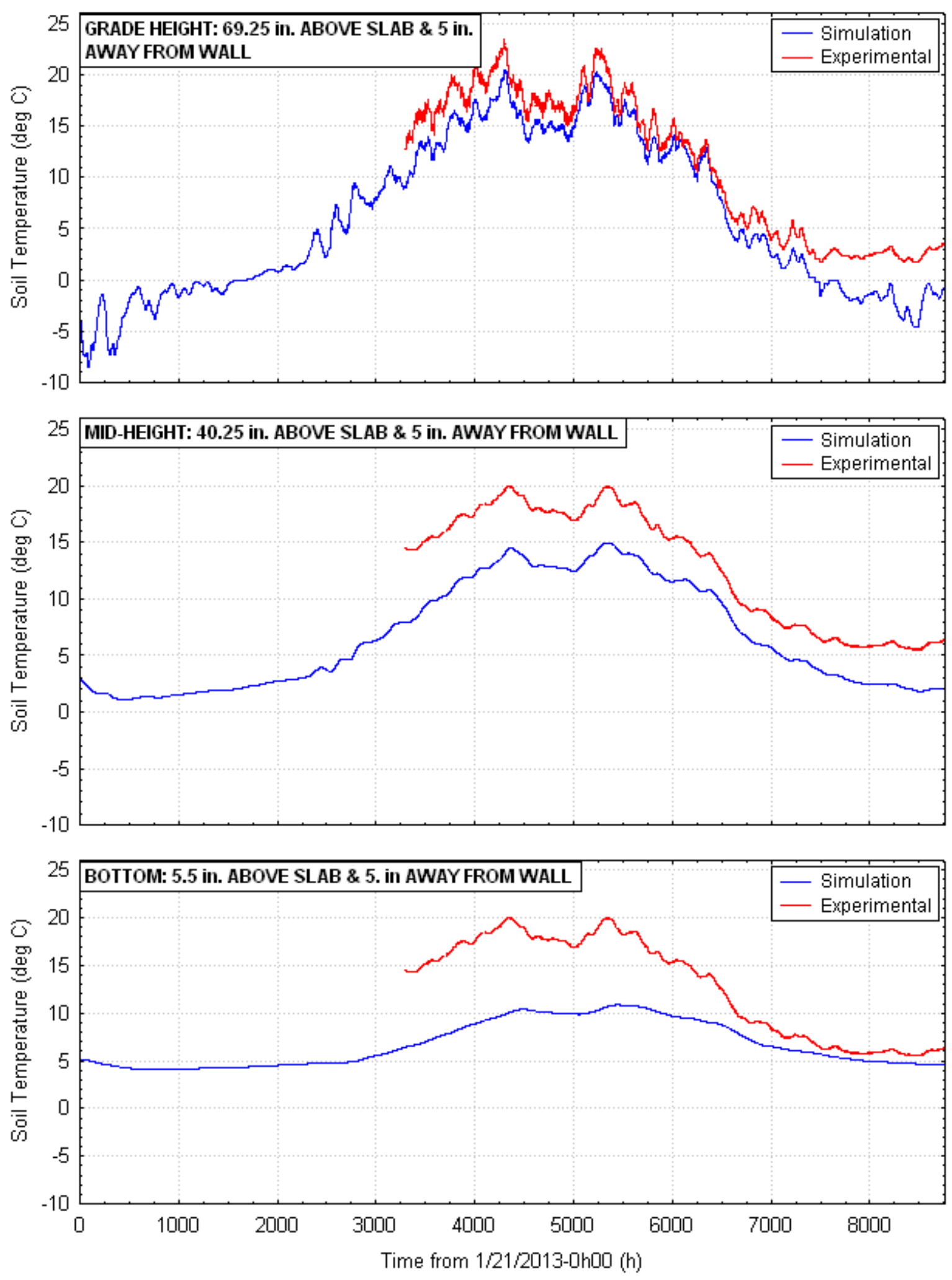

Figure 79. Bay $3 \mathrm{~N}$ soil vertical profile experiment/BUFETS simulation temperature comparison 

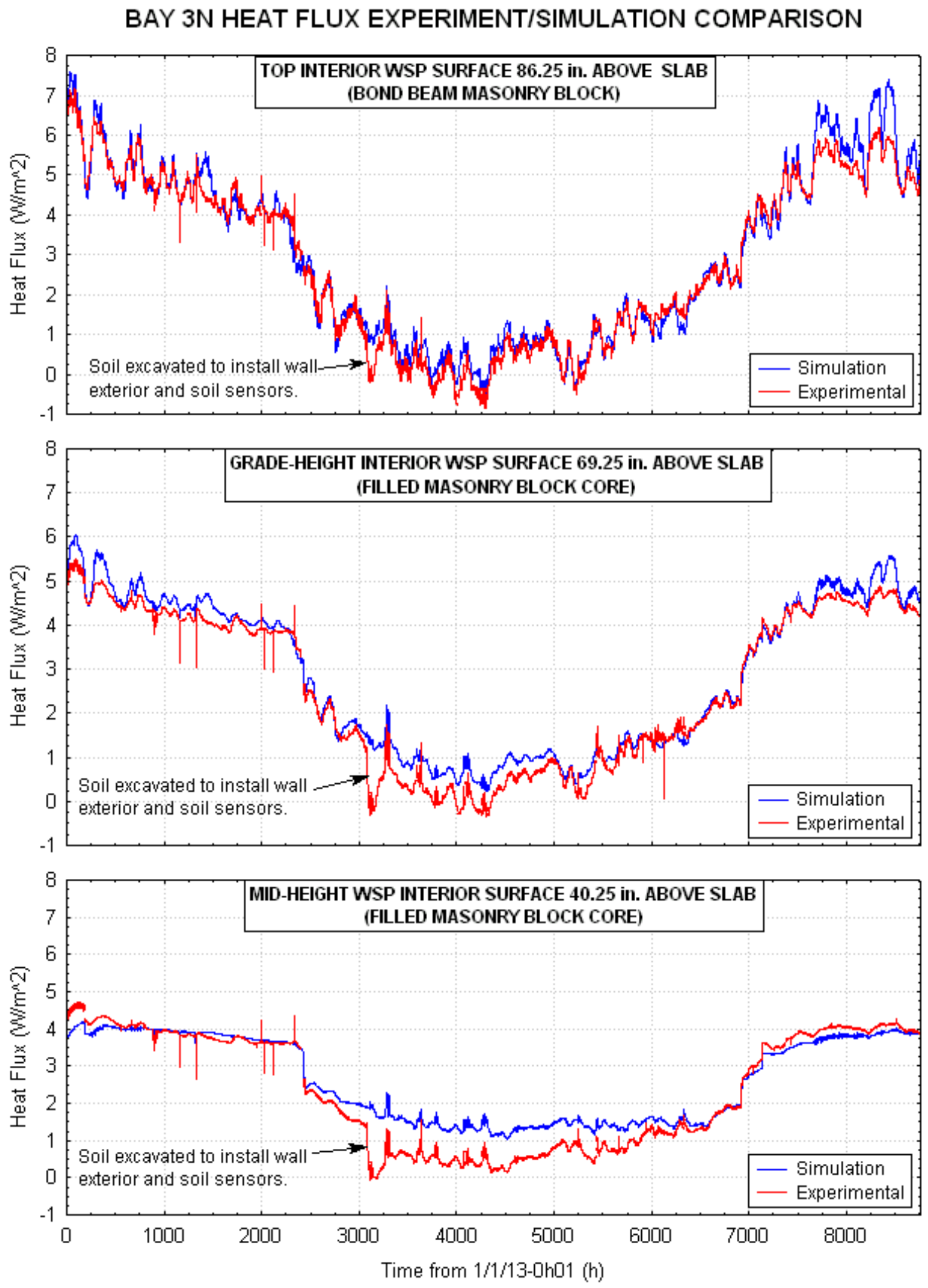

Figure 80. Bay $3 \mathrm{~N}$ wall experiment/BUFETS simulation heat flux comparison 
In the case of the comparison of the BUFETS simulation and experimental results discussed, the experimental data point to two possible causes for the discrepancies observed:

- Buoyant cavity flow loops in the hollow masonry block cores are not modeled in BUFETS.

- The Dirichlet boundary condition at the base of the simulation domain is incorrectly modeled (the assumed constant height and temperature water table model is incorrect for the circumstances prevailing at the CRRF). This was confirmed by Harmon (2014). However, the comparison also reveals some deficiencies in the experimental data set, the most significant of which are:

- No temperatures were measured in the drain tile system.

- The initial and settled vertical soil density and thermal conductivity profiles were not measured.

- The simulation domain bottom soil temperature and moisture content boundary conditions were not measured.

- The density of temperature and moisture content measurements should be increased in the soil and the walls.

In this experiment, the first deficiency was not considered in the experimental design because it had not been an issue in prior research. The second and fourth deficiencies were a result of limitations imposed by the ORNL and NREL test plans. The second deficiency (as far as the settled soil density and thermal conductivity profile is concerned) can be corrected in the future if additional funding becomes available. Correcting the third deficiency ${ }^{32}$ for measurements beneath the slab is really feasible for new construction only, but it could be addressed if a sensor array were installed within $10 \mathrm{ft}$ or so of the CRRF.

\subsection{Hygrothermal}

The WUFI-2D program was selected for evaluation against the hygrothermal experimental data. As discussed in Appendix D, a hygrothermal solution (combined solution of the thermal and moisture transport equations) could unfortunately not be obtained for the experimental domain despite numerous attempts and a lengthy interaction with the program developers. A thermal solution was obtained and the resulting simulated temperatures were compared against their experimental counterparts. The resulting discrepancies initiated a lengthy collaboration with ORNL in an attempt to resolve the errors and some progress was made in this regard. However, DOE terminated the ORNL WUFI-2D program before definitive solutions could be found. At this time, WUFI-2D in its current form is not ready for modeling the hygrothermal performance of full basement walls. However, based on the progress made in resolving the thermal discrepancies, there is hope that it may become useful as a building foundation hygrothermal simulation tool in the future.

\footnotetext{
32 This would require installing a vertical soil temperature and moisture content sensor array to the depth of the marsh near the CRRF that would require a drilling rig to reach the required depth.
} 


\section{Answers to Research Questions}

The conclusions drawn in this section are preliminary because they are applicable to the results from a single experiment conducted in a cold climate for a limited period of about $1-1 / 2$ years. The research questions posed in the two project plans for this project at the outset are answered directly in the order that they were posed (answers are given in bold):

1. Do the selected interior foundation wall insulation retrofit designs to be tested meet the hygrothermal performance criteria (of the Minnesota Energy Code)? In particular:

i. Is the annual wetting/drying cycle stable (moisture content at the beginning of the year lower than or equal to that of the beginning of the year)? YES.

ii. Are all monitored components of the foundation wall system interior to the WSP free of surface condensation for at least 4 months over a full calendar year (sensible [or dry bulb] temperature higher than dew point temperature)? YES.

iii. Is there any visible or olfactory evidence of mold or rot when the test retrofit systems are dismantled at the end of the experiment? UNKNOWN. Will be determined only when the test bays are dismantled.

iv. Has any liquid water been observed on the floor beneath the test retrofit systems during the course of the experiment? NO.

2. Do the measured interior foundation wall surface heat fluxes agree with those predicted by foundation energy simulation programs (such as BUFETS)? The agreement achieved with BUFETS was a function of the discrepancy between the measured and simulated wall temperatures that were as large as $8^{\circ} \mathrm{C}$ in some instances. However, the disagreement between the measured and simulated heat fluxes was no more than $1.2 \mathrm{~W} / \mathrm{m}^{2}$. This disagreement was in terms of the magnitude of the profiles, not their shape. The level of agreement was judged adequate to render predictions of cumulative seasonal basement wall heat flow adequate relative to those measured.

3. Can the test wall systems meet the performance criteria in the presence of a severe internal humidity load during the heating season? Severity in this case was defined to be a period of internal basement humidity of $50 \%$ for a period of about 2 weeks. Under these circumstances, the data indicate that the answer is a provisional "yes" subject to confirmation when the wall systems eventually are dismantled and inspected.

4. Is an adhered WSP susceptible to delamination with a high wall moisture contents? Unknown, but expected to be "yes." The data show that maintaining an interior face shell saturation ratio of 0.25 or lower is feasible for adhered WSPs over the long term, so that under these conditions, delamination is not likely. A long-term measured interior face shell saturation ratio of 0.25 is recommended conservatively at this stage as a requirement for using adhered WSPs. A final determination will be made when test bays are dismantled. 
5. Do either adhered or nonadhered WSPs result in perpetually wet walls? NO. The data show that even after a period of prolonged wetting of the drainage cavity on the exterior of a nonadhered WSP, the wall surface dries out to prewetting moisture contents. However, the RH in the drainage cavity remains saturated regardless of the interior block face shell moisture content.

If so, is the moisture content/temperature profile sufficient to produce freeze/thaw cycle structural damage? Not applicable.

6. Is the $\mathrm{RH} /$ temperature/time profile within the drainage cavity between a nonadhered WSP and the wall sufficient to grow mold? YES.

If so, how severe is this potential? There is a high potential for mold growth as the drainage cavity RH remains elevated $(>90 \%)$ over an entire year yielding prolonged periods when mold growth is possible.

Are there sufficient nutrients in the cavity to produce significant amounts of mold? Unknown. Will be determined when the test bays are eventually dismantled.

7. What is the experimental thermal effectiveness of exterior partial wall insulation? Is it comparable with that of full wall insulation? The reduction in heat loss is comparable with full wall insulation at the center of the partial wall insulation only. The heat loss reduction diminishes as the upper and lower edges of the board are approached because of thermal bridging. This is particularly noticeable if the exterior insulation is installed to the top of the wall only. We recommend that partial exterior wall insulation extend to at least the top of the rim-joist cavity.

8. Are positive hygrothermal benefits afforded by partial wall exterior insulation (such as reduced rim-joist cavity $\mathrm{RH}$ ) compared with an uninsulated wall? Benefits are afforded by partial exterior wall insulation if such insulation extends to the top of the rimjoist cavity at least. For example, the rim board interior surface RH was $30 \%$ lower during the heating season with exterior insulation. However, in terms of the M-MC of the rim-joist cavity wood bounding components, no measurable advantage was found for the insulated case under the experimental conditions in which the rimjoist cavity was sealed and vapor isolated from the basement interior. This would not be the case if the cavity were in vapor communication with the basement interior when much larger amounts of condensation can be expected on the rim board and sill plate interior faces. If the partial exterior wall insulation extends only to the top of the wall, no rim-joist cavity hygrothermal benefits were observed under the experimental conditions (uninsulated and unsealed rim-joist cavities).

9. (An extension of question 5 posed at a later time and partially answered above.) Do leaking foundation walls covered with a nonadhered WSP ever dry out? YES.

If they remain perpetually wet, what are the structural and mold impacts? Not applicable because the walls did not remain perpetually wet. Unknown for the case in which this is not true, such as in the presence of continuous bulk water leakage into the drainage cavity (will require additional experiments to evaluate). 
Is it safe to install a foundation insulation retrofit that creates a perpetually wet wall? Unknown from the experiments conducted.

10. Are existing hygrothermal simulation codes (such as WUFI-2D) useful in any way for retrofit foundation insulation designs? Are their predictions qualitatively or quantitatively valid? At this point, no. Despite repeated attempts, no hygrothermal solution for a simulation on the instrumented test plane through Bay $1 \mathrm{~N}$ or $2 \mathrm{~N}$ could be obtained with WUFI-2D. The moisture transport algorithm failed after repeated attempts at different solutions as explained in Appendix D. Efforts to resolve the problems encountered with the program developers also were of no avail. A thermal solution was obtained in terms of simulated temperatures only (WUFI-2D does not report heat fluxes) for Bays $1 \mathrm{~N}$ and $2 \mathrm{~N}$ only. The comparison with the experimental temperature data yielded larger temperature differences on average than those achieved with BUFETS.

11. What is the extent of the vapor coupling between the interior condensing surface of the rim board and vapor sources within masonry block wall cavities? No coupling observed with either an insulated or uninsulated rim board. A saturated masonry block core humidity had no impact on the rim board M-MC that remained below $6 \%$ throughout the experiment.

12. How does the sill plate moisture content relate to the masonry block core humidity and the moisture content of the underlying bond beam? No coupling was observed between the sill plate M-MC and a saturated masonry block core humidity. The sill plate MMC remained at $8 \%$ or lower throughout the experiment. No coupling was observed between the masonry block face shell V-MC and the sill plate M-MC. A transient VMC increase on the interior face shell produced by elevated humidity in the basement interior was not reflected in the sill plate M-MC.

13. What is the potential for the rim board to dry to the exterior, particularly when covered with exterior vapor retarding insulation? With an uninsulated rim board, potential drying to the exterior (interior surface vapor pressure >exterior surface vapor pressure) was possible from November through April. The same potential existed with the insulated rim board except the measured interior-exterior vapor pressure difference was consistently lower than the uninsulated case.

14. To what extent does exterior foundation wall insulation that extends upward to cover the rim joist decrease the condensation arising from vapor transmission from masonry block wall cores? No impact under the experimental conditions with a solid bond beam block separating the rom joist cavity from the masonry block cores. 


\section{Conclusions}

The conclusions drawn in this section also are preliminary because they are applicable to the results from a single experiment conducted in a cold climate for a limited period of about $1-1 / 2$ years. The primary project objectives described in Section 1.3 were met as follows:

- Physically credible and reliable long-term hygrothermal performance data have been developed for retrofit foundation wall insulation systems that are fully compliant with the performance criteria in the Minnesota Energy Code. These data currently span the period from November 10, 2012 through May 31, 2014, although only the data collected through the end of April 2014 are discussed in this report.

- Public experimental data sets to validate and calibrate building foundation hygrothermal simulation codes have been developed.

- Retrofit foundation wall systems with both interior and exterior insulation placements were tested. No particular advantage for the partial wall exterior insulation system was found unless the insulation extends at least to the top of the rim joist. In this case, the interior rim board surface RH was lowered substantially compared with the uninsulated case. However, the exterior insulation had no impact on the moisture content of the rimjoist cavity wood component moisture content that was the same as the uninsulated case. The heat flux performance of the partial wall exterior insulation was equivalent to that of full-wall interior insulation only at the vertical center of the insulation, it deteriorated as the top and bottom edges were approached.

- The full-wall interior foundation insulation retrofits tested using adhered and nonadhered WSPs was shown by the experimental data to be in compliance with the Minnesota Energy Code performance criteria over the calendar year from January 10, 2013 through January 9, 2014.

- The experimental thermal data were used to investigate the validity of the threedimensional BUFETS earth contact energy simulation code when applied to the test bay walls under field conditions. The agreement between the experimental and simulation heat flux data was acceptable for calculating seasonally integrated wall heat flows that are necessary for accurate foundation enclosure seasonal energy load calculations. Agreement between the measured and simulated wall and soil temperatures was within $8^{\circ} \mathrm{C}$ in the heating season and within $10^{\circ} \mathrm{C}$ in the cooling season; the average discrepancy in the wall temperatures decreased with height above the slab. The primary cause of the discrepancy was shown by subsequent research to be an incorrectly modeled water table in terms depth beneath the footing and height. Two omissions in the BUFETS program were recognized as contributing to the discrepancies:

- The absence of the ability to model buoyant cavity flow loops in hollow masonry block walls

- The inability to model a water table with a seasonally varying height and temperature. 
Secondary effects such as the absence of a soil moisture transport model enabling the calculation of seasonally varying thermal conductivities as a function of soil moisture content were also recognized from the data.

- The WUFI-2D hygrothermal simulation program in its standard form was unable to model the basement foundation systems tested. The program failed to yield a solution to the moisture transport equation included in its algorithm. The thermal component of the simulation did yield results that were compared to the experimental data. In almost every case, a comparison of the experiment/simulation temperatures yielded larger temperature differences on average than those obtained with BUFETS.

- The test wall systems were exposed to conditions of high basement interior humidity (50\% RH for 2 weeks) during January and February of 2014. The experimental data tentatively show that the wall systems did meet the Minnesota Energy Code performance criteria for this period. This cannot be confirmed until the formal end of the experiment in November 2014, when sufficient experimental data will become available to make the final determination (the NREL part of the experiment terminated on April 30, 2014). A final determination also will require the wall systems to be dismantled.

- The vapor coupling between hollow masonry block walls and a sealed rim-joist cavity with and without exterior rim board insulation was measured. The experimental data revealed no coupling between moisture-saturated $(100 \% \mathrm{RH})$ cores and the moisture content of any rim-joist cavity wooden boundary component with and without exterior insulation. In addition, no coupling between an elevated wall top course face shell moisture content and the wooden boundary components was revealed. This was ascribed to the top course of the wall being a solid bond beam block that provides an adequate class II vapor retarder. The retarder effectively isolates the rim-joist cavity from the masonry block wall cores and from elevated basement interior humidity conditions when the bond beam block is not wetted by exterior bulk water.

- Exterior rim board thermal insulation with a class II permeance rating did not reduce the condensation on the rim board interior surface under the experimental conditions. This arose because the vapor transport from all sources (including the masonry block cores and the basement interior) was so low that the potential for condensation was severely restricted. Further, even without exterior insulation, the $\mathrm{RH}$ on the rim board interior face never reached saturation.

- The experimental data were configured into a standard format that can be published online. The calibrated data were compiled into a standard flat-form CSV (comma separated value) format with one data file for each day. These files can be read by standard commercially available spreadsheet and database software. A description of the format of the database and the meanings and descriptions of the individual data readings (metadata) was also developed.

The secondary project objectives were mostly achieved as follows:

- It will not be possible to finally determine whether the adhered WSPs delaminated from the interior face shell until the walls are dismantled (the walls cannot be dismantled until 
the ORNL part of the project is completed in November 2014). The experimental data suggest that the wall interior face shells were never wet enough to permit delamination.

- The data reveal that neither adhered nor nonadhered interior WSPs produced perpetually wet walls during the experiment. Thus, the potential for freeze/thaw cycle structural damage could not be assessed.

- The data show that the $\mathrm{RH} /$ temperature/time profile in the drainage cavity between the nonadhered WSP and the wall during the experiment is sufficient to grow mold if sufficient nutrients are available.

- The thermal effectiveness of exterior partial wall thermal insulation is equivalent to that of full-wall interior insulation only at the vertical center of the exterior insulation board. The effectiveness diminishes closer to the vertical edges of the board.

- Calibrated instrumentation was developed to continuously measure the exterior and interior masonry block face shell moisture contents. This instrumentation was effective on the interior of the masonry block walls where excessive wall moisture contents were not measured. The moisture probes failed on the exterior wall surfaces where high levels of moisture speculatively caused the conductive epoxy coating the graphite electrodes to de-adhere from the masonry producing an electrical open circuit. The inexpensive signal conditioning electronics operated without any failures. 


\section{Prognosis}

A large and extensive public domain database of the hygrothermal performance of basement walls in a cold climate (zone 7) was developed and can effectively evaluate the accuracy of thermal earth contact simulation codes. However, whether this database will be made available for full long-term public access is not known. An attempt was made to find funding for this publication, but ultimately, without success. 


\section{References}

ASHRAE (2001). 2001 Fundamentals. Atlanta, GA: American Society of Heating, Refrigerating and Air-Conditioning Engineers.

Bird, N.R.A.; Perrier, E.M.A. (2003). "The Pore-Solid Fractal Model of Soil Density Scaling." European Journal of Soil Science, 54 (3), 467-476.

Bird, N.R.A.; Perrier E.; Rieu, M. (2000). "The Water Retention Function of a Model Soil of Soil Structure With Pore and Solid Fractal Distributions." European Journal of Soil Science, vol. 51, pp. 55-63.

Bowers, S.A.; Hanks, R.J. (1962). "Specific Heat Capacity of Soils and Minerals as Determined With a Radiation Calorimeter." Soil Science, 94 (6), 392-396.

Calonne, N.; Flin, F.; Morin, S.; Lesaffre, B.; du Roscoat S.R.; Geindreau, C. (2011). "Numerical and Experimental Investigations of the Effective Thermal Conductivity of Snow." Geophysical Research Letters, 38 (L23501), 1-6.

Davies, M.; Ye, Z. (2009). “A 'Pad' Sensor for Measuring the Moisture Content of Building Materials.” Building Services Engineering Research and Technology, 30 (3), 263-270.

EPA (2013). Average Temperature of Shallow Groundwater. Washington, D.C.: U.S. Environmental Protection Agency. Accessed December 8, 2014:

http://www.epa.gov/athens/learn2model/part-two/onsite/ex/jne henrys_map.html.

Friedlund, D.G.; Rahardjo, H. (1995). Soil Mechanics for Unsaturated Soils, Chap. 4, p. 64, John Wiley \& Sons.

Goldberg, L.F.; Huelman P.H. (2001). Rim Joist and Foundation Insulation Project Final Report, Project Research Report. Cloquet, MN: University of Minnesota.

http://www.buildingfoundation.umn.edu/RimJoist/default.htm.

Goldberg, L.F. (2011). The Foundation Test Facility. Rosemount, MN: University of Minnesota. Accessed December 8, 2014: http://www.buildingfoundation.umn.edu/ftf.htm.

Goldberg, L.F.; Steigauf, B. (2011). Cold Climate Foundation Retrofit Energy Savings: The Simulated Energy and Experimental Hygrothermal Performance of Cold Climate Foundation Wall Insulation Retrofit Measures - Phase I, Energy Simulation. Washington, D.C.: U.S. Department of Energy. Accessed December 8, 2014:

http://apps1.eere.energy.gov/buildings/publications/pdfs/building_america/cold climate foundatio n retrofit.pdf.

Goldberg, L.F.; Stender, M.L. (2013). "The Experimental Hygrothermal Performance of a Robust Cold-Climate Retrofit Interior Foundation Wall Insulation System.” In Proceedings of the Buildings XII Conference, December 1-5, 2013, Clearwater Beach, FL. 
Goldberg, L.F.; Huelman, P.H. (2005). Minnesota Energy Code Building Foundation Rule: Amendment Proposal Development Project Final Report, Project Research Report. Rosemount, MN: University of Minnesota. Accessed December 8, 2014:

http://www.buildingfoundation.umn.edu/FinalReportWWW/default.htm.

Goldberg, L.F. (2004). Icynene Foundation Insulation Project Final Report. Rosemount, MN: University of Minnesota. Accessed December 8, 2014:

http://www.buildingfoundation.umn.edu/IcynenFinalReport/default.htm.

Goldberg, L.F. (2012). 2012 MN Energy Code: Due Diligence Review of Performance and Prescriptive Foundation System Durability Rules with R-15/R-19 Wall Thermal Insulation. Rosemount, MN: University of Minnesota.

Goldberg, L.F.; Huelman, P.H.; Gatland II, S.D. (2010). “A Prototype Universal Building Envelope Hygrothermal Performance Standard for Successful Net-Zero Energy Building Design. In Proceedings of the Buildings XI Conference, ASHRAE, Clearwater Beach, FL.

Gossard D.; Lartigue, B.; Sambou, V. (2011). "Nusselt Number Correlations for Laminar Convection in Three-Dimensional Air-Filled Cavities." Journal ofo Building Physics, 35 (4), 327 337.

Harmon, A.H. (2014). M.S. Thesis (in preparation), Department of Bioproducts and Biosystems Engineering, University of Minnesota.

Huelman, P.H.; Goldberg, L.F.; Jacobsen, R. (2013). Innovative Retrofit Insulation Strategies for Concrete Masonry Foundations, draft research report in review prepared for Building America Building Technologies Program.

Johansen, O. (1975). Thermal Conductivity of Soils. Ph.D. thesis. Trondheim, Norway (CRREL Draft Translation 637, 1977) ADA 044002.

Kehrer, M. Pallin, S.; Harmon, A.; Goldberg, L.F. (2012). Hygrothermal Simulation of Foundations: Part 1, Soil Material Properties. ORNL Research Report ORNL/TM-2012/289, UT Batelle.

Kersten, M.S. (1948). “The Thermal Conductivity of Soils." In Proceedings of the Highway Research Board, vol. 29, pp. 391-409.

Khoshbakht M.; Lin, M.W. (2006). "Development of an Electrical Time Domain Reflectometry (ETDR) Distributed Moisture Measurement Technique for Porous Media." Measurement Science and Technology, 17 (11), 2989, doi:10.1088/0957-0233/17/11/019.

Kunzel, H.W. (1995). Simultaneous Heat and Moisture Transport in Building Components - One and Two-Dimensional Calculation Using Simple Parameters. Fraunhofer-Institut fur Bauphysik, ISBN 3-8167-4103-7. 
Maksimovic M.; Stojanovic, G.C.; Goran, M.; Radovanovic, M.; Malesev, M.; Radonjanin, V.; Radosavljevic G.; Smetana, W. (2012). “Application of a LTCC Sensor for Measuring Moisture Content in Building Materials. Construction and Building Materials, 26 (1), 327-333.

McBride, M.F. (2013). "Natural Convection in Below Grade Open Cell Concrete Block Walls.” In Proceedings of Thermal Performance of the Exterior Envelopes of Whole Buildings, ASHRAE, paper no. 181.

Minnesota Statutes (2009). Chapter 1322, Department of Labor and Industry, Residential Energy Code, Section N1102.2.6 Basement Walls.

Naik, T.R.; Kumar, R.; Ramme B.W.; Kraus, R.N. (2010). "Effect of High-Carbon Fly Ash on the Electrical Resistivity of Fly Ash Concrete Containing Carbon Fibres.” Second International Conference on Sustainable Construction Materials and Technologies, June 2010, Ancona, Italy. https://www4.uwm.edu/cbu/Papers/2009\%20CBU\%20Reports/REP-645.1.pdf

Neymark, J.; Judkoff, R. (2008). International Energy Agency Building Energy Simulation Test and Diagnostic Method (IEA BESTEST) In-Depth Diagnostic Cases for Ground Coupled Heat Transfer Related to Slab-On-Grade Construction. Golden, CO: National Renewable Energy Laboratory, NREL/TP-550-43388.

Petit, A-T; Dulong, P.L. (1819). "Recherches sur quelques points importants de la Théorie de la Chaleur." Annales de Chimie et de Physique (in French) 10, 395-413. (translation in Annals of Philosophy, 14, pp. 189-198).

Rasmussen, T.C.; Rhodes, S.C. (1995). "Energy-Related Methods: Psychrometers.” In Handbook of Vadose Zone Characterization and Monitoring, Wilson, L.G., L.G. Everett, and S.J. Cullen, editors, CRC Press, Inc.

Sedlbauer, K.; Krus M.; Breuer, K. (2003). "Mould Growth Prediction with a New Biohygrothermal Method and Its Application in Practice.” In Proceedings of Materials Conference, Lodz, pp. 594-601. Accessed December 8, 2014:

http://www.hoki.ibp.fhg.de/ibp/publikationen/konferenzbeitraege/pub1 43.pdf.

Shen, L.S. (1986). An Investigation of Transient, Two-Dimensional Coupled Heat and Moisture Flow in Soils. Ph.D. thesis, University of Minnesota.

Sturm, M.; Taras, B.; Liston, G.E.; Derksen, C.; Jonas T.; Lea, J. (2010). "Estimating Snow Water Equivalent Using Snow Depth Data and Climate Classes." Journal of Hydrometeorology, vol. 11, pp. 1380-1394.

Sturm, M.B.; Holmgren, J.; Liston, G.E. (1995). “A Seasonal Snow Cover Classification System for Local to Global Applications.” Journal of Climate, vol. 8, pp. 1961-1283. 


\section{Appendix A: Instrumentation and Experimental Fabrication Record}

Table 7. Purchased Instrumentation Schedule

\begin{tabular}{|c|c|c|c|c|}
\hline Instrument & Measurement & Manufacturer & Model No. & $\begin{array}{c}\text { Manufacturer's } \\
\text { Listed Performance }\end{array}$ \\
\hline $\begin{array}{c}\text { Pyrgeometer } \\
\text { FIR } \\
(4500-42000 \\
\text { nm) }\end{array}$ & $\begin{array}{l}\text { Long wave sky } \\
\text { radiation }\end{array}$ & $\begin{array}{l}\text { Kipp and } \\
\text { Zonen }\end{array}$ & CGR3 & Nonlinearity: $<1 \%$ \\
\hline $\begin{array}{l}\text { Ultrasonic } \\
\text { Snow Depth } \\
\text { Gauge }\end{array}$ & Snow depth & $\begin{array}{l}\text { Campbell } \\
\text { Scientific }\end{array}$ & SR50A-1 & $\begin{array}{l}\text { Accuracy: maximum } \\
( \pm 0.4 \text { in., } 0.4 \% \text { of } \\
\text { target distance })\end{array}$ \\
\hline $\begin{array}{c}\text { Heated } \\
\text { Precipitation } \\
\text { Gauge }\end{array}$ & $\begin{array}{l}\text { Precipitation } \\
\text { (solid and } \\
\text { liquid) }\end{array}$ & RM Young & 52202 & Resolution: $\pm 0.1 \mathrm{~mm}$ \\
\hline $\begin{array}{l}\text { Thin Film } \\
\text { Capacitance } \\
\text { RH Sensor* }\end{array}$ & $\mathrm{RH}$ & Honeywell & HIH-4000-003 & $\begin{array}{c}\text { Calibrated accuracy: } \\
\pm 3.5 \%\end{array}$ \\
\hline Thermocouple & Temperature & $\begin{array}{l}\text { Omega } \\
\text { Engineering }\end{array}$ & PR-T-24-SLE & $\begin{array}{c}\text { Accuracy: maximum } \\
\left( \pm 0.5^{\circ} \mathrm{C}, \pm 0.4 \% \text { of }\right. \\
\text { reading })\end{array}$ \\
\hline Heat Flux Plate & Heat flux & $\begin{array}{c}\text { Concept } \\
\text { Engineering }\end{array}$ & F-002-4 HFP & Accuracy: $\pm 5 \%$ \\
\hline $\begin{array}{l}\text { Soil Dielectric } \\
\text { Sensor Used on } \\
\text { Bays } 1 \text { and } 2\end{array}$ & $\begin{array}{l}\text { Soil moisture } \\
\text { content and } \\
\text { temperature }\end{array}$ & $\begin{array}{l}\text { Stevens Water } \\
\text { Monitoring } \\
\text { Systems, Inc. }\end{array}$ & Hydraprobe & $\begin{array}{c}\text { Moisture content } \\
\text { accuracy: } \pm 0.03 \\
\text { volumetric MC } \\
\text { Temperature } \\
\text { accuracy: } \\
\pm 0.6^{\circ} \mathrm{C}\end{array}$ \\
\hline $\begin{array}{l}\text { Soil Dielectric } \\
\text { Sensor Used on } \\
\text { Bays } 3 \text { and } 4\end{array}$ & $\begin{array}{l}\text { Soil moisture } \\
\text { content and } \\
\text { temperature }\end{array}$ & $\begin{array}{l}\text { Stevens Water } \\
\text { Monitoring } \\
\text { Systems, Inc. }\end{array}$ & Hydraprobe II & $\begin{array}{c}\text { Moisture content } \\
\text { accuracy: } \pm 0.03 \\
\text { volumetric } \mathrm{MC} \\
\text { Temperature } \\
\text { accuracy: } \pm 0.1^{\circ} \mathrm{C}\end{array}$ \\
\hline Barometer & $\begin{array}{l}\text { Atmospheric } \\
\text { pressure }\end{array}$ & $\begin{array}{l}\text { Setra Sensing } \\
\text { Solutions }\end{array}$ & 276 & $\begin{array}{c}\text { Accuracy: } 0.25 \% \text { of } \\
\text { full scale }\end{array}$ \\
\hline Pyranometer & $\begin{array}{c}\text { Solar } \\
\text { irradiance flux }\end{array}$ & $\begin{array}{l}\text { Kipp and } \\
\text { Zonen }\end{array}$ & CMP 3 & $\begin{array}{c}\text { Nonlinearity: } \\
< \pm 2.5 \% \text {, temperature } \\
\text { dependence: } \pm 5 \%\end{array}$ \\
\hline $\begin{array}{l}\text { Pelton Wheel } \\
\text { Flow Sensor }\end{array}$ & Water flow & Kobold & $\begin{array}{c}\text { DPM1157N2F50 } \\
0\end{array}$ & $\begin{array}{l}\text { Accuracy: } \pm 1.5 \% \text { of } \\
\text { full scale }\end{array}$ \\
\hline
\end{tabular}

* The AH sensors referred to in Figure 1 and Figure 3 through Figure 6 comprise $\mathrm{RH}$ and temperature sensors in close proximity in the same sensor body. 


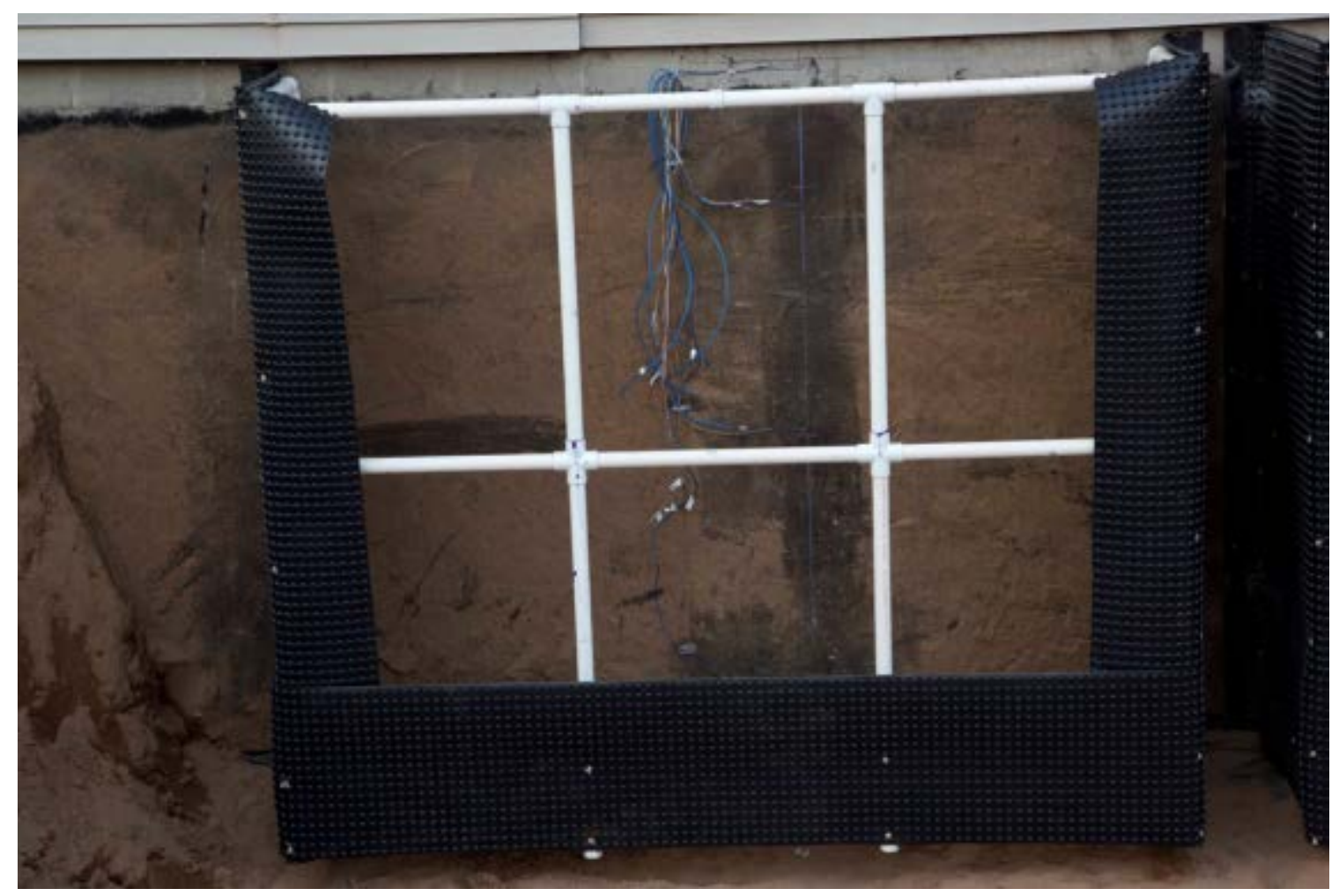

Figure 81. Exterior soil crib and sensors

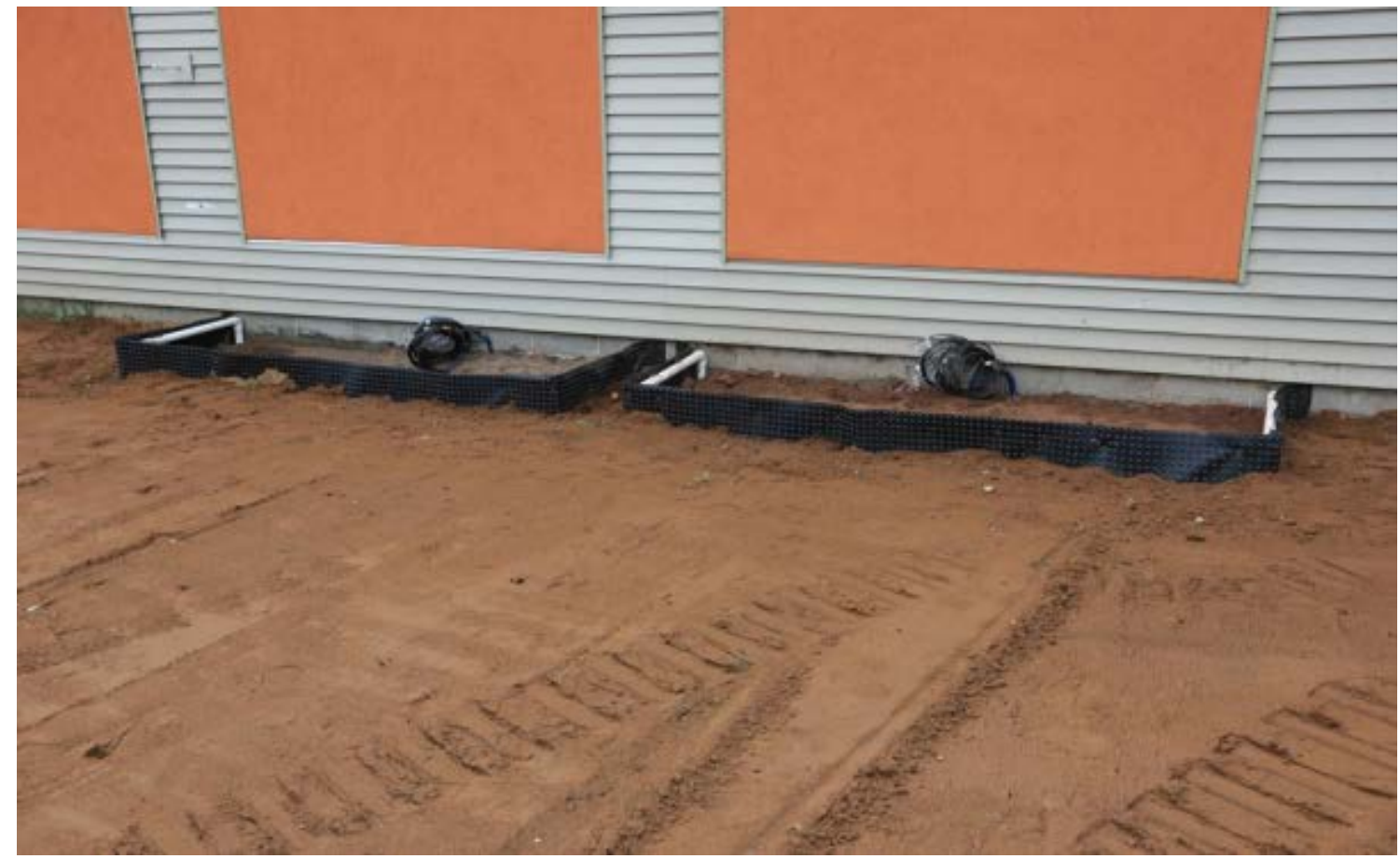

Figure 82. Backfilled exterior soil crib 


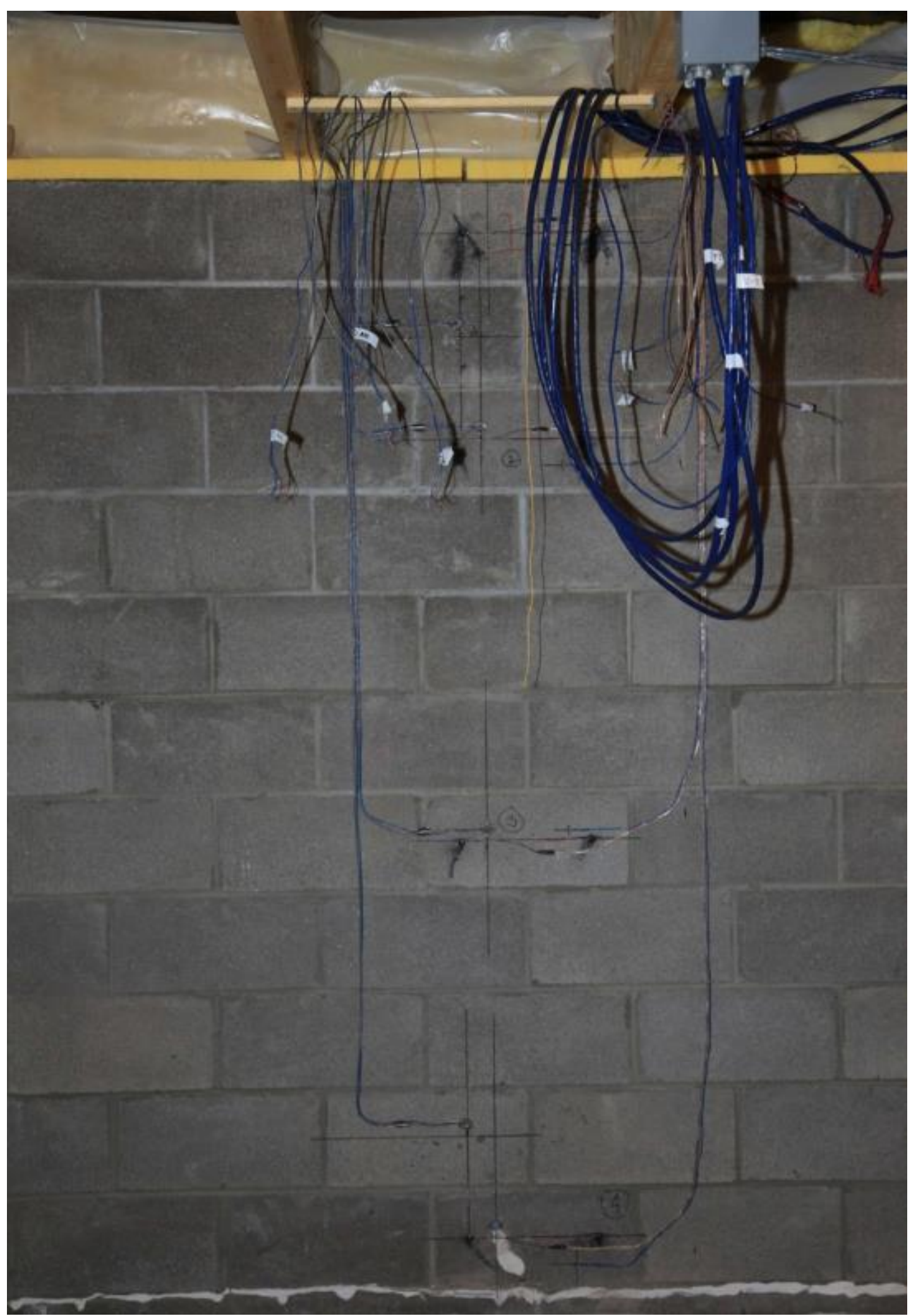

Figure 83. Interior block wall sensors (block moisture content, core humidity, and surface temperature) 


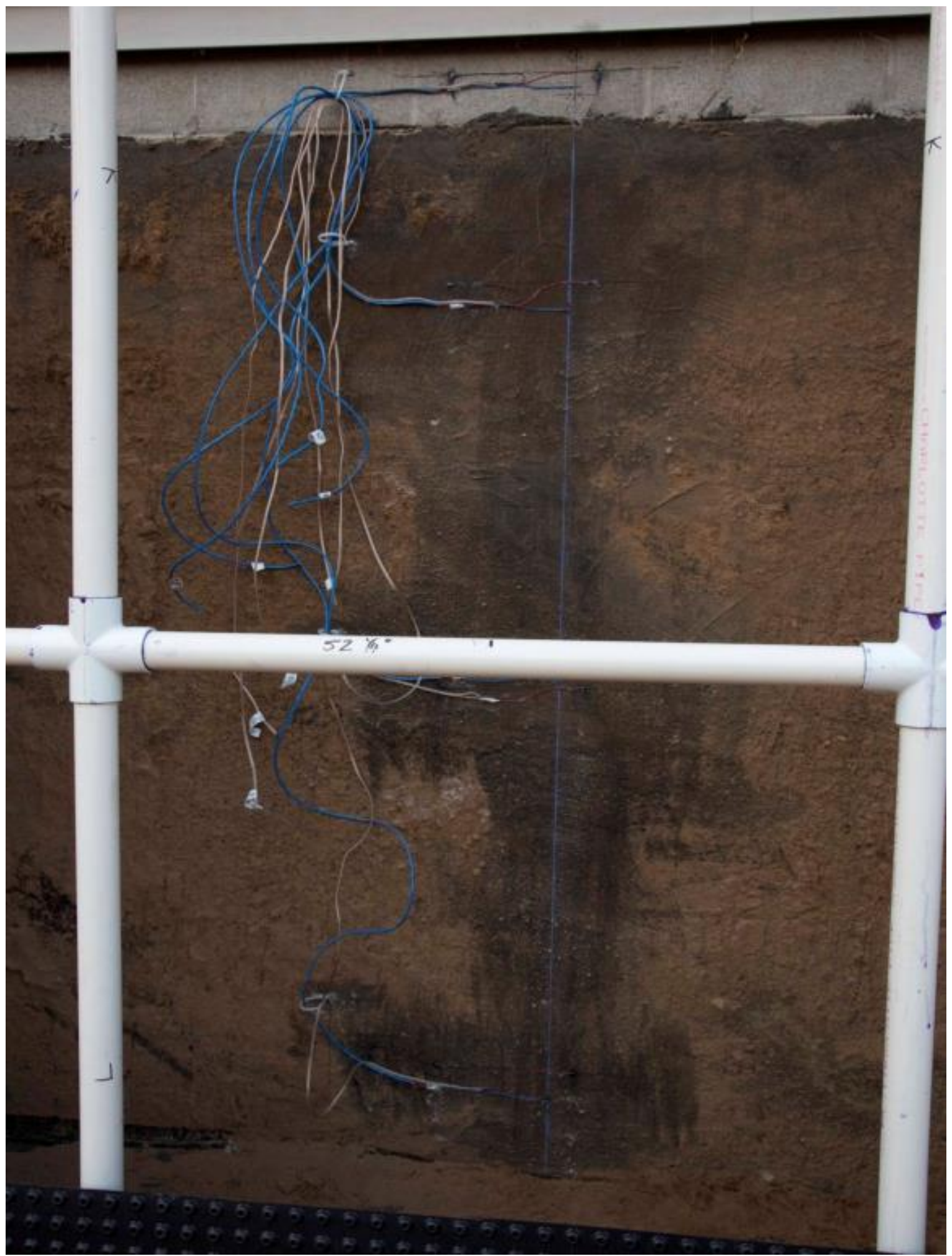

Figure 84. Exterior sensors (block moisture content and temperature) 


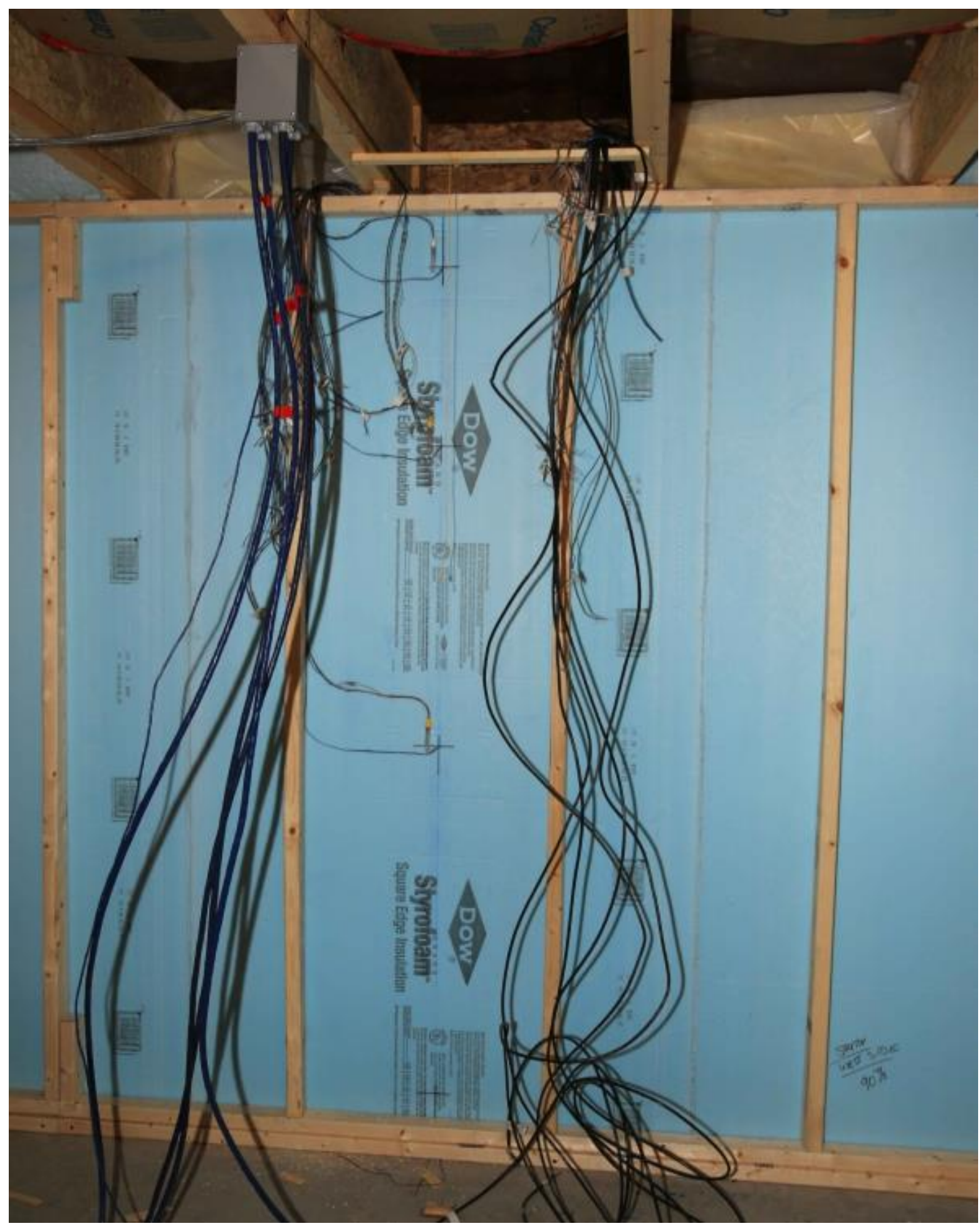

Figure 85. Sensors on the insulation interior face (humidity and temperature) 


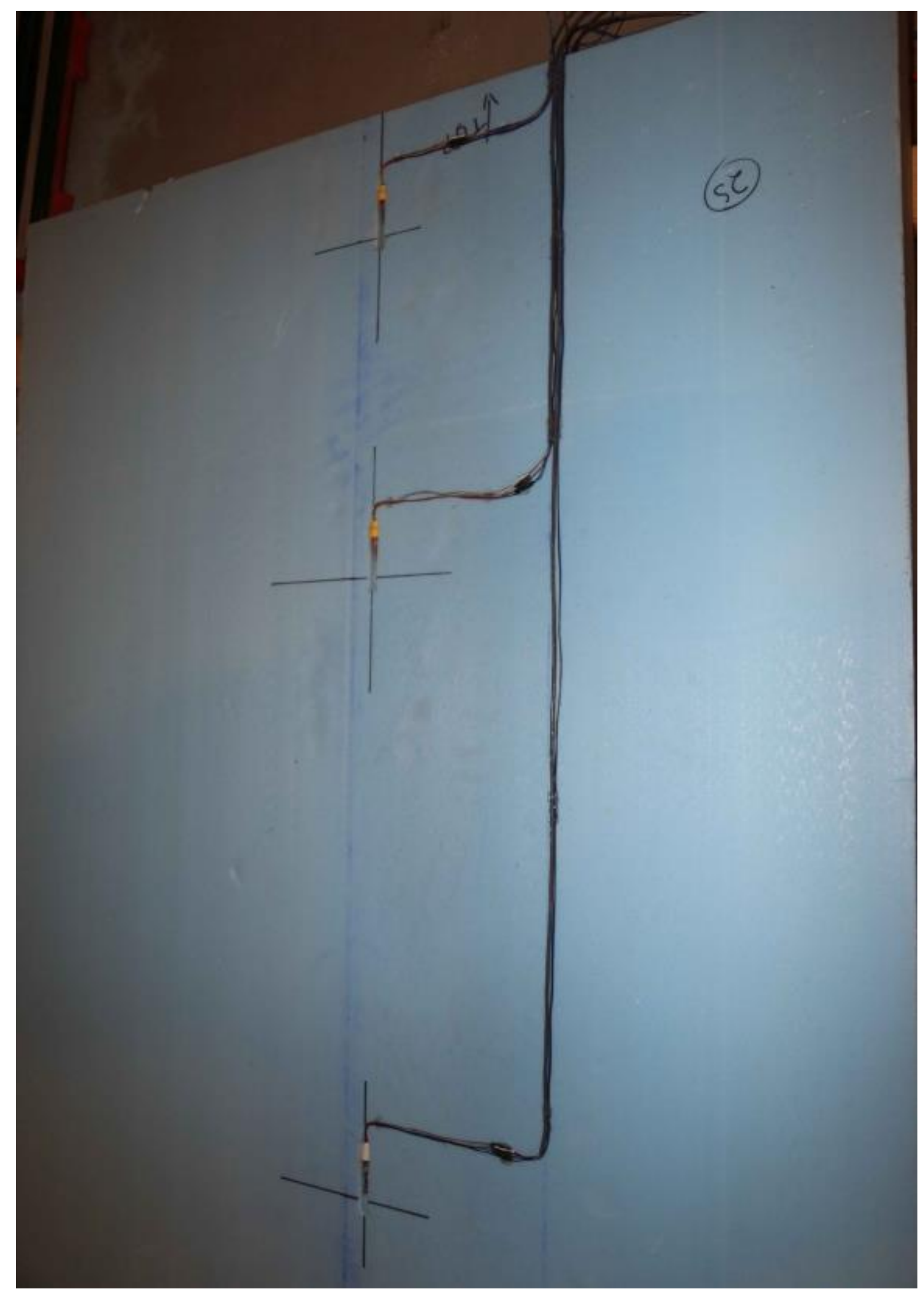

Figure 86. Humidity sensors installed in pockets on rear insulation face 


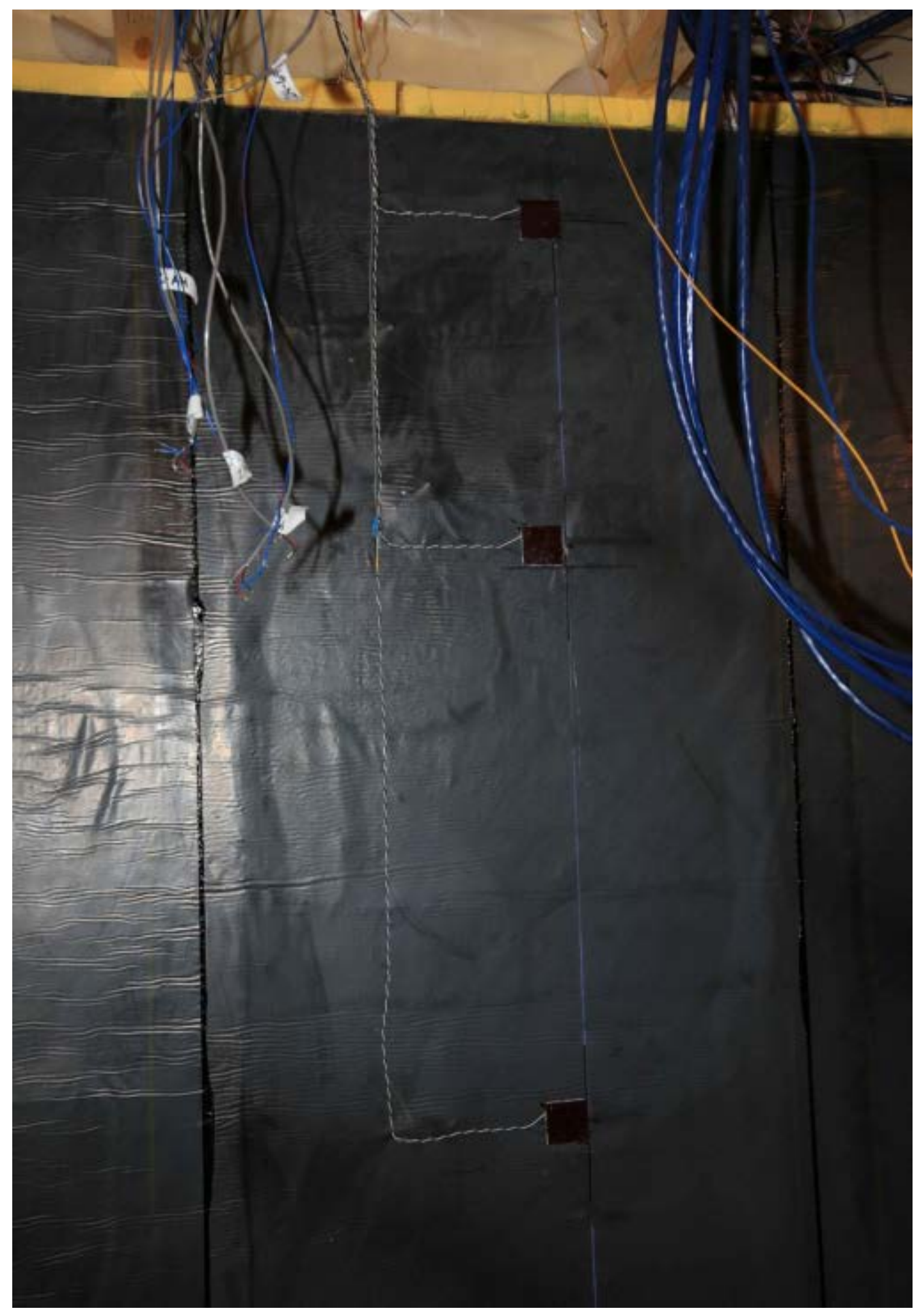

Figure 87. Heat flux plates mounted on interior face of WSP 


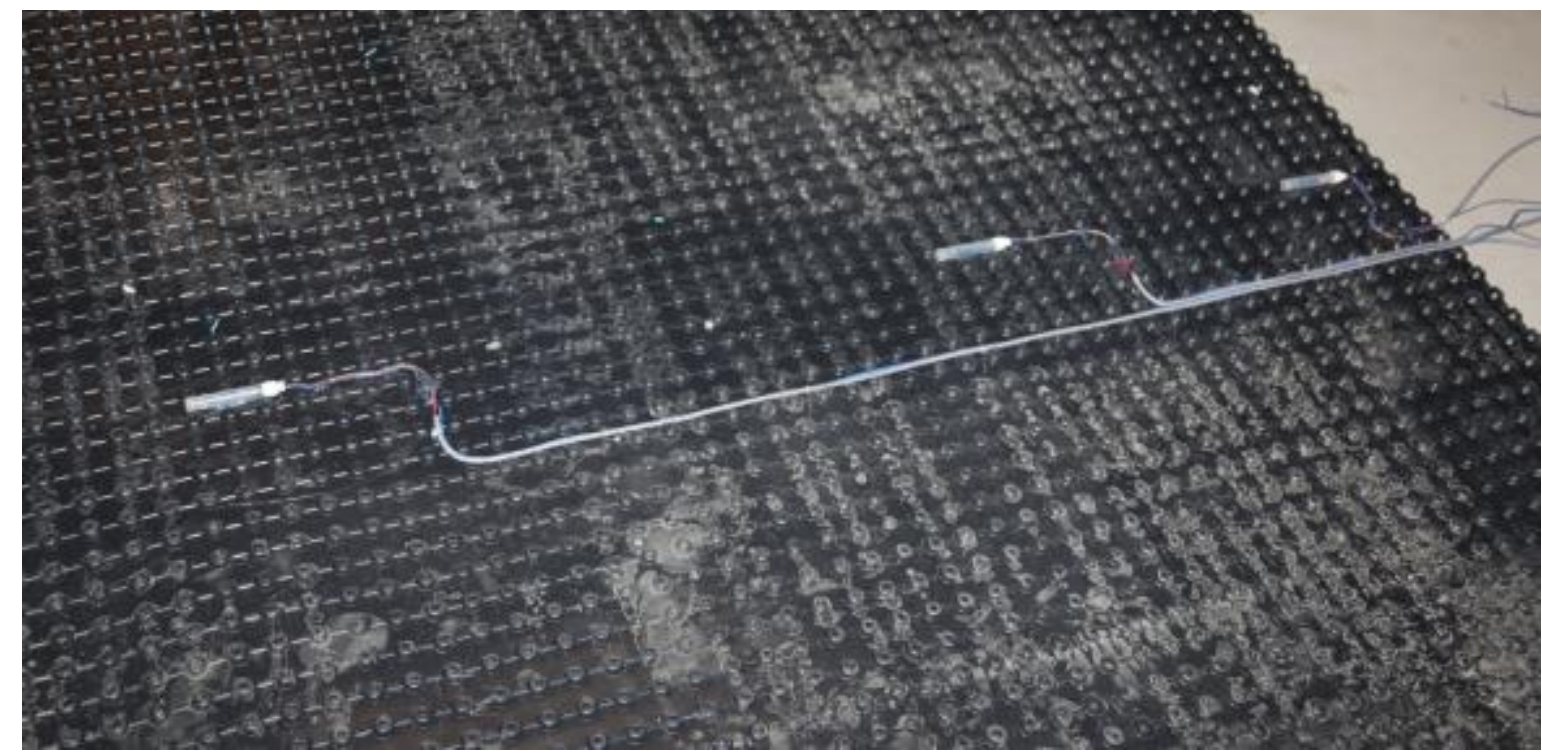

Figure 88. Nonadhered WSP with attached humidity sensors (dimpled side faces the wall)

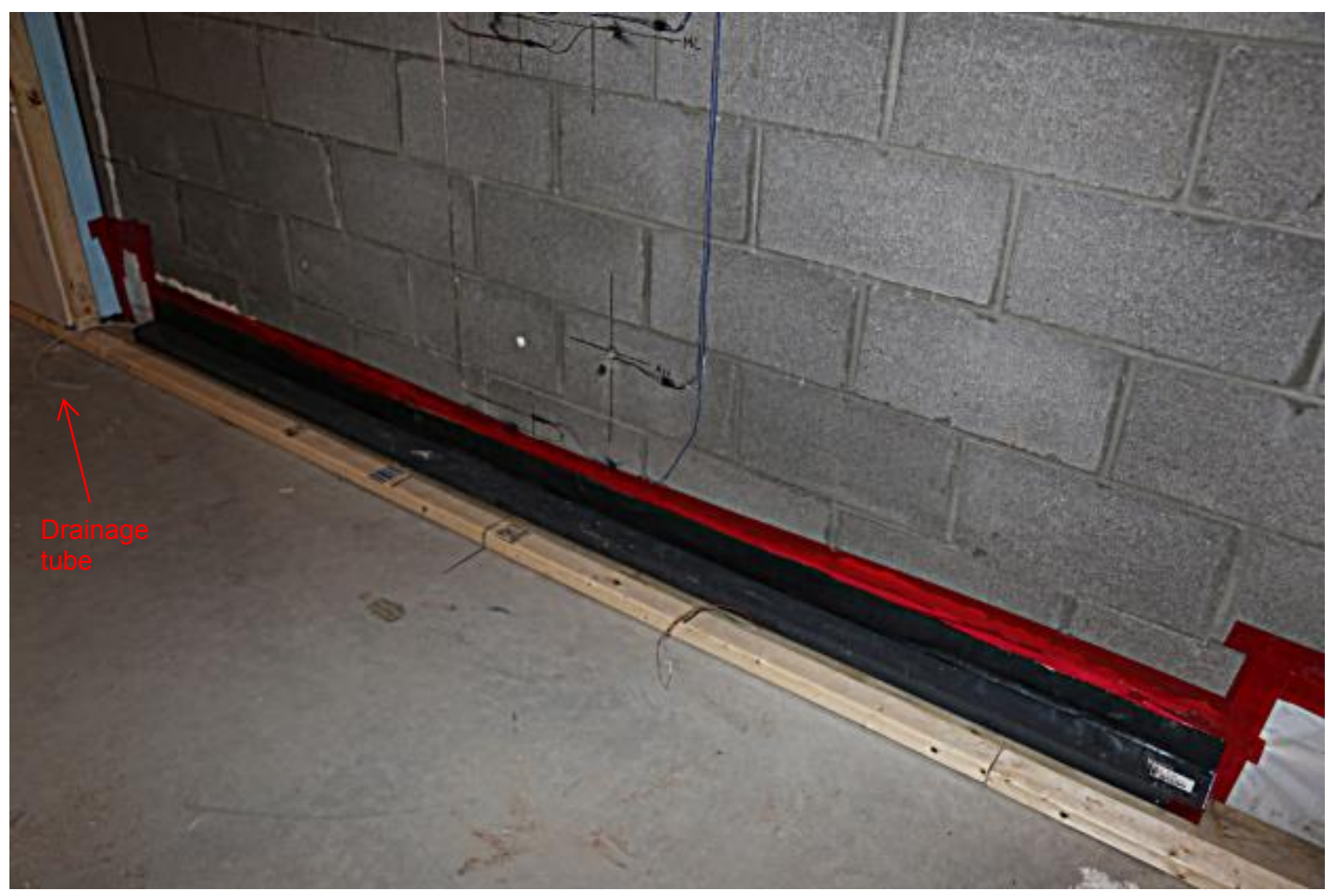

Figure 89. Nonadhered WSP drainage cavity with drainage tube at the left end 


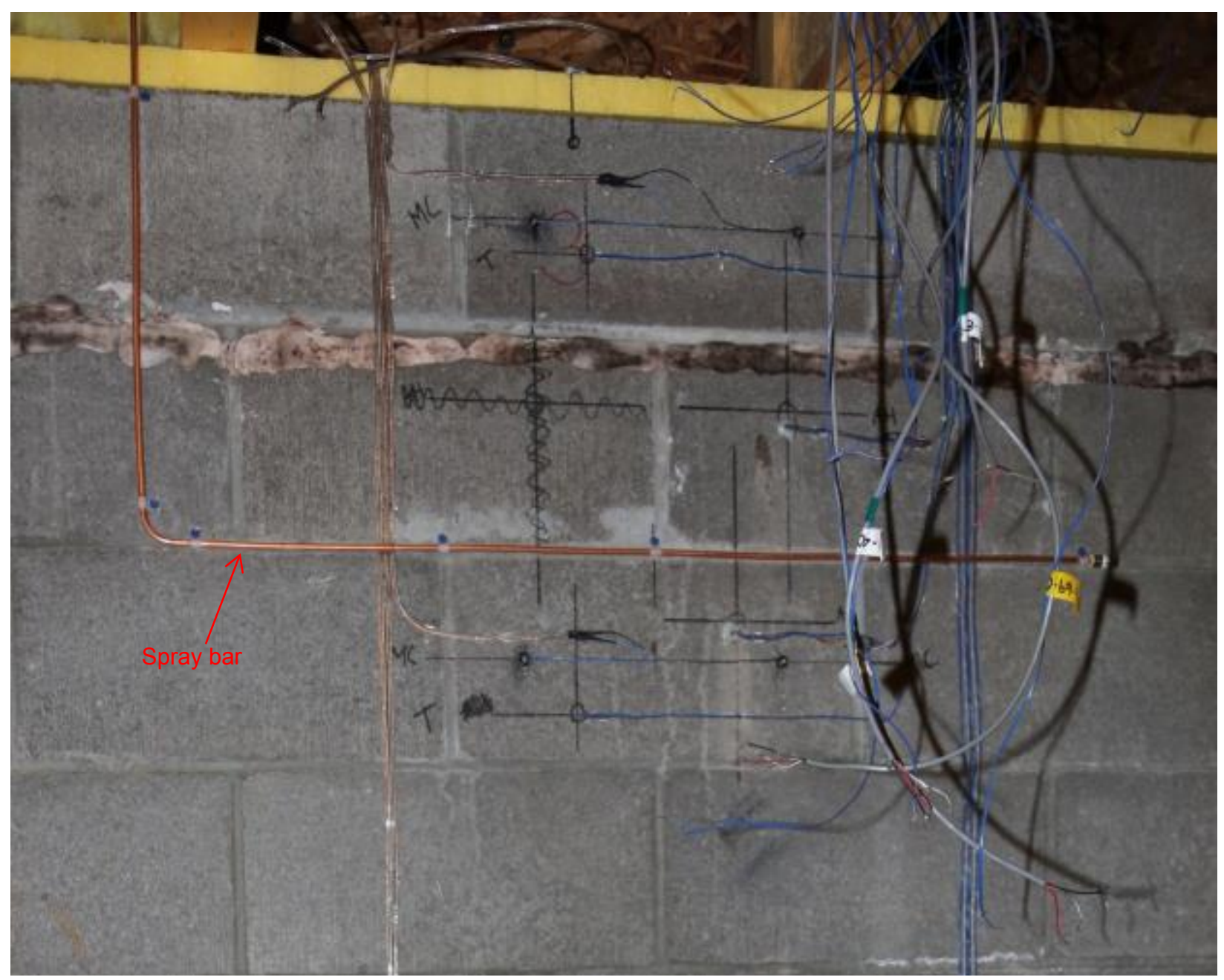

Figure 90. Spray bar system 


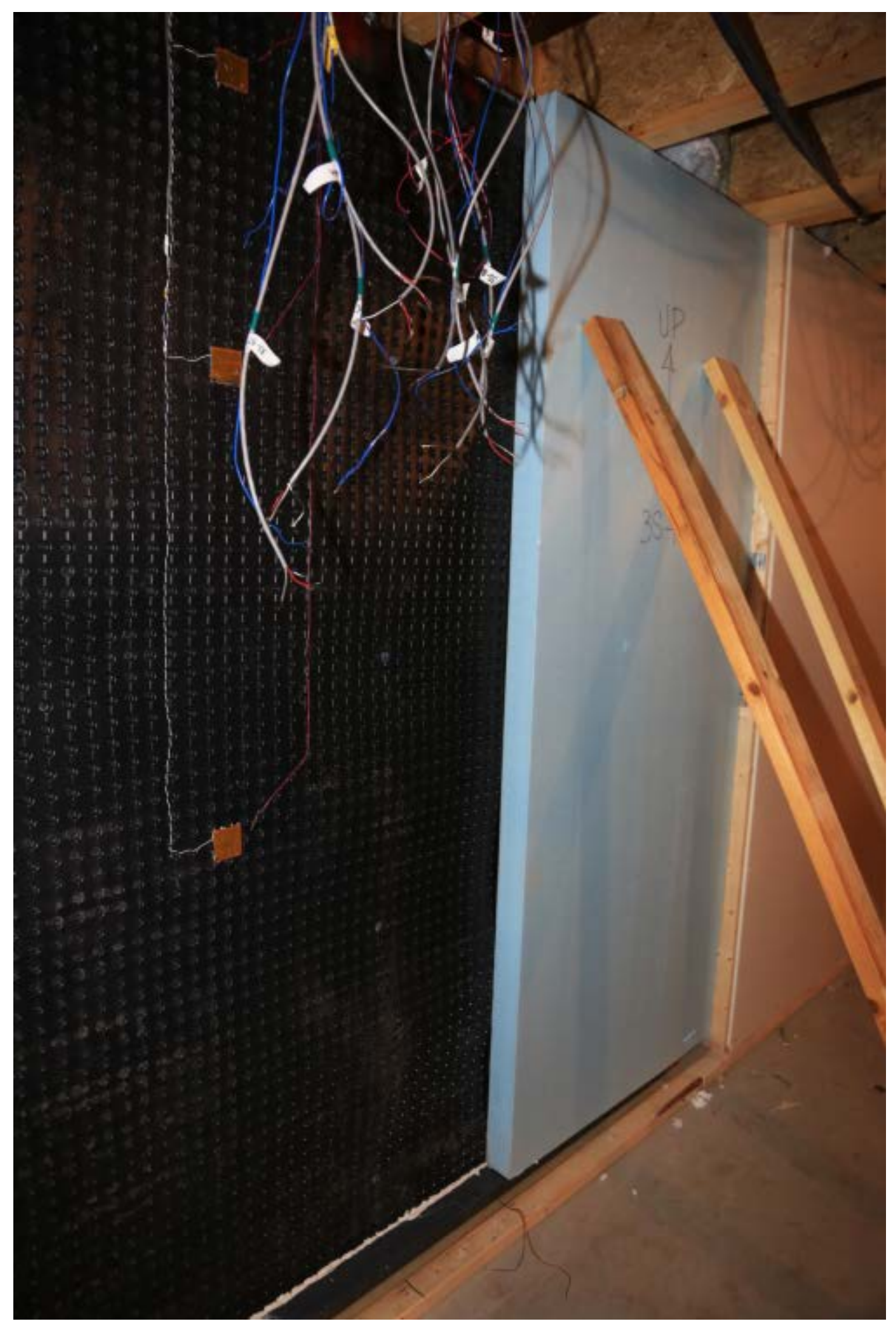

Figure 91. Insulation placement on nonadhered WSP 


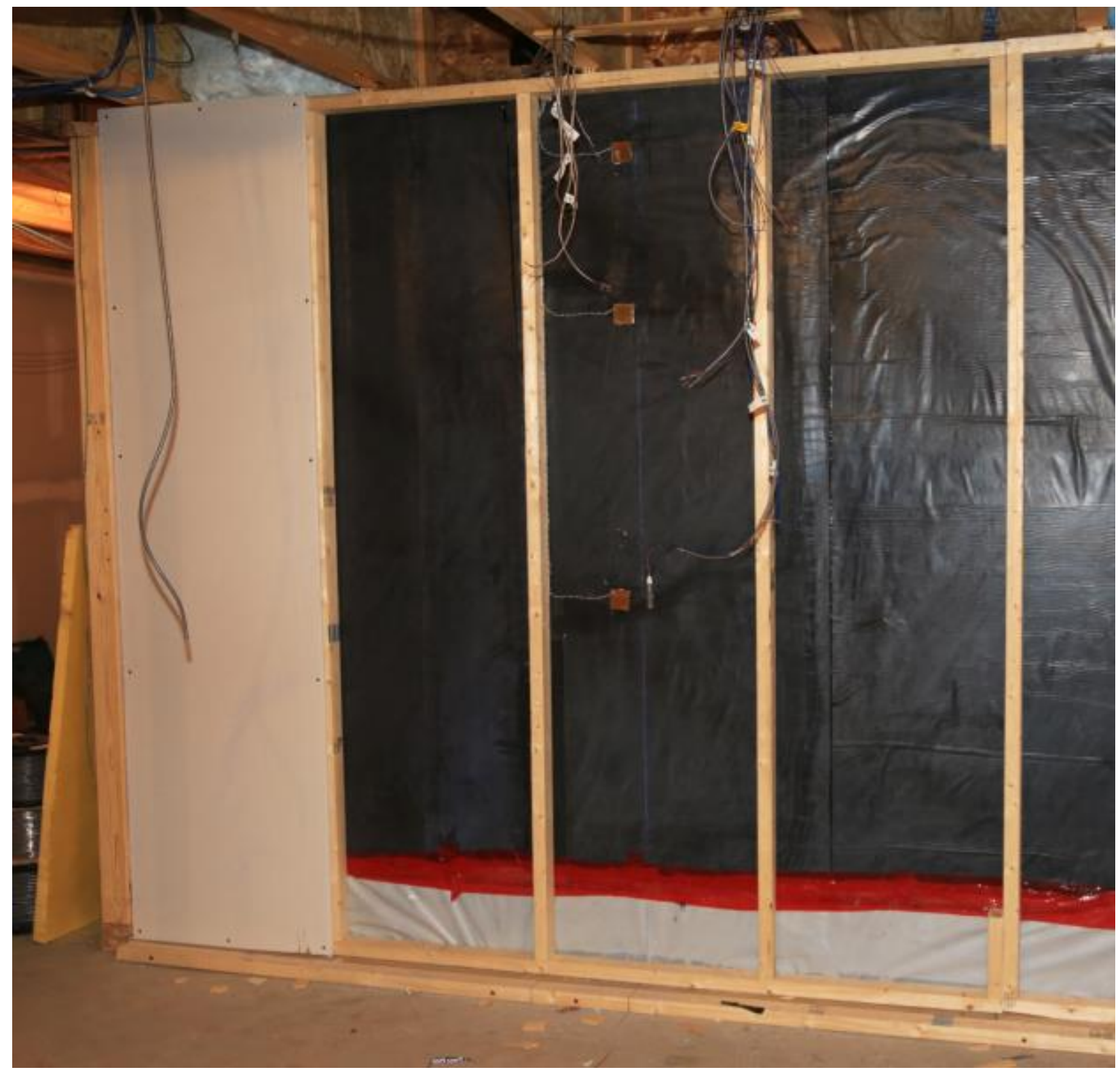

Figure 92. Framing and gypsum wallboard over adhered WSP 


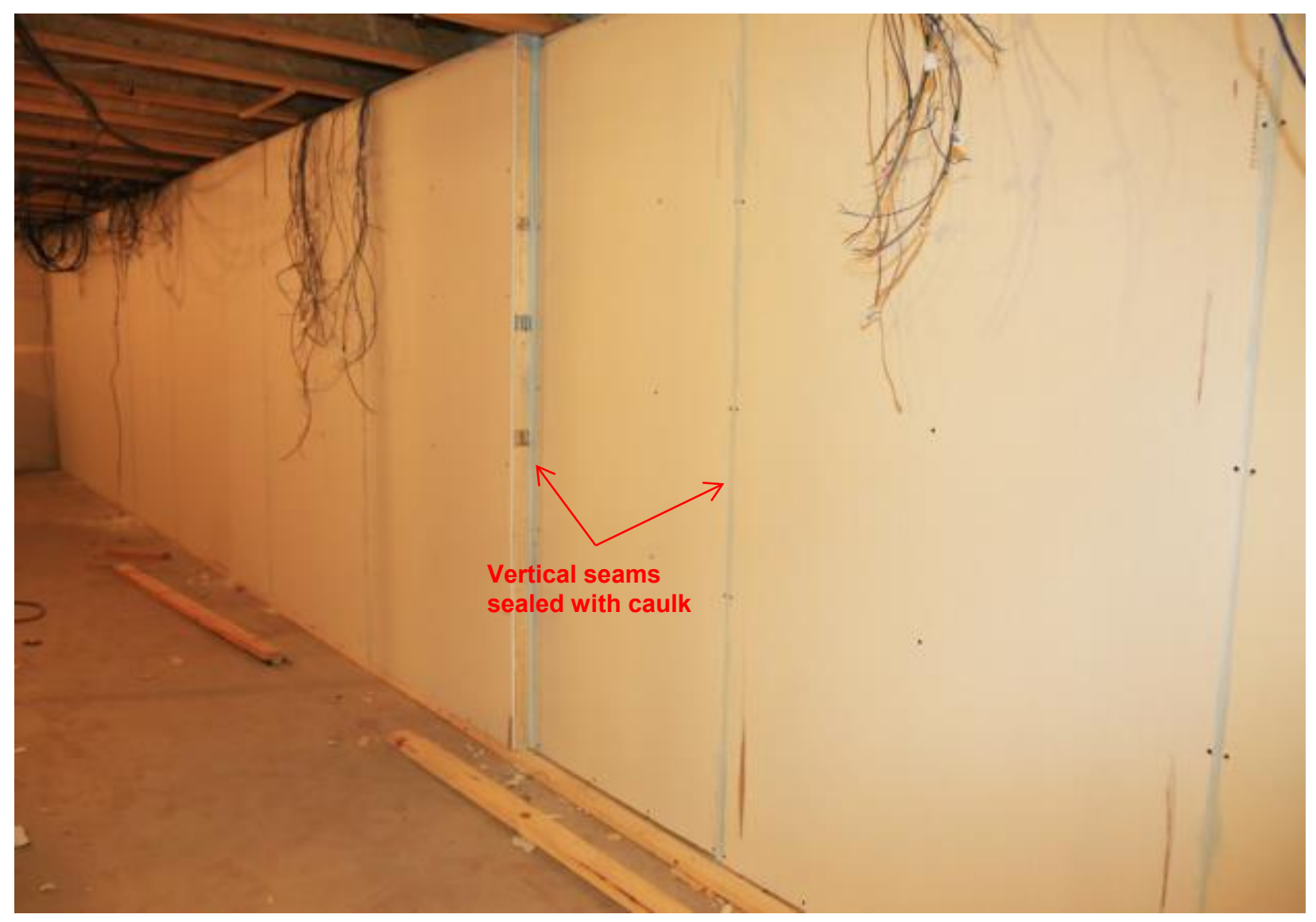

Figure 93. Finished interior surface test bays 1-4 


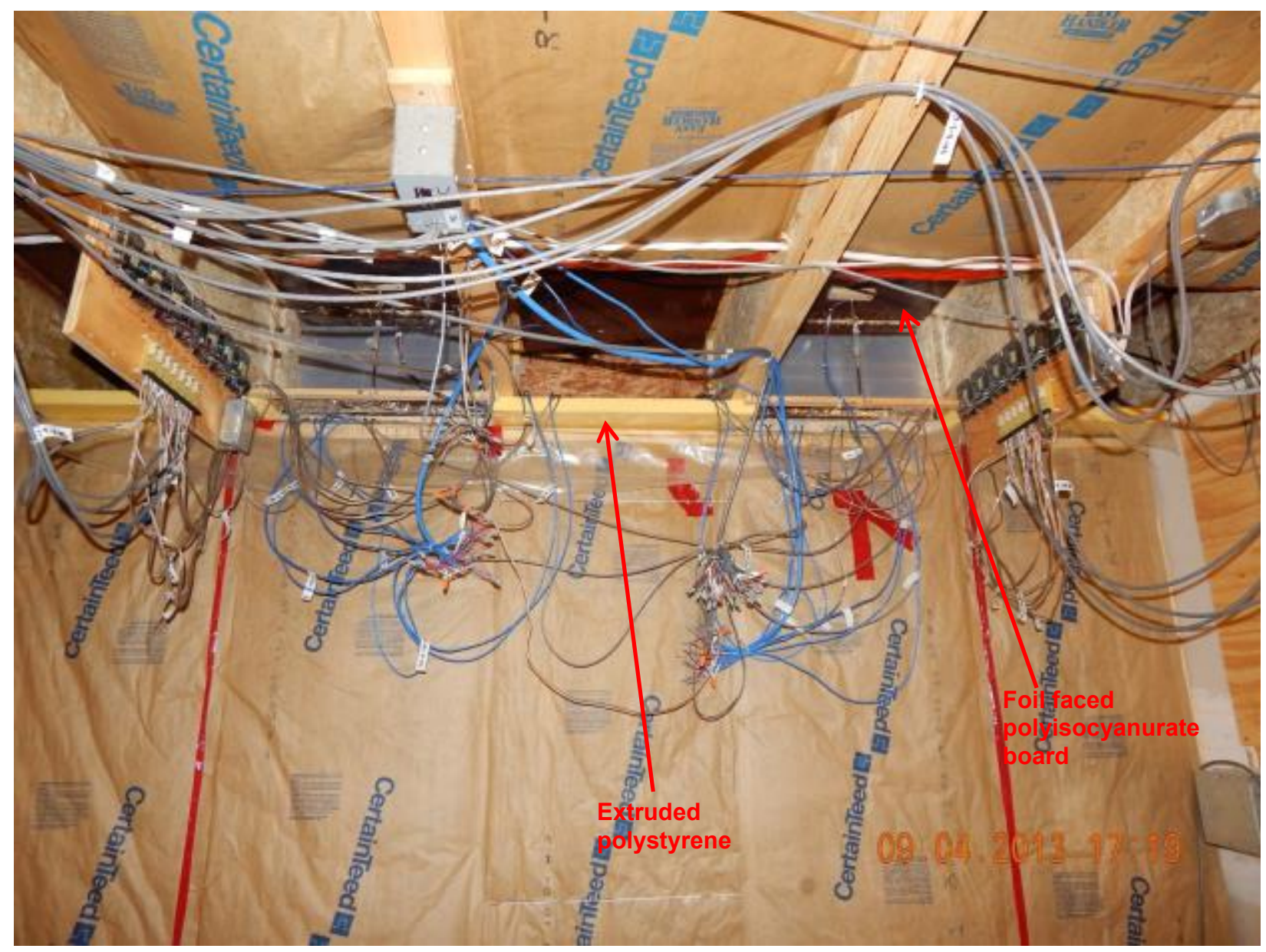

Figure 94. Completed Bay 5N rim-joist test cavities 


\section{Appendix B: Moisture Content Sensor Development ${ }^{33}$}

The moisture contents of the masonry block face shells and the wood boundary components of the rim-joist test cavities were measured using instrumentation developed and deployed for the first time in this experiment.

\section{B.1 Masonry Block}

One objective of the research was to collect data on the moisture content of the masonry block walls. This was likely the first time that the measurement of this parameter had been attempted on a significant scale (that is, multiple locations simultaneously, even on the same block) and a continuous sampling basis in the public domain. ${ }^{34}$

In the context of developing hygrothermal simulation code validation-grade data, foundation wall moisture contents are essential to overcome the limitations of RH measurements under condensing conditions on the face shells and in the cores of masonry blocks. Because sorption isotherms at RHs in excess of $90 \%$ in masonry materials are very steep, very small changes in RH correspond with large changes in moisture content. The RH sensors used in this experiment (individually calibrated Honeywell HIH-4000-003 thin-film capacitance) have a rated accuracy of $\pm 3.5 \%$, which is too large to adequately track the masonry moisture content in the crucial vapor condensing range. Indeed, extensive experience with these sensors has demonstrated that they tend to read $100 \%$ RH at actual RHs above 95\%. Thus, a low-cost, conductance based method for measuring masonry moisture contents with high precision developed by the principal investigator (Goldberg 2013) was adopted and refined for application in this project. The advantage of the methodology is its low cost in comparison with other reported techniques such as electrical time domain reflectometry (ETDR) (Khoshbakht and Lin 2006), heated "pad" temperature time constant (Davies and Ye 2009), and low-temperature confined ceramic resonator sensor for measuring the dielectric constant of the masonry (Maksimovic et al. 2012).

The sensors collecting the masonry block moisture content data consist of two probes spaced approximately 10-1/16 in. apart and centered across the height and width of the block. The probes are constructed by drilling two 1/4-in. diameter by 1-in. deep holes in the face shell of the block and installing equally sized graphite rods with their perimeters coated with an electrically conducting epoxy paste with graphite particles providing the conductance. A \#2 stainless steel screw (0.089-in. diameter) is then installed in each graphite rod and a wire lead is connected to each screw. Lastly, the top of the screw and graphite rod are covered with epoxy to isolate the probe from surface moisture, further reduce the potential for corrosion, and minimize the intrusion of water around the perimeter of the rod and screw. The screws are installed in the graphite rod and not directly into the concrete to minimize the galvanic potential between the screw and water in the block. The electrical conducting paste fills any voids around the rod that would otherwise have the potential to fill with water and cause irregular readings from variable graphite rod/masonry contact electrical resistance.

\footnotetext{
${ }^{33}$ Appendix B is based on and excerpted from a chapter in Harmon (2014).

${ }^{34}$ No references through 2012 were revealed by a search of the Compendex engineering database.
} 
The wire leads are attached to a half resistance bridge energized by a continuously operating $24 \mathrm{~V}$ DC power supply that supplies a constant voltage across the bridge. The voltage across the probes and the current flowing through them (on the order of $1 \mu \mathrm{A}$ to $1 \mathrm{~mA}$ ) are measured via the half bridge circuit and converted to a steady-state conductance. As the masonry block functions as a parallel resistance/capacitance circuit, the constant applied voltage eliminates the transients produced by capacitor charging and discharging, thus allowing the steady-state conductance to be measured in isolation (transients are eliminated). To achieve the necessary precision, the half bridge voltages are measured with a 24-bit analog-to-digital converter. The conductance reading correlates to the block moisture content; high conductance correlates to high moisture content and low conductance to low moisture content. The correlation is determined in the laboratory on a test masonry block by taking conductance readings for a known set of moisture contents. The moisture content is determined by periodic mass measurements of the concrete block as it dries between water-saturated and ambient equilibrium states.

Normal weight masonry blocks in compliance with ASTM C $90^{35}$ exhibit a wide range of porosities usually far lower than the maximum specified in the standard (about 20.8\%). ${ }^{36}$ Five calibration blocks were obtained from different sources for experimental evaluation. The amount of water uptake in a masonry block is dependent on its porosity, so having a range of calibration samples that bracket the installed block's porosity is necessary to infer its moisture content by interpolation. The in-situ block porosity was determined by removing coupon samples from the face shell of masonry blocks at the CRRF. These samples were tested per ASTM C140. ${ }^{37}$ Because the coupons were taken from existing construction, a single full block face shell (16 in. wide $\times 8$ in. high) could not be obtained. In lieu of a full face shell, three coupons were removed and tested in aggregate to reduce the error introduced from the low sample weight of a single sample. Fortunately, the measured aggregate porosity of the CRRF face shells fell within the porosity range of the five calibration blocks already obtained.

The wide variation in masonry block porosities poses a particular challenge for hygrothermal analysis. The porosity results from the five calibration stretcher masonry blocks (the type used in the CRRF test walls) are given in Table 8. The ASTM C140 test procedure is augmented with a mathematical analysis of porosity that enables the skeleton density and total volume of the specimen also to be calculated from the ASTM results. These data are also given in Table 8. The porosity data in Table 8 demonstrate that using "standard" masonry block material properties, especially porosity, may be invalid in any particular case (such as the CRRF). This is of great importance in attempting to validate hygrothermal simulation codes with experimental data.

\footnotetext{
${ }^{35}$ Standard Specification for Loadbearing Concrete Masonry Units.

36 The description of the calibration methodology and results is extracted from Harmon (2014).

${ }^{37}$ Standard Test Methods for Sampling and Testing Concrete Masonry Units and Related Units.
} 
Table 8. Masonry Block ASTM C140 Test Results

\begin{tabular}{c|c|c|c}
\hline $\begin{array}{c}\text { Face } \\
\text { Shell }\end{array}$ & $\begin{array}{c}\text { Porosity } \\
\mathbf{( \% )}\end{array}$ & $\begin{array}{c}\text { Total } \\
\text { Volume }\left(\mathbf{m}^{\mathbf{3}}\right)\end{array}$ & $\begin{array}{c}\text { Skeleton } \\
\text { Density }\left(\mathbf{k g} / \mathbf{m}^{\mathbf{3}}\right)\end{array}$ \\
\hline $\mathbf{1}$ & 13.18 & 0.0110 & 2477 \\
$\mathbf{2}$ & 10.808 & 0.0110 & 2446 \\
$\mathbf{3}$ & 11.27 & 0.0093 & 2441 \\
$\mathbf{4}$ & 13.24 & 0.0059 & 2469 \\
$\mathbf{5}$ & 9.30 & 0.0121 & 2481 \\
\hline
\end{tabular}

Because the moisture content was measured on the interior and exterior face shells of the masonry blocks and the current path between the electrodes is through the face shell only, the calibration needs to be performed on the face shells only, not the entire block. Thus, each of the five masonry block samples was carefully split into two face shells by removing as many of the webs as possible. An example of the resultant test sample is shown in Figure 95.

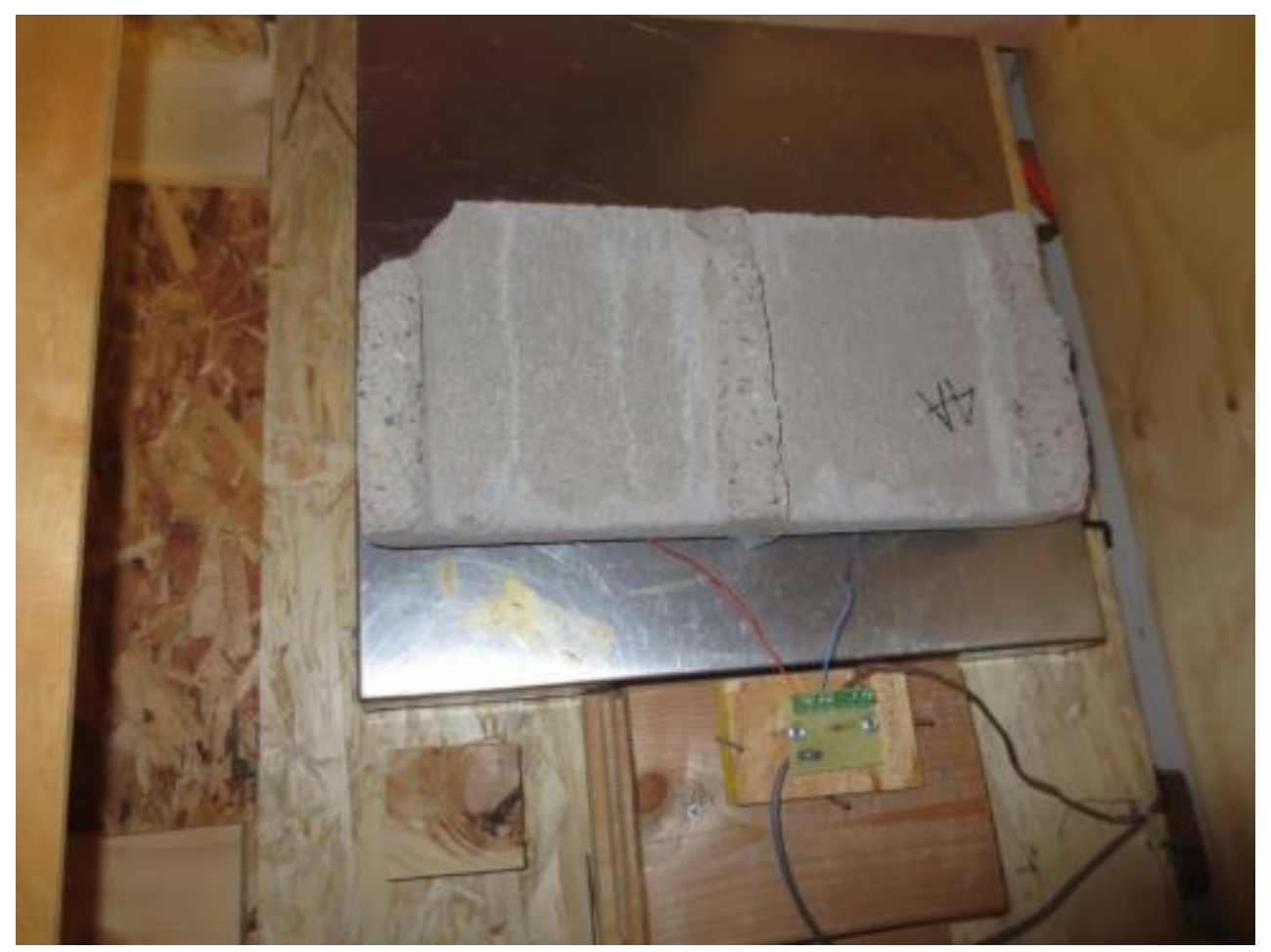

Figure 95. Face shell test sample

A set of graphite rod probes was installed in each face shell, but the screws, wire leads, and epoxy were not installed. Using the ASTM C140 methodology for determining saturated weight, the face shell was saturated in a bath of water for 24-28 hours, then removed and weighed. Because the graphite rods are not porous, the weight represents the water absorbed by the face shell. The difference in weight between the drilled out concrete block and the installed graphite rods is negligible. The results of the ASTM C140 test for the 10 face shells as well as the aggregate of the three face shell coupons removed from masonry blocks at the CRRF are shown in Table 9. 
Table 9. Masonry Block Face Shell ASTM C140 Test Results

\begin{tabular}{c|c|c|c}
\hline $\begin{array}{c}\text { Face } \\
\text { Shell }\end{array}$ & $\begin{array}{c}\text { Porosity } \\
(\mathbf{\%})\end{array}$ & $\begin{array}{c}\text { Total Volume } \\
\left(\mathbf{m}^{\mathbf{3}}\right)\end{array}$ & $\begin{array}{c}\text { Skeleton Density } \\
\left(\mathbf{k g} / \mathbf{m}^{\mathbf{3}}\right)\end{array}$ \\
\hline 1A & 12.45 & 0.0037 & 2472 \\
1B & 12.41 & 0.0038 & 2488 \\
2A & 9.62 & 0.0031 & 2415 \\
2B & 9.51 & 0.0039 & 2429 \\
3A & 10.81 & 0.0040 & 2416 \\
3B & 10.85 & 0.0039 & 2425 \\
4A & 11.15 & 0.0027 & 2418 \\
4B & 12.00 & 0.0024 & 2421 \\
5A & 8.88 & 0.0034 & 2475 \\
5B & 9.06 & 0.0035 & 2446 \\
CRRF & 11.73 & 0.0026 & 2530 \\
\hline
\end{tabular}

A comparison of Table 8 and Table 9 shows clearly that the porosities of the face shell are different from those of the entire block. That is, the porosity of the webs in general is different from the porosity of the face shells that in turn can be different from each other. The largest difference was measured for face shell $4 \mathrm{~A}$ that has a smaller porosity than the whole block by $2.09 \%$.

The block was then allowed to dry and the screws, wire leads, and epoxy were installed. After the epoxy cured, the block was again saturated in a bath of water for 24-28 hours. The block was then removed from the bath of water and placed on the scale. The probes were connected to the data acquisition system. Figure 95 shows the essence of the calibration apparatus. In this case, because of the weight of the face shells, the only suitable remote reading digital scale available had a precision of $0.02 \mathrm{~kg}$ and a manufacturer's specified accuracy of $0.01 \%$ full scale.

A data acquisition system read the electrical circuit data (supply and half-bridge resistor voltages) and the mass of the face shell every 10 minutes. The first reading represented $100 \%$ saturation. Readings were taken until the face shell reached equilibrium with ambient conditions, which was evident when the mass and conductance reached equilibrium (see Figure 97). A climate chamber approximately $4 \mathrm{ft}$ wide $\times 12 \mathrm{ft}$ long $\times 8 \mathrm{ft}$ high with regulated temperature and humidity was used to dry the face shell from saturation to equilibrium with controlled ambient conditions. The room was equipped with an air conditioner and a humidistat that was used to maintain an $\mathrm{RH}$ of approximately $30 \%$. A standalone convection heater was used to increase the temperature of the room with its air flow directed over the test sample via a drying duct enclosure (Figure 96). 


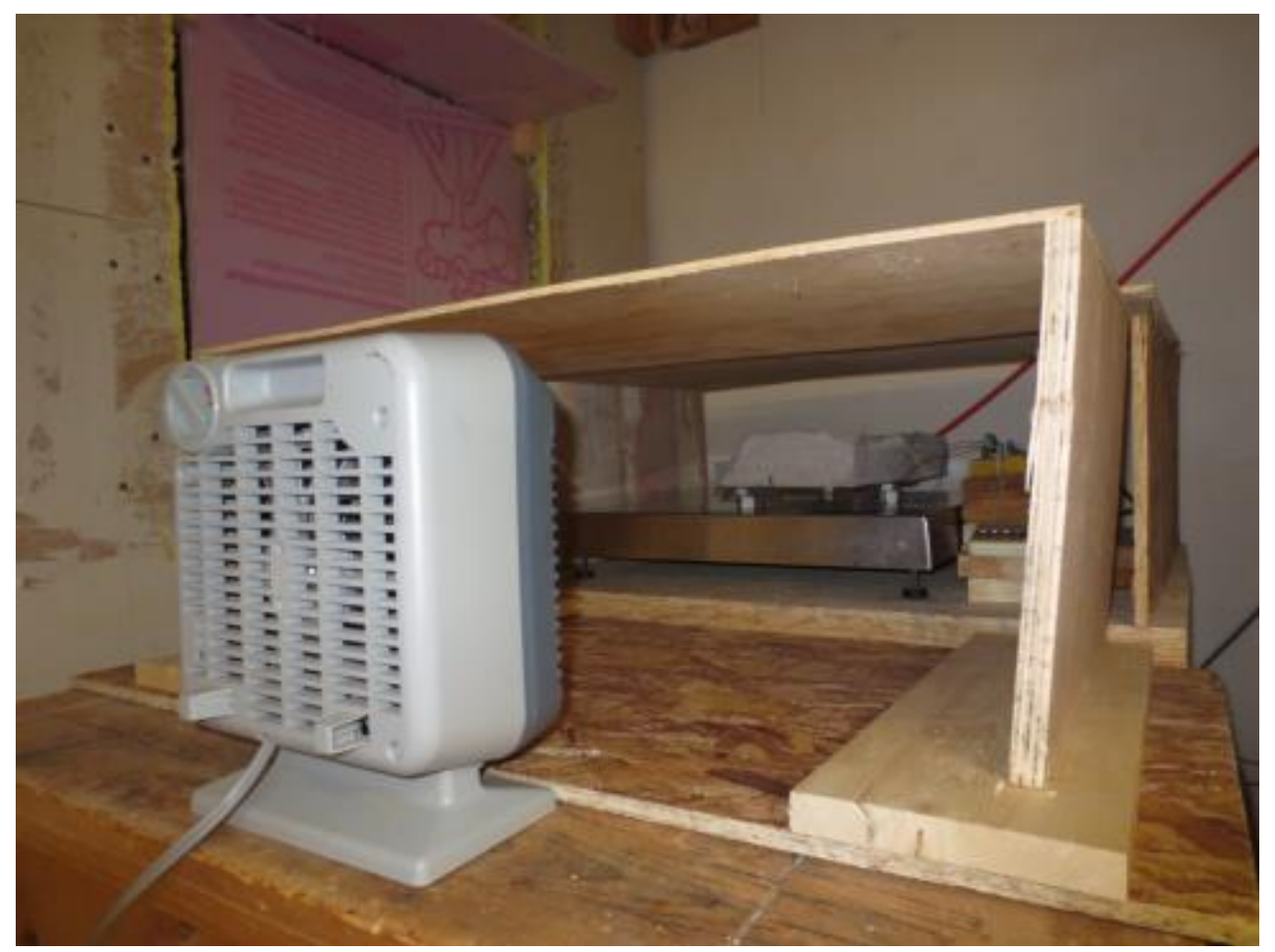

Figure 96. Calibration rig drying enclosure

The intent was to maintain conditions in the room that allowed the face shell to dry to a sufficiently low moisture content so that a full calibration curve could be drawn (that is, with the amount of moisture in the block approaching zero).

The conductance across the probes in the block was calculated indirectly using a half resistance bridge comprising a series circuit with a $24-\mathrm{V}$ power supply, the concrete block and a 249 -ohm resistor with a $1 \%$ tolerance. The voltage across the probes was determined by subtracting the measured voltage across the resistor from the measured total supply voltage to avoid contaminating the calculated current between the electrodes with the current passing through the voltmeter. The current through the circuit was calculated by dividing the measured voltage across the resistor by its resistance. The electrical conductance of the block between the electrodes was calculated using the calculated current and voltage across the electrodes.

Figure 97 depicts the raw time series drying data for face shell 4B (Table 9). This graph shows that the method is highly sensitive to small changes in moisture content at higher saturations (a large change in conductance for a small change in mass). This is exactly the characteristic desired to compensate for the low sensitivity and accuracy of thin-film capacitance RH transducers at moisture contents above $90 \%$. 


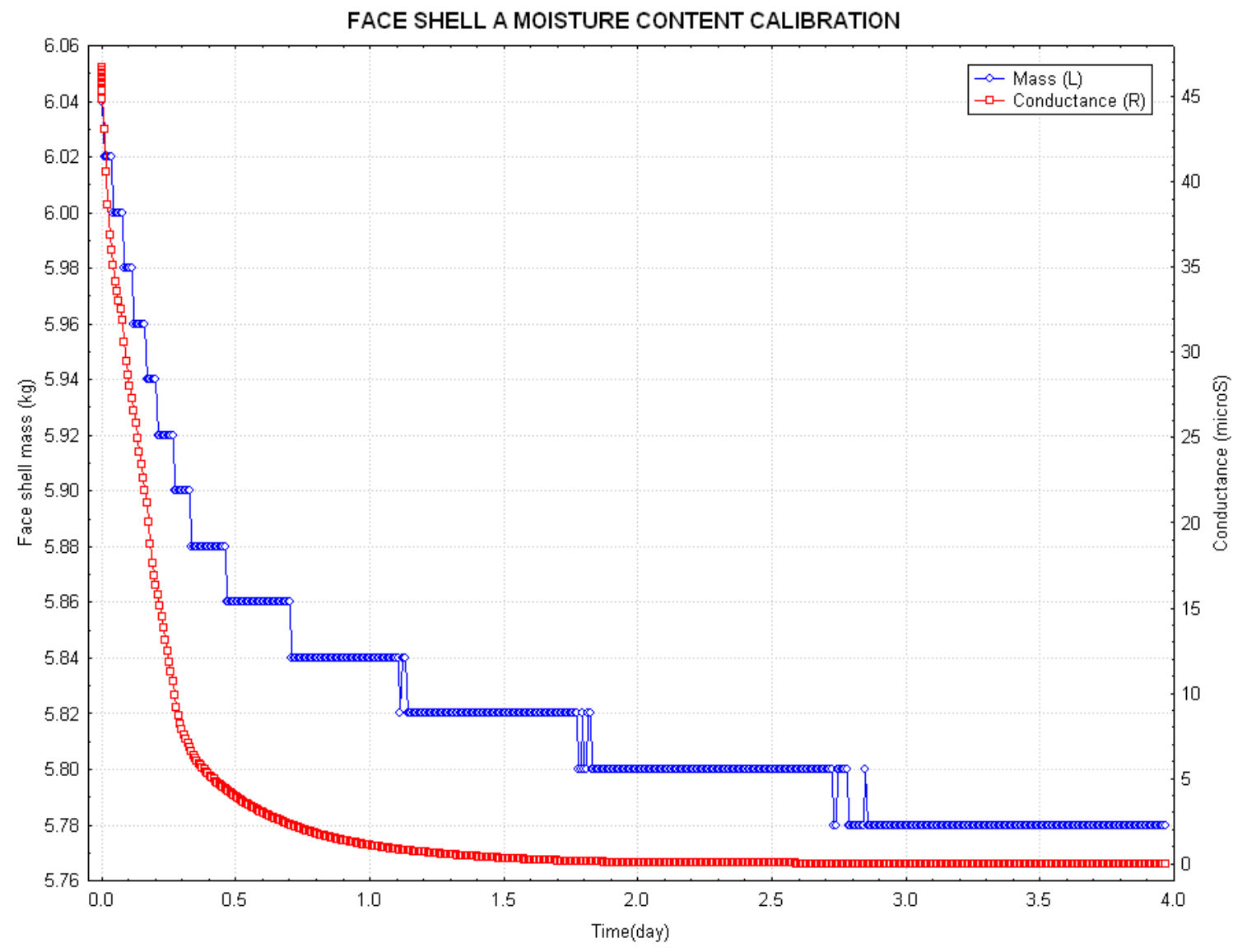

Figure 97. Raw calibration data for a masonry block face shell

The equilibrium conductance at lower moisture contents is also visible in Figure 97 and Figure 98. The profile representing the mass of the block is stepped because the scale's precision is $\pm 0.02 \mathrm{~kg}$ and it is not sensitive enough to measure the intermediate change in mass. ${ }^{38}$ For a given mass (i.e., moisture content) the corresponding conductance is the first reading on a given mass plateau.

Figure 98 shows raw conductance/volumetric moisture content profiles for the block 4 face shells derived from the raw time series data (such as Figure 97). The volumetric moisture content $M C_{V}$ is calculated as follows:

$$
\begin{gathered}
V_{T O T}=\frac{M_{\text {sat }}}{\left[\xi \rho_{W}+(1-\xi) \rho_{s k}\right]}(B .1) \\
V_{W}=\frac{M_{\text {sat }}-M_{d r y}}{\rho_{W}} \\
M C_{V}=V_{W} /_{V_{T O T}}
\end{gathered}
$$

\footnotetext{
${ }^{38}$ The scale used in the calibration procedure was an OHAUS PBI with a range of $0-68 \mathrm{~kg}$ and a precision of \pm 0.02 $\mathrm{kg}$. Clearly a balance with a higher precision is desirable, but was not available.
} 
where:

$V_{\text {TOT }}=$ total volume of masonry block

$V_{W}=$ volume of water

$M_{\text {sat }}=$ water saturated mass of masonry block

$M_{d r y}=$ oven-dried mass of masonry block

$\xi=$ porosity (ASTM C140 measurement - Table 9)

$\rho_{w}=$ density of water

$\rho_{s k}=$ masonry block skeleton density (ASTM C140 measurement - Table 9)

The final calibration curves for all 10 face shells (Table 9) are shown in Figure 99. Each color corresponds to the pair of face shells with the porosities depicted in the legend. There a few interesting features in this graph to be noted:

- As the face shells approach $0 \%$ saturation, the conductance approaches zero, demonstrating that the conductance decreases as the proportion of air in the voids increases. In general, the data show that higher porosity face shells have lower conductance readings than low porosity face shells for a given volumetric moisture content $\left(\mathrm{V}_{\mathrm{w}} / \mathrm{V}_{\text {tot }}\right)$. This arises because at a given volumetric moisture content, the volume of water in the high and low porosity face shells was approximately the same, ${ }^{39}$ but in the low porosity face shells the pores were filled to a greater extent (higher saturation) than in the high porosity face shells. The critical factor affecting the conductance reading and the relationship between different porosity face shells is the ratio of air to water. The greater the ratio, the lower the conductance reading. The volumetric moisture content was plotted instead of the degree of saturation, because at a given volumetric content it reflects approximately the same volume of water in all of the face shells, regardless of porosity. ${ }^{40}$

- The face shell profiles are closely correlated with each other except for face shells 5 that are divergent. It is thus clear that something other than a porosity difference is producing this effect. It was presumed that curve 5B (9.06\% porosity) was accurate because it followed the general pattern of the graph (decreasing porosity for increasing conductance). The saturated conductance reading for face shell 5A was taken a second time and confirmed that there was not an error in the data collection procedure. It was speculated that there was a problem with the insulation of the sensor, such as a crack in one of the graphite electrodes.

- The location of the block 2 face shell profiles ( $9.62 \%$ and $9.51 \%$ porosity) is out of sequence in terms of its porosity. The block 2 profiles would be expected to fall between the profiles from blocks 3 and 5 (10.81\%/10.85\% and 8.88\%/9.06\% porosity,

\footnotetext{
${ }^{39}$ Differences arising from inconsistencies in the amount of web material left attached to the face shell.

${ }^{40}$ Saturation ratio $=$ Volumetic moisture content/porosity.
} 
respectively). The block 2 face shell profiles are consistent with each other, indicating that there was likely not an error with the data collection procedure. It is speculated that the block material mix affected the conductance readings. For example, if block 2 contained a fly ash admixture, its conductance would be increased relative to blocks without a fly ash admixture (Naik et al. 2010). Block 2 was acquired from a construction waste yard and there was no way to learn the details of its source and no ability to test the masonry block composition.

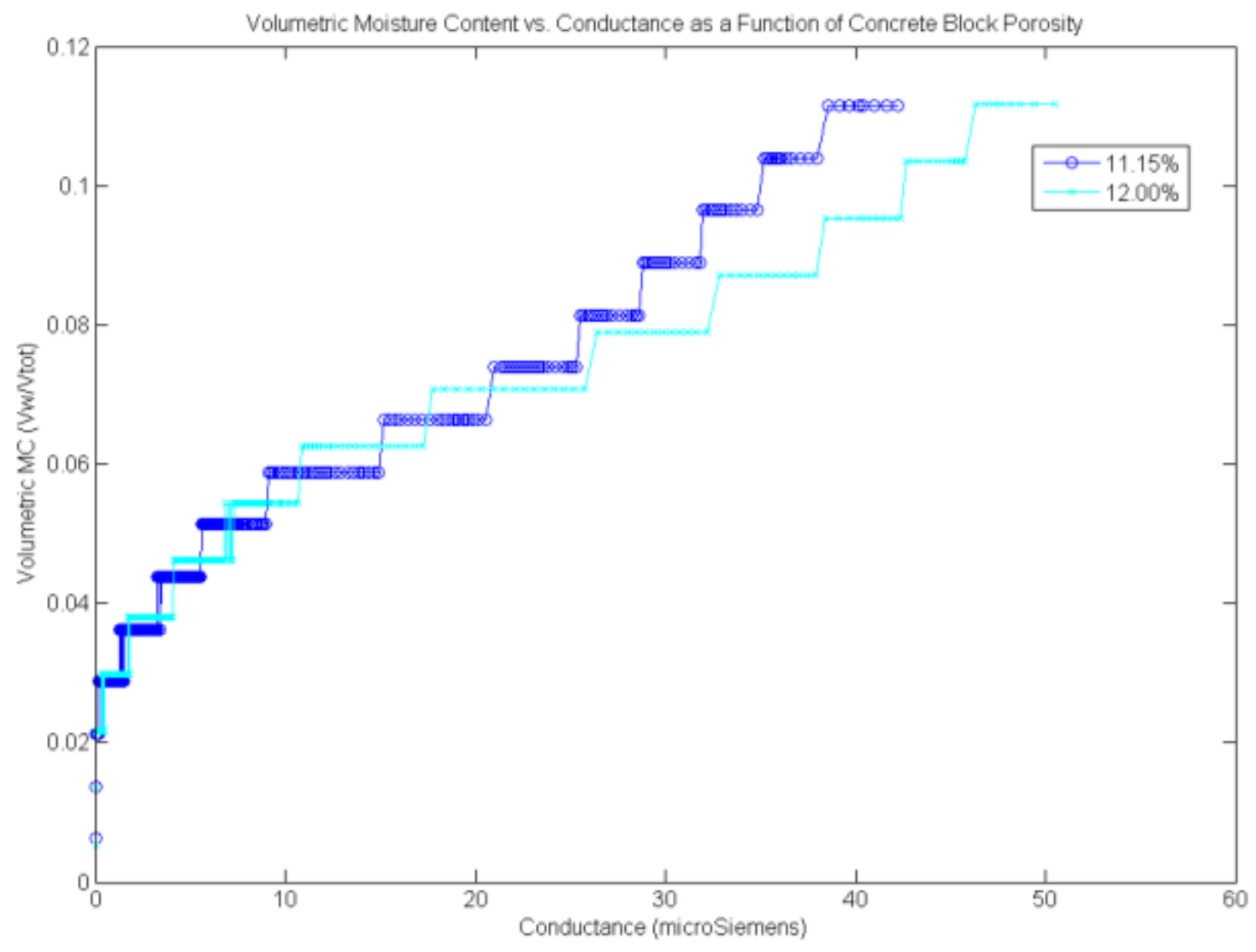

Figure 98. Drying data for block 4 face shells 


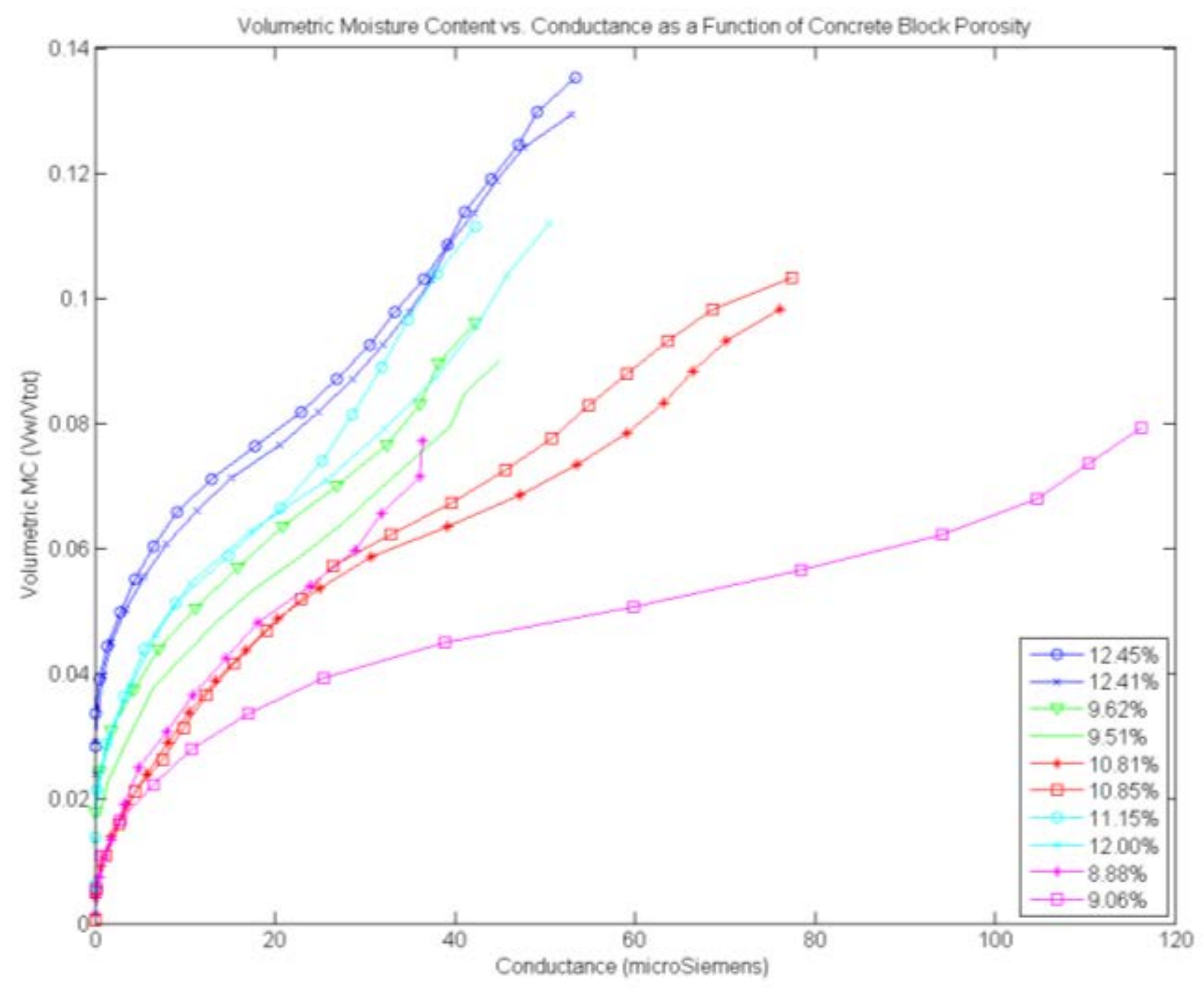

Figure 99. Face shell calibration curves

Fortunately, the CRRF masonry block porosity $(11.73 \%)$ fell neatly between the porosities of the face shells of block $4(11.15 \%$ and $12 \%)$ and the block 4 profiles showed no anomalies. Therefore, it was a simple matter to interpolate the CRRF masonry block conductance/volumetric moisture content profile from the block 4 face shell profiles.

Two refinements to the methodology may be evaluated in future research:

- Investigate the use of alternate nonmetallic electrode materials that are less susceptible to cracking than graphite rods.

- Clearly it is preferable to calibrate multiple whole masonry blocks used in the construction if possible (such as for new construction). In general this is not possible, so including a material composition test for the target masonry block coupons to determine their carbon content is desirable. The calibration curve could then be derived from masonry bocks spanning both the porosity and carbon content of the target block. 


\section{B.2 Wood}

The same approach was used to measure the wood moisture content as was used for the concrete block moisture content. Two insulated stainless steel pins formed the electrodes and were inserted into the wood component to approximately half the depth of the component $1 \mathrm{in}$. apart. The exposed portion of the pin was coated in marine epoxy to protect it from moisture. The pins were connected to the same circuit used for the masonry blocks.

Calibrations of the wood moisture content sensors were conducted in the laboratory to create a correlation to the field data. The calibration was conducted on a 6 -in. $\times 6$-in. $\times 1 / 2$-in. OSB sample and a 6 -in. $\times 5-1 / 2$-in. $\times 1-1 / 2$-in. sample of $2 \times 6$ treated lumber. The OSB sample was scrap material from the CRRF and the $2 \times 6$ sample was purchased new because a coupon could not be extracted from the CRRF sill plate for structural and airtightness reasons. The wood species and treatment method were not labeled on the purchased $2 \times 6$ sample. The treated $2 \times 6$ was the only available product at a national building supply store and considered a standard product. Note that the $2 \times 6$ sill plate at the CRRF would likely have been treated with chromated copper arsenate because it was standard in 1997 when the building was constructed; however, chromated copper arsenate is no longer used for such applications.

After the samples were cut to size, the oven-dry weight was determined using method B from ASTM D4442: Standard Test Methods for Direct Moisture Content Measurement of Wood and Wood- Base Materials (ASTM International 2007). The samples were dried in a $103^{\circ} \mathrm{C}$ oven until there was no change in the mass over a 4-hour period. The $1 / 2$-in. OSB took 3 days to reach ovendry and the $2 \times 6$ took 8 days. All mass measurements were taken using a scale with a $\pm 0.1 \mathrm{~g}$ precision. The results of the oven drying are shown in Table 10.

Table 10. Wood Sample Drying Data (per ASTM D4442)

\begin{tabular}{c|c|c}
\hline Sample & $\begin{array}{c}\text { Oven-Dry Mass } \\
(\mathbf{g})\end{array}$ & $\begin{array}{c}\text { Moisture Content at } \\
\text { Drying Termination } \\
(\mathbf{m}-\mathbf{\%})\end{array}$ \\
\hline $\mathbf{1} 2$-in. OSB & 161.3 & 2 \\
$\mathbf{2} \times \mathbf{6}$ & 449.9 & 6 \\
\hline
\end{tabular}

Immediately after the oven-dry mass was attained, the pins with leads were installed and coated in epoxy. The mass was then taken to determine the mass of the pins, leads, and epoxy. After a minimum of 24 hours for the epoxy to cure, the sample was placed in a water bath to saturate. The sample was removed from the bath when there was no appreciable change in mass over an approximate 24 -hour period $(2.4 \%$ for the $1 / 2$-in. OSB and $1 \%$ for the $2 \times 6)$.

When the saturated condition was reached, the sample was placed onto the scale and connected to the data acquisition system described above (Section 2.4.1), except, in this case, the scale had a precision of $\pm 0.1 \mathrm{~g}$. The sample was elevated off the scale approximately $1-1 / 8 \mathrm{in}$. by two nonporous spacers. The drying process using the same apparatus used for the masonry block calibrations (see Figure 96). The drying fan was set on low fan speed and placed 25 in. from the 
edge of the scale. The scale was set to take readings at the first scale reading as opposed to a stable scale reading because the fan resulted in a noisy mass reading $\left(<1 \mathrm{~g}\right.$ noise level). ${ }^{41}$

Data were collected at an interval of 30 seconds or shorter for at least the first 12 minutes, after which the collection interval was increased to 2 minutes. After 10 minutes the scale was checked for accumulated water; none was ever present. The readings continued until the conductance plateaued. The $1 / 2$-in. OSB reached a measured conductance $0 \mu \mathrm{S}$ and the $2 \times 6$ plateaued at $0.000333 \mu \mathrm{S}$.

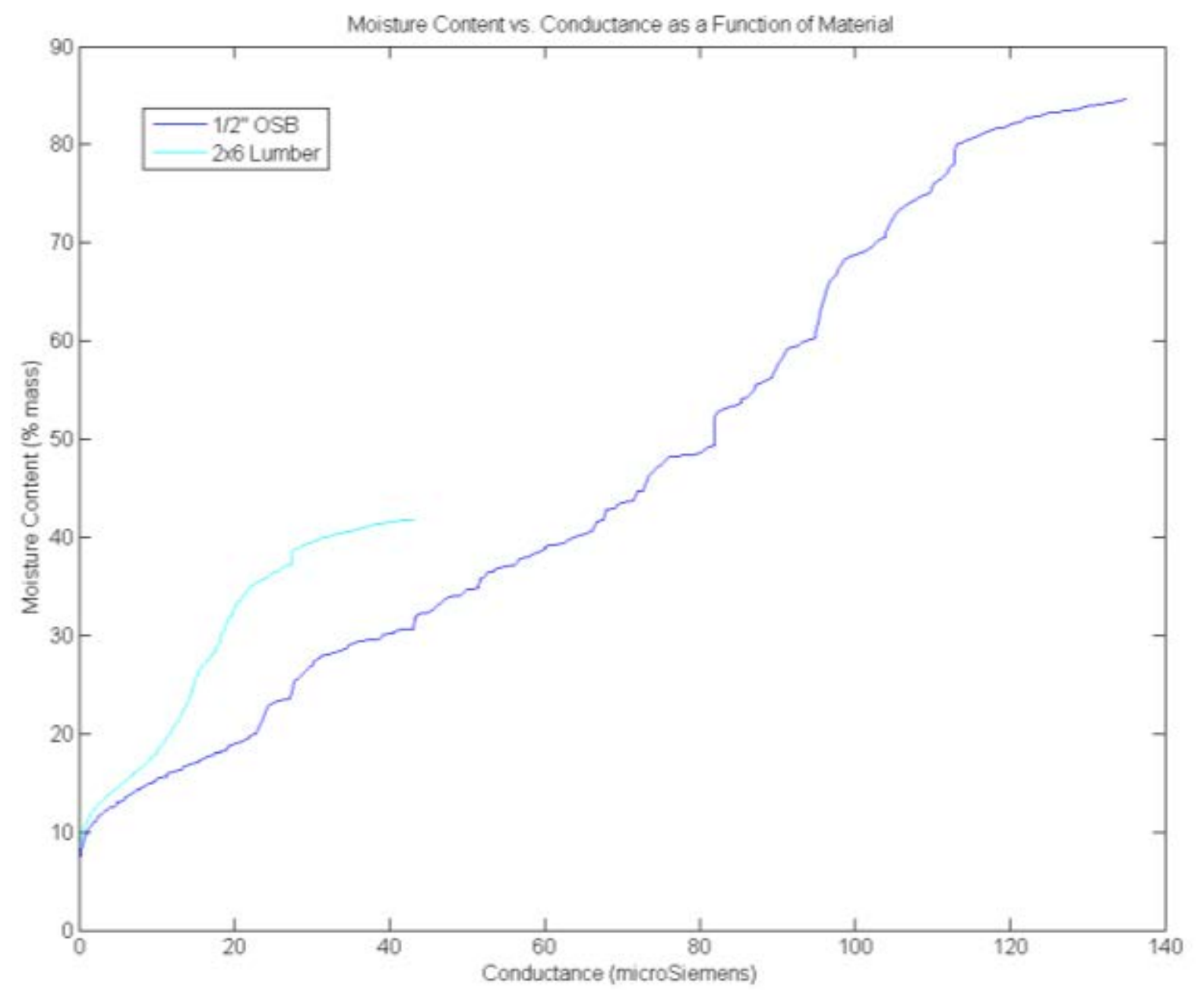

Figure 100. Wood moisture content calibration curves

The drying process generated a data set with a conductance and mass at every time interval. The data set was filtered by taking the first reading at a given mass and eliminating all data points that followed that had a mass of equal or greater value. This reduced data set was further filtered by

\footnotetext{
${ }^{41}$ Owing to the sensitivity of the scale, it would have been preferable to dry the sample in a radiant heat drying chamber with sample surface temperature control.
} 
removing all data points where the conductance increased over a time interval. These two filters generated a smoothed data set (see Figure 100).

The moisture content by mass for each data point was calculated using the following equation:

$$
M C_{(\% \text { mass })}=\frac{M-M_{\text {oven }-d r y}}{M_{0 v e n-d r y}}
$$

To determine the moisture content, the mass of the pins, epoxy, and leads was subtracted from the mass readings taken during the drying process.

The conductance was plotted against the mass moisture content to create the calibration curves for the measured field conductance data (Figure 100) for OSB and the treated $2 \times 6$ sill plate. As noted above, the final conductance reading for the OSB was $0 \mu \mathrm{S}$ and for the $2 \times 6$ was $0.000333 \mu \mathrm{S}$. In reality, the OSB did not reach a conductance of $0 \mu \mathrm{S}$ or infinite resistance, but the zero reading was due to the quantization error in the 16-bit analog-to-digital converter used in the data acquisition apparatus. In this experiment the quantization error was $0.000166 \mu \mathrm{S}$. At one quantization error, the OSB was at $2 \%$ moisture content. Anything below this value was not determinable. The final reading for the $2 \times 6$ was within two quantization errors of $0 \mu \mathrm{S}$ and was at a moisture content of $6 \%$. This method was therefore accurate down to $6 \%$ moisture content for the $2 \times 6$. For the field data, any conductance below the lower limit $(0.000166 \mu \mathrm{S}$ for OSB and $0.000333 \mu \mathrm{S}$ for a $2 \times 6)$ was reported as unmeasurable.

After the samples finished drying they were left sitting in ambient conditions. The moisture content of the samples was checked using a Lignomat pin moisture content meter with a lower measurement limit of 5\%. The OSB was checked 16 days after and the $2 \times 6$ was checked 7 days after the calibration drying was completed. For both samples, the moisture content was less than $5 \%$. The ambient conditions at the time of testing were approximately $70^{\circ} \mathrm{F}$ and $22 \% \mathrm{RH}$.

Refinements to the calibration methodology include:

- Increasing the sample size of each material to check result repeatability.

- Investigating the impacts of wood treatments on the electrical conductance / moisture content correlation. 


\section{Appendix C: Supplementary Experimental Data}
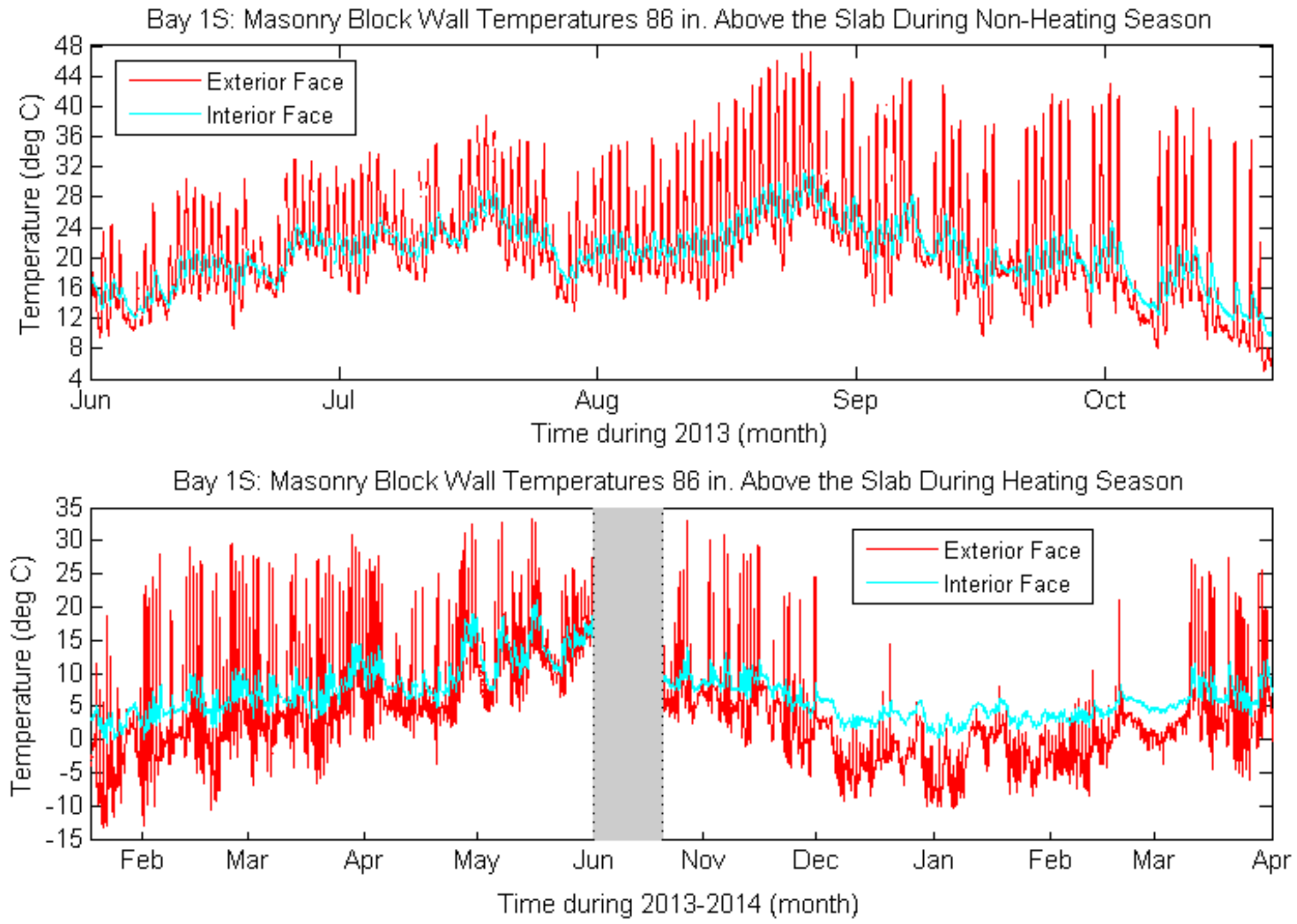

Figure 101. Bay 1S above-grade masonry block wall temperature profiles 
Bay 1S: Masonry Block Wall Temperatures 79 in. Above the Slab
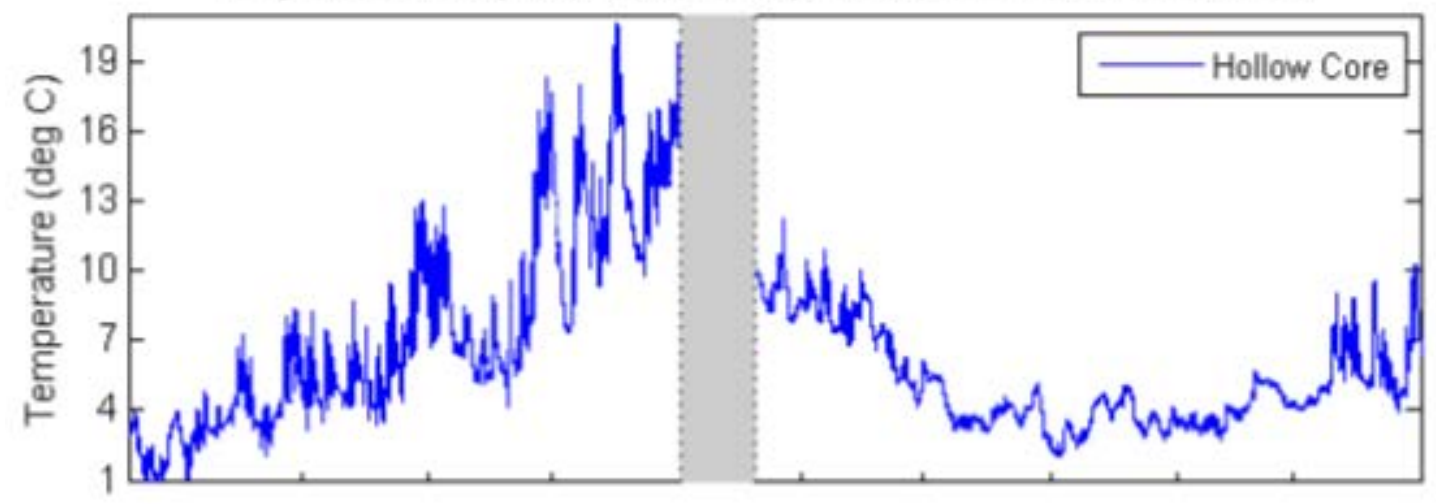

Bay 1S: Masonry Block Wall Temperatures 69 in. Above the Slab
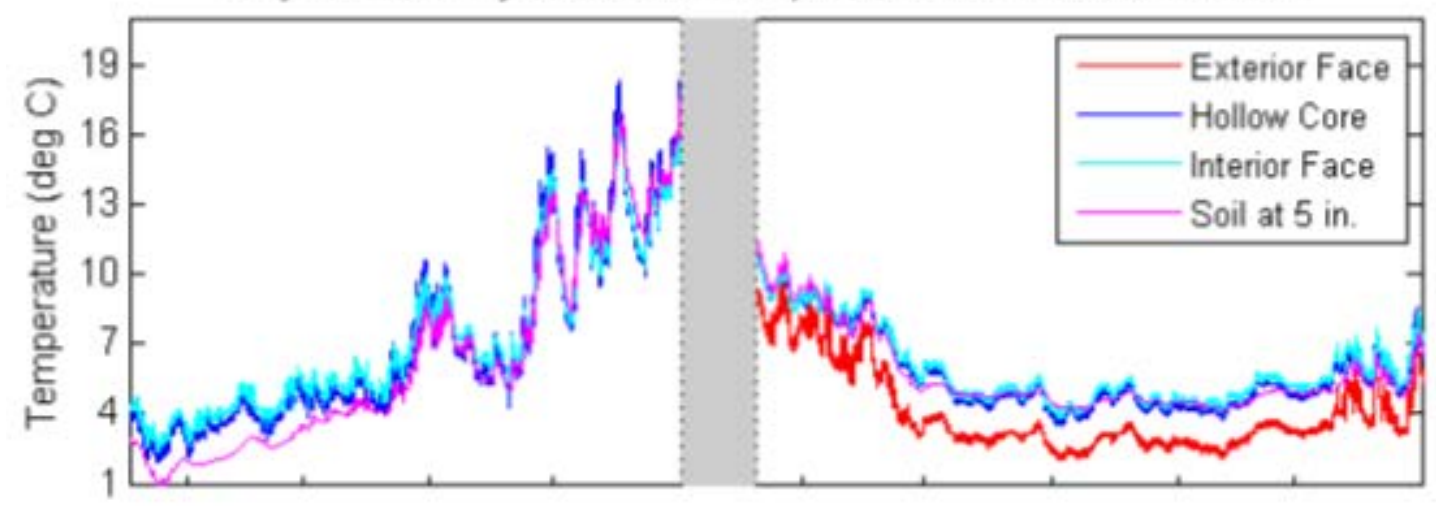

Bay 1S: Masonry Block Wall Temperatures 40 in. Above the Slab

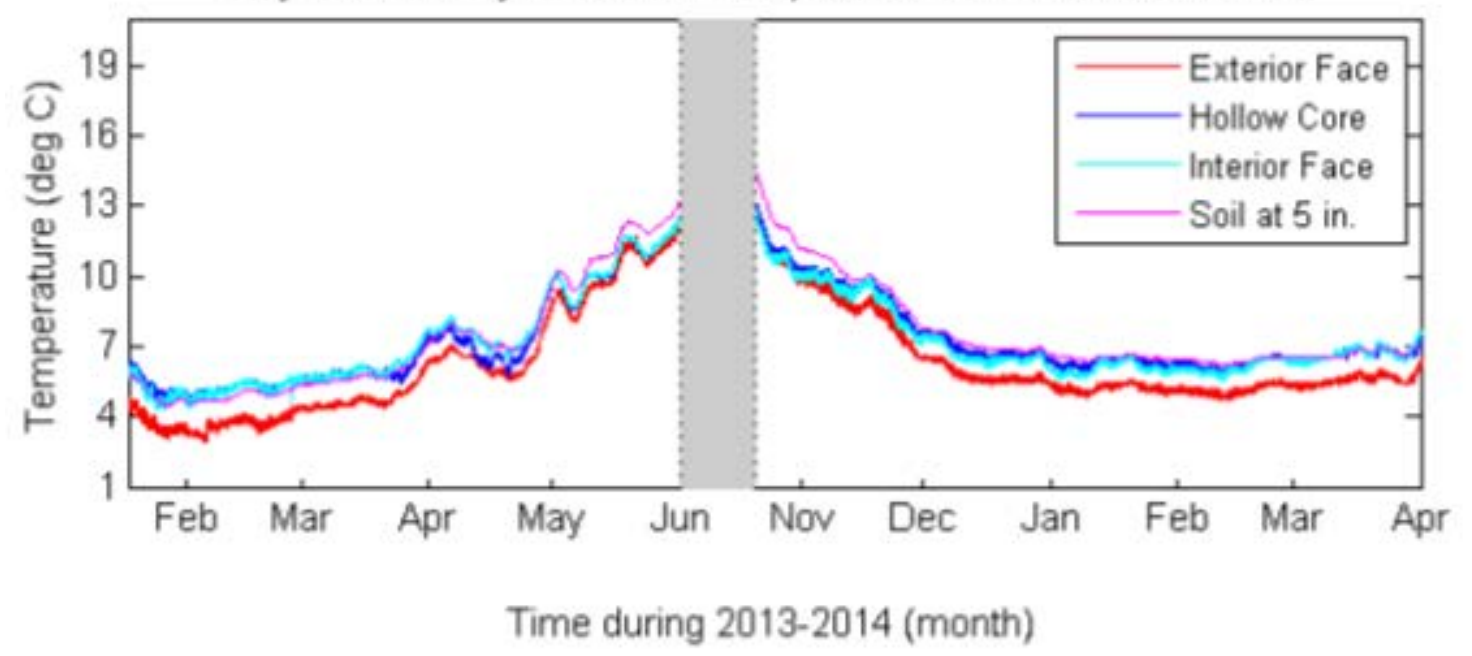

Figure 102. Bay $1 \mathrm{~S}$ heating season masonry block wall and soil temperature profiles $\mathbf{4 0}$ to $\mathbf{7 9} \mathrm{in}$. above the slab 

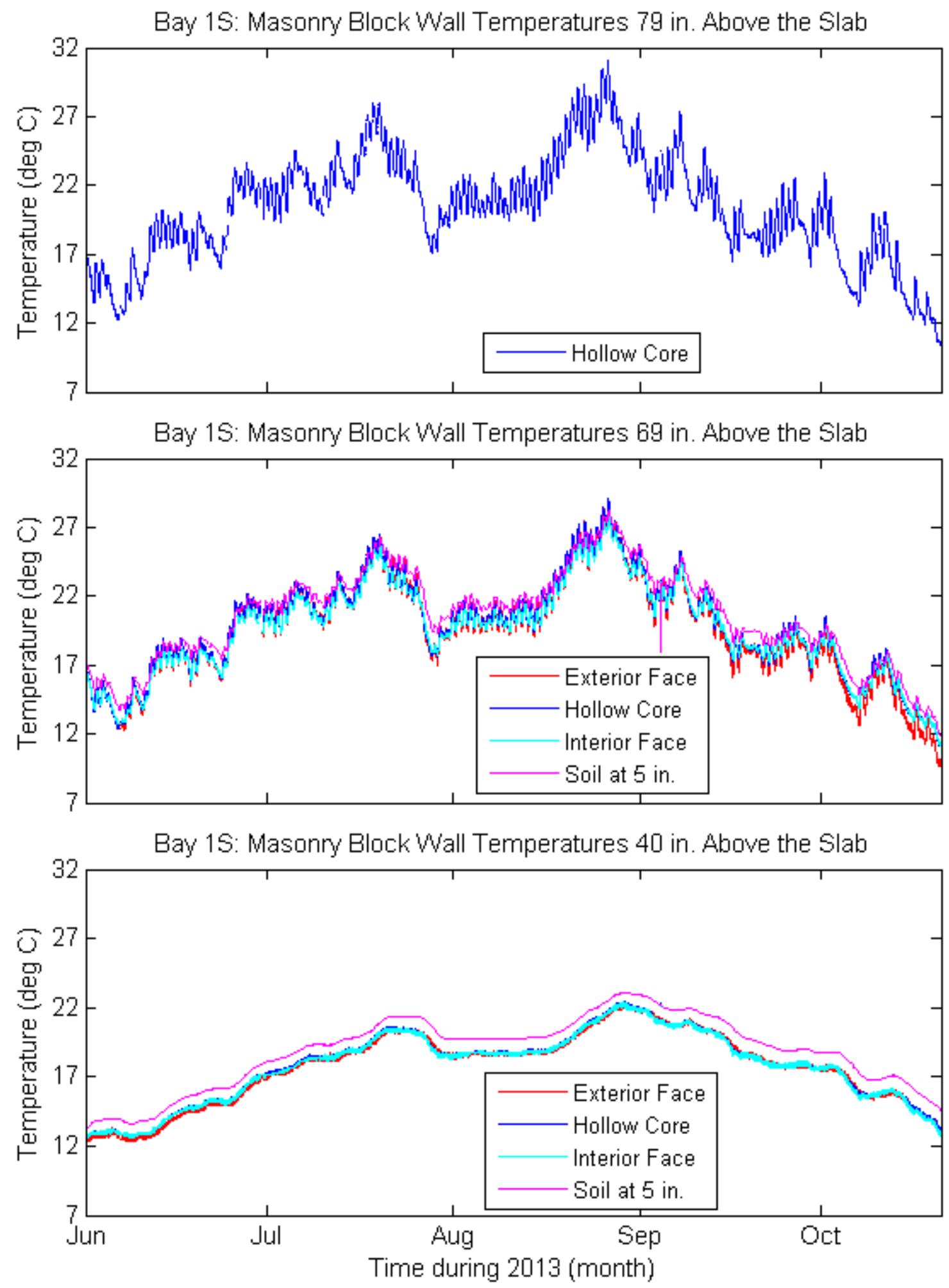

Figure 103. Bay $1 \mathrm{~S}$ cooling season masonry block wall and soil temperature profiles $\mathbf{4 0}$ to 79 in. above the slab 
Bay 1S: Masonry Block Wall Temperatures 16 in. Above the Slab

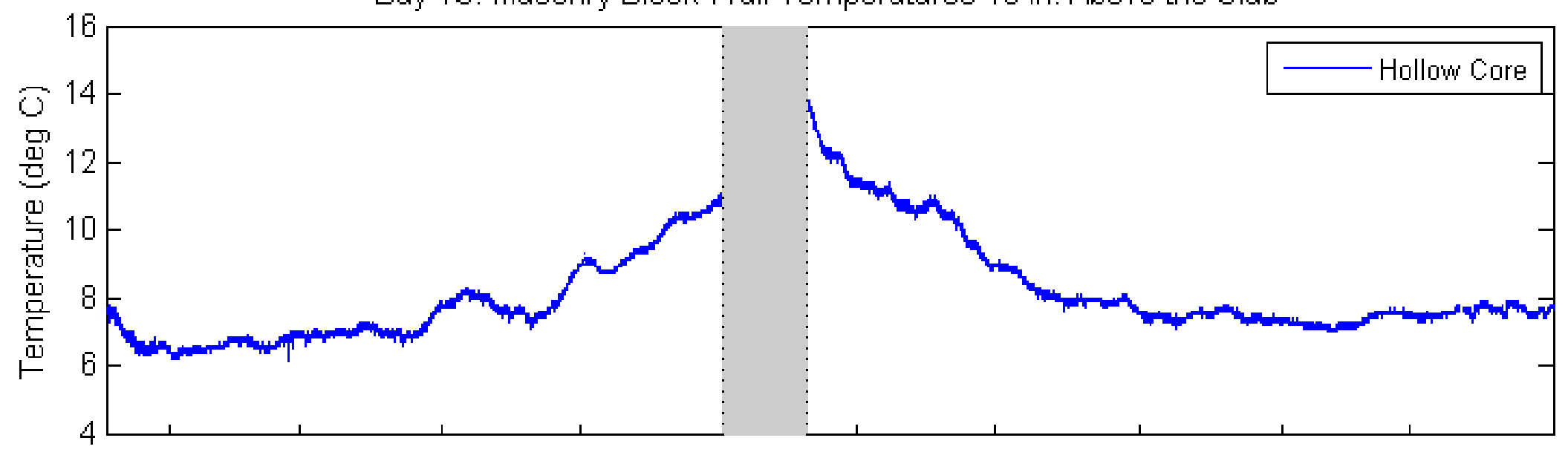

Bay 1S: Masonry Block Wall Temperatures 5.5 in. Above the Slab

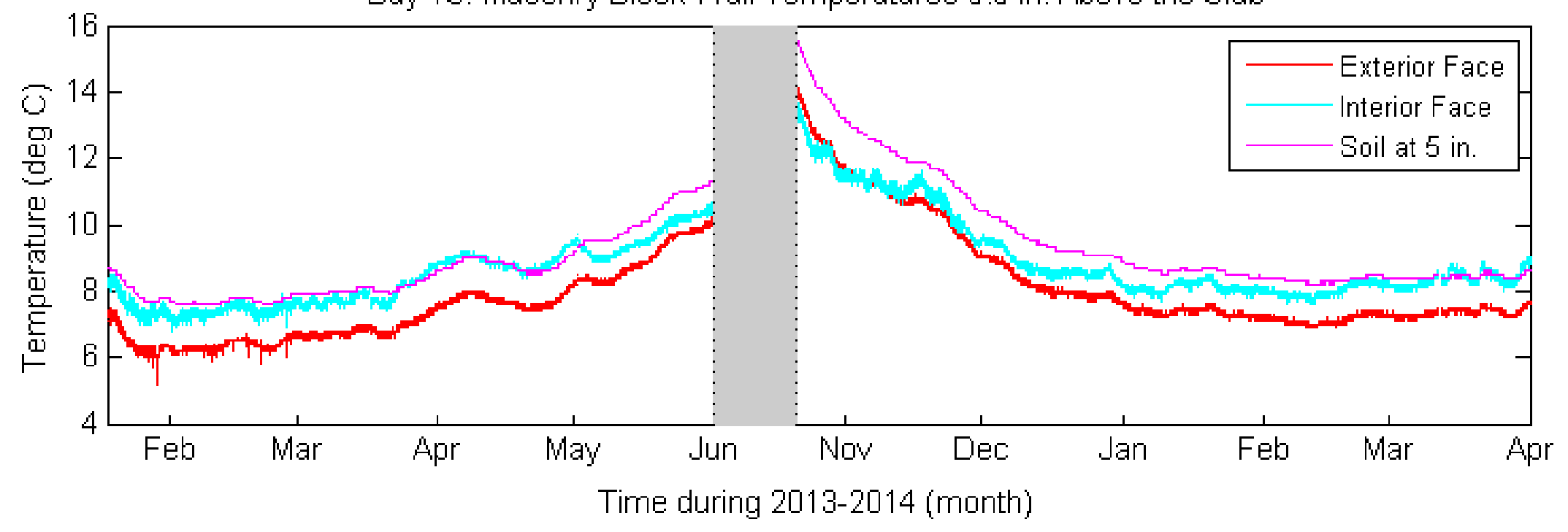

Figure 104. Bay $1 \mathrm{~S}$ heating season masonry block wall and soil temperature profiles $5-1 / 2$ to $16 \mathrm{in}$. above the slab 


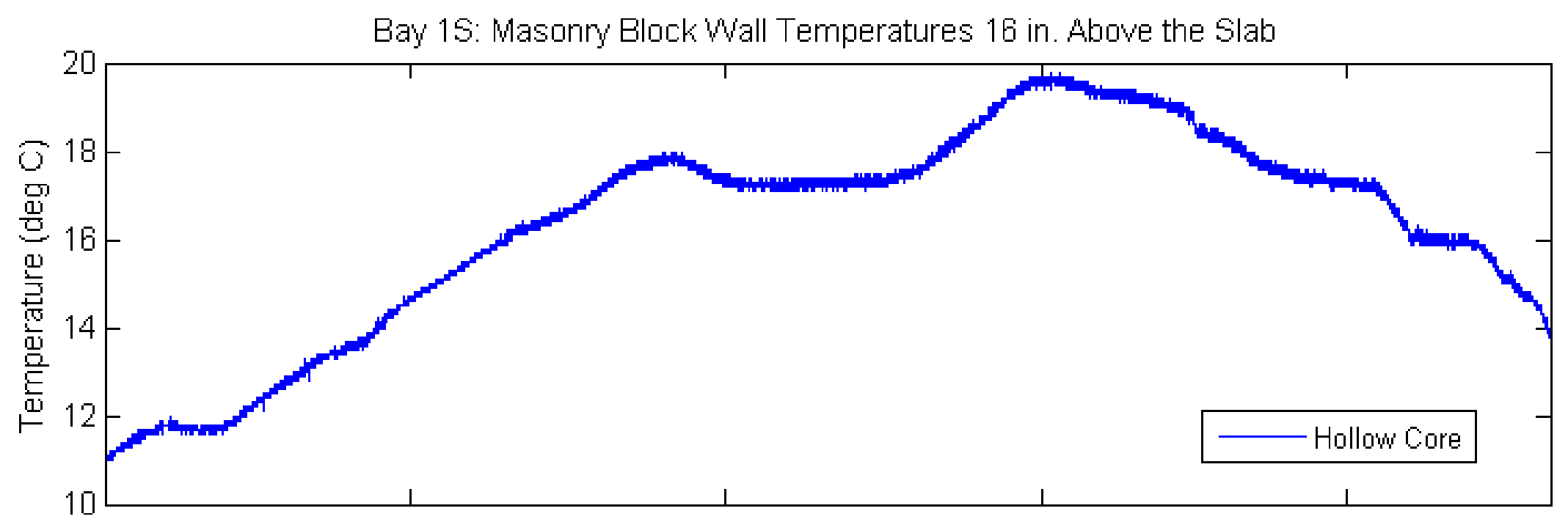

Bay 1S: Masonry Block Wall Temperatures 5.5 in. Above the Slab

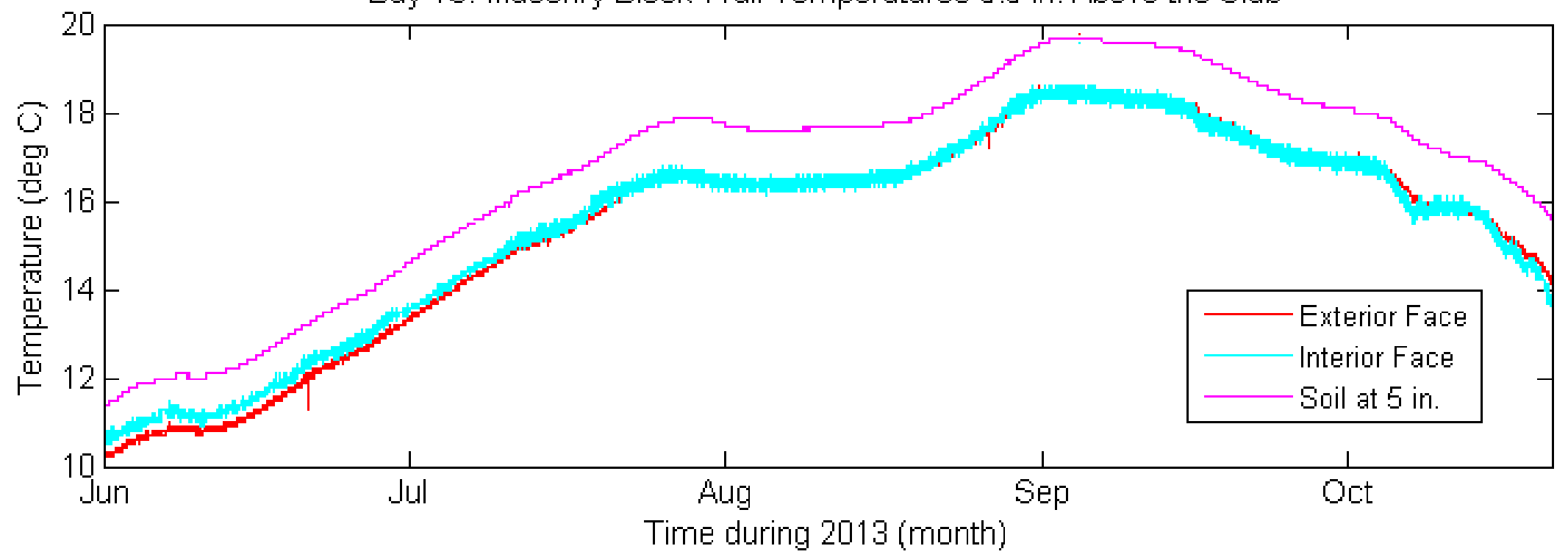

Figure 105. Bay $1 \mathrm{~S}$ cooling season masonry block wall and soil temperature profiles $5-1 / 2$ to 16 in. above the slab 
Bay 3N: Masonry Block Wall Temperatures 86 in. Above the Slab During Non-Heating Season

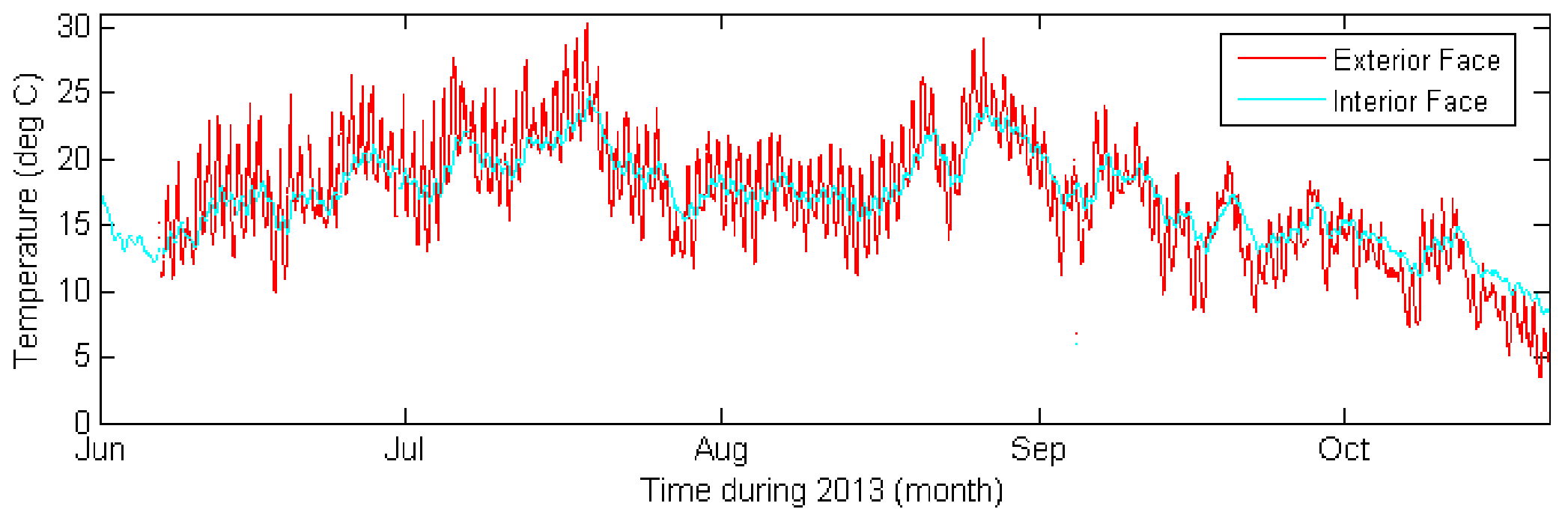

Bay 3N: Masonry Block Wall Temperatures 86 in. Above the Slab During Heating Season

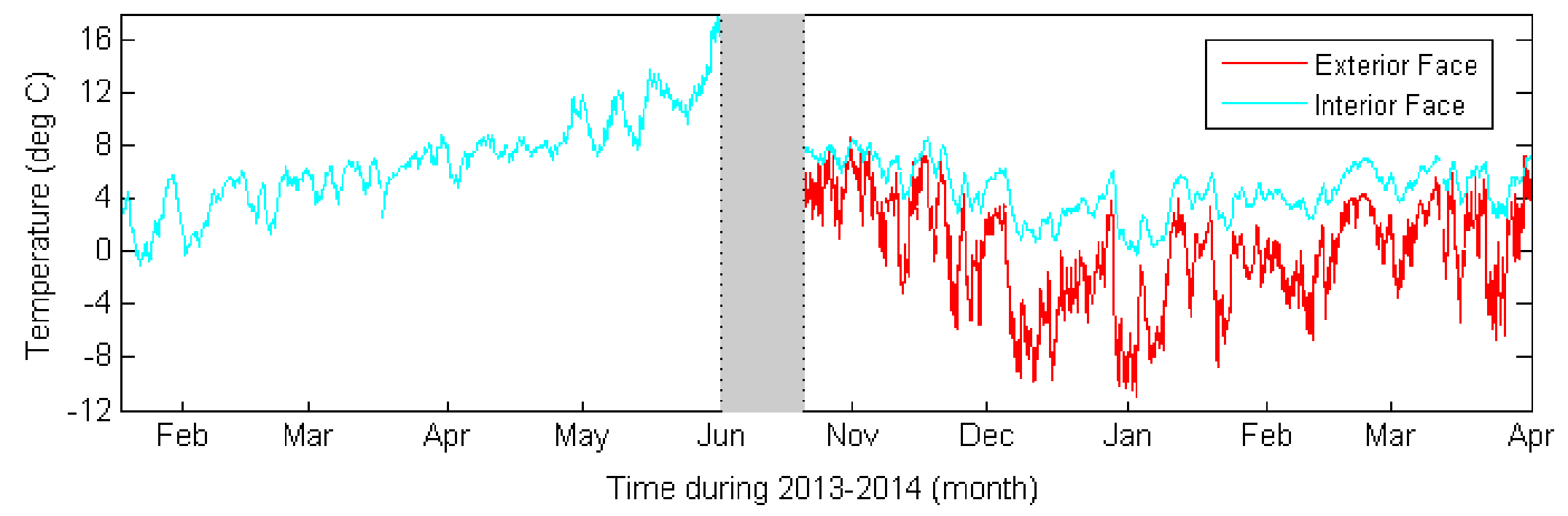

Figure 106. Bay $3 \mathrm{~N}$ above-grade masonry block wall temperature profiles 
Bay 4S: Masonry Block Wall Temperatures 5.5 in. Above the Slab

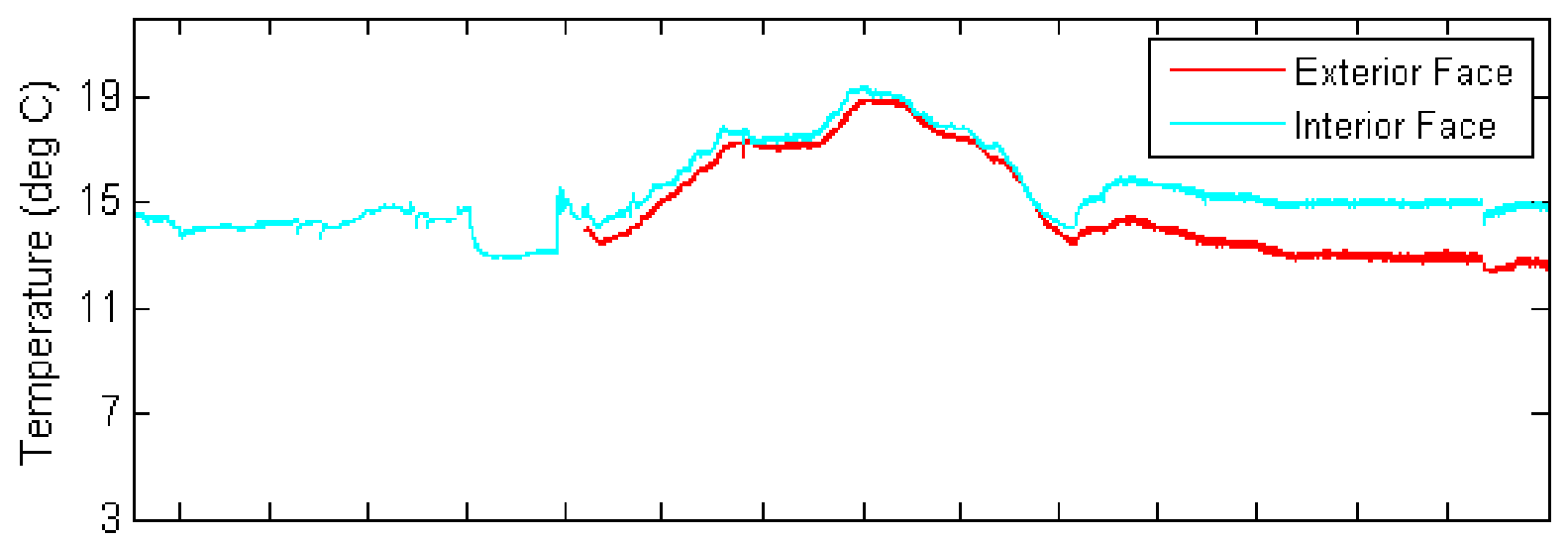

Bay 2S: Masonry Block Wall Temperatures 5.5 in. Above the Slab

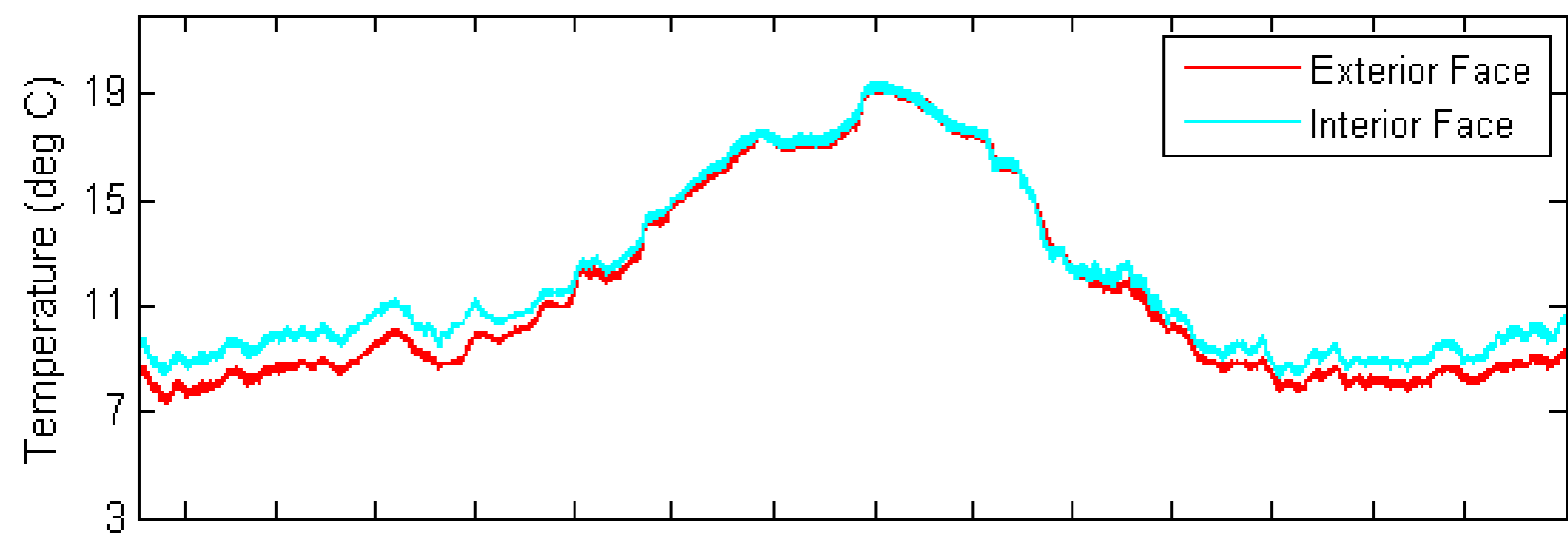

Masonry Block Wall Hollow Core Temperatures 16 in. Above the Slab

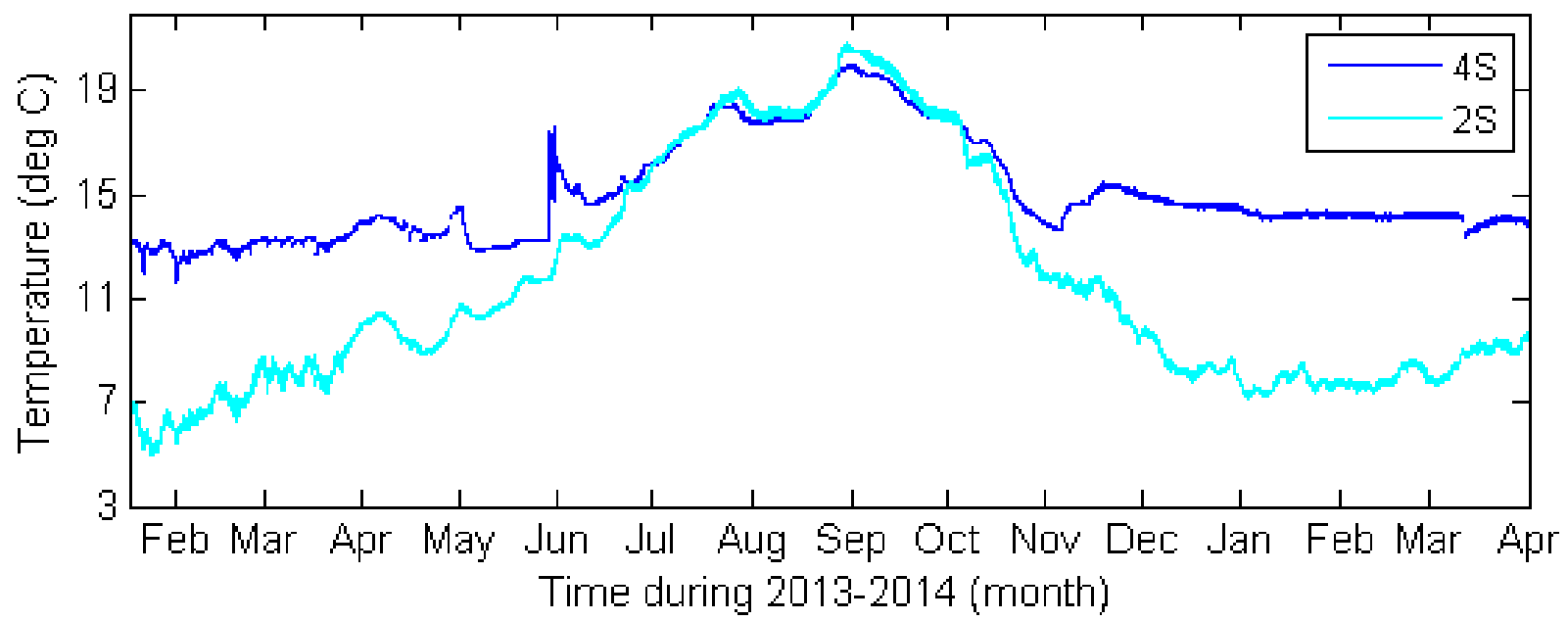

Figure 107. Bay $2 S$ (interior insulation)/Bay $4 S$ (exterior half-wall insulation) wall temperature comparison $5-1 / 2$ in. and 16 in. above the slab 
Bay 4S: Masonry Block Wall Temperatures 86 in. Above the Slab

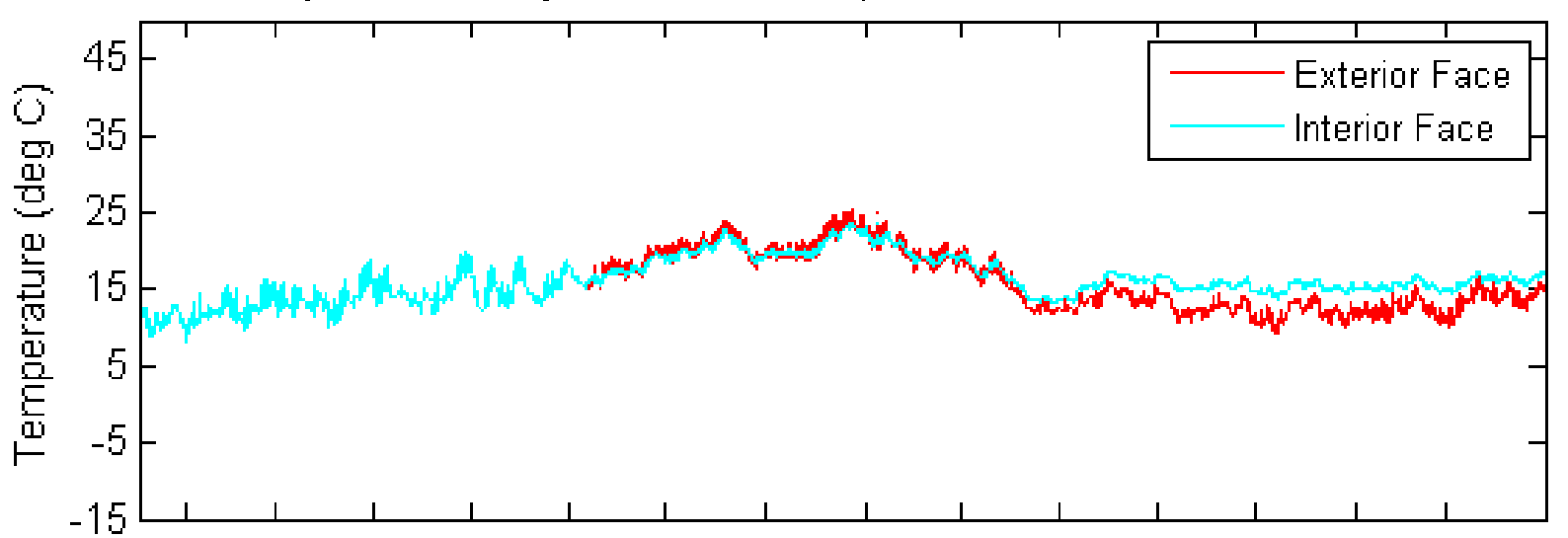

Bay 2S: Masonry Block Wall Temperatures 86 in. Above the Slab

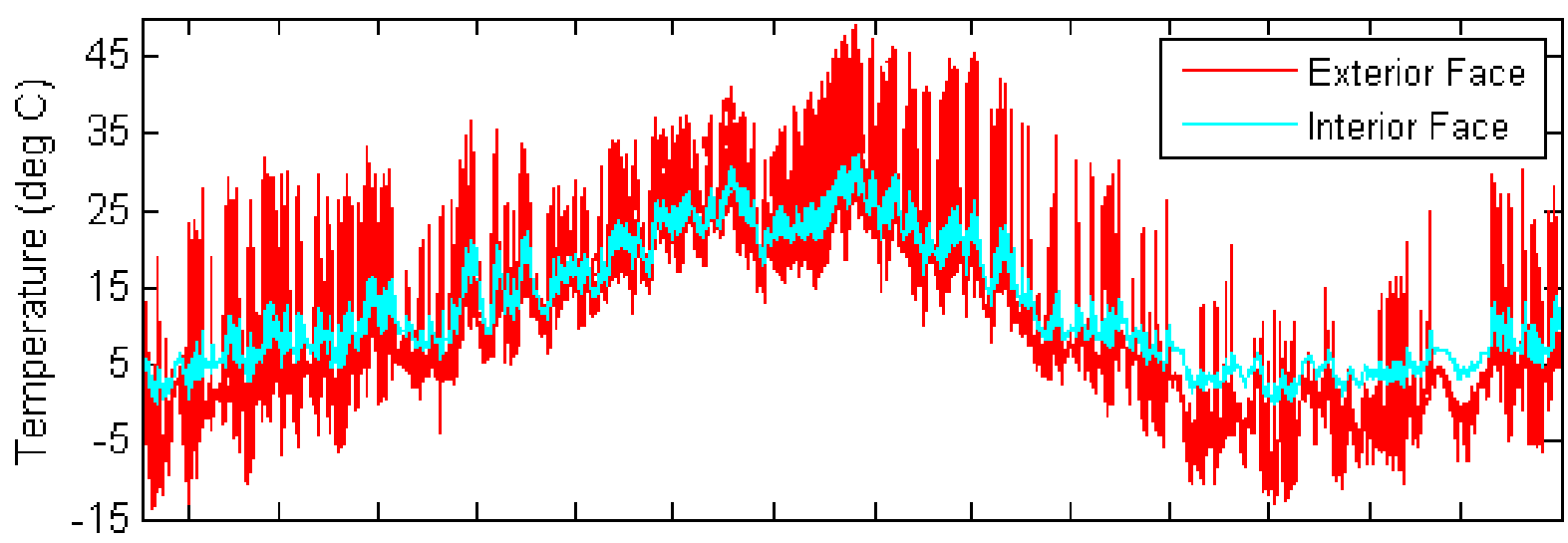

Masonry Block Wall Hollow Core Temperatures 79 in. Above the Slab

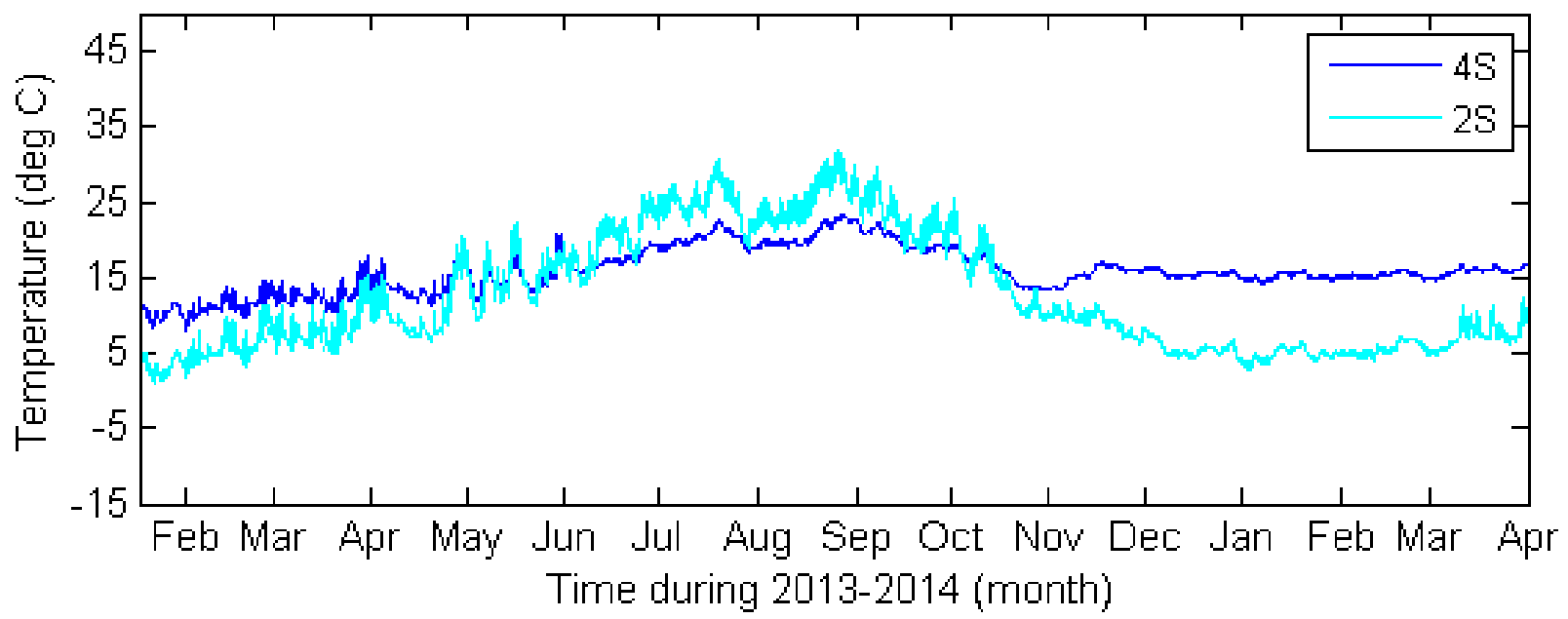

Figure 108. Bay 2S (interior insulation)/Bay 4S (exterior half-wall insulation) above-grade wall temperature comparison 

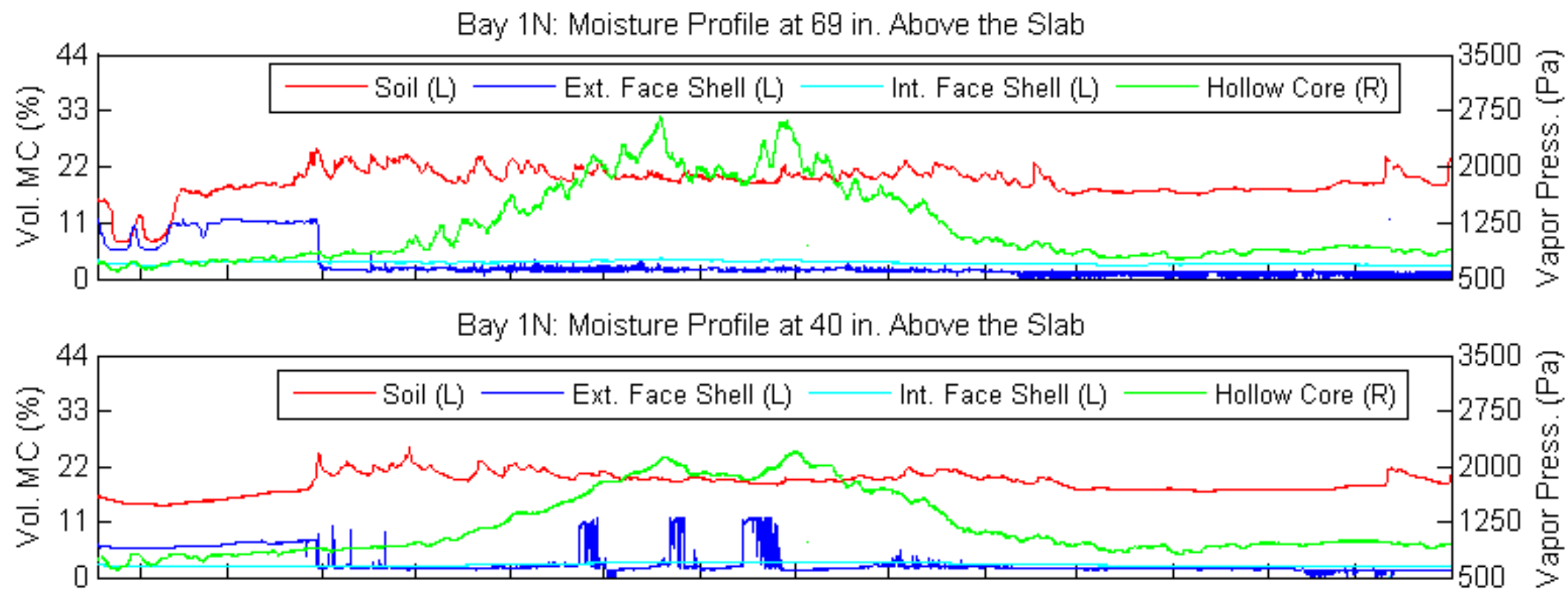

Bay $1 \mathrm{~N}$ : Moisture Profile at 5.5 in. Above the Slab

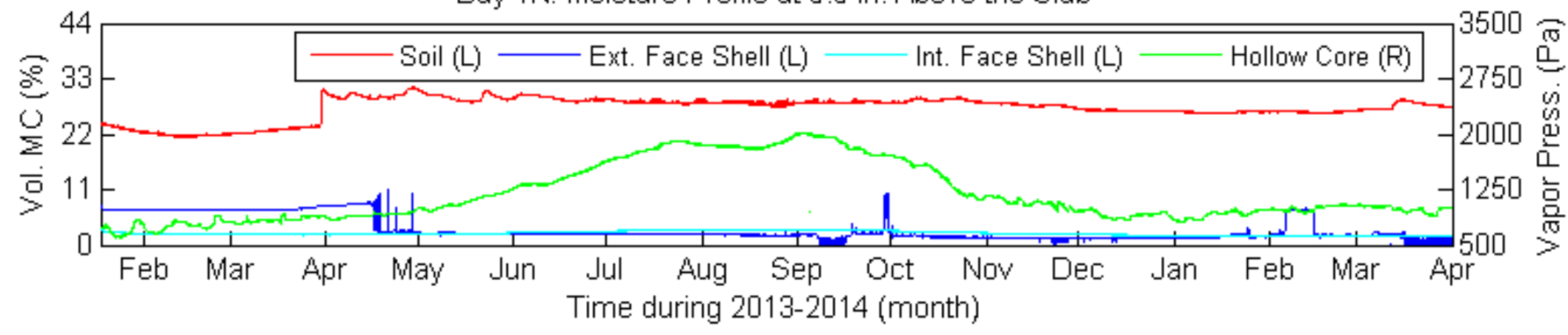

Figure 109. Bay $1 \mathrm{~N}$ moisture transport phenomenology 
Bay 2N: Masonry Block Wall Temperatures 86 in. Above the Slab During Non-Heating Season
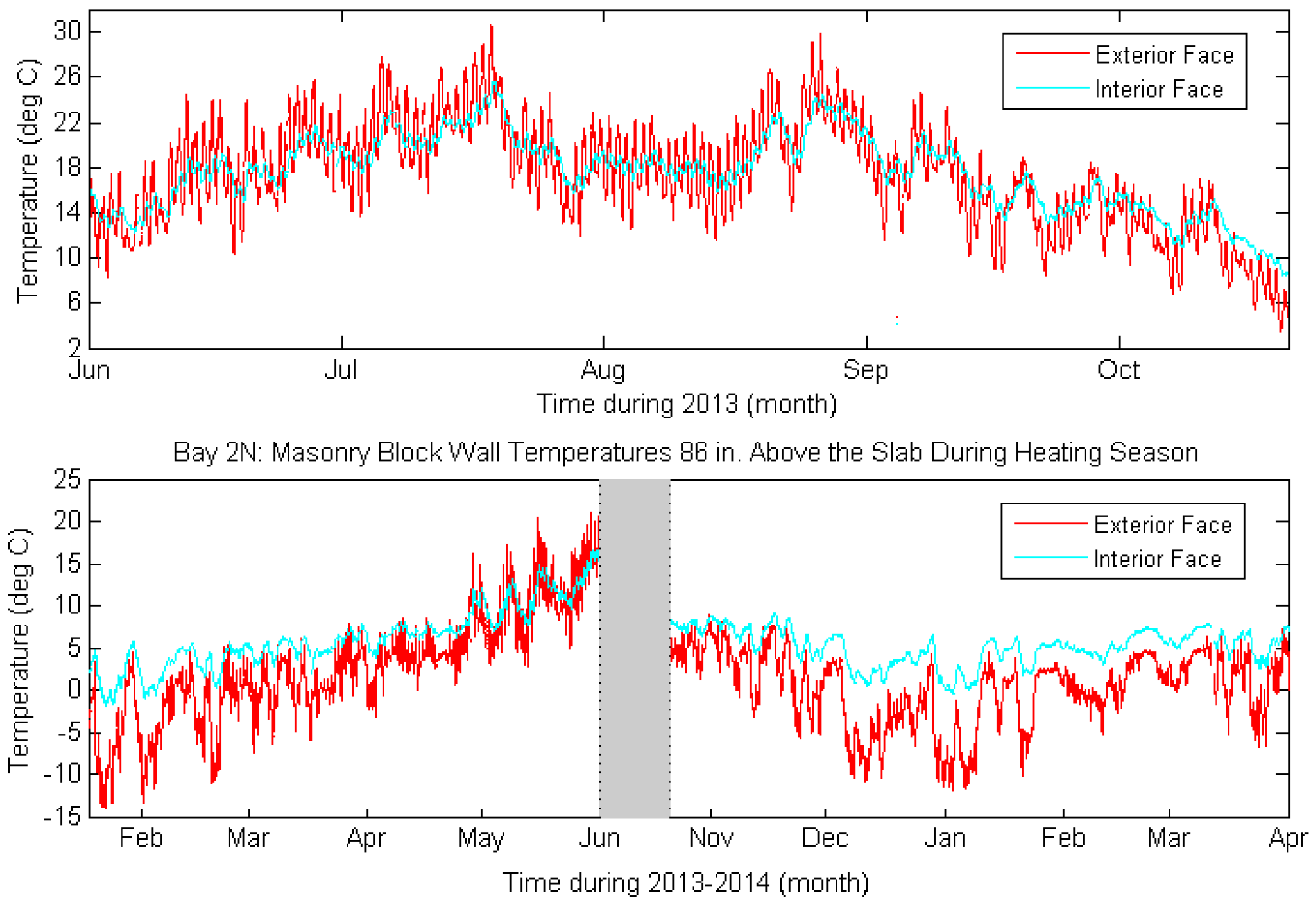

Figure 110. Bay 2N heating season above-grade masonry block wall temperature profiles 
Bay 2N: Masonry Block Wall Temperatures 79 in. Above the Slab
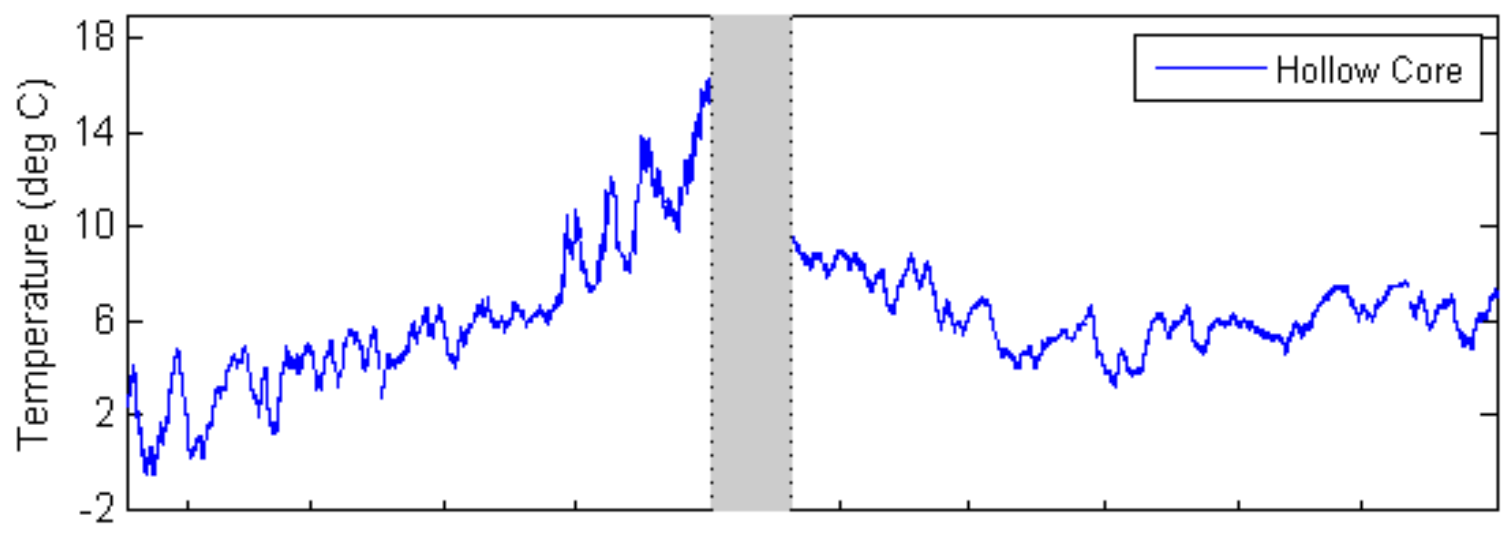

Bay 2N: Masonry Block Wall Temperatures 69 in. Above the Slab
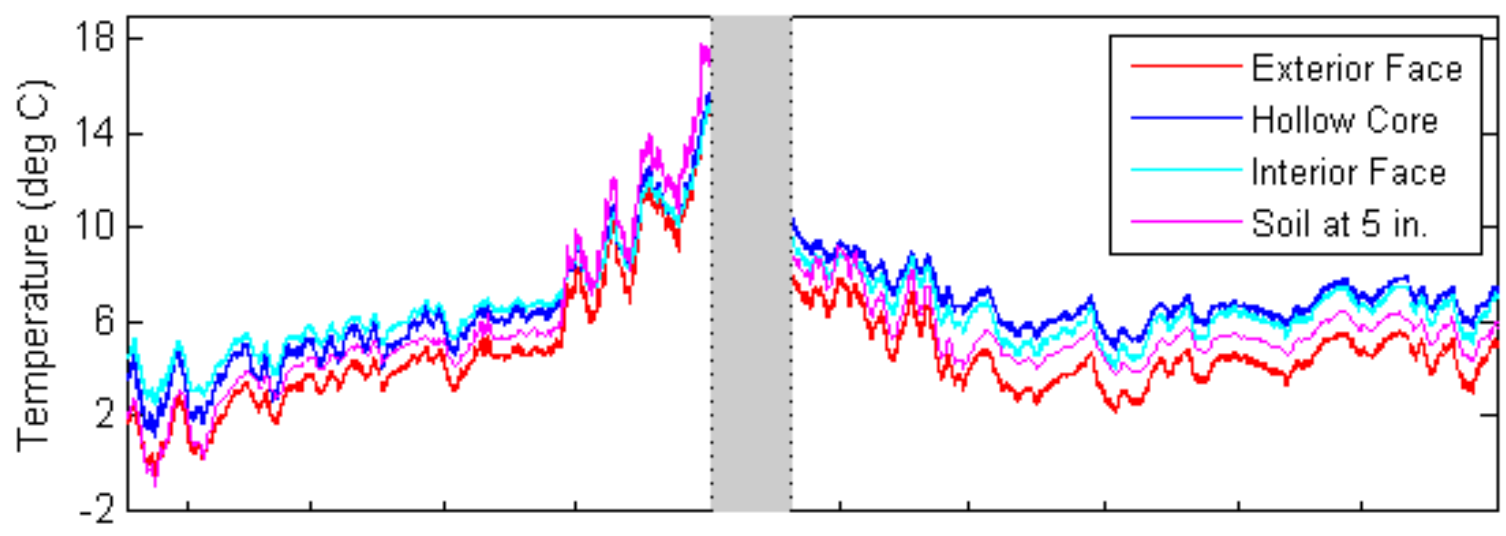

Bay 2N: Masonry Block Wall Temperatures 40 in. Above the Slab

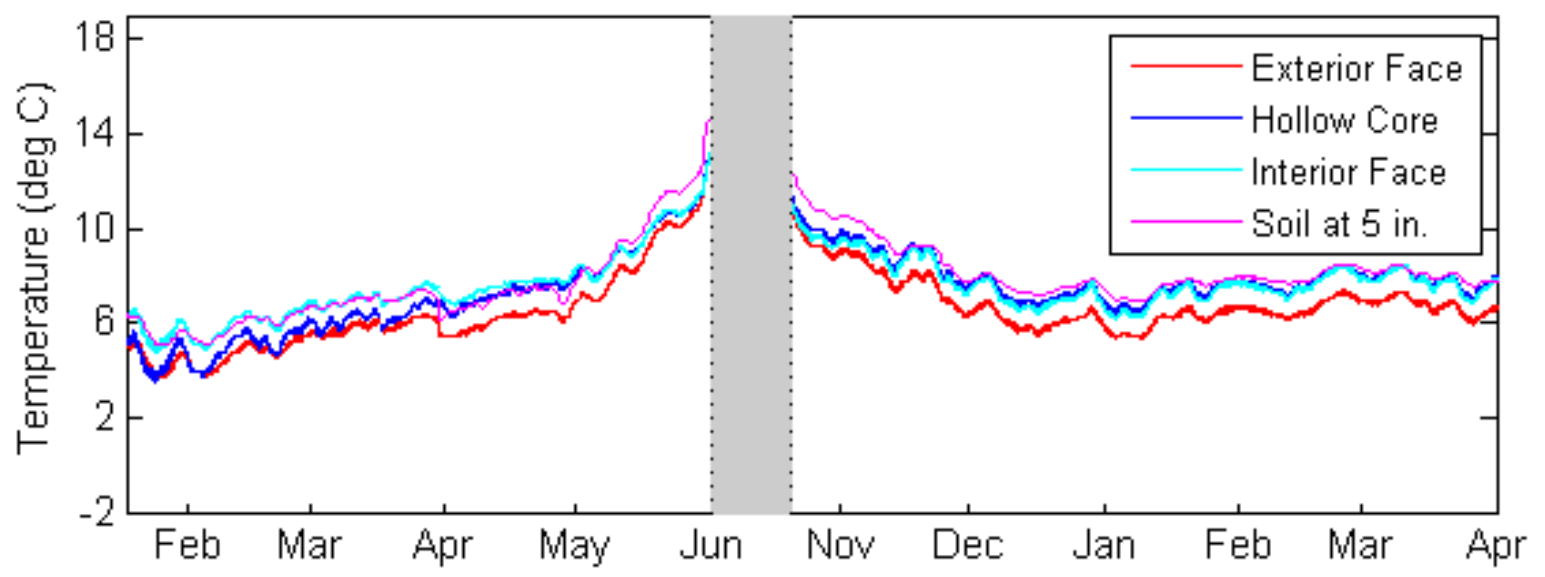

Time during 2013-2014 (month)

Figure 111. Bay $2 \mathrm{~N}$ heating season masonry block wall and soil temperature profiles 40 to 79 in. above the slab 
Bay 2N: Masonry Block Wall Temperatures 79 in. Above the Slab

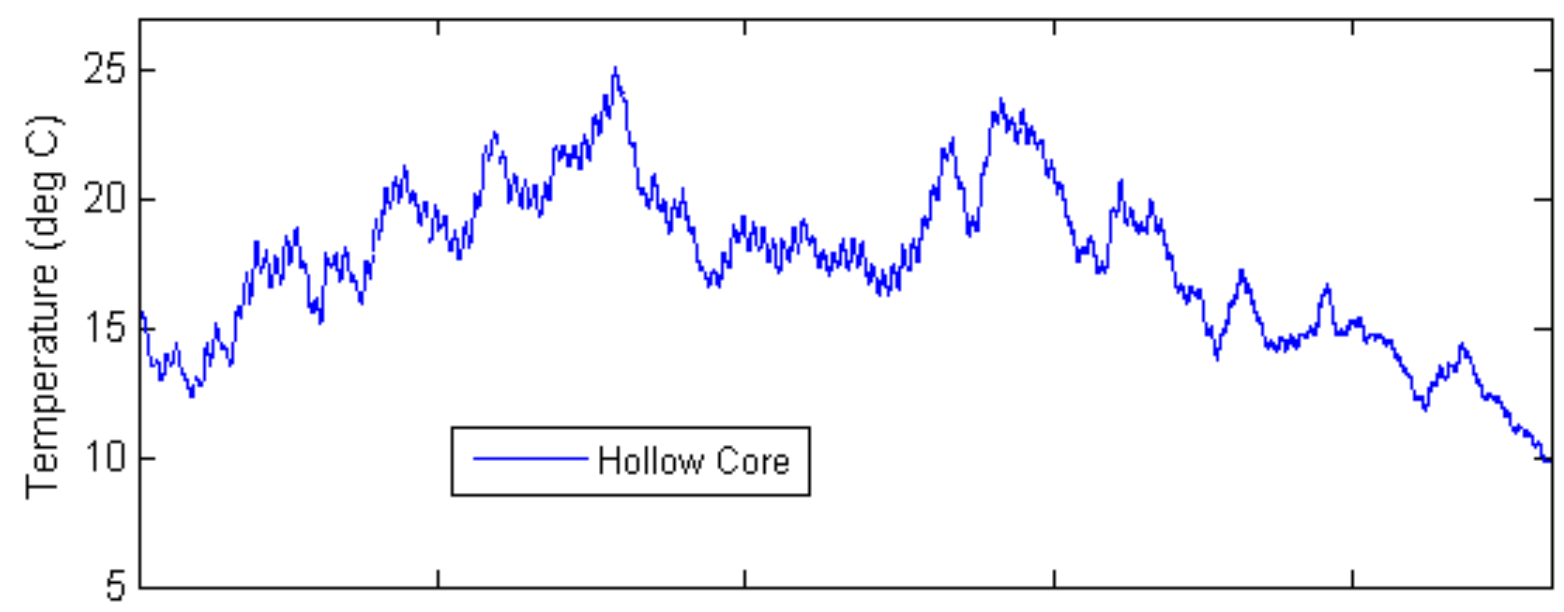

Bay 2N: Masonry Block Wall Temperatures 69 in. Above the Slab

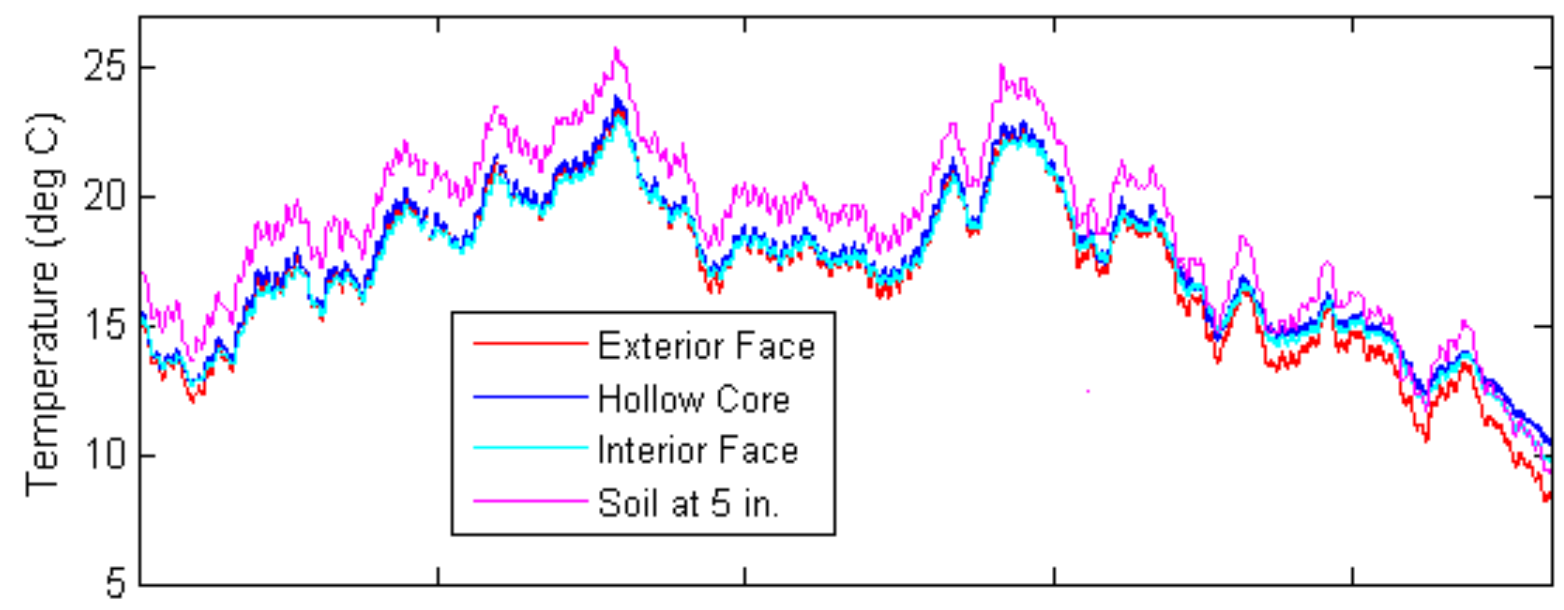

Bay 2N: Masonry Block Wall Temperatures 40 in. Above the Slab

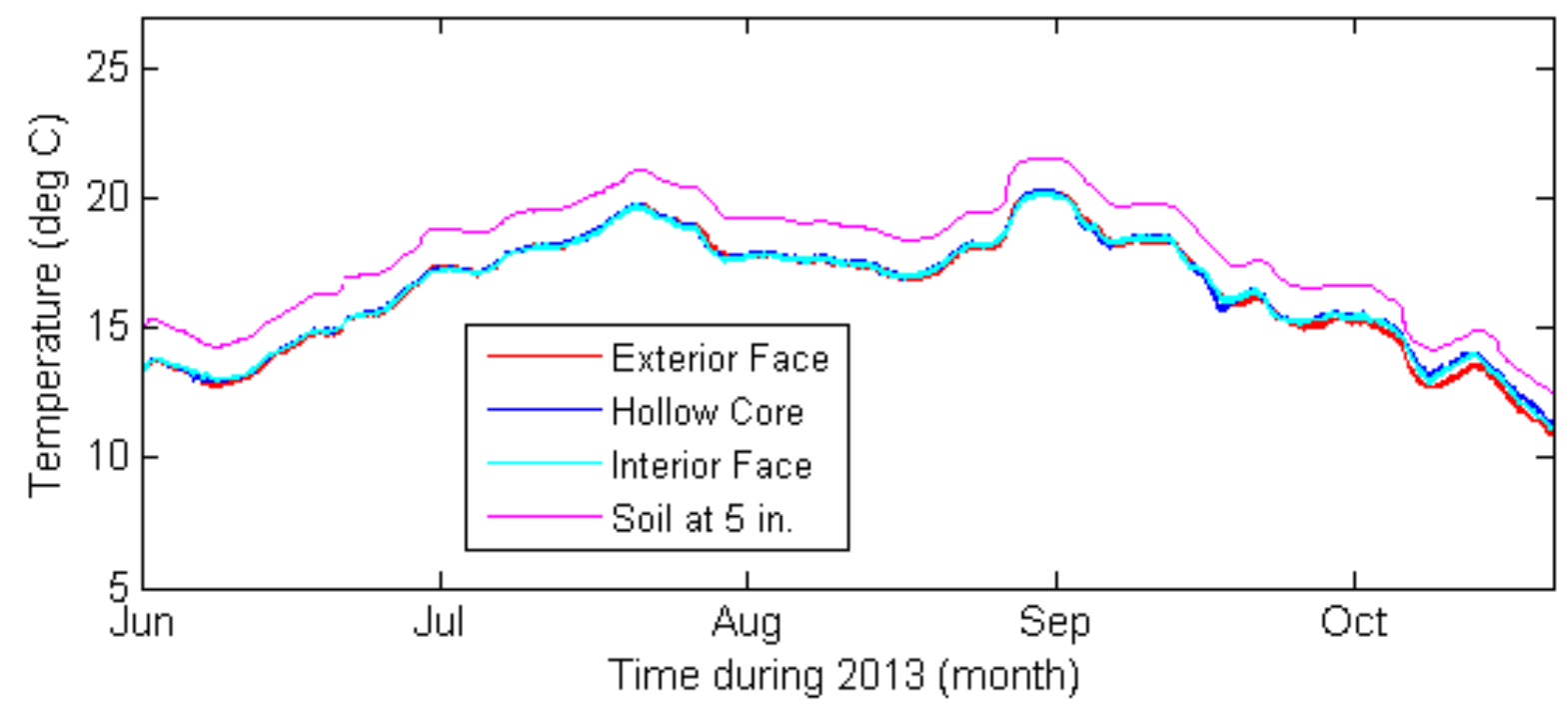

Figure 112. Bay $2 \mathrm{~N}$ cooling season masonry block wall and soil temperature profiles 40 to 79 in. above the slab 

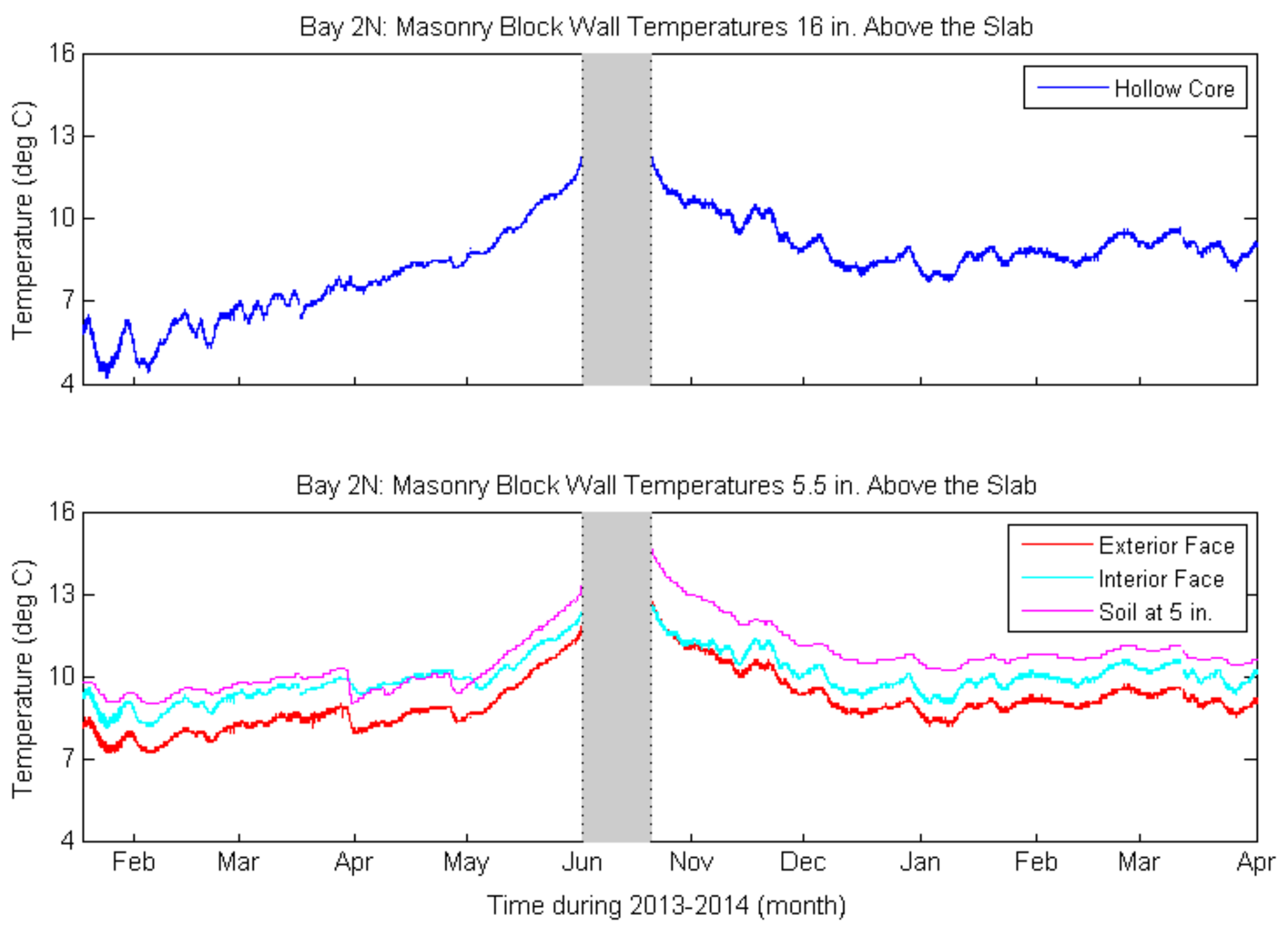

Figure 113. Bay $2 \mathrm{~N}$ heating season masonry block wall and soil temperature profiles $5-1 / 2$ to 16 in. above the slab 


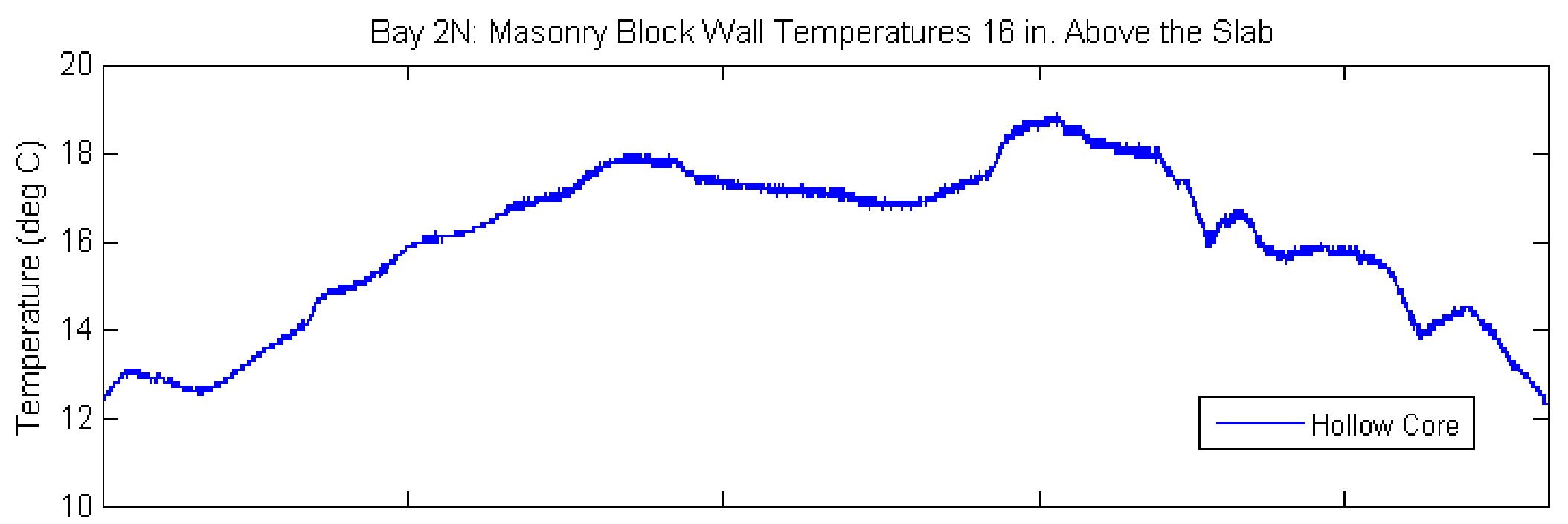

Bay 2N: Masonry Block Wall Temperatures 5.5 in. Above the Slab

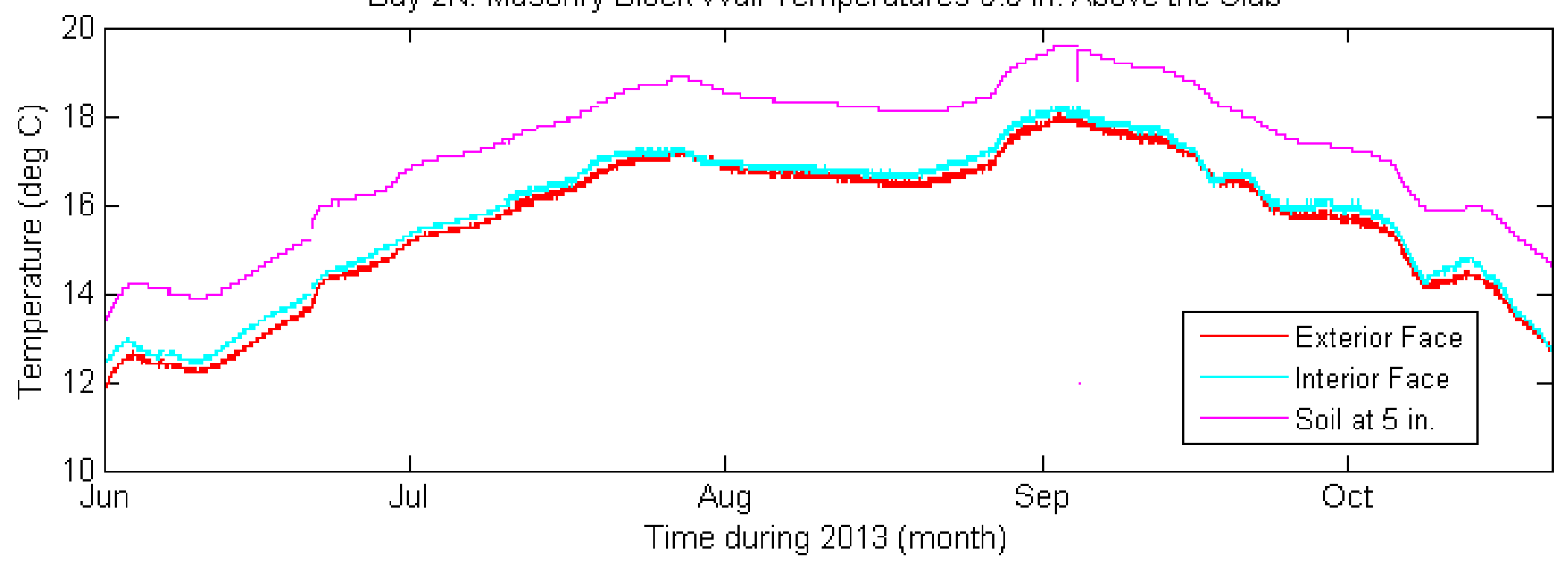

Figure 114. Bay $2 \mathrm{~N}$ cooling season masonry block wall and soil temperature profiles $5-1 / 2$ to 16 in. above the slab 
Bay 2N: Moisture Profile at 69 in. Above the Slab

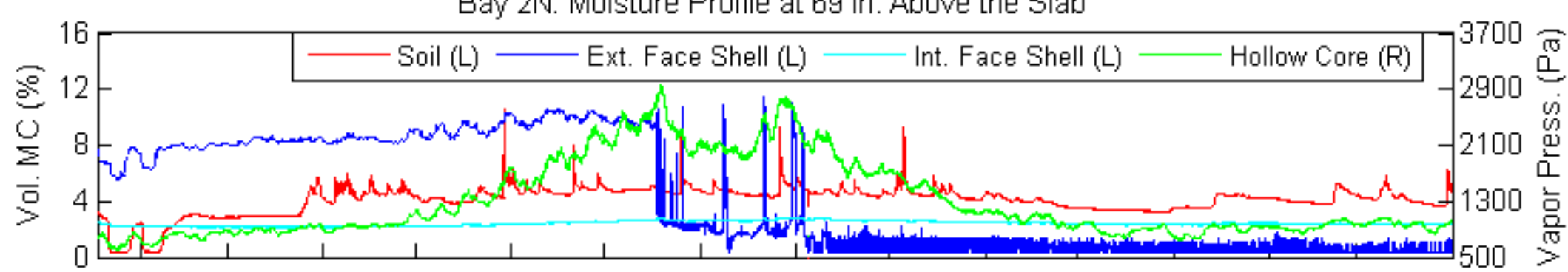

Bay 2N: Moisture Profile at 40 in. Above the Slab

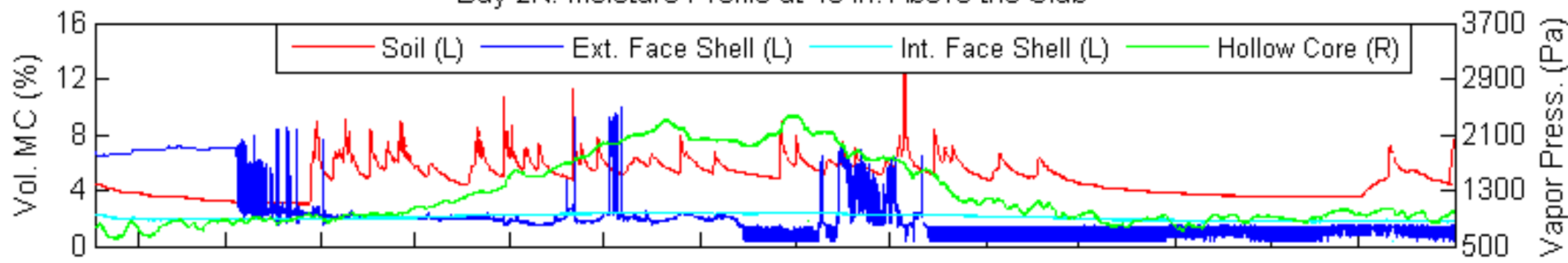

Bay 2N: Moisture Profile at 5.5 in. Above the Slab

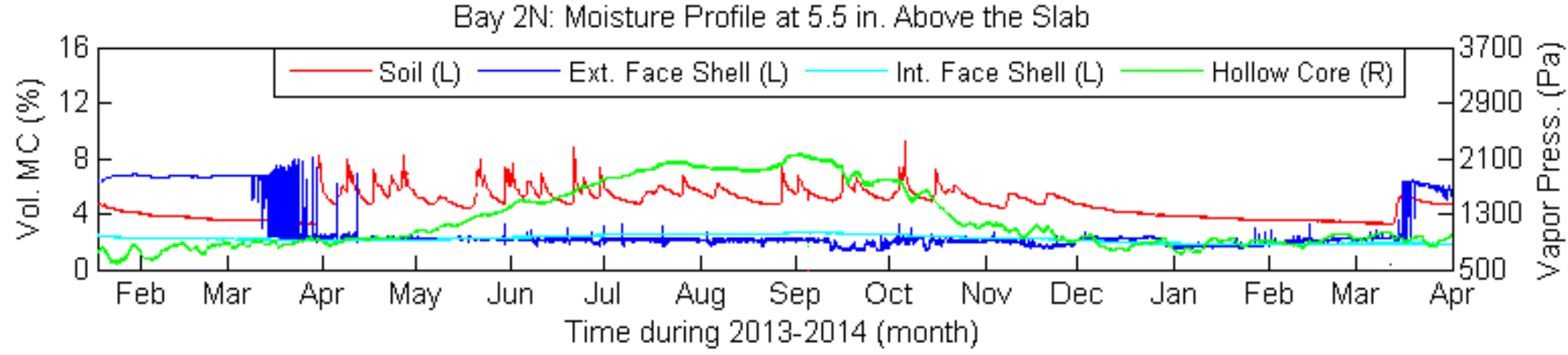

Figure 115. Bay $2 \mathrm{~N}$ moisture transport phenomenology 
Bay $3 \mathrm{~N}$ : Moisture Profile at 69 in. Above the Slab

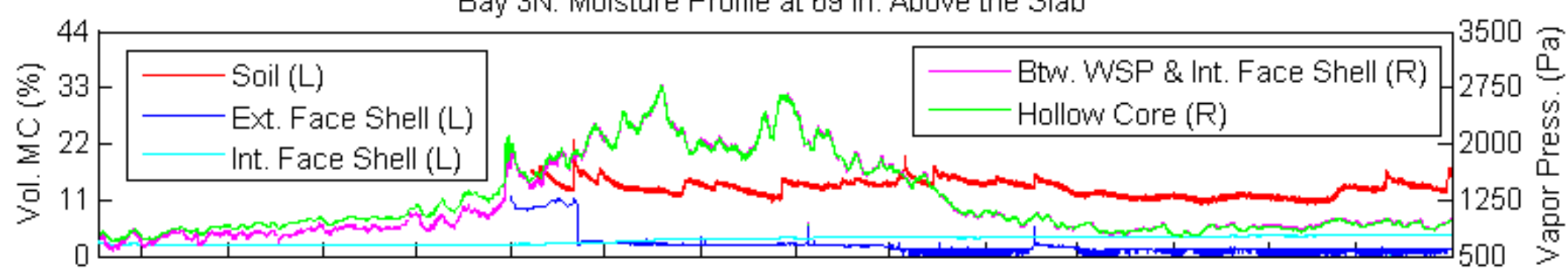

Bay 3N: Moisture Profile at 40 in. Above the Slab

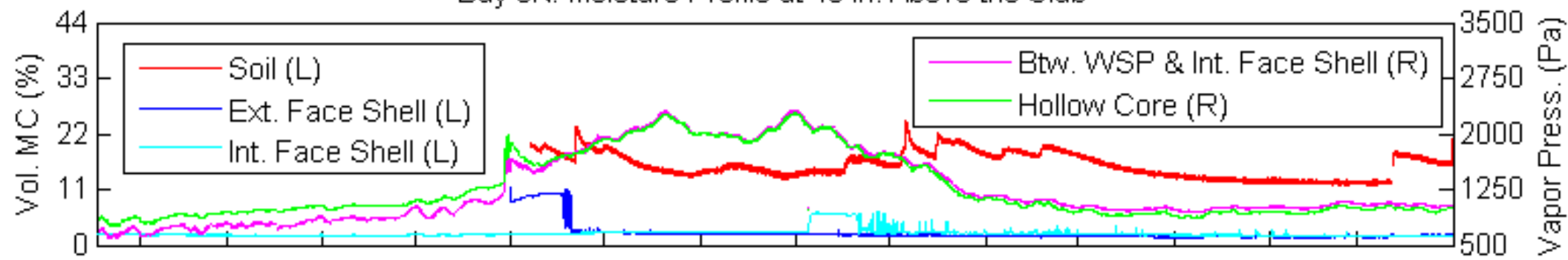

Bay 3N: Moisture Profile at 5.5 in. Above the Slab

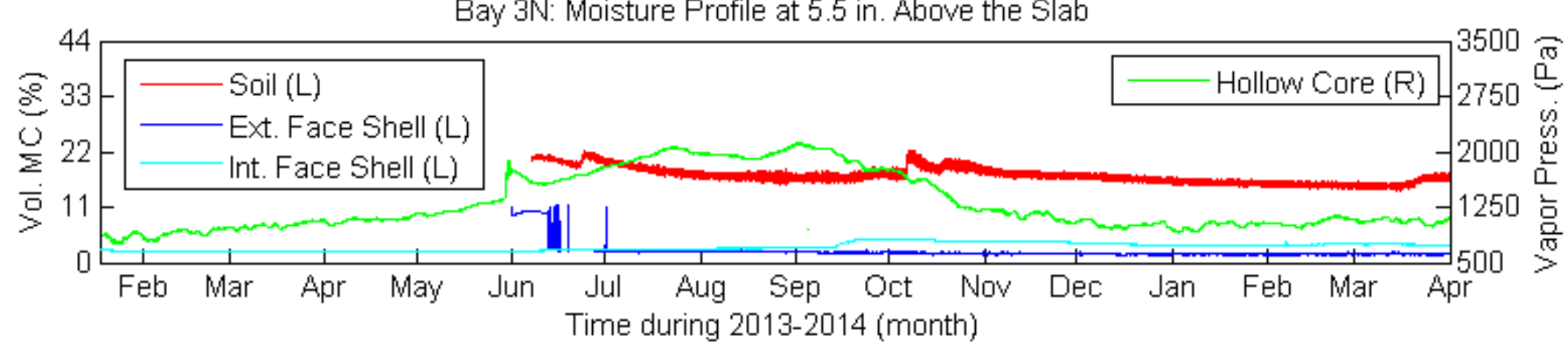

Figure 116. Bay $3 \mathrm{~N}$ moisture transport phenomenology 
Relative Humidity Across Water Separation Plane at 86 in. Above the Slab

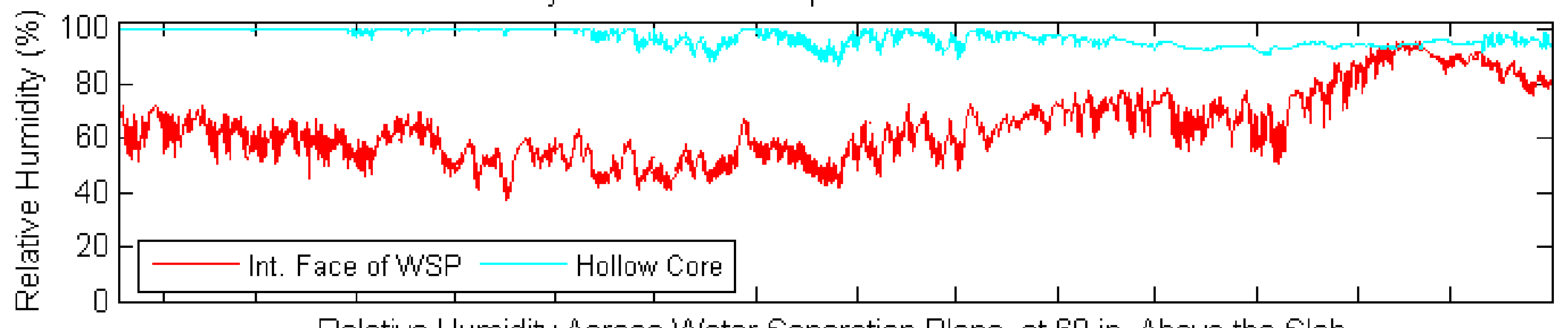

Relative Humidity Across Water Separation Plane at 69 in. Above the Slab

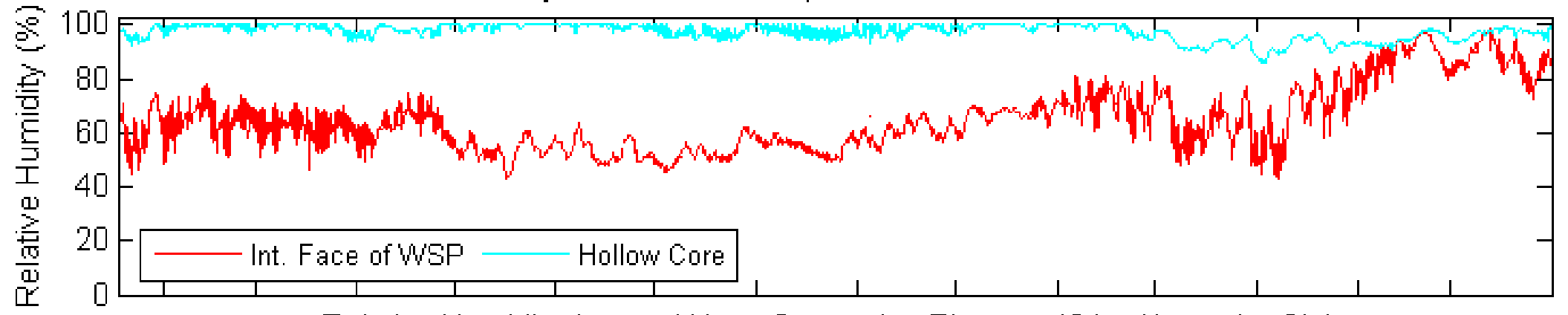

Relative Humidity Across Water Separation Plane at 40 in. Above the Slab

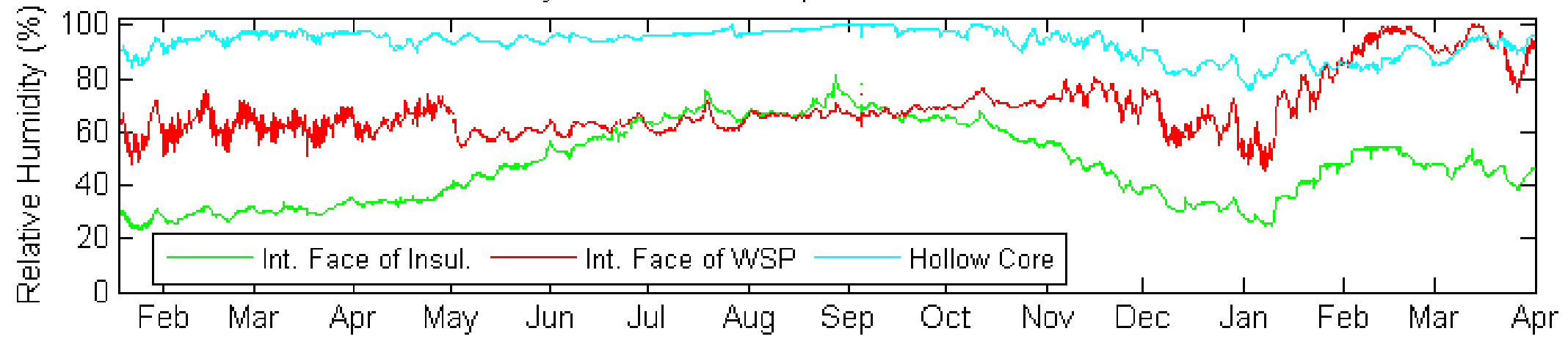

Figure 117. Bay 2S WSP vapor retarding performance 
Relative Humidity Across Water Separation Plane at 86 in. Above the Slab

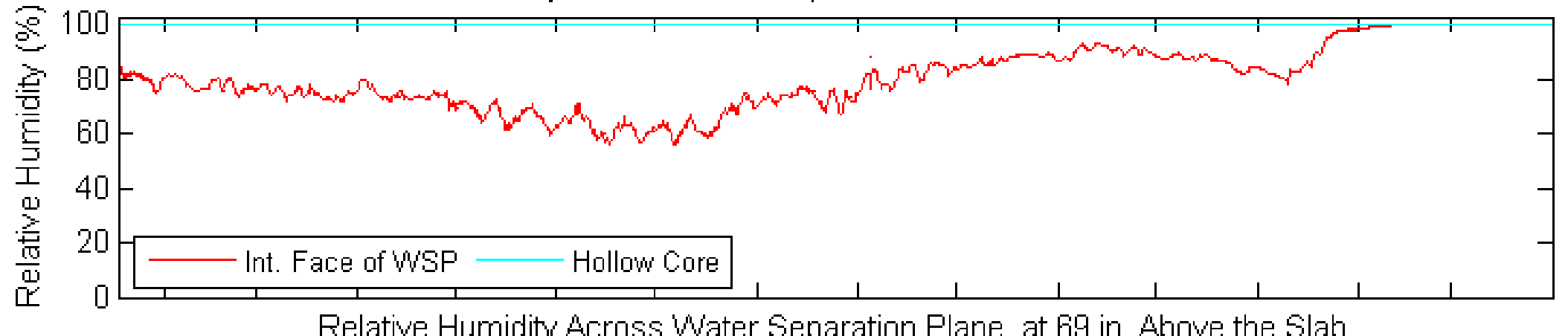

Relative Humidity Across Water Separation Plane at 40 in. Above the Slab

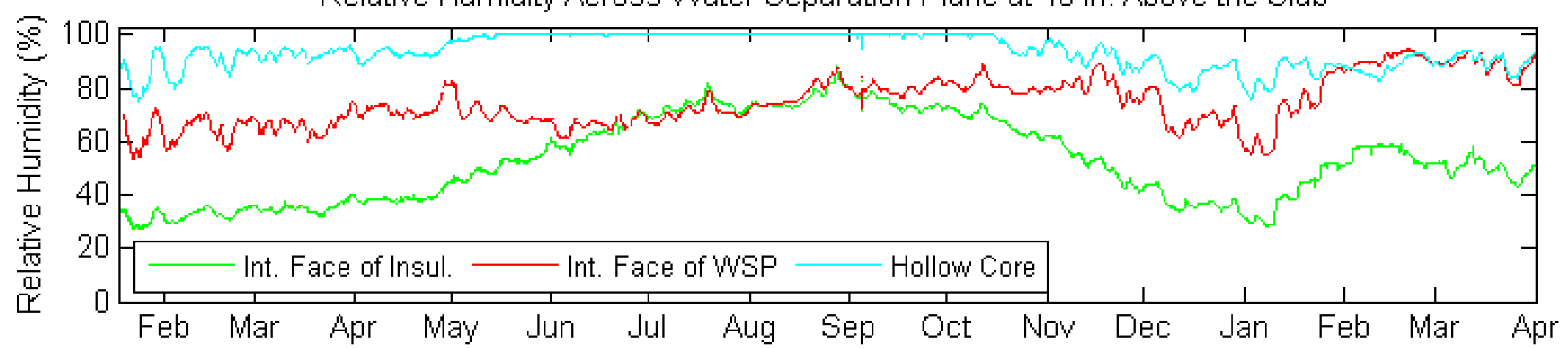

Figure 118. Bay 2N WSP vapor retarding performance 

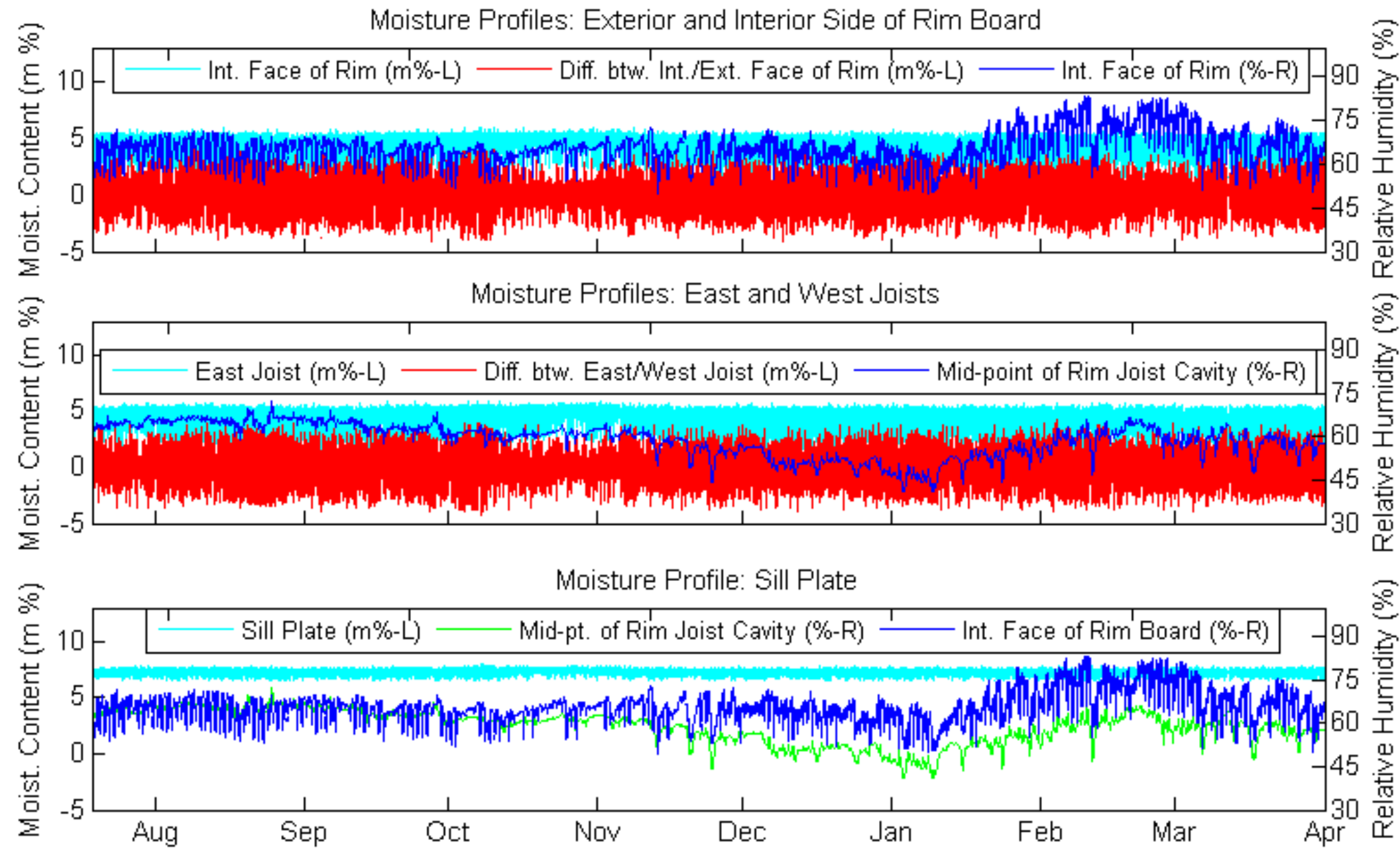

Figure 119. Moisture performance of Bay $5 \mathrm{~S}$ rim-joist cavity with uninsulated rim board 


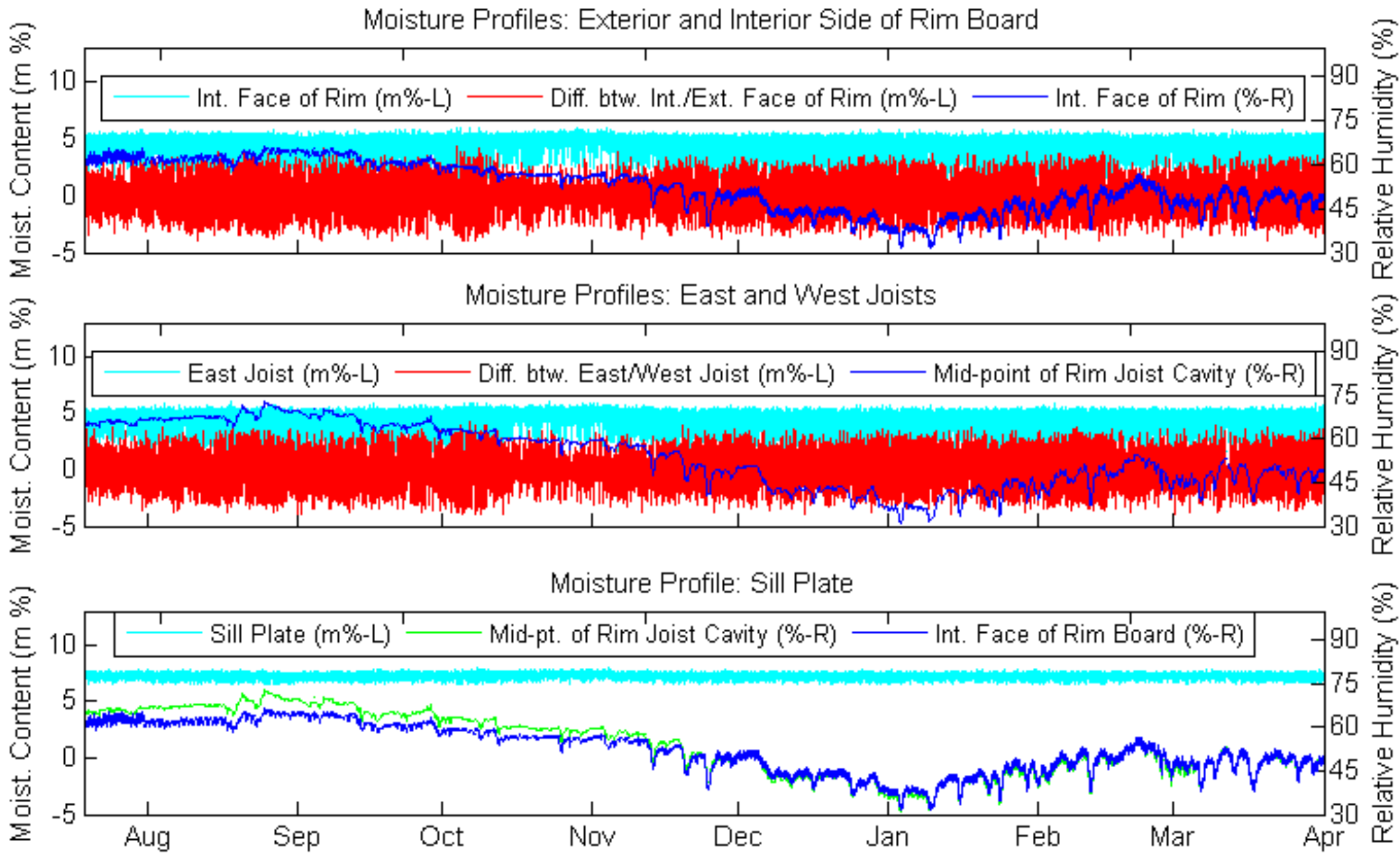

Figure 120. Moisture performance of Bay $5 \mathrm{~S}$ rim-joist cavity with insulated rim board 
South Uninsulated Rim Joist Cavity. Rim Board Interior Face Wetting and Drying Profile
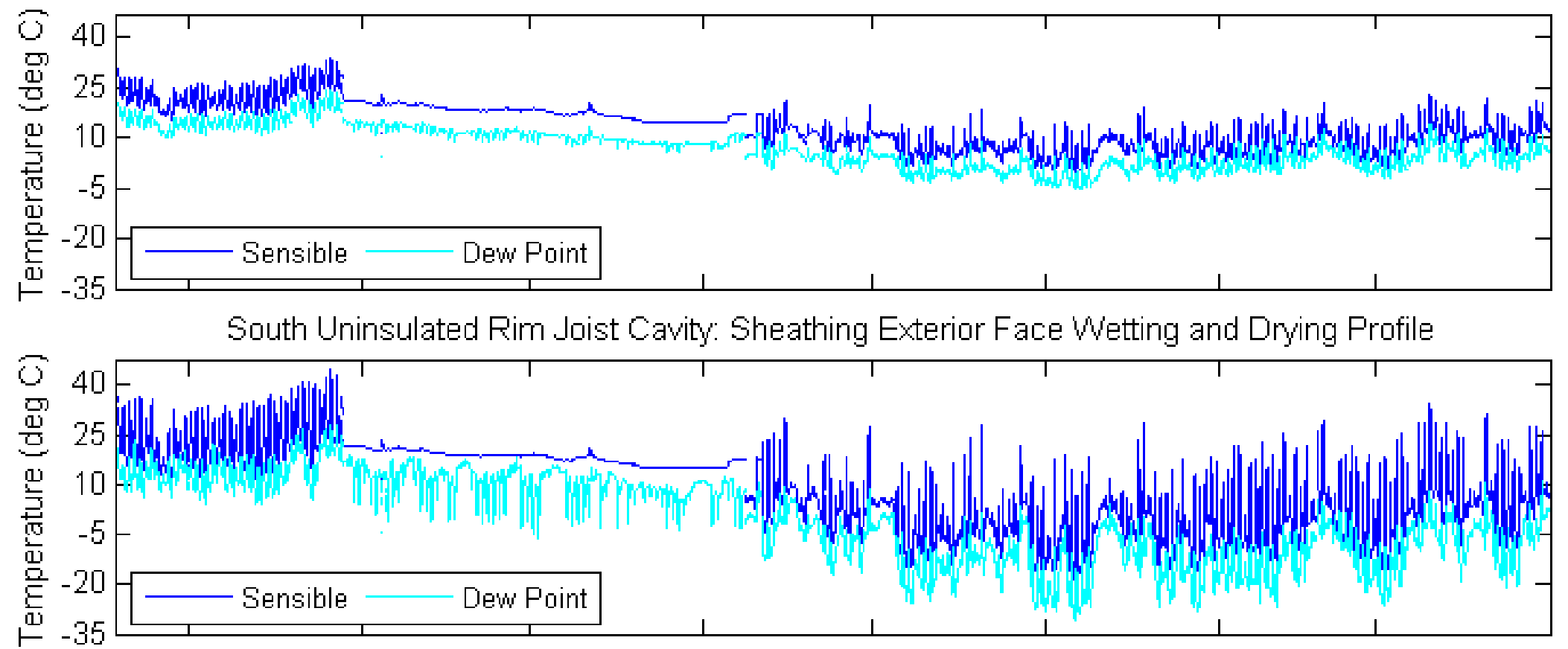

South Uninsulated Rim Joist Cavity: Vapor Retarder Cavity Side Wetting and Drying Profile

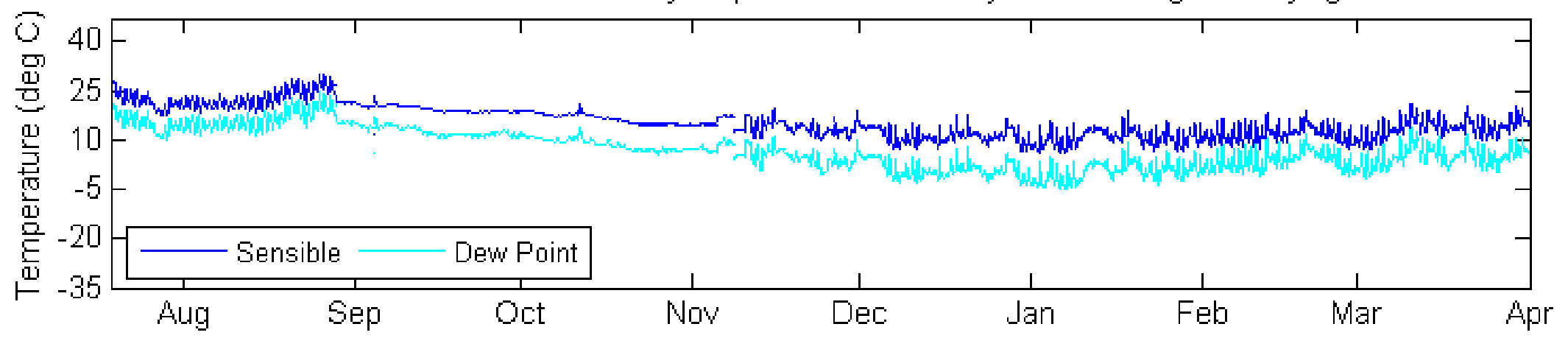

Figure 121. Wetting/drying profiles for Bay $5 S$ rim-joist cavity with uninsulated rim board 
South Insulated Rim Joist Cavity. Rim Board Interior Face Wetting and Drying Profile

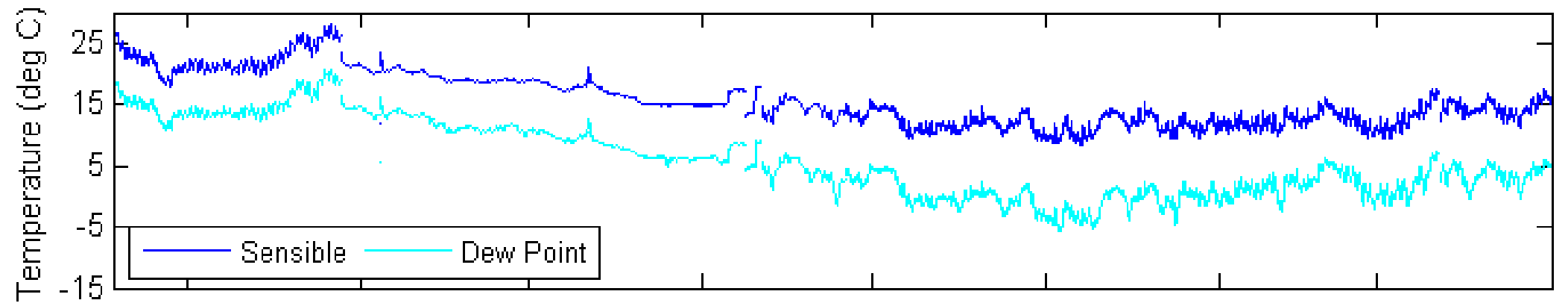

South Insulated Rim Joist Cavity: Sheathing Exterior Face Wetting and Drying Profile

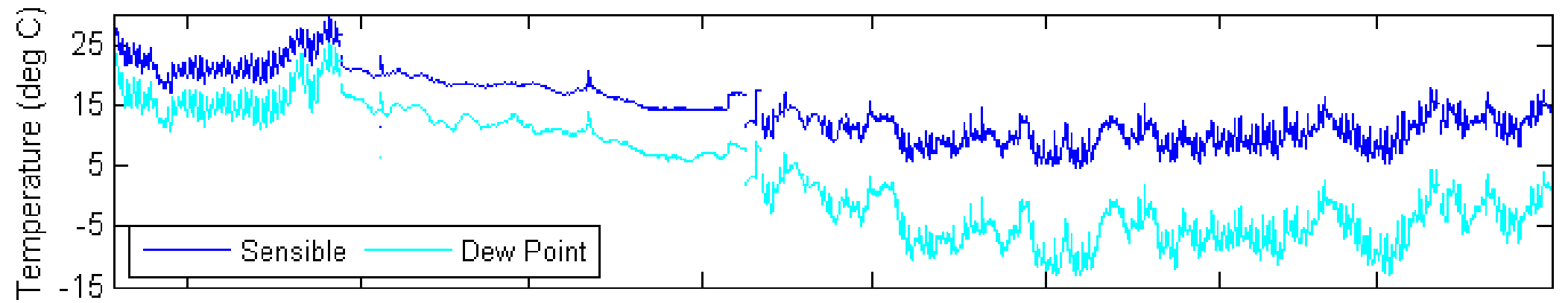

South Insulated Rim Joist Cavity. Vapor Retarder Cavity Side Wetting and Drying Profile

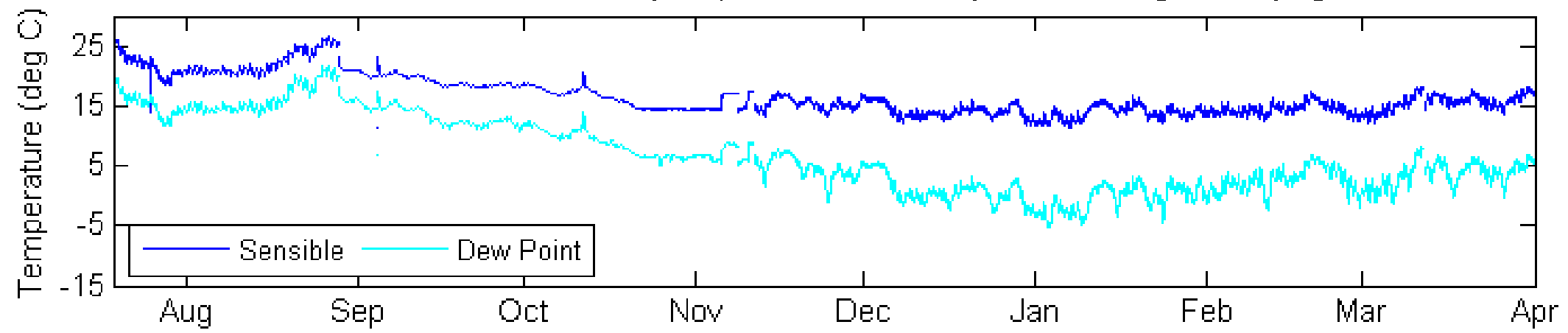

Figure 122. Wetting/drying profiles for Bay $5 \mathrm{~S}$ rim-joist cavity with insulated rim board 

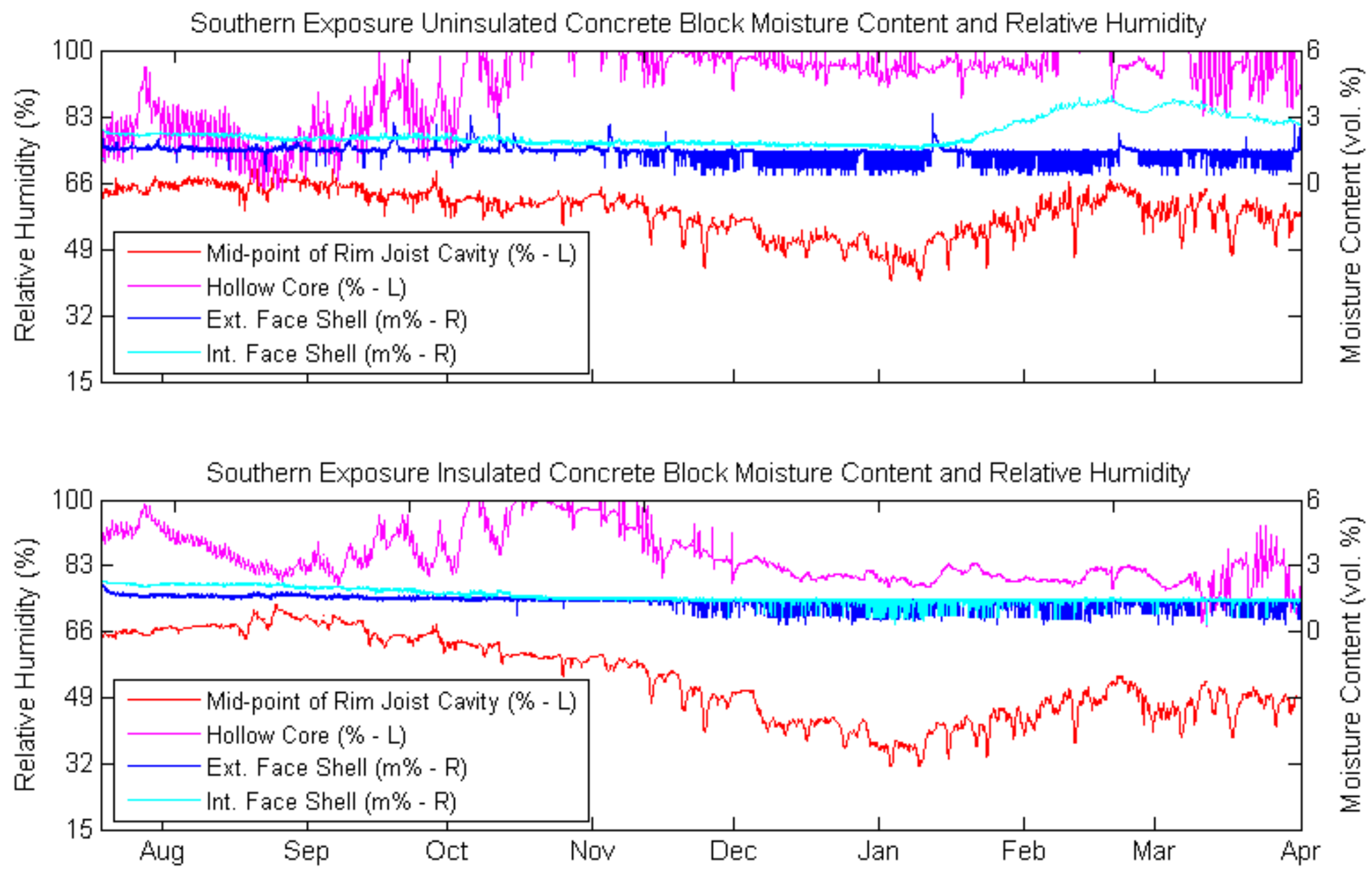

Figure 123. Moisture performance of Bay $5 \mathrm{~S}$ bond beam block below rim-joist cavity 


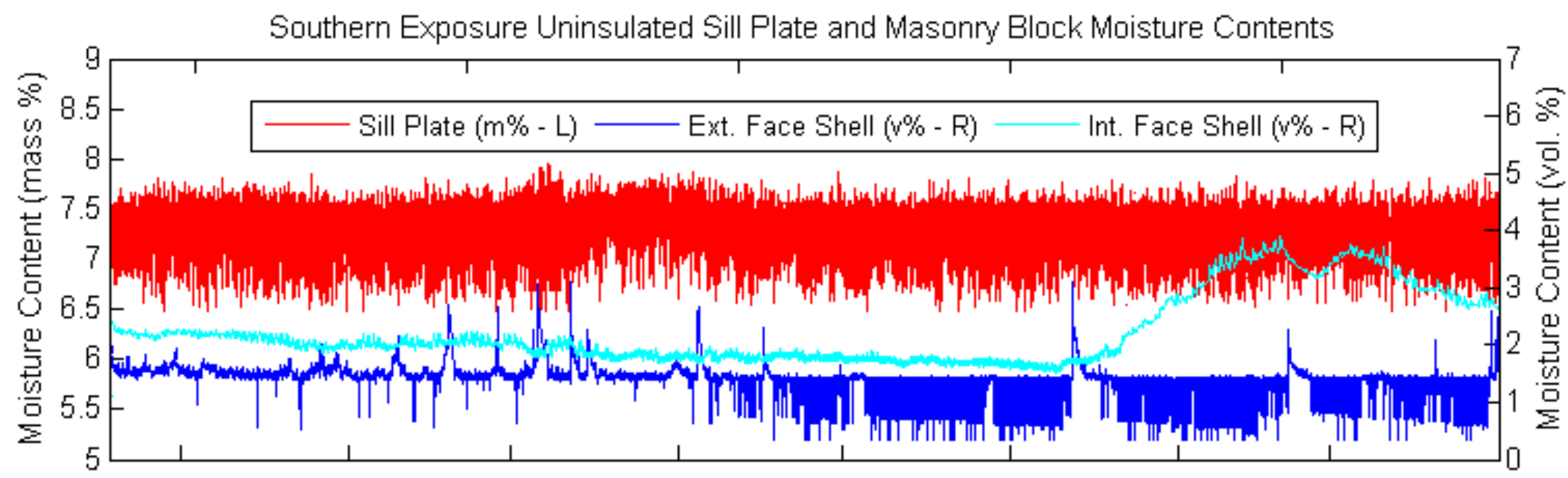

Southern Exposure Insulated Sill Plate and Masonry Block Moisture Contents

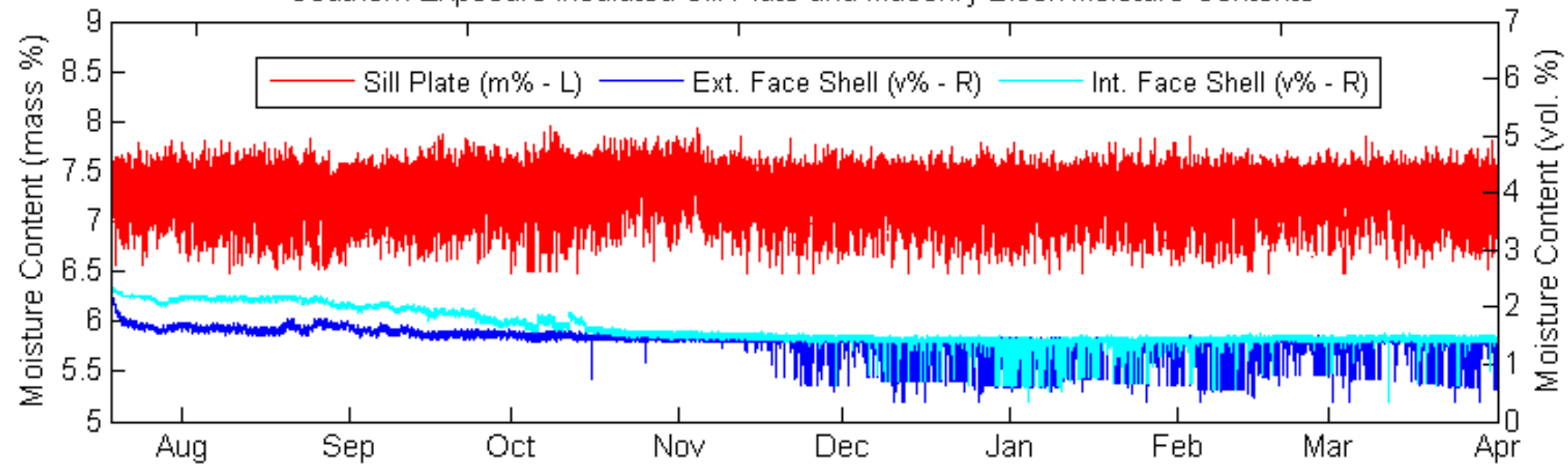

Figure 124. Water diffusion through Bay $5 S$ bond beam block below rim-joist cavity 

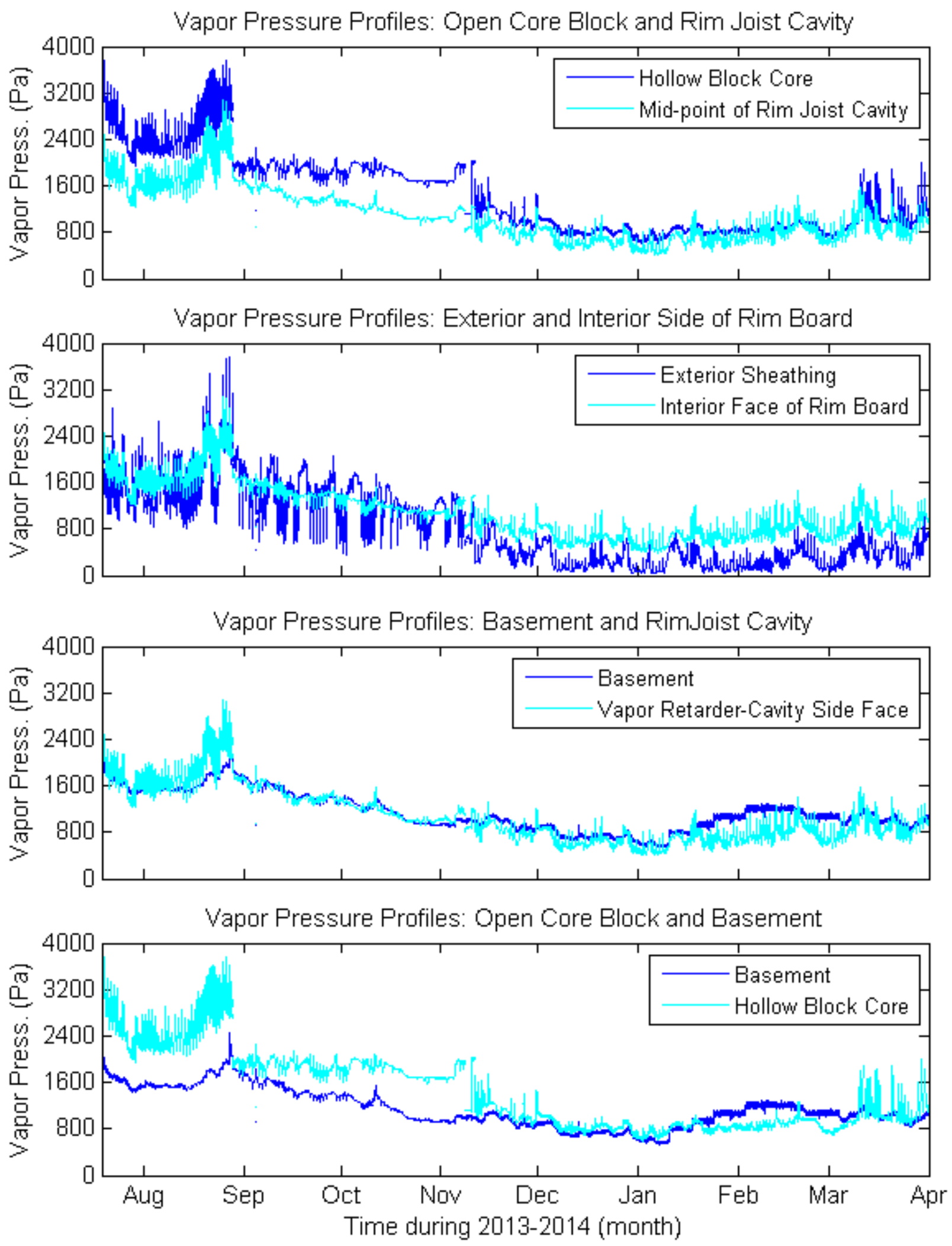

Figure 125. Bay 5S rim-joist cavity bounding surface vapor pressure profiles with uninsulated rim board 

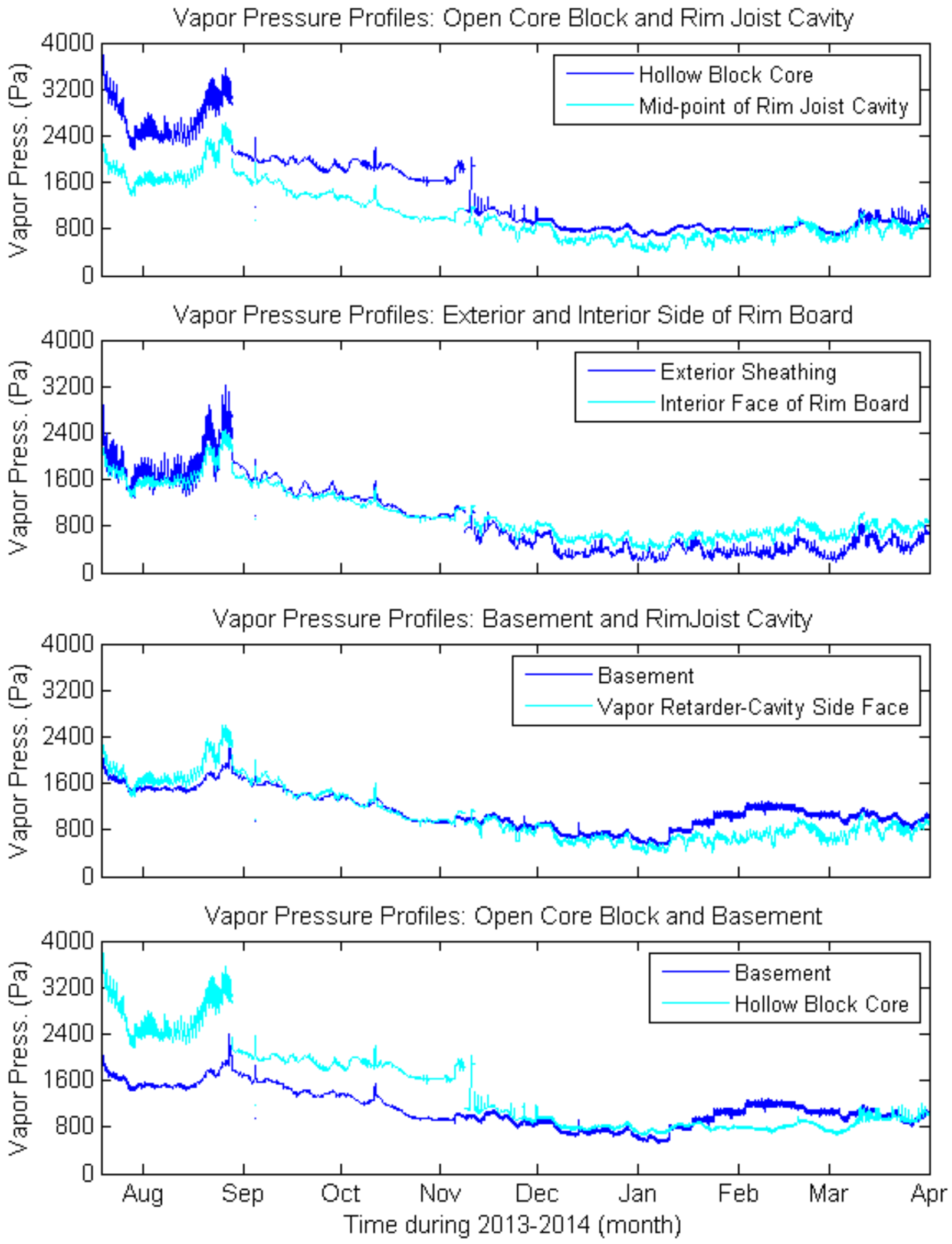

Figure 126. Bay $5 S$ rim-joist cavity bounding surface vapor pressure profile with insulated rim board 


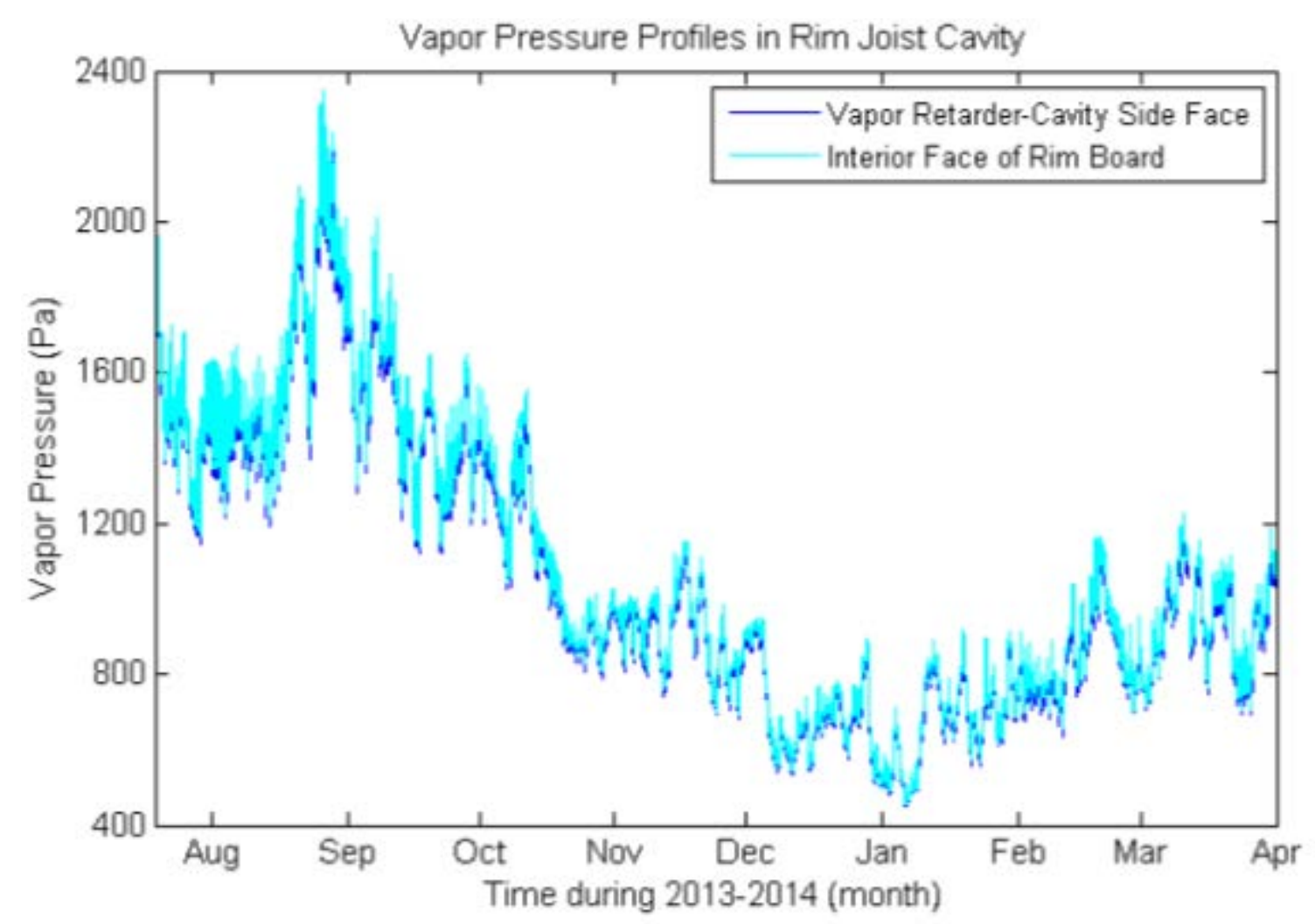

Figure 127. Bay $5 \mathrm{~N}$ rim-joist cavity interior vapor pressure gradient with uninsulated rim board

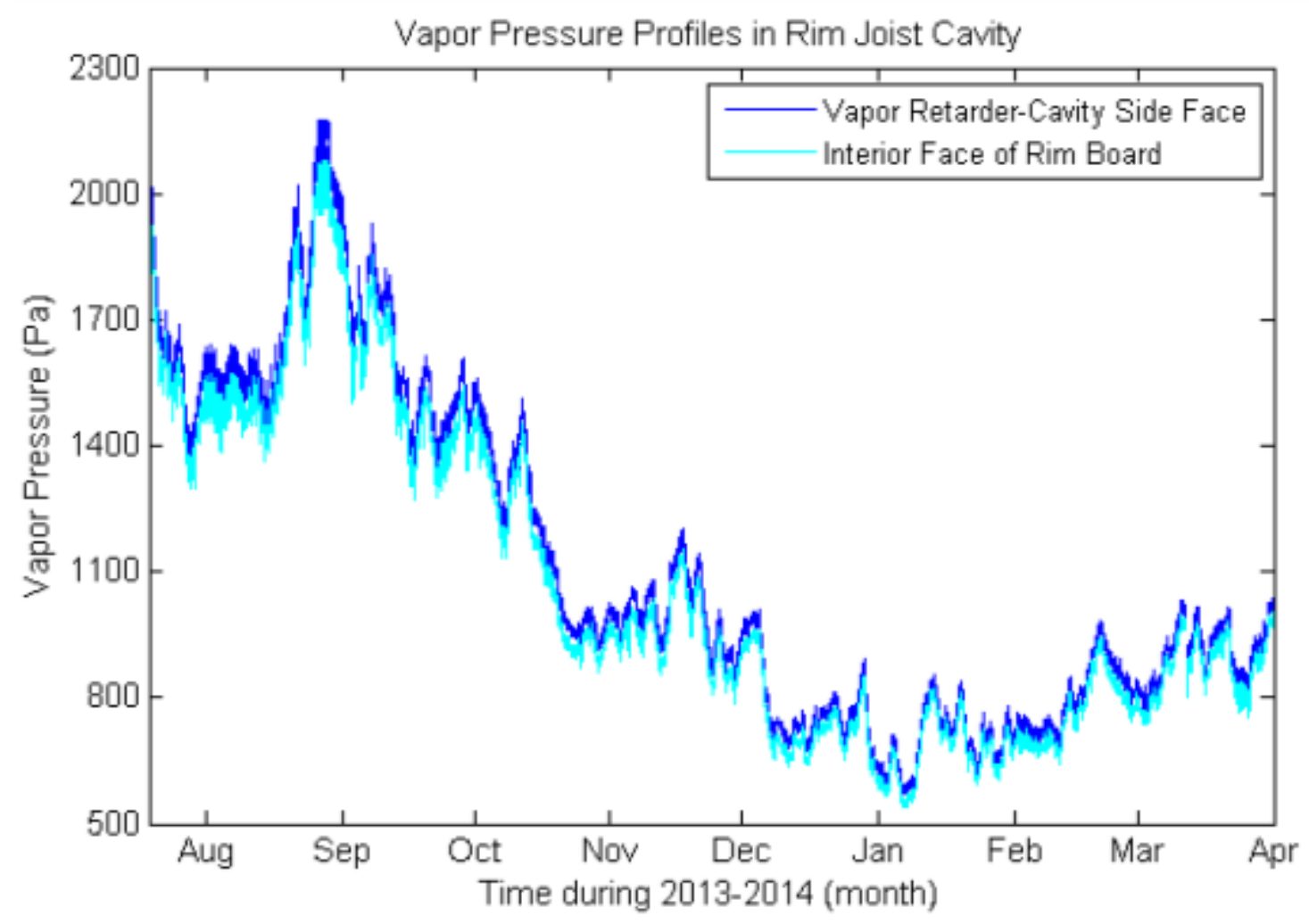

Figure 128. Bay $5 \mathrm{~N}$ rim-joist cavity interior vapor pressure gradient with insulated rim board 


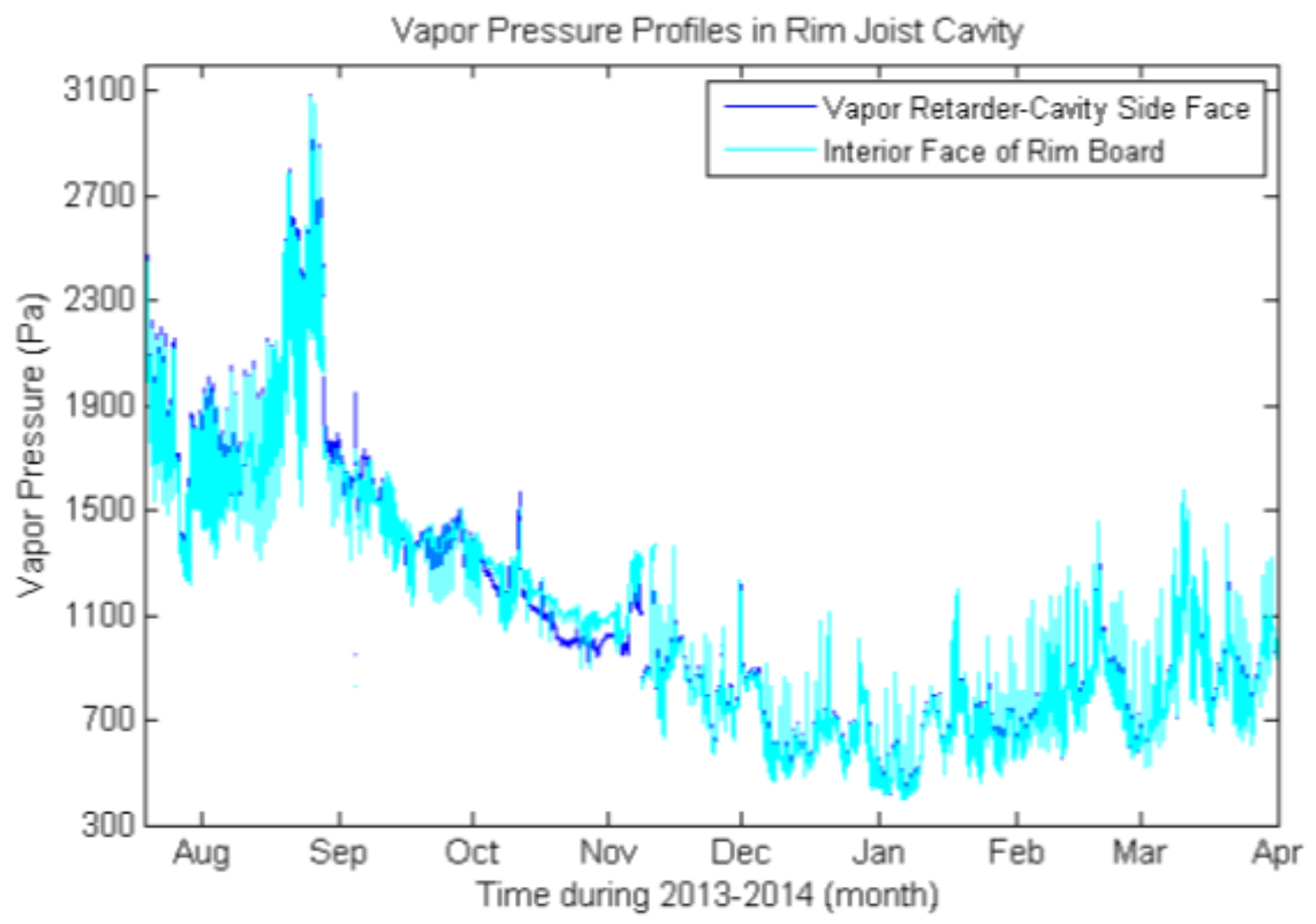

Figure 129. Bay 5S rim-joist cavity interior vapor pressure gradient with uninsulated rim board

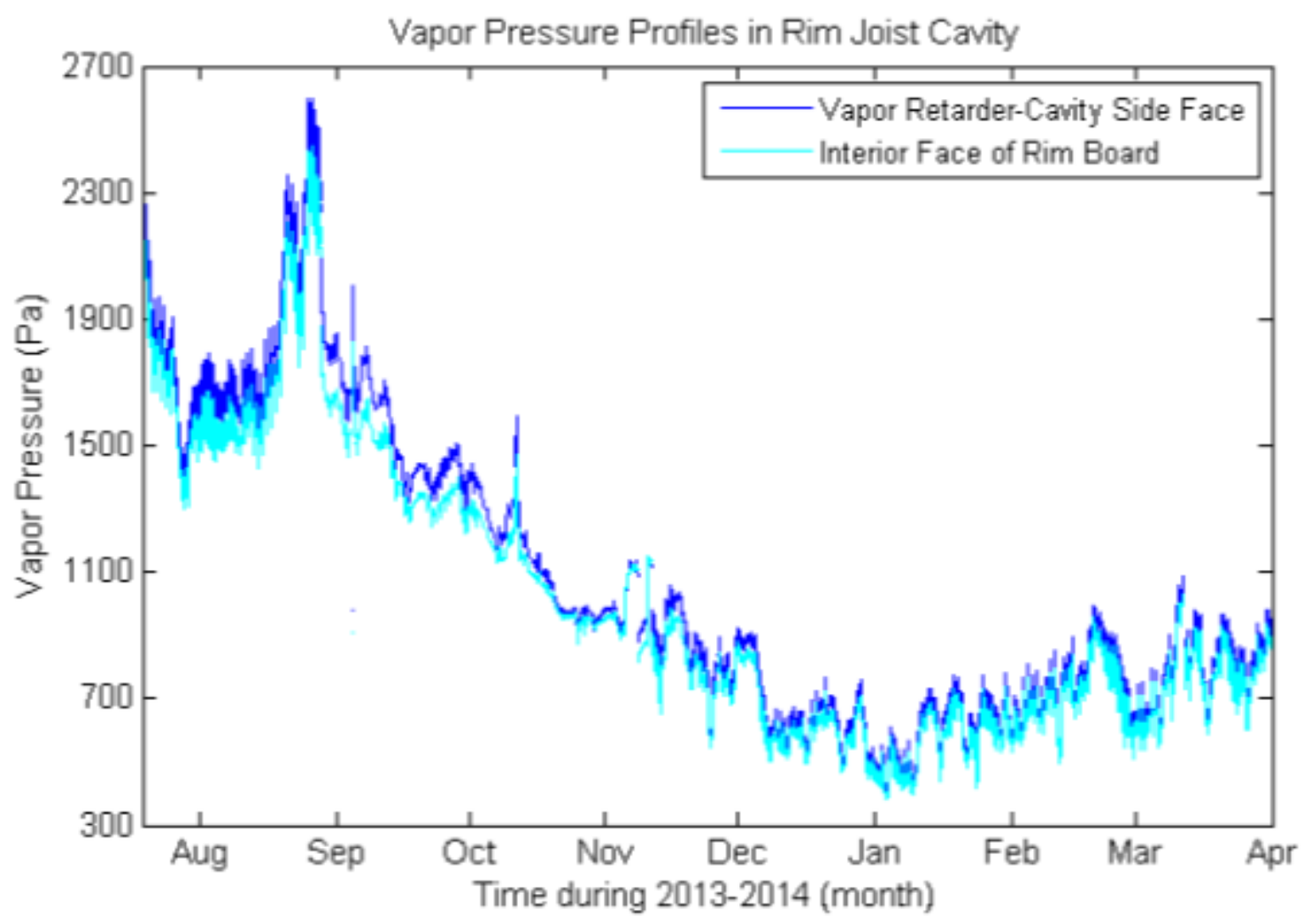

Figure 130. Bay 5S rim-joist cavity interior vapor pressure gradient with insulated rim board 

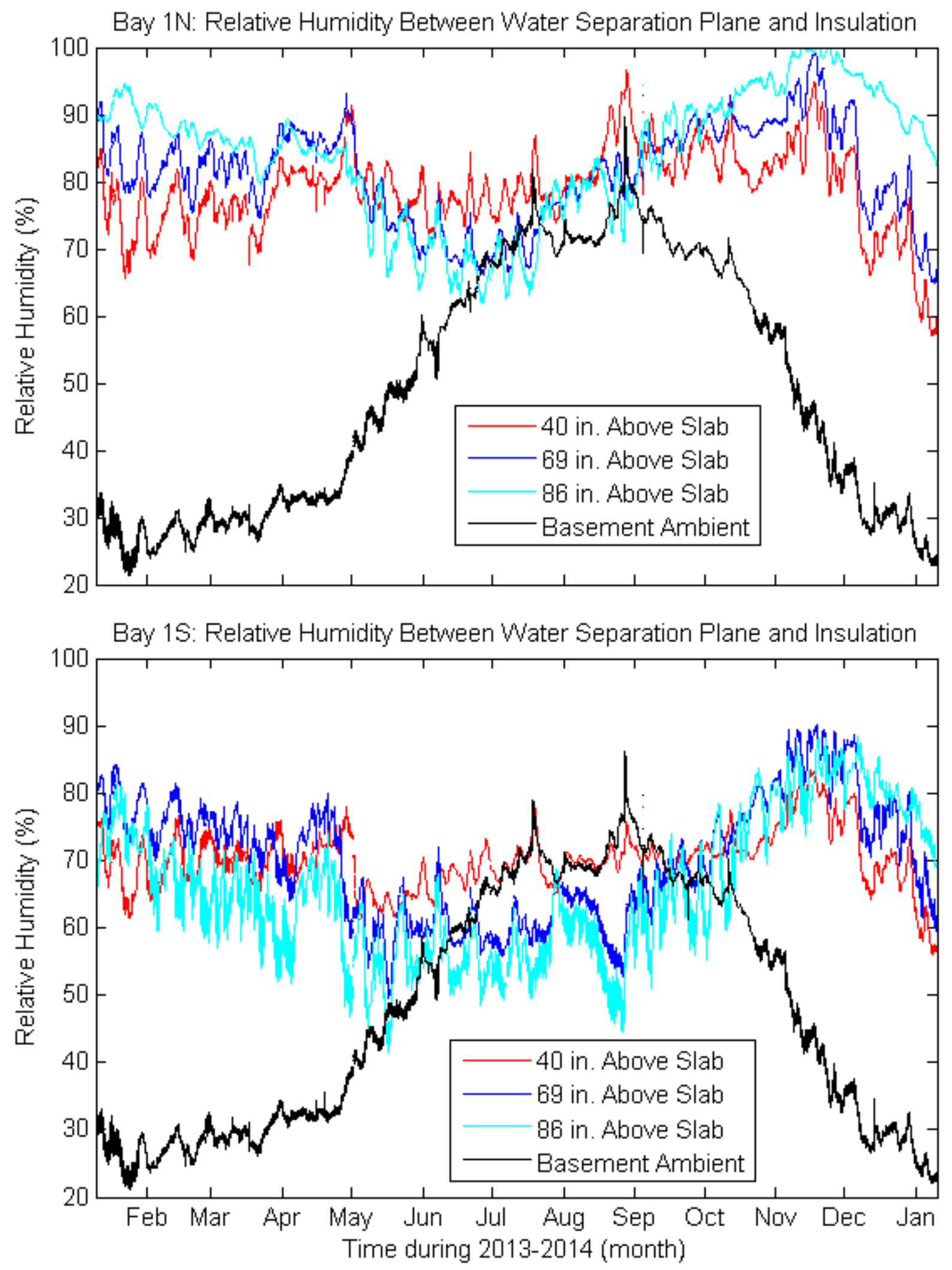

Figure 131. Bay 1 WSP interior condensing surface Minnesota Energy Code compliance performance 


\section{Appendix D: WUFI-2D Experiment/Simulation Result Comparison}

As noted in Section 4, WUFI-2D was selected as the hygrothermal code with which to evaluate the usefulness of the experimental moisture data (RH and moisture content) for simulation code evaluation purposes. However, in its standard configuration, WUFI-2D may not be capable of modeling soils directly. This arises because WUFI uses a single transport equation using $\mathrm{RH}$ as the transport variable for modeling both water vapor and liquid water diffusion fluxes (Kunzel 1995). This relies on invoking a material "moisture storage function" (Kehrer et al. 2012) (more conventionally referred to as a sorption isotherm) to convert RH into a moisture content for calculating the water transport. This works satisfactorily for most building materials where the sorption isotherms are generally monotonic with moderate gradients. However, in soils adjacent to the basement, this becomes problematic because, in the Vadose Zone (soil region above the groundwater table), the soil RH generally exceeds $99 \%$ with a dew point depression less than $0.2^{\circ} \mathrm{C}$ (Rasmussen and Rhodes 1995 ). Using a conventional sorption isotherm to meaningfully model liquid transport in soils ${ }^{42}$ becomes problematic because of the extremely steep slope (almost vertical) of the sorption isotherm for soils at high $\mathrm{RH}$ so that, typically, for all saturation ratios above 0.5 , the RH $>99 \%$. For example, Bird et al. (2000) shows that for Ariana silt clay loam (texturally similar to the soil adjacent to Bay 1) at $10^{\circ} \mathrm{C}$, the $\mathrm{RH}^{43}$ increases from 0.99953 at a moisture content of $18 \mathrm{V-} \%$ (saturation ratio $=0.39$ ) to 0.99998 at a moisture content of $46 \mathrm{~V}-\%$ $($ saturation ratio $=1$ ). This also places severe numerical stability strains on the composite moisture transport equation. These numerical issues have been acknowledged by $\mathrm{ORNL}^{44}$ and, apparently, are generally managed using a trial-and-error process by manipulating the sorption isotherms and the spatial discretization. However, no documented procedures for performing these manipulations were available and no precise verbal information about them could be obtained from ORNL.

Because WUFI-2D is two-dimensional, it had to be applied with care to the masonry block walls in the experiment. As demonstrated in Section 4.1.4, the heat transfer through the solid or grouted core in Bay $3 \mathrm{~N}$ is intrinsically three-dimensional, so WUFI-2D cannot be used in this case. It was evaluated for Bays $1 \mathrm{~N}$ and $2 \mathrm{~N}$ only, on a plane passing through the center of a masonry block core. The cross-sectional geometry at the center of a masonry block core and the boundary conditions are shown in Figure 132. Both the geometry and the boundary conditions are identical to those of BUFETS (Figure 57), except that the horizontal far field width is reduced from 108 in. to 12 in. The reduced far field width is intended purely as a thermal guard for the soil crib. The spatial discretization is given in Figure 133.

Soil properties were developed by ORNL (Kehrer et al. 2012) for use with WUFI-2D. Twelve sets of soil properties were developed, one for each textural class region in the U.S. Department of Agriculture soils triangle. ${ }^{45}$

\footnotetext{
42 The soil sorption isotherm is derived from the water retention curve which expresses the relationship between volumetric moisture content and suction pressure. The RH can be calculated from the suction pressure by invoking the Kelvin-Thomson equation (Fredlund and Rahardjo 1993).

${ }^{43}$ Converted from the water suction pressures reported in the paper.

${ }^{44}$ Personal communication with M. Kehrer.

${ }^{45}$ Note that these material properties are different from those used in BUFETS as shown in Table 4.
} 


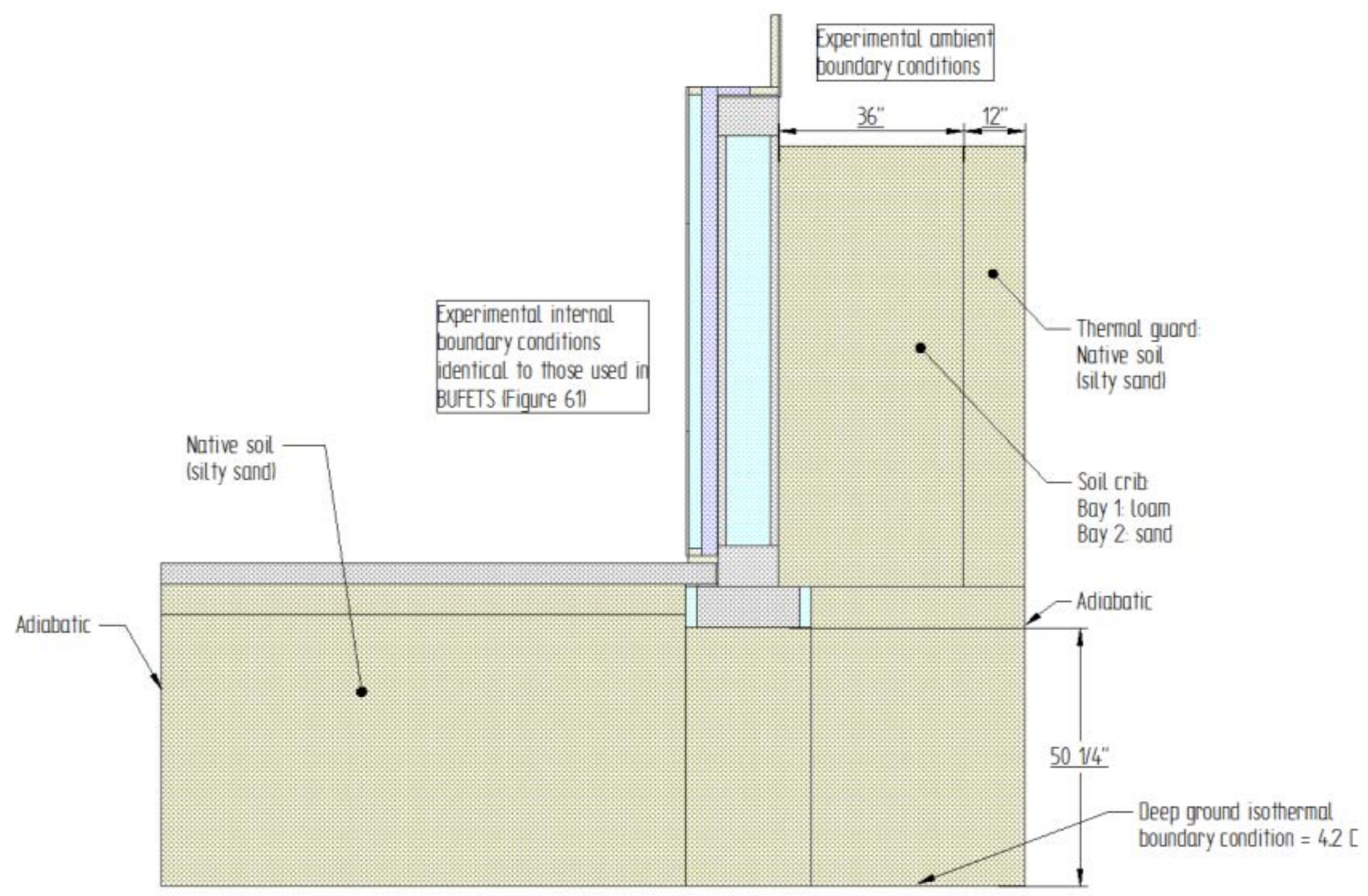

Figure 132. Two-dimensional WUFI simulation domain and boundary conditions 


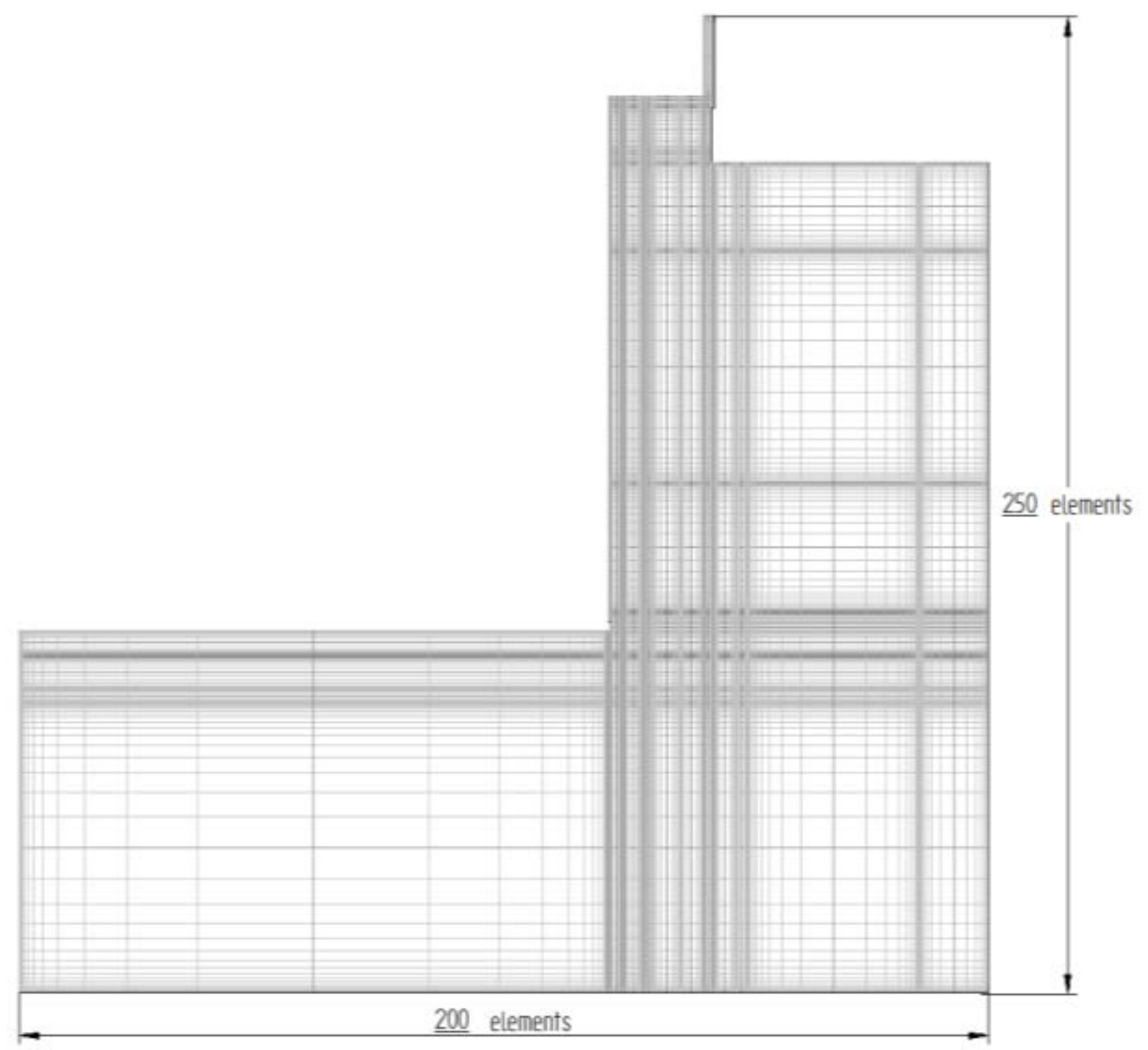

Figure 133. Two-dimensional WUFI simulation domain discretization 
The "standard" commercial version of the WUFI-2D kernel (rev. 3.3.2.52) was used for the simulations ${ }^{46}$ together with the ORNL soil properties. Unfortunately, a hygrothermal solution could not be obtained for the simulation domain. The thermal part of the simulation (energy transport equation) functioned satisfactorily with good numerical convergence, but the moisture transport equation failed to converge and generated software errors related to the convergence of the inner iterations of the equations' solution algorithm. A solution that partially succeeded was to deactivate the bulk water capillary hydraulic conduction transport in the WUFI-2D algorithm. This yielded about 3 months of data before the simulation failed. For these 3 months, a comparison of the simulated masonry block core RH profiles against those measured revealed a very substantial difference between the measured and simulation results. Every effort was made to glean insight into these results and to solve the problems by communicating at length with the software developers at ORNL as well as at the IBP in Germany, but to no avail. ${ }^{47}$ Only the thermal results of WUFI-2D can be evaluated against the experimental data here.

Like BUFETS, WUFI-2D also does not explicitly include advective thermal flows in the energy equation; only diffusive thermal flows are modeled. The limitations of not modeling the buoyant cavity flows in the masonry block cores discussed for BUFETS apply to WUFI-2D as well, and the expectation at the outset was that WUFI-2D would replicate the experimental data no better than BUFETS, the two-dimensional limitation of the former in modeling a fundamentally threedimensional problem notwithstanding. ${ }^{48}$ The same heat transport physics discussed in relation to the BUFETS/experimental data comparison also apply to WUFI-2D so this discussion will not be repeated here. Instead the discussion will focus on the differences in the simulated data produced by BUFETS and WUFI-2D because these are more instructive for improving the models and demonstrating the efficacy of the experimental data for evaluating such simulations.

With this in mind, an attempt was made to improve the information yield from the comparison exercise as a whole. As the BUFETS simulations were undertaken on the north side of the building for which the soil cribs were shaded for most of the year, direct solar irradiance was not included as a boundary condition. In general, as shown in Sections 4.1.1 through 4.1.4, the simulated temperature profiles consistently had lower values than those measured with the larger discrepancies occurring in the cooling season. The question arises about whether an additional heat source at the ground surface would improve the experiment/simulation agreement. It was decided to use the WUFI simulations to evaluate this proposition so as to maximize the yield from the very time-consuming simulation exercise. Solar irradiation on the soil and above-grade wall surfaces for the Bay $1 \mathrm{~N}$ and $2 \mathrm{~N}$ cases was included in the WUFI-2D simulations to determine whether this would improve the agreement. Conversely, no improvement would tentatively suggest (because many other factors are involved) that surface irradiance may not be a factor in the BUFETS/experimental temperature discrepancies. Further, if the WUFI-2D discrepancies would be worse than those of BUFETS, surface solar irradiance as a boundary condition likely is of minor importance in earth contact simulations for accurate modeling of the deeper ground temperatures in

\footnotetext{
${ }^{46}$ A more recent special version that allows the importation of external dynamic link libraries to describe sources and sinks was not used.

${ }^{47}$ A copy of the model was sent to ORNL for review and comment. No response was received.

${ }^{48}$ See Figure 58.
} 
general and the causes for the discrepancies must be sought elsewhere (as suggested in Section 4.1.5).

As the WUFI-2D data output includes only temperatures within the simulation domain (not heat fluxes, as is the case with BUFETS), the experiment/simulation comparison is reported for temperatures only. A complete set of experiment/WUFI-2D temperature comparison graphs for Bays $1 \mathrm{~N}$ and $2 \mathrm{~N}$ corresponding to the experiment/BUFETS graphs in Sections 4.1.1 and 4.1.2 is reported in Appendix E. An illustrative excerpt of the comparisons sufficient to illustrate the essential features is discussed below.

\section{D.1 Test Bay $1 \mathrm{~N}$}

The BUFETS and WUFI-2D wall temperature comparisons $40-1 / 4$ in. above the slab are shown in Figure 134. The worst disagreement between the experimental and simulation data is about $7^{\circ} \mathrm{C}$ for WUFI-2D and about $3^{\circ} \mathrm{C}$ for BUFETS. The BUFETS temperature predictions are closer to the experimental data during the heating season while the summer discrepancy is reduced for WUFI$2 \mathrm{D}$ but is still about $3.5^{\circ} \mathrm{C}$ larger then BUFETS at 5000 hours.

At the top of the wall in Figure 135, the differences between BUFETS and WUFI-2D are reduced as this region is least influenced by the soil. The effect of the solar irradiance is discernable in the large WUFI-2D simulated diurnal temperature variations on the exterior face shell that are carried through to the core and interior face shell temperatures. 
BAY 1N WALL EXPERIMENT/SIMULATION TEMPERATURE COMPARISON MID-HEIGHT: 40.25 in. ABOVE SLAB (HOLLOW MASONRY BLOCK CORE)

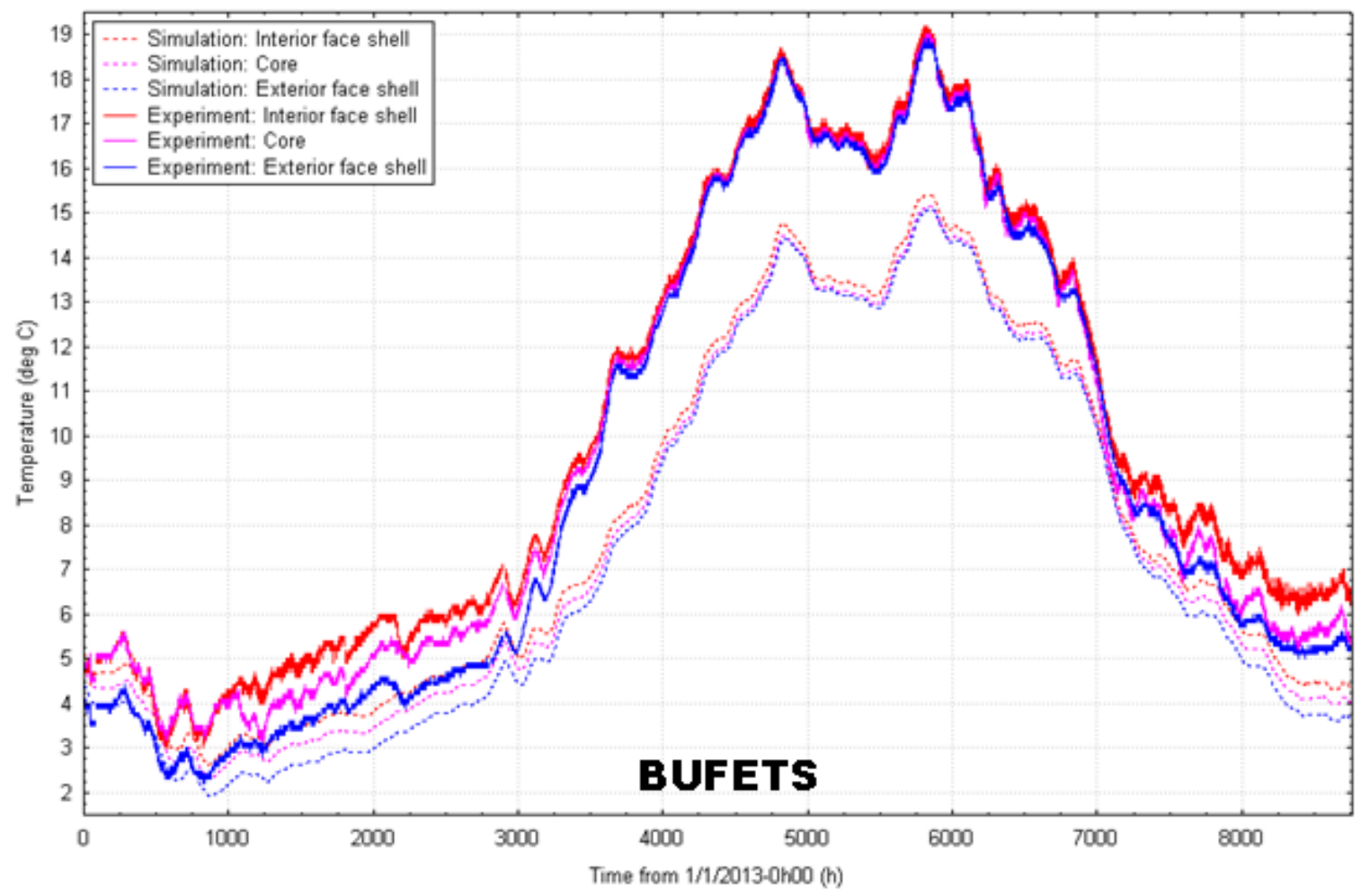

BAY 1N WALL EXPERIMENTISIMULATION TEMPERATURE COMPARISON MID-HEIGHT: 40.25 in. ABOVE SLAB (HOLLOW MASONRY BLOCK CORE)

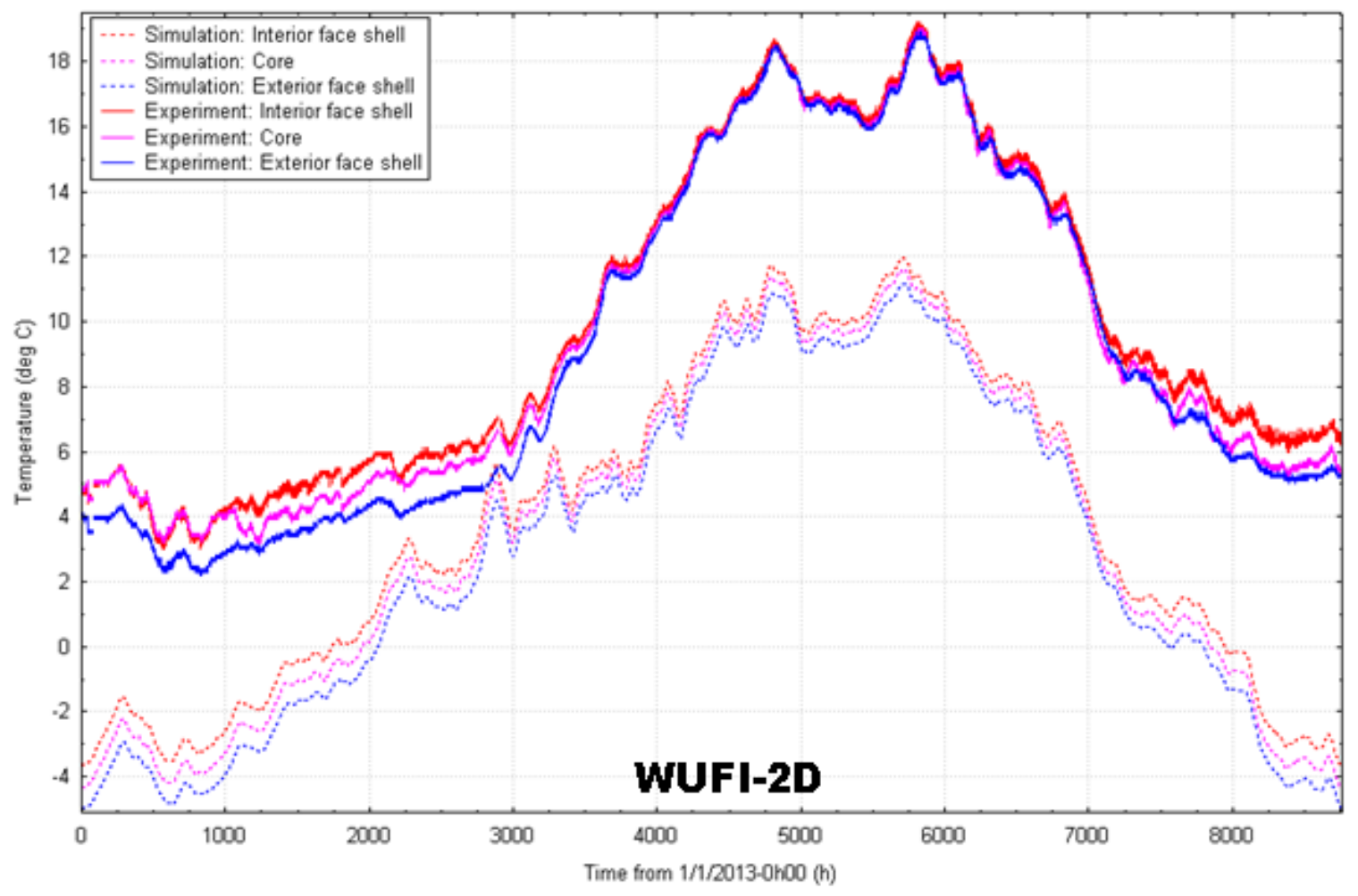

Figure 134. Bay 1N BUFETS/WUFI-2D wall temperature comparisons $40-1 / 4$ in. above the slab 
The agreement between the BUFETS and experimental exterior face shell temperatures confirm that in reality the north side is almost always shaded. ${ }^{49}$ In terms of the core and interior face shell temperatures, WUFI-2D yields agreement with the experimental data (allowing for the increased diurnal variations) during the cooling season, but not in the heating season when again, the discrepancies are larger than those of BUFETS. For example, at the end of the simulation year, WUFI-2D shows a core temperature discrepancy of about $16^{\circ} \mathrm{C}$ compared with about $8^{\circ} \mathrm{C}$ for BUFETS. At the top of the wall, this difference is likely a result of the absence of threedimensional heat flow in WUFI-2D.

The comparison of the vertical soil temperature profiles shown in Figure 136 is instructive. At the base of the wall, $5-1 / 2$ in. above the slab, BUFETS yields discrepancies $<2^{\circ} \mathrm{C}$ during the heating season and 8 to $10^{\circ} \mathrm{C}$ during the cooling season, whereas the corresponding discrepancies are $<4^{\circ} \mathrm{C}$ and no more than $10^{\circ} \mathrm{C}$ for WUFI-2D. This correspondence suggests that at the base of the wall, both programs are showing the omission of a heat source resultant from a seasonally varying water table depth and temperature (see Section 4.1.5).

As the height above the slab increases, the WUFI-2D/BUFETS discrepancy difference increases at the end of the simulation year from about $2^{\circ} \mathrm{C}$ at $5-1 / 2$ in. above the slab to $>20^{\circ} \mathrm{C}$ at $69-1 / 4 \mathrm{in}$. above the slab (12 in. below grade). As grade is approached, the differences between the BUFETS and WUFI-2D energy transport equation solution algorithms increase. ${ }^{50}$ The inclusion of solar irradiance on the ground surface would be expected to manifest 12 in. below grade. However, the results do not support this expectation. At 5000 hours, for example, when solar irradiance might be expected to have the largest impact, the BUFETS and WUFI-2D temperature discrepancies are about $3^{\circ}$ and $16^{\circ} \mathrm{C}$, respectively. So it is very unlikely that solar irradiance has a significant impact on the soil heat transport phenomenology 12 in. below grade and deeper.

\footnotetext{
${ }^{49}$ Around the winter solstice, the north face is sunlit just after sunrise. Surrounding forest shades the north side just before sunset.

${ }^{50}$ Chiefly, three-dimensionality and discontinuous phase change in BUFETS compared with two-dimensionality and continuous phase change in WUFI-2D.
} 
BAY 1N WALL EXPERIMENT/SIMULATION TEMPERATURE COMPARISON
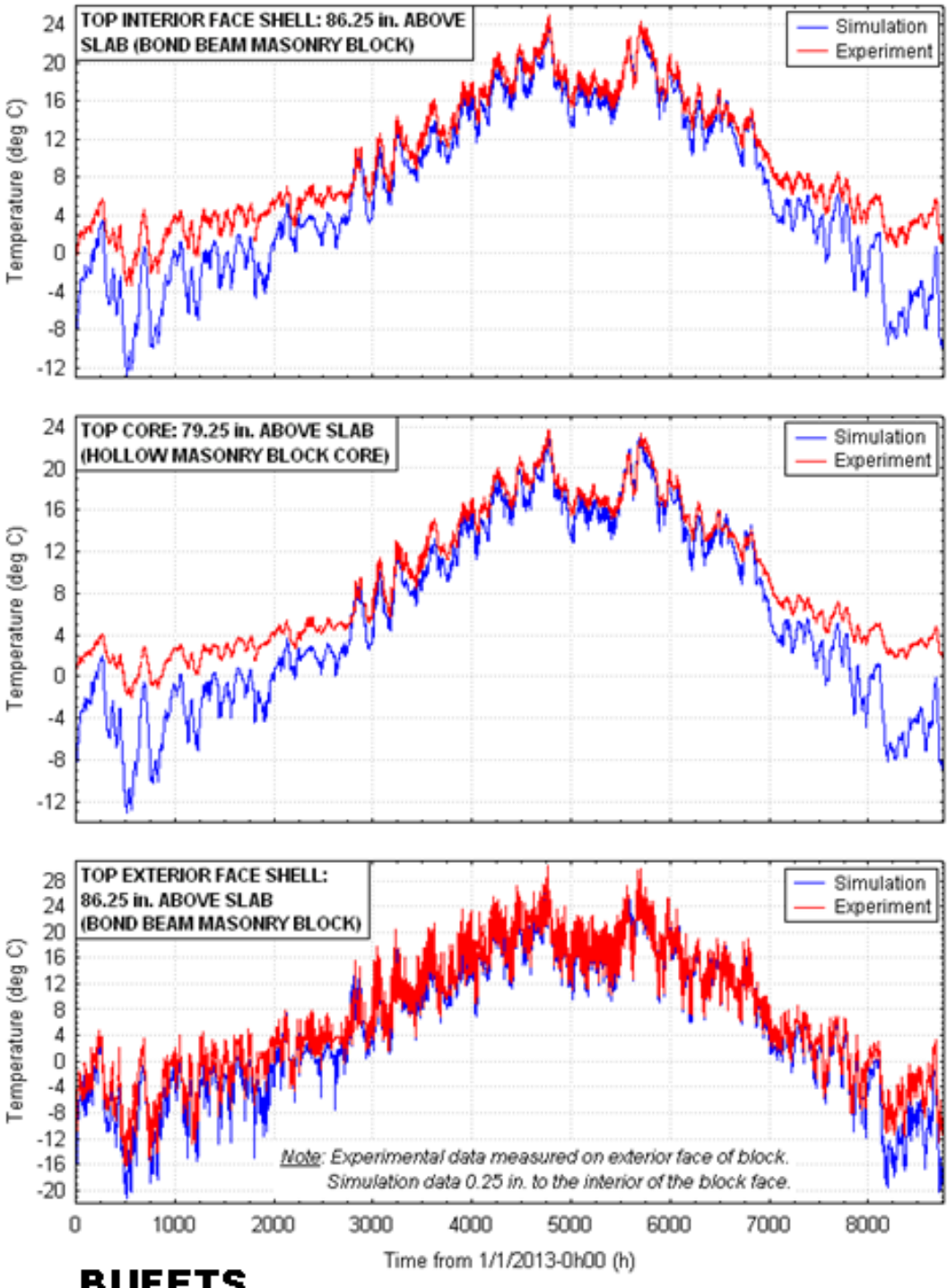

BUFETS
BAY 1N WALL EXPERIMENT/SIMULATION TEMPERATURE COMPARISON
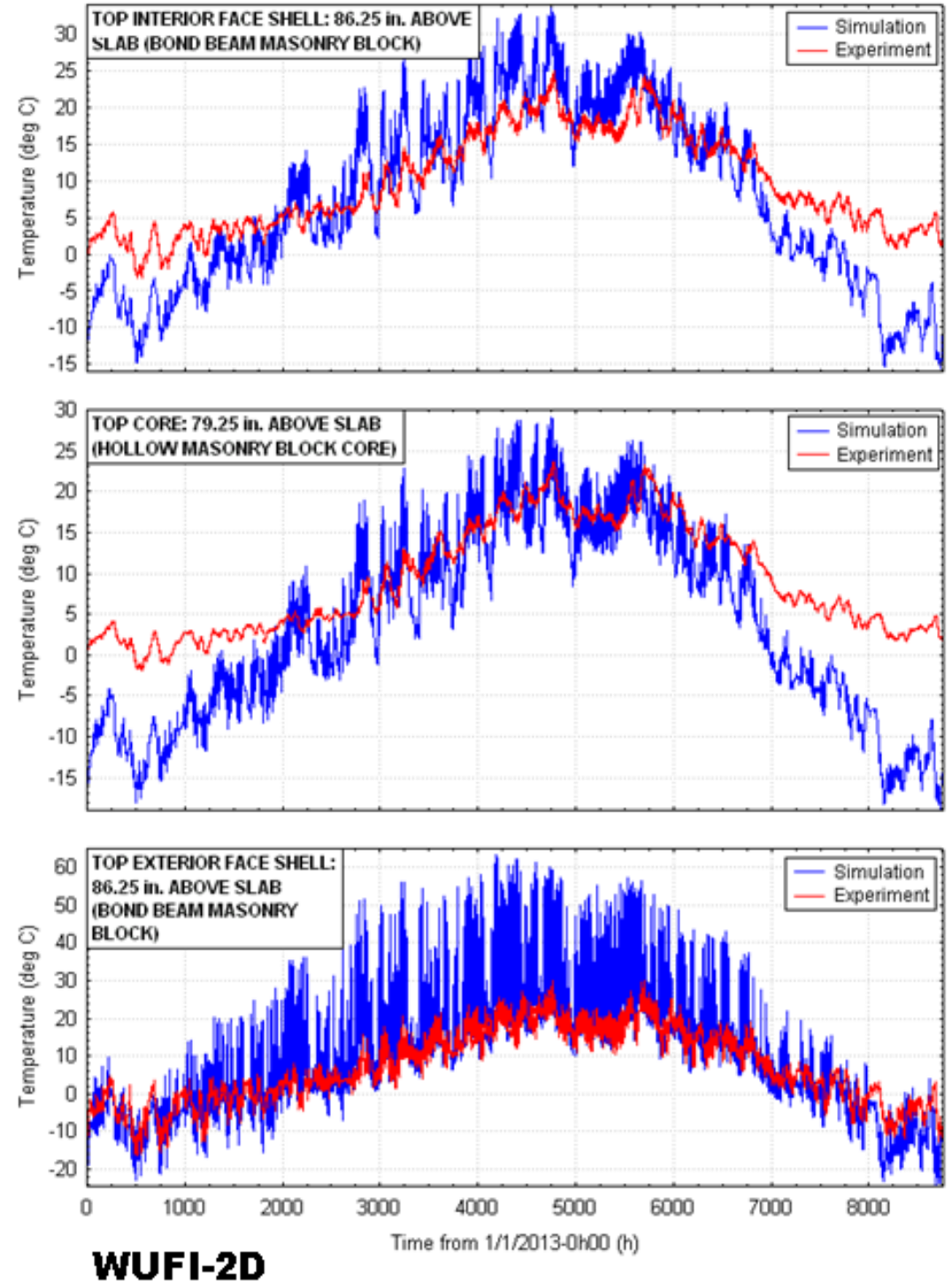

Figure 135. Bay 1N BUFETS/WUFI-2D wall temperature comparisons $86-1 / 4$ in. above the slab 
BAY 1 N VERT. SOIL TEMP. PROFILE EXPERIMENT/SIMULATION COMPARISON
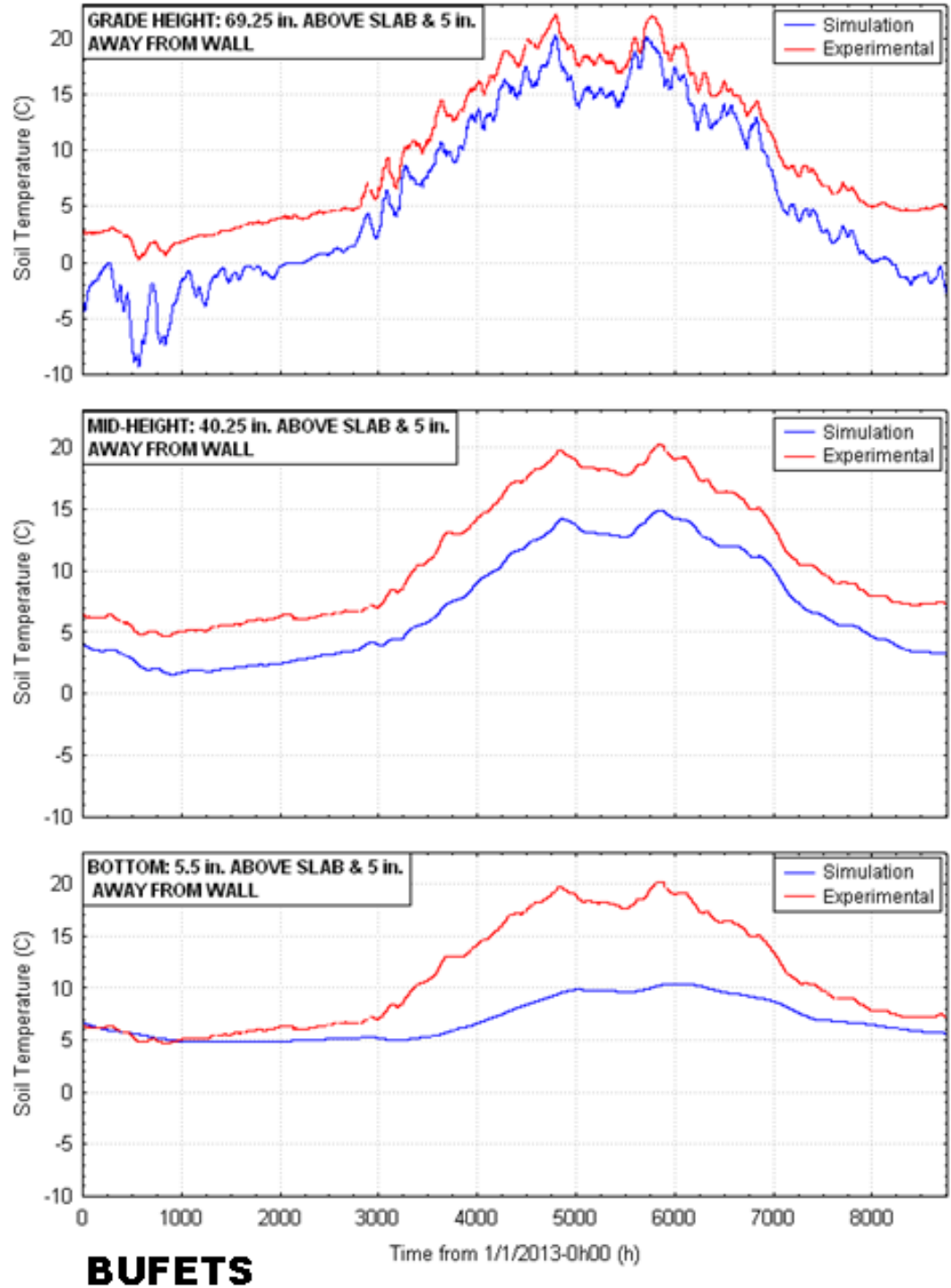

BAY $1 \mathrm{~N}$ VERT. SOIL TEMP. PROFILE EXPERIMENT/SIMULATION COMPARISON
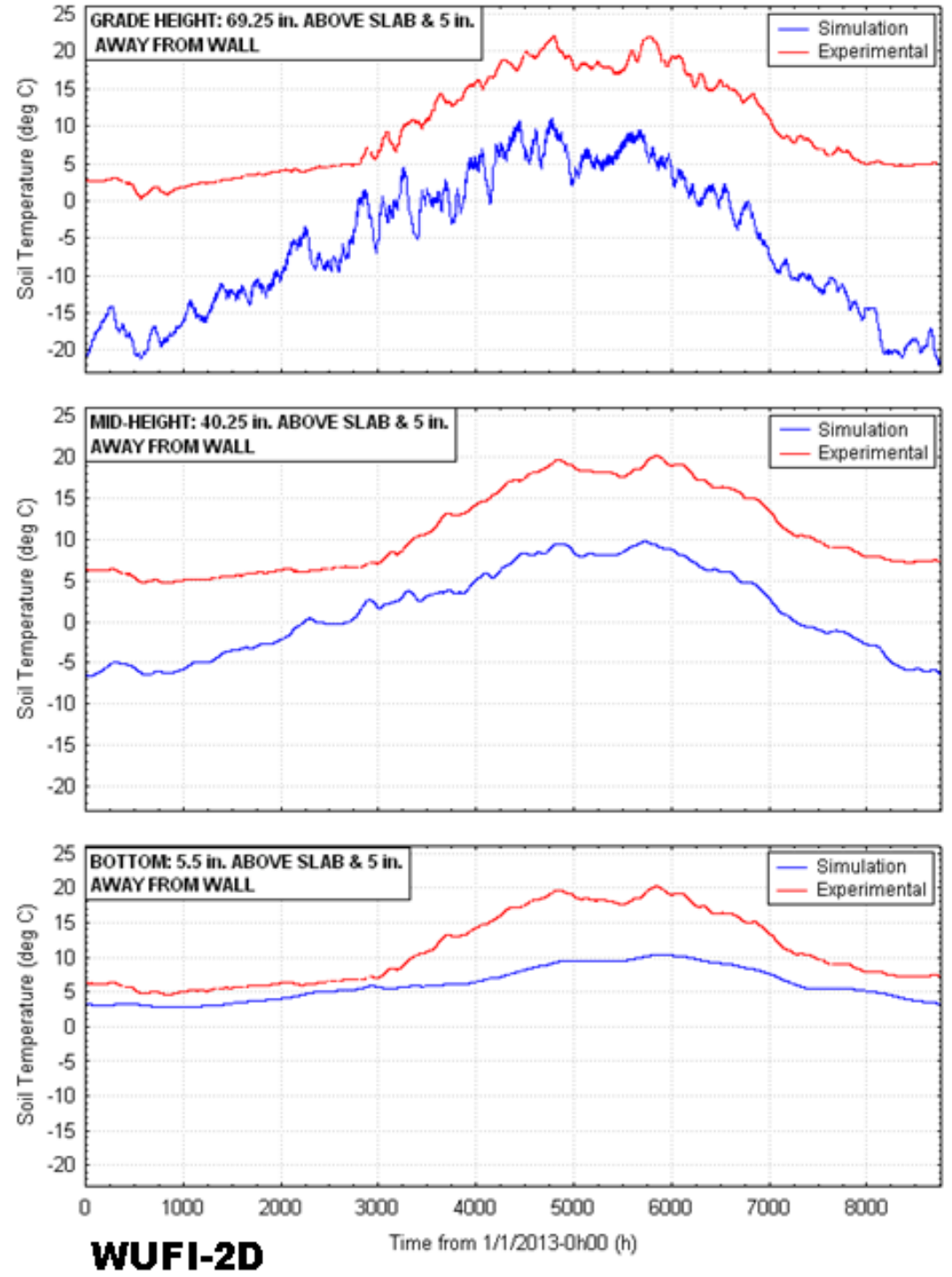

Figure 136. Bay 1N BUFETS/WUFI-2D vertical soil temperature profile comparisons 


\section{D.2 Test Bay 2N}

The same pattern in the BUFETS/WUFI-2D discrepancy comparisons shown in Bay $1 \mathrm{~N}$ continues to Bay 2N. For both BUFETS and WUFI-2D, the experiment/simulation discrepancies increase a little as a consequence of the crib soil changing from loam to sand. In the case of the wall temperatures $40-1 / 4$ in. above the slab, at the end of the simulation, the WUFI-2D discrepancy increases from $10.5^{\circ} \mathrm{C}$ in Bay $1 \mathrm{~N}$ (Figure 134) to $12^{\circ} \mathrm{C}$ in Bay $2 \mathrm{~N}$ (Figure 137), while the corresponding increase for BUFETS is $2^{\circ}-3^{\circ} \mathrm{C}$. Thus change in soil thermal properties affects both WUFI-2D and BUFETS with the former experiencing a slightly bigger impact. However, the pattern of discrepancies is unaltered, suggesting that soil material property inaccuracies are not the primary cause of the experiment/simulation discrepancies.

The same pattern is evident at the top of the wall $86-1 / 4$ in. above the slab in both Bays $1 \mathrm{~N}$ and $2 \mathrm{~N}$. The discrepancy increases for both programs in Bay 2N (Figure 139) with the discrepancy increase for WUFI-2D being slightly larger. The Bay 2N vertical soil temperature profile (Figure 139) shows very little change for BUFETS compared with Bay $1 \mathrm{~N}$, but shows a noticeable change for WUFI-2D. For example, at the end of the simulation period, the WUFI-2D temperature discrepancy $5-1 / 2$ in. above the slab increases from $4^{\circ} \mathrm{C}$ in Bay $1 \mathrm{~N}$ to $8^{\circ} \mathrm{C}$ in Bay $2 \mathrm{~N}$ (for BUFETS there is no change, the ending discrepancy is $2^{\circ} \mathrm{C}$ in both bays). Thus in the soil, remote from grade, the change in material properties appears to have a much bigger impact on WUFI-2D than on BUFETS. This is most likely a result of the different soil thermal properties used in BUFETS (Table 4) compared with the soil properties developed by Kehrer et al. (2012).

\section{D.3 Summary}

The WUFI-2D experiment/simulation temperature results comparison has also demonstrated the value of the experimental data in evaluating at least the thermal performance of earth contact simulation codes. A comparison of the results from two programs relative to the experimental data provides additional insight to the sensitivity of the results to differences in simulation algorithms, boundary conditions, and material properties. The ability of the experimental data to evaluate the performance of the moisture transport aspects of earth contact simulation programs could not be ascertained because the authors could not find a solution for the WUFI-2D moisture transport equation despite attempts to resolve the problems with the program developers. The moisture transport evaluation usefulness of the experimental results will have to be postponed to future research.

In terms of the usefulness of the two programs evaluated for predicting building foundation energy transport through masonry block walls in the context of whole building energy simulation, it appeared at the time of the evaluation that BUFETS yielded heat transfer results with lower wall temperature discrepancies than those available from WUFI-2D. In the whole building context, it appears that three-dimensional foundation heat transfer simulation is a better solution than twodimensional simulation in terms of accuracy, particularly when the wall cross-section is nonuniform (as is the case with a masonry block wall) and the nonuniformities are included in the geometry of the wall simulation model. 
BAY 2N WALL EXPERIMENTISIMULATION TEMPERATURE COMPARISON MID-HEIGHT: 40.25 in. ABOVE SLAB (HOLLOW MASONRY BLOCK CORE)

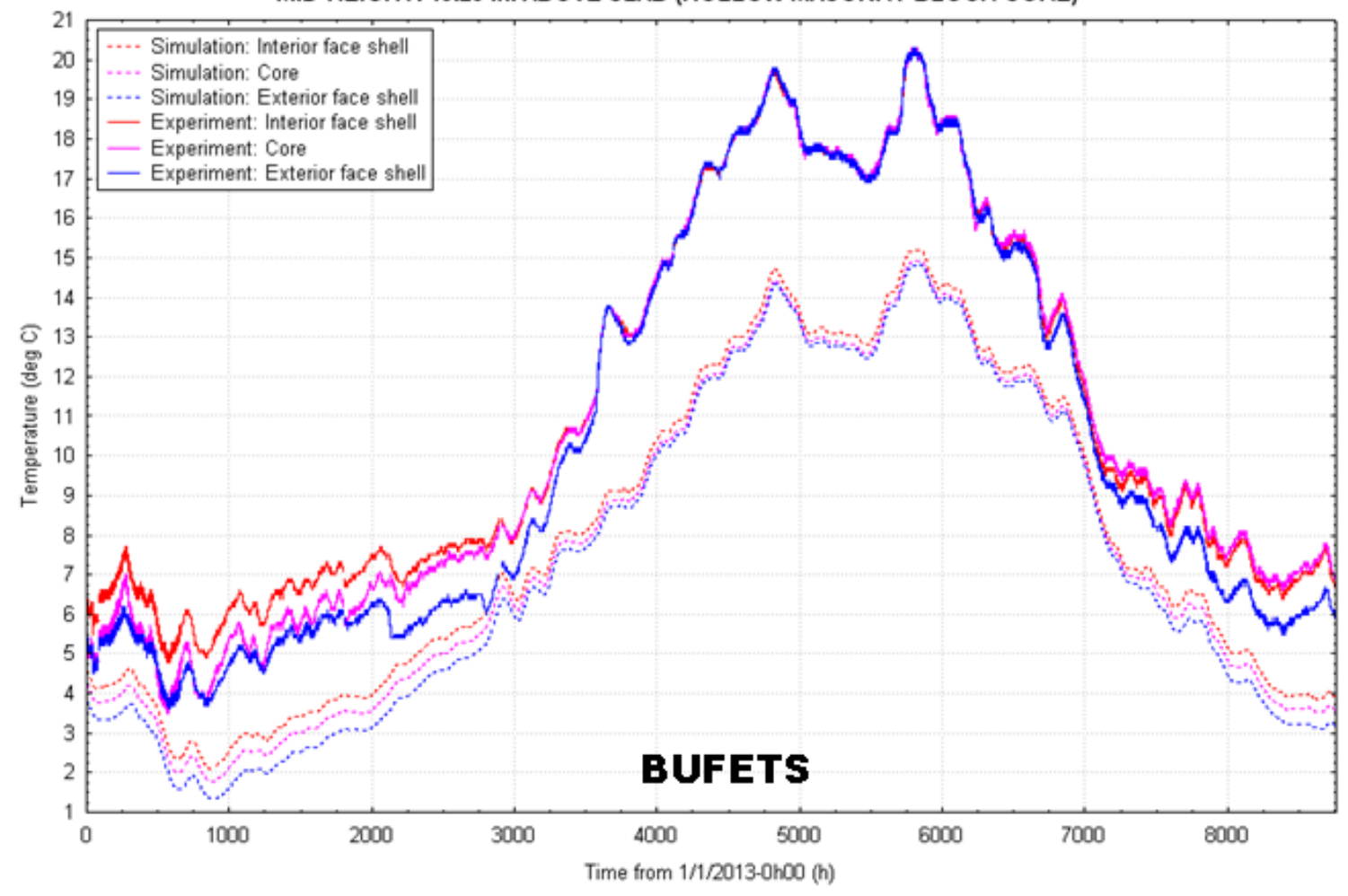

BAY 2N WALL EXPERIMENTISIMULATION TEMPERATURE COMPARISON MID-HEIGHT: 40.25 in. ABOVE SLAB (HOLLOW MASONRY BLOCK CORE)

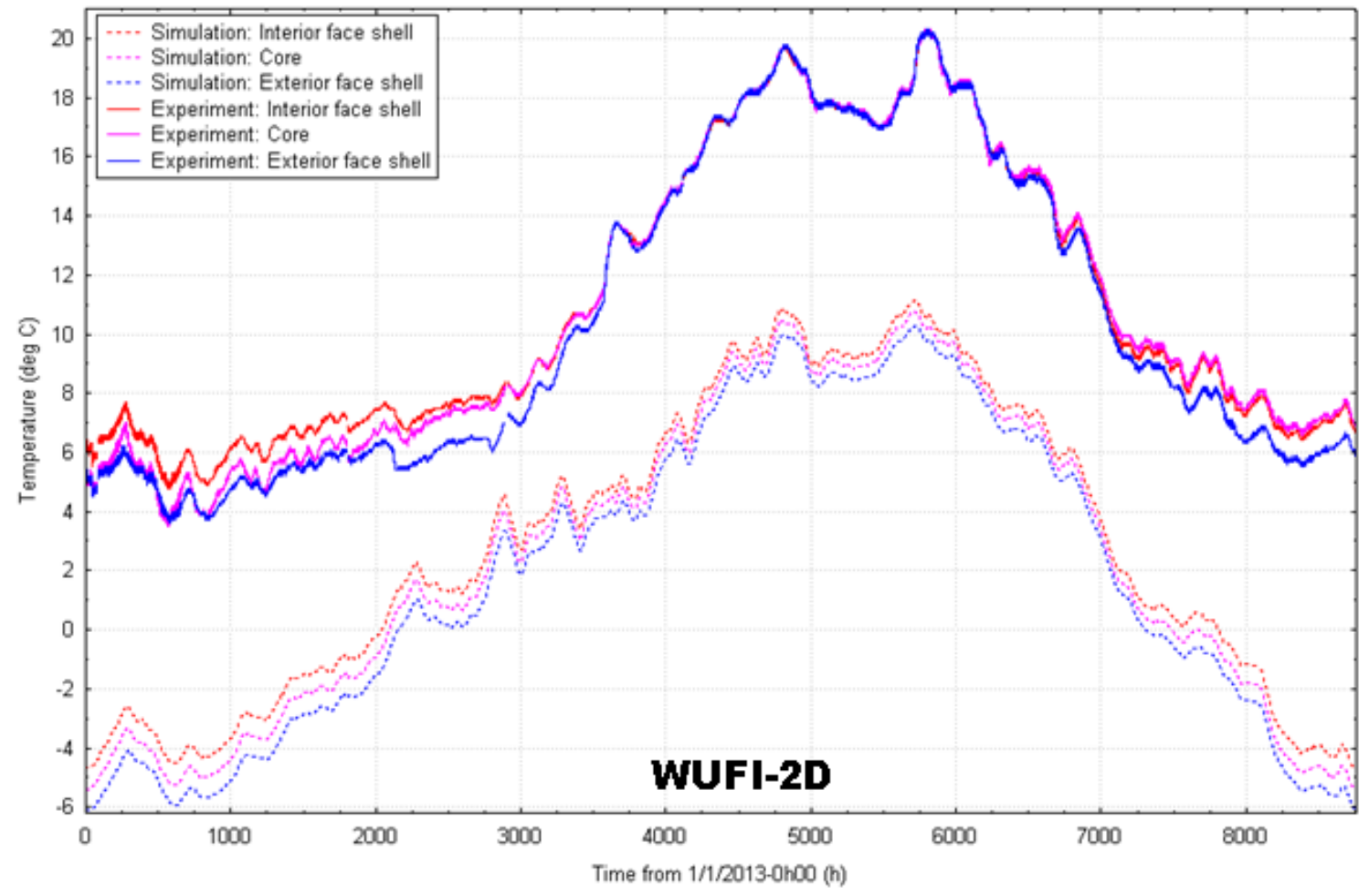

Figure 137. Bay 2N BUFETS/WUFI-2D wall temperature comparisons $40-1 / 4$ in. above the slab 
BAY 2N WALL EXPERIMENT/SIMULATION TEMPERATURE COMPARISON
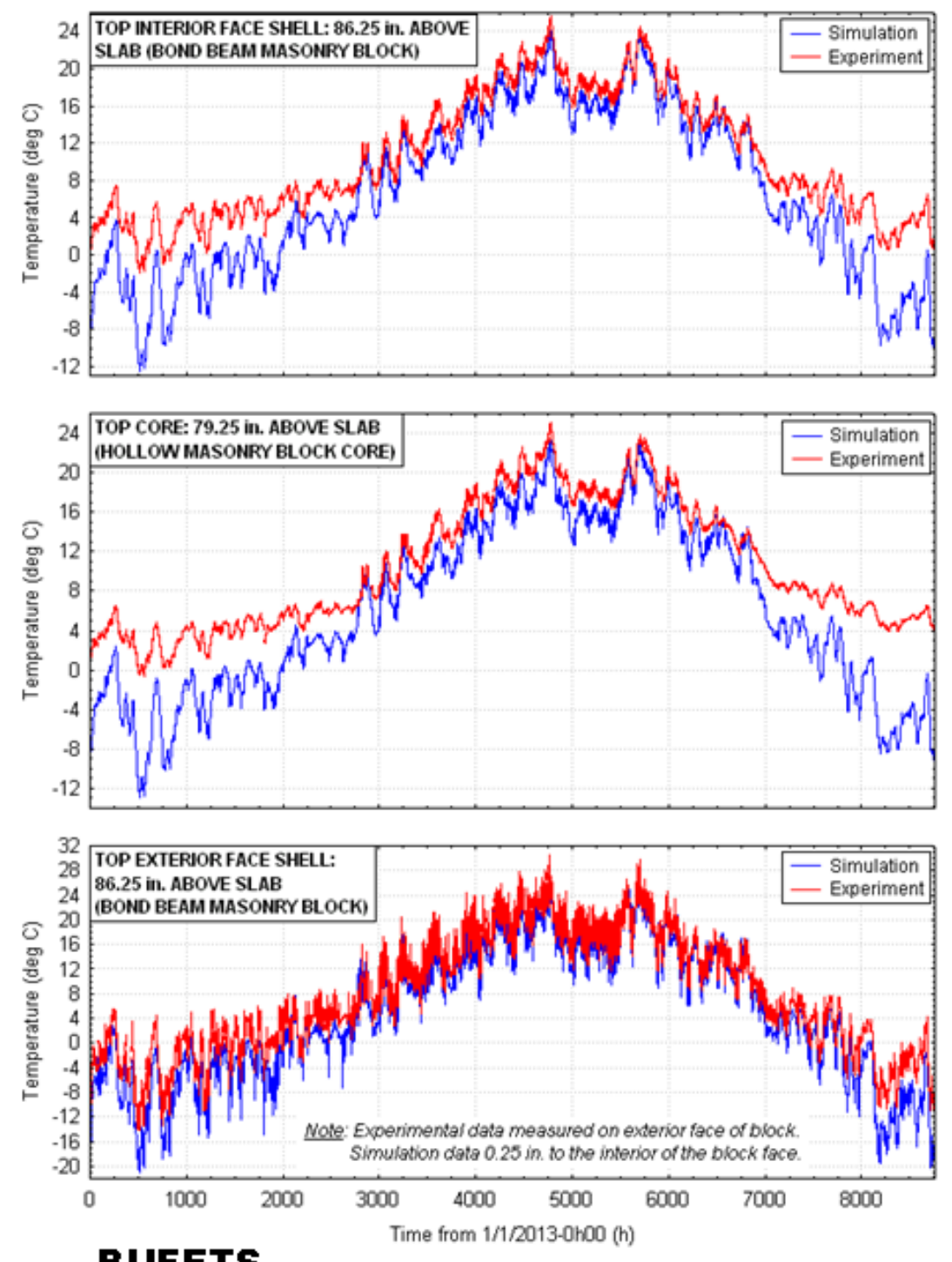

BUFETS
BAY 2 N WALL EXPERIMENT/SIMULATION TEMPERATURE COMPARISON
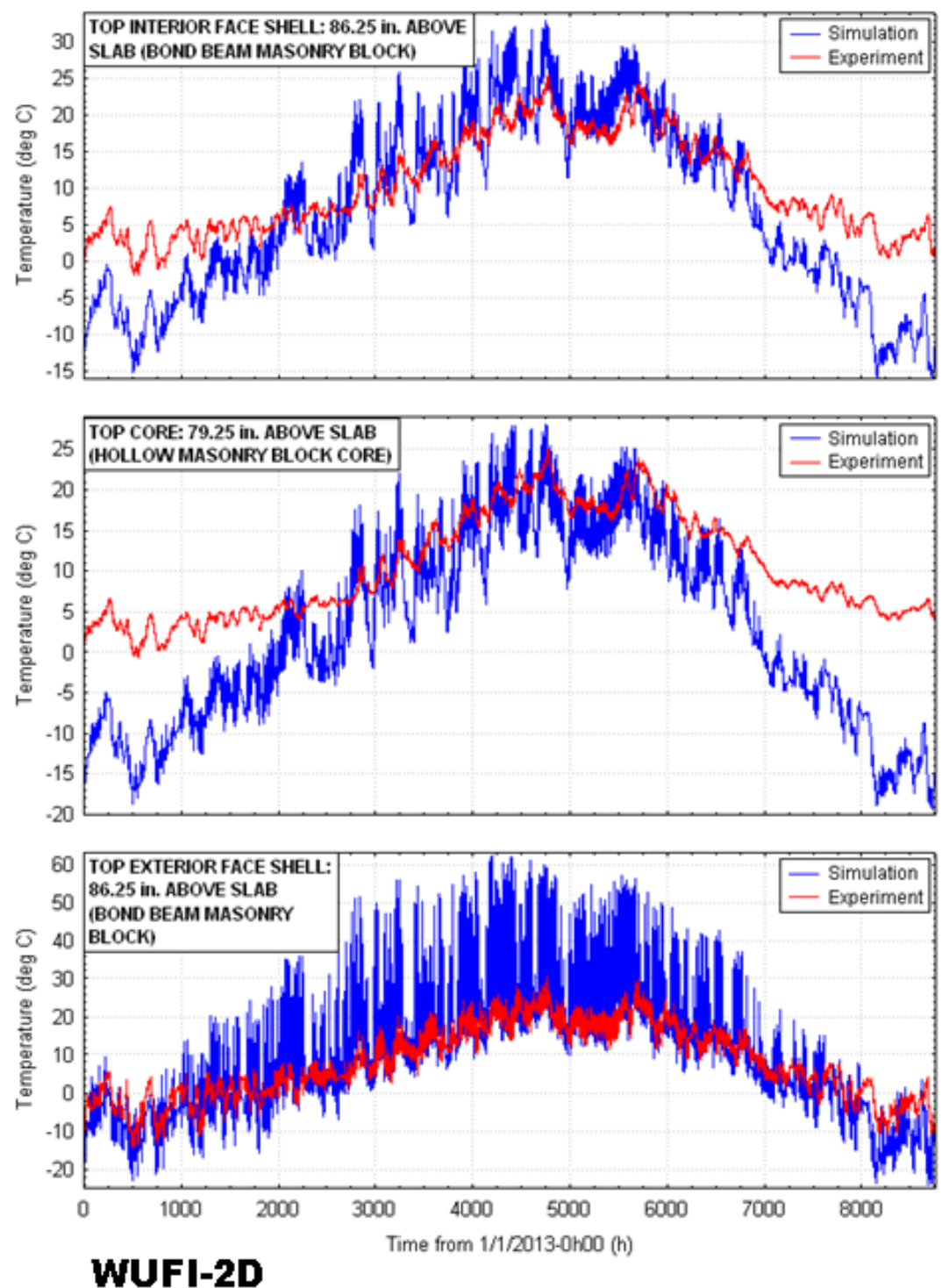

Figure 138. Bay $2 \mathrm{~N}$ BUFETS/WUFI-2D wall temperature comparisons $86-1 / 4 \mathrm{in}$. above the slab 
BAY 2 N VERT. SOIL TEMP. PROFILE EXPERIMENT/SIMULATION COMPARISON
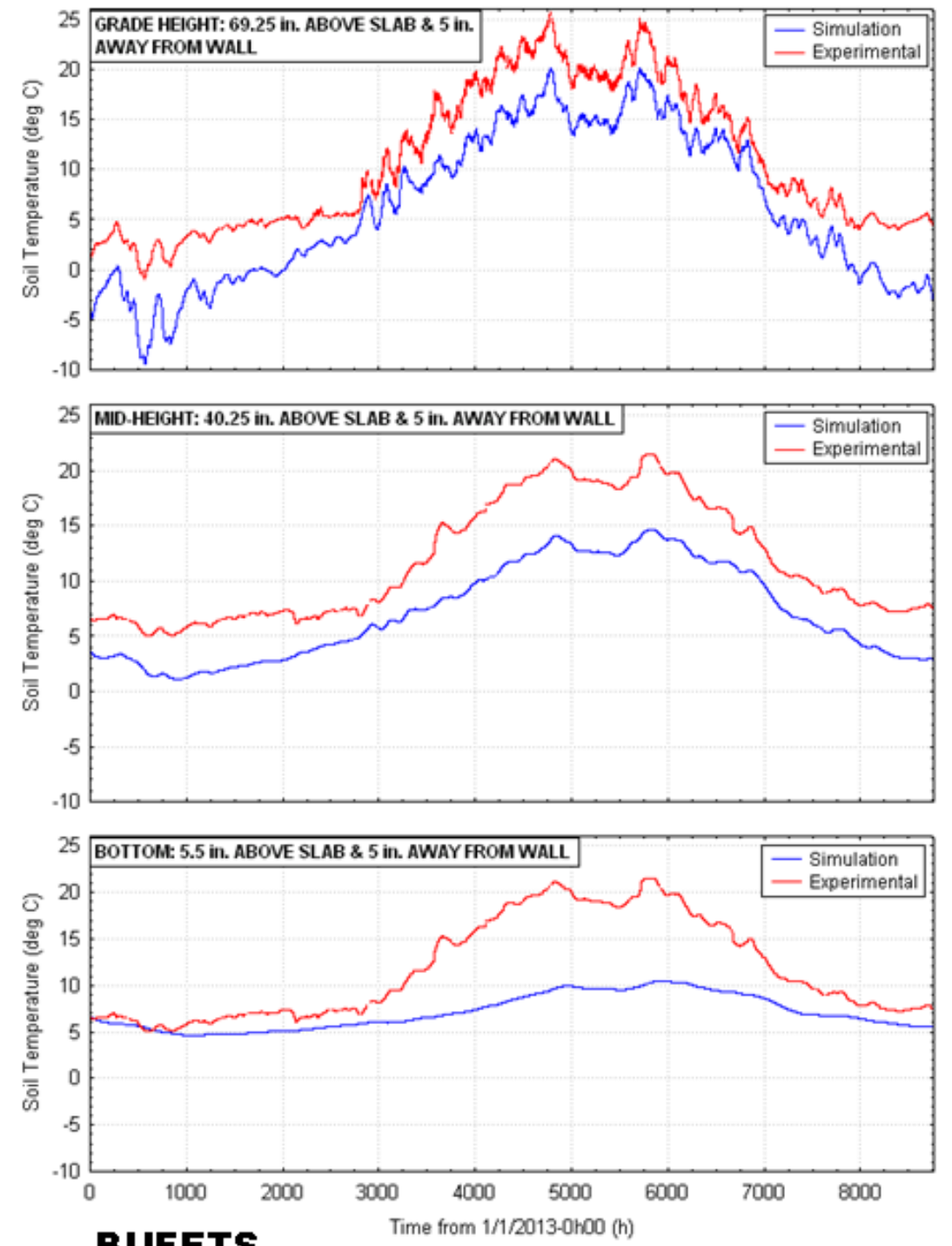

BUFETS
BAY $2 N$ VERT. SOIL TEMP. PROFILE EXPERIMENT/SIMULATION COMPARISON
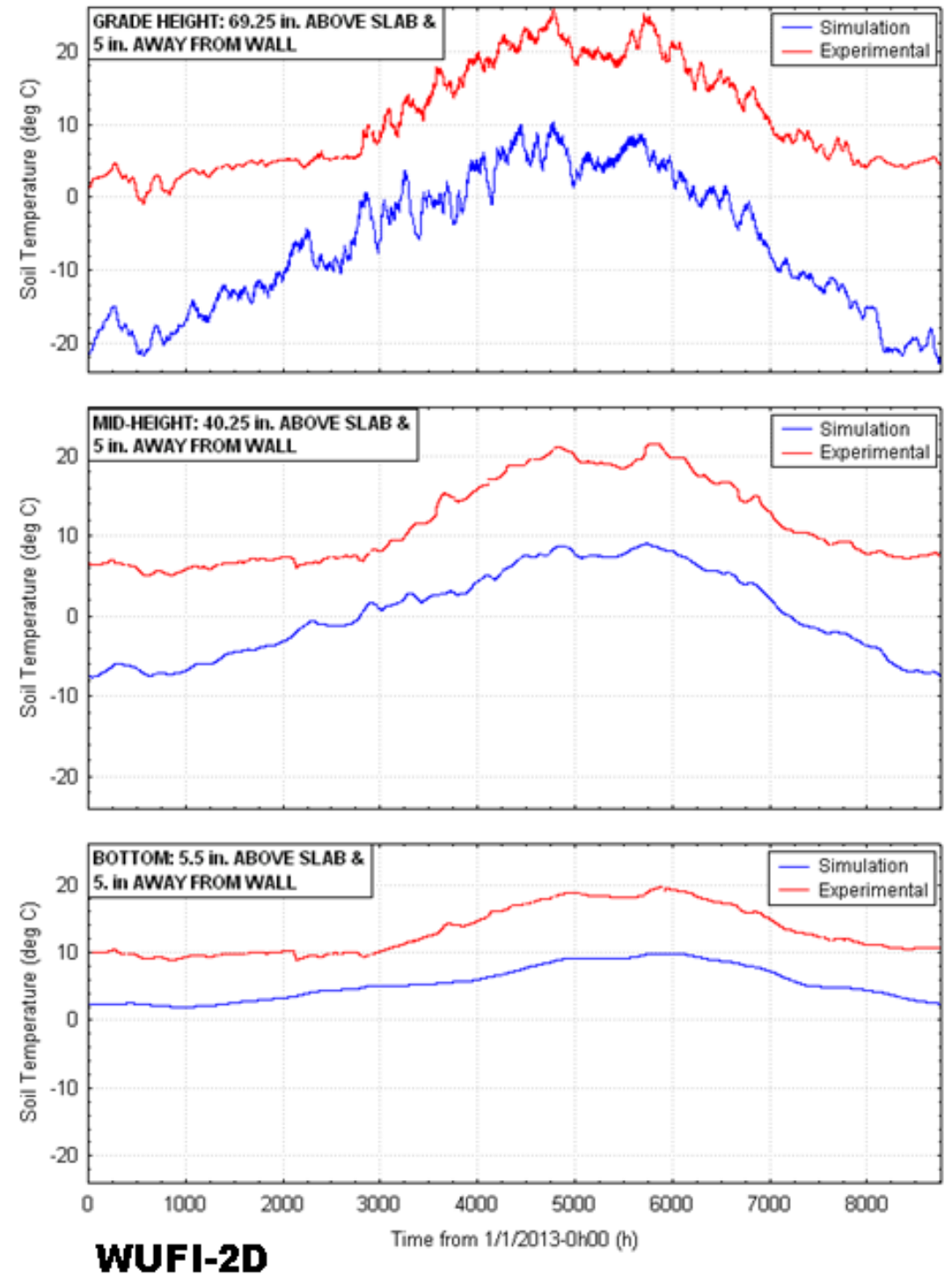

Figure 139. Bay 2N BUFETS/WUFI-2D vertical soil temperature profile comparisons 


\section{Appendix E: WUFI-2D Experiment/Simulation Comparison Data}

BAY 1N WALL EXPERIMENTISIMULATION TEMPERATURE COMPARISON BOTTOM: 5.5 in. ABOVE SLAB (HOLLOW MASONRY BLOCK CORE)

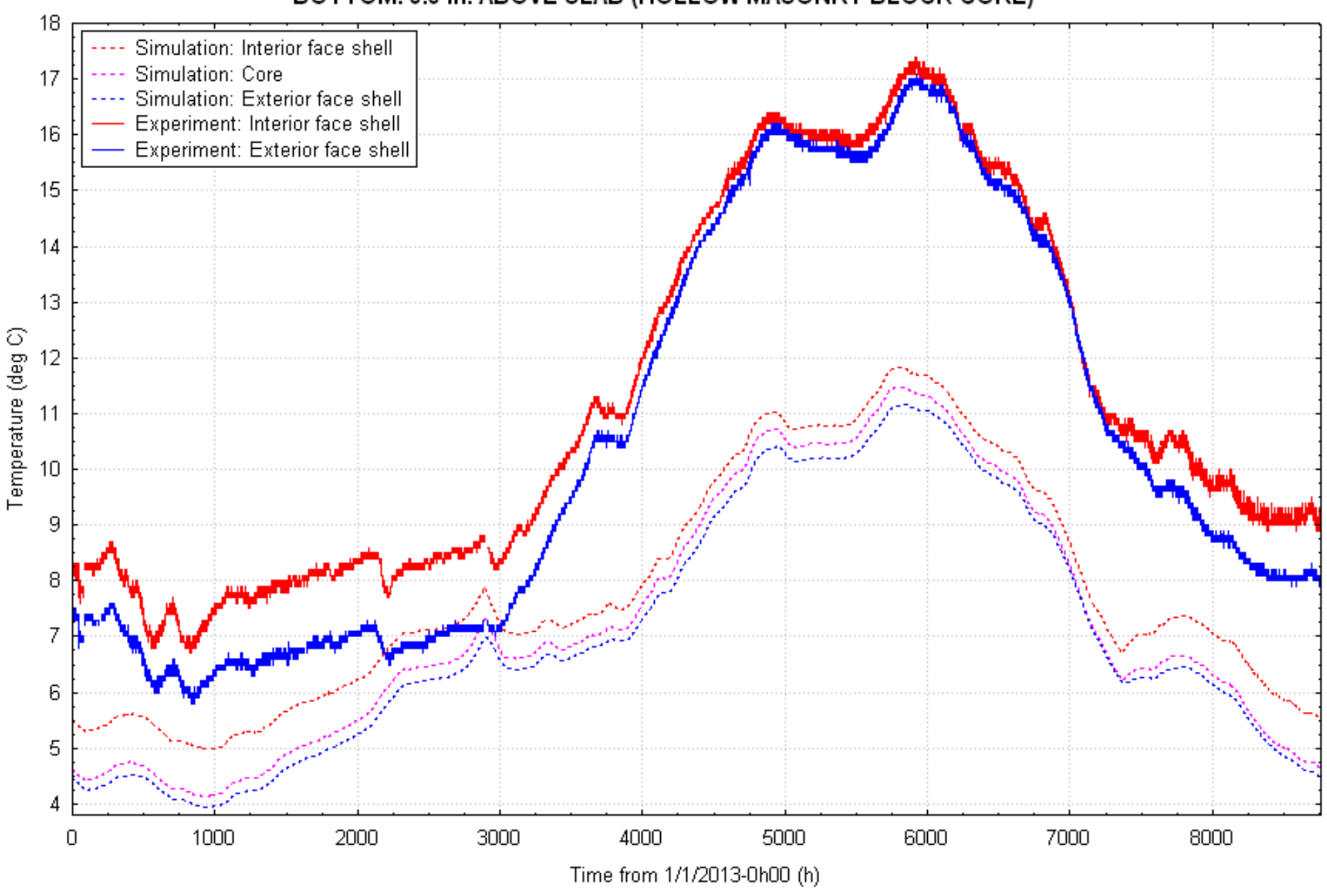

Figure 140. Bay $1 \mathrm{~N}$ wall experiment/WUFI simulation temperature comparison $5-1 / 2$ in. above the slab 
BAY 1N WALL EXPERIMENTISIMULATION TEMPERATURE COMPARISON

MID-HEIGHT: 40.25 in. ABOVE SLAB (HOLLOW MASONRY BLOCK CORE)

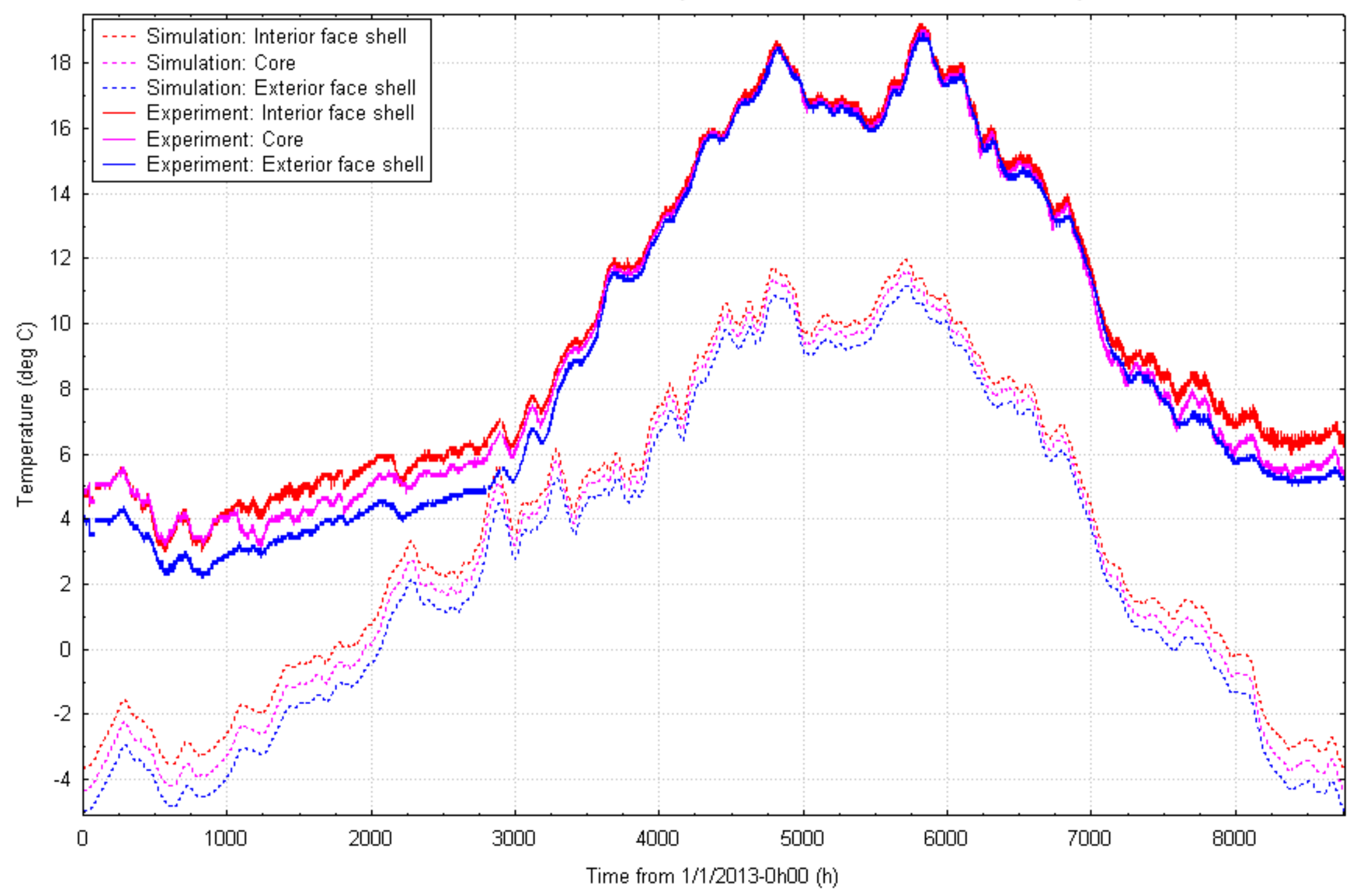

Figure 141. Bay $1 \mathrm{~N}$ wall experiment/WUFI simulation temperature comparison $40-1 / 4 \mathrm{in}$. above the slab 


\section{BAY 1N WALL EXPERIMENTISIMULATION TEMPERATURE COMPARISON}

GRADE-HEIGHT: 69.25 in. ABOVE SLAB (HOLLOW MASONRY BLOCK CORE)

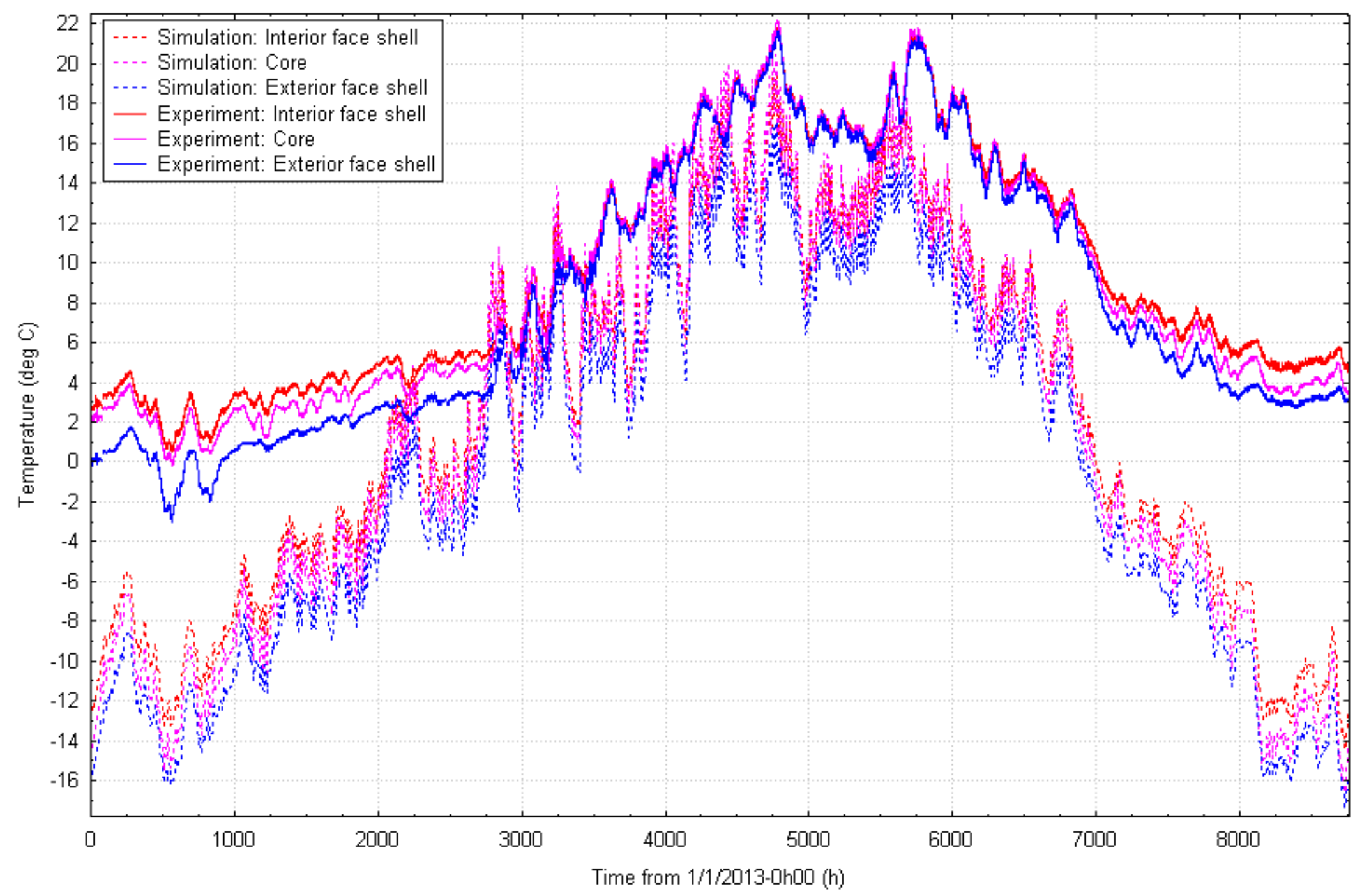

Figure 142. Bay $1 \mathrm{~N}$ wall experiment/WUFI simulation temperature comparison $69-1 / 4 \mathrm{in}$. above the slab 


\section{BAY 1N WALL EXPERIMENTISIMULATION TEMPERATURE COMPARISON}
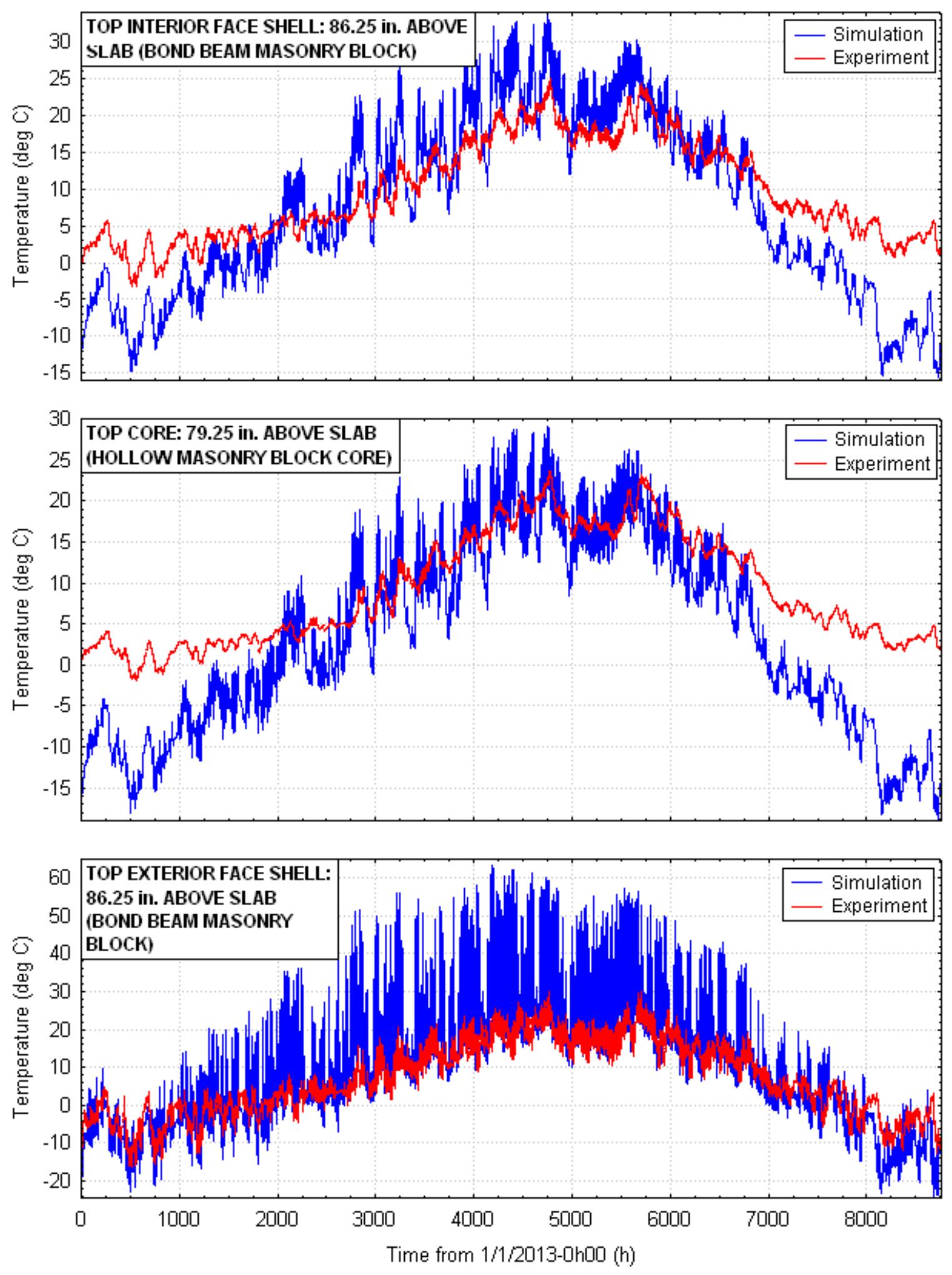

Figure 143. Bay $1 \mathrm{~N}$ wall experiment/WUFI simulation temperature comparison $79-1 / 4 / 86-1 / 4$ in. above the slab 
BAY 1N VERT. SOIL TEMP. PROFILE EXPERIMENT/SIMULATION COMPARISON
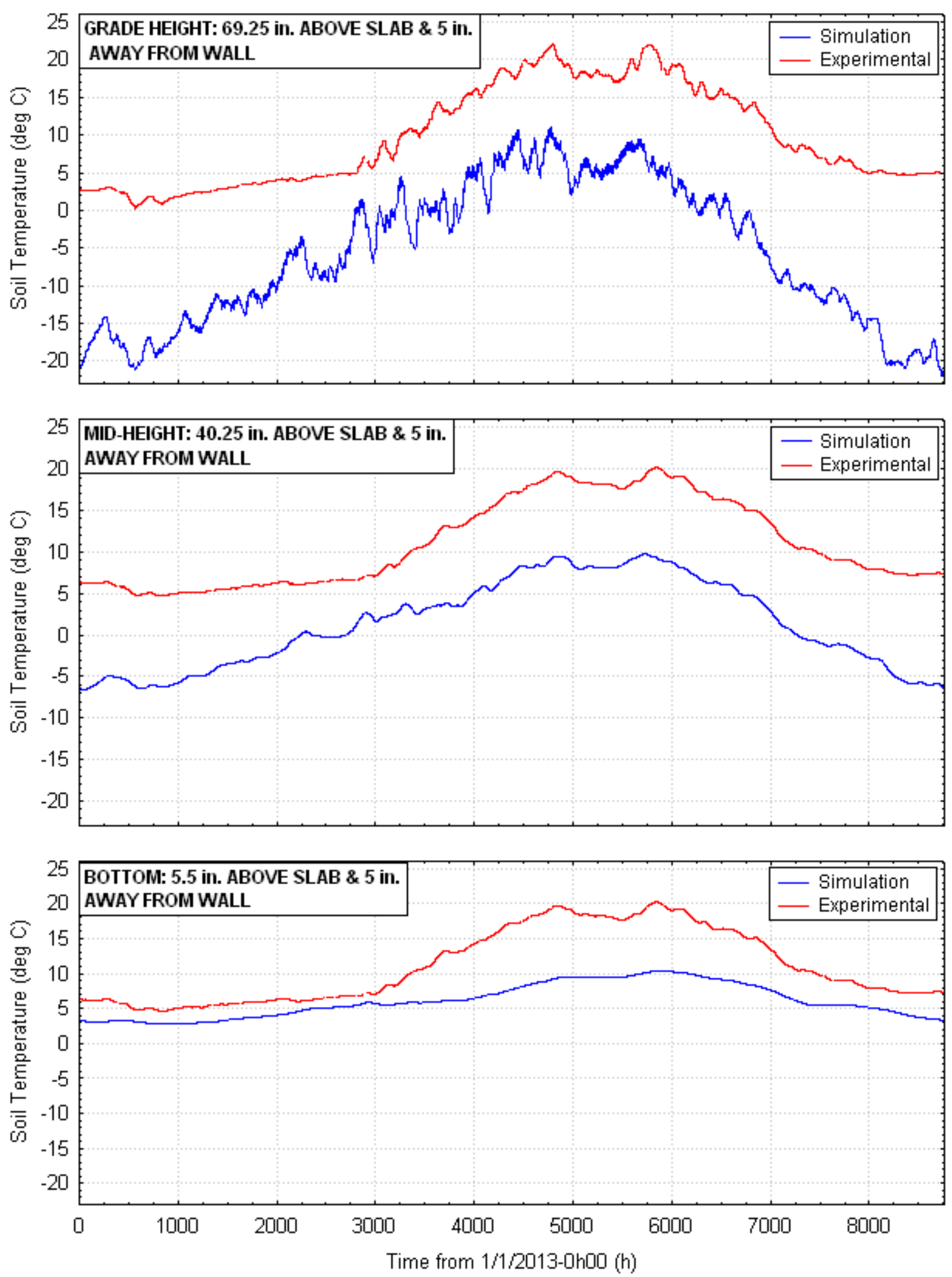

Figure 144. Bay $1 \mathrm{~N}$ soil vertical profile experiment/WUFI simulation temperature comparison 
BAY 1N HORIZ. SOIL TEMP. PROFILE EXPERIMENTISIMULATION COMPARISON
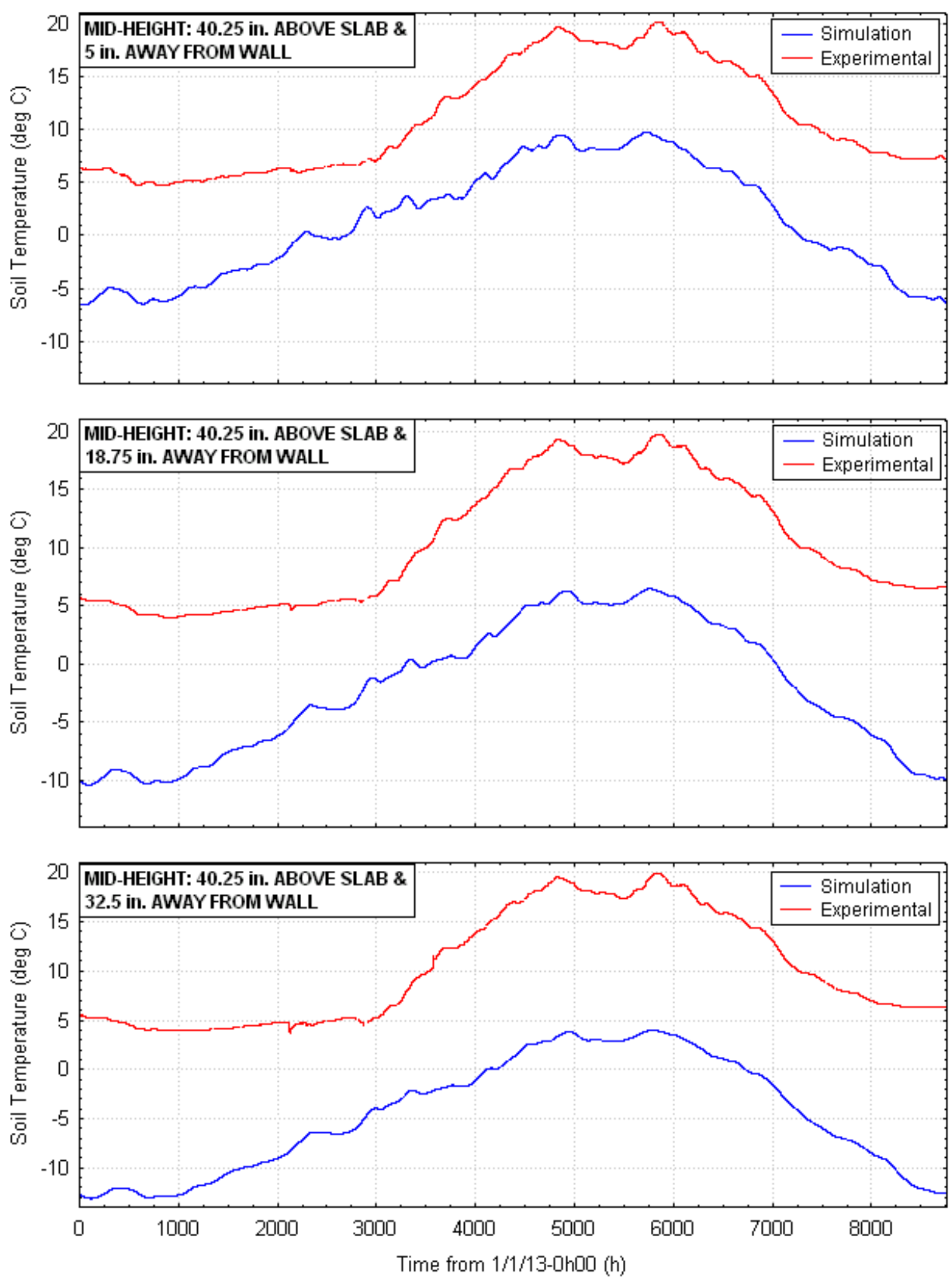

Figure 145. Bay $1 \mathrm{~N}$ soil horizontal profile experiment/WUFI simulation temperature comparison 


\section{BAY 2N WALL EXPERIMENTISIMULATION TEMPERATURE COMPARISON}

BOTTOM: 5.5 in. ABOVE SLAB (HOLLOW MASONRY BLOCK CORE)

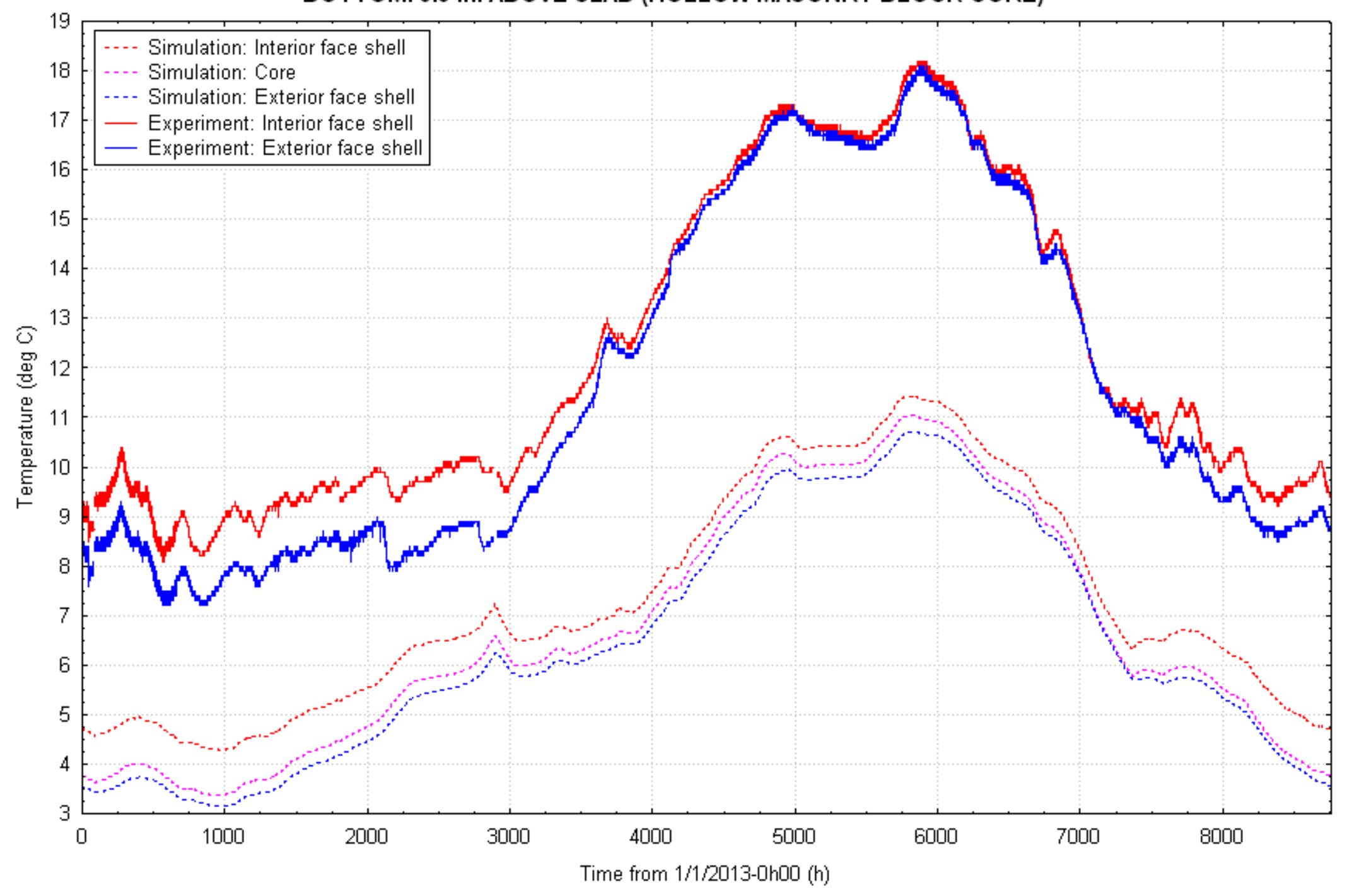

Figure 146. Bay $2 \mathrm{~N}$ wall experiment/WUFI simulation temperature comparison $5-1 / 2$ in. above the slab 
BAY 2N WALL EXPERIMENTISIMULATION TEMPERATURE COMPARISON

MID-HEIGHT: 40.25 in. ABOVE SLAB (HOLLOW MASONRY BLOCK CORE)

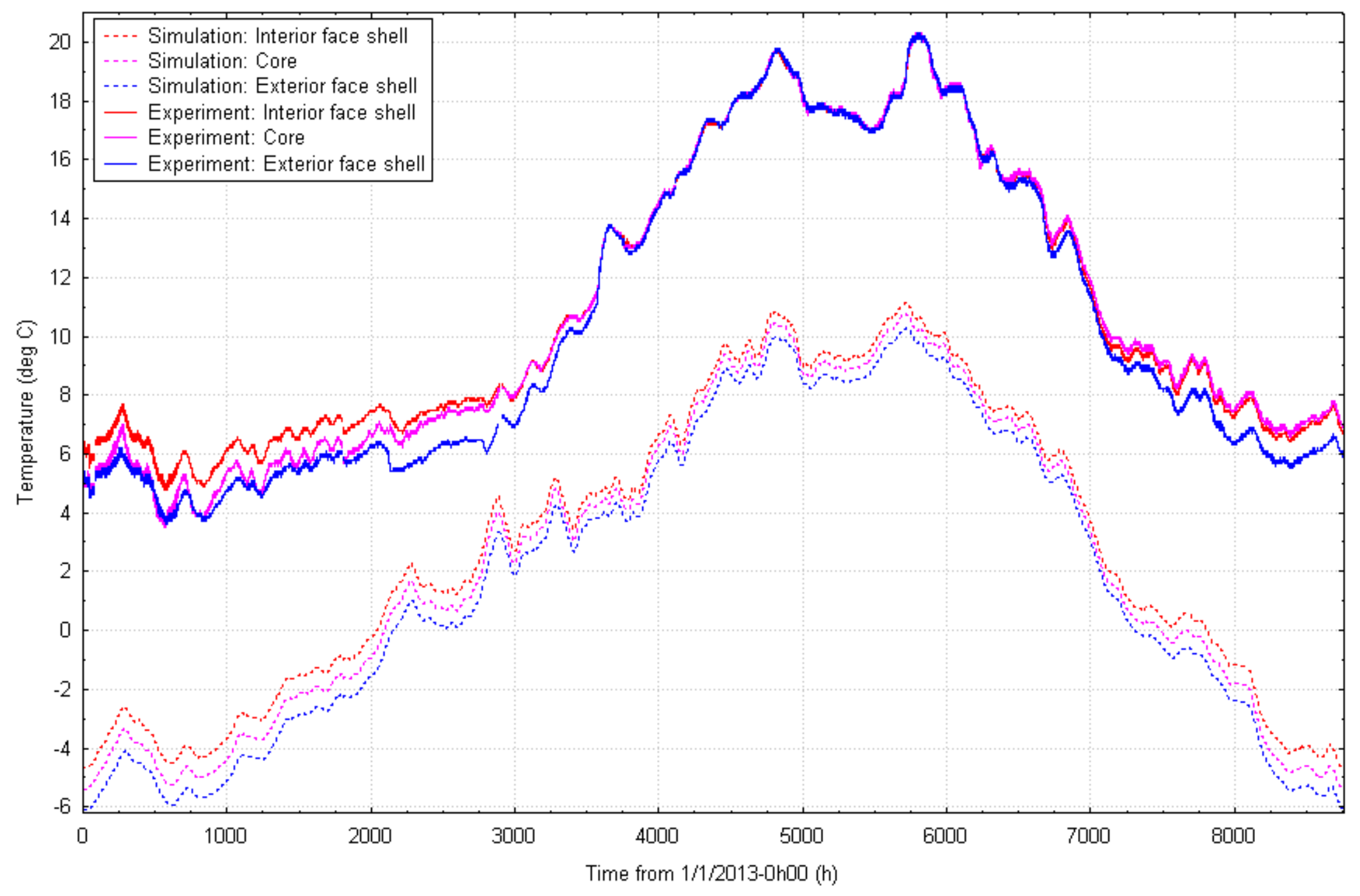

Figure 147. Bay $2 \mathrm{~N}$ wall experiment/WUFI simulation temperature comparison $40-1 / 4 \mathrm{in}$. above the slab 


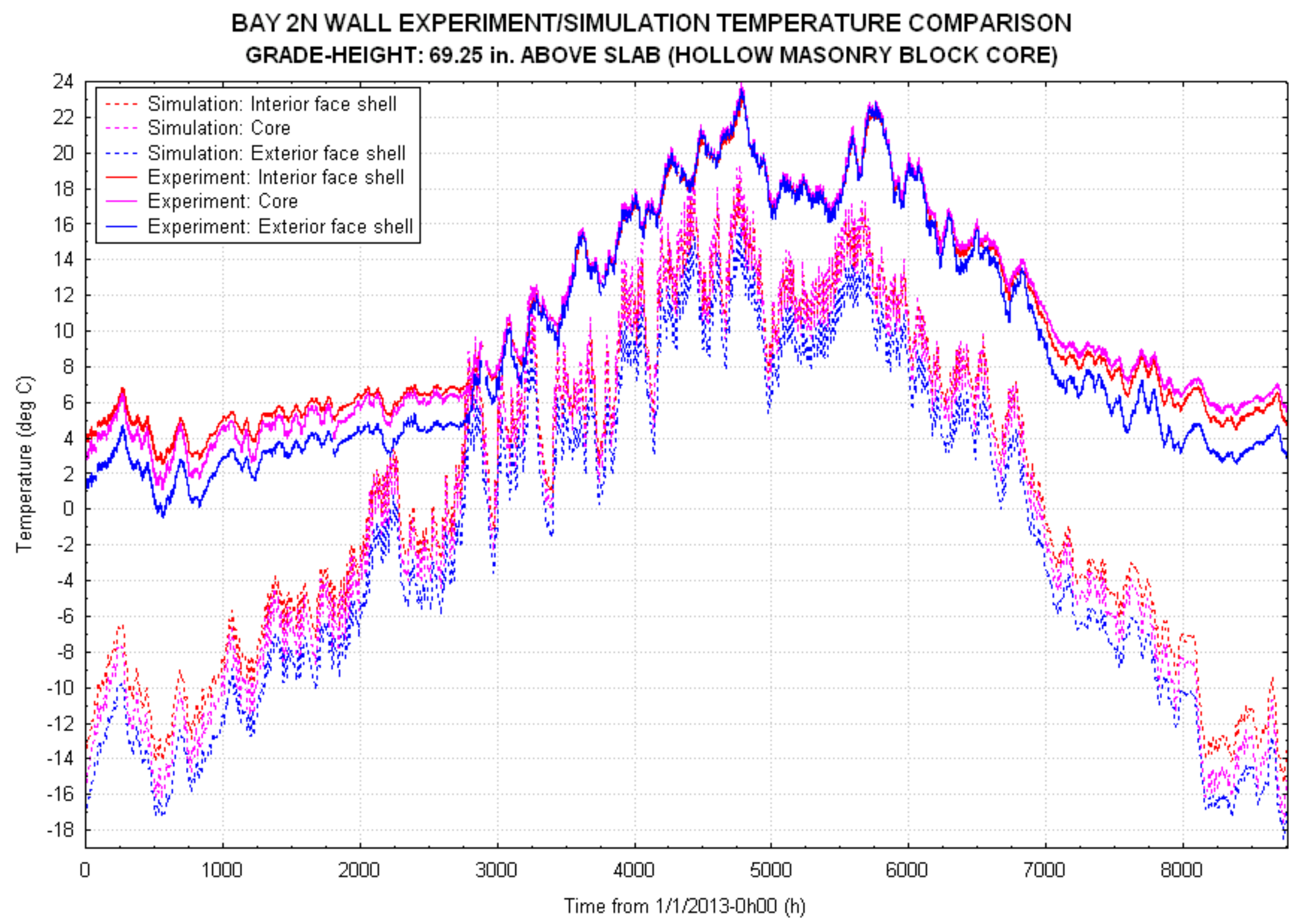

Figure 148. Bay $2 \mathrm{~N}$ wall experiment/WUFI simulation temperature comparison $69-1 / 4$ in. above the slab 


\section{BAY 2N WALL EXPERIMENTISIMULATION TEMPERATURE COMPARISON}
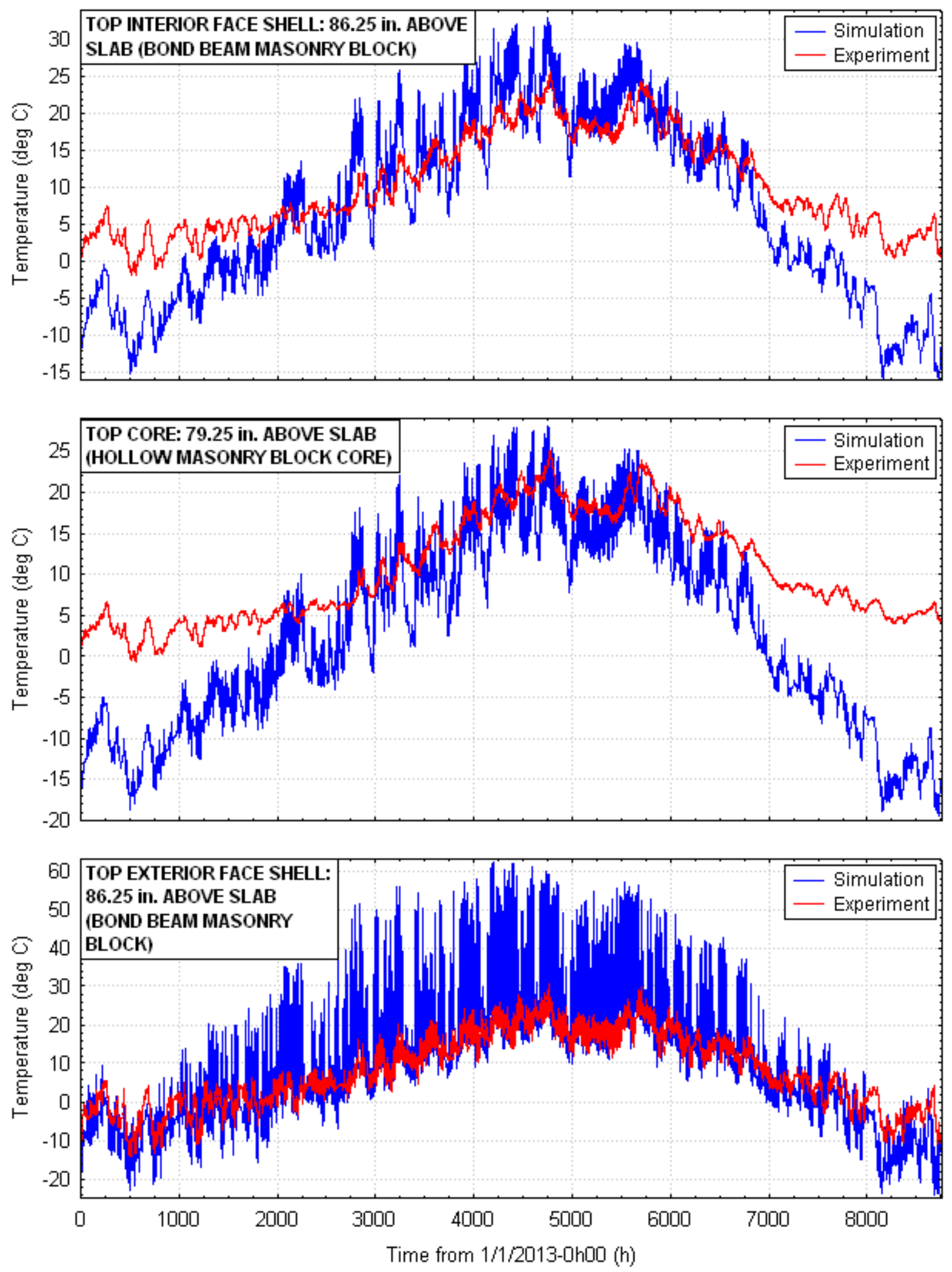

Figure 149. Bay $2 \mathrm{~N}$ wall experiment/WUFI simulation temperature comparison $79-1 / 4$ and $86-1 / 4$ in. above the slab 
BAY 2N VERT. SOIL TEMP. PROFILE EXPERIMENTISIMULATION COMPARISON
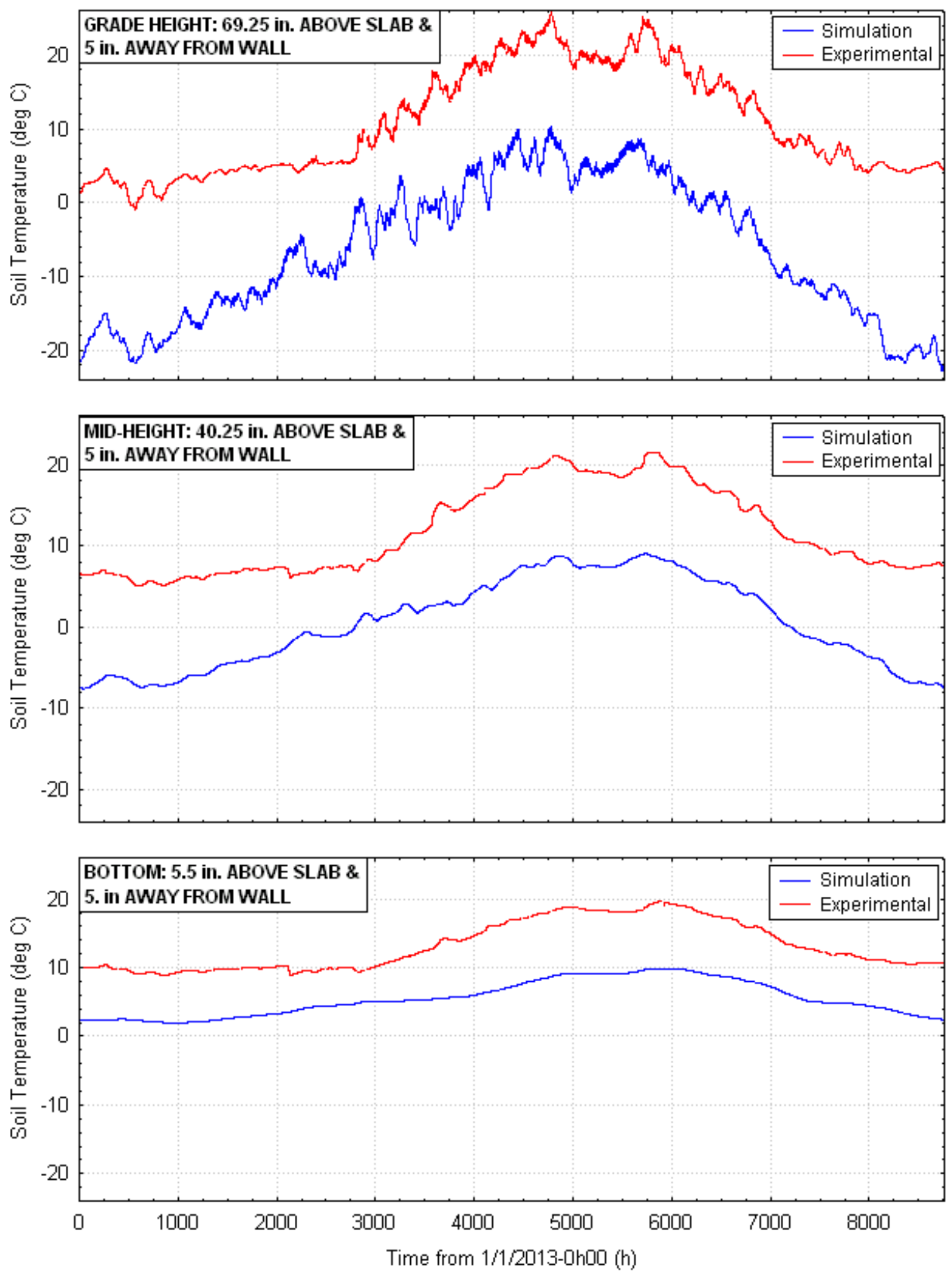

Figure 150. Bay $2 \mathrm{~N}$ soil vertical profile experiment/WUFI simulation temperature comparison 
BAY 2N HORIZ. SOIL TEMP. PROFILE EXPERIMENT/SIMULATION COMPARISON
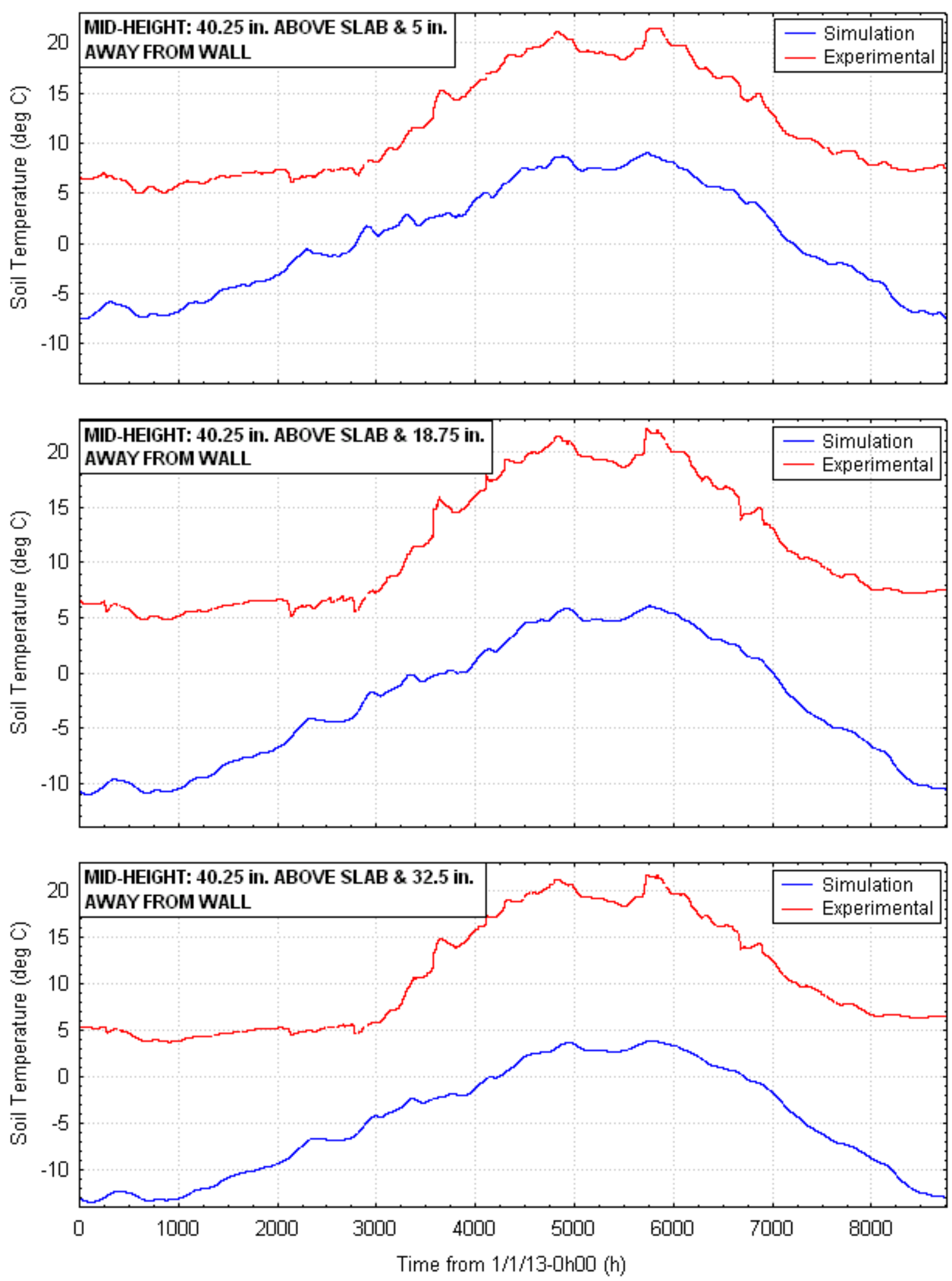

Figure 151. Bay $2 \mathrm{~N}$ soil horizontal profile experiment/WUFI simulation temperature comparison 


\section{Appendix F: Solution Center Guide}

\section{Guide Title: Durable Interior Foundation Insulation Retrofits}

Keywords: Foundation, Basement, Water Separation Plane (WSP), Interior Insulation

Climate Zone: 6 and 7 (Cold Climates)

Construction Types: Existing Homes

Disclaimer: The Regents of the University of Minnesota and its employees assume no liability for the use of this guide.

\section{Scope: Moisture Control and Thermal Insulation Retrofits for Existing Basements}

Thermal and moisture problems in existing basements create a unique challenge because the exterior face of the wall is not easily or inexpensively accessible. This approach addresses thermal and moisture management from the interior face of the wall without disturbing the exterior soil and landscaping. It effectively reduces energy loss through the wall, principally during the heating season, increasing occupant comfort throughout the year and creating a WSP between the interior and exterior environments. This approach has the potential for improving durability, comfort, and indoor air quality. The solution also is compliant with the hygrothermal performance requirements of the Minnesota Energy Code (Minnesota Statutes (2009), Chapter 1322, Section N1102.2.6.12).

\section{Description}

The following approach applies to hollow masonry block and cast-in-place concrete walls and uses a continuous, full-height WSP applied directly to the wall. Full-height, rigid insulation is then installed directly against the WSP. Optionally, a hollow stud wall and gypsum wallboard can be installed against the insulation. There are two options for the WSP depending on the wetness of the existing wall. In all cases, proper exterior surface water drainage must first be addressed.

Insulation: Shall meet the 2012 IECC requirements. Vapor-retarding insulation, such as XPS board, is preferred. Otherwise, the insulation system selected should not permit condensate rundown on the WSP interior face at 50\% indoor $\mathrm{RH}$ while allowing the insulation system to dry to the interior.

Self-adhered WSP: A "peel-and-stick" membrane adhered directly to the wall. Generally, the wall must be primed before the WSP is installed. The WSP can be used on walls that are bare, clean (or can be rendered clean), and reasonably smooth and dry with a saturation ratio $\leq 25 \%$.

Nonadhered WSP: Sheet products that provide a small gap between the sheet and the wall (e.g., dimpled high-density polyethylene sheet with dimples facing the wall). Because a drainage plane is located between the membrane and the wall, it must be drained to a drainage system at the base of the WSP. The WSP is adhered to the wall with mechanical fasteners. If the saturation 
ratio ${ }^{*}>25 \%$, there is visible evidence of current or past bulk water leakage, or the wall surface is unfit for an adhered WSP, a nonadhered WSP must be used.

\section{How-To:}

Test the moisture content of the interior face of the wall for at least 1 month (preferably during a wet time of year such as spring) using the conductance based method described in Goldberg and Harmon [2014]).

Calculate the average moisture saturation ratio of the interior wall face. If the saturation ratio $>25 \%$, a nonadhered WSP must be used.

For hollow masonry block walls, determine if the top course is grouted solid (bond-beam or equivalent). If not, the top course must be grouted solid. Insert a plug into the wall to support the grout.

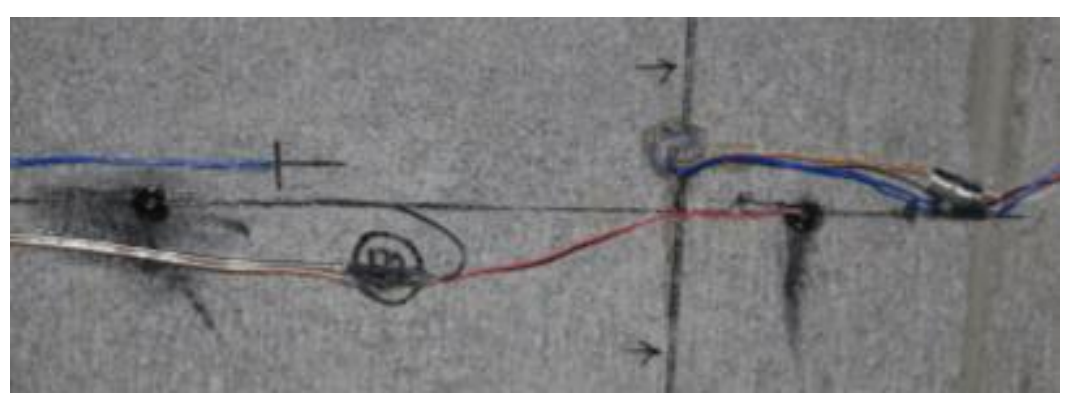

Image Title: Wall Moisture Content Sensors.

Image Source: ESDP, 2013, Unpublished

Display Image Filename:

Self-adhered WSP: If the saturation ratio $\leq 25 \%$ and the surface of the wall is bare, clean (or can be rendered clean), and reasonably smooth, a self-adhered WSP may be used.

Prime the wall per the manufacturer's instructions using a compatible primer.

Install the WSP from the top of the slab to the top of the wall with all vertical joints overlapped a minimum of 6 in. Horizontal seams are not recommended but, if necessary, should be shiplapped with a 6-in. overlap.

\footnotetext{
* The saturation ratio in porous materials is defined as the volume of water/total pore volume. In terms of a measured volumetric moisture content, it may be calculated from the ratio: volumetric moisture content/material porosity.
} 


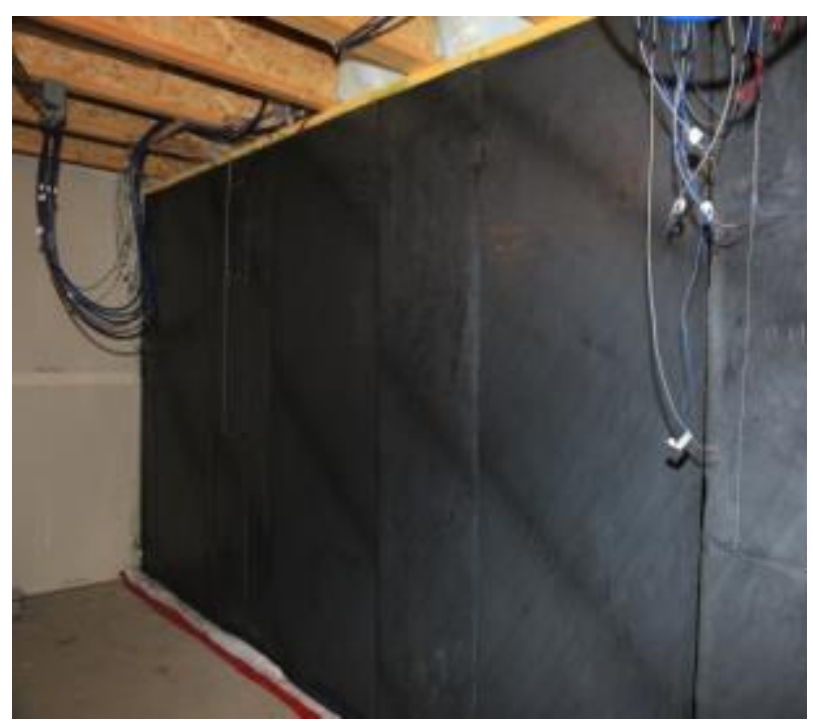

Image Title: Self-Adhered WSP With Vertical Lapped Joints.

Image Source: ESDP, 2013, Unpublished

Display Image Filename:

Nonadhered WSP: If the saturation ratio $>25 \%$, there is visible evidence of current or past bulk water leakage, or the wall surface is unfit for an adhered WSP, a nonadhered WSP must be used.

A small gap will exist between the sheet and the wall that requires a drainage system at the base of the WSP. Options for the base drainage system include:

- A channel at the base of the wall above the slab. The channel must provide a means to drain water to a sump or floor drain.

- Drain tile beneath the slab (requiring perimeter slab removal) with the WSP extended to the top of the footing.

Install the WSP to the top of the wall, avoiding horizontal joints. All vertical joints should be overlapped a minimum of 6 in. Adhere the WSP to the wall with mechanical fasteners.

Seal all fastener penetrations. All vertical joints should be sealed with a compatible, durable, vapor resistant adhesive (not caulk). The exposed perimeter of the WSP and the drainage system should be vapor sealed from the basement interior. 


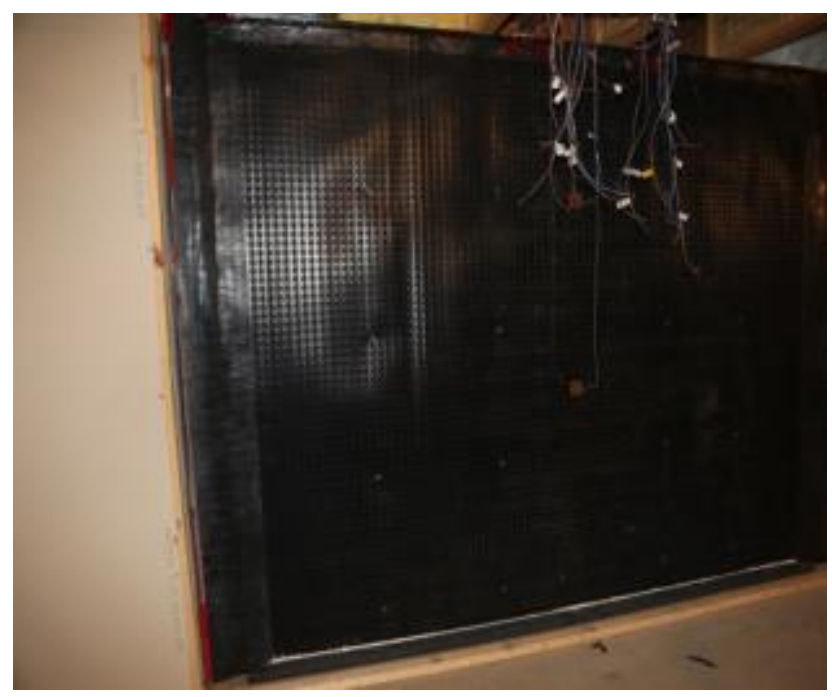

Image Title: Nonadhered WSP With Vertical Lapped Joints.

Image Source: ESDP, 2013, Unpublished

Display Image Filename:

\section{Insulation:}

Install the insulation against the face of the WSP so that it does not damage the WSP in any way (penetrations of the WSP are prohibited).

All insulation joints and vapor bypasses must be air sealed.

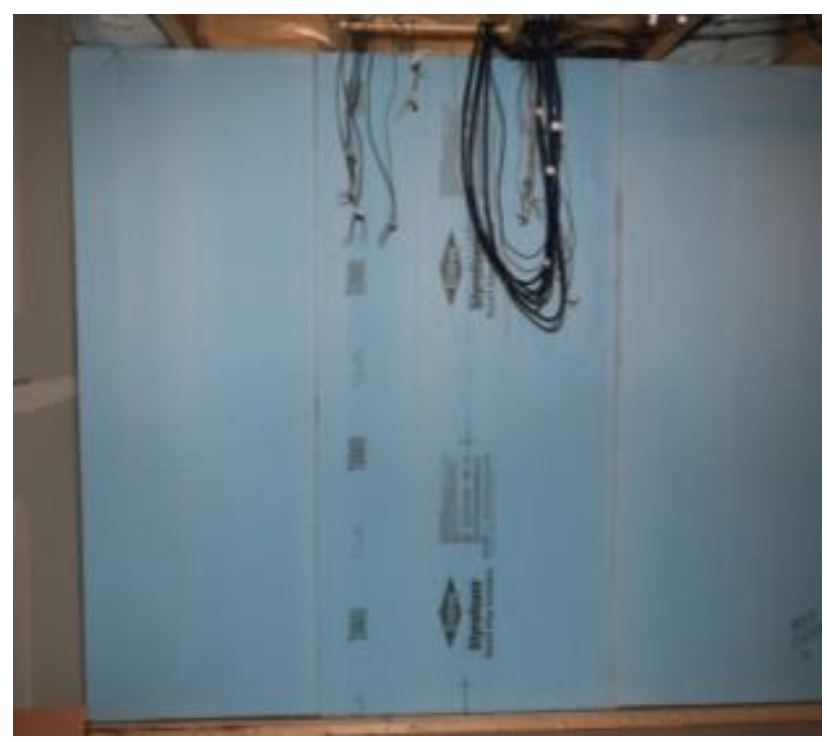

Image Title: Rigid XPS Insulation.

Image Source: ESDP, 2013, Unpublished

Display Image Filename: 


\section{Framing:}

If desired, install an open stud frame wall with gypsum wallboard tight to the insulation.

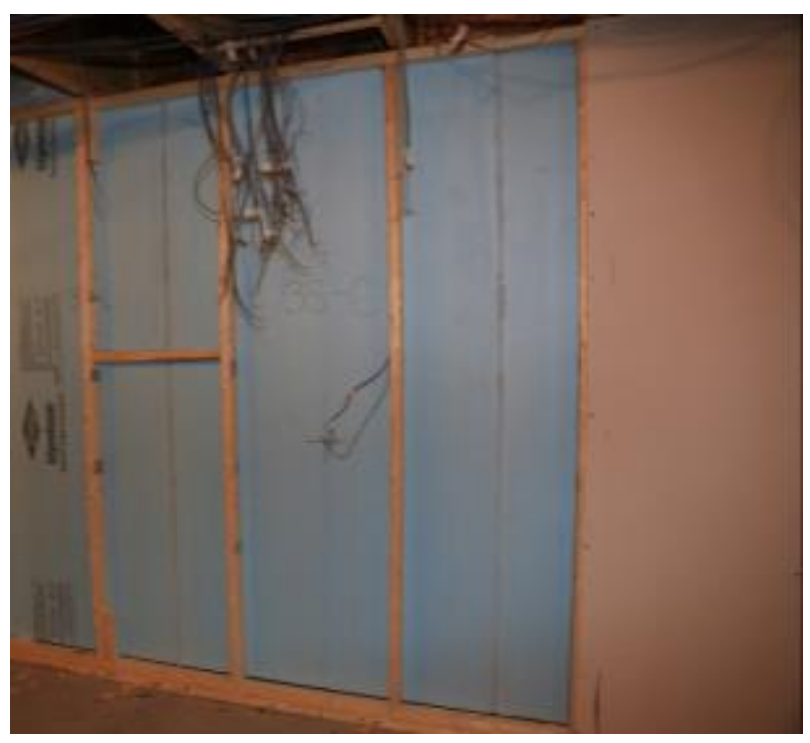

Image Title: Open Frame Stud Wall and Gypsum Wallboard.

Image Source: ESDP, 2013, Unpublished

Display Image Filename:

\section{Ensuring Success}

Considerations to include:

- Has the basement been converted to conditioned living space? Will it be converted in the near future?

- Are there significant moisture problems such as bulk water seepage or penetration?

- Has exterior drainage been addressed through grade, gutters, surface materials, etc.?

- Does the wall moisture content test adequately reflect the conditions of the wall by testing for a sufficient duration and during a wet time of year?

- For the nonadhered WSP, does the base wall drainage system adequately handle the volume of water expected?

\section{Climate-Specific Factors/Details}

Applies to cold climates (U.S. Department of Energy climate zones 6 and 7).

\section{Architectural CAD Files}

None available 


\section{Compliance}

Local building codes have specific requirements such as the R-value of insulation, WSPs, fire and combustion requirements, radon mitigation requirements, flood prevention requirements, and requirements for pest control. Begin by checking with local authorities to ensure that all materials and work will comply with local code requirements.

\section{References}

Goldberg, L.F. and A.C. Harmon, (2014) Cold-Climate Foundation Retrofit Experimental Hygrothermal Performance: CRRF Laboratory Results. NREL project report.

ESDP (Energy Systems Design Program), (2013). Unpublished Cloquet Residential Research Facility image archive, University of Minnesota. 


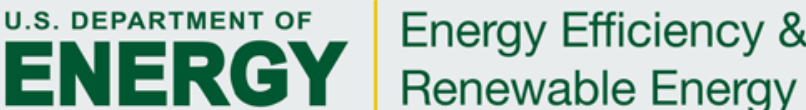

